NUCLA CIRCULATING ATMOSPHERIC FLUIDIZED BED DEMONSTRATION PROJECT

Final Report

October 1991

Work Performed Under Contract No. FC21-89MC25137

For

U.S. Department of Energy Morgantown Energy Technology Center Morgantown, West Virginia

By Colorado-Ute Electric Assoclation, Inc. Montrose, Colorado 


\section{DISCLAIMER}

This report was prepared as an account of work sponsored by an agency of the United States Government. Neither the United States Government nor any agency thereof, nor any of their employees, makes any warranty, express or implied, or assumes any legal liability or responsibility for the accuracy, completeness, or usefulness of any information, apparatus, product, or process disclosed, or represents that its use would not infringe privately owned rights. Reference herein to any specific commercial product, process, or service by trade name, trademark, manufacturer, or otherwise does not necessarily constitute or imply its endorsement, recommendation, or favoring by the United States Government or any agency thereof. The views and opinions of authors expressed herein do not necessarily state or reflect those of the United States Government or any agency thereof.

This report has been reproduced directly from the best available copy.

Available to DOE and DOE contractors from the Office of Scientific and Technical Information, P.O. Box 62, Oak Ridge, TN 37831; prices available from (615)576-8401, FTS 626-8401.

Available to the public from the National Technical Information Service, U.S. Department of Commerce, 5285 Port Royal Rd., Springfield, VA 22161. 


\title{
Nucla Circulating Atmospheric Fluidized Bed Demonstration Project
}

\author{
Final Report
}

Work Performed Under Cooperative Agreement No.: DE-FC21-89MC25137

\author{
For \\ U.S. Department of Energy \\ Office of Fossil Energy \\ Morgantown Energy Technology Center \\ P.O. Box 880 \\ Morgantown, West Virginia 26507-0880 \\ Colorado-Ute Electric Association, Inc. \\ P.O. Box 1149 \\ Montrose, Colorado 81402
}


Final Technical Report

Table of Contents

Section

Page

FOREWORD

1 SUMMARY

1.1 Project Overview

1.2 Unit Operating Statistics $1-9$

1.3 Reliability Issues $1-10$

1.4 Cold and Hot Mode Shakedown 1-11

1.5 Unit Performance Testing 1-11

1.6 Emissions Performance 1-13

1.7 Combustion and Boiler Efficiency 1-14

1.8 Start-Up and Dynamic Test Results 1-15

1.9 Materials Monitoring $1-16$

1.10 Other Testing $1-16$

$\begin{array}{ll}1.11 \text { Summary } & 1-17\end{array}$

2 PLANT OPERATING HISTORY

2.1 Overview 2-1

2.2 Operations and Outage Summary 2-1

2.3 Acceptance Tests 2-19

2.4 Summary of Equipment and Operating Problems 2-23

3 PLANT COMMERCIAL PERFORMANCE STATISTICS 3-1

3.1 Summary $3-1$

3.2 Definitions for Plant Commercial Performance 3-39 Statistics

4 COLD-MODE SHAKEDOWN AND CALIBRATION 4-1

4.1 Instrumentation Calibrations $4-1$

4.2 System Commissioning 4-14

5 HOT-MODE SHAKEDOWN 5-1

5.1 Pre-Hot-Mode Test Results 5-1

5.2 Objectives and Procedures for Hot-Mode 5-3

5.3 Test Matrix 5-6

$\begin{array}{ll}5.4 \text { Hot-Mode Test Results } & 5-6 \\ 5.5 & 5-7\end{array}$

$\begin{array}{ll}5.5 \text { Conclusions } & 5-18\end{array}$

6 PERFORMANCE TESTING 6-1

6.1 Emissions Data Summary 6-5

6.2 Combustion Efficiency $6-30$

6.3 Boiler Efficiency 6-35 
7 START-UP, COLD AND HOT RESTART CHARACTERISTICS

$7-1$

$7-1$

$\% .1$ Summaxy of Results

7.2 Objectives and Approach

7.3 Cold Start-ups

7.4 Warm Restart

7.5 Hot Restart

$7-2$

$7-2$

$7-11$

$7-18$

8 LOAD FOLLOWING AND RATE OF LOAD CHANGE

\subsection{Objectives and Approach}

8.2 Test Matrix

8.3 'iest Results

8.47MWe/min Ramp Decrease over 40 MWe

$8-1$

$8-1$

$8-2$

$8-4$

$8-12$

9-1

$9-1$

$9-1$

$9-4$

$9-25$

9.3 Gas Traverse Results

9.4 Discussion of Results

$10-1$

$10-1$

$10-1$

$10-2$

$10-7$

$10-14$

10.4 Heat Flux Correlation

10.5 Discussion of Results

$11-1$

11-1

11-1

$11-3$

11-10

12-1

12-1

$12-6$

13-1

13-1

13-8

13.1 Bottom Ash Removal System
13.2 Fly Ash Handling System

14-1

14-1

14-1

14-3

14-4

$14-9$ 
15 BAGHOUSE OPERATION AND PERFORMANCE

$15-1$

15.1 Objectives and Approach

$15-1$

15.2 System Description

$15-2$

15.3 Operational and Performance Data 15-4

15.4 Summary of Bag Failures

$15-17$

15.5 Conclusions

$15-20$

16 MATERIALS MONITORING

$16-1$

16.1 Overview and Summary

16.2 Objectives and Approach

$16-1$

16.3 Summary of Inspections

$16-3$

16.4 Summary of Materials Related Problems

$16-4$

$16-6$

17 RELIABILITY MONITORING

$17-1$

18 ALTERNATE FUELS TESTING

$18-1$

18.1 Test Matrix and Fuel Properties

$18-1$

18.2 Test Results

$18-4$

19 ENVIRONMENTAL PERFORMANCE

$19-1$

19.1 Summary of Environmental Permitting and

$19-1$

19.2 Compliance Monitoring

$19-2$

19.3 Additional Monitoring by the Test Program

$19-2$

19.4 Results from Compliance Monitoring

$19-4$

19.5 Additional Test Program Monitoring

$19-27$

Appendix

Page

A Test Instrumentation Calibration Schedule A-1

B Unit Start-up Sequence B-1 


\section{ILLUSTRATIONS}

\begin{tabular}{|c|c|c|}
\hline $1-1$ & Location of CUEA's Nucla Station & $1-2$ \\
\hline $1-2$ & Original 36 MWe Nucla Station & -4 \\
\hline & Construction of the New 110 MWe CFB Boiler & $1-5$ \\
\hline & Completed 110 MWe Nucla Station with CFB Boiler & $1-6$ \\
\hline & Side View of 110 MWe Nucla CFB Boiler & $1-8$ \\
\hline & Hours on Coal by Month for the Nucla CFB & $2-2$ \\
\hline & Breakdown of Outage Houxs & $2-3$ \\
\hline-3 & $\begin{array}{l}\text { Comparison of Outage and In-Service operation } \\
\text { from Completion of Acceptance Tests }\end{array}$ & $2-4$ \\
\hline-4 & Original PA Fan Wheel Design & $2-27$ \\
\hline & Modified PA Fan Wheel Design & $2-27$ \\
\hline $3-$ & Nucla CFB Operating Availability & 3 \\
\hline $3-2$ & Nucla CFB Equivalent Availability & 4 \\
\hline-3 & Nucla CFB Capacity Factors & 5 \\
\hline-4 & Nucla CFB Net Plant Heat Rate & $3-6$ \\
\hline-1 & $\begin{array}{l}\text { Schematic of Air Flow Measurement System at } \\
\text { Nucla }\end{array}$ & $4-2$ \\
\hline & Typical Air Foil & $4-6$ \\
\hline & $\begin{array}{l}\text { Schematic of Revised Fly Ash Collection and } \\
\text { Measurement System }\end{array}$ & $4-12$ \\
\hline $4-4$ & Isokinetic Sample Probe & $4-16$ \\
\hline-5 & Coal Preparation Flow sheet & -22 \\
\hline-6 & Limestone Preparation Flow Sheet & -24 \\
\hline-7 & Bottom Ash Preparation Flow Sheet & $4-25$ \\
\hline-8 & Fly Ash Preparation Flow Sheet & $4-26$ \\
\hline & $\begin{array}{l}\text { Absolute Uncertainty in Efficiency (Loss } \\
\text { Method) vs. Time }\end{array}$ & $5-9$ \\
\hline-2 & $\begin{array}{l}\text { Absolute Uncertainty in Boiler Efficiency } \\
\text { (I/O Method) vs. Time }\end{array}$ & $5-10$ \\
\hline $5-3$ & $\begin{array}{l}\text { Absolute Uncertainty is Ca/S Molar Ratio } \\
\text { (Sorbent) vs. Time }\end{array}$ & $5-11$ \\
\hline $5-4$ & $\begin{array}{l}\text { Absolute Uncertainty in Sulfur Dioxide } \\
\text { Retention vs. Time }\end{array}$ & $5-12$ \\
\hline $5-5$ & $\begin{array}{l}\text { Absolute Uncertainty in Calcium Utilization } \\
\text { (Sorbent) vs. Time }\end{array}$ & $5-13$ \\
\hline $5-6$ & $\begin{array}{l}\text { Absolute Uncertainty in Net Plant Heat Rate } \\
\text { vs. Time }\end{array}$ & $5-14$ \\
\hline $5-7$ & $\begin{array}{l}\text { Absolute Uncertainty in Combustion Efficiency } \\
\text { vs. Time }\end{array}$ & $5-15$ \\
\hline-8 & Sorbent Feed Rate and $\mathrm{SO}_{2}$ Output & $5-19$ \\
\hline & Sorbent Feed Rate and $\mathrm{SO}_{2}$ Output & $5-20$ \\
\hline-10 & Sorbent Feed Rate and $\mathrm{SO}_{2}$ Output & $5-21$ \\
\hline-11 & Cyclone B Refractory Temperature & $5-22$ \\
\hline-12 & Cyclone B Refractory Temperature & $5-23$ \\
\hline-13 & Cyclone B Refractory Temperature & $5-24$ \\
\hline-1 & Effect of CA/S Molar Ratio on Sulfur & $6-12$ \\
\hline
\end{tabular}




\begin{tabular}{|c|c|c|}
\hline-2 & $\begin{array}{l}\text { Effect of Bed Temperature on Calcium } \\
\text { Requirements for } 75 \% \text { Sulfur Retention }\end{array}$ & $6-14$ \\
\hline $6-3$ & $\begin{array}{l}\text { Calcium Requirements and Sulfur Retentions } \\
\text { for Various Fuels }\end{array}$ & $6-15$ \\
\hline $6-4$ & Effect of Load on Calcium Requirements & $6-16$ \\
\hline-5 & $\begin{array}{l}\text { Effect of Coal Feed Configuration on Calcium } \\
\text { Requirement for Salt Creek Coal }\end{array}$ & $6-17$ \\
\hline-6 & $\begin{array}{l}\text { Effect of Limestone Feed Configuration on } \\
\text { Calcium Requirements }\end{array}$ & $6-19$ \\
\hline-7 & Effect of Excess Air on Calcium Requirements & $6-20$ \\
\hline-8 & Effect of SA/PA Ratio on Calcium Requirements & $6-21$ \\
\hline-9 & Effect of Bed Temperature on NOx Emissions & $6-23$ \\
\hline-10 & Effect of Ca/N Ratio on NOx Emissions & $6-26$ \\
\hline-11 & NOx Emissions by Fuel Type & $6-27$ \\
\hline-12 & $\begin{array}{l}\text { Effect of Coal Feed Configuration on NOx } \\
\text { Emissions }\end{array}$ & $6-28$ \\
\hline-13 & Effect of Excess Air on NOx Emissions & $6-29$ \\
\hline & Effect of Bed Temperature on CO Emissions & -31 \\
\hline-15 & CO Emissions by Fuel Type & $6-32$ \\
\hline-16 & $\begin{array}{l}\text { Effect of Coal Feed Configuration on } \mathrm{CO} \\
\text { Emissions }\end{array}$ & $6-33$ \\
\hline-1 & Effect of Excess Air on CO Emissions & $6-34$ \\
\hline & Temperature vs. Combustion Efficiency & \\
\hline-19 & $\begin{array}{l}\text { Effect of Excess Air on Dry Flue Gas } \\
\text { Exit Loss }\end{array}$ & $6-43$ \\
\hline-20 & $\begin{array}{l}\text { Effect of Combustor Gas Velocity on Unburned } \\
\text { Carbon Loss }\end{array}$ & $6-44$ \\
\hline-21 & $\begin{array}{l}\text { Effect of Bed Temperature on Unburned Carbon } \\
\text { Loss }\end{array}$ & $6-45$ \\
\hline $6-22$ & $\begin{array}{l}\text { Effect of Load on Boiler Heat Losses } \\
\text { (All Salt Creek Coal Tests) }\end{array}$ & $6-47$ \\
\hline-1 & Load \& Steam Conditions for Cold Start-up & $7-4$ \\
\hline-2 & Coal and Gas Flow for cold Start-up & $7-4$ \\
\hline-3 & Air Flow \& Bed Temperatures for Cold Star & $7-5$ \\
\hline $7-4$ & $\begin{array}{l}\text { Cyclone Refractory Temperatures for Cold } \\
\text { Start-up }\end{array}$ & $7-5$ \\
\hline-5 & $\mathrm{O}_{2}$ and CO Emissions During Cold Start-up & \\
\hline-6 & NOx and $\mathrm{SO}_{2}$ Emissions During Cold Start-up & $7-6$ \\
\hline $7-7$ & Dx/Dt of Cyclone Refractory - Cold Start-up & $7-7$ \\
\hline & Dx/Dt of Drum Metal Temperature - Cold Start-up & $7-7$ \\
\hline $7-9$ & $\begin{array}{l}\text { Steam \& Turbine Metal Temperatures - cold } \\
\text { Start-up }\end{array}$ & $7-8$ \\
\hline $7-10$ & $\begin{array}{l}\text { Dx/Dt of Turbine Metal Temperatures - Cold } \\
\text { Start-up }\end{array}$ & $7-8$ \\
\hline 1 & Load \& Steam Conditions for Warm Restart & $7-12$ \\
\hline & Coal and Gas Flow for Warm Restart & $7-12$ \\
\hline & Air Flow \& Bed Temperatures for Warm Restart & $7-13$ \\
\hline & Cyclone Refractory Temperatures for Warm Restart & $7-13$ \\
\hline & $\mathrm{O} 2$ and $\mathrm{CO}$ Emissions During Warm Restart & $7-14$ \\
\hline & NOx and $\mathrm{SO}_{2}$ Emissions During Warm Restart & $7-14$ \\
\hline & Dx/Dt of Cyclone Refractory - Warm Restart & \\
\hline & Dx/Dt of Drum Metal Temperature - Warm Restart & $7-15$ \\
\hline
\end{tabular}




\begin{tabular}{|c|c|c|}
\hline-19 & $\begin{array}{l}\text { Steam \& Turbine Metal Temperatures - } \\
\text { Warm Restart }\end{array}$ & $7-16$ \\
\hline $7-20$ & $\begin{array}{l}\text { Dx/Dt of Turbine Metal Temperatures - } \\
\text { Warm Restart }\end{array}$ & $7-16$ \\
\hline $\begin{array}{l}7-21 \\
7-22\end{array}$ & $\begin{array}{l}\text { Load \& Steam Conditions for Hot Restart } \\
\text { Coal and Gas Flow for Hot Restart }\end{array}$ & $\begin{array}{l}7-19 \\
7-19\end{array}$ \\
\hline-2 & Air Flow and Bed Temperatures for Hot Restart & \\
\hline $\begin{array}{l}7-2 \\
7-2\end{array}$ & $\begin{array}{l}\text { Cyclone Refractory Temperatures for Hot Restart } \\
\mathrm{O}_{2} \text { and CO Emissions During Hot Restart }\end{array}$ & $\begin{array}{l}-20 \\
-21\end{array}$ \\
\hline $7-26$ & NOx and $\mathrm{SO}_{2}$ Emissions During Hot Restart & -21 \\
\hline $7-2$ & Dx/Dt of Cyclone Refractory - Hot Restart & -22 \\
\hline $7-2$ & Dx/Dt of Drum Metal Temperature - Hot Restart & -22 \\
\hline $7-29$ & Steam \& Turbine Metal Temperatures - Hot Restart & -23 \\
\hline $7-30$ & $\begin{array}{l}\text { Dx/Dt of Turbine Metal Temperatures - } \\
\text { Hot Restart }\end{array}$ & -23 \\
\hline-1 & $\begin{array}{l}\text { Schematic of New } 74 \text { MWe Turbines and Three } \\
\text { Existing } 12.5 \text { MWe Turbines }\end{array}$ & $8-3$ \\
\hline-2 & 74 MWe Generator Output and Demand & $8-5$ \\
\hline 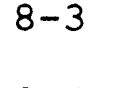 & $\begin{array}{l}74 \text { MWe Generator Output, Boiler Master Output } \\
\text { and } 74 \text { MWe Turbine Throttle Pressure }\end{array}$ & \\
\hline $8-4$ & $\begin{array}{l}\text { Total Plant Load, Main Steam Flow, and } \\
\text { Feedwater Flow }\end{array}$ & $8-6$ \\
\hline-5 & 74 MWe Generator Output and Drum Level & -6 \\
\hline 07 & $\begin{array}{l}\text { Final Superheater Steam Out let Temperature, } \\
\text { Total Attemporator Flow, and Total Plant } \\
\text { Load }\end{array}$ & $8-7$ \\
\hline $8-7$ & $\begin{array}{l}74 \text { MWe Generator Output, lst Stage Pressure, } \\
\text { Extraction Line Pressure to Old Turbines }\end{array}$ & $8-7$ \\
\hline $8-8$ & $\begin{array}{l}74 \text { MWe Generator Output, Governor Valve } \\
\text { Position, Main Steam Flow }\end{array}$ & $8-8$ \\
\hline $8-9$ & $\begin{array}{l}\text { Total Plant Load, Boiler Master Output, and } \\
\text { Combustor A Coal Flow }\end{array}$ & $8-8$ \\
\hline $8-10$ & $\begin{array}{l}\text { Combustor } \mathrm{B} \mathrm{SO}_{2} \text {, Combustor } \mathrm{B} \text { Limestone } \\
\text { Feed Rate, Total Plant Load }\end{array}$ & $8-9$ \\
\hline $8-11$ & Stack $\mathrm{SO}_{2}$, Total Plant Load & $8-9$ \\
\hline $8-12$ & Total Plant Load, A-side $\mathrm{O}_{2}, \mathrm{~B}-\mathrm{side} \mathrm{O}_{2}$ & $3-1$ \\
\hline $8-13$ & Total Plant Load, CO Emissions, Stack NOx & $8-1$ \\
\hline $8-14$ & $\begin{array}{l}\text { Summary of Load Responses Tests for } 40 \text { MWe } \\
\text { Increase in Load }\end{array}$ & $8-1$ \\
\hline & Test LF3: 74 MWe Generator Output and Demand & $8-1<$ \\
\hline & $\begin{array}{l}\text { Test LF3: Total Plant Output, Boiler Master } \\
\text { Output, and } 74 \text { MWe Turbine Throttle Pressure }\end{array}$ & \\
\hline $8-17$ & $\begin{array}{l}\text { Test LF3: Total Plant Output, Main Steam Flow, } \\
\text { and Feedwater Flow }\end{array}$ & $8-15$ \\
\hline $8-18$ & $\begin{array}{l}\text { Test LF3: } 74 \text { MWe Generator Output and } \\
\text { Drum Level }\end{array}$ & $8-15$ \\
\hline $8-19$ & $\begin{array}{l}\text { Test LF3: } 74 \text { MWe Generator Output, Governor } \\
\text { Valve Position, Main Steam Flow }\end{array}$ & $8-16$ \\
\hline $8-20$ & $\begin{array}{l}\text { Test LF3: } 74 \text { MWe Generator Output, 1st Stage } \\
\text { Pressure, Extraction Line Pressure }\end{array}$ & $8-16$ \\
\hline $8-21$ & $\begin{array}{l}\text { bustor } \mathrm{A} \mathrm{SO}_{2} \text { and Limestone } \\
\text { and Total Plant Load }\end{array}$ & $8-1$ \\
\hline
\end{tabular}


Ejgure

Page

\begin{tabular}{|c|c|c|}
\hline $8-22$ & $\begin{array}{l}\text { Test LF3: Total Plant Load, and Final Steam } \\
\text { Pressure and Temperature }\end{array}$ & $8-17$ \\
\hline $8-23$ & $\begin{array}{l}\text { Effect of Extraction Pressure on Main Steam } \\
\text { Flow Calculation }\end{array}$ & $8-19$ \\
\hline $9-1$ & $\begin{array}{l}\text { Plan view of Nucla B Combustor showing location } \\
\text { of fuel, limestone, loop seal and secondary } \\
\text { air feeders }\end{array}$ & $9-3$ \\
\hline $9-2$ & O2 traverses for Peabody coal at three loads & $9-5$ \\
\hline $9-3$ & CO traverses for Peabody coal at three loads & $9-6$ \\
\hline $9-4$ & NOx traverses for Peabody coal at three loads & $9-7$ \\
\hline $9-5$ & SO2 traverses for Peabody coal at three loads & $9-8$ \\
\hline $9-6$ & $\begin{array}{l}\text { O2 traverses for Salt Creek and Peabody coal } \\
\text { at two loads }\end{array}$ & $9-10$ \\
\hline $9-7$ & $\begin{array}{l}\text { Co traverses for Salt Creek and Peabody coal } \\
\text { at two loads }\end{array}$ & $9-11$ \\
\hline $9-8$ & $\begin{array}{l}\text { Nox traverses for Salt Creek and Peabody coal } \\
\text { at two loads }\end{array}$ & $9-12$ \\
\hline $9-9$ & $\begin{array}{l}\mathrm{SO}_{2} \text { traverses for Salt Creek and Peabody coal } \\
\text { at two loads }\end{array}$ & $9-13$ \\
\hline $9-10$ & $\begin{array}{l}\text { Effect of coal feed configuration on } \mathrm{O}_{2} \\
\text { traverses for Salt Creek Coal }\end{array}$ & $9-16$ \\
\hline $9-11$ & $\begin{array}{l}\text { Effect of coal feed configuration on } \mathrm{CO} \\
\text { traverses for Salt Creek Coal }\end{array}$ & $9-18$ \\
\hline $9-12$ & $\begin{array}{l}\text { Effect of coal feed configuration on NOx } \\
\text { traverses for Salt Creek Coal }\end{array}$ & $9-19$ \\
\hline $9-13$ & $\begin{array}{l}\text { Effect of coal feed configuration on } \mathrm{SO}_{2} \\
\text { traverses for Salt Creek Coal }\end{array}$ & $9-20$ \\
\hline $9-14$ & $\begin{array}{l}\text { Comparison of } \mathrm{O}_{2} \text { traverses for } 50 / 50 \text { coal } \\
\text { feed and balanced coal feed }\end{array}$ & $9-21$ \\
\hline $9-15$ & $\begin{array}{l}\text { Comparison of CO traverses for } 50 / 50 \text { coal } \\
\text { feed and balanced coal feed }\end{array}$ & $9-22$ \\
\hline $9-16$ & $\begin{array}{l}\text { Comparison of NOx traverses for } 50 / 50 \text { coal } \\
\text { feed and balanced coal feed }\end{array}$ & $9-23$ \\
\hline $9-17$ & $\begin{array}{l}\text { Comparison of } \mathrm{SO}_{2} \text { traverses for } 50 / 50 \text { coal } \\
\text { feed and balanced coal feed }\end{array}$ & $9-24$ \\
\hline $10-1$ & $\begin{array}{c}\text { Measured vs. Predicted Bed Temperatures for } \\
\text { Phase I Testing on Peabody Coal }\end{array}$ & $10-6$ \\
\hline $10-2$ & $\begin{array}{l}\text { Measured vs. Predicted Bed Temperatures for } \\
\text { Phase II Testing on Salt Creek Coal }\end{array}$ & $10-8$ \\
\hline $10-3$ & Suspension Density vs. Superficial Velocity & $10-11$ \\
\hline $10-4$ & $\begin{array}{l}\text { Bed } \Delta p \text { vs. Superficial velocity for } \\
\text { Combustor } B\end{array}$ & $10-11$ \\
\hline $10-5$ & $\begin{array}{l}\text { Normalized Suspension Density vs. Superficial } \\
\text { Velocity }\end{array}$ & $10-12$ \\
\hline $10-6$ & Heat Flux vs. Superficial velocity & $10-12$ \\
\hline $10-7$ & Heat Flux vs. Suspension Density & $10-13$ \\
\hline $10-8$ & Heat Flux Correlation & $10-13$ \\
\hline $10-9$ & Temperature Response to Load Changes & $10-17$ \\
\hline $\begin{array}{l}10-10 \\
11-1\end{array}$ & $\begin{array}{l}\text { Waterwall } \Delta \mathrm{P} \text { Response to Load Changes } \\
\text { Cvclone } \Delta \mathrm{P} \text { vs. Bed } \Delta \mathrm{P}\end{array}$ & $\begin{array}{l}10-18 \\
11-2\end{array}$ \\
\hline $11-2$ & Cyclone $\Delta \mathrm{P} / \mathrm{Vs}^{2}$ vs & $\begin{array}{l}11-2 \\
11-4\end{array}$ \\
\hline
\end{tabular}


11-3 Measured vs. Calculated Cyclone $\Delta \mathrm{P}$

$11-4$

$11-5$

$11-6$

$11-7$

$11-8$

$11-9$

$12-1$

$12-2$

$12-3$

$12-4$

$12-5$

$12-6$

12-7

13-1

13-2

13-3

$13-4$

13-5

14-1

14-2

14-3

14-4

14-5

14-6

15-1

15-2

$15-3$

$15-4$

15-5

$15-6$

$15-8$

Estimated Cyclone Efficiency vs. Combustor Superficial Velocity

Estimated Recycle Ratio vs. Cyclone Efficiency

Estimated Recycle Rate vs. Superficial Velocity

Temperature Rise Across Cyclone vs. Bed Superficial Velocity

Seal Leg Temperature Minus Cyclone Inlet Temperature vs. Superficial Velocity

Temperature Rise Across Cyclone vs. Cyclone Outlet Pressure

Schematic of Coal Preparation System

Schematic of Coal Feed System

Plan View of Combustor Coal Feed Configuration

Partial Schematic of Limestone Preparation system

Schematic of Limestone Preparation System

Schematic of Limestone Feed system (typical of two)

Plan View of Limestone Feed Configuration

Schematic of Bottom Ash Removal System

Bottom Ash Piping Modification

Modifications to Bottom Ash Weigh Hopper

Exposed Return Bends

Schematic of Fly Ash Disposal System

Schematic of Tubular Air Heater Arrangement

Air Heater Effectiveness vs. Gross Boiler Load

Air Heater Effectiveness vs. Air Heater Inlet

Flue Gas Temperature

Air Heater Effectiveness vs. Flue Gas Moisture

Air Heater Effectiveness vs. Air Heater Log Mean Temperature Differential

Effect of Air Heater Soot Blowing

General arrangement of the baghouse at Nucla

Nucia Baghouse \#4 Pressure Drop vs. Air-toCloth Ratio for Peabody and Salt Creek Coal

Nucla Baghouse \#4 Pressure Drop vs. Air-to-Cloth Ratio for All Coals Tested

Comparison of Tubesheet Pressure Drop vs. Air-to-Cloth Ratio for the New Nucla \#4 Baghouse and the TVA 20MW AFBC Baghouse

Pressure Drop vs. Time Data for Baghouse \#1 and \#4 for Salt Creek and Peabody coals at $60 \mathrm{MW}$ and $101 \mathrm{MW}$

Average Cumulative Percent Mass less than incicated size for the Nucla Unit \#4 Baghouse Inlet

\section{$15-7$}

Average cumulative percent mass less than indicated size for the Nucla Unit \#4 Baghouse Outlet

Average Fractional Efficiency versus Particle Size for the Nucla unit \#4 Baghouse
$11-5$

$11-7$

$11-8$

$11-9$

$11-11$

$11-12$

11-13

12-2

$12-3$

$12-5$

12-7

$12-8$

12-10

12-12

13-2

$13-6$

13-7

13-9

13-10

14-2

14-5

$14-6$

14-7

14-8

14-10

$15-3$

15-8

15-9

15-10

15-11

15-13

$15-13$

15-15 
16-1 Side View Schematic of Windbox Layout 16-8

16-2 Combustor A Lower West Wall Refractory 16-11

Condition (February 1991 Outage)

16-3 Combustor A Lower Refractory Condition (February 1991 Outage)

$16-4$

$16-5$

Refractory Breakage at Refractory/Water-wall Interface in Combustor $B$

$16-6$

Refractory Condition Around Recycle Return in Combustor A (February 1991 Outage)

$16-7$

Bubble Cap Design Modifications

Plan View of Combustor Showing Areas of waterwall and Bubble Cap Erosion

16-8 Bubble Cap Erosion in Combustor A (February 1991 Outage)

$16-9$

Weld Overlay in Good Condition at Refractory/ Water-wall Interface in Combustor B (February 1991 Outage)

16-10 Worn Weld Overlay at Water-wall/Refractory Interface in Combustor B (February 1991 Outage)

16-11 Worn Weld Overlay at Refractory/Water-wali Interface in Combustor B (February 1991 Outage)

16-12 Shelf Formation in the weld overlay in Combustor A (February 1991 Outage)

16-13 Shelf Formation in the weld Overlay in Combustor A (F'ebruary 1991 Outage)

$16-11$

$16-12$

$16-12$

$16-14$

$16-16$

$16-17$

$16-19$

$16-20$

$16-20$

$16-21$

$16-21$

$16-14$

Schematic of waterwall Tube Erosion

$16-22$

$16-15$

Erosion Patterns Initiating from the Membrane in Combustor A (February 1991 Outage)

16-16 Erosion Patterns Initiating from the Membrane

$16-23$ in Combustor B (February 1991 Outage)

16-17 Erosion of Butt welds at Adjoining Water-wall
Panels (February 1991 Outage)

$16-23$

$16-25$

$16-18$

Bowed Section of Waterwall on Front wall of Combustor A (February 1991 Outage)

16-19 Erosion in Waterwalls at the Nose of the Bowed

$16-25$

$16-27$

Water-wall section, Combustor A at $22 \mathrm{ft}$. Elevation (February 1991 Outage)

16-20 Localized Water-wall Erosion Site at the Location of a Scale Discontinuity

16-21 Location of Tube Sample in Superheater II

16-22 Superheater Tube Failures from Combustor B, Second Panel from Erosion on Inside Radius (October 1989 Outage)

16-23 Erosion to Superheater Tubes on Panel 3, Northwest Corner, Tube 32 (February 1991 Outage)

16-24 Secondary Superheater Shelf Arrangement and $16-27$

$16-28$

$16-30$ Erosion Locations Around Water-Tube Supports (February 1991 Outage) 
16-25 Failed Superheater Tube on Combustor $A$ in 16-32

16-26 Bottom Ash Cooler Arrangement

16-27 Schematic of Cyclone Arrangement (typical of 16-37

16-28 "Bullnose" Refractory Condition 16-38

16-29 Refractory Erosion at Impact Area Cyclone B 16-38

16-30 Example of Solids Layering at a Cold Joint 16-40

16-31 Condition of Cyclone A Vortex Finde:- 16-40

16-32 Schematic of Loopseal Arrangement $16-42$

16-33 Brick Reconstruction in Loopseals 16-43

16-34 Pinch Spaling at Brick Joints in the 16-43

17-1 PERFORM Reliability Monitoring set-up sheets 17-3

Required for Generating MWR's
19-1 4th Quarter $1988 \mathrm{SO}_{2}$ Emissions Summary -

19-2 $1989 \mathrm{SO}_{2}$ Emissions Summary - Nucla CFB 19-6

19-3 $1990 \mathrm{SO}_{2}$ Emissions Summary - Nucla CFB 19-7

19-4 1st Quarter $1991 \mathrm{SO}_{2}$ Emissions Summary - 19-8

19-5 4th Quarter 1988 NOx Emissions Summary - 19-9

19-6 1989 NOx Emissions Summary - Nucla CFB 19-10

19-7 1990 NOx Emissions Summary - Nucla CFB 19-11

19-8 1st Quarter 1991 NOx Emissions Summary - 19-12 Nucla CFB 
TABLES

Table

Page

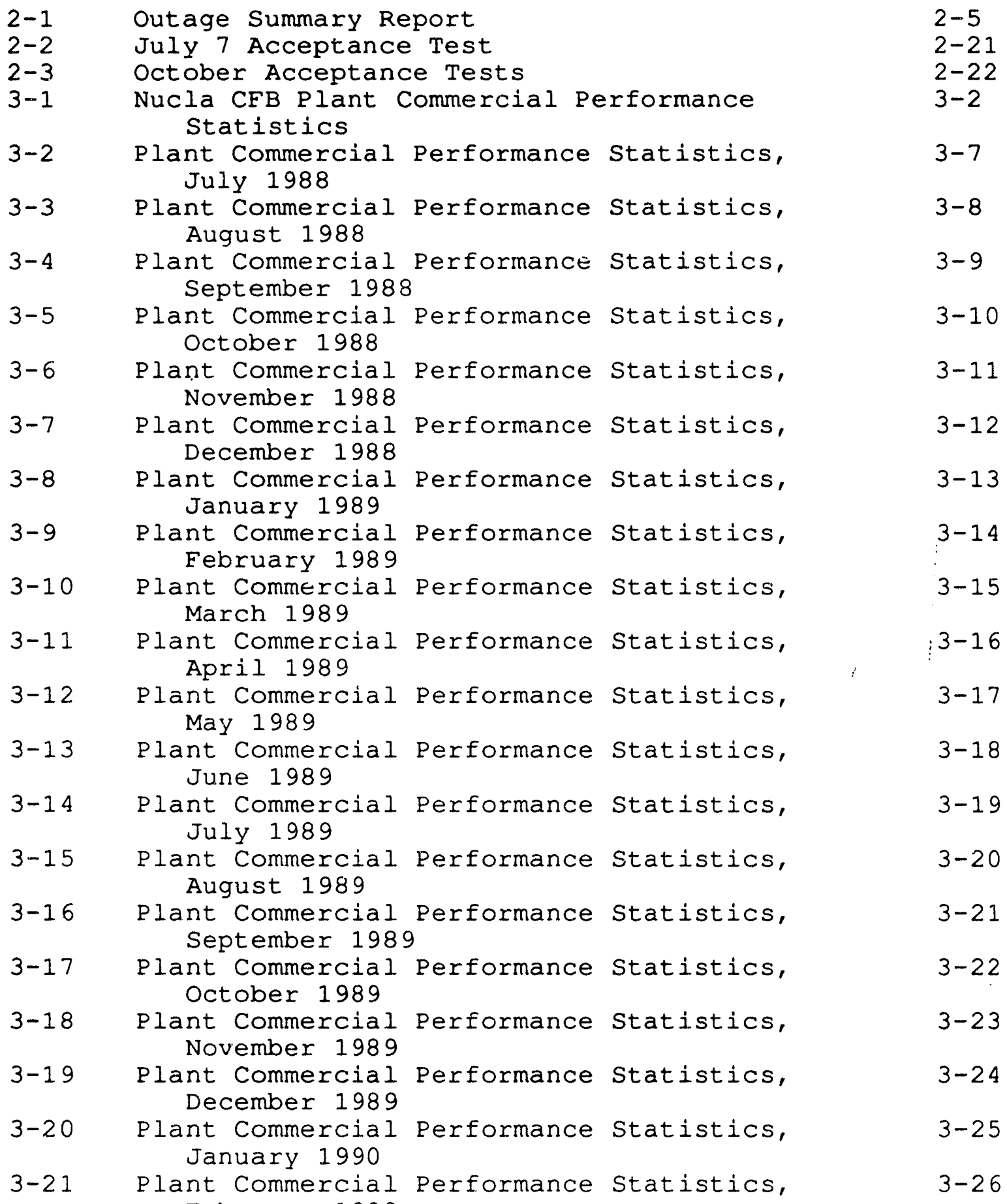
February 1990 

March 1990

3-23 Plant Commercial Performance Statistics, 3-28

3-24 Plant Commercial Performance statistics, 3-29

3-25 Plant Commercial Performance Statistics, 3-30

3-26 Plant Commercial Performance Statistics, 3-31

3-27 Plant Commercial Performance Statistics, 3-32

3-28 Plant Commercial Performance statistics, 3-33

3-29 Plant Commercial Performance Statistics, 3-34

3-30 Plant Commercial Performance statistics, 3-35

3-31 Plant Commercial Performance Statistics, 3-36

3-32 Plant Commercial Performance Statistics, 3-37

3-33 Plant Commercial Performance Statistics, 3-38

4-1 Bottom Cooling Air Flow GFT25 4-7

(Airfoil Pressure Differential \& Flow Data)

$4-2$

$4-4$

Limestone Weigh Feeder Calibration

Bottom Ash Hopper Calibration Data

Isokinetic Sampling Repeatability Test Results

$4-5$

$4-6$

E/FGAS Analyzer Calibration Gasses

$4-8$

$4-10$

$4-17$

$4-20$

Summary Sheets for Test PS17

Student's $t$ Values at the 95\% Probability

$4-29$ Level

5-1 Boiler Efficiency (Loss Method)

$5-2$

$5-3$

$5-4$

$5-5$

$5-6$

$5-7$

$5-8$

$6-1$

$6-2$

$6-3$

$6-4$

$6-5$

$6-6$

Boiler Efficiency (I/O Method)

$\mathrm{Ca} / \mathrm{S}$ Molar Ratio (Sorbent Only)

$4-41$

$5-9$

$5-10$

$5-11$

Sulfur Dioxide Retention Percent

$5-12$

Calcium Utilization (Sorbent Only)

$5-13$

Net Plant Heat Rate

Combustion Efficiency

$5-14$

$5-15$

Results of Variance Analysis

$5-17$

Summary of Performance Test Results

$6-2$

Flue Gas Analys is Summary

Plant Stack Emission Summary

Air Heater Flue Gas Analysis: $\mathrm{SO}_{2}$ Emission

$6-6$

$6-8$

$6-10$

Effect of Limestone Feed on Nox Emissions

$6-24$

Combustion Efficiency and Related Parameters

$6-36$ for All Tests 
6-7 Contributions to Boiler Heat Loss 6-39

6-8 Contributions to Boilex Heat Loss 6-40

6-9 Contributions to Boiler Heat Loss 6-41

$7-1$

$8-1$

$9-1$

$9-2$

$10-1$

$10-2$

$10-3$

$10-4$

$14-1$

$15-1$

$15-2$ Dorchester Coal Tests

Start-Up and Restart Data Summary

Summary of Load Response Tests

Test Conditions for Gas Traverse Tests

$7-3$

$8-2$

$9-2$

Fuels Analyses for Traverse Tests

$9-14$

Location of Pressure Taps and Chordal Thermocouples

Boiler Heat Absorption for Salt Creek Coal 10-3

Boiler Heat Absorption for Peabody Coal 10-4

Heat Flux Data for Combustor B 10-9

Air Heater Gas Outlet Temperature Decrease 14-9

Design Information for the Nucla Baghouse 15-2

Nucla Unit \#4 Baghouse Inlet and Outlet 15-5

Particulate Concentration Data

15-3 Nucla Unit \#4 Baghouse Performance Data 15-7

15-4 Summary of Laboratory Analyses of Dustcake 15-16 Ashes

15-5 Average Flow and Pressure Drop Data for Warp- 15-17 in and Warp-out Bags

$15-6$

CUEA Nucla Station - Bag Failure Documentation

$15-18$

$16-1$

Summary of Unit Inspections

$16-5$

$16-2$

Outage Summary from October 1989 to January 1990

$18-1$

Summary of Alternate Fuels Tests

$16-29$

$18-2$

Summary of Fuel Properties for Salt Creek,

$18-2$ Peabody, and Dorchester Coals

19-1 1988 Quarterly Upper Pond Discharge Monitoring\#003- Cooling Tower.

19-2 1989 Quarterly Upper Pond Discharge Monitoring- 19-15 \#003- Cooling Tower.

19-3 1990 Quarterly Upper Pond Discharge Monitoring- 19-16 \#003- Cooling Tower.

19-4 1991 1st Quarter Upper Pond Discharge

$19-17$ Monitoring- \#003- Cooling Tower.

19-5 1988 Quarterly Lower Pond Discharge Monitoring\#004- Boiler System.

19-6 1989 Quarterly Lower Pond Discharge Monitoring\#004- Boiler System.

19-7 1990 Quarterly Lower Pcnd Discharge Monitoring\#004-Boiler System.

19-8 1991 lst Quarter Lower Pond Discharge

$19-18$

$19-19$

$19-20$ Monitoring- \#004- Boiler System.

$19-y \quad 1988$ Monthly Nucla Station Ash Accounting

$19-21$ Spreadsheet.

19-10 1989 Monthly Nucla Station Ash Accounting spreadsheet. 
19-11 1990 Monthly Nucla Station Ash Accounting $19-24$ Spreadsheet.

19-12 1991 lst Quarter Monthly Nucla Station Ash

$19-25$

Accounting Spreadsheet.

19-13 Nucla CFB Groundwater Monitoring Report Summary

19-14 Initial Nucla CFB Fly Ash Characterization.

19-15 ASTM Water Extractions of Initial and Landfilled Nucla CFB Fly Ash (mg/L, except as noted). 


\section{Policy statement}

The Project Participant does hereby designate this Project Final Technical Report as the official document submission to DOE in accordance with the Cooperative Agreement.

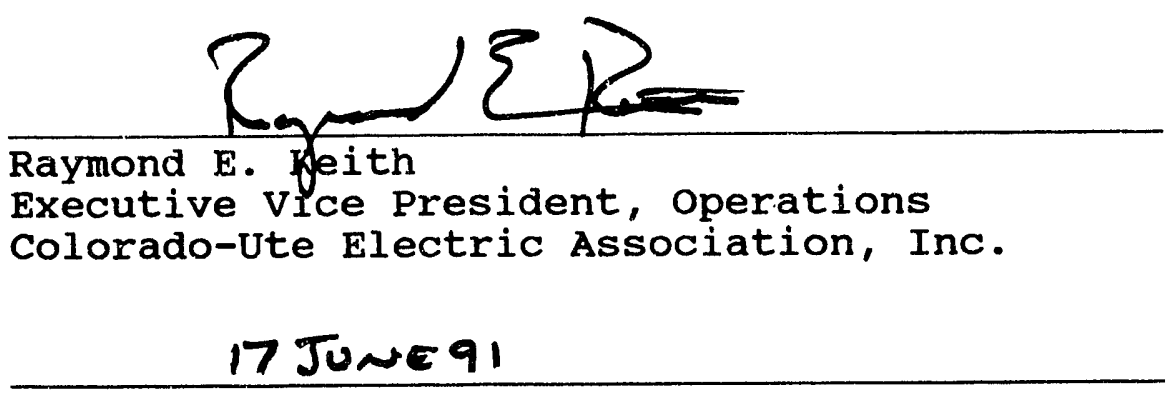

Date 


\section{FOREWORD}

This Final Report on Colorado-Ute Electric Association's (CUEA) Nucla Circulating Fluidized Bed (CFB) Demonstration Program cove:s the period from February 1987 through January 1991. Key results from the Phase I and Phase II test programs are presented. The Phase I test program began in February 1987 and was completed in June 1990. This segment was jointly sponsored by the United States Department of Energy (DOE) and the Electric Power Research Institute (EPRI). The Phase II test program commenced at the conclusion of this period and was completed in January 1.991 with sole sponsorship by the DOE. The DOE Cooperative Agreement, DE-FC21-89MC25137, was awarded to CUEA for this project in August 1988.

The primary objective of this Cooperative Agreement is to conduct a cost shared clean coal technology project to demonstrate the feasibility of circulating fluidized bed combustion technology and to evaluate the economic, environmental, and operational benefits of CFB steam generators on a utility scale. At the conclusion of testing in January 1991, this objective was completed and the analysis of results is documented in this final report, three annual progress reports, and an economic evaluation report.

CUEA's original Nucla station was built in 1959 and consisted of three identical stoker-fired units, each rated at 12.5 MWe. Due to its reduced position on the dispatch order resulting from poor station efficiency and increased maintenance costs, the decision was made in 1984 to upgrade and repower the station with a new $925,000 \mathrm{lb} / \mathrm{hr}$ circulating fluidized bed boiler and 74 MWe turbine-generator. This followed a detailed review of existing technologies, including several bubbling and circulating fluidized bed designs.

At this time, there were several small bubbling FBC's operating in the United States, but it wasn't until 1985 that the first two industrial CFB's built by Pyropower came into commercial operation. The boiler contract for Nucla was eventually awarded to Pyropower for their proposed CFB design. Utilizing twin combustion chambers, each chamber represented a 2:1 scaleup in height and plan area from their pilot plant in Karhula, Finland.

Except for the old stoker-fired units, most of the equipment from the old plant, including the turbine-generator sets, was refurbished and reused, bringing the total plant electrical output to $110 \mathrm{MWe}$. Using finalized capital cost numbers, this upgrade and life extension using CFB technology was accomplished for approximately $\$ 1021 /$ gross $\mathrm{kW}$. The project 
offered several advantages to CUEA including a station heat rate improvement of $15 \%$, reduced fuel costs due to the inherent fuel flexibility of the CFB design, lower emissions required by New Source Performance Standards, and life extension 30 years beyond that of the plant's original design.

Construction of the new CFB boiler began in the spring of 1985 and was completed over a two year period. First turbine roll was initiated in May 1987 and first coal fires were achieved in June of that year. Following a start-up period which was prolonged by a two month outage from an overheat incident, acceptance tests on the design western bituminous coal were performed in October 1988, and operational tests on a high ash ( $\sim 35$ wt. $\left.\frac{8}{8}\right)$ and high sulfur $\left(\sim 1.5\right.$ wt. $\left.\frac{\circ}{8}\right)$ western bituminous coals were conducted the following year.

Detailed planning for a test program was initiated by EPRI in 1985. Preparation for the test program commenced in February 1987 with the arrival on site of a permanent testing staff. Through the third quarter of 1988, the Cold-Mode Shakedown Plan was implemented. This involved calibrating instruments, commissioning the data acquisition system, developing specialized software, procuring and commissioning equipment for the solids preparation laboratory and other specialized test instrumentation, developing procedures, and training test personnel. This work was largely completed by October 1988. Also during this period and through the remainder of the test program, data were collected to satisfy the requirements of ongoing test plans. These included the collection of plant commercial performance statistics and information related to the operating performance of the solids feed and disposal systems, tubular air heater, baghouses, and CFB materialsrelated components.

In August 1988, after expressing interest in the Nucla project as part of its Clean CoaI Technology Program, the U.S. Department of Energy awarded a cooperative agreement to the Colorado-Ute Electric Association as co-sponsors of the test program. This was after careful review of the overall scope and objectives of the Nucla project to verify the DOE's criteria for demonstrating clean coal technology in new and retrofit/upgrade applications.

Detailed performance testing of the Nucla CFB at specified unit operating conditions commenced in March 1989 with the completion of the Hot-Mode Test Plan. The objective of this plan was to establish the conduct for performing future boiler performance tests, including the required times to steadystate, the required number of solids samples and data points to assure results accuracy, and the required duration of each test.

From April 1988 through the completion of the Phase I test program in June 1990, a total of 45 steady-state performance 
tests were completed. These tests established the effects of load, excess air, primary to secondary air ratio, unit operating temperatures, coal and limestone feed configurations, and coal type and size distributions on emissions performance, and combustion and boiler efficiencies. Data were also collected from these tests to quantify heat transfer in the combustion chambers, tubular air heater effectiveness, and baghouse collection efficiency. Dynamic response and unit start-up data were collected to determine any CFB technology limitations and to optimize unit performance. Using watercooled traversing probes, gas samples were extracted from two elevations in the freeboard region of each combustion chamber to determine the extent of solids and gas mixing.

During the Phase II test program between July 1990 and January 1991, an additional 27 steady-state performance tests were conducted. These additional tests provided new information in areas with limited test results from Phase I. Tests were also completed on Dorchester coal as part of alternate fuels testing. This coal had a much higher sulfur content $(\sim 1.5$ wt. of) compared to Salt Creek coal ( 0.5 wt. \%) and a local Nucla coal ( 0.7 wt. $\frac{\circ}{0}$ ) used in earlier tests. In addition, dynamic response tests were completed at rates up to $7 \mathrm{MWe} / \mathrm{min}$.

In summary, a total of 72 steady-state performance tests were completed during the Phase I and II test programs. Of these tests, 8 were conducted on a local Nucla coal and 2 on a local Dorchester coal as part of alternate fuels testing, and 62 were completed on Salt Creek coal. This latter coal was the baseline fuel used for the test program. A total of 22 tests were performed at $50 \%$ MCR, 6 tests at $75 \%$ MCR, 2 tests at $90 \%$ MCR, and 42 tests at full load ( $110 \mathrm{MWe}$ ). Except for limestone sizing tests, which were not possible with existing plant preparation equipment, all independent process variables proposed in the original test matrix were completed.

Test results and information collected to satisfy the objectives of the original test plans are presented in this Final Report. Detailed data and support information are contained in the Annual Reports for 1987-1988, 1989, and 19901991. The outline for presentation in this report includes a summary of unit operations along with individual sections for each of the study plan areas. These include cold-mode shakedown and calibration, hot-mode shakedown, plant commercial performance statistics, performance testing, unit start-up (cold, warm, and hot), load following and rates of load change (dynamic response), solids and gas mixing, heat transfer, hot cyclone performance, coal and Iimestone preparation and handling, ash handling system performance and operating experience, tubuiar air heater, baghouse operation and performance, materials monitoring, reliability monitoring, and alternate fuels testing. 
The program on the Nucla CFB began in February 1987 with the mobilization of permanent staff to the site. Since then, unit operations, acceptance test results, equipment reliability, performance statistics, and steady-state performance test results have been documented in three Annual Reports and this Final Report. These reports are a valuable resource for utilities, industrial users, and independent power producers planning new capacity and considering CFB technology as an option. The database and information generated during the course of the Phase I and II test programs is the most comprehensive and available resource of its kind in the CFB technology area.

This report was prepared by Combustion Systems Incorporated for the Colorado-Ute Electric Association with assistance and input from CUEA. The following individuals from CUEA are responsible for the implementation of the DOE agreement:

Raymond E. Keith, Acting Project Manager, Business Contact Thomas J. Heller, Technical Contact

Stuart A. Bush, Senior Engineer, Project Coordinator

CUEA, Inc. would like to acknowledge the Electric Power Research Institute (EPRI) for providing use of their test hardware and software in completing this report and for their direct involvement and sponsorship of the Phase I test program, of which some data are reported herein. 
Section 1

SUMMARY

This report summarizes information and test data collected during the course of the Phase I and Phase II test programs on Colorado-Ute Electric Association's Nucla CFB. Both phases of testing were completed between the period from February 1987 through January 1991. Results in sixteen topical areas are presented as individual sections in this report. In addition, section 2 contains highlights of the unit operating history and includes an outage summary and review of equipment problems. Detailed background and supporting data for each of the topical report areas are contained in the three Annual Reports for 1987-1988, 1989, and 1990-1991.

\subsection{PROJECT OVERVIEW}

Colorado-Ute Electric Association began a study to evaluate options for upgrading and extending the life of its Nucla power station in 1982. Located in southwestern Colorado near the town of Nucla (see Figure 1-1), this station was commissioned in 1959 with a local bituminous coal as its design fuel for three identical stoker-fired units, each rated at 12.6 MWe. Poor station efficiency, high fuel costs, and spiraling boiler maintenance costs forced the Nucla Station into low priority in the CUEA dispatch order as early as 1981 .

Among the options CUEA considered was to serve as a host utility to demonstrate Atmuspheric Fluidized Bed Combustion (AFBC) technology. The anticipated environmental benefits and apparent attractive economics of a circulating $A F B C$ led to Colorado-Ute's decision to proceed with the design and construction of a demonstration project in 1984 at the Nucla facility.

Studies produced by the company in 1983 and 1984 indicated that the new circulating $A F B C$ boiler technology would:

- Increase plant capacity from 36 MWe net to 100 MWe net for an investment of approximately $\$ 840 / \mathrm{kW}$;

- Improve the station heat rate by approximately 15\%;

- Reduce fuel costs (approximately 30\%) by burning the local area, lower quality coal; 


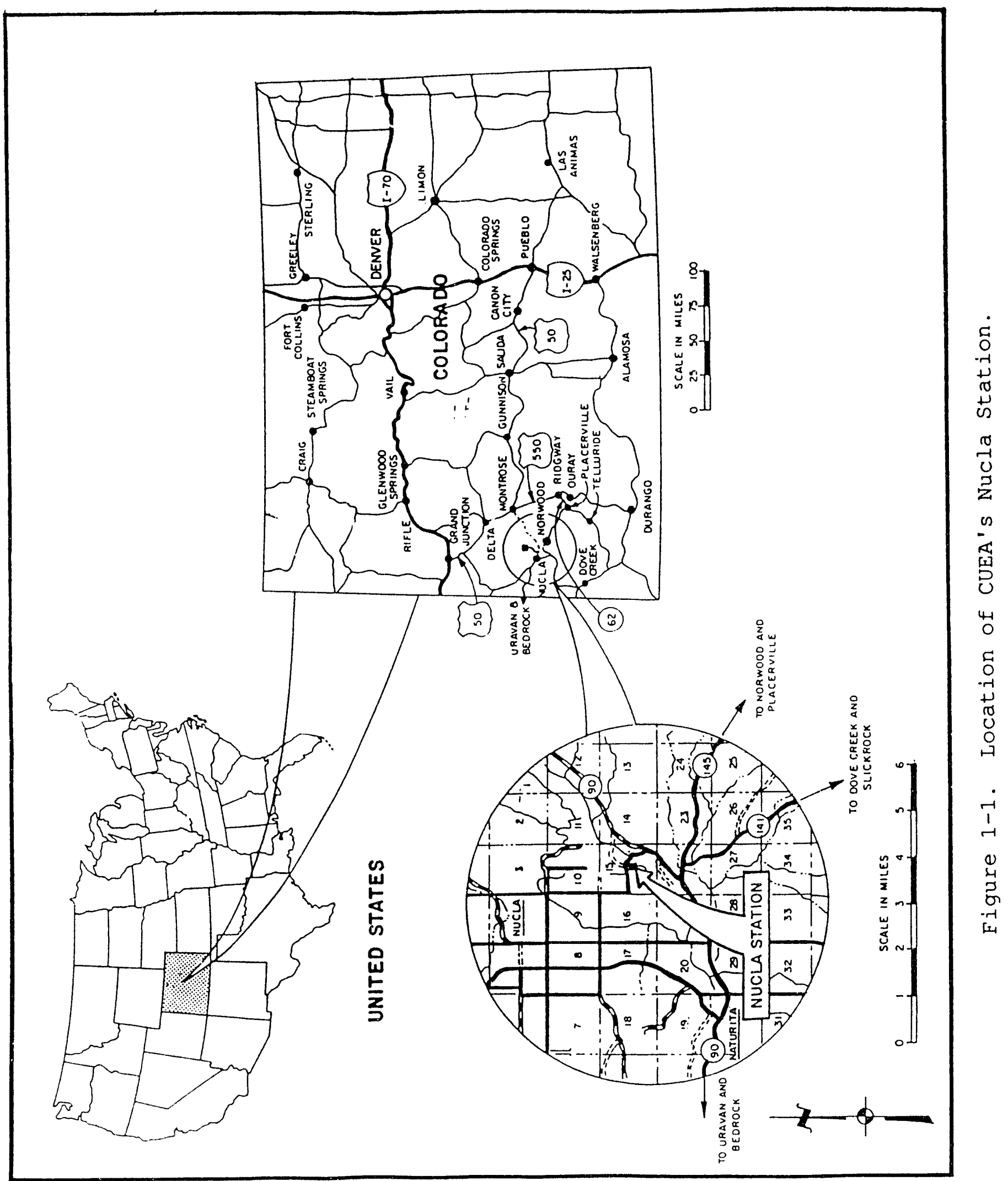


- Reduce emissions to the point where anticipated New Source Performance Standards for $\mathrm{SO}_{2}$ and $\mathrm{NO} x$ could be met; and

- Extend the plant operating life by approximately 30 years.

Many factors went into Colorado-Ute's decision to proceed with the demonstration project. Among these were two Electric Power Research Institute (EPRI)-sponsored boiler design studies conducted by Combustion Engineering/Lurgi and Pyropower Corporation (a subsidiary of Ahlstrom) in late 1983. Based on lower combined capital and life-cycle costs, a boiler contract was awarded to Pyropower for its CFB design in late 1984. Tests of the local Nucla coal and limestone at Ahlstrom's CFB pilot plant in Karhula, Finland produced results that enabled further refinement of tre design of the boiler and complementary auxiliary equipment.

To reduce the potential technical risks assumed by CUEA in this first utility-sized circulating AFBC demonstration in the Unites States, CUEA negotiated the following two agreements:

- The various equipment vendors and the architect/engineer of the project agreed to postpone payments intil the unit was operational.

- A two-year test program was funded by EPRI to characterize performance of the plant. EPRI assumed the risk for non-economical operation during the same period.

In 1984, the National Rural Utilities Cooperative Finance Corporation (CFC) approved a loan for the total project cost of $\$ 87$ million. Regarding permits and licensing, the Rural Electrification Administration (REA) gave its approval on the basis of the borrower's environmental report in a relatively short period of time. This was possible because an environmental impact statement was not required.

The Nucla Circulating AFBC demonstration project consisted of in-place retirement of the three stoker-fired boilers and replacement with a new circulating AFBC boiler and balanceof-plant equipment to increase the station's net generating capacity from 36 MWe to 100 MWe. The original station is shown in Figure 1-2. Construction of the new boiler began in 1985. The completed boiler house superstructure is shown in Figure 1-3. The completed plant is shown in Figure 1-4. The balance-of-plant equipment included a new single automaticextraction turbine-generator unit. The modification and refurbishment of the three existing steam turbine-generator units, addition of coal-handling equipment and a baghouse to 


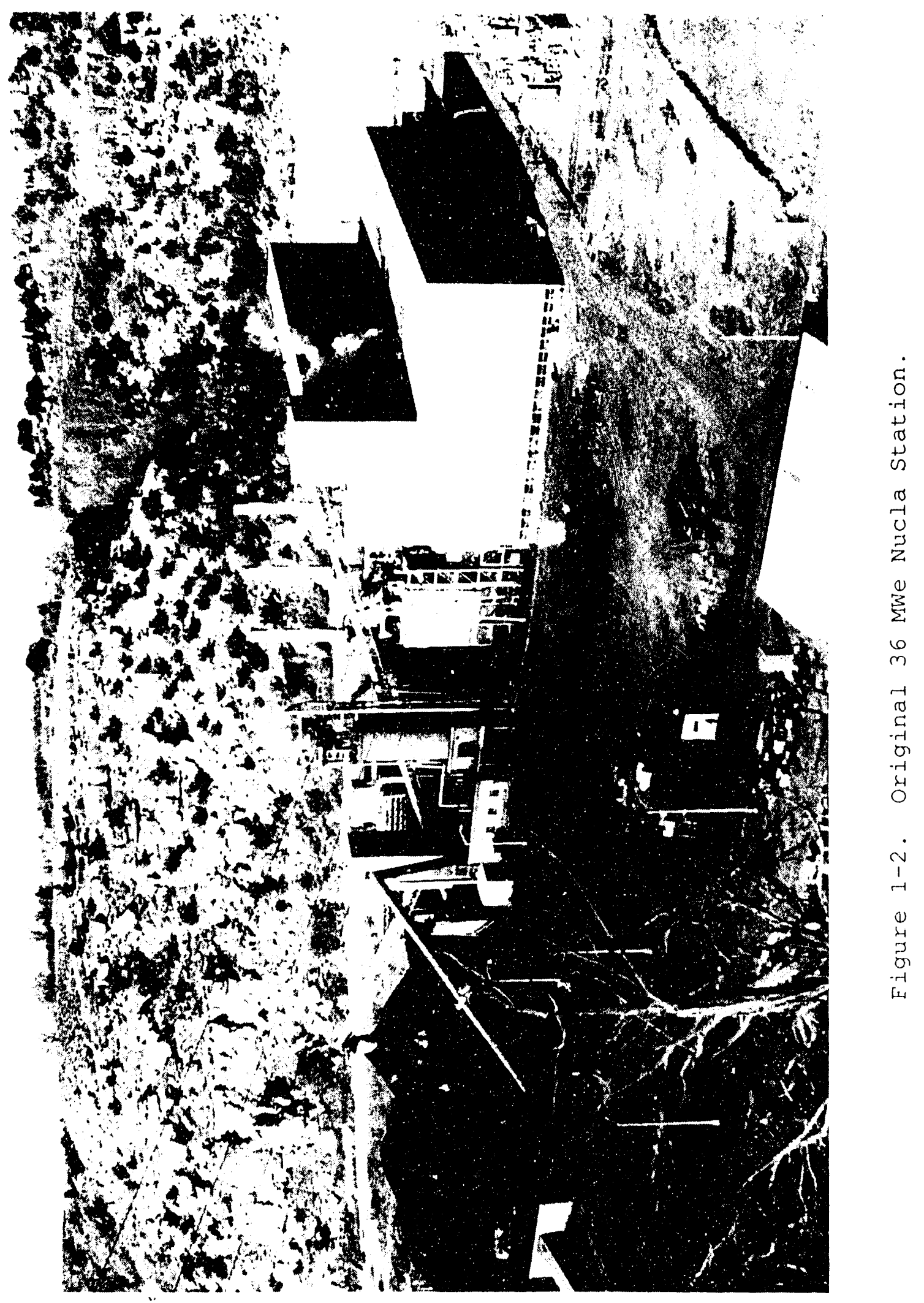




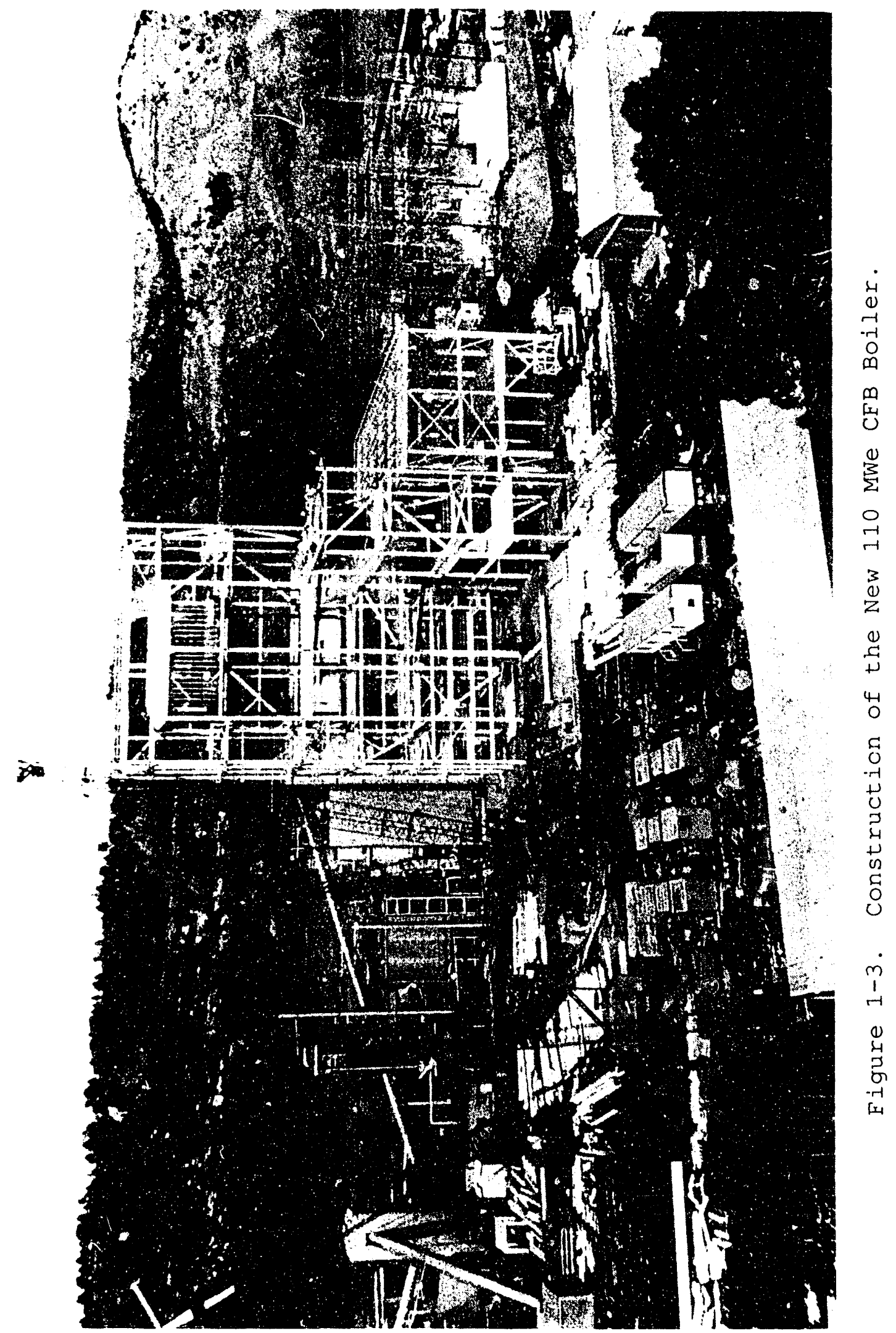




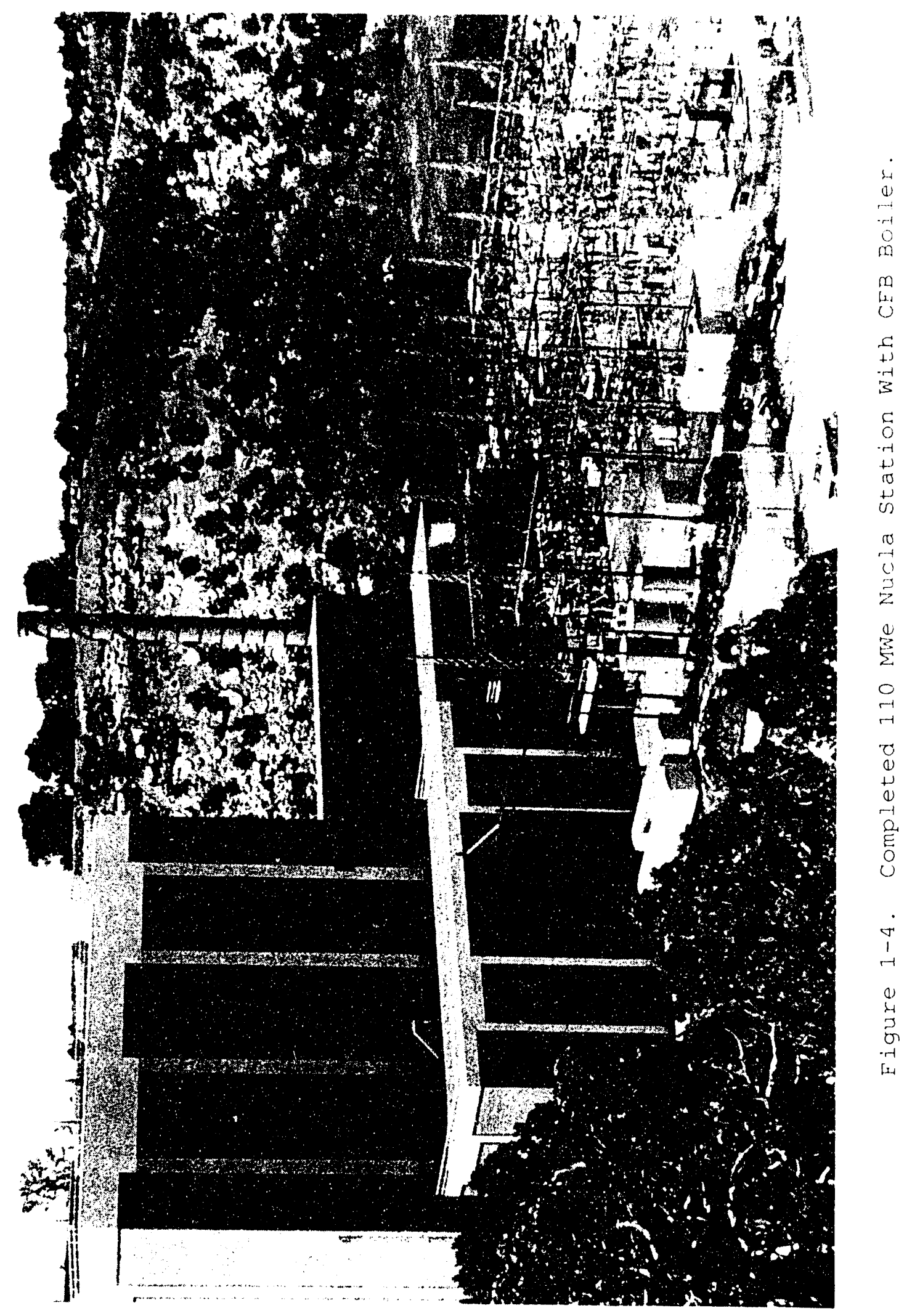


the existing plant system, and installation of new limestonehandling equipment rounded out the project.

The circulating fluidized-bed boiler (CFB) generates 925 $\mathrm{klb} / \mathrm{h}$ of steam at $1500 \mathrm{psig}$ and $1005^{\circ} \mathrm{F}$, utilizing a twin combustion chamber design with a height of approximately 110 feet and a total plan area of 1055 square feet. At the time of the design, the twin chamber design allowed for a safer 2:1 scale-up from the previous plant designs.

The two combustion chambers have individual systems for fuel. air, and sorbent supply and ash removal. Because both chambers share a common steam/water circuit and steam drum, independent firing is not possible. Coal is gravity fed at two locations along the front wall and to the recycle loop seal return leg along the rear wall of each chamber.

Limestone is pneumatically conveyed in the vicinity of the coal feed points along the front and rear walls and to a single location along the side wall of each chamber.

Figure 1-5 is a side view of the combustion chambers, cyclone separator, convection pass, and tubular air heater. Each combustion chamber is equipped with wrap-around, radiant superheater surface along three walls in the upper furnace section. The cyclones are approximately 23 feet in diameter and are refractory lined with a combined 1 foot layer of insulating and abrasion resistant refractory surface. The outlets of the cyclones join together and enter a common convection pass. Captured solids are recycled to the combustion chambers through loop seals located near the bottom of each chamber. Flue gas flows through a commion convection pass, tubular air heater, shake/deflate type baghouses (three from the original stoker-fired units and a fourth new baghouse), and induced draft fan to the stack.

Extensive use of existing equipment was made during the plant modifications. This includes the coal receiving, preparation and storage equipment, baghouses, feed water systems, condensers, and the three 12.5 MWe turbine generators. Extraction steam from a new 74 MWe turbine is used to supply the existing 610 psig turbines. The three old stoker units, including their feed and draft systems and high pressure feed water heaters, represent the major equipment items retired for the upgrade.

The plant was designed to burn a locally mined western bituminous coal, Peabody, with a high variability ash, heating value, moisture, and sulfur content. Table 1-1 summarizes the properties of this coal and the ranges of values burned. The coal supply was changed in the summer of 1989 to take advantage of a more economical fuel supply. The new coal, Salt Creek, is also a western bituminous coal, but is more homogeneous and has less ash than the design coal. The properties of Salt Creek coal are also listed in Table 1- 


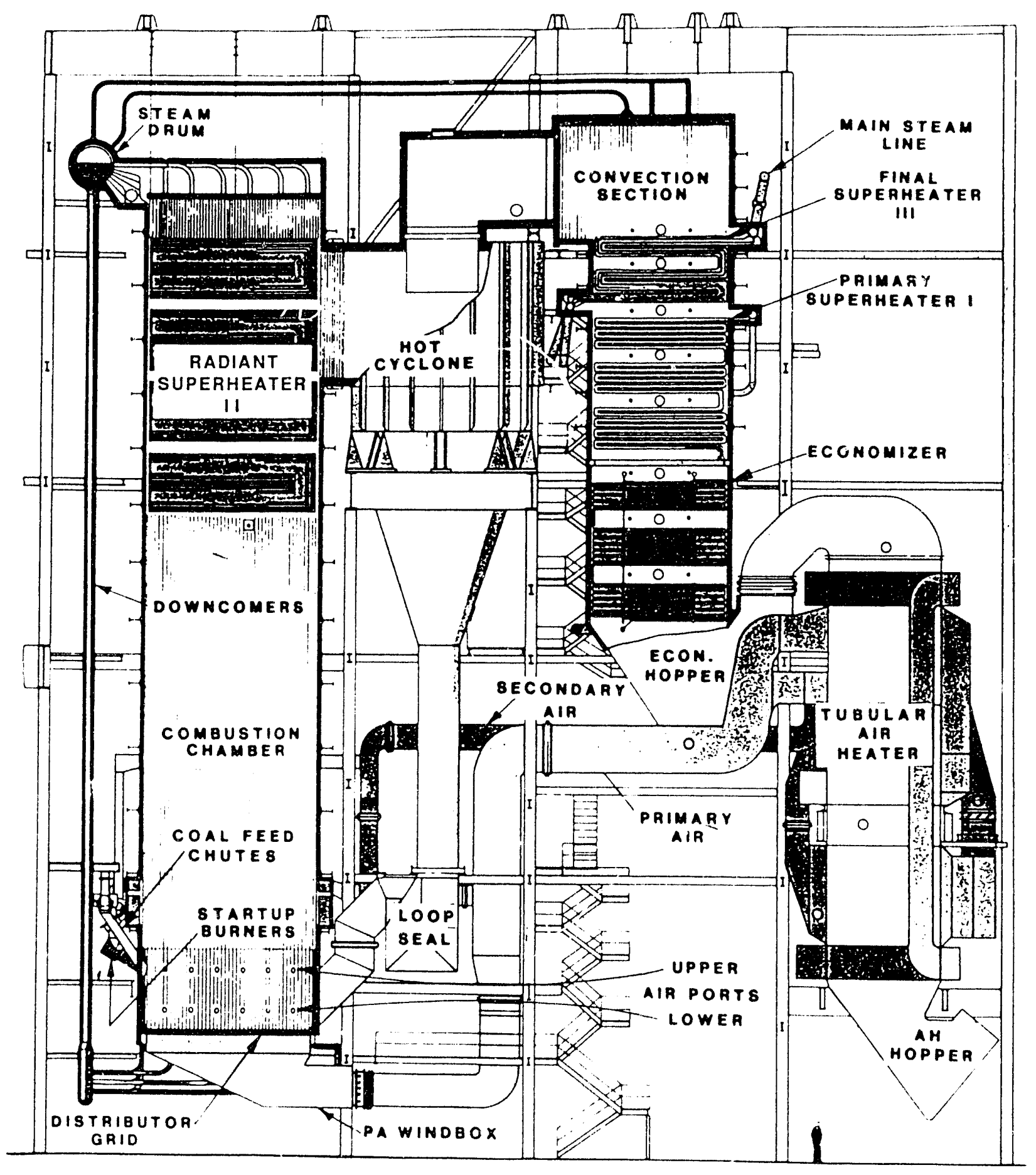

Figure 1-5. Side View of 110 MWe Nucla CFB Boiler. (Source: Pyropower Corporation) 
1. The state emission regulations are compatible with the New Source Performance Standards for this size unit and are shown in Table 1-2. Supplemental NOx control schemes are not required to meet these standards. $\mathrm{SO}_{2}$ emissions are controlled with limestone addition to the lower region of the combustion chambers.

Table 1-1. Properties of Peabody and Salt Creek Coals

$\begin{array}{lcc}\text { Heating Value, BTU/lb } & \text { Peabedy } & \text { Salt Creek } \\ \text { Sulfur, wt } & 790-11,840 & 10,460 \\ \text { Ash, wt \% } & 0.51-2.75 & 0.44 \\ \text { Moisture, wt \% } & 9.8-42.8 & 14.6 \\ \text { Fixed Carbon, wt } & 4.1-14.9 & 10.0 \\ \quad \text { (acceptance test value) } & 43.5 & 43.4 \\ \text { Volatiles, wt \% } & 28.4 & 32.3 \\ \quad \text { (acceptance test value) } & & \end{array}$

$\begin{array}{ll}\text { Table 1-2. Nucla Plant Emission Requirements } \\ \\ \text { Particulates } & 0.03 \text { lb/MBtu } \\ \mathrm{NO}_{\mathrm{X}} & 0.5 \mathrm{~b} / \mathrm{MBtu} \\ \mathrm{SO}_{2} & 0.4 \mathrm{~b} / \mathrm{MBtu} \\ \mathrm{CO} & \text { No Requirements }\end{array}$

Because of the potential offered by use and commercialization of circulating AFBC technology to the electric power industry, Colorado-Ute Electric Association, Inc. and the Electric Power Research Institute initiated a program to study the Nucla $C F B$ and its operating characteristics. This project is being conducted in conjunction with two other EPRI-sponsored AFBC demonstration projects: Northern States Power Company's bubbling AFBC 130 MWe Black Dog demonstration and Tennessee Valley Authority's bubbling AFBC 160 MWe Shawnee demonstration. For the Nucla demonstration, EPRI installed special hardware for the program including instrumentation, data acquisition and processing equipment, and facilities necessary to conduct a two-year test program. The U. S. Department of Energy likewise participated in the project through the Clean Coal Technology Program - Phase I. The Cooperative Agreement, DE-FC21-89MC25137, was administered by DOE's Morgantown Energy Technology Center located in Morgantown, West Virginia.

\subsection{UNIT OPERATING STATISTICS}

In section 3, monthly unit operating statistics are presented since July 1988, at which time the test program's data acquisition system and software became fully operational. From this point through January 1991, the plant operated with 
an average availability of $58.3 \%$ and a capacity factor of 39. $6 \%$. Since first coal fires in June 1987, the plant has accumulated 15,700 operational hours on coal. The average on-line net plant heat rate since september 1988 has been $12,099 \mathrm{Btu} / \mathrm{kWh}$. A comparison of these values with averages compiled by the North American Reliability Council Generating Availability Data System (NERC GADS) for non-CFB coal-fired units in the 100-199 MWe size range between 1984 and 1988 indicates average availability and capacity factors of 83.9 \% and $49.7 \%$, respectively.

Although many of the operating problems which contributed to these statistics at Nucla can be attributed to "firstgeneration" CFB equipment component design, the total quantity and duration of outages were often affected by factors related to the demonstration nature of this project. For example, periodic boiler inspections were made as part of the test program's materials monitoring plan (Section 16), which initiated or extended unit outages. The lack of power demand during certain periods also contributed to the latter. In addition, capacity factors were affected by extensive part-load testing.

The largest CFB-related contributor to plant outage time has been from secondary superheater tube failures. Although this problem has been addressed temporarily through an operational change, it contributed to over $70 \%$ of the outage time between October 1989 and January 1991. Other CFB-related outages over the course of the test program have been required for refractory repairs, primary air fan upgrades, bubble cap replacement, bottom ash disposal system upgrade, and limestone feed system modifications. Most of these problems have been addressed, and unit operating availabilities have shown marked improvements through the fourth quarter of 1990.

\subsection{RELIABILITY ISSUES}

In order to demonstrate long-term reliability, operability, and reduced maintenance costs of the Nucla CFB, several problems remain to be addressed at the conclusion of the four year test program. These are summarized below and are discussed in greater detail in this report.

- Refractory condition in the lower combustion chambers, cyclone "bull nose" and impact areas, the cyclone conical sections and downcomers, and certain regions in the loop seals.

- Structural integrity of the cyclone vortex finders.

- Air distributor bubble cap erosion and retention.

- Adequate means for the collection and removal of backsifted bed material in the windboxes. 
- Water-wall tube erosion at the lower combustion chamber refractory interface and on sections of the water walls that were warped during the 1987 overheat incident.

- Secondary superheater erosion on out-of-plane tubes and on the back side of panels in regions conducive to solids flow channeling.

- Long-term overheat of secondary superheater tubes. This has been addressed temporarily through an operational change resulting in an increase in plant heat rate.

- Temperature matching between combustion chambers in order to optimize limestone consumption for $\mathrm{SO}_{2}$ control.

\subsection{COLD - AND HOT-MODE SHAKEDOWN}

Results from these two topical areas are discussed in Sections 4 and 5 of this report. Both cold- and hot-mode shakedown testing are the first activities to be completed in the conduct of a test program and form the foundation for all future testing. Cold-mode calibration and preparation covers the basic scope and design of the test program and involves calibrating instruments, commissioning the data acquisition system, developing specialized software, procuring and commissioning equipment for the solids preparation laboratory and other specialized test instrumentation, developing detailed test plans and procedures, and training test personnel.

Hot-mode testing follows and is used to establish required times to steady-state, test duration, and data quantities necessary to assure the proper uncertainty in test results. Based on this testing, a 24 to 48 hour period was established as the time required for the unit to reach steady-state following changes to unit operating conditions such as load and $\mathrm{Ca} / \mathrm{S}$ ratio. A total of 5 coal, 2 limestone, 2 bottom ash, and $6 \mathrm{fly}$ ash samples were required to achieve the proper uncertainty levels in calculated results. This established a test duration for performance testing of 6 hours, based on the manpower availability for solids sampling. All other data points are collected on the plant's digital control system at a frequency much higher than necessary for assuring proper results uncertainties.

\subsection{UNIT PERFORMANCE TESTING}

Following the completion of cold- and hot-mode testing, a total of 72 steady-state performance tests were conducted between April 1989 and January 1991 as part of the Phase I and II test programs. Unit performance testing, discussed in section 6 , formed the bulk of the overall test program 
effort, including manpower resources and expenses, and also generated the most substantial database compared to that acquired in other topical report areas. A total of 22 tests at $50 \% \mathrm{MCR}, 6$ tests at $75 \% \mathrm{MCR}, 2$ tests at $90 \% \mathrm{MCR}$, and 42 tests at $100 \%$ MCR were completed. Operating variables that were tested include load, operating temperature, excess air, primary to secondary air ratio, $\mathrm{Ca} / \mathrm{S}$ molar ratio, coal and limestone feed distribution, and coal type and sizing.

Performance testing was complicated by the inability to control operating temperatures within set ranges during series of tests. This made parametric testing, in which one variable is changed while all other variables are fixed, difficult to implement. Unit operating temperatures were found to increase with unit load from approximately 1450-1550 ${ }^{\circ} \mathrm{F}$ at half load to over $1700^{\circ} \mathrm{F}$ at full load. For tests conducted at the same load under nearly identical operating conditions, differences in operating temperatures were related to the solids distribution in the freeboard region of the combustors. Adjustments to ash cooler classifying velocities, total bed inventory, and primary to secondary air ratio did not significantly affect the solids distribution or operating temperatures. Rather, the ash content in the input coal stream, which is an uncontrollable parameter, had the greatest impact on solids density profiles and combustor operating temperatures.

Another difficulty with performance testing, particularly at full load, was the existence of a temperature differential between combustors which, at times, exceeded $100^{\circ} \mathrm{F}$ at full load. Operating temperatures are higher on combustion chamber $B$ due to poorer distribution of solids in the freeboard region when compared to chamber $A$. This results in lower heat transfer rates to the water walls. The cause for the denser bed at the bottom of chamber $B$ is not clearly understood. Gross physical differences between the combustion paths include the warped water walls in combustor A (which may improve internal circulation) and cyclone orientation. The vortex finder on cyclone $B$ was straightened in March 1990, but this did not improve solids collection efficiencies or eliminate the temperature differential.

As a result, tests with a large temperature differential were conducted as "split" combustor tests in which emissions performance from each combustor is analyzed separately. Because fly ash samples are common to both combustion chambers and cannot be separated, combustion and boiler efficiency calculations are based on average operating conditions, i.e., combustor temperatures from both chambers. This method of testing provides a simultaneous comparison of the effects of process temperature on emissions performance, and yields two data sets for each test. 


\section{6 EMISSIONS PERFORMANCE}

Emissions data are presented in this report for all steadystate performance tests. Results indicate strong correlations of absolute $\mathrm{CO}, \mathrm{SO}_{2}$, and $\mathrm{NO}_{\mathrm{x}}$ emission levels with combustor operating temperatures. Although compliance is maintained within NSPS for each emission type, a penalty on limestone feed requirements for sulfur retention is realized at the higher operating temperatures. For temperatures below $1620^{\circ} \mathrm{F}, 70 \%$ retention is achieved with a $\mathrm{Ca} / \mathrm{S}$ ratio of 1.5 . 95\% retention is achieved witli a $\mathrm{Ca} / \mathrm{S}$ ratio of 4.0. At combustor operating temperatures around $1700{ }^{\circ} \mathrm{F}$, a $\mathrm{Ca} / \mathrm{S}$ ratio of greater than 5.0 is required to maintain $70 \%$ sulfur retention. In addition to the costs of higher limestone consumption, solids waste quantities also increase along with associated disposal costs. Increased limestone feed, with all other operating conditions held constant, also resulted in an increase in $\mathrm{NO}_{\mathrm{x}}$ emissions. Despite this increase, $\mathrm{NO}_{x}$ emissions remained within compliance levels at Nucla for all performance test configurations.

During performance tests, emissions were monitored for different coal and limestone feed distributions, primary to secondary air ratios, and excess air ratios. Uniform coal distribution between the front and rear walls of each combustion chamber gave the best sulfur capture results, particularly at full. load and at high operating temperatures. This suggests that additional coal feed points or enhanced mixing in the lower chambers may improve performance. Only a limited number of limestone feed configuration tests were conducted because of mectanical limitations with the feed equipment. Tests with limestone feed points out of service did not indicate any significant change in sulfur capture performance compared to baseline tests.

The effect of excess air on emissions performance is difficult to interpret since increased excess air results in lower combustor operating temperatures at a given load. This generally results in lower $\mathrm{NO}_{\mathrm{X}}$ emissions and $\mathrm{Ca} / \mathrm{S}$ ratio requirements, and higher Co emissions. Excess air below 10\% resulted in increases in $\mathrm{CO}$ emissions due to incomplete combustion. These tests were restricted at full load due to combustion air fan capacity limitations. Primary to secondary air ratio had. for the spacing between locations used at Nucla, no discernable effect on emissions. This is a significant conclusion and should be considered in the design of the next generation of $\mathrm{CFB}$ boilers.

The ability to significantly change the coal size distribution was restricted due to limitations with the coal preparation and handling equipment. Tests conducted did not indicate a substantial change in operating performance over 
the range of sizes that were affected. Limestone sizing tests were not possible with the as-installed preparation equipment.

As part of alternate fuels testing, 8 tests were performed on a local Nucla coal with a similar sulfur content compared to the baseline Salt Creek coal (0.5 wt. \%), but with a higher variability in ash content. Two tests were also performed on a Dorchester coal that had higher sulfur content (1.53 wt. \%) and ash content (20 wt. $\left.\frac{\circ}{0}\right)$ than salt Creek coal. Changes in unit performance were subtle with the Nucla coal and differences are discussed in Section 18. With the higher sulfur Dorchester coal, results favorably indicated lower $\mathrm{Ca} / \mathrm{S}$ ratio requirements for comparable sulfur retentions.

Freeboard gas sampling traverses were conducted at the $40^{\prime}$ and $80^{\prime}$ ports located on the outside wall of combustion chamber $B$ as part of the solids and gas mixing test plan discussed in section 9. Two water-cooled probes allow combustor gas samples to be collected from the outside wall to the centerline of the combustion chamber at each elevation. Data were collected at full and half load for various coal and limestone feed configurations. Although data suggest poor lateral mixing between elevations, firm conclusions regarding combustion and emissions performance cannot be made due to the limited number of traverse points. Additional testing to obtain temperature and solids density profiles, along with the use of tracer gases, may provide additional, useful information. Existing data should be reviewed by CFB combustion and particle experts and incorporated into their models.

\subsection{COMBUSTION AND BOILER EFFICIENCY}

For all performance tests, combustion efficiency ranged between $96.9 \%$ and $98.9 \%$. No significant difference between Salt Creek and the local Nucla coals was apparent and no single process parameter (e.g., boiler load, bed temperature, excess air, primary to secondary air ratio, coal feed configuration, etc.) appeared to have a direct impact on the results.

Boiler efficiencies (by the ASME losses method) varied between $85.6 \%$ and 88.6 \% for the tests completed. Peabody coal resulted in the highest efficiencies due to the lowest losses from moisture in the fuel. Dorchester coal produced the lowest boiler efficiencies due to a higher moisture content in the fuel and a larger sorbent calcination loss. The latter was the result of the higher sulfur content of the Dorchester coal. Net plant heat rate decreased with increasing boiler load from $12,400 \mathrm{Btu} / \mathrm{NkWh}$ at $50 \% \mathrm{MCR}$ to $11,600 \mathrm{Btu} / \mathrm{NkWh}$ at full load. The lowest value achieved during a full load steady-state test was $10,980 \mathrm{Btu} / \mathrm{NkWh}$. These values are affected by the absence of reheat, the 
presence of the three older 12.5 MWe turbines in the overall steam cycle, the number of unit restarts, and part-load testing. Since 1988, the Nucla CFB has been restarted almost 175 times following various intervals of unit outage.

\subsection{START-UP AND DYNAMIC TEST RESULTS}

Data from cold, warm, and hot restarts are presented in section 7 of this report. In general, under optimum circumstances, the unit can achieve full load from a cold condition in 10 to 12 hours. The first five hours are required to achieve $100^{\circ} \mathrm{F}$ of superheat at approximately 600 psig prior to turbine roll. Drum-metal temperature limitations of $100^{\circ} \mathrm{F} / \mathrm{h}$ are a restriction during the first two hours of gas firing, but decrease to less than $75^{\circ} \mathrm{F} / \mathrm{h}$ for the remainder of start-up. Refractory temperature increases generally do not exceed $60^{\circ} \mathrm{F} / \mathrm{h}$, which is well under the $100^{\circ} \mathrm{F} / \mathrm{h}$ limitation suggested by the manufacturer. Between 2 and 5 hours, the firing rate on propane is established to limit pressure part metal temperature increases to less than $100^{\circ} \mathrm{F} / \mathrm{h}$ and to minimize drum-level fluctuations caused by swell from the increase in the specific volume. This is followed by a 3-hour turbine soak, a 1-hour period at minimum load on propane at 5 MWe to stabilize, and finally, the initiation of coal flow and increase in power to 45 MWe for stabilization.

Except for the time required to bring each of the three 12.5 MWe turbines on line, the remainder of time to full load is dictated by the boiler/turbine ramp rate. The latter has been tested successfully at $5 \mathrm{MWe} / \mathrm{min}$ without any process or control limitations. Additional testing at $7 \mathrm{MWe} / \mathrm{min}$ during the Phase II test program identified drum-level control as a limitation. This may be correctable with adjustments to the steam flow rate calculation under certain conditions. Calculated steam flow rate is used for three-element drum level control. Dynamic test results are discussed in greater detail in section 8.

Warm restarts (off-line for less than 12 hours) generally require 2 to 4 hours to achieve the minimum safe operating load on coal of 45 MWe. This interval is dictated by the time required to reestablish superheat temperatures and/or minimum bed temperatures of $950^{\circ} \mathrm{F}$ necessary for the initiation of coal feed. The former condition is determined by how quickly the turbine is brought off-line following a controlled shutdown or unit trip. The latter is controlled by the time required to remove fans from service. Hot restarts (unit off-line for less than six hours) typically follow the same scenario although, in some cases, the turbine can remain on-line and gas and/or coal feed can be reestablished immediately. 


\subsection{MATERIALS MONITORING}

A materials monitoring report is included in section 16 and highlights results from boiler inspections made during the Phase I and II test programs. Current areas of concern to the plant include: 1) bubble cap retention and erosion, 2) lower combustor refractory condition, particularly around the recycle port entrances to the combustor and at the water-wall interface, 3) water-wall erosion at the refractory interface, especially along the front wall and front-side walls, 4) water-wall erosion in areas where combustor water walls are warped from the overheat incident, which is most pronounced along the front wall of combustion chamber $A$ approximately 22' above the distributor plate, 5) erosion and long term overheat damage to the radiant, secondary superheater tubes in isolated, localized areas, 6) cyclone vortex finder warpage, 7) upper cyclone refractory condition around the "bull nose", target area, and inlet spiral shelf, 8) spalling of large refractory pieces in the conical sections of each cyclone, 9) generally poor condition of the cyclone downcomer and sections of the loop seals. These areas have been photographed and are documented in this and the Annual Reports.

\subsection{OTHER TESTING}

Sections are presented in this report on testing and operational performance of the baghouse, air heater, and solids feed and disposal systems. Baghouse efficiency and pressure drop (Section 15) were primary concerns during the design stage of the Nucla CFB because of differences between CFB fly ash and that from a pulverized unit. However, the system has operated reliably with a collection efficiency of 99.96\% and full-load pressure drop between 5.0 and 6.5 in. wg. Bag failure rate has been $7.8 \%$ of total since initial start-up, but has been reduced considerably after the first year of operation by decreasing the deflation pressure to less than 0.5 in. wg. This pressure initially was set much higher than design. Results of Mullen-Burst tests on selected bags after approximately 10,000 hours of service do not indicate significant deterioration in bag strength compared to similar measurements made after 5000 hours cf service.

The air heater (Section 14) also has operated reliably with an effectiveness ranging from $70 \%$ to $76 \%$ across the load range. Leakage of primary air across the tube sheet into the secondary air pass at low loads remains a performance consideration. Solids feed and disposal systems, discussed in Sections 12 and 13, operate with improved reliability following upgrades and modifications to the limestone feed and bottom ash disposal systems prior to the operational acceptance tests on high ash and high sulfur coals. The limestone feed system continues to be a source of relatively 
high fugitive dust emissions within the boiler room. Erosion in the fly ash disposal transport lines, cyclone separator, and lock hopper valves, along with high pressure drop across the pulsed-jet baghouse separation system, continue to be areas of high maintenance.

Heat transfer correlations to the combustor water walls are presented in section 10 from data gathered using chordal thermocouples located on the rear wall of combustion chamber $B$ at $10 \mathrm{ft}$. elevations. Correlations are made between heat transfer and solids density profiles in the combustors. A correlation is also developed which predicts combustor operating temperatures for the local Nucla and Salt Creek coals.

Cyclone performance, particularly collection efficiency and recycle rates, are difficult measurements on a CFB due to high temperatures and solids loadings and the presence of a thick outer shell and refractory layer. Using size distribution data from fly ash collected downstream of the cyclones, the collection performance has been estimated using two classical cyclone models. These results are presented in section 11 of this report.

\subsection{SUMMARY}

Although unit start-up problems delayed performance testing by over a year, most of these problems have been addressed during the period covering the Phase I and II test programs. The list of equipment responsible for these delays includes the primary air fan, bottom ash removal system, limestone feeders, refractory components, windbox ash removal system, and balance of plant equipment such as boiler feed pumps, circulating water pumps, fan controls, generator exciter, etc. Other problems that may not have been readily apparent during the first two years of operation include superheater erosion and long term overheat, bubble cap erosion in the region in front of the recycle return, continued refractory degradation, and water-wall erosion in warpage areas left over from the overheat incident. These areas will require capital expenditure in the future in order to improve unit reliability and availability.

Steady-state performance testing has been completed in all areas of the original performance test matrix outlined in the Detailed Test Plan, except for coal and limestone sizing tests. Coal size tests were attempted by adjusting the final coal crushers, but the results indicate only minor changes in size distribution. Limestone sizing tests were also attempted by adjusting the classifier bar and pulverizer speeds on the air-swept pulverizer, but the results were similar. 
Performance testing on the Nucla CFB has been complicated by the inability to control combustor operating temperatures and by differences in temperatures between combustion chambers. This makes parametric testing difficult since more than one variable often changes during a test sequence. The test program has accommodated this to a degree by running tests on individual combustion chambers, thereby satisfying the original objectives of the test program. Efforts should continue towards understanding and controlling combustor operating temperatures at Nucla since it has such a significant impact on emissions performance. Three areas that may benefit in this regard include: 1) measurements of combustor solids density profiles through the $40^{\prime}$ and $80^{\prime}$ traverse ports, 2) pulsed-tracer gas injection into the windbox with subsequent measurement through the traverse ports to identify mixing, and 3) measurement of cyclone collection efficiency and recycle rate versus unit load. 
Section 2

PLANT OPERATING HISTORY

\subsection{OVERVIEW}

During the period from July 1988 through January 1991, the plant operated with an average availability of $58.3 \%$ and a capacity factor of $39.6 \%$. Since initial coal fires in June 1987, the cumulative time on coal is 15,700 hours. A breakdown of the coal hours by month since this period is shown in rigure 2-1. This section also contains a monthly summary of operations at the Nucla plant from May 1985 through January 1991. Following the operations summary is Figure 2-2, which shows a breakdown of outage hours to date, and Figure 2-3, which shows a comparison of outage and inservice hours. These are followed by Table 2-1, an outage summary report which contains the date, outage duration, and summary description of the outage cause. Section 2.3 is a description of boiler acceptance test results, and section 2.4 is a description of equipment and operating problems.

\subsection{OPERATIONS AND OUTAGE SUMMARY}

\section{May 15, 1985}

Started construction

October 23, 1986

Boiler hydrostatic test.

March 29, 1987

Boil-out.

\section{April 2, 1987}

Steam blows (66 total blows).

May 28,1987

Steam to turbine with sand bed.

Completed vibration and trip logic checkout of 74 MWe (No. 4) turbine/generator.

\section{May 29, 1987}

Synchronized No. 4 generator and on-line at 7 MWe firing propane.

June 10, 1987

First coal fires in boiler supported with propane start-up burners. 

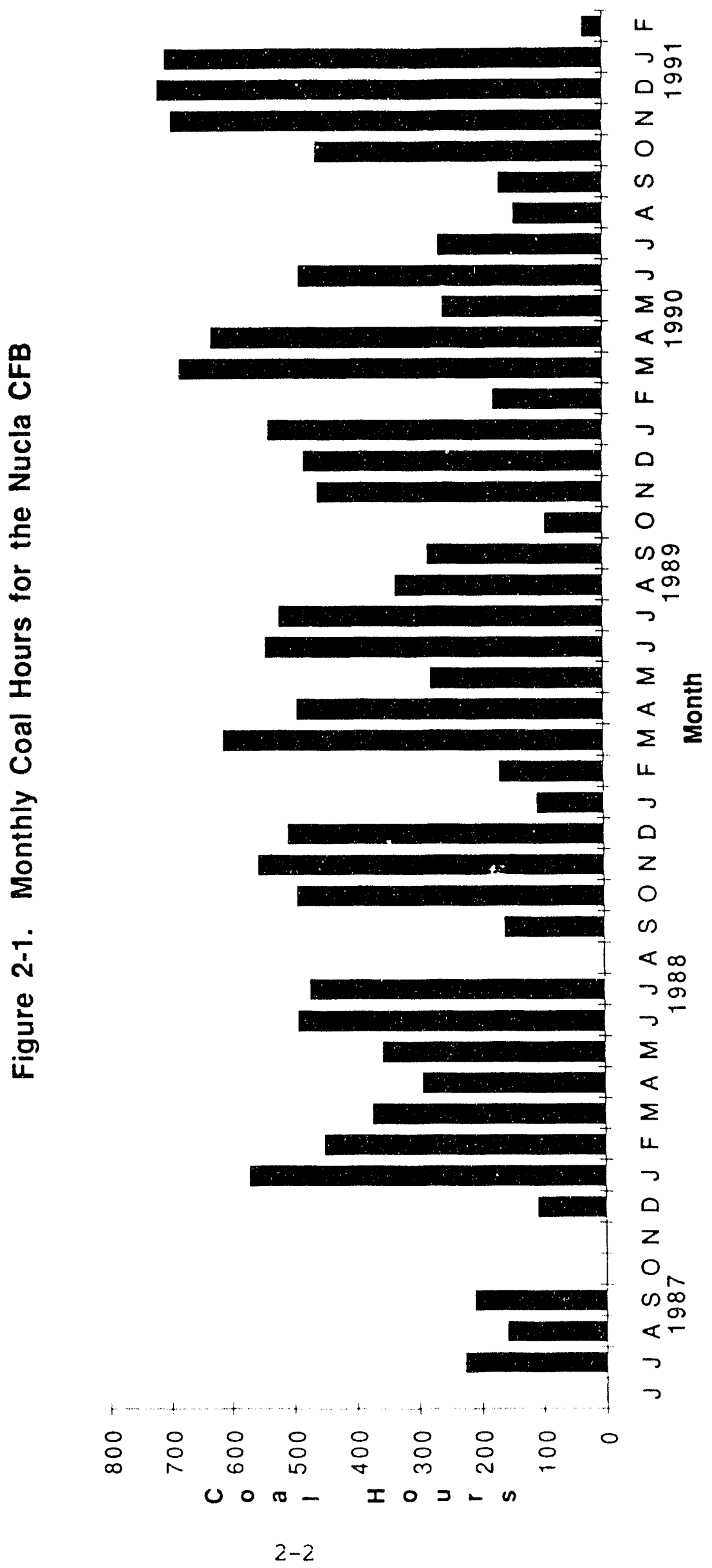


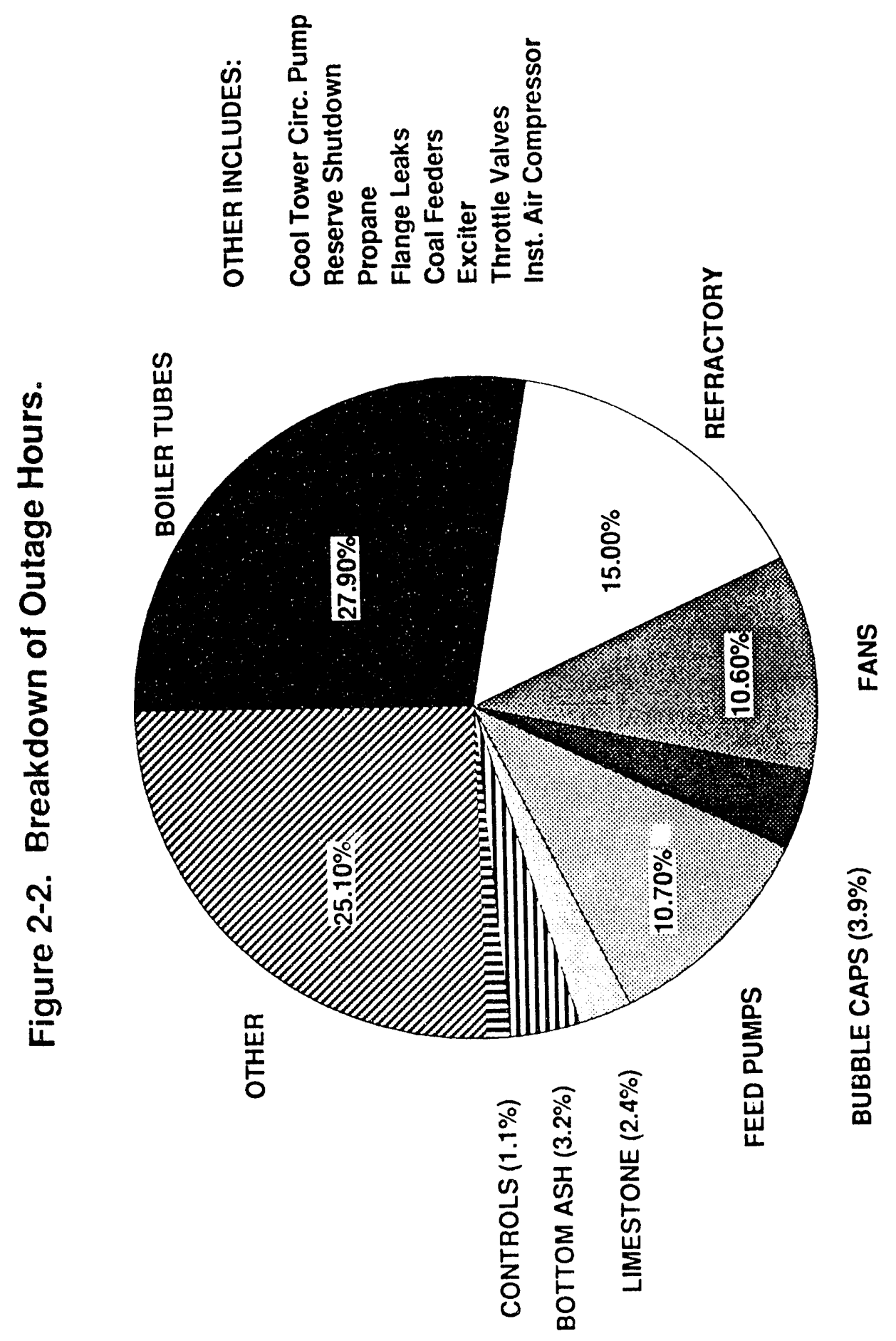




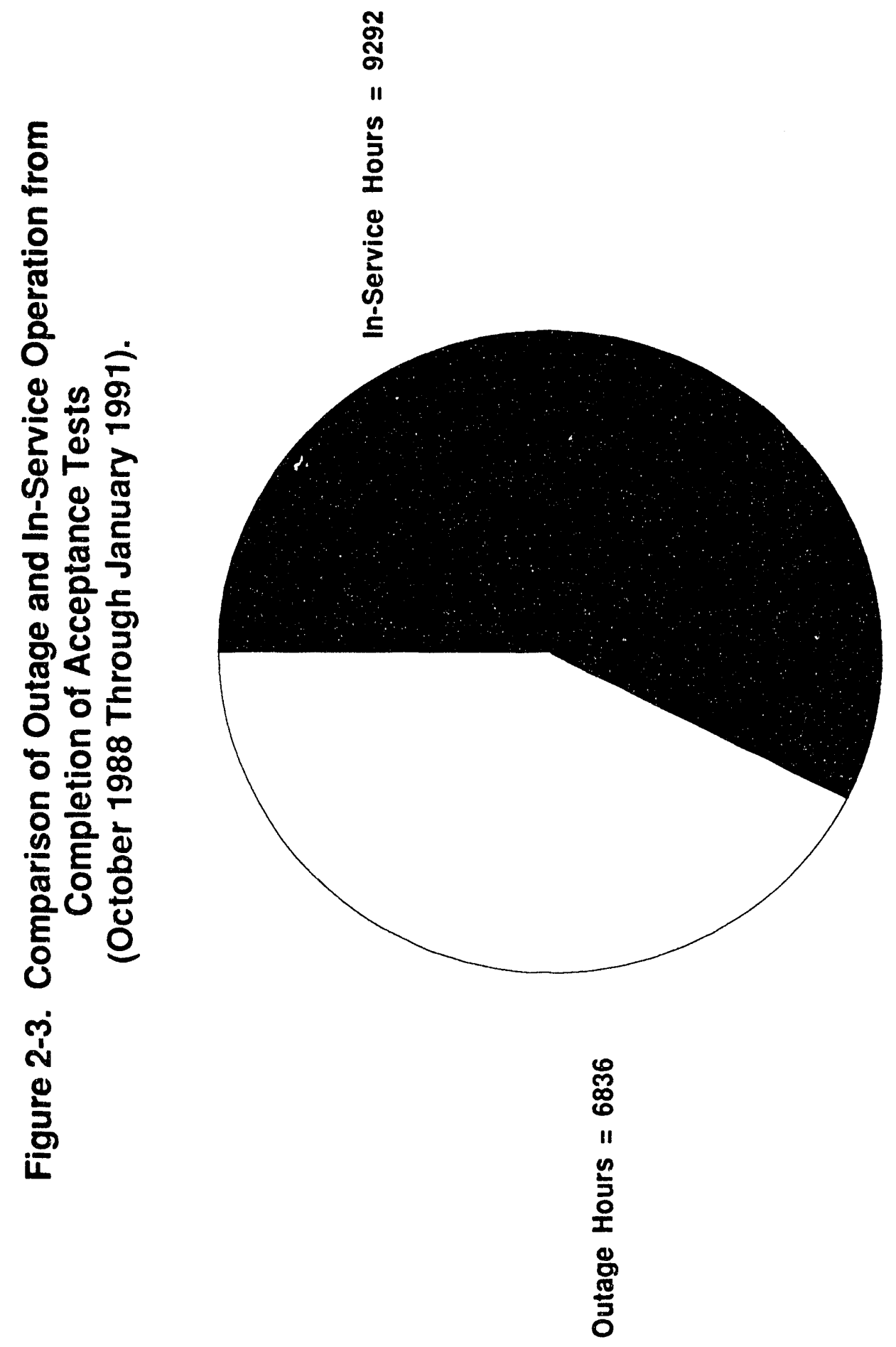


Table 2-1. OUTAGE SUMMARY

\begin{tabular}{|c|c|c|c|c|c|}
\hline \multicolumn{2}{|l|}{$\begin{array}{c}\text { START } \\
\text { OUTAGE }\end{array}$} & \multicolumn{2}{|l|}{$\begin{array}{c}\text { STOP } \\
\text { OUTAGE }\end{array}$} & \multirow{2}{*}{$\begin{array}{l}\text { DURATION } \\
\text { (APPROX.) } \\
\text { HRS. }\end{array}$} & \multirow[t]{2}{*}{ CAUSE } \\
\hline DATE & TIME & DATE & TIME & & \\
\hline $1-0 c t-88$ & $14: 30$ & $2-0 c t-88$ & $5: 00$ & 14.5 & $\begin{array}{l}\text { FAILURE OF AN INPUT/OUTPUT MODULE POWER } \\
\text { SUPPLY ON THE DCS CAUSED MAIN FUEL TRIP (MFT). }\end{array}$ \\
\hline $2-0 c t-88$ & $12: 00$ & $3-0 c t-88$ & $15: 00$ & 27 & $\begin{array}{l}\text { CONTROULED SHUTDOWN AS A RESULT OF LOW BED } \\
\text { TEMPERATURES FROM HIGH ASH, LOW HHV COAL } \\
\text { SUPPLY. UNIT HELD OFF UNE TO RESTORE PROPANE } \\
\text { INVENTORY. }\end{array}$ \\
\hline $6-0 c t-88$ & $14: 00$ & $6-0 \mathrm{ct}-88$ & $16: 00$ & 2 & $\begin{array}{l}\text { INDUCED DRAFT (ID) FAN TRIP FROM A SYSTEM } \\
\text { GROUND FAULT DURING A UGHTNING STORM. }\end{array}$ \\
\hline $17-0 \mathrm{ct}-88$ & $20: 00$ & $26-0 \mathrm{ct}-88$ & $2: 00$ & 198 & $\begin{array}{l}\text { CONTROLLED SHUTDOOWN RESULTING FROM UNIT BEING } \\
\text { OUT OF SO2 COMPLIANCE ON HIGH SULFUR COAL TEST. } \\
\text { WENT INTO EXTENDED OUTAGE TO REPLACE MISSING } \\
\text { BUBBLE CAPS AND TO WORK ON LIMESTONE FEEDERS. }\end{array}$ \\
\hline $28-0 \mathrm{ct}-88$ & $8: 00$ & $28-0 c t-88$ & $9: 30$ & 1.5 & $\begin{array}{l}\text { TWO OF THREE COAL FEEDERS OUT OF SERVCE ON } \\
\text { FURNACE B. BOILER TRIPPED WHEN THIRD COAL } \\
\text { FEEDER TRIPPED ON BELT MISALIGNMENT. }\end{array}$ \\
\hline $4-N o v-88$ & $11: 30$ & 10-Nov-88 & $4: 00$ & 136.5 & $\begin{array}{l}\text { CONTROUED SHUTDOWN TO INSPECT COMBUSTORS } \\
\text { FOR SUSPECTED REFRACTORY BLOCKAGE INLOOP } \\
\text { SEALS AND ASH CLASSIFIERS. }\end{array}$ \\
\hline 19-Nov-88 & $12: 00$ & 19-Nov-88 & $22: 30$ & 10.5 & $\begin{array}{l}\text { CONTROLLED SHUTDOWN TO REPAIR PACKING LEAK } \\
\text { ON STEAM DRUM BLOW DOWN VALVE. }\end{array}$ \\
\hline 20-Nov-88 & $12: 00$ & 20-Nov-88 & $12: 30$ & 0.5 & ID FAN TRIP DURING DELTAWYE SWITCH. \\
\hline $24-N o v-88$ & $14: 00$ & 24-Nov-88 & $18: 30$ & 4.5 & $\begin{array}{l}\text { MFT FROM MALFUNCTION OF FURNACE } 4 A \text { PRESSURE } \\
\text { SWITCHES FOR DRAFT CONTROL. }\end{array}$ \\
\hline 3-Dec-88 & $9: 00$ & 3-Dec-88 & $11: 30$ & 2.5 & MFT DUE TO HIGH PRIMARY AIR (PA) FAN AMPS. \\
\hline $11-$ Dec-88 & $21: 00$ & 20-Dec-88 & $10: 30$ & 205.5 & FAILURE OF GENERATOR $4 A$ EXCITOR COLECTOR RING. \\
\hline 26-Dec-88 & $2: 30$ & 26-Dec-88 & $10: 30$ & 8 & $\begin{array}{l}\text { MFT FROM FAULTY PRESSURE SWITCH ON ID FAN } \\
\text { INLET. }\end{array}$ \\
\hline 27-Dec-88 & $12: 00$ & 27-Dec-88 & $17: 30$ & 5.5 & $\begin{array}{l}\text { MFT FROM OVERHEAT OF VARIABLE SPEED DRIVE (VSD) } \\
\text { CONTROL CARD ONSECONDARY AIR (SA) FAN DUE TO } \\
\text { ROOM AIR CONDITIONING PROBLEMS. }\end{array}$ \\
\hline $5-J a n-89$ & $10: 45$ & 13-Feb-89 & $7: 41$ & 933 & $\begin{array}{l}\text { CONTROLLED SHUTDOWN DUE TOHOT SPOT ATLOOP } \\
\text { SEAL 4B WELDED JOINT. DECISION MADE TO START } \\
\text { PPCOOUTAGE TO REPAIR DAMAGED REFRACTORY IN } \\
\text { THE LOOP SEALS AND CONES OF THE CYCLONES. }\end{array}$ \\
\hline
\end{tabular}


Table 2-1. OUTAGE SUMMARY (Continued)

\begin{tabular}{|c|c|c|c|c|c|}
\hline \multicolumn{2}{|c|}{$\begin{array}{l}\text { START } \\
\text { OUTAGE }\end{array}$} & \multicolumn{2}{|c|}{$\begin{array}{l}\text { STOP } \\
\text { OUTAGE }\end{array}$} & \multirow{2}{*}{$\begin{array}{l}\text { DURATION } \\
\text { (APPROX.) } \\
\text { HRS. }\end{array}$} & \multirow[t]{2}{*}{ CAUSE } \\
\hline DATE & TIME & DATE & TIME & & \\
\hline 13-Feb-89 & $16: 36$ & 16-Feb-89 & $2: 33$ & 58 & $\begin{array}{l}\text { UNIT TRIP ON FUELAIR RATIO MISMATCH. THE MFT } \\
\text { RESULTED FROM SYSTEM SOFTWARE UPDATE. } \\
\text { PROBLEM. ALSO FOUND LEAKNG FLANGE GASKET } \\
\text { ONSHSAFETY VALVE. }\end{array}$ \\
\hline 16-Feb-89 & $2: 33$ & 16-Fob-89 & $3: 44$ & 1 & $\begin{array}{l}\text { UNIT TRIP IMMEDIATELY AFTER SYNCHCRONIZATION } \\
\text { ON MFT DUE TO ID FAN UNDERVOLTAGE TRIP. }\end{array}$ \\
\hline 17-Feb-89 & $15: 15$ & 23-Feb-89 & $12: 14$ & 141 & $\begin{array}{l}\text { CONTROLLED SHUTDOWN TO REPAIR SEIZED } 4 B \\
\text { CIRCULATING WATER PUMP. INLET AND DISCH. } \\
\text { VALVES LEAKING BY TOO MUCH TO ISOLATE PUMP } \\
\text { AND REPAIR ON LINE. }\end{array}$ \\
\hline 3-Mar-89 & $12: 24$ & 3-Mar-89 & $19: 40$ & 7 & $\begin{array}{l}\text { UNIT TRIP ON MFT DUE TO LOW PA FLOW TO 'B' } \\
\text { FURNACE. THE LOW PA FLOW WAS CAUSED BYA } \\
\text { SUDDEN LOOP SEAL SURGE WHICH INCREASED BED } \\
\text { PRESSURE TO APPROXIMATELY } 60^{*} \text { WC. }\end{array}$ \\
\hline 24-Mar-89 & $23: 23$ & 29-Mar-89 & $22: 46$ & 119 & $\begin{array}{l}\text { SCHEDULED SHUTDOWN TO INSPECT COMBUSTORS } \\
\text { AFTER COMPLETING TEST BURN WITH 'SALT CREEK' } \\
\text { COAL. REPAIRED } 4 A \text { BOILER FEED PUMP MECHAN- } \\
\text { ICAL SEAL DURING THIS OUTAGE. }\end{array}$ \\
\hline 12-Apr-89 & $16: 53$ & 18-Apr-89 & $17: 31$ & 145 & $\begin{array}{l}\text { CONTROLLED SHUTDOWN DUE TO ASHREMOVAL } \\
\text { PROBLEMS IN "A" FURNACE RESULTING FROM A } \\
\text { BENT FLUIDIZING TUBE AT THE ENTRANCE TOEACH } \\
\text { BOTTOMASHCOOLR. }\end{array}$ \\
\hline $21-A p r-89$ & $17: 02$ & 21-Apr-89 & $21: 17$ & 4 & $\begin{array}{l}\text { UNIT TRIP ON MFT DUE TO LOSS OF THE ID FAN } \\
\text { RESULTING FROM A TRANSMISSION SYSTEM } \\
\text { DISTURBANCE. }\end{array}$ \\
\hline 27-Apr-89 & $22: 00$ & 10-May-89 & $7: 06$ & 297 & $\begin{array}{l}\text { CONTROLLED SHUTDOWN DUE TO MECHANICAL SEAL } \\
\text { LEAKS ON BOTH } 4 \text { A AND 4B FEEDWATER PUMPS. } \\
\text { 4B FEED PUMP ALSO REQUIRED CASING REPAIRS WHICH } \\
\text { WERE COMPLETED OFF SITE. }\end{array}$ \\
\hline 10-May- 89 & $7: 21$ & 10-May-89 & $23: 25$ & 16 & $\begin{array}{l}\text { UNIT TRIP ON MFT DUE TO LOSS OF THE ID FAN } \\
\text { RESULTING FPOM LOOSE ELECTRICAL CONNECTION } \\
\text { WHICH CAUSED THE COMMUTATOR TO SHORT OUT. }\end{array}$ \\
\hline 14-May-89 & $11: 22$ & 22-May-89 & $17: 30$ & 198 & $\begin{array}{l}\text { UNIT TRIP ON MFT DUE TO SA FAN TRIP. REPLACED } \\
\text { BAD FAN CONTROL CARD. DURING OUTAGE } \\
\text { REINSTALLED 4B FEEDWATER PUMP. UNIT ON } \\
\text { RESERVE SHUTDOWN AT 20:50 ON 5/19. }\end{array}$ \\
\hline 22-May-89 & $20: 00$ & 23-May-89 & $6: 31$ & 11 & CONTROLLED SHUTDOWN DUE TO LACK OF PROPANE \\
\hline
\end{tabular}


Table 2-1. OUTAGE SUMMARY (Continued)

\begin{tabular}{|c|c|c|c|c|c|}
\hline $\begin{array}{l}\text { START } \\
\text { OUTAGE }\end{array}$ & & $\begin{array}{c}\text { STOP } \\
\text { OUTAGE }\end{array}$ & & $\begin{array}{l}\text { DURATION } \\
\text { (APPROX.) }\end{array}$ & CALSE \\
\hline DATE & TIME & DATE & TIME & HRS. & \\
\hline 23-May-89 & $13: 17$ & 23-May-89 & $16: 47$ & 3 & CONTROLLED SHUTDOWN DUE TO LACK OF PROPANE \\
\hline 30-May-89 & $9: 17$ & 30-May-89 & $10: 33$ & 1 & $\begin{array}{l}\text { UNIT TRIP ON MFT DUE TO 'PHANTOM' SA FAN TRIP } \\
\text { REASON UNDER INVESTIGATION. }\end{array}$ \\
\hline 9-Jun-89 & $13: 57$ & $9-J u n-89$ & $18: 12$ & 4 & $\begin{array}{l}\text { CONTROULD SHUTDOWN TO REMOVE "CLINKER" } \\
\text { FROM } 4 \text { C BOTTOM ASH COOLER. THREE BUBBLE CAPS } \\
\text { WERE ALSO FOUND ADRIFT IN THIS COOLER AND } \\
\text { REPLACED. }\end{array}$ \\
\hline 23-Jun-89 & $19: 47$ & $9-J u l-89$ & $3: 29$ & 368 & $\begin{array}{l}\text { SCHEDULED SHUTDOWN AT THE COMPLETION OF } \\
\text { ALTERNATE FUEL. TESTING TO COMPLETE PA FAN INLET } \\
\text { BOX AND LIMESTONE FEED SYSTEM MODIFICATIONS. }\end{array}$ \\
\hline $28-J u l-89$ & $14: 47$ & $28-J u l-89$ & $16: 49$ & 2 & $\begin{array}{l}\text { UNIT TRIP ON MFT DUE TO LOSS OF ID FAN RESULTING } \\
\text { FROM SYSTEM DISTURBANCE. } 4 \text { A BFP SIEZED DURING } \\
\text { THE UNIT ROLLDOWN WHEN ITS RECIRCULATION VALVE } \\
\text { DID NOT PROPERLY OPERATE. }\end{array}$ \\
\hline $30-J u l-89$ & $22: 47$ & 7-Aug-89 & $18: 24$ & 188 & $\begin{array}{l}\text { CONTROLLED SHUTDOWN TO ISOLATE } 4 A \text { BFP FOR } \\
\text { REMOVAL AND OFF-SITE REPAIR. UNIT STATUS } \\
\text { CHANGED TO RESERVE SHUTDOWN FROM } 12: 00 \text { HRS ON } \\
\text { 8/2 TO } 16: 10 \text { ON 8/4. THE INSTRUMENT AIR } \\
\text { COMPRESSOR CHECK VALVE BETWEEN THE HIGHAND } \\
\text { LOW PRESSURE STAGES FAILED AND WAS REPLACED. }\end{array}$ \\
\hline 20.Aug-89 & $0: 45$ & 26-Aug-89 & $4: 43$ & 148 & $\begin{array}{l}\text { CONTROLLED SHUTDOWN TO REINSTALL } 4 \text { A BFP. } \\
\text { OUTAGE EXTENDED TO REPLACE } 23 \text { DISTRIBUTOR } \\
\text { PLATE "BUBBLE CAPS" IN A COMBUSTOR AND TO } \\
\text { COMPLETE ADDITIONAL INSTRUMENT AIR } \\
\text { COMPRESSOR REPAIRS. }\end{array}$ \\
\hline 26-Aug-89 & $5: 43$ & 26-Aug-89 & $16: 28$ & 11 & CONTROLLED SHUTDOWN DUE TO LACK OF PROPANE \\
\hline 28-Aug-89 & $11: 35$ & $11-\operatorname{Sep}-89$ & $13: 25$ & 338 & $\begin{array}{l}\text { CONTROLLED SHUTDOWN DUE TO WATERWALL TUBE } \\
\text { LEAK AT WAL BOX CONNECTION ON OUTSIDE OF BOILER. } \\
\text { THE UNIT MFT DURING RESTART DUE TO A TRIP ON } \\
\text { EXCITER VOLTAGE CABINET FAN FAILURE. THE NO. } 2 \\
\text { THROTTLE VALVE REMAINED } 11 \% \text { OPEN AFTER THE } \\
\text { UNIT TRIP. THE VALVE WAS DISASSEMBLED AND THE } \\
\text { UPPER STEM GUIDE BUSHING WAS REMACHINED TO THE } \\
\text { MANUFACTURERS SPECIFICATIONS. TWO ADRIFT } \\
\text { NOZZLE CAPS NEAR THE LOOP SEAL IN } 4 B \text { COMBUSTOR } \\
\text { WERE ALSO CAPPED FROM THE WINDBOX SIDE AS A } \\
\text { TEMPORARY REPAIR. }\end{array}$ \\
\hline
\end{tabular}


Table 2-1. OUTAGE SUMMARY (Continued)

\begin{tabular}{|c|c|c|c|c|c|}
\hline $\begin{array}{r}\text { STAR } \\
\text { OUTAG } \\
\end{array}$ & & $\begin{array}{c}\text { STOP } \\
\text { OUTAGE }\end{array}$ & & $\begin{array}{l}\text { DURATION } \\
\text { (APPROX.) }\end{array}$ & CAUSE \\
\hline DATE & TIME & DATE & TIME & HRS. & \\
\hline 13-Sep-89 & $3: 03$ & 13-Sep-89 & $11: 50$ & 9 & $\begin{array}{l}\text { UNIT TRIP ON MFT DUE TO LOSS OF THE SA FANON } \\
\text { "PHANTOM" TRIP. AFTER SEVERAL UNSUCCESSFUL } \\
\text { ATTEMPTS TO RESART THE FAN IN A NORMAL } \\
\text { FASHION, THE FAN WAS RESTARTED “ACROSS THE } \\
\text { UINE". A CONDENSER TUBE LEAK WAS ISOLATED AND } \\
\text { REPAIRED BEFORE UNIT I WAS RETURNED TO SERVICE. }\end{array}$ \\
\hline 17-Sep-89 & $14: 01$ & 17-Sep-89 & $14: 46$ & 1 & $\begin{array}{l}\text { UNIT MFT ON LOW DRUM LEVEL DUE TO IMPROPER } \\
\text { OPERATION OF THE MAIN FEEDWATER CONTROL VALVE. }\end{array}$ \\
\hline 23-Sep-89 & $22: 21$ & $9-0 c t-89$ & $22: 29$ & 384 & $\begin{array}{l}\text { UNIT MFT DUE TO LOSS OF THE PA FAN ON "PHANTOM" } \\
\text { TRIP. STARTED SCHEDULED OUTAGE FOR PYROPOWER } \\
\text { TO REPLACE THE PA FAN WHEEL. }\end{array}$ \\
\hline $13-0 \mathrm{ct}-89$ & $19: 41$ & 11-Nov-89 & $18: 08$ & 694 & $\begin{array}{l}\text { UNIT MFT ON HIGH FURNACE DRAFT PRESSURE DUE TO } \\
\text { A BOILER TUBE LEAK IN 4B FURNACE. WATER FROM } \\
\text { THE TUBE CAUSED AGGLOMERATON OF THE BED } \\
\text { MATERIAL IN 4B COMBUSTOR, } 4 B \text { WINDBOX, AND } 40 \\
\text { BOTTOMASH COOLER. SUBSEOUENT INSPECTIONOF } \\
\text { THE SUPERHEATER II PLATENS IN BOTH COMBUSTORS } \\
\text { REVEALED MANY AREAS OF LOCALIZED EROSION WHICH } \\
\text { WERE REPAIRED. }\end{array}$ \\
\hline 12-Nov-89 & $18: 27$ & 12-Nov-89 & $20: 27$ & 2 & $\begin{array}{l}\text { UNIT MFT ON LOW AIRFUEL RATIO DUE TO AN } \\
\text { IMPROPER BTU BIAS SETTING. }\end{array}$ \\
\hline 4-Dec-89 & $10: 33$ & 4-Dec-89 & $11: 36$ & 1 & $\begin{array}{l}\text { UNIT MFT ON LOW ELECTRO-HYDRAUUC CONTROL (EHC) } \\
\text { SYSTEM PRESSURE. PROBLEM OCCURRED WHILE I\&C } \\
\text { TECHNICIAN WAS VALUNG AN EHC ACCUMULATOR } \\
\text { BACK IN-SERVICE AFTER BEING RECHARGED. }\end{array}$ \\
\hline 8-Dec-89 & $4: 37$ & 15-Dec-89 & $14: 00$ & 177 & $\begin{array}{l}\text { CONTROLLED SHUTDOWN DUE TO HIGH BED PRESSURE IN } \\
\text { 4A COMBUSTOR DURING TYPE "B" COAL ACCEPTANCE } \\
\text { TESTING USING A HIGH SULFUR COAL (1.8\% S). SUB- } \\
\text { SEQUENT INSPECTIONS REVEALED A TOTAL OF TWENTY } \\
\text { SEVEN BUBBLE CAPS ADRIFT IN } 4 A \text { COMBUSTOR (25), } \\
\text { 4B COMBUSTOR (1). AND 4B LOOP SEAL (1). }\end{array}$ \\
\hline 17-Dec-89 & $23: 26$ & 18-Dec-89 & $5: 27$ & 6 & $\begin{array}{l}\text { UNIT MFT DUE TQ UNIT } 4 \text { EXCITER FIRING CIRCUIT CARD } \\
\text { FAILURE. }\end{array}$ \\
\hline 18-Dec-89 & $\epsilon: 42$ & 20-DeC-89 & $17: 27$ & 59 & $\begin{array}{l}\text { UNIT MFT DUE TO UNIT } 4 \text { EXCITER AFTER AN UNSUC- } \\
\text { CESSFUL ATTEMPT TO RESTART THE UNIT. CUEA } \\
\text { OBTAINED ENOUGH GOOD CARDS BETWEEN THE TWO } \\
\text { REDUNDENT F'ZING CIRCUITS TO RETURN THE UNIT TO } \\
\text { SERVICE. }\end{array}$ \\
\hline
\end{tabular}


Table 2-1. OUTAGE SUMMARY (Continued)

\begin{tabular}{|c|c|c|c|c|c|}
\hline \multicolumn{2}{|c|}{$\begin{array}{l}\text { START } \\
\text { OUTAGE }\end{array}$} & \multicolumn{2}{|l|}{$\begin{array}{l}\text { STOP } \\
\text { OUTAGE }\end{array}$} & \multirow{2}{*}{$\begin{array}{l}\text { DURATION } \\
\text { (APPROX.) } \\
\text { HRS. }\end{array}$} & \multirow[t]{2}{*}{ CAUSE } \\
\hline DATE & TIME & DATE & TIME & & \\
\hline 30-Dec-89 & $5: 08$ & 30-Dec-89 & $8: 56$ & 4 & $\begin{array}{l}\text { UNIT MFT ON LOW DRUM LEVEL DUE TO A UNIT } 4 \text { TUR- } \\
\text { BINE UPSET. THE UPSET WAS THE RESULT OF A } \\
\text { TURBINE CONTROL PROBLEM CAUSED BY AN IMPROP. } \\
\text { ERLY CALIBRATED MW TRANSDUCER. }\end{array}$ \\
\hline 30-Dec-89 & $9: 11$ & 30-Dec-89 & $18: 34$ & 9 & $\begin{array}{l}\text { CONTROLLED SHUTLOWN DUE TO LEAK IN UNIT } 4 \\
\text { GOVERNOR OLL CIRCUIT. }\end{array}$ \\
\hline $7-\operatorname{Jan}-90$ & $18: 14$ & $9-J a n-90$ & $20: 40$ & 50 & $\begin{array}{l}\text { CONTROLLED SHUTDOWN DUE TO LOSS OF THE COAL } \\
\text { PREP SYSTEM FROMA } 4 A \text { COAL CRUSHER MOTOR } \\
\text { BEARING FAILURE THE OUTAGE WAS EXTENDED } \\
\text { BECAUSE OF A STEAM LEAKON THE WEST STEAM LEAD } \\
\text { FLANGE BETWEEN THE WEST THROTTLE VALVE AND THE } \\
\text { GOVERNOR VALVE WHICH DEVELOPED DUHING RESTART. }\end{array}$ \\
\hline $18-J a n-90$ & $14: 10$ & $19-J a n-90$ & $18: 51$ & 29 & $\begin{array}{l}\text { UNIT MFT ON GENERATOR LOW FREQUENCY RESULTING } \\
\text { FROM A RELAY WIRING ERROR. DURING RESTART A SH } \\
\text { SAFETY VALVE FLANGE LEAK WAS DISCOVERED AND } \\
\text { REPAIRED AFTER THE BOILER WAS COOLED DOWN. }\end{array}$ \\
\hline 26-Jan-90 & $18: 37$ & $6-\mathrm{Feb}-90$ & $21: 16$ & 267 & $\begin{array}{l}\text { CONTROLLED SHUTDOWN TO REPAIR THE VORTEX FIN- } \\
\text { DER" IN } 4 B \text { COMBUSTOR CYCLONE AND TO CLEANOUT } \\
\text { BACKSIFTED MATERIAL FROM } 4 \text { A AND } 4 \text { B COMBUSTOR } \\
\text { WINDBOXES. }\end{array}$ \\
\hline $9-F \in b-90$ & $4: 18$ & $9-F e b-90$ & $21: 36$ & 17 & $\begin{array}{l}\text { CONTROLLED SHUTDOWN DUE TO VIBRATION IN THE SA } \\
\text { FAN INLET DUCT. TWO STIFFENERS WERE ADDED TO A } \\
\text { FAN INLET TURNING VANE TO RESOLVE THE PROBLEM. }\end{array}$ \\
\hline $9-F e b-90$ & $22: 36$ & $10-\mathrm{Feb}-90$ & $2: 36$ & 4 & UNIT MFT DUE TO LOW VACUUM ON UNIT 4 CONDENSER. \\
\hline $10-F e b-90$ & $17: 23$ & $21-\mathrm{Feb}-90$ & $6: 55$ & 254 & $\begin{array}{l}\text { UNIT MFT ON HIGH FURNACE DRAFT PRESSURE DUE TO } \\
\text { A BOILER TUBE LEAK IN } 4 A \text { FURNACE. WATER FROM } \\
\text { THE TUBE CAUSED AGGLOMERATIONOF THE BED } \\
\text { MATERIAL IN } 4 A \text { COMBUSTOR AND WINDBOX. } 4 \text { A BFP } \\
\text { WAS FOUND SEIZED WHILE ATTEMPTING BOILER HYDRO- } \\
\text { STATIC TEST AFTER COMPLETING TUBE REPAIRS. }\end{array}$ \\
\hline $26-F e b-90$ & $0: 08$ & $3-$ Mar-90 & $9: 41$ & 130 & $\begin{array}{l}\text { CONTROLLED SHUTDOWN DUE TO WATERWALL TUBE } \\
\text { LEAKOUTSIDE THE BOILER. THE LEAK WAS LOCATED } \\
\text { IN A FLOOR TUBE WHERE THE WINDBOX TIES INTO THE } \\
\text { FLOOR TUBES. THE OUTAGE WAS EXTENDED TO REPAIR } \\
\text { A SECTION OF ABRASION RESISTANT REFRACTORY IN } \\
\text { 4B CYCLONE CONE SECTION. }\end{array}$ \\
\hline $22-\mathrm{Mar}-90$ & $13: 36$ & $22-$ Mar-90 & $15: 23$ & 2 & $\begin{array}{l}\text { UNIT TRIP ON MFT DUE TO LOSS OF ID FAN RESULTING } \\
\text { FROM SYSTEM DISTURBANCE. }\end{array}$ \\
\hline
\end{tabular}


Table 2-1. OUTAGE SUMMARY (Continued)

\begin{tabular}{|c|c|c|c|c|c|}
\hline \multicolumn{2}{|c|}{$\begin{array}{l}\text { START } \\
\text { OUTAGE }\end{array}$} & \multicolumn{2}{|l|}{$\begin{array}{c}\text { STOP } \\
\text { OUTAGE }\end{array}$} & \multirow{2}{*}{$\begin{array}{l}\text { DURATION } \\
\text { (APPROX.) } \\
\text { HRS. }\end{array}$} & \multirow[t]{2}{*}{ CALSE } \\
\hline DATE & TIME & DATE & TIME & & \\
\hline 3-Apr-90 & $18: 02$ & 3-Apr-90 & $20: 20$ & 2 & $\begin{array}{l}\text { UNIT TRIP ON MFT DUE TO LOSS OF ID FAN RESULTING } \\
\text { FROM SYSTEM DISTURBANCE. }\end{array}$ \\
\hline 18-Apr-90 & $19: 00$ & 22-Apr-90 & $10: 30$ & 88 & $\begin{array}{l}\text { UNIT TRIP ON MFT DUE TO LOSS OF EXCITATION DUE TO } \\
\text { EXCITER TRANSFORMER FAILURE. }\end{array}$ \\
\hline 2-May-90 & $6: 29$ & 20-May-90 & $6: 16$ & 432 & $\begin{array}{l}\text { UNIT MFT ON LOW DRUM LEVEL AT THE TIME OF THE } \\
\text { TRIP.OPERATIONS PERSONNEL WERE REDUCING LOAD TO } \\
\text { REMOVE THE BOILER FROM SERVICE VIA A CONTROLLED } \\
\text { SHUTDOWN SEQUENCE AFTER AN INDICATION OF A } \\
\text { TUBE LEAK IN } 4 A \text { COMBUSTOR. }\end{array}$ \\
\hline 20-May-90 & $6: 29$ & 20-May-90 & $15: 33$ & 9 & $\begin{array}{l}\text { UNIT TRIP ON MFT DUE TO LOSS OF SA FAN RESULTING } \\
\text { FROM A } 4 \text { KV LINE VOLTAGE. THE GENERATOR BREAKER } \\
\text { HAD TO BE OPENED MANUALLY. }\end{array}$ \\
\hline 20-May-90 & $15: 59$ & 22-May-90 & $6: 19$ & 38 & $\begin{array}{l}\text { UNIT TRIP ON MFT DUE TO LOSS OF SA FAN RESULTING } \\
\text { FROM A } 4 \text { KV VOULTAGE LNE SURGE. THE GENERATOR } \\
\text { REVERSE CURRENT RELAY HAD TO BE MANUALLY } \\
\text { TRIPPED. THE BOILER WAS BC TTLED UP WHILE A RELAY } \\
\text { WIRING FAULT WAS IDENTIFIED AND CORRECTED. }\end{array}$ \\
\hline 28-May-90 & $14: 24$ & 28-May-90 & $15: 31$ & 1 & $\begin{array}{l}\text { DURING A CONTROLLED SHUTDOWN DUE TO HIGH VIBRA- } \\
\text { TION READINGS ON NO. } 3 \text { TURBINE BEARING, SWITCH- } \\
\text { YARD BREAKER N-521 TRIPPED THE HIHG VIBRATION } \\
\text { SOURCE WAS DETERMINED TO BE TRANSIENT AND A HOT } \\
\text { RESTART FOLLOWED. }\end{array}$ \\
\hline 31-May-90 & $9: 16$ & $7-J u n-90$ & $1: 38$ & 160 & $\begin{array}{l}\text { UNIT MFT ON LOW DRUM LEVEL DUE TO A BOILER WW } \\
\text { TUBE LEAK IN } 4 \text { A COMBUSTOR. }\end{array}$ \\
\hline $7-J$ un -90 & $8: 11$ & 7-Jun-90 & $20: 21$ & 12 & CONTROLLED SHUTDOWN - PROPANE SUPPLY $<22 \%$ \\
\hline $7-J u n-90$ & $22: 21$ & $7-J u n-90$ & $23: 37$ & 1 & PROPANE VAPORIZER TRIP \\
\hline $27-J u n-90$ & $20: 14$ & $28-J u n-90$ & $0: 47$ & 5 & SA INVERTER FAULT \\
\hline $28-J u n-90$ & $14: 27$ & $10-\mathrm{Jul}-90$ & $4: 48$ & 278 & SHII $4 A$ COMBUSTOR TUBE LEAK \\
\hline $17-\mathrm{Jul}-90$ & $18: 25$ & $28-J u 1-90$ & $8: 56$ & 255 & $\begin{array}{l}\text { UNIT MFT ON HIGH FURNACE DRAFT DUE TO A BOILER } \\
\text { TUBE LEAK IN } 4 A \text { COMBUSTOR. AT THE TIME OF THE } \\
\text { TRIP,OPERATIONS PERSONNEL WERE REDUCING LOAD TO } \\
\text { REMOVE THE BOILER FROM SERVICE VIA A CONTROLLED } \\
\text { SHUTDOWN SEQUENCE. }\end{array}$ \\
\hline
\end{tabular}


Table 2-1. OUTAGE SUMMARY (Continued)

\begin{tabular}{|c|c|c|c|c|c|}
\hline $\begin{array}{l}\text { START } \\
\text { OUTAGE }\end{array}$ & & $\begin{array}{l}\text { STOP } \\
\text { OUTAGE }\end{array}$ & & $\begin{array}{l}\text { DURATION } \\
\text { (APPROX.) }\end{array}$ & CAUSE \\
\hline DATE & TIME & DATE & TIME & HRS. & \\
\hline $1-A \cup g-90$ & $18: 08$ & $19-A \cup g-90$ & 17:06 & 431 & $\begin{array}{l}\text { CONTROUED SHUTDCWN DUE TO WATERWAL TUBE } \\
\text { LEAKIN } 4 A \text { COMBUSTOR. REPAIRS WERE COMPLETED } \\
\text { AND THE UNIT WAS AVAILABLE FOR SERVICE AT 15:00 } \\
\text { ON 8/16. HOWEVER, THE UNIT WAS PLACED ON } \\
\text { RESERVE SHUTDOWN UNTIL 8/19 }\end{array}$ \\
\hline $25-A \cup g-90$ & $0: 12$ & 7-Sep-90 & $12: 09$ & 324 & CONTROLLED SHUTDOWN FOR RESERVE SHUTDOWN \\
\hline 8-Sep-90 & $1: 43$ & 8-Sep-90 & $6: 32$ & 5 & $\begin{array}{l}\text { UNIT MFT ON PHANTOM PA FAN TRIP. A BLOWN FUSE IN } \\
\text { THE FAN Y SIDE CONTROLLER WAS REPLACED. }\end{array}$ \\
\hline 12-Sep-90 & $0: 12$ & 13-Sep-90 & $4: 05$ & 28 & $\begin{array}{l}\text { CONTROLLED SHUTDOWN DUE TO A WATERWALL TUBE } \\
\text { LEAK IN 4B COMBUSTOR. THE LEAK WAS EXTERNAL TO } \\
\text { THE BOILER AT THE LOOPSEAL WALLBOX CONNECTION. }\end{array}$ \\
\hline 13-Sep-90 & $21: 27$ & 13-Sep-90 & $23: 46$ & 2 & UNIT MFT ON PHANTOM PA FAN TRIP. \\
\hline 14-Sep-90 & $0: 34$ & 14-Sep-90 & $1: 53$ & 1 & $\begin{array}{l}\text { UNIT MFT ON HIGH DRUM LEVEL DURING START-UP } \\
\text { SHORTLY AFTER SYNCHRONIZATION. }\end{array}$ \\
\hline 16-Sep-90 & $5: 52$ & $6-0 c t-90$ & $15: 47$ & 490 & $\begin{array}{l}\text { UNIT MFT ON HIGH FURNACE DRAFT PRESSURE DUE TO } \\
\text { A BOILER TUBE LEAK IN 4A COMBUSTOR. DURING THE } \\
\text { REPAIR OUTAGE B\&W CONDUCTED A REMAINING USE- } \\
\text { FUL LIFE ANALYSES ON THE RADIANT SUPERHEATER } \\
\text { TUBES (SH II) AN TUBE METAL TEMPERATURE THERMO- } \\
\text { COUPLES NERE INSTALLED. }\end{array}$ \\
\hline $6-0 c t-90$ & $17: 06$ & $7-0 \mathrm{ct}-90$ & $0: 36$ & 8 & $\begin{array}{l}\text { CONTROLLED SHUTDOWN DUE TO A FLANGE LEAK } \\
\text { BETWEEN THE THROTTLE AND CONTROL VALVES. DUR- } \\
\text { ING START-UP. }\end{array}$ \\
\hline $19-0 c t-90$ & $2: 04$ & $19-$ Oct-90 & $5: 45$ & 4 & $\begin{array}{l}\text { UNIT MFT ON PHANTOM ID FAN TRIP.TWO CONTROL } \\
\text { FUSES IN THE FAN DELTA SIDE CONTACTOR WERE } \\
\text { REPLACED PRIOR TO RESTART. }\end{array}$ \\
\hline $23-$ Oct -90 & $13: 00$ & $23-0 c t-90$ & $14: 16$ & 1 & $\begin{array}{l}\text { UNIT MFT ON LOW AIR FUEL RATIO DUE TO A STUCK } 4 B \\
\text { UNDERBED DAMPER. DESSICANT DUST FROM THE } \\
\text { CONTROL AIR DRYER CAUSED THE DAMPER TO STICK }\end{array}$ \\
\hline $26-0 \mathrm{ct} \cdot 90$ & $17: 13$ & $1-$ Nov-90 & $20: 05$ & 147 & $\begin{array}{l}\text { CONTROULD SHUTDOWN FOR PYROPOWER TO INSPECT } \\
4 A \text { AND } 4 B \text { COMBUSTOR REFRACTORY AS PART OF THE } \\
\text { CONTRACT CLOSEOUT. CUEA HIRED UNITED ENGINEERS } \\
\text { AND CONSTRUCTORS TO PERFORM ANINDEPENDENT } \\
\text { EVALUATION OF THE BOILER REFRACTORY. }\end{array}$ \\
\hline 14-Dec-90 & $5: 01$ & 14-Dec-90 & $12: 27$ & 7 & $\begin{array}{l}\text { UNIT TRIP ON MFT DUE TO LOSS OF ID FAN RESULTING } \\
\text { FROM SYSTEM DISTURBANCE. THE FAN TRIP OCCURRED } \\
\text { DURING A RECLOSURE ON 69KV BREAKER N-931. }\end{array}$ \\
\hline
\end{tabular}


Table 2-1. OUTAGE SUMMARY (Continued)

\begin{tabular}{|c|c|c|c|c|c|}
\hline \multicolumn{2}{|c|}{$\begin{array}{c}\text { START } \\
\text { OUTAGE }\end{array}$} & \multicolumn{2}{|l|}{$\begin{array}{l}\text { STOP } \\
\text { OUTAGE }\end{array}$} & \multirow{2}{*}{$\begin{array}{l}\text { DURATION } \\
\text { (APPROX.) } \\
\text { HRS. }\end{array}$} & \multirow[t]{2}{*}{ CAUSE } \\
\hline DATE & TIME & DATE & TIME & & \\
\hline 17-Dec-90 & $10: 29$ & 17-Dec-90 & $12: 24$ & 2 & UNIT TRIP ON MFT DUE TO MYSTERY TRIP OF ID FAN \\
\hline 20-DeC-90 & $17: 19$ & 20-Dec-90 & $19: 59$ & 3 & $\begin{array}{l}\text { UNIT MFT ON LOW DRUM LEVEL DURING DYNAMIC LOAD } \\
\text { RMMP TESTING AS PART OF THE DOE TEST PROGRAM. }\end{array}$ \\
\hline 22-Dec-90 & $16: 19$ & 22-Dec-90 & $20: 08$ & 4 & $\begin{array}{l}\text { UNIT MFT ON SA FAN TRIP DUE TO LOSS OF WDPF DROP } \\
\text { 2. THE DROP WAS LOST DUE TO PROBLEMS WITH THE } \\
\text { WDPF LOGIC ROOM HVAC SYSTEM. }\end{array}$ \\
\hline 2-Jan-91 & $15: 05$ & 2-Jan-91 & $18: 32$ & 3 & $\begin{array}{l}\text { CONTROUED SHUTDOWN TO INSPECT A SWITCH ON THE } \\
\text { \#4 GENERATOR TRANSFORMER RAPID PRESSURE } \\
\text { RELAY ALARM WHICH HAD ANNUNCIATED ON } \\
\text { 12/31/90 AND DID NOT CLEAR. THE SWITCH WAS } \\
\text { FOUND TO BE DEFECTIVE AND REPAIRED. }\end{array}$ \\
\hline $8-J a n-91$ & $12: 04$ & $8-J a n-91$ & $13: 48$ & 2 & $\begin{array}{l}\text { UNIT MFT ON HIGH ID FAN INLET PRESSURE DUE TO AN } \\
\text { OUT-OF-CALIBRATION PRESSURE TRANSMITTER. }\end{array}$ \\
\hline 13-Jan-91 & $1: 36$ & 13-Jan-91 & $3: 00$ & 1 & $\begin{array}{l}\text { UNIT MFT ON LOSS OF COAL FEED TO } 4 A \text { COMBUSTOR. } \\
\text { THE MFT WAS DETERMINED TO BE THE RESULT OF } \\
\text { COAL FEEDER ROTARY VALVE PLUGGAGE RESULTING } \\
\text { FROM THE USE OF "DORCHESTER" COAL }\end{array}$ \\
\hline 13-Jan-91 & $3: 38$ & 13-Jan-91 & $12: 12$ & 9 & $\begin{array}{l}\text { CONTROLLED SHUTDOWN, AFTER AND MFT ON LOW } \\
\text { DRUM LEVEL, DUE TO A SUSPECTED TUBE LEAK IN } 4 A \\
\text { COMBUSTOR. UPONFURTHER INVESTIGATION, THE } \\
\text { INDICATIONS OF A TUBE LEAK WEFIE FOUND TO BE } \\
\text { FALSE AND UNIT START-UP WAS RE-INITIATED. }\end{array}$ \\
\hline $16-J a n-91$ & $12: 18$ & $17-J a n-91$ & $2: 30$ & 14 & $\begin{array}{l}\text { UNIT MFT ON LOW-LOW UNDERBED PA AIR FLOW TO } 4 B \\
\text { COMBUSTOA DUE TO A STUCK OONTROL DAMPER. } \\
\text { DESSICANT DUST FROM THE CONTROL AIR SYSTEM } \\
\text { DRYER CAUSED THE DAMPER TO STICK. REPAIRS } \\
\text { WERE MADE TO THE WARM UP LINE FOR } 4 B \text { BOILER } \\
\text { FEED PUMP DURING THE SHUTDOWN. }\end{array}$ \\
\hline $18-J a n-91$ & $11: 44$ & $18-\mathrm{Jan}-91$ & $12: 35$ & 1 & UNIT MFT ON PHANTOM SA FAN TRIP. \\
\hline
\end{tabular}


July 9, 1987

First coal fires without propane.

First limestone feed to boiler.

Baghouse \#4 in service for the first time.

74 MWe turbine/generator on-line at 30 MWe.

\section{July 1987}

Continuous operation for 91 hours on coal at 35 to 45 MWe.

Completed steam blow to old turbines.

Started commissioning old turbines.

\section{August and september 1987}

Continued commissioning of old turbines and raising load.

Maximum load to date - 65 MWe.

Overheat incident occurred on evening of $9 / 29 / 87$, unit off-line for inspection and repairs.

October, November and December 1987

Repair outage for overheat incident.

\section{January 1988}

571 hours on coal firing. Outage to replace drum safety gasket.

control tuning at $35 \%, 50 \%, 75 \%$ and $100 \%$ MCR.

\section{February 1988}

468 hours on coal firing.

Outage to repair coal conveyor $\mathrm{C}$ gearbox.

Outage to repair floor tube failure in combustor A.

Outage to repair floor tube failure in combustor B.

\section{March 1988}

354 hours on coal firing.

Outage due to secondary air fan trip.

Outage due to bed pressure swings.

Outage due to 74 Mwe turbine exciter transformer failure.

April 1988

293 hours on coal firing.

Unit outage for No. 4 turbine fine screen removal and repair of exciter transformer.

Refractory repairs made to hot cyclones and furnaces.

\section{May 1988}

356 hours on coal firing.

Completed No. 4 turbine fine screen and exciter transformer outage. Completed stack monitoring certification test.

Unit outage to replace demisters in drum.

Unit outage due to secondary air fan trip. 


\section{June 1988}

492 hours on coal firing.

Completed dry run boiler acceptance test.

Test high ash design "B" cual; test abandoned due to bottom ash conveying capacity limitations.

Test high sulfur design "B" coal; test abandoned due to failure of limestone feed system.

\section{July 1988}

446 hours on coal firing

Full load acceptance test conducted on design "A" coal.

Completed 2 hour dry run turbine acceptance test. Maximum unit load of 116.4 MWe achieved.

Increased frequency of bubble cap loss.

\section{August 1988}

1.5 hours on coal firing.

Outage for modifications of bottom ash conveying system.

Refractory repair in loop seals, hot cyclones and furnaces.

Replacement of all bubble cap locking washers.

\section{September 1988}

184 hours on coal firing.

Test high sulfur design "B" coal; test abandoned due to limestone feeder failures.

Outage to repair combustor $B$ tube leak at loop seal wall box.

Outage due to loop seal flow surges.

\section{October 1988}

492 hours on coal firing.

Completed second boiler acceptance test using design "A" coal.

Completed baghouse pressure drop test.

Completed $750 \mathrm{klb} / \mathrm{hr}, 500 \mathrm{klb} / \mathrm{hr}$ and $350 \mathrm{klb} / \mathrm{hr}$ emissions compliance tests.

Test on high sulfur design "B" coal; test abandoned due to limestone feeder failures.

outage to inspect for loose refractory in combustors, ash coolers and loop seals.

Test on high ash design "B" coal with water sprays in two bottom ash coolers.

\section{November 1988}

552 hours on coal firing.

Outage to inspect refractory and add water sprays to bottom ash coolers.

Test on high sulfur design "B" coal; test abandoned due to limestone feeder failures. 


\section{December 1988}

504 hours on coal firing.

Load curtailment due to limestone feeder failures.

Test on high ash design "B" coal with bottom ash cooler sprays in service.

Load curtailment due to high PA fan amps.

Unit outage due to No.4 generator exciter collector ring failure.

\section{January 1989}

106.5 hours or coal firing.

Unit outage for major refractory repairs to hot cyclones, loop seals, and furnaces.

\section{February 1989}

180 hours on coal firing.

$4 \mathrm{~B}$ circulating water pump failure.

\section{March 1989}

610 hours on coal firing.

Completed Salt Creek coal test burn and hot-mode shakedown test.

\section{April 1989}

493 hours on coal firing.

Test on high sulfur design "B" coal; test abandoned due to limestone feeder problems.

Test on high ash design "B" coal with water sprays in two bottom ash coolers. Test was terminated due to pluggage of bottom ash coolers from over-spraying.

Testing on high ash design "B" coal with modified bottom ash cooler sprays. Test was terminated due to plant outage caused by boiler feed pump problems.

\section{May 1989}

277 hours on coal firing.

Plant limited to $50 \%$ MCR due to $4 B$ boiler feed pump problems.

Conducting freeboard gas traverse (FGAS) tests on peabody coal at $50 \%$ MCR.

Bottom ash screw cooler $4 \mathrm{~A}$ out of service.

\section{June 1989}

541 hours on coal firing.

Peabody coal deliveries extended to allow test program to complete test series $A O 2$ thru $A O 8$ and FGAS test $B-6$.

Flant off-line to allow modifications to PA fan inlet box.

\section{July 1989}

518 hours on coal firing.

PA fan inlet box modifications completed and fan tests conducted by PPC/Howden-Sirocco.

westinghouse tuning turbine controls.

Switch to Salt Creek coal.

Test program ran test $\mathrm{P} 49$ and $\mathrm{P} 50$.

MET due to ID fan trip caused by system disturbance.

$4 \mathrm{~A}$ boiler feed pump seized lip; unit derated to $50 \% \mathrm{MCR}$. 


\section{August 1989}

333 hours on coal firing.

Unit derated to $50 \%$ MCR due to loss of $4 \mathrm{~A}$ boiler feed pump.

Test program testing at $50 \%$ MCR on Salt Creek coal.

Unit in outage to replace $4 \mathrm{~A}$ boiler feed pump and to replace 23 bed nozzles in combustor A.

Unit in outage due to water-wall tube leak at $4 \mathrm{~F}$ coal feed wall box in combustor $B$.

\section{September 1989}

281 hours on coal firjing.

Unit off-line to repair sticking throttle valve on No. 2 (12.5 MWe) turbine.

All units on-line at 98 MWe; MFT due to SA fan trip.

All units on-line at 82 MWe; MFT due to malfunction of main feed water control valve.

Tests on various bed pressures to determine effect on bed temperature.

EPRI contractor conducted series of baghouse tests.

Unit down for installation of new PA fan wheel.

\section{October 1989}

91 hours on coal firing.

Completed installation of new PA fan wheel and PPC added shelf between superheat panels 2 and 3 in both furnaces.

Experiencing high opacity; several bags replaced.

\section{December 1989}

480 hours on coal firing.

All units on-line and the test program conducting tests.

Testing on high sulfur design "B" coal.

I'ube leak in bottom ash cooler $4 \mathrm{~B}$ due to water sprays.

Unit had to be shut down due to inability to remove ash from combustor $A$.

Twenty-five nozzles off in combustor $A$ and 1 off in combustor $B$.

Inspected cyclone $B$ vortex finder, 9 panels badly warped.

unit back on-line but problem developed with No. 4 generator exciter firing circuit and unit down again.

All units on-line and test program conducting tests.

\section{January 1990}

543 hours on coal firing.

All units on-line at 108 MWe and test program conducting tests.

Dynamic testing successfully completed.

Unit outage to clear blockage in coal feed system to in-plant silos and repair superheater safety flange leak. Combustion chamber bed temperature difference of approximately 100
${ }^{\circ} \mathrm{F}$.

Unit in scheduled outage to repair combustor $B$ cyclone vortex finder. 


\section{Eebruary 1990}

178 hours on coal firing.

UT inspection of SHII panels in both combustors.

Air flow tests conducted.

Multiple tube leak in combustor A SHII and water wall.

$4 \mathrm{~A}$ boiler feed pump seized.

Low load test conducted.

Leak in bottom southwest corner of combustor B.

\section{March 1990}

681 hours on coal firing.

Expansion joints installed in windbox corners.

Test program performance testing conducted.

Fan power test conducted.

Test program soot blowing test conducted.

\section{April 1990}

629 hours on coal firing.

Test program performance tests conducted.

Unit 4 generator exciter transformer explosion and MFT.

Inspection during outage.

\section{May 1990}

258 hours on coal firing.

Unit off-line for water-wall tube weld repair on outside wall box.

3 SA fan trips

High dP's in baghouses $1-4$.

\section{June and July 1990}

752 hours on coal firing.

All units out of service due to SH II tube leak.

59 bubble caps missing in combustor $A ; 3$ in combustor $B$. 4 bottom ash cooler nozzles replaced.

EPRI concluded testing on June 15 .

\section{August 1990}

143 hours on coal firing.

Unit shut down due to water-wall tube leaks due to bed material

blockage in combustor $A$.

Cemented bed material in tubes and headers hydro-blasted.

Boiler chemistry problems persisted. 


\section{September 1990}

167 hours on coal firing.

4 bubble caps replaced in combustor $A$; 1 bubble cap replaced in combustor B.

External leak found at the loop seal wall box connection to combustor $B$.

There were two PA fan trips.

Unit shut down due to SHII and water-wall tube leaks.

Inspections of SHII, refractory, water walls, bubble caps.

100 bubble caps replaced in combustor $A ; 20$ bubble caps replaced in combustor B.

Large chunks of refractory missing from combustor $A$ bull nose and cyclone cone and from scroll piece in both combustors.

Combustor $B$ center wall refractory interface pad welded in places.

\section{October 1990}

461 hours on coal firing.

Water-wall tube leak discovered during boiler fill after outage.

Flange leak on main steam line.

Leaking bags in baghouse 3 .

DOE testing conducted.

Clinkers developed during DOE coal size testing.

Combustor B primary air damper stuck twice.

Controlled shutdown in preparation for inspections.

Six nozzles replaced in combustor $A$; one nozzle replaced in combustor $B$.

\section{November 1990}

697 hours on coal firing.

DOE testing conducted.

High pressure across baghouse 3 due to accumulated fly ash.

At temperator tests conducted.

\section{December 1990}

718 hours on coal firing.

Test conducted to determine the effect of high bed inventory.

Stack testing conducted to verify previous particulate measurements

taken as part of the environmental characterization plan.

Alternate coal (Dorchester) deliveries begun.

$4 \mathrm{~A}$ coal feeder drag conveyor bearing failure.

MFT due to ID fan trip.

DOE dynamic testing conducted.

Three MFT's due to loss of WDPF drops and subsequent SA fan trips. 


\section{January 1991}

706 hours on coal firing.

Controlled shut down to repair switch on \#4 generator transformer rapid pressure relay alarm.

4C Iimestone conveyor was taken out of service due to a bad rotary valve motor.

Alternate fuels testing conducted at half load.

MFT due to loss of coal feed resulting from high coal moisture content.

Orchard Valley (gob) coal deliveries started.

4C limestone rotary valve repairs completed.

2 MFT's due to PA and SA fan trips.

Successful operation on a combination of salt creek and gob coals. DOE testing concluded on January 18, 1991.

\subsection{ACCEPTANCE TESTS}

In June of 1988, a dry run acceptance test was completed at full load with Design Coal $A$, followed by operability tests with high ash and high sulfur Design Coals B. Although the dry run acceptance was successful in establishing operating and sampling procedures, the high ash and high sulfur coal tests were unsuccessful due to capacity limitations with the original bottom ash transport system. Modifications that were made to the bottom ash system to increase transport capacity are discussed in section 13.

The first acceptance tests on Design Coal A were completed on July 7, 1988. Fan power consumption in excess of contract guarantees at full load was identified prior to the test. Other boiler performance guarantees were met at full load operation except the calcium to sulfur ratio and total draft loss. The guarantee value for the former is 1.5 (excluding calcium in the coal ash), while the actual value for the test was 3.0. There were four reasons that were cited for failure to meet the guaranteed value:

- High combustion chamber temperatures. For the performance period of 16 hours, combustor $A$ and $B$ temperatures averaged $1647^{\circ} \mathrm{F}$ and $1707^{\circ} \mathrm{F}$, respectively (as measured approximately 20 inches above the distributor plate around the perimeter of the combustor). These temperatures should have been in the vicinity of $1550^{\circ} \mathrm{F}$ to $1600^{\circ} \mathrm{F}$.

- Low ash content. The ash content of the coal averaged 16.8 percent versus the value for design $A$ coal of 26.9\%. This resulted in a deficiency of calcium and other potential sorbents in the ash.

- Improper limestone sizing, particularly excessive fines fraction. The small particles pass through the hot cyclones and do not recirculate.

- Poor combustion balance between the two chambers. Better matching of air and coal flows may improve performance and reduce mean bed temperatures. 
The acceptance test was originally scheduled for 24 hours, with solids sampling covering a 12-hour interval in the middle of this period. Sixteen hours into the test period and 9 hours into the solids sampling interval, coal feeder $4 \mathrm{~A}$ tripped and caused a significant-enough boiler upset that the run was terminated 8 hours earlier than the 24-hour agreement. However, CUEA and PPC agreed that the two complete isokinetic samples and five sets of solids samples that were taken would suffice.

On July 8, 1988, following the full-load acceptance test, load was increased to a gross output of 116.4 MWe to establish equipment and design limitations on the plant. In this case, a drop in drum water level suggested a possible limitation with the feed water system. This was subsequently found to be controls related.

Load was subsequently ramped between $925 \mathrm{klb} / \mathrm{h}$ and $750 \mathrm{klb} / \mathrm{h}$ steam flow. Maximum rate of change was limited to approximately $8.4 \mathrm{klb} / \mathrm{min}$ ( $1 \mathrm{MWe} / \mathrm{min})$. This limitation is dictated by turbine control settings which require final tuning by Westinghouse before this rate can be significantly increased. Nearly full load was maintained through July 11 when load was shed at an improved rate of $1.5 \mathrm{MWe} / \mathrm{min}$ to approximately $750 \mathrm{klb} / \mathrm{h}$ steam flow. This was achieved without final tuning of the turbine controls by Westinghouse.

Stack emissions were also verified at the $750 \mathrm{klb} / \mathrm{h}$ load. The $\mathrm{Ca} / \mathrm{S}$ ratio limit for meeting the $\mathrm{SO}_{2}$ emission limit of $0.4 \mathrm{lb} / 10^{6} \mathrm{Btu}$ at these reduced loads is not stipulated contractually. Emissions were satisfactory at $750 \mathrm{klb} / \mathrm{h}$.

On July 12, turbine testing was completed with the unit 4 governor valves $100 \frac{c}{b}$ open and gross plant output at 117 Mwe. Load was then reduced to 80 MWe to test various schemes for reducing bed temperatures, which were in the range of $1650^{\circ} \mathrm{F}$ to $1700^{\circ} \mathrm{F}$ at the peak load. At the reduced load, there is enough fan margin for adjusting the primary air to secondary air ratios. Adjustment of the relative air flows appeared to have little effect on bed temperatures. The tests, however, were not conducted in a controlled fashion for a sufficient duration to reach positive conclusions. Ash cooler/classifier air flows were also adjusted between $4 \mathrm{ft} / \mathrm{s}$ and $10 \mathrm{ft} / \mathrm{s}$ fluidizing velocities to determine if bed particle sizing could be altered enough to influence bed temperature. Again, these tests were inconclusive due to inadequate test duration.

Although acceptance tests for Design Coal A were repeated in October 1988 at lower operating temperatures, process conditions for the July 7, 1988 test were as follows: 
Table 2-2. Acceptance Test Process Conditions

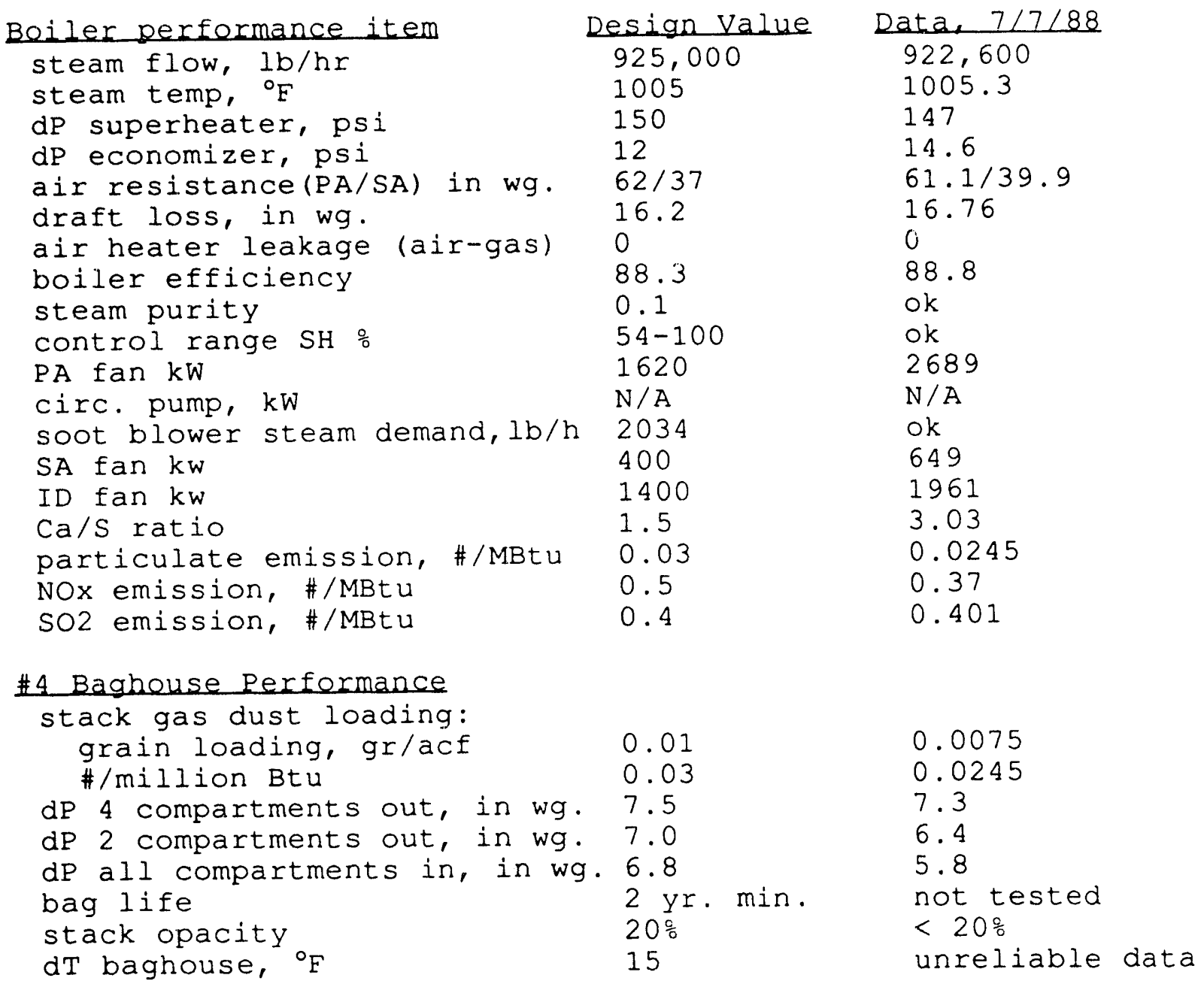

Notes:

all data by Colorado-Ute

$\mathrm{Ca} / \mathrm{S}$ ratio guaranteed at full load only

SO2 emission guarantee is without a limit on the Ca/s ratio

On October 7, 1988, a repeat of the July 7 Design Coal A boiler performance acceptance test was run. The calcium to sulfur ratio was substantially lower during the second acceptance test than during the first test. The ratio was 1:4 when only the calcium present in the limestone was considered (1:7 when the calcium in the coal was also included). Both of these values correspond to an SO2 retention rate of 72 percent. Factors that may have contributed to the improvement in $\mathrm{Ca} / \mathrm{S}$ ratio included lower overall combustor temperature, better temperature balance between the two combustors, and change in limestone size distribution as indicated by a larger median size in the second test. 
Process conditions during this Design Coal A acceptance test in October, 1988 were as follows:

Table 2-3. Acceptance Test Process Conditions

\begin{tabular}{|c|c|c|}
\hline Beiler performance item & Design Value & Data, $10 / 88$ \\
\hline steam flow, $1 \mathrm{~b} / \mathrm{hr}$ & 925,000 & 959,672 \\
\hline steam temp, ${ }^{\circ} \mathrm{F}$ & 1005 & 1003 \\
\hline air resistance $(\mathrm{PA} / \mathrm{SA})$ in $\mathrm{wg}$. & $62 / 37$ & $54.0 / 37.3$ \\
\hline draft loss, in wg. & 16.2 & \\
\hline boiler efficiency & 88.3 & 88.55 \\
\hline$P A$ fan $\mathrm{kW}$ & 1620 & \\
\hline $\mathrm{Ca} / \mathrm{S}$ ratio & $1: 5$ & $3: 03$ \\
\hline particulate emission, & 0.03 & 0.0245 \\
\hline NOx emission, \#/MBtu & 0.5 & 0.37 \\
\hline SO2 emission, \#/MBtu & 0.4 & 0.401 \\
\hline Particulate, \#/MBtu & & \\
\hline $925 \mathrm{klb}$ steam flow & 0.03 & 0.018 \\
\hline 750 & 0.03 & $<0.03$ \\
\hline 500 & 0.03 & $<0.03$ \\
\hline 350 & 0.03 & $<0.03$ \\
\hline NOx, \#/MBtu & & \\
\hline 925 & 0.5 & 0.2 \\
\hline 750 & 0.5 & 0.18 \\
\hline 500 & 0.5 & 0.17 \\
\hline 350 & 0.5 & 0.08 \\
\hline SO2, \#/MBtu & & \\
\hline 925 & 0.4 & 0.39 \\
\hline 750 & 0.4 & 0.28 \\
\hline 500 & 0.4 & 0.27 \\
\hline 350 & 0.4 & 0.19 \\
\hline
\end{tabular}

\section{\#4 Baghouse Performance}

$\begin{array}{lll}\text { Grains/cf of gas } & 0.01 & 0.0094 \\ \mathrm{dP}(2 \times 2), \text { in wg. } & 7.5 & 7.1 \\ \mathrm{dP}(2 \times 2) \text { soot blow, in wg. } & 7.5 & 7.6 \\ \mathrm{dP} \text { all compartments in, in wg. } & 6.8 & 6.6 \\ \text { stack opacity } & 20 \% & 6.3-9.4\end{array}$

Notes:

all data by Coloraco-Ute

$\mathrm{Ca} / \mathrm{S}$ ratio guaranteed at full load only

SO2 emission guarantee is without a limit on the $\mathrm{Ca} / \mathrm{S}$ ratio

Concerning acceptance tests with high ash coal, demonstrations of sustained operability on the high ash coal were initially unsuccessful due to excessive temperatures of bed material discharging from the ash classifiers at full load. The high temperatures were reduced to acceptable operational levels by operating two ash classifiers and the water-cooled screw cooler on each combustion chamber. The two ash classifiers operate in parallel and the water-cooled 
screw cooler operates in series with either or both of the ash classifiers. By design, only two of the three ash cooling systems should be in service on each combustion chamber simultaneously. Modifications to the fluidizing air flow control logic also helped reduce bed material drain temperatures and improve bottom ash disposal flow rate. However, PA fan limitations terminated the tests in during the fourth quarter of 1988.

High sulfur coal testing was also attempted at full load on several occasions through the fourth quarter of 1988. Limitations in limestone feed flow rate of feeder failures prevented the successful completion of these tests.

\subsection{SUMMARY OF EQUIPMENT AND OPERATING PROBLEMS}

Problems with equipment and operation of the Nucla CFB facility are summarized below (and are discussed in the sections in parentheses and/or in the Annual Reports): Report)

- September 1987 overheat incident (1987-1988 Annual

- Leaks in the secondary superheater and water-wall

tubes (Section 16)

- Temperature differential between combustors (Section

- Distortion of the cyclone vortex finders (Section 16)

- Air distributor bubble cap / nozzle wear and loss (Section 16)

- Refractory breakage, particularly in the cyclones, loop seals, and at the water wall/refractory interface (Section 16)

- High initial rate of replacement required for baghouse bags (Section 15)

- Bottom ash cooler limitations (Sections 13 and 16)

- Primary air fan limitations (1989 Annual Report)

- Limestone feed system limitations (Section 12)

- Loop seal flow instabilities

- Boiler feed water pump failures (non CFB-related)

- Drum level swings

- Backsifting of bed material into the windboxes (Section 16)

After plant start-up, many problems encountered were routine in nature, including a number of equipment trips before fine tuning of the controls system, minor steam leaks at flanges and relief valves, and generator synchronization difficulties. A second group of problems could be traced back to design or construction inadequacies. Steam line expansion interference, steam leaks at field welds, boiler casing leaks, primary and secondary air cross-leakage in the air heater, plugging of various pressure taps, faulty 02 and so2 analyzers, and faulty air dampers and actuators fall into this category. A third group of difficulties may be ascribed to the new technology and scale-up uncertainties. Items such 
as drum level instability, back-sifting of bed material into the primary air plenum, and initial poor performance of the ash coolers are included in this group.

While the correction of many of these problems caused relatively short outages (days), repairs after the overheat incident of september 1987 required an outage of 10 weeks. This incident is described in section 16 of this report and in more detail in the 1987-1988 Annual Report. However, the persistent problem of secondary superheater tube leaks has caused the largest amount of CFB-related outage time through January 1991. This issue is also discussed in section 16.

One serious problem that has disrupted unit operation is that of secondary superheater tube leaks. From October 1989 to January 1991, there have been seven separate tube failures, contributing significantly to total outage hours. Causes for these failures include particle erosion, long term overheat, and short term overheat from flow restrictions. Erosioncaused tube leaks were addressed by installation of horizontal shelves along the top tube of the second superheater panel. To address superheater I tube failures due to long term overheat, the attemperator spray flow logic was modified, and there have not been any additional tube failures since october 1990. Failures attributed to short term overheat due to flow restrictions have been addressed by modifications to shutdown procedures in an effort to reduce the likelihood of solids ingestion into failed tubes.

One operational problem that has proved difficult to resolve is a temperature differential between combustors, primarily during full-load operation. Since initial startup, combustors $A$ and $B$ have operated with a temperature differential in the lower combustor zone of as high as 150 ${ }^{\circ} \mathrm{F}$. Although the root cause of the temperature differential is still not fully understood, sufficient tests and normal operating data exist for characterizing the behavior of the boiler when the differential is present.

Summarizing the operating characteristics of the Nucla CFB boiler during periods of high combustor temperature differential:

- Combustor B generally has the higher operating bed temperature and cycle inlet temperature.

- Furnace water-wall differential pressure is lowest in the combustor with the higher temperature. The differential pressure is a direct indication of solids loading and is generally lower in combustor $4 \mathrm{~B}$ compared to $4 \mathrm{~A}$

- Circulating material is consistently coarser in combustor $4 \mathrm{~B}$ as indicated by samples taken from each loop seal. At full load operation, this material generally gets coarser after three of four days following a startup until and equilibrium is achieved. 
Loss of air distributor bubble caps has occurred frequently during the first years of operation. Design changes to the bubble caps and retentions washers have helped to minimize bubble cap loss. Bubble cap erosion has also been pronounced in the region in front of the recycle return line and extending three quarters of the distance across the air distributor to the front wall. Erosion has been severe enough that replacement of many bubble caps has been required.

Refractory breakage has also been an operational problem. In the lower combustion chambers, "gunned-on" refractory has broken and spalled over most surfaces, particularly around the lower 2 to 3 feet above the air distribution plate, near the water-wall interface, around the recycle return line, and around the start-up burners and manways. In the cyclones, the abrasion resistant layers of refractory on the inlet spirals, cyclone barrels, and conical sections have also suffered breakage and spalling. Modified refractory anchors were installed in some regions and refractory "stops" were placed around the bull nose to reduce movement and breakage. In the loop seals, the original archways suffered severe breakage after 5500 hours of service and were subsequently cast using a combination of brick, castable refractory, and gunned-on refractory.

During the first four years of operation, the Nucla baghouses have experience numerous bag failures, equal to approximately 8 of the total number of installed bags. Baghouse 2 experiences a particularly high rate of failure, with was found to be due to high deflate air flow rates. The deflate flow rate to the older baghouses was subsequently adjusted to equal the deflate pressure in baghouse 4 , the new baghouse. Although the bag failure rate is still higher than acceptable, this may be due to damage to the bags during initial operation at the higher deflate air flow rate. The majority of failures have occurred in the bottom of the bag, where the dirty gas enters, and are believed to be caused by abrasion of the bag by the entering ash.

Bottom ash cooler problems have not been severe. Minor problems included the infrequent loss of bubble caps and warping of and packing of bed material around manual isolation gates. The most significant problem has been that the drains from the combustors have occasionally blocked with refractory and large pieces of bed material. In addition, the auxiliary hardware for fluidizing the inlet drains have suffered from blockage by bed material, erosion, and damage from air lances.

Concerning primary air fan flow limitations, full load had been restricted to approximately 105 MWe to allow some margin for control of excess air. Air flow tests on the fans were 
conducted in the fourth quarter of 1988 to determine causes for performance shortfalis. After these tests, the fan vendor concluded that there were major air flow distribution problems in the PA fan inlet boxes. Inlet fan box modifications were made, followed by additional air flow testing. These modifications produced only limited improvement in PA fan performance.

In the fourth quarter of 1989, the wheel and inlet cones of the $P A$ fan were replaced with a more aerodynamic design as shown in Figures $2-4$ and 2-5. Subsequent testing indicated that approximately two thirds of the desired improvement in performance was achieved.

Limestone feeder problems have included multiple eccentric wejght bearing failures, motor burnouts, and feeder instability. The motor systems were repiaced with totally enclosed motors, integral bearing, and eccentric weights, and have experienced no additional failures. Feeder stability has been poor due to pressurization of the charge hopper from transport air leaking past the rotary valves, and to a high pressure drop across the feeder cone. The addition of vent lines seems to have improved feeder stability.

Concerning loop seal flow instabilities, considerable time was spent on measuring pressure profiles and adjusting air flow distribution to the loop seals in an initially unsuccessful effort to resolve this problem. During inspection of the internals of the solids recycle system in March 1988, loose refractory pieces in the bottom of the loop seal and bent aeration nozzles in the recycle downcomers were discovered. Refractory pieces were removed, damaged nozzles were replaced, and the loop seal air distribution geometry was modified. These modifications resolved this problem.

Drum level control MFT's frequently caused difficulties during boilel restarts. This places a strain on the propane startup system both mechanically and in keeping propane inventories ready for startup. Drum level MFT's also resulted in high consumption of boiler makeup water because of delays in start-up when blowdown and drain rates are highest. This places an increased burden on the demineralizer train. This problem has never been completely corrected.

Concerning backsifting, bed material backsifts through the air distributor bubble caps into the windbox and accumulates on the windbox floor. This occurs particularly during startup, shutdown, and low-load operation at low underbed air flow. Most of the material backsifts through bubble caps located in front of the recycle return, at the entrance to the bottom ash coolers, and along the front wall corners. Modifications to correct this problem included an accumulated bed material reinjection line and collection canisters to 


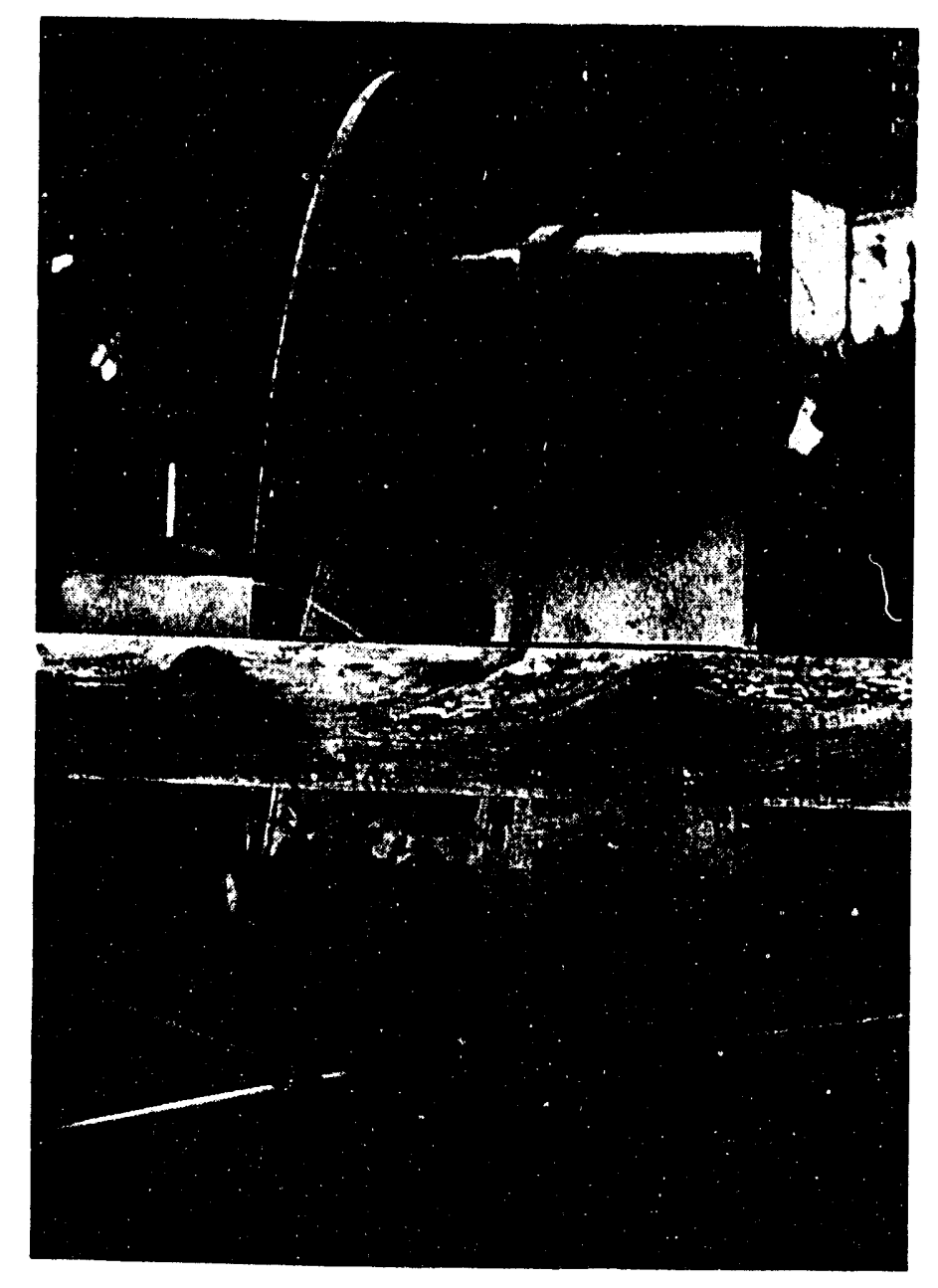

Figure 2-4. Original

PA Fan Wheel Design.

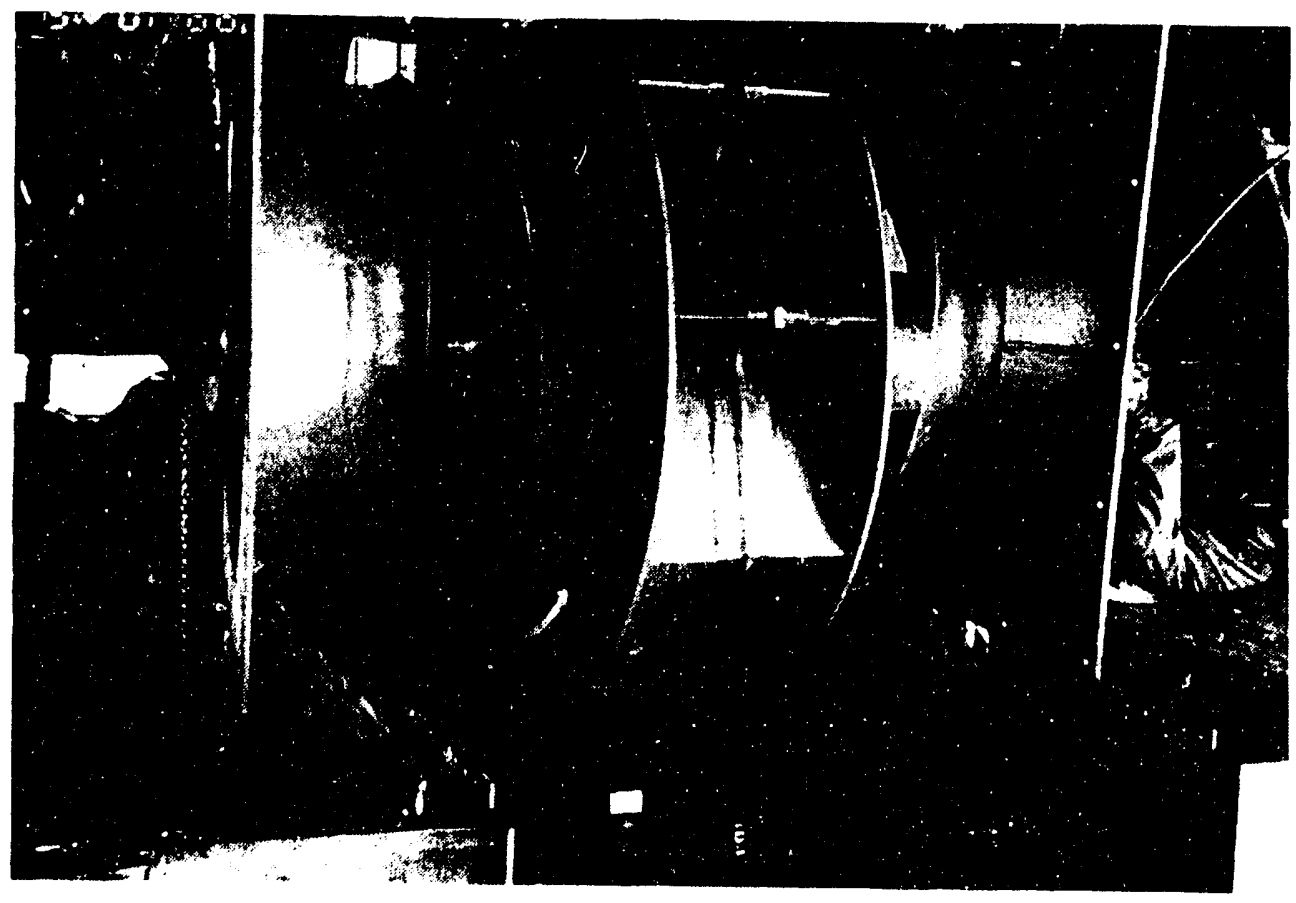

Figure 2-5. Modified PA Ean Wheel Design. 
collect bed material accumulations in front of the windbox. These modifications did not effectively resolve the problem. 
Section 3

PLANT COMMERCIAL PERFORMANCE STATISTICS

\subsection{SUMMARY}

This section describes plant commercial performance statistics for the period July 1988 through January 1991. During this time period, the plant operated with an average operating availability of $58.3 \frac{5}{5}$ and a capacity factor of $39.6 \%$. The average equivalent availability for the period July 1989 through January 1991 is 56.5\%. The average net plant heat rate for the period september 1988 through January 1991 is $12055 \mathrm{Btu} / \mathrm{Nkwh}$. Typical averages for non-CFB coal-fired units in the size range of the Nucla plant between 1984 and 1988 showed an availability of $83.9 \%$ and a capacity factor of $49.7 \%$. This is according to NERC GADS data for units in the 100-199 MWe size range.

Although average availability and capacity factors are below the typical averages, there are several factors that can account for some of the differences. The demonstration nature of the project required outages for inspections of materials as detailed in section 16. Equipment modification outages were also required for some non-design fuel tests.

CEB technology-related outages also contributed to the low average availability and capacity factors. These CFB-related problems are described in section 2. Section 2 also contains the following information relevant to plant commercial performance statistics:

- Figures 2-2 and 2-3 show total outage time compared to in-service time and percentage contributions of various boiler components to these outages.

- Table 2-1, a detailed description of outages for the period October 1988 through January 1991.

Table 3-1 shows monthly plant commercial performance statistics including operating availability, equivalent availability, capacity factor and net plant heat rate. These items are also shown graphically in Figures $3-1$ through $3-4$. Tables 3-2 through $3-33$ show detailed plant commercial performance statistics for each month from July 1988 through February 1991. Section 3.2 presents the definitions used in determining these statistics. More detailed plant commercial performance statistics information is available in each Annual Report. 
Table 3-1. Nucla CFB Plant Commercial Performance Statistics

\begin{tabular}{|c|c|c|c|c|}
\hline MONTH & OPERATING AVAIL & EQUIVALENT AVAIL & CAPACITY FACTOR & HEAT RATE \\
\hline & $(\%)$ & $(\%)$ & $(\%)$ & (Btu/Nkwh) \\
\hline Jul-88 & 65.2 & NIA & 51.8 & N/A \\
\hline Aug.88 & 0.5 & NIA & 0.1 & $N+A$ \\
\hline Sep-88 & 23.5 & $N / A$ & 12.6 & 12427 \\
\hline Oct-88 & 68.1 & N/A & 47.6 & 12168 \\
\hline Nov-88 & 78.9 & $N / A$ & 48.5 & 11673 \\
\hline$D e C-88$ & 81.8 & N/A & 46.1 & 12301 \\
\hline Jan-89 & 14.3 & N/A & 9.3 & 11883 \\
\hline Feb.89 & 25.0 & NIA & 13.0 & 13424 \\
\hline Mar-89 & 83.0 & $N / A$ & 60.2 & 11710 \\
\hline Apr-89 & 69.1 & N/A & 46.2 & 12069 \\
\hline May-89 & 48.5 & $N / A$ & 17.0 & 13131 \\
\hline Jun-89 & 75.5 & N/A & 53.3 & 11800 \\
\hline Jul-89 & 70.1 & 64.9 & 50.4 & 11911 \\
\hline Aug-89 & 52.5 & 29.2 & 23.8 & 12429 \\
\hline Sep-89 & 40.0 & 36.0 & 30.4 & 12054 \\
\hline Oct-89 & 12.5 & 12.5 & 10.0 & 11876 \\
\hline Nov -89 & 63.9 & 60.3 & 57.9 & 11854 \\
\hline Dec- 89 & 65.5 & 64.8 & 56.2 & 11934 \\
\hline Jan-90 & 72.5 & 57.0 & 54.3 & 11817 \\
\hline Feb-90 & 27.3 & 18.4 & 14.9 & 11638 \\
\hline Mar-90 & 92.1 & 79.9 & 78.3 & 11672 \\
\hline Apr.90 & 87.8 & 75.1 & 83.9 & 11596 \\
\hline May-90 & 33.1 & 30.9 & 26.2 & 12127 \\
\hline Jun-90 & 69.4 & 69.0 & 54.2 & 12313 \\
\hline Jul.90 & 36.1 & 29.9 & 21.4 & 12456 \\
\hline Aug.90 & 51.8 & 51.7 & 11.4 & 12585 \\
\hline Sep-90 & 45.8 & 45.7 & 18.3 & 11992 \\
\hline Oct.90 & 63.0 & 62.5 & 31.3 & 12258 \\
\hline Nov-90 & 97.2 & 97.0 & 85.7 & 11604 \\
\hline Dec-90 & 97.8 & 97.6 & 58.2 & 11767 \\
\hline Jan-91 & 96.0 & 92.0 & 57.5 & 11102 \\
\hline AVG & 58.3 & 56.5 & 39.6 & 120545 \\
\hline
\end{tabular}



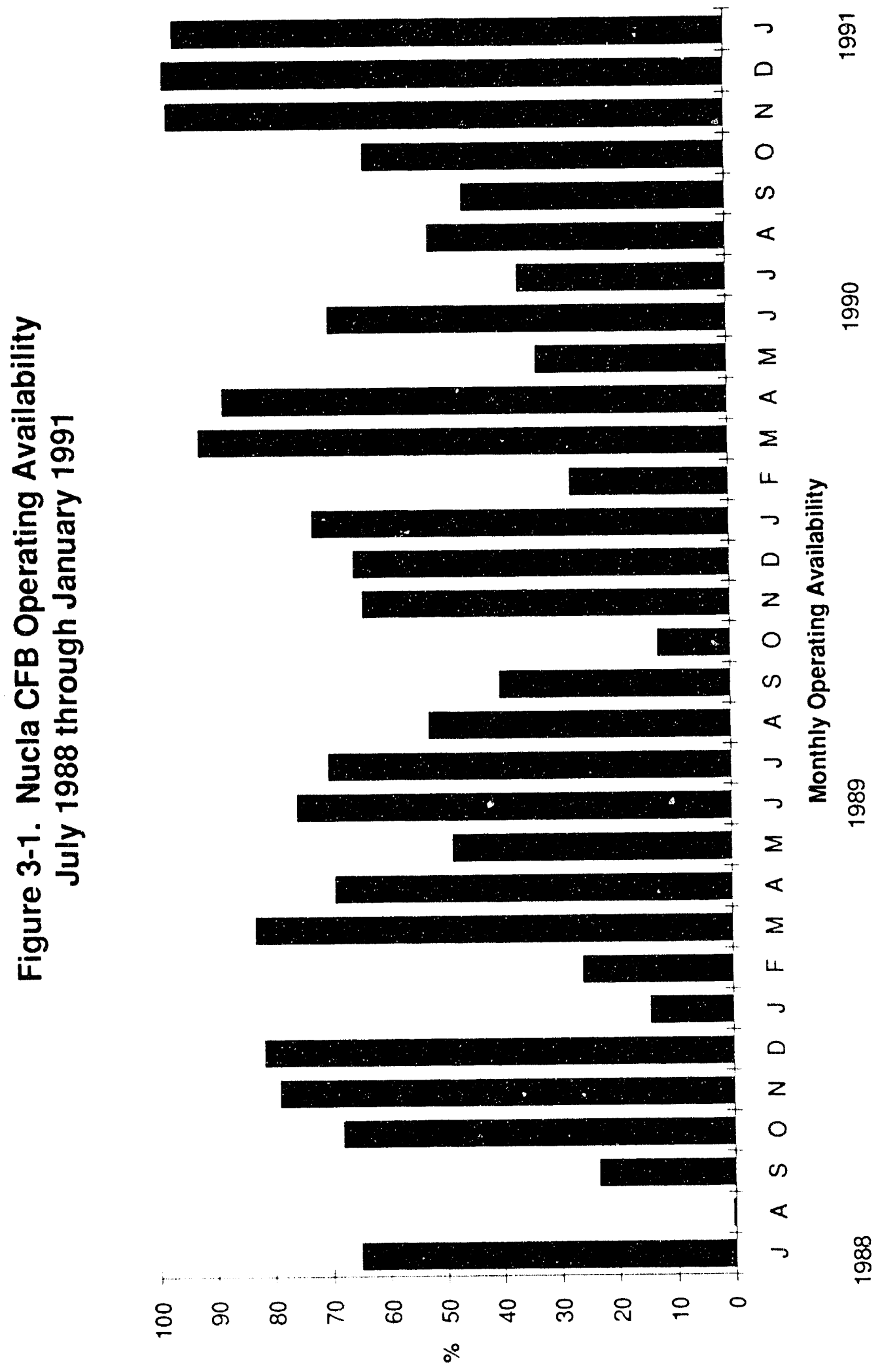

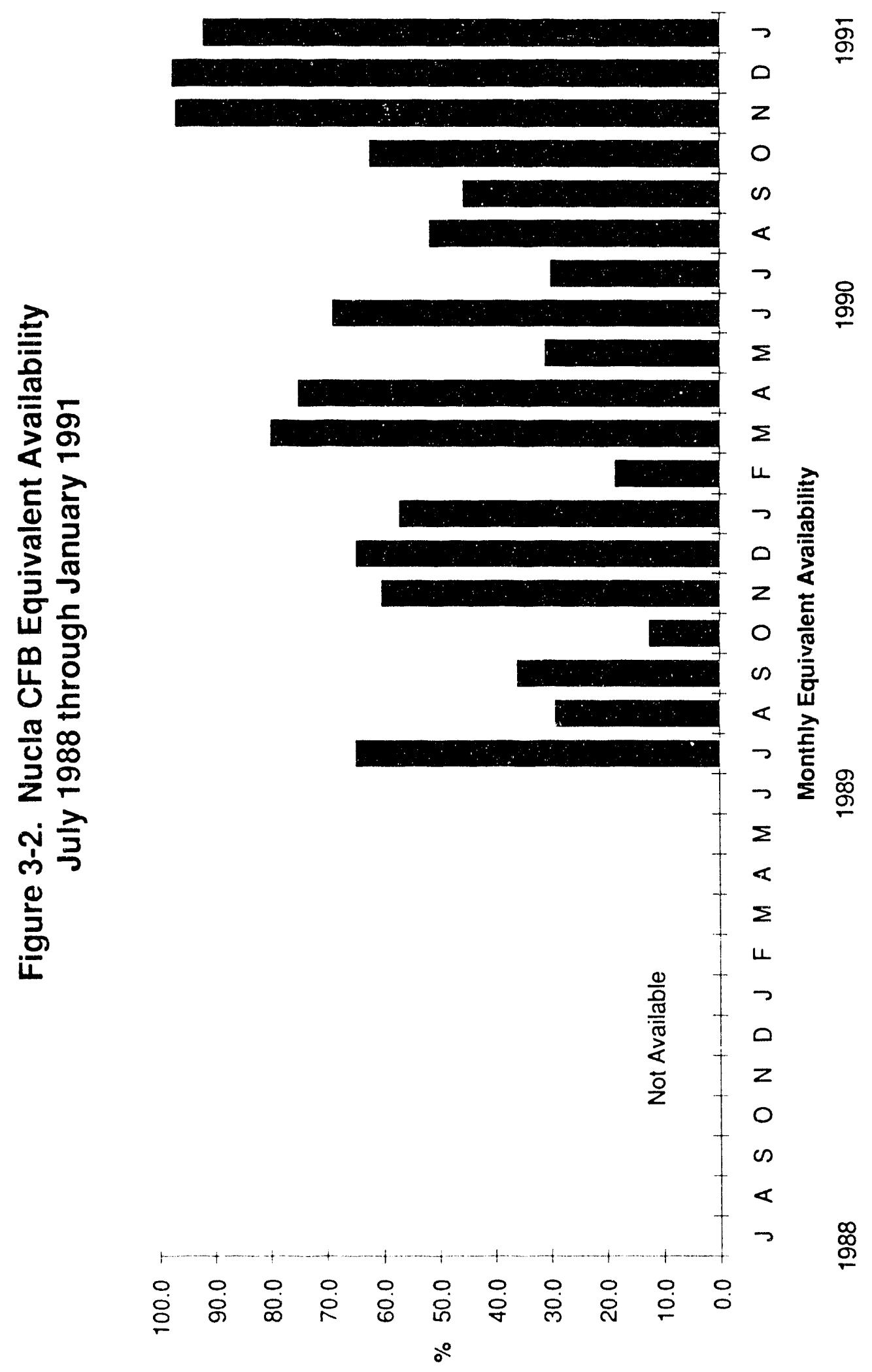

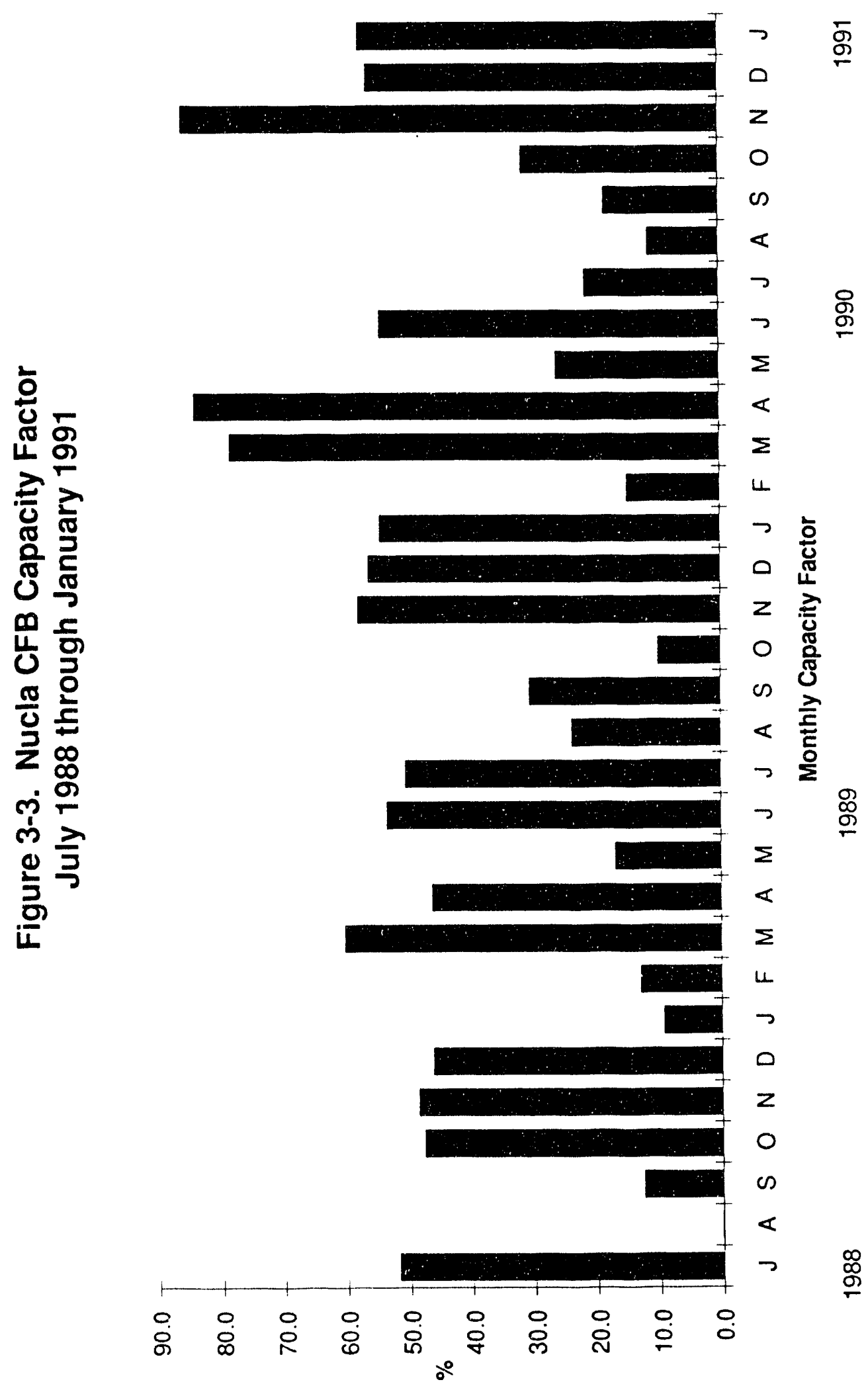

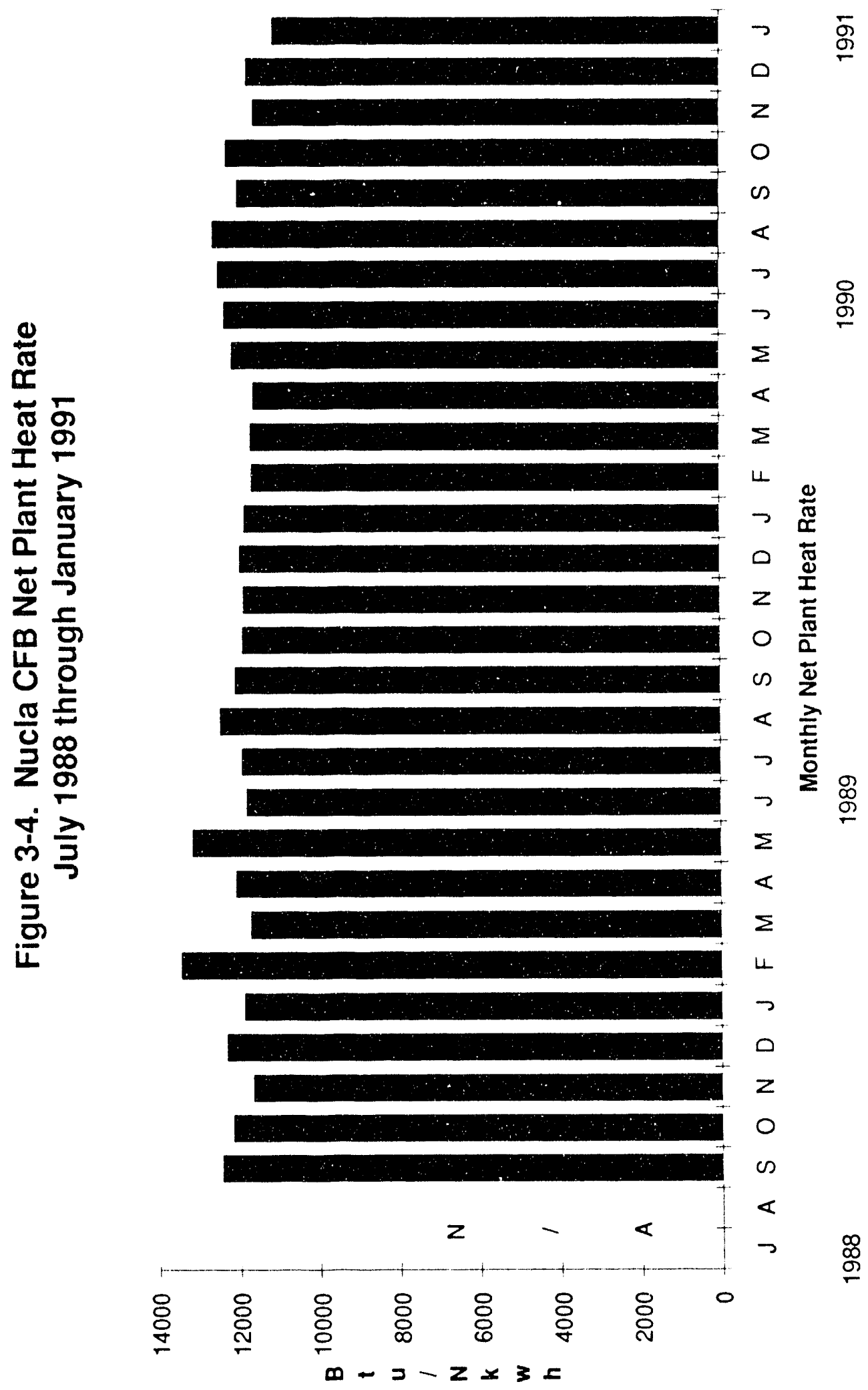
Table 3-2

PLANT COMMERICAL PEREORMANCE STATISTICS July 1988

1. Plant eutputs and consumptions

- Gross generation:

41705 mWhr

- Net generation:

- Period

37042 mWhr

- On line

37500

mWhr

- Aux power use:

- Period

4663 mWhr

- On line

4205 mWhr

- Aux power use (in o):

- Period

11.18 응

- On line

10.08 응

2. Operating Hours

- Period hours:

744

- In Service:

485

470

- Coal hours:

0

- Scheduled outage:

- Unscheduled outage:

259

3. Individual Unit Qutputs

$\begin{array}{cc}\text { Unit } & \text { Qutput (mbirs) } \\ 1 & 46642 \\ 2 & 4848 \\ 3 & 3865 \\ 4 & 28,250\end{array}$

Ave Load (min)
10.50
11.04
9.86
59.06

Heurs

4. eperating Rvailabizity

- Percent:

5. Capacity Earter

- Percent:

6. Major Equipment Usages

- Boiler feed pumps:

- Primary air fan:

- Secondary air fan:

- Induced draft fan:

- High pressure blowers:

$1,091,100 \quad \mathrm{kwhir}$

- Botiom ash cooler fan.

$1,077,400$

283,500

$k$ Whr

665,600

kWh $r$

63,000

kWhr

kWhr

$84,900 \quad \mathrm{kWhr}$

7. Material consumptions

- Total coal $f^{\prime}, w$ :

- Total limescone flow:

20,491 tons

- Total warm-up gas (propane) flow:

* This report includes hand-calculated performance statistics for the $160 \mathrm{hr}$ period between $7 / 22 / 88,1700$ hrs, and $7 / 29 / 88,0900$ hrs, when the vax computer was uut of services 
Table 3-3

PLANT COMMERICAL PERFORMANCE STATISTICS

August 1988

1. Plant outputs and consumptions

- Gross generation:

50 mWhrs

- Net generation:

- Period

904 mWhrs

- on line

38 mWhrs

- Aux power use:

- Period

954 mWhrs

- On line

12 mWhrs

- Aux power use (in o ):

- Period

- on line

$1,908.00 \quad \frac{8}{8}$

23.40 \%

2. Operating Hours

- Period hours:

- In Service:

- Cnal hours:

- On standby:

- Scheduled outage:

- Unscheduled outage:

$\begin{aligned} 744 & \text { hrs } \\ 4 & \text { hrs } \\ 1.4 & \text { hrs } \\ 0 & \text { hrs } \\ 0 & \text { hrs } \\ 740 & \text { hrs }\end{aligned}$

3. Individual unit Qutputs

$\begin{array}{cc}\text { Unit } & \text { Qutput (mWhr) } \\ 1 & 0 \\ 2 & 0 \\ 3 & 0 \\ 4 & 50\end{array}$

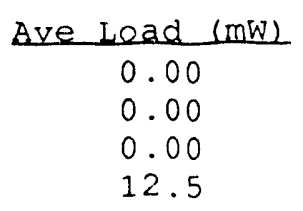

Heurs

0

0

0

4. eperating Availability

- Percent:

$0.54 \%$

5. Capacity Eactor

- Percent:

0.06 을

6. Majer Equipment Usages

- Boiler feed pumps:

41,500

172,600

30,100

- Secondary air fan:

48,500

- Induced draft fan:

13,200

8,500

kWhr

kWhr

kwhr

kWhr

- High pressure blowers:

- Bottom ash cooler fan:

kWhr

kWhr

9. Material censumptions

- Total coal flow:

- Total limestone flow:

5.25 tons

- Total warm-up gas

.58 tons

(propane) flow:

$2,276.594 \quad \mathrm{kscf}$ 
Table 3-4

PLANT COMMERICAL PERFORMANCE STATISTICS

September 1988

1. Rlant outputs and consumetions

- Gross generation:

$9,978 \quad$ mWhrs

- Net generation:

- Period

- On line

7,900 mWhrs.

8,819 mWhrs

- Aux power use:

- Period

$2,078 \quad \mathrm{mWhrs}$

- On line

1,159 mWhrs

- Aux power use (in 8 ):

- Period

20.83 8

- On line

11.62 \%

2. eperating Hours

- Period hours:

720 hrs

- In Service:

- Coal hours:

- On standby:

- Scheduled outage:

- Unscheduled outage:

169 hrs

161 hrs

0 hrs

0 hrs

3. Individual Unit Outputs

$\begin{array}{cc}\text { Unit } & \text { output (mWhel } \\ 1 & 759 \\ 2 & 660 \\ 3 & 980 \\ 4 & 7,580\end{array}$

Ave Lead (mW)

Heurs

10.12

8.80

10.32

75

95

44.85

4. Qperating Availability

- Percent:

5. Capacity Eactor

- Percent:

6. Majer Equipment Usages

- Boiler feed pumps:

413,300

kWhr

- Primary air fan:

- Secondary air fan:

428,300

kwhr

$74,00 \quad \mathrm{kWhr}$

- Induced draft fan:

190,200

kWhr

- High pressure blowers:

34,700

kWhr

- Bottom ash cooler fan:

38,900

kWhr.

7. Material Consumptions

- Total coal flow:

- Total limestone flow:

4,527

tons

- Total warm-up gas

(propane) flow:

405 tons

$7,436 \quad \mathrm{kscf}$ 
Table 3-5

PLANT COMMERICAL PERFORMANCE STATISTICS

October 1988

$\therefore$ Dlant Qutputs and censumptions

- Gross generation:

$38,974 \quad \mathrm{mWhr}$

- Net generation:

- Period

- On line

$34,310 \quad \mathrm{mWhr}$

- Aux power use:

- Period

- On line

34,755 mWhr

- Aux power use (in \&):

- Period

- On line

4,663 mWhr

4.219 mWhr

12.0

2. Qperating Heurs

- Period hours:

- In Service:

- Coal hours:

- On siandby:

- Scheduled outage:

- Unscheduled outage:

$\begin{aligned} 744 & \text { hrs } \\ 507 & \text { hrs } \\ 492 & \text { hrs } \\ 0 & \text { hrs } \\ 0 & \text { hrs } \\ 237 & \text { hrs }\end{aligned}$

3. Individial Uni: Qutputs

\begin{tabular}{|c|c|}
\hline (1) & Qutent (misine) \\
\hline i & 3,783 \\
\hline ? & 4.067 \\
\hline 3 & 3,602 \\
\hline 4 & 27,521 \\
\hline & 38,874 \\
\hline
\end{tabular}

\begin{tabular}{cr} 
Ave lead dofil & Heins \\
\hline 8.8 & 430 \\
10.0 & 405 \\
8.1 & 494 \\
54.3 & 507 \\
76.9 & 507
\end{tabular}

4. Qperating Avadiabinity:

5. Equivalen: Avaidabiliti:

6. Sapacity Facter:

7. Average Heat Rate for period:

12168.1 btu/nkwh

8. $\quad M=i 0$ Equioment Usages

- Boiler feed pumps:

- Primary air fan:

- Secondary air fan:

- Induced drat fan:

- High pressure biowers:

- Bottom ash cooler fan:

$\begin{array}{rl}68.1 & 8 \\ 63.1 & 8 \\ 47.6 & 8 \\ 12168.1 & \text { btu/nkwh }\end{array}$

9. Material cersumptions

- Tozal coal flow:

- Total limesione flow:

- Total warm-up gas (propane) flow:

$\begin{aligned} 1.119 & \text { mWhr } \\ 1.067 & \text { mWhr } \\ 222 & \text { mWhr } \\ 572 & \text { mWhr } \\ 70 & \text { mWhr } \\ 8: & \text { mW: }\end{aligned}$

- Avg higher heating value of propane gas:

$\begin{aligned} 20.320 & \text { tons } \\ 849 & \text { tons } \\ 4.632 & \text { kscf } \\ 2.516 & \text { btu/sct }\end{aligned}$

10. Average ceal Analysis

- Higher heating value:

- Sulfur:

- Astr:

- Moisture:

$\begin{array}{rl}10218 & \text { btu/1b } \\ 0.8 & 8 \\ 23.7 & 8 \\ 4.9 & 8 \\ 1482 & \text { tors }\end{array}$

1i. Scitid baste to disposa lwo.l: 
Table 3-6

PLANT COMMERICAL PERFORMANCE STATISTICS

November 1988

1. Plant Qutputs and consumptiens

- Gross generation:

$38,4 i 4$

mwhrs

- Net generation:

- Period

33.559 mWhrs

- On iine

34,040

mWhrs

- Aux power use:

- Period

- On line

4.756 mWhrs

- Aux power use (in \&):

- Period

- On line

4.374 mWhrs

12.4 8

11.4

2. Operating Hours

- Period hours:

- In service:

- Coal hours:

- Or stanaby:

- Scheduled outage:

- Unschediled outage:

$\begin{array}{rr}720 & \text { hrs } \\ 568 & n=s \\ 496 & n r s \\ 0 & n r s \\ 6 & n r s \\ 252 & \text { rrs }\end{array}$

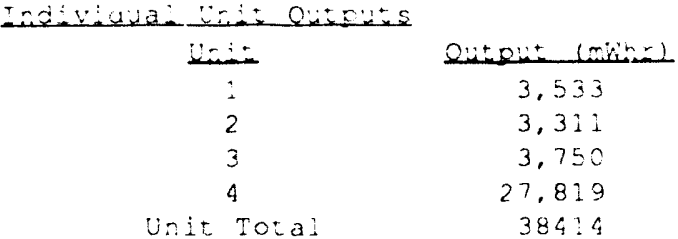

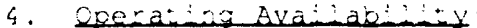

5. Equivalent Availabilizy:

6. Capacity Eactex:

7. Average Hea: Rate for Period:

Ave icas (mid)

7.2

8.5

7.7

49.0

६?. 6
:

rs

his

hes

hiss

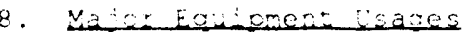

- Boiler feec pumps:

- Primary air tan:

- Secondary air far:

- Induced araft far:

- High pressire bioners:

- Bottom ash cooler fan:

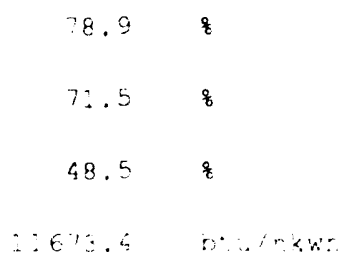

2.245 rites

i, 6 : rists

Q. 9 minits

le mint

8: rivits

84 mWires

9. Material Consumptions

- Total coal flow:

- Total limestone flow:

- Total warm-up gas (propane) flow:

20,732

1,237

3,902

tons

$25: 6 \quad b=i / s c t$

ic. Average ceal Analysis:

- Higher heating value:

- Sulfur:

- Ast: :

- Moisture:

1: seida baste te dispesal (wet):

$9,424 \quad b t u / 2 b$

0.9 \&

26.5 웅

$6.1 \quad \frac{9}{6}$

$9.798 \quad 02-5$ 
Tabie $3-7$

PLAN" COMMERICA: PERFORMANCE S:ATSSTICS

December 1988

$\therefore$ Dan ouputs and consumpisons

- Gross generaition:

37.744 mwhrs

- Period

33056 mWhrs

- On line

33531 mhis:s

- Aux power use:

- Persod

468 ? rines

- On line

4207 minis

- Aux power use (in o):

- Period

- Or line

$12.4 \quad 8$

$11.2 \quad 8$

2. Qperating hairs

- Period hours:

- Ir service:

- Coai hours:

- On sianaby:

- Scheduled outage:

- Unschediled outage:

$\begin{array}{rl}744 & n+s \\ 522 & n r s \\ 505 & n=s \\ 85 & n: s \\ 0 & n: 5 \\ 3 & n=s\end{array}$

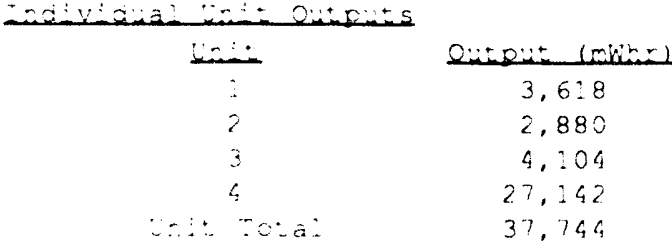

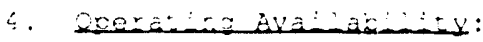

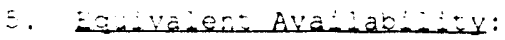

Qve inesin

8.6

S

8.5

8.9

$52 . \mathrm{C}$

72.2

6. $200 a+0 y$ Eacton:

$\because$ Average Heat Ràe tor perica:

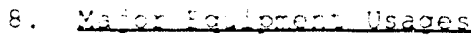

- 3ojer feej oumos:

- Primary air far:

- Secondarýair far:

- Irauced araf: tar:

- High pressire biowers:

- Boztor asr coojer fan.

\begin{tabular}{|c|c|}
\hline $8: .6$ & $\therefore: s$ \\
\hline $7=.3$ & r.rs \\
\hline 46. & $\therefore \therefore \mathrm{s}$ \\
\hline $22,304$. & $b: i / r<v:$ \\
\hline$\therefore \therefore \varepsilon^{\circ}$ & rbitss \\
\hline$\therefore 239$ & mins \\
\hline$: 57$ & minitss \\
\hline $5: \epsilon$ & minis s \\
\hline 53 & mitses \\
\hline 76 & minas \\
\hline 20.895 & tons \\
\hline 1,425 & tons \\
\hline 5,050 & ksc: \\
\hline $25: 6$ & bia/sc: \\
\hline
\end{tabular}

ic. Average coal Acalysis

- Higher heating value:

- Sulfur:

- Asti:

- Mo:sture:

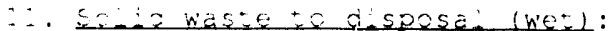

$\begin{array}{rl}9.7: 7 & b t=/ 1 b \\ 1.2 & 8 \\ 18.2 & 8 \\ 9.9 & 8\end{array}$

\&.: : ions 
Table 3-8

PLAN: COMMERICAI, PERYORMANCE, STATISTICS January 1989

1. Riant Outputs and consumptions

- Gross generation:

- Net generation:

- Period

- On line

7580

mWhrs

- Aux power use:

- Period

- On line

6013 mWhrs

6736 mWhrs

- Aux power use (in 8 ):

- Period

- On line

1567 mWhrs

844 mWhrs

$20.7 \quad 8$

11.18

2. Qpera:sis tivins

- Period hours:

- In service:

- Coal nours:

- Or standby:

- Screduled outage:

- Unscheduied outage:

- Number of Unli Starts:

3.

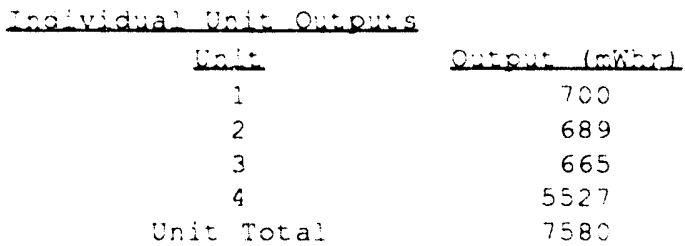

4. Qserating Ava: yo:

Ave Lea L

6.7

6.6

6.3

51.9

71.2

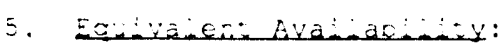

6. Cacacisyasicr:

Heنs:

7. Average Hea: Rave far jeripd:

- Or ine (coai and gas):

9.3

- On line lcoail:

$11883 .: \quad b t u / n k w h$ i1 886.9 btu/nkwh

9. Vator Equipment usages

- Boiler feed pumps:

- Primary air fan:

- Secondary air far:

- Induced draft fan:

- High pressure blowers:

- Bottom ash cooler fan:

228

202

33

106

17

16

4140

444

23

2550

9659

1.7

16.5

12.0
mWhrs

mWhrs

mWhrs

mwhrs

mWhrs

mWhrs

tons

tons

kscf

btu/scf

bt $: / 1 b$

of

8

8 
Tabie 3-9

PLANT COMMER:CA: PERFORMANCE STATISTICS

Feoruary 1989

2. Riant Qutputs and consumptions

- Gross generation:

9580 niwhs

- Net generation:

- Period

- On line

7663 mikirs

8380 minrs

- Aux power use:

- Period

1917 mWhrs

- On line

1199 mwhrs

- Aux power use $(i n$ o $)$ :

- Period

- On line

20.0 minrs

12.5 mWhrs

2. Qperating Hours

- Period hours:

- in Service:

- Coal hours:

- On stanaby:

- Schedulea outage:

- Unscheduled oitage:

- Number of Unit Starts:

$\begin{aligned} 672 & \text { hrs } \\ 175 & \text { hrs } \\ 167 & \text { hrs } \\ 0 & \text { r.s } \\ 296 & \text { hrs } \\ 20 ? & \text { nes } \\ 4 & \text { hrs }\end{aligned}$

3. Individuad Unitenguts

\begin{tabular}{|c|c|}
\hline Z & 年 \\
\hline 1 & 667 \\
\hline 2 & 835 \\
\hline 3 & 3387 \\
\hline 4 & 6690 \\
\hline Tota: & $958=$ \\
\hline
\end{tabular}

Ave iead dirie
$\begin{aligned} & 6.3 \\ & 7.7 \\ & 9.3 \\ & 38.3 \\ & 34.8\end{aligned}$

Hoincs

4. Qrevating Avainabinit:

5. Equivaien=Ava:ias:

E. Sapacity Eactor:

26.2 훈

$: 9.2 \quad 8$

23.

7. Average Hea: Rate fer Rerica:

- On ine lcoa ana gas):

- On ine (coai):

:3424.7 bes/ring

2605.0 bi../rkn.

Q. Va:0r Eanemer Usares

- Bojier teec furros:

- Frimaryas fan:

- Secondary air far:

- Inauced dratt far:

- High pressure biowers:

- Scitor ast conel tan:

\begin{tabular}{|c|c|}
\hline $4: 9$ & mits: \\
\hline .364 & mars \\
\hline 48 & mirings \\
\hline$: 4 \hat{7}$ & miness \\
\hline $2 \epsilon$ & marrs \\
\hline 36 & rincss \\
\hline
\end{tabular}

9. Materia-Cansuacors

- Tozar coas ton:

- Tosal imestore t. eni:

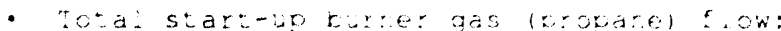

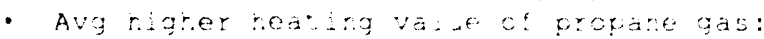

$$
\begin{aligned}
& \text { E94 tors } \\
& 48 \text { ars } \\
& 3922 \quad x 606 \\
& 2: 56 \quad \text { cotsos }
\end{aligned}
$$

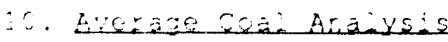

- hager hea.jag va af:

- Shing

- Asr:

- Mo-sture: 
Table 3-10

PLANT COMMERICAL PERFORMANCE STATISTICS

March 1989

1. Riane eutcuis and consumpions

- Gross genezation:

- Net generation:

- Period

- On line

mWhrs

- Aux power use:

- Period

mWhrs

- On line

44070

mWhr

5537

mWhrs

- Aux power use (in f):

- Period

- On line

11.2

$10.6 \quad 8$

2. Qberating Heurs

- Period hours:

- Ir service:

- Coal hours:

- Or: szandby:

- Scredulec outage:

- Unscheduled outage:

- Number of Urit starts:

3.

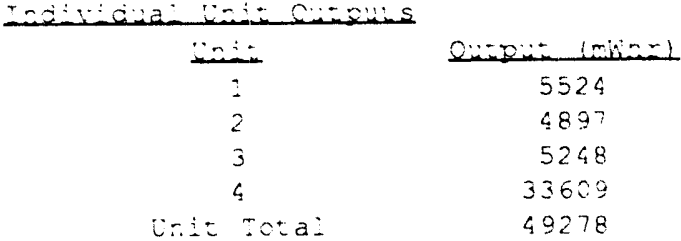

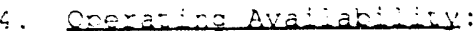

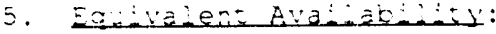

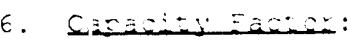

7. Lverage Heà Zeje Sor Deriesi

- Cr. Ine (coai and gas):

- On line (coal):

8.

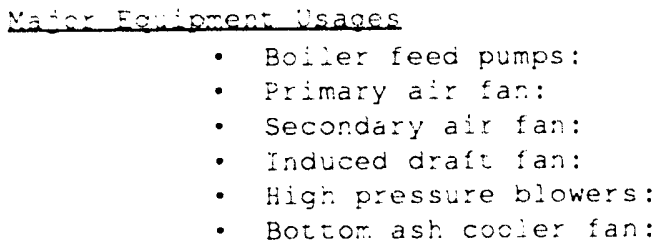

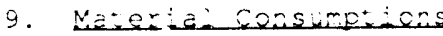

- Total coal flow.

- Total imestone flon:

- Tosá start-up burner gás (propanel flow:

- Avg higher heating vaille of propane gas:

20. Average coal Aralysis:

- Higher heating vaiue:

- Suifur:

- Asti:

- Vossure:

\begin{tabular}{c} 
Ave 20 as (xib) \\
\hline 9.5 \\
8.7 \\
9.0 \\
54.4 \\
19.8
\end{tabular}

Bours

582

561

581

$6 \div 8$

618

$83.0 \%$

$75.4 \quad 8$

60.28

117.20 .1 btu/nkwh

11645.9 btu/nkwt.

$\begin{aligned} 1378 & \text { mwhrs } \\ 1275 & \text { mwhrs } \\ 272 & \text { mwhrs } \\ 729 & \text { mWhrs } \\ 57 & \text { mwhrs } \\ 84 & \text { mwhrs }\end{aligned}$

$\begin{array}{rl}: 0.63 & \text { btu/ib } \\ 0.7 & 8 \\ -8.8 & 8 \\ 8.6 & 8\end{array}$


Table 3-11

PLANT COMMERICAL PERFORMANCE STATISTICS

April 1989

1. Rlart Qutputs and censumptiens

- Gross generation:
- Net generation:

- Period

- On line

92648

81616

82827

- Aux power use:

- Period

- On line

- Aux power use (in of):

- Period

- On line
11032

9821

11.9

10.6

2184

1334

130

69

173

609

9

Ave iead $(\mathrm{min})$

8.3

8.9

8.4

52.3

69.5
6780

92648 inst rotal

4. Desating Avainab:iris::

5. Ecuivajert Avainatintey:

6. Capacity Eacis:

7. Average Heat Rate fer. Peried:

- On line (coaj and gas):

- On line (coal):

8. Nater Equivmen Usages

- Boiler feed purps:

- Primary air fan:

- Secondary air far:

- Induced drafi tan:

- High pressure blowers:

- Bottom ash cooler fan:
mWhrs

mWhrs

mWhrs

mWhrs

mWhrs

8

hrs

hrs

hrs

hrs

hrs

hirs

hrs

Heurs
692
765
1239
1334
1334

64.28

36.58

$38.6 \quad 8$

12099.4 btu/nkwis 12080.7 btu/nkw'h

2541 mihrs

2437 mihrs

266 mWrirs

1278 mhings

130 mwhrs

207 minits

9. Mazerian Consumptiens

- Totá coal flow:

- Tozal limestone flon:

- Total start-up burner gas (f roparel flon':

- Avg higher heating value of propane gas:

20. Average crai Araiysis

- Higrer heating váno:

- Suitur:

- Asn:

- Moisture:
48842 tons

2651 tons

693 ! ksci

2516 beulsc:

ic:53 b: $1: 1: b$

0.9 के

20.48

6." 8 
Table 3-12

PLANT COMMERICAL PERFORMANCE STATISTICS

May 1989

1. Rlant outputs and consumptiens

- Gross generation:

13894 mWhrs

- Net generation:

- Period

11663 mWhrs

- On line

12293 mWhrs

- Aux power use:

- Period

2231 mWhrs

- On line

1601 mWhrs

- Aux power use (in z):

- Period

- On line

$16.1 \quad 8$

11.58

2. eperating Howrs

- Period hours:

744 hrs

292 hrs

- In Service:

- Coal hours:

- On standby:

- Scheduled cutage:

- Unscheduled outage:

- Number of Unit Starts:

276 hrs

69 hrs

0 hrs

383 hrs

3. Individual unit outouts

\begin{tabular}{cc} 
Unit & eutout dowitite \\
\hline 1 & 0 \\
2 & 0 \\
3 & 1800 \\
4 & 12094 \\
Unit Total & 13894
\end{tabular}

Ave lead (mil)
ERR
ERR
7.0
41.4
47.6

Hours

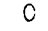

4. Qperasing Availabilitex:

48.5

$30.7 \quad 8$

5. Equivalent Availability:

$77.0 \quad 8$

6. Capacity Facter:

8. Majer Equipment Usages

- Boiler feed pumps:

- Primary air fan:

- Secondary air fan:

- Induced draft fan:

- High pressure blowers:

- Bottom ash cooler fan:

9. Material Consumptions

- Total coal flow:

- Total limestone fjon:

- Total start-up burner gas (propane) flow

2516

kscf

- Avg higher heating value of propane gas:

btu/scf

10. Average ceal Analysis:

- Higher heating value:

$9890 \mathrm{btu} / \mathrm{lb}$

- Sulfur:

- Ash:

- Moisture:

0.5

23.7 8

5.38 
Tabje 3-13

PLAN COMMERICAL PEREORYANCE STATISTICS

June 1989

1. Riani Quiputs and censumptiens

- Gross generation:

Ne: generation:

- Period

- On line

42175

mWhrs

37613

mWhrs

Aux yower use:

- Period

37965

mWhrs

- On line

4562

minrs

- Aux power use (in 8 ):

- Period

4210

mwing

- On line

$10.8 \quad 8$

10.0

2. Qperating Hours

- Period hours:

- Ir Service:

- Coal hours:

- On stardiby:

- Scheduled outage:

- Unscheculed outage:

- Number of Unis Siarts:

3.

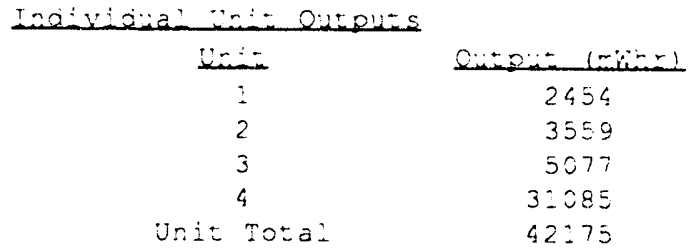

Eve $=202(\mathrm{mil})$
9.8
20.5
9.9
57.2
77.6

720

544

$54:$

hrs

c

173

hrs

hrs

hrs

4 hrs

hres
r.rs

Unit Totà 42:75

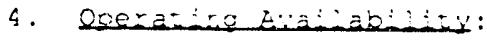

5. Equivaient Ava:iabinis:

6. Cacacisy actor:

$53.3 \%$

7. Averace Heat saze for Deriod:

- On line (coal and gas):

- On ine (coai):

11800.3 btu/nkwh $2: 780.7 \quad b=2 / n k b$

8. Vaicr =quipment isages

- Boiler feed purps:

- Primary aiz far:

- Secondary air fan:

- Incuced draft fan:

- High pressure blowers:

- Botzor ash cooler fan:

9. Neteria: consumptions

- Total coal flow:

- Total ilmestone fion:

- Total start-up burner gas (propane) flow:

- Avg righer heating value of propane gas:

1035 minhes

1077 mintes

13: mwirs

$6: 1$ mWhrs

59 miners

84 minhes

21677 tons

987 tons

$394 \mathrm{ksc}$ :

$25: 6$ btu/sct

10. Average Ceal Aralysis

- Higner heatirg value:

- Suisur:

- Ast:

- Noisture:

$\begin{array}{rl}20313 & b 50 / 20 \\ 0.7 & 8 \\ : 9.4 & 8 \\ 7.2 & 8\end{array}$


Table 3-14

PLANT COMMERICAI PERFORMANCE STATISTICS JulY 1989

1. Riant Qutputs and censumptions

- Gross generation:

41285

mWhrs

- Net generation:

$$
\text { - Period }
$$

36688 mWhrs

- On line

36982 mWhrs

- Aux power use:

- Period

- On line

4597 mWhrs

4303 mWhrs

- Aux power use (in of):

- Period

- on line

11.18

10.4 \%

2. Socrating biurs

- period hours:

- In service:

- Coal hours:

- Or stardby:

- Scheaudec outage:

- Urischedued dutage:

- Number of Unit Stares:

3.

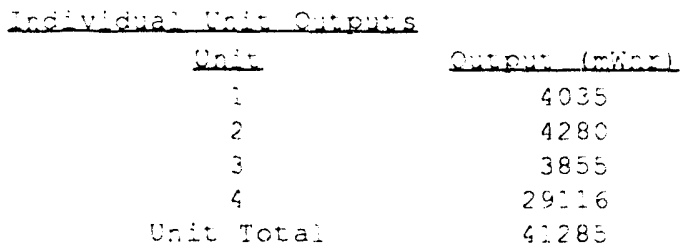

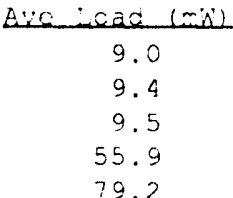
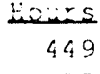

455

406

52

$52:$

$70: \div$

5. Esvaen Arajabin:

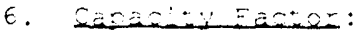

64.9 8

50.4 \%

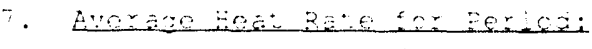

- Or lone loos aró gasl:

- on inne (coa)

1:9:2. beu/nkw

i: 877.5 btu/nkwis

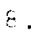

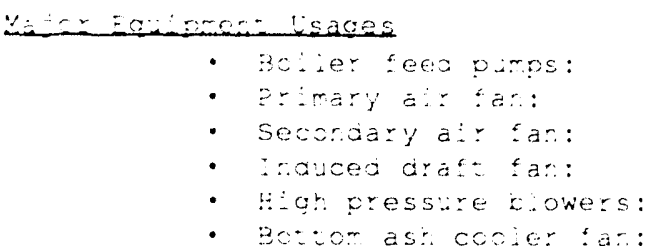

2105

mint:

138 mints

585 mWris

59 mWhrs

73 minhes

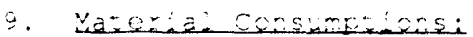

- Totá coaj fon:

- Totá : restone Elow:

- Totas ster-yoburner gas (ercoane) s:ow:

- Avg hogher hedang value of propare gas:

\begin{tabular}{|c|c|}
\hline 20414 & Eons \\
\hline$: 342$ & tons \\
\hline$: 30 \%$ & kscf \\
\hline $25: 6$ & btu/sc: \\
\hline$: 0 \div 5$ & $p: \cup /:$ \\
\hline$\therefore .5$ & $\varepsilon$ \\
\hline ; & 8 \\
\hline$a$ & $\tilde{\varepsilon}$ \\
\hline
\end{tabular}


Table 3-15

PLANT COMMERICAL PERFORMANCE STATISTICS

August 1989

i. Rlant evtputs and censumptions

- Gross generation:

- Net generation:

- Period

- On line

- Aux power use:

- Period

- On line

19509 mWhrs

16600 mWhrs

17467 mWhrs

- Aux power use (in \&):

- Period

- On line

2909 mWhrs

2042 mWhrs

14.9 8

2. Qperating Heurs

- Period hours:

- In Service:

- Coal hours:

- On standby:

- Scheduled outage:

- Unscheduled outage:

- Number of Unit Starts:

10.5 \%

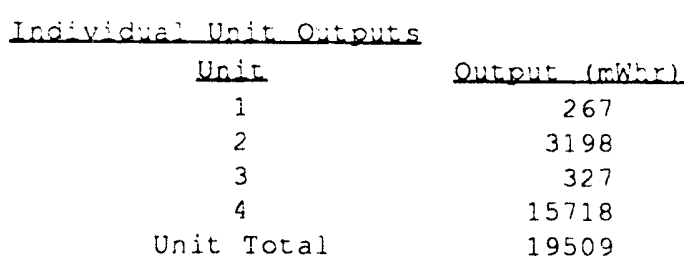

Ave load (mil)
$\begin{array}{r}10.4 \\ 9.8 \\ 10.2 \\ 46.4 \\ 57.6\end{array}$

$\begin{array}{rr}744 & \text { hrs } \\ 338 & \text { hrs } \\ 333 & \text { hrs } \\ 52 & \text { hrs } \\ 59 & \text { hrs } \\ 294 & \text { hrs } \\ 3 & \text { hrs }\end{array}$

3.

4. ecerating Availabivity:

52.5

5. Equivaiert Availability:

6. Savacity Eacter:

29.28

23.8 8

7. Average Heat Rate for Peried:

- On line (coal and gas):

12429.1 btu/nkwh

- On line (coai):

8. Nator Egivioment lisages

- Boiler feed pumps:

- Primary air fan:

- Secondary air fan:

- Induced draft fan:

- High pressure blowers:

- Bottom ash cooler fan:

12325.0 btu/nkw2.

9. Naterial Consumptions

- Total coal flow:

- Total limestone flow:

- Total start-up burner gas (propane) flow:

- Avg higher heating value of propane gas:

482 mwinrs

770 mWhrs

56 mirirs

326 mWhrs

55 mWhrs

49 mWhrs

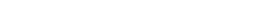

ic. Average ceai Analysis

- Higher heating value:

- Sulfur:

- Ast:

- Moistlire:

9860 tons

587 tons

3501 kscf

2615 btu/scf

10907 btu/lb

0.6 \&

13.0 8

9.9 \& 
Table 3-16

PLANT COMMERICAL PERFORMANCE, STATISTICS

September, 1989

1. Rlant Qutputs and Censumptions

- Gross generation:

24095

Net generation:

- Period

- On line

- Aux power use:

- Period

- On line

- Aux power use (in \&):

- Period

- On line

21108

21607

2988

2488

12.4

10.3

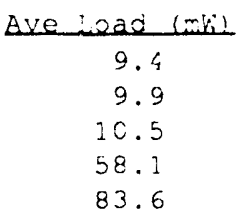

Unit Total 24095

4. Operatinc Bvailability:

5. Equivalent Availability:

6. Capacity Eactor:

7. Everage Heat Rate fer Peried:

- On line (coai and gas):

- On line (coal):

8. Vater Exidioment Usaces

- Boiler feed pumps:

- Primary air fan:

- Secondary air fan:

- Induced draft fan:

- High pressure blowers:

- Bottom ash cooler far:

9. Material consumptions

- Total coal flow:

- Total limestone flow:

- Total start-up burner gas (propane) flow:

- Avg higher heating value of propane gas:

10. Average coal Analysis:

- Higher heating value:

- Sulfur:

- Ash:

- Moisture:
720

288

28

170

262

3

Hevirs

222

256

260

288

288

mWhrs

mWhrs

mWhrs

mWhrs

mWhrs

$\frac{8}{8}$

hrs

hes

rirs

hrs

hrs

hrs

hrs

$40.0 \quad 8$
36.0
$30.4 \quad 8$

12064.2 btu/nkw:

11936.7 btu/nkwt.

643 minrs

651 mWhrs

mines

mWhrs

mWhrs

mWrers

12069 tons

871 tons

$2123 \mathrm{kscf}$

$2516 \mathrm{btu} / \mathrm{sc}$ ?

10674 btu/1b

C. 6 \%

15.5 q

8.8 웅 
Table 3-17

PLANT COMMERICAL PERFORMANCE STATISTICS

October 1989

1. Plant eutputs and consumptiens

- Gross generation:

- Net generation:

- Period

- On line

- Period

- On line

- Aux power use (in \&):

- Period

- On line

2. Qeerating Heurs

- Period hours:

- In Service:

- Coal hours:

- On standioj:

- Scheduled outage:

- Unscheduled oltage:

- Number of Unie starts:

3. Incividuai init evisuts

\begin{tabular}{cc} 
Un: & outeut (minte) \\
\hline 1 & 767 \\
2 & 853 \\
3 & 784 \\
4 & $577 !$ \\
Unit Total & 8184
\end{tabular}

4. Doerating Ava: lab: itu:

5. تcivalent Ava: ab: ity:

6. Sanacity Eactor:

7. Average Hea- Ra:e for periaci

- On ine (coa: ana gas):

- Or. line (coal):

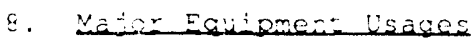

- Boiler feed purps:

- Primary aji fan:

- Secondary air far:

- inauced drafi far:

- High pressure blowers:

- Bottom as:: cooier ta:

9. Naterial Consumprions:

- Total coal flow

- Total limestone fion:

- Tozal start-up burner gas (propanel flow:

- Avg nigher heatina value of propare gas:

10. Averace Cual Analysis.

- Higner heát no valvo:

- Sir:iz:

- Ast:

- Mo:stire:
8184

6705

7326

1479

858

mWhrs

mWhrs

mWhrs

mWhrs

mWhrs

18.1 \%

10.5 웅

745 hrs

93 hrs

91 hrs

0 hrs

214 hrs

437 hrs

1 hrs

$\begin{array}{cc}\text { Ave iead (mil) } & \text { beves } \\ 10.0 & 76 \\ 10.5 & 81 \\ 9.9 & 79 \\ 61.8 & 93 \\ 87.6 & 93\end{array}$

11875.7 btu/nkin

1.1752.9 btu/nixu't.

210

237

27

160

11

12

4812

274

1038

2516

tons

$\mathrm{kscf}$

btu/lb

8933 btuilib

0.6 \%

$28.0 \quad 8$ 
Table 3-18

PLANT COMMERICAL PERFORMANCE STATISTICS

November 1989

1. Plant Outputs and Consumptions

- Gross generation:

- Net generation:

- Period

- On line

$\begin{aligned} 45854 & \text { mWhrs } \\ 40999 & \text { mWhrs } \\ 41317 & \text { mWhrs } \\ 4856 & \text { mWhrs } \\ 4538 & \text { mWhrs } \\ & \\ 10.6 & \$ \\ 9.9 & \&\end{aligned}$

2. Qeeratiog Hours

- Period hours:

- In Service:

- Coal hours:

- Or standby:

- Scheduled outage:

- Unscheduled outage:

- Number of Unit Starts:

$\begin{aligned} 720 & \text { hrs } \\ 460 & \text { hrs } \\ 452 & \text { hrs } \\ 0 & \text { hrs } \\ 0 & \text { hrs } \\ 260 & \text { hrs } \\ 2 & \text { hrs }\end{aligned}$

3. Individual Unit outputs

$\begin{array}{cc}\text { Unit } & \text { euteut }\left(m h^{2} h r\right) \\ 1 & 4443 \\ 2 & 4783 \\ 3 & 5057 \\ 4 & 31570 \\ & 45854\end{array}$

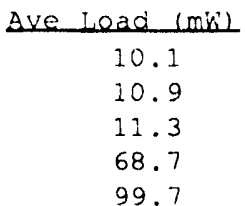

Hours

4. Qperating Availability:

63.9

5. Eguivaleri Avairabidity:

60.3

6. Capacitiv Eacter:

57.9 $q$

7. Average Heat Rate for Period:

- On line (coal and gas):

12853.9

bt. $u / n k w h$

- On ine (coal):

8. Mator Equipment Usages

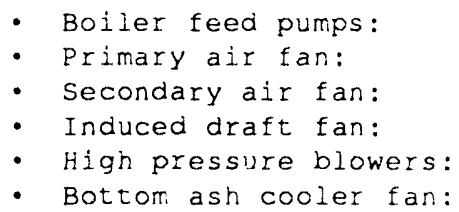

1083

976

178

867

43

60

24532

1420

1443

2516
mWhrs mWhrs mWhrs mWhrs mwhrs mWhrs

tons tons kscf btu/scf

1i. Average coal Analysis

- Higher heating value:

- Sulfur:

- Ash.

- Moisture:

$\begin{array}{rl}1005 i & \text { btilib } \\ 0.6 & 8 \\ 20.4 & 8 \\ 7.8 & 8\end{array}$


Table 3-19

PLANT COMMERICAL PERFORMANCE STATISTICS December 1989

1. Pant outputs and consumptiens

- Gross generation:

- Net generation:

- Period

- On line

- Aux power use:

- Period

- On line

- Aux power use (in \&):

- Period

- On line

46023

3.

Indivinad unit entouts

\begin{tabular}{|c|c|}
\hline z & eutou- cmins \\
\hline$i$ & 4812 \\
\hline 2 & 4828 \\
\hline 3 & 5022 \\
\hline 4 & $3: 360$ \\
\hline Toza! & 46023 \\
\hline
\end{tabular}

- Period hours:

- In Service:

- Coaz hours:

- On standby:

- Scheduled outage:

- Unscheduied outage:

- Number os Unit Starts:

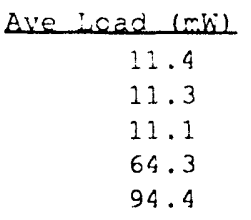

4. Qcerasinc Eva: $a b: 1: 4 x$ :

5. Equivalent Availability:

6. Sapacity Eactor:

7. Average Hea: Rate fer Pericd:

- Or ine (coal and gas):

- On line (coal):

8. Vaior Eguiprent Usages

- Boiler feed pumps:

- Primary air fan:

- Secondary air fan:

- Induced draft fan:

- High pressure blowers:

- Bottom ash cooler fan:

9. Naterial censumptiers

- Total coal flow:

- Total iimestore flow:

- Tozal start-up burner gas (propane) flow:

- Avg higher heating value of propane gas:

20. Average ccai Anaiysis

- Higher heating vaiue:

- Suifur:

- Ast:

- No:sture:
40847

41417

5176

4606

11.2

10.0

$\begin{aligned} 744 & \text { hrs } \\ 488 & \text { hrs } \\ 479 & \text { hrs } \\ 0 & \text { hrs } \\ 0 & \text { hrs } \\ 256 & \text { hrs } \\ 6 & \text { hrs }\end{aligned}$

mWhrs

mWhrs mWhrs

mWhrs mWhrs

8

8

irs

hrs

hrs

hrs

Leirs

422

426

451

488

488

65.5 \%

$64.8 \%$

$56.2 \div$

21933.8 btu/nkwh

11826.9 btu/riknh

$\begin{aligned} 1128 & \text { mWhrs } \\ 1170 & \text { mwhrs } \\ 120 & \text { mWhrs } \\ 816 & \text { mWhrs } \\ 51 & \text { mwhrs } \\ 77 & \text { mWhrs }\end{aligned}$

tons

$\mathrm{kscf}$

btu/scf

$\begin{array}{rl}10223 & \text { btu/ib } \\ 0.6 & 8 \\ 18.3 & \frac{8}{8} \\ 9.3 & \frac{9}{6}\end{array}$


Table 3-2C

PLANT COMMERICAL PERFORMANCE STA.ISTICS JanuarY 1990

2. Rlant Quzouts and consumotions

- Gross generation:

- Net generation:

$$
\begin{aligned}
& \text { - Pericd } \\
& \text { - On line }
\end{aligned}
$$

- Aux power use:

- Period

- On line

- Aux power use (in 8):

- Period

- On line

2. Qperating Heirs

- Period hours:

- In Service:

- Coal hours:

- On stardby:

- Scheduled outage:

- Unscheduled outage:

- Number of Unit Starts:

$\begin{aligned} 44,441 & \text { mWhr } \\ 39,791 & \text { mWhr } \\ 40,091 & \text { mWhr } \\ 4,649 & \text { mWhr } \\ 4,349 & \text { mWhr } \\ 10.5 & \text { o } \\ 9.8 & \text { of } \\ & \\ 744 & \text { hrs } \\ 540 & \text { hrs } \\ 536 & \text { hrs } \\ 0 & \text { hrs } \\ 126 & \text { hrs } \\ 79 & \text { hrs } \\ 2 & \text { hrs }\end{aligned}$

\begin{tabular}{|c|c|}
\hline مت & Qutent (minting \\
\hline 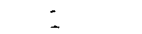 & 5970 \\
\hline 2 & 3599 \\
\hline 3 & 3702 \\
\hline 4 & $3: \div 70$ \\
\hline$\therefore=$ To:a: & 44441 \\
\hline
\end{tabular}

3. Individual in:- euteits

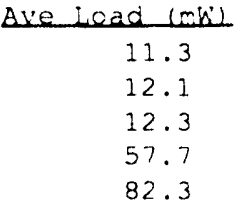

Hevirs

4. Pcora:ina Avai abisini:

72.58

E. Earvaient Availability:

$57.0 \quad 8$

6. Sapacity Factor:

54.38

7. Average Hear Rate for Pericd:

- On ilire (coal and gas):

11817.2 btu/nkwh

- On line (coal):

8. Natar Exitoment isazes

- Boiler feed pumps:

991

mWhrs

1069

mwhrs

mWhrs

66] mWhrs

secondary air fan:

- Induced draft fan:

- Higr pressure biowers:

- Botsom ash cooler far:

mWhrs

mWhes

9. Vateriai Censumpticrs

- Total coal flow:

23509

1141

2172

tons

- Total imestone flow:

- Totar siart-lp burner gas (propane) fiow:

2516

ksci

- Avg higher heating value of propane gas:

$\begin{array}{rl}10013 & \text { btu/10 } \\ 0.5 & \text { 8 } \\ 19.2 & 8 \\ 9.5 & 8\end{array}$


Table 3-21

PLANT COMMERICAL PERFORMANCE STATISTICS

February 1990

1. Rlant Qutputs and censumptions

- Gross generation:

- Net generation:

$$
\text { - Period }
$$

- On line

11046

9397

9886

- Aux power use:

- Period

- On line

- Aux power use (in 8):

- Period

- On line

1649

1160
14.98

10.5 \&

$\begin{aligned} 672 & \text { hrs } \\ 183 & \text { hrs } \\ 176 & \text { hrs } \\ 0 & \text { hrs } \\ 164 & \text { hrs } \\ 325 & \text { hrs } \\ 4 & \text { hrs }\end{aligned}$

3. Individual Unit outputs

$\begin{array}{cr}\frac{\text { Unit }}{1} & \text { eutrut (mbinc) } \\ 2 & 469 \\ 3 & 329 \\ 4 & 1302 \\ \text { Unit Total } & 8945 \\ & 11046\end{array}$

4. eperating Availability:

5. Equivalent Availability:

6. Capacity Eactor:

7. Average Heat Rate for Period:

- On line (gas and coal):

- On line (coal):

\section{Majer Equidment Usages}

- Boiler feed pumps:

- Primary air fan:

- Secondary air fan:

- Induced draft fan:

- High pressure blowers:

- Bottom ash cooler fan:

9. Mazerial Consumptiens

- Total coal flow:

Ave iead $\left(m b^{\prime}\right)$

8.9

9.9

9.4

48.8

60.3

Heirs

53

33

138

183

183

$27.3 \quad 8$

$18.4 \div$

$14.9 \quad 8$

11637.7 btu/nkwh. 11432.4 biu/nkwh

$\begin{aligned} 101 & \text { mWhrs } \\ 131 & \text { mWhrs } \\ 4 & \text { mWhrs } \\ 26 & \text { mWhrs } \\ 31 & \text { mWhrs } \\ 10 & \text { mWhrs }\end{aligned}$

5882 tons

271 tons

$3160 \mathrm{kscf}$

2516 btu/sce

- Avg higher heating value of propane gas:

10. Average Ceal Analysis

- Higher heating value:

- Sulfur:

- Ash:

- Moisture:

$\begin{array}{rl}10268 & \text { btu/lb } \\ 0.5 & 8 \\ 18.1 & 8 \\ 9.1 & 8\end{array}$

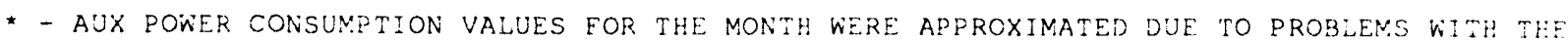
ASSOCIATED MEGANATT METER. 
Table 3-22

PLANT COMMERICAL PERFORMANCE, STATISTICS

March 1990

2. Rlart Qutputs and consumptions

- Gross gereration:

- Net generation:

- Period

- On line

64088

58020

58131

- Aux power use:

- Period

- On line

- Aux power use (in 8$)$ :

- Period

- On line

2. Operating Hours

- Period hours:

- In Service:

- Coal hours:

- On standry:

- Schediled outage:

- Unscheduled outage:

- Number of Unit Starts:

3.

Indvidual init outeuts

\begin{tabular}{r} 
Unit. \\
\hline 2 \\
2 \\
3 \\
4
\end{tabular}

Unit Total

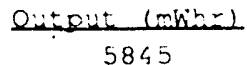

5956

8067

44221

64088

4. Operat: a dya:1 ab: 1:

5. Equivalent Availability:

E. Capacity Eacier:

7. Everace Heat Fate for Period:

- On line (coal ana gas):

- Cr line (coal):

Q. Vator Equinmert Usages

- Boiler feed pumps:

- Primary air fan:

- Secondary air fan:

- Induced draft fan:

- High pressure blowers:

- Bottom ash cooler fan:

9. Materià Consumpiciens

- Total coal flow:

- Total ilmestone flow:

- Total start-up burner gas (propanel flow:

- Avg nigh heating value of propane gas:

$\therefore$ Average Crai Aralysis

- Higher neating value:

- Silfur:

- Astr:

- Mo:sture:

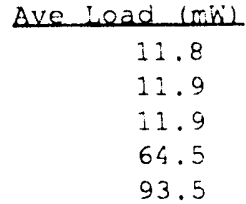

bives

493

499

677

585

685

\subsection{8}

$79.9 \quad \frac{8}{8}$

78.38

$11672.0 \quad b \pm v / n k w^{\prime}$

11643.7 btu/nkwh

1382

1358

152

994

99

90

mwhrs

mwites mhites

mwhrs

mihes

mwtirs

32528

$\$ 75 \%$

1294

tons

tons

kscf

2526 btu/sct

$10405 \quad 0+2 i: b$

$0.5 \quad \&$

$\because .3 \quad$ \&

$8.8 \quad 9$ 
Tabie 3-23

PLANT COMMERICAL PERFCRMANCE STATISTICS

Ap:L: 1990

1. Riani eutputs and consumptiens

- Gross generation:

- Net generation:

- Period

- On line

- Aux power use:

- Period

- on line

66417 mWr.rs

- Aux power use (in \&):

- Period

- On inine

60050 mWhrs

60244 mWhrs

6367 mWhrs

6173 mWhrs

9.68

2. Operating Hours

- Period hours:

720 hrs

- In Service:

- Coal hours:

- On standicy:

- Scheduled outage:

- Unschedujea outage:

- Number of unit Starts:

632 hrs

629 hrs

0 nrs

0 hrs

88 hrs

3.

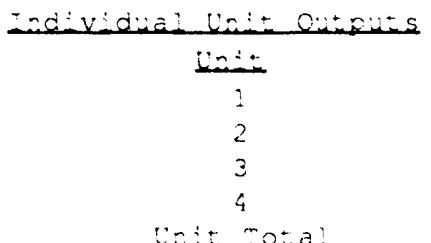

$\frac{0+20}{7203}$
7365
7430
$4492 ?$
$664 ?$

Ave cad $(-\mathrm{in})$
12.4
12.3
11.9
70.3
105.1

Hours

583

599

625

632

632

4. Poerating Ava: ac: isy:

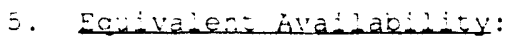

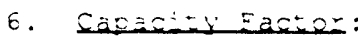

87.8 응

$75 .:$ 8

83.98

7 Averajt Hea Rate fur Periog:

- Or ine (ccal and gas):

- On ilre (coai):

$: 1596 . i$ btu/nkwis

$\therefore 576.6$ beu/riknh

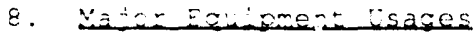

- 3osier feed purps:

- Primary air fan:

- Secondary air tar:

- induceo draft fan:

- thigh pressire blowers:

- Boztom ast cooler fari:

1422 mintrs

1523 minites

274 minirs

$1: 34$ mWhrs

109 mitirs

92 mirit.rs

9. Material Censumptions

- Total coal flow:

- Tozal limestone flow:

- Total start-up burner gas (propane) flow:

- Avg highor heating value of propane cas:

ic. Averace coat Anaiysis

- Higher heating váduo:

- Siziz:

- As:.:

- Moisiuge:
33504 tors

i956 tors

1092 kscf

$25: 6$ btu/sct

$\begin{array}{rl}0.0407 & b=u / 1 b \\ 0.5 & 8 \\ 2.2 & 8 \\ 8 . ? & 8\end{array}$


Table 3-24

PLANT COMMERICAL PERFORMANCE STATISTICS

MaY 1990

1. Rlant Qutputs and censumptions

- Gross generation:

- Net generation:

- Period

- On line

- Period

- On Jine

- Aux power use (in z):

- Period

- On line

2. Operating Hours

- Period hours:

- In Service:

- Coal hours:

- On standby:

- Scheduled outage:

- Unscheduled outage:

- Number of Unit Starts:

3. Individual Unit Outputs

\begin{tabular}{cc} 
Unit & outeut (mbitr) \\
\hline 1 & 2370 \\
2 & 2116 \\
3 & 2189 \\
4 & 14737 \\
nit Total & 21412
\end{tabular}

4. Ocerating Availability:

5. Equivalent Availability:

6. Capacity Facter:

7. Average heat Rate for Period:

- On line (coal and gas):

- On line (coal):

8. Vator Equiprent Usages

- Boiler feed pumps:

- Primary air fan:

- Secondary air fan:

- Induced draft fan:

- High pressure blowers:

- Bottom ash cooler fan:

9. Material consumptions

- Total coal flow:

- Total limestone flow:

- Total start-up burner gas (propane) flow:

- Avg higher heating value of propane gas:

10. Average Coal Analysis

- Higher heating value:

- Sulfur:

- Ash:

- Moisture:
21412

18558

19286

2854

mWhrs

mithrs

mWhrs

mWhrs

mWhrs

13.38

744 hrs

246 hrs

240 hrs

nirs

hres

498 hrs

$4 h: s$

Ave Lead ( $\mathrm{mbi}$ )
$\begin{gathered}10.8 \\ 10.0 \\ 10.4 \\ 59.8 \\ 86.9\end{gathered}$

HeUrs

220

212

211

246

246

33.18

30.9 \&

26.28

12127.1 btu/nkwt. 12092.1 btu/nkwh

$\begin{aligned} 538 & \text { mwhrs } \\ 542 & \text { mwhrs } \\ 63 & \text { mWhrs } \\ 354 & \text { mWhrs } \\ 98 & \text { mWhrs } \\ 38 & \text { mWhrs }\end{aligned}$

tons

tons

$\mathrm{ksc}$

$2516 \mathrm{btu} / \mathrm{scf}$

$\begin{array}{rl}10369 & b=i / 2 b \\ 17.8 & 8 \\ 0.6 & 8 \\ 8.4 & 8\end{array}$


Table 3-25

PLANT COMMERICAL PERFORMANCE STATISTICS

June 1990

1. Rlant Qutputs and Censumptions

- Gross generation:

- Net generation:

- Period

42965

38249

38652

- Aux power use:

- Period

- On line

- Aux power use (in s):

- Period

- On line
mWhrs

mWhrs

mWhrs

4716 mWhrs

4313 mWhrs

$11.0 \quad 8$

10.0 \&

$\begin{array}{rr}720 & \text { hrs } \\ 500 & \text { hrs } \\ 486 & \text { hrs } \\ 0 & \text { hrs } \\ 0 & \text { hrs } \\ 220 & \text { hrs } \\ 4 & \text { hrs }\end{array}$

\begin{tabular}{cr} 
Ave Lead (mi) & Hewrs \\
\hline 9.5 & 481 \\
9.9 & 469 \\
9.8 & 463 \\
58.5 & 500 \\
86.0 & 500
\end{tabular}

$\begin{array}{rl}69.4 & \text { 8 } \\ 69.0 & 8 \\ 54.2 & 8 \\ & \\ 12313.9 & \text { btu/nkwh } \\ 12272.3 & \text { btu/nkwh }\end{array}$

1088 mWhrs

986 mWhrs

122 miwhrs

703 mWhrs

133 mWhrs

69 mWhrs

- Hot pressure blowers

22290

1960

2517

tons

tons

ksci

2516 btu/scf

- Avg higher heating value of propane gas:

10. Averige ceal Analysis

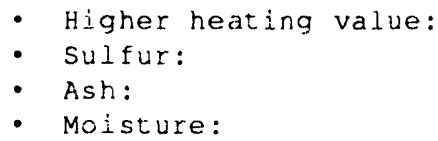

$\begin{array}{rl}10596 & \text { btu/lb } \\ 0.6 & q \\ 16.6 & q \\ 7.8 & 8\end{array}$


Table 3-26

PLANT COMMERICAL PERFORMANCE STATISTICS

July 1990

$\begin{array}{cccc}\text { CURRENT } & \text { YEAR TO } & \text { TWELVE } & \text { LIFE TO } \\ \text { MONTH } & \text { DATE } & \text { MONTHS } & \text { DATE }\end{array}$

PRODUCTION

GENERATION

GROSS, MWh

NET, MWh

$\begin{array}{rrrr}17,846 & 268,301 & 414,020 & 969,108 \\ 15,920 & 243,462 & 374,594 & 867,982 \\ & & & \\ 1,926 & 24,839 & 39,426 & 101,126 \\ 10.8 & 9.3 & 9.5 & 10.4 \\ 100 & 100 & 100 & 100\end{array}$

MAX. NET CAPACITY, MW

ATION SERVICE

MWh

MONTH

DATE

MONTHS

DATE

NIT OPERATION

\begin{tabular}{|c|c|c|c|c|}
\hline PERIOD HOURS & 744.00 & $5,087.00$ & $8,760.00$ & $27,768.00$ \\
\hline SERVICE HOURS & 268.28 & $3,047.75$ & $4,712.32$ & $15,386.22$ \\
\hline $\begin{array}{l}\text { SCHEDULED OUTAGES } \\
\text { NET GEN. LOSS, MWh } \\
\text { HOURS }\end{array}$ & $\begin{array}{r}0 \\
0.00\end{array}$ & $\begin{array}{l}28,937 \\
289.37\end{array}$ & $\begin{array}{l}73,288 \\
732.88\end{array}$ & $\begin{array}{r}246,343 \\
2,463.43\end{array}$ \\
\hline $\begin{array}{l}\text { FORCED OUTAGES } \\
\text { NET GEN. LOSS, MWh } \\
\text { HOURS }\end{array}$ & $\begin{array}{l}47,572 \\
475.72\end{array}$ & $\begin{array}{r}174,988 \\
1,749.88\end{array}$ & $\begin{array}{r}356,263 \\
3,262.63\end{array}$ & $\begin{array}{r}971,258 \\
9,712.58\end{array}$ \\
\hline $\begin{array}{l}\text { SCHEDULED CURTAILMENTS } \\
\text { NET GEN. LOSS, MWh } \\
\text { HOURS }\end{array}$ & $\begin{array}{r}0 \\
0.00\end{array}$ & $\begin{array}{r}0 \\
0.00\end{array}$ & $\begin{array}{r}0 \\
0.00\end{array}$ & $\begin{array}{r}2,850 \\
100.00\end{array}$ \\
\hline $\begin{array}{l}\text { FORCED CURTAILMENTS } \\
\text { NET GEN. LOSS, MWh } \\
\text { HOURS }\end{array}$ & $\begin{array}{r}4,604 \\
149.42\end{array}$ & $\begin{array}{l}34,433 \\
753.15\end{array}$ & $\begin{array}{r}54,618 \\
1,515.58\end{array}$ & $\begin{array}{r}205,763 \\
5,513.83\end{array}$ \\
\hline $\begin{array}{l}\text { FACTORS (NET) } \\
\text { AVAILABILITY, } \frac{\circ}{6} \\
\text { EQUIV. AVAILABILITY, } \\
\text { CAPACITY, } \frac{\circ}{\circ}\end{array}$ & $\begin{array}{l}36.1 \\
29.9 \\
21.4\end{array}$ & $\begin{array}{l}59.9 \\
53.1 \\
47.9\end{array}$ & $\begin{array}{l}54.4 \\
48.2 \\
42.8\end{array}$ & $\begin{array}{l}56.2 \\
48.6 \\
31.3\end{array}$ \\
\hline REORMANCE DATA & & & & \\
\hline $\begin{array}{l}\text { UNIT HEAT RATE } \\
\text { GROSS, Btu/kWh } \\
\text { NET, Btu } / \mathrm{kWh}\end{array}$ & $\begin{array}{l}11,111.9 \\
12,456.3\end{array}$ & $\begin{array}{l}10,697.8 \\
11,789.2\end{array}$ & $\begin{array}{l}10,649.3 \\
11,770.2\end{array}$ & $\begin{array}{l}10,797.4 \\
12,055.4\end{array}$ \\
\hline
\end{tabular}


Table 3-27

PLANT COMMERICAL PERFORMANCE STATISTICS

August 1990

$\begin{array}{cccc}\text { CURRENT } & \text { YEAR TO } & \text { TWELVE } & \text { LTFE TO } \\ \text { MCNTH } & \text { DATE } & \text { MONTHS } & \text { DATE }\end{array}$

RRODUCTION

GENERATION

GROSS, MWh

9,494

277,795

403,943

978,602

NET, MWh

8,458

251,920

365,521

876,440

STATION SERVICE

MWh

1,036

10.9

25,875

38,422

102,162

9.3

9.5

10.4

MAX. NET CAPRCITY, MW

100

100

100

100

UNIT OPERATION

PERIOD HOURS

744.00

$5,831.00$

$8,760.00$

$28,512.00$

SERVICE HOURS

145.33

$3,193.08$

$4,519.40$

$15,531.55$

SCHEDULED OUTAGES

NET GEN. LOSS, MWh

HOURS

0

28,937

289.37

67,348

673.48

246,343

0.00

$2,463.43$

FORCED OUTAGES

NET GEN. LOSS, MWh

35,830

210,818

332,675

$2,108.18$

$3,326.75$

$1,007,088$

358.30

2.108.18

SCHEDULED CURTAILMENTS

NET GEN. LOSS, MWh

0.00

0.00

0.00

2,850

HOURS

135

12.23

34,567

765.38

40,038

$1,233.53$

205,897

HOURS

51.8

51.7

58.9

53.0

54.3

49.8

43.2

41.7

56.0

48.7

30.7

\section{PEREORMANCE RATA}

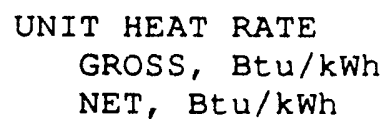

$11,211.1$

$12,584.7$

$10,715.3$

$10,645.5$

$10,801.4$

NET, Btu/kWh

$11,815.9 \quad 11,764.5$

$12,060.5$

NOTE: GENERATION Is IN MWh; CAPACITY IS IN MW 


\begin{tabular}{|c|c|c|c|c|}
\hline \multirow[t]{2}{*}{ PLANT } & $\begin{array}{r}\text { Table } \\
\text { COMMERICAL PE } \\
\text { Septemb }\end{array}$ & $\begin{array}{l}28 \\
\text { RMANCE S } \\
1990\end{array}$ & T ICS & \\
\hline & $\begin{array}{l}\text { CURRENT } \\
\text { MONTH }\end{array}$ & $\begin{array}{l}\text { YEAR TO } \\
\text { DATE }\end{array}$ & $\begin{array}{l}\text { TWELVE } \\
\text { MONTHS }\end{array}$ & $\begin{array}{l}\text { LIFE TO } \\
\text { DATE }\end{array}$ \\
\hline
\end{tabular}

\section{RRORUCTION}

GENERATION GROSS, MWh NET, MWh

14,692

13,206

292,487

$$
265,126
$$

394,182

356,800

993,294

889,646

STATION SERVICE

MWh

PERCENT OF GROSS

MAX. NET CAPACITY, MW

\section{UNIT OPERATION}

PERIOD HOURS

SERVICE HOURS

SCHEDULED OUTAGES

NET GEN. LOSS, MWh HOURS

FORCED OUTAGES

NET GEN. LOSS, MWh HOURS

$\begin{array}{rrrr}1,486 & 27,361 & 37,382 & 103,648 \\ 10.1 & 9.4 & 9.5 & 10.4 \\ 100 & 100 & 100 & 100\end{array}$

$\begin{array}{llll}720.00 & 6,551.00 & 8,760.00 & 29,232.00 \\ 173.63 & 3,366.72 & 4,405.62 & 15,705.18\end{array}$

$\begin{array}{llll}0 & 28,937 & 50,363 & 246,343\end{array}$

$\begin{array}{llll}0.00 & 289.37 & 503.63 & 2.463 .43\end{array}$

$39,022 \quad 249,840 \quad 345,423 \quad 1,046,110$

$390.22 \quad 2,498.40 \quad 3,454.23 \quad 10,461.10$

SCHEDULED CURTAILMENTS NET GEN. LOSS, MWh HOURS

0

0.00

0

0

2,850

F JRCED CURTAILMENTS NET GEN. LOSS, MWh HOURS

41
3.45

$$
\begin{aligned}
& 34,609 \\
& 768.83
\end{aligned}
$$

37,383

981.47

205,939

$5,529.52$

EACTORS (NET)

AVAILABILITY, 음

45.8

EQUIV. AVAILABILITY,

CAPACITY, 응

45.7

18.3
54.8

50.6

40.7
55.8

48.6 30.4

\section{PERFORMANCE DATA}

UNIT HEAT RATE
GROSS, Btu/kWh
NET, Btu/kWh

$$
\begin{array}{llll}
10,778.8 & 10,718.5 & 10,653.3 & 10,801.1 \\
11,991.7 & 11,824.7 & 11,769.5 & 12.059 .5
\end{array}
$$

1769.5

NOTE: GENERATION IS IN MWh; CAPACITY IS IN MW 
Table 3-29

PLANT COMMERICAL PERFORMANCE STATISTICS

October 1990

$\begin{array}{cccc}\text { CURRENT } & \text { YEAR TO } & \text { TWELVE } & \text { LIFE TO } \\ \text { MONTH } & \text { DATE } & \text { MONTHS } & \text { DATE }\end{array}$

\section{RRODUCTION}

GENERATION

GROSS, MWh

NET, MWh

$\begin{array}{rrrr}26,347 & 318,834 & 412,209 & 1,019,641 \\ 23,560 & 288,685 & 372,904 & 913,205 \\ & & & \\ 2,787 & 30,149 & 39,305 & 106,435 \\ 10.6 & 9.5 & 9.5 & 10.4 \\ 100 & 100 & 100 & 100\end{array}$

MAX. NET CAPACITY, MW

\section{TATION SERVICE}

MWh

PERCENT OF GROSS

\section{UNIT OPERATION}

PERIOD HOURS

$7,296.00$

$8,760.00$

$29,977.00$

469.35

$3,836.07$

$4,781.67$

$16,174.53$

SCHEDULED OUTAGES

NET GEN. LOJS, MWh

12,738

HOURS

127.38

41,675

416.75

41,675

259,082

$416.75 \quad 2,590.82$

FORCED OUTAGES

NET GEN. LOSS, MWh

HOURS

14,827

264,667

$2,646.67$

316,507

$1,060,937$

148.27

$3,165.07$

$10,609.37$

SCHEDULED CURTAILMENTS

NET GEN. LOSS, MWh

HOURS

0.00

FORCED CURTAILMENTS

NET GEN. LOSS, MWh

HOURS

339

33.87

34,947
802.70

37,721

1015.33

206,277

$5,563.38$

FACTORS (NET)

AVAILABILITY, 号

63.0

62.5

58.0

59.1

56.0

EQUIV. AVAILABILITY, 官

31.6

53.2

54.8

42.6

49.0

39.6

30.5

\section{PEREORMANCE DATA}

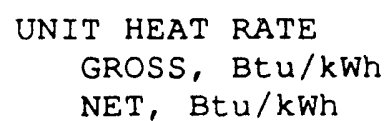

$10,961.5$

$12,254.4$

$10,738.6$

$10,679.8$

$11,860.1 \quad 11,805.5$

$10,805.2$

$12,064.6$

NOTE: GENERATION IS IN MWh; CAPACITY IS IN MW 
Table 3-30

PLANT COMMERICAL PERFORMANCE STATISTICS

November 1990

$\begin{array}{cccc}\text { CURRENT } & \text { YEAR TO } & \text { TWELVE } & \text { LIFE TO } \\ \text { MONTH } & \text { DATE } & \text { MONTHS } & \text { DATE }\end{array}$

\section{RRORUCTION}

GENERATION

GROSS, MWh

67,614

386,448

432,947

$1,087.255$

NET, MWh

61,449

$350,134 \quad 392,023$

974,654

STATION SERVICE

MWh

PERCENT OF GROSS

6,165

9.1

36,314
9.4

40,924

112,600

100

100

100

100

MAX. NET CAPACITY, MW

UNIT OPERATION

PERIOD HOURS

720.00

$8,016.00$

$8,760.00$

$30,697.00$

SERVICE HOURS

699.92

$4,535.98$

$5,021.75$

$16,874.45$

SCHEDULED OUTAGES

NET GEN. LOSS, MWh

2,008

20.08

43,683

43,683

261,090 HOURS

436.83

436.83

$2,610.90$

F'ORCED OUTAGES

NET GEN. LOSS, MWh HOURS
0.00

264,667

290,490

$1,060,937$

$2,646.67$

$2,904.90$

$10,609.37$

SCHEDULED CURTAILMENTS NET GEN. LOSS, MWh HOURS

0.00

175

13.00

NET GEN. LOSS, MWh

HOURS

FACTORS (NET)

AVAILABILITY, :

97.2

97.0

85.3
$10,546.4$

$11,604.5$
$10,705.0$

$11,815.2$
$10,677.6$

$11,792.3$
2,850

100.00

206,452

$5,576.38$

NET, Btu/kWh

NOTE: GENERATION IS IN MWh; CAPACITY IS IN MW

$10,789.2$

$12,035.6$

56.9

50.1

31.8

57.8

\section{PEREORMANCE DATA}


Table 3-31

PLANT COMMERICAL PERFORMANCE STATISTICS

December 1990

$\begin{array}{cccc}\text { CURRENT } & \text { YEAR TO } & \text { TWELVE } & \text { LIFE TO } \\ \text { MONTH } & \text { DATE } & \text { MONTHS } & \text { DATE }\end{array}$

\section{RRODUCTION}

GENERATION

GROSS, MWh

NET, MWh

$\begin{array}{rrrr}60,860 & 447,308 & 447,308 & 1,148,115 \\ 55,039 & 405,174 & 405,174 & 1,029,694 \\ 5,821 & 42,134 & 42,134 & 118,421 \\ 9.6 & 9.4 & 9.4 & 10.3 \\ 100 & 100 & 100 & 100\end{array}$

MAX. NET CAPACITY, MW

\section{UNIT OPERATION}

PERIOD HOURS

$744.00 \quad 8,760.00 \quad 8,760.00 \quad 31,441.00$

SERVICE HOURS

728.18

$5,264.17$

$5,264.17$

$17,602.63$

SCHEDULED OUTAGES

NET GEN. LOSS, MW:I HOURS

0
0.00

43,683

436,83

43,683

436.83

261,090

$2,610.90$

FORCED OUTAGES

NET GEN. LOSS, MWh HOURS

266,248

266,248

$2,662.48$

$1,062,518$

$2,662.48$

$10,625.18$

SCHEDULED CURTAILMENTS NET GEN. LOSS, MWh HOURS

0
0.00

0
0.00

0.00

2,850

FORCED CURTAILMENTS NET GEN. LOSS, MTNh HOURS

165

35,288

35,288

827.00

206,618

11.3

827.00

$5,587.68$

FACTORS (NET)

AVAILABILITY, \%

97.9

EQUIV. AVAILABILITY, 음

97.7

CAPACITY, \%

$$
\begin{aligned}
& 64.6 \\
& 60.6 \\
& 46.3
\end{aligned}
$$

64.6

60.6

57.9

74.0

46.3

51.2

32.8

\section{PEREORMANCE DATA}

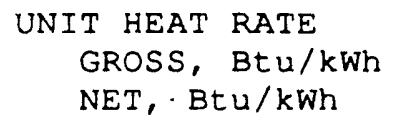

$10,641.9$
$11,767.3$
$10,696.4$

$11,808.7$
$10,781.3$

$12,021.3$

NOTE: GENERATION IS IN MWh; CAPACITY IS IN MW 
Table 3-32

PLANT COMMERICAL PERFORMANCE STATISTICS

January 1991

$\begin{array}{cccc}\text { CURRENT } & \text { YEAR TO } & \text { TWELVE } & \text { LIFE TO } \\ \text { MONTH } & \text { DATE } & \text { MONTHS } & \text { DATE }\end{array}$

\section{PRODUCTION}

GENERATION

GROSS, MWh

$\begin{array}{rrrr}47,774 & 47,774 & 450,293 & 1,195.889 \\ 42,767 & 42,767 & 407,509 & 1,072,461 \\ 5,007 & 5,007 & 42,784 & 123,428 \\ 10.5 & 10.5 & 9.5 & 10.3 \\ 100 & 100 & 100 & 100\end{array}$

MAX. NET CAPACITY, MW

TATION SERVICE

MWh

PERCENT OF GROSS

100

744.00

744.00

$8,760.00$

$32,185.00$

SERVICE HOURS

713.95

713.95

$5,438.67$

$18,316.58$

SCHEDULED OUTAGES NET GEN. LOSS, MWh HOURS

345

3.45

345

3.45

31,482

261,435

FORCED OUTAGES

NET GEN. LOSS, MWh

HOURS

2,660

26.60

2,660

26.60

261,000

$2,610.00$

$1,065,178$

SCHEDULED CURTAILMENTS NET GEN. LOSS, MWh HOURS

0

0

0.00

0
0.00

$10,651.78$

FORCED CURTAILMENTS NET GEN. LOSS, MWh HOURS

2,957

62.92

$$
\begin{aligned}
& 2,957 \\
& 62.92
\end{aligned}
$$

26,723

659.48

209,575

$5,650.60$

FACTORS (NET)

AVAILABILITY, : 96.0

EQUIV. AVAILABILITY, \%

CAPACITY,

96.0

92.0

57.5
66.6

63.6

46.5
2,850

100.00

58.8

52.2

33.3

\section{PEREORMANCE DATA}

UNIT HEAT RATE GROSS, Btu/kWh NET, Btu/kWh 
Table 3-33

PLANT COMMERICAL PERFORMANCE STATISTICS

February 1991

$\begin{array}{cccc}\text { CURRENT } & \text { YEAR TO } & \text { TWELVE } & \text { LIFE TO } \\ \text { MONTH } & \text { DATE } & \text { MONTHS } & \text { DATE }\end{array}$

PRODUCTION

GENERATION

GROSS, MWh

NET, MWh

2,955

50,729

442,343

$1,198,844$

2,664

45,431

399,668

$1,075,125$

STATION SERVICE

MWh

291

5,298

42,675

123,719

PERCENT OF GROSS

9.8

9.6

10.3

MAX. NET CAPACITY, MW

100

100

100

100

UNIT OPERATION

PERIOD HOURS

$8,760.00$

$32,857.00$

SERVICE HOURS

32.18

746.13

$5,288.05$

$18,348.77$

SCHEDULED OUTAGES

NET GEN. LOSS, MWh HOURS

58,472

584.72

58,817

588.17

73,563

735.63

319,907

FORCED OUTAGES

NET GEN. LOSS, MWh

HOURS

0

2,660

228,470

26.60

$2,284.70$

$1,065.178$

0.00

$10,651.78$

SCHEDULED CURTAILMENTS

NET GEN. LOSS, MWh

HOURS

0

0
0.00

0.00

2,850

0.00

100.00

FORCED CURTAILMENTS

NET GEN. LOSS, MWh

HOURS

2,957

20,776

528.68

209,575

0.000

62.92

$5,650.60$

FACTORS (NET)

AVAILABILITY, \%

13.0

56.6

65.5

57.8

EQUIV. AVAILABILITY,

13.0

54.5

63.1

51.4

CAPACITY, 号

4.0

32.1

45.6

32.7

\section{PEREOBMANCE DATA}

UNIT HEAT RATE

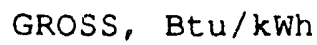

NET, Btu/kWh

$$
\begin{array}{llll}
10,434.2 & 11,063.1 & 10,758.2 & 10,794.2 \\
11,573.3 & 12,353.2 & 11,907.0 & 12,036.3
\end{array}
$$

NOTE: GENERATION IS IN MWh; CAPACITY IS IN MW 


\subsection{DEFINITIONS FOR PLANT COMMERCIAL PERFORMANCE STATISTICS}

The following definitions are used by CUEA in generating plant commercial performance statistics that are presented and discussed in section 3.1. These definitions are adopted from those used by the North American Electric Reliability Council in their report "Data Reporting Instructions for the Generating Availability Data System", October, 1990.

The definition for equivalent availability does not include seasonally adjusted derate hours which is included with planned and unplanned derate hours in the NERC GADS definition.

Availability Factor:

Available:

Available Hours $(A H)$ :

Average Reriod Heat Rate lon Line, Net):

\section{Capacity Eactor:}

(Available Hours/Period Hours) *100\%

State in which a unit is capable of providing service, whether or not it is actually in service, regardless of the capacity level that can be provided.

Sum of all Service Hours and Reserve Shutdown Hours;

Period Hours less Planned Outage Hours, Forced Outage Hours, and Maintenance Outage Hours.

[Coal HHV * Coal Consumed] + [ (Gas HHV * Gas Consumed (On-Line)) / Net Generation]

(Gross Generation / Gross Maximum Capacity) * $100 \%$

Note: In Section 3 tailes and figures, Capacity Factors are calculated using the capacity factor equation prior to July, 1990 and using the net capacity factor equation from July, 1990 to present.

Equivalent Availability: [(Available Hours - (Planned Derate + Unplanned Derate))/Period Hours] $* 100 \%$

Note: In Section 3 tables and figures, Equivalent Availabilities are calculated using the gross equivalent availability equation prior to July, 1990 and using the equivalent availability equation from July, 1990 to presert. 
Eorced Derating/Curtailment:

Eerced Outage:

Gross Actual Generation:

Gross Capacity Factor:

An unplanned component failure or other concition that requires the load on the unit be reduced immediately or before the next weekend.

An unplanned component failure or other condition that requires the unit be removed from service immediately or before the next weekend.

Actual number of electrical megawatt hours generated by the unit during the period being considered.

(Gross Actual Generation / (Period Hours * Gross Maximum Capacity)l * $100 \%$

Gross Equivalent Availability: (Gross Maximum Capacity * Available Hours - MWh loss due to Derating) / (Gross Maximum Capacity * Period Hours)

Note: In Section 3 tables and figures, Equivalent Availabilities are calculated using the gross equivalent availability equation prior to July, 1990 and using the equivalent availability equation from July, 1990 to present.

Gross Maximum Capacity:

Maintenance Derating:

Maintenance Outage:
Maximum capacity a unit can sustain over a specified period of time when not restricted by seasonal, or other deratings.

The removal of a component for scheduled repairs that can be deferred beyond the end of the next weekend, but requires a reduction of capacity before the next planned outage.

The removal of a unit from service to perform work on specific components that can be deferred beyond the end of the next weekend, but requires the unit be removed from service before the next planned outage. Typically, a maintenance outage may occur anytime during the year, have flexible start dates, and may or may not have a predetermined duration. 
Net Actual Generation (MWh): Actual number of electrical megawatt hours generated by the unit during the period being considered less any generation (MWh) utilized for that unit's station service or auxiliaries.

Net Capacity Factor:

[Net Actual Generation/(Period Hours

* Net Maximum Capacity) ]*100\%

Note: In Section 3 tables and figures, Capacity Factors are calculated using the capacity factor equation prior to July, 1990 and using the net capacity factor equation from July, 1990 to present.

Net Maximum Capacity:

Number of Unit Starts:

Reriod Hours:

Planned Derating:

Planned Qutage:

Reserve Shutdown:

Scheduled Derating Extension:

Scheduled Deratings/ curtailments:

Scheduled Qutage Extension:
Gross maximum capacity less the unit capacity utilized for that unit's station service or auxiliaries.

The number of times Unit 4 was electrically connected to the system during the reporting period.

Number of hours a unit was in the active state.

The removal of a component for repairs that is scheduled well in advance and has a predetermined duration.

The removal of a unit from service to perform work on specific components that is scheduled well in advance and has a predetermined duration (e.g., annual overhaul, inspections, testing).

A state in which a unit is available but not in service for economic reasons.

The extension of a maintenance or planned derating.

Scheduled deratings are a combination of maintenance and planned deratings.

The extension of a maintenance or planned outage. 
Scheduled Outages:

Service Hours:

Unavailable:

Unavailable Hours:

Unplanned Derated:

Unplanned Outage:
Scheduled outages are a combination of maintenance and planned outages.

Total number of hours a unit was electrically connected to the system.

State in which a unit is not capable of operation because of the failure of a component, external restriction, testing, work being performed, or some adverse condition.

Sum of all Forced Outage Hours, Maintenance Outage Hours, and Planned Outage Hours.

Sum of all hours experienced during Forced Deratings, Maintenance Deratings and Scheduled: Derating Extensions of any Maintenarce Deratings.

Sum of all hours experienced during Furced Outages, Maintenance Outages, and Scheduled Outage Extensions of any Maintenance Outages. 
Section 4

\author{
COLD-MODE SHAKEDOWN AND CALIBRATION
}

During the period from February 1987 through March 1989, the cold-mode shakedown phase of the testing program was completed. The purpose of the cold-mode shakedown and calibration phase was to verify the manufacturer's calibration curves for the various instruments and to develop calibration curves for instruments that did not have calibration information provided. Furthermore, specialized instrumentation and computer programs were developed to support the test program. The solids preparation laboratory was also commissioned and sample preparation procedures were developed.

\title{
4.1 INSTRUMENTATION CALIBRATIONS
}

Calibrations were performed on the following instrument systems:

- Air flow Instruments

- Coal Flow Weigh Belts

- Limestone Feeders

- Bottom Ash Weigh Bins

- Fly Ash flow Measurements

- Test Instrumentation

Activities in each of these tasks are discussed below.

\subsubsection{Air Flow Calibration}

Figure 4-1 shows a schematic of tre air system on the Nucla CFB. The primary air fan supplies air to the windbox, two sets of lower injection ports, three in-bed start-up burners, and miscellaneous air flows to one coal feeder, one loop seal expansion joint and one lower injection point for combustors $A$ and $B$. Air flow to the primary air fan is manually measured at the inlet of the fan by an annubar (in 1990 this measurement was added to the data highway). Air foils are used to measure the air flow to the windbox (GFT1C \& GFTID), the Lower injection ports (GFTIW, GFTIX, GFT1Y, \& GFT12), and the start-up burners (GFT2I, GFT2J, \& GFT2K for combustor A and GFT2L, GFT2M, \& GFT2N for combustor B). The miscellaneous air flows shown in Figure $4-1$ are not measured. The air flows to the loop seal injection point contain rotometers that were not calibrated. The loop seal expansion joint air flow is also not measured. Other unmeasured air flows include the vortex finder cooling air, limestone transport air, and miscellaneous instrument air flows. Only 


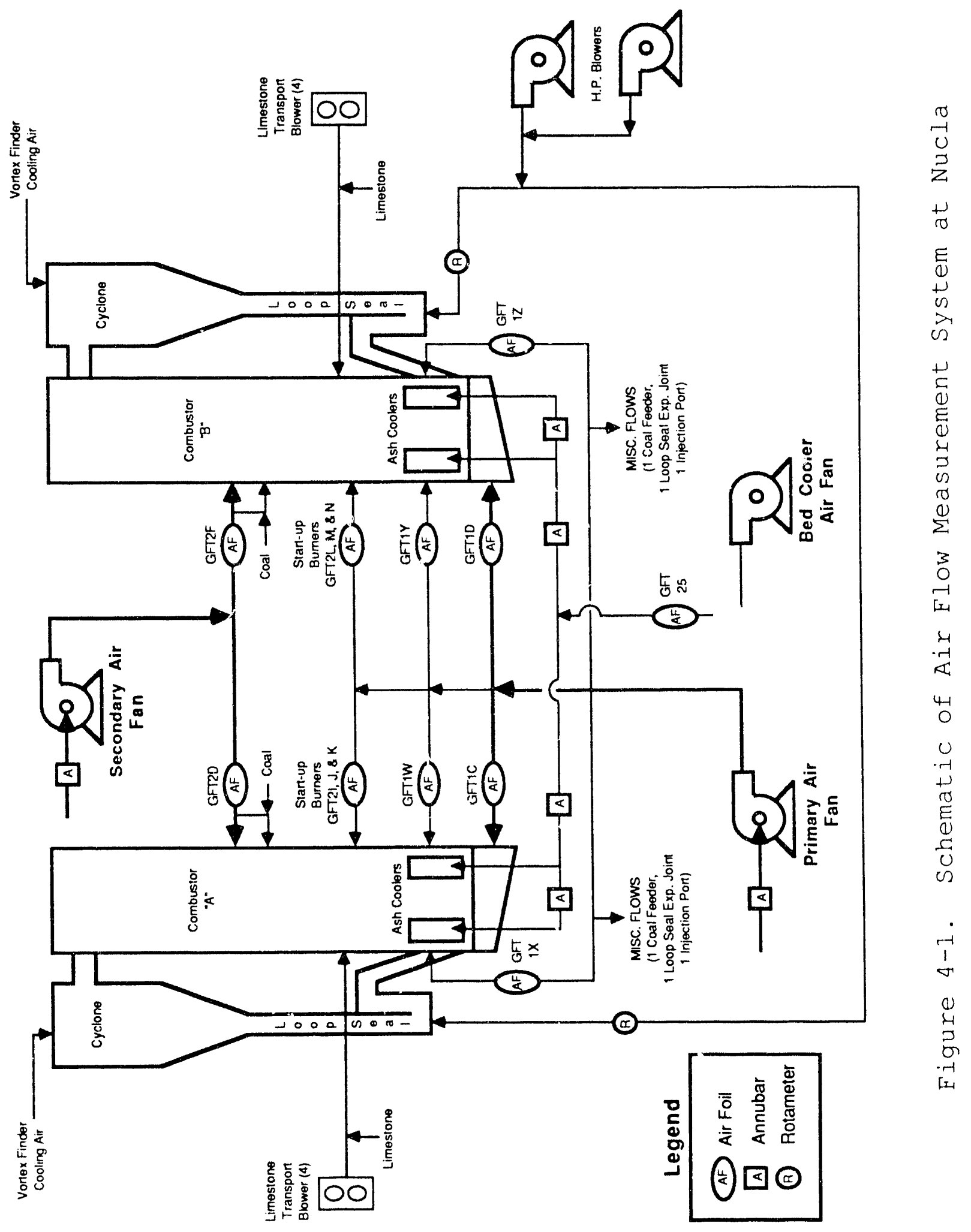


one of the six start-up burner air foils were calibrated. These are similar in design and were assumed to have the same calibration. This is a safe assumption with regard to unit performance testing since the contribution to the total air flow from the start-up burners is small.

The secondary air fan provides air to the secondary air injection ports and to the front wall coal feeders. The air flow to the secondary air fan is measured manually at the fan inlet by an annubar (this measurement was also added to the data highway in 1990). Air foils measure the flow of secondary air to each of the combustors (GFT2D \& GFT2F), including the coal feeder air. Two $100 \%$ high pressure blowers supply aeration air to the loop seals. Rotometers measure the air flow to the loop seals. The bottom ash cooling fan provides cooling air to the four bed ash coolers (two for each combustor). Air foil GFT25 measures the total air to all four bed ash coolers. Annubars measure the air flow to the individual ash coolers.

In addition to the air flow calibrations, an air foil is installed to measure the flue gas flow rate at the outlet of the new baghouse. This air foil was also calibrated as part of the air flow calibration program.

Air flow calibrations were performed using a Fechheimer probe which traverses the ducts upstream of the air foils. The Fechheimer probe is a air flow measuring device, similar to a pitot tube, that measures not only the velocity of the gas, but also measures the airectional component of the flow. Because of the probe's ability to measure the directional component flow, the Fechheimer is considered more appropriate than a pitot tube for this type of applicaticn. Two Fechheimer probes of different lengths were used for the air flow calibrations. Both probes were calibrated at the Babco:'s \& Wilcox Instrument Laboratory prior to use at Nucla.

Air flow calibrations were performed by measuring the velocity within the duct at several traverse points upstream of the air foil. Sample locations were installed in the ducts to conform to ASME Performance Test Code 4.4. Most of the traverses were performed at three flow rates in a V-nocch load ramp, where the gas flow rate was first increased and then decreased. This flow pattern was used to look for possible hysteresis in the flow elements.

Calibrations were performed under hot conditions when the unit was operating and cold conditions when the unit was shut down with just the fans operating. The following flow traverse calibrations were made during the reporting period:

- Hot calibration of combustor A windbox flow (GFT1C) at $50 \frac{5}{6}$ load during plant operation. 
- Hot calibrations of lower injection ports for both combustors (GFT1W, GFT1X, GFTIY, \& GFT1Z) at 50 load during plant operation.

- Cold caliorations were performed for the secondary air airfoils GFT2D \& GFT2F, and the combustor windbox flows GFT1C \& GFT1D.

- Hot calibrations at 40 and 75 percent load for the secondary air airfoils GFT2D \& GFT2F, for the combustor $A \& B$ windbox flows GFTIC \& GFTID, and for the lower injection nozzles GFT1W, GFT1X, GFT1Y, \& GFT1z.

- Hot calibration of the bottom ash cooling air airfoil, GFT25, at 40,27 , and $53 \mathrm{klb} / \mathrm{hr}$.

- Hot calibration of the new baghouse outlet duct at 40 and 80 percent load.

- Cold calibration of the bottom ash cooling air airfoil, GFT25, at 50, 75, and 100 percent of design flow in a Vnot ch load ramp.

- Cold calibration of the primary air aucts to the lower air injection ports (GFT1W, GFT1X, GFT1Y, and GFT1Z) at minimum flow, 100 percent design flow, and halfway between minimum and design load in a V-notch ramp.

- Hot calibration of the air duct to start-up burner 4C. This air foil was considered to be representative of all of the start-up burner airfoils. Traverses were performed at approximately 50,75,100,75, and 50 percent of design air flow, in that order. An additional traverse was performed under cold conditions at 15 percent of design air flow. This flow corresponds to the amount of cooling air passing through the burners under normal operations of the boiler.

Based on these calibration runs, constants within the plant control system and the performance calculation package were changed to correspond to the new calibrations. Adjustments were made to the DCS calculations for secondary air readings from both combustors (GFT2D\& GFT2F), the windbox primary air flow to both combustors (GFT1C and GFT1D), and the new baghouse out let gas flow rate. The calibrated flow rate correlations were used to calculate the flow rate of all air streams in the performance calculation package used by the demonstration program. In addition, the air flow inputs to the performance calculation package were pressure compensated while those on the plant's distributed control system are not.

A hand-held anemometer was used to measure the cooling air flow to the two cyclone vortex finders during hot operations 
with the unit at $55 \mathrm{MW}$. The air flow to each vortex finder was measured to be approximately $3,550 \mathrm{lb} / \mathrm{hr}$. Air flow into the vortex finder is drawn into the cyclones from the boiler house by the negative pressure in the cyclones. Therefore a constant value of $7,100 \mathrm{lb} / \mathrm{hr}$ was used for this flow rate in the performance calculations.

Most of the air flow instruments provided for the Nucla CFB are airfoil sensors. Figure 4-2 shows a schematic of an air foil. The configuration shown is typical of large ducts. In smaller ducts, such as the bottom ash cooling air duct, only the center foil is installed. The present installation at Nucla has a $\Delta \mathrm{P}$ transmitter installed between the total pressure tap and only one of the static pressure taps. There was concern that the use of only one static pressure tap could introduce an unacceptable measurement error due to maldistribution of air flow between both sides of the central foil.

In order to assess the potential error of this installation, a test was performed on the bottom ash cooling airfoil, GFT25. During this test, a manometer was hooked up between the unused static pressure tap and the total pressure tap. Pressure drop readings were taken at four air flow rates. Air flow rate data were also taken from the DCS. Table 4-1 contains the results of this test. The recorded DCS flow rate was used to back-calculate the $\Delta \mathrm{P}$ reading across the connected pressure taps. The actual flow rate shown in column 6 is based on the flow traverses that were described above and the $\Delta \mathrm{P}$ in column 2 (the used tap $\Delta \mathrm{P}$ ). These tests were conducted prior to correcting the DCS constants.

The results in Table 4-1 show that there is some error associated with the use of only one static pressure tap. However, the error appears to be systematic and nearly linear. The air flow calculated from the average $\Delta \mathrm{P}$ (column $5)$ is only slightly different than that obtained from the single pressure tap, and is not sufficient to account for differences between the indicated flow and actual flow. Nevertheless, since the error is systematic, the use of only one pressure tap with the new air flow calibrations should not introduce any new errors.

\subsubsection{Coal Flow Measurements}

The coal flow rate is used in several of the performance calculations and is an important input to boiler efficiency and material balances. Analysis of the performance calculations has shown that the coal feed rate should be measured to an accuracy of \pm 1 percent in order to achieve the desired accuracy of the performance calculations. 


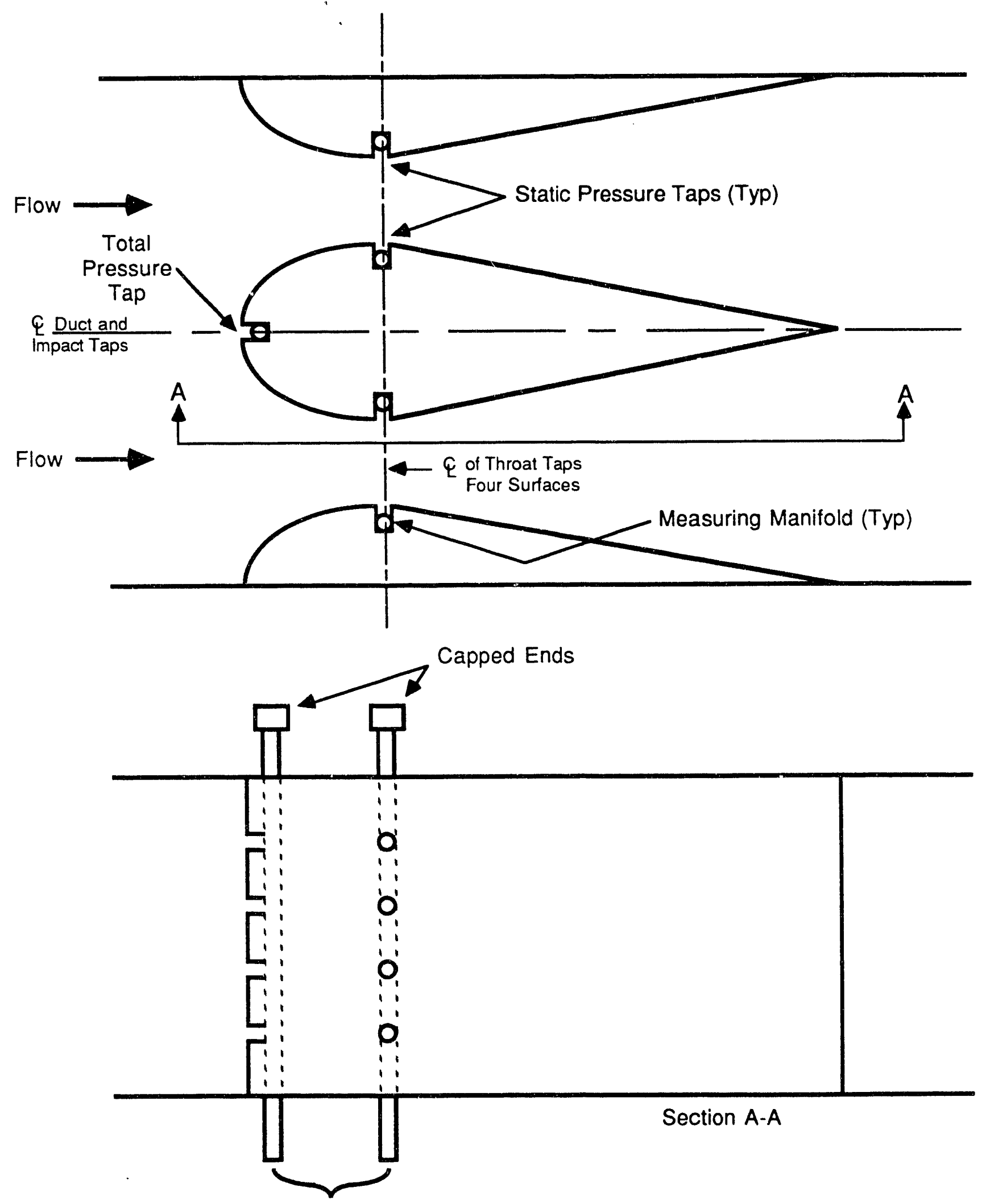

Manifolds to

Instruments

Figure 4-2. Typical Air Foil 
Table 4-1

Bottom Ash Cooling Air Flow GFT25

(Airfoil Pressure Differential and Flow Data)

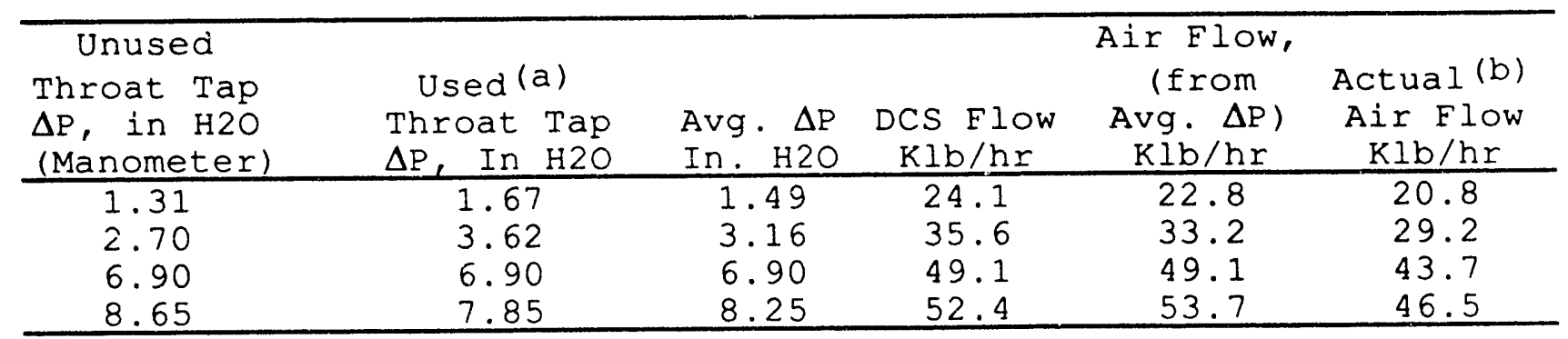

(a) Back calculated from DCS flow rate.

(b) Based on flow traverse correlations and column 2 .

The coal feed rate at Nucla is measured using six gravimetric weigh belt feeders. A review of three calibration options available for this type of feeder indicated that calibration using test chains was required to insure this level of accuracy. Subsequently, the demonstration program purchased a calibrated test chain. To facilitate the frequent calibrations required by the test program, a large wooden rolling dolly was built to assist installing and removing the test chain from the rear of each coal feeder. Furthermore, a centering device was built to facilitate alignment of the test chain during calibration.

After initial calibration trials, the calibration procedures were modified to include the following four step procedure:

- Tare calibration

- Test weight (chain)

- Electronic factoring to the test chain

- Electronic calibration with an applied voltage.

Initially this procedure was employed monthly during the demonstration program. Later it was found that the calibrations only needed to be performed once every 60 days to yield coal feed readings that were within the \pm 1 percent error band required by the test program. Data from the calibrations of the coal feeders were used to establish the measurement bias of the individual coal feeders.

\subsubsection{Limestone Feeder Calibration}

The limestone feed rate at Nucla is regulated by a variablespeed eccentric shaker that feeds limestone over a vibrating cone through an adjustable gap formed by sector plates (see section 12). The flow rate is measured by a loss-in-weight system that uses load cells mounted on the hopper above the 
shaker cone. The weight change from two successive readings is divided by the time between the readings to produce the feed rate.

To calibrate the limestone feeders, weigh chains are hung onto the hoppers and the output signal of the load cells is adjusted to match the weight gain. A length of ship anchor chain was purchased and cut into lengths that could be handled by a technician. These chains were then weighed and tagged. Hangers were also installed onto the four legs of the limestone hoppers to hold the test chains.

After repeated efforts to correct various malfunctions in the weigh system, a final calibration confirmation was performed during June and July, 1988. Table 4-2 shows the results of these calibration runs. The calibrations showed that the limestone feeder for combustor $B$ was more accurate than for combustor $A$. The average error for $A$ feeder is 16 pounds and for B Feeder is 4.5 pounds. When compared to the capacity of the load cells, these errors correspond to a $0.5 \%$ error for feeder $A$ and a $0.2 \%$ error for feeder $B$, which is within the accuracy limits required for the demonstration program of \pm $1 \div$

Initially limestone calibrations were performed monthly during the demonstration program. It was later found that the calibrations could be performed once every 90 days. Errors recorded during these monthly calibrations were used to establish the measurement biases for the limestone feeders.

$$
\text { Table 4-2 }
$$

LIMESTONE WEIGH FEEDER CALIBRATION

Feeder A June 30, 1988

\begin{tabular}{ccccc}
\hline Weigh Hopper & Hectual & Actins & Error \\
Weight & Reading & Weight Added & |Difference & \begin{tabular}{c} 
o \\
\hline
\end{tabular} \\
\hline 0 & 0 Bouncing & 0 & 0 & - \\
4 & 353 & 374 & 21 & 5.6 \\
0 & 0 & 0 & 0 & - \\
4 & 350 & 374 & 24 & 6.4 \\
8 & 693 & 705 & 12 & 1.7 \\
4 & 347 & 366 & 19 & 5.2 \\
0 & 13 & 0 & 13 & - \\
\hline
\end{tabular}




\section{Table 4-2 (cont.) \\ LIMESTONE WEIGH FEEDER CALIBRATION \\ Feeder B July 5, 1988}

\begin{tabular}{ccccc}
\hline & Weigh Hopper & \multicolumn{1}{c}{ Actual } & & Error \\
Chains & Weight Reading & Weight Added & Difference & $\frac{8}{0}$ \\
\hline 0 & 0.6 & 0 & 0.6 & - \\
4 & 364 & 363 & 1 & 0.3 \\
0 & 0 & 0 & 0 & - \\
4 & 356 & 363 & 7 & 1.9 \\
8 & 700 & 705 & 5 & 0.7 \\
4 & 354 & 363 & 9 & 2.5 \\
0 & 0 Steady & 0 & 0 & - \\
\hline
\end{tabular}

\subsubsection{Bottom Ash Weigh Bin Calibration}

The bottom ash flow rate is measured by using a weigh bin that receives bed material from both bed drain coolers on a combustor. The weigh bin fills with bed material to a pre-set weight and then begins an emptying cycle down to a pre-set level. The weight of ash is determined starting at the time when the emptying cycle is complete. The weight of the ash added during the fill cycle is measured every 15 minutes until the high level is reached and the emptying cycie begins. The total. weight added and the total time between cycles is used to calculate the average bed drain rate for a performance test.

Calibration of the bed drain weigh bin involves checking the accuracy of the load cells in a similar fashion to the limestone feeders. Chains, weighing a total of 1,648 1bs, were added to each hopper when it was filled with three different quantities of bed materlal. The weight gain on the hopper was recorded, then the chains were removed and the weight recorded again. This process was repeated at least two times at each level of bed material. Table $4-3$ shows the results of this calibration procedure. The average error on the weight readings for hopper $A$ was 16 pounds, and the average error on the weight readings for hopper $B$ was 19 pounds. These errors correspond to less than $0.3 \%$ of the full scale reading for each hopper.

Initially the bottom ash weigh hopper was calibrated on a monthly basis during the demonstration program. It was later found that the calibrations only needed to be performed once every 120 days. Errors in the weight readings were used to establish the instrument biases for these two weight measurement devices. 
Table 4-3

BOTTOM ASH HOPPER CALIBRATION DATA

Hopper A April 22, 1988

\begin{tabular}{|c|c|c|c|c|c|c|c|c|}
\hline $\begin{array}{l}\text { Initial } \\
\text { weight }\end{array}$ & $\begin{array}{r}\text { Wei } \\
\text { Cha } \\
\text { or }\end{array}$ & $\begin{array}{l}\text { ght Afte } \\
\text { ins Adde } \\
\text { Removed }\end{array}$ & & $\begin{array}{c}\text { Weight } \\
\text { Gain }\end{array}$ & IDif & Efere & encel & \& Error \\
\hline 480 & & 2110 & & 1630 & & 18 & & 1.09 \\
\hline 2110 & & 480 & & -1630 & & 18 & & 1.09 \\
\hline 480 & & 2130 & & 1650 & & 2 & & 0.12 \\
\hline 2130 & & 480 & & -1650 & & 2 & & 0.12 \\
\hline & Hopper & Filled & to & $2100 \mathrm{lbs}$ & With & Bed 1 & Material & \\
\hline 2100 & & 3750 & & 1650 & & 2 & & 0.12 \\
\hline 3750 & & 2065 & & -1685 & & 37 & & 2.25 \\
\hline 2065 & & 3750 & & 1685 & & 38 & & 2.25 \\
\hline 3750 & & 2080 & & -1670 & & 22 & & 1.33 \\
\hline & Hopper & Filled & to & $36201 \mathrm{bs}$ & With & Bed & Material & \\
\hline 3620 & & 5280 & & 1660 & & 12 & & 0.73 \\
\hline 5280 & & 3650 & & -1630 & & 18 & & 1.09 \\
\hline 3650 & & 5300 & & 1650 & & 2 & & 0.12 \\
\hline 5300 & & 3650 & & -1650 & & 2 & & 0.12 \\
\hline & Hopper & Filled & to & $5340 \mathrm{lbs}$ & With & Bed & Material & \\
\hline 5304 & & 7010 & & 1670 & & 22 & & 1.33 \\
\hline 7010 & & 5340 & & -1670 & & 22 & & 1.33 \\
\hline 5340 & & 7010 & & 1670 & & 22 & & 1.33 \\
\hline
\end{tabular}

Hopper B February 22, 1988

\begin{tabular}{|c|c|c|c|c|c|c|c|c|}
\hline $\begin{array}{l}\text { Initial } \\
\text { weight }\end{array}$ & $\begin{array}{l}\text { Weic } \\
\text { Cha } \\
\text { or }\end{array}$ & $\begin{array}{l}\text { ght Afte } \\
\text { ins Adde } \\
\text { Removed }\end{array}$ & & $\begin{array}{c}\text { Weight } \\
\text { Gain }\end{array}$ & IDif & Eere & ncel & $\because$ Error \\
\hline-67 & & 1630 & & 1697 & & 49 & & 2.97 \\
\hline 1630 & & -67 & & -1697 & & 49 & & 2.97 \\
\hline-67 & & 1580 & & 1647 & & 1 & & 0.06 \\
\hline 1580 & & -67 & & -1647 & & 1 & & 0.06 \\
\hline & Hopper & Filled & to & $1550 \mathrm{lbs}$ & With & Bed & Material & \\
\hline 1550 & & 3245 & & 1695 & & 47 & & 2.85 \\
\hline 32.45 & & 1600 & & -1645 & & 3 & & 0.18 \\
\hline 1600 & & 3260 & & 1660 & & 12 & & 0.73 \\
\hline 3260 & & 1610 & & -1650 & & 2 & & 0.12 \\
\hline & Hopper & Filled & to & $3195 \mathrm{lbs}$ & With & Bed & Material & \\
\hline 3195 & & 4895 & & 1700 & & 52 & & 3.16 \\
\hline 4895 & & 3230 & & -1665 & & 17 & & 1.03 \\
\hline 3230 & & 4910 & & 1680 & & 32 & & 1.94 \\
\hline 4910 & & 3245 & & 1665 & & 17 & & 1.03 \\
\hline & Hopper & Filled & to & $4740 \mathrm{lbs}$ & with & Bed & Material & \\
\hline 4740 & & 6390 & & 1650 & & 2 & & 0.12 \\
\hline 6390 & & 4740 & & -1650 & & 2 & & 0.12 \\
\hline 4740 & & 6390 & & 1650 & & 2 & & 0.12 \\
\hline
\end{tabular}




\subsubsection{Fly Ash Flow Measurement}

During the Phase I test period, the fly ash metering system was modified extensively in an effort to obtain an accurate measurement of the flow rate and a representative sample of fly ash. Figure 4-3 shows a schematic of the fly ash system at Nucla following modifications. The problem with measurement of the flow rate and with the representativeness of the sample stems from the fact that fly ash is collected at 34 separate locations throughout the plant. The air heater and economizer each have two hoppers that collect fly ash. The new baghouse has 12 hoppers and baghouses 1, 2, and 3 each have six hoppers that collect fly ash. Each of these hoppers is equipped with a gate valve that periodically dumps fly ash into a vacuum ash transport system where it is delivered to the fly ash weigh bin. The hoppers are sequentially emptied into the vacuum ash transport system.

Experience has shown that the composition and quantity of ash collected in each of the ash hoppers differs sufficiently, such that none of the hoppers are representative of all of the fly ash. Therefore, a full-cut sampler was installed to continuously sample the fly ash leaving the weigh bin.

The fly ash flow rate meter is a schenck impact flow meter. This meter measures the flow rate of fly ash that hits a deflector plate as it falls out of the fly ash weigh bin. Numerous attempts to obtain a reliable calibration of the fly ash flow meter failed to produce a reliable and repeatable signal.

In order to overcome the difficulties in sbtaining a fly ash flow rate, an alternative method of calcuiating the flow rate was developed. The calculation involves ail inerts balance around the boiler. Inerts are defined as all constituents except $\mathrm{CO}_{2}$ and $\mathrm{SO}_{3}$ in the limestone, coal ash, bottom ash, and fly ash. Inerts enter the boiler through the coal stream and the limestone stream.

Inerts In

Coal inerts, $1 \mathrm{~b} / \mathrm{hr}=\frac{\mathrm{CI}}{100} \times$ coal flow

Limestone inerts, $1 \mathrm{~b} / \mathrm{hr}=\frac{\mathrm{LI}}{100} \times$ limestone flo:

Where: $C I=\frac{\circ}{\circ}$ ash, as fired coal

$L I=100-\mathrm{CO} 21$

$\mathrm{CO}_{1}=\frac{\circ}{\circ} \mathrm{CO}_{2}$ in limestone 
Air Heater Hoppers (2)
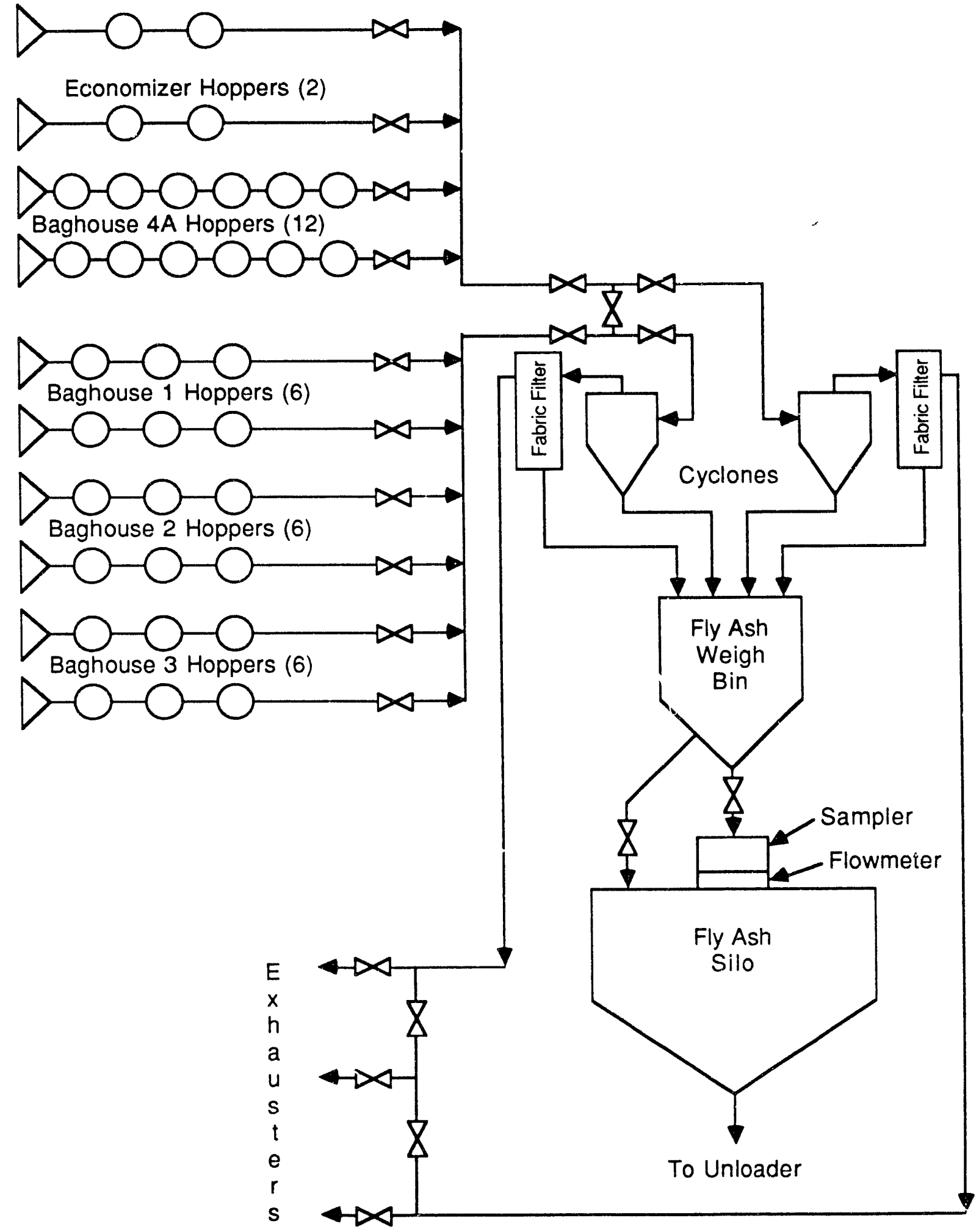

Figure 4-3. Schematic of Revised Fly Ash

collection and Measurement system 
Inerts leave the boiler via the bed ash stream and the fly ash stream.

Inerts out

Bottom ash inerts, $1 \mathrm{~b} / \mathrm{hr}=\frac{\mathrm{BI}}{100} \times$ Bottom Ash Elow

Fly ash inerts, $1 \mathrm{~b} / \mathrm{hr}=\mathrm{coal}$ inerts + limestone inerts

- bottom ash inerts

Fly Ash flow rate, $1 \mathrm{~b} / \mathrm{hr}=100 \times \frac{\text { fly ash inerts }}{\text { FAI }}$

Where: $\quad B I=100-\operatorname{CO} 2 b-\frac{80}{32} s_{b}-\left(C_{b}-\frac{12}{44} \operatorname{co} 2 b\right)$

$E A I=100-\operatorname{Co} 2 f a-\frac{80}{32} S_{f a}-\left(C_{f a}-\frac{12}{44} \mathrm{CO} f a\right)$

$\mathrm{CO} 2 \mathrm{~b}, \mathrm{fa}=\frac{\mathrm{C}}{\mathrm{C}} \mathrm{CO}_{2}$ in bed ash or fly ash

$\mathrm{Sb}, \mathrm{fa}_{\mathrm{a}}=\frac{\mathrm{c}}{\mathrm{c}}$ Sulfur in bed ash or fly ash

$\mathrm{Cb}_{\mathrm{b}}, \mathrm{fa}=\frac{\circ}{\circ}$ Carbon in bed ash or fly ash

Note that the carbon in the bed material and fly ash is reported as total carbon and includes carbon contained in the $\mathrm{CO} 2$.

This calculation procedure has been incorporated into the performance calculations. The uncertainty analysis performed during the hot mode shakedown tests showed that the above equations gave a satisfactory estimate of the fly ash flow rate within the accliacy required for performance testing.

\subsubsection{Test Instrumentation}

A detailed list of all of the instrumentation required by the demonstration progsam was developed during the reporting period. This iist included all instrumentation needed for steady-state performance tests and for dynamic load following tests. Included in the 1 ist is the required accuracy for each instrument, the calibration schedule for that instrument, the measurement range, and the last calibration date. Appendix A cnntains a copy of the instrumentation calibration schedule.

In developing the calibration schedule, consideration was given to the contribution of a particular instrument to calculated results uncertainties in the performance calculation package. The calibration schedule was modified on several occasions during the test program after it was found that certain instruments remained in calibration or were not significant contributors to the final results uncertainties. 
The calibration data from the instruments also provided an estimate of the instrument bias, which is used in the performance calculation software to calculate the final results uncertainties. The instrument drift between calibration periods was averaged on a sum squared basis to determine the average drift of the instrument. This value was substituted for the instrument bias that was originally based on manufacturer's specification data. In many cases, this average drift exceeded the manufacturer's accuracy claim. In others, the instrument drift was found to be less than the manufacturer's accuracy.

\subsection{SYSTEM COMMISSIONING}

As a prelude to the demonstration program, several specialized sampling systems were developed and/or commissioned. Isokinetic sampling probes were needed to measure the baghouse inlet and outlet dust loadings as part of the baghouse monitoring program. Freeboard gas analysis probes were required to sample the flue gas at various points within the combustor as part of the solids and gas mixing test plan discussed in section 9. A gas analysis system was required to analyze flue gas for oxygen, carbon dioxide, nitrogen oxides, sulfur dioxide, and carbon monoxide at the exit of the control boundary used in the performance calculations to calculate boiler efficiency. Several systems were developed to sample the various solid streams in the plant to ensure that representative samples were obtained. A sample preparation laboratory was established to process the samples prior to off-site analysis. Finally, the VAX computer was commissioned and software was developed in support of the demonstration program. This section documents the commissioning of these systems for the demonstration program, and provides details of each system.

\subsubsection{Sampling Probes}

The demonstration program utilizes three specialized sample systems to test either the solids loading or the chemical composition of the flue gas. These three systems are:

- Isokinetic sampling probes to periodically measure the solids loading in the flue gas.

- Freeboard Gas Analysis System (FGAS) probes to periodically measure the gas composition in the freeboard of the combustor.

- Economizer Exit Gas Analysis System (EGAS) probes to continuously measure the flue gas concentrations at the economizer exit.

During the initial phases of the test program all three systems were designed, procured, and placed into service. 


\subsubsection{Isokinetic Sampling Probes}

The isokinetic sampling probes were used to measure the dust loading at the inlet and outlet of the baghouse. At the baghouse inlet, the dust loading was expected to be quite high (on the order of 10 to $12 \mathrm{gr} / \mathrm{dscf}$ ). Two fiitration options were evaluated for the isokinetic sampling probes: an in-duct filtration method, and an external filtration method. The in-duct filtration method is simpler to operate and less expensive. However, there was some concern that this type of probe would be subject to plugging due to the high dust loadings. In order to evaluate the applicability of this option, an in-duct filtration probe was obtained on loan from an off-site contractor for trial tests.

Tile sampling tests have shown that in-duct filtration performs satisfactorily without plugging for a substantial portion of the expected test duration. Accordingly, a complete sampling train was purchased for the demonstration program. The train consisted of the following equipment:

- $\quad 1$ sampling console
- $\quad 1$ sample pump
- $\quad 3$ stailical cord
- $\quad 1$ sample probe
- $\quad 1$ thimble filter holders
- $\quad 4$ nozman filter holder

Figure 4-4 shows a schematic of the isokinetic sampling train.

Two plant technicians were trasned to operate the sampling equipment and to perform the isokinetic sampling. After approximately two weeks of training and working with the equipment, the sampling crew attained full proficiency with the isokinetic equipment. Once training was complete, the sampling team was subjected to a detailed audit of their procedures and techniques. The audit did not reveal any problems that would affect the accuracy of the results.

To demonstrate the repeatability of the sampling process, the sampling team performed two separate runs back-to-back while the unit was at a stable load. The results of these runs are shown in Table 4-4. These tests showed that results are repeatable to within $1 \%$.

\subsubsection{Ereeboard Gas Analysis System (EGAS)}

The FGAS probe is designed to sample the gas composition across two traverse planes inside combustor $B$ at elevations $44^{\prime} 6^{\prime \prime}$ or 86'6". Gas sampling is possible from near the 


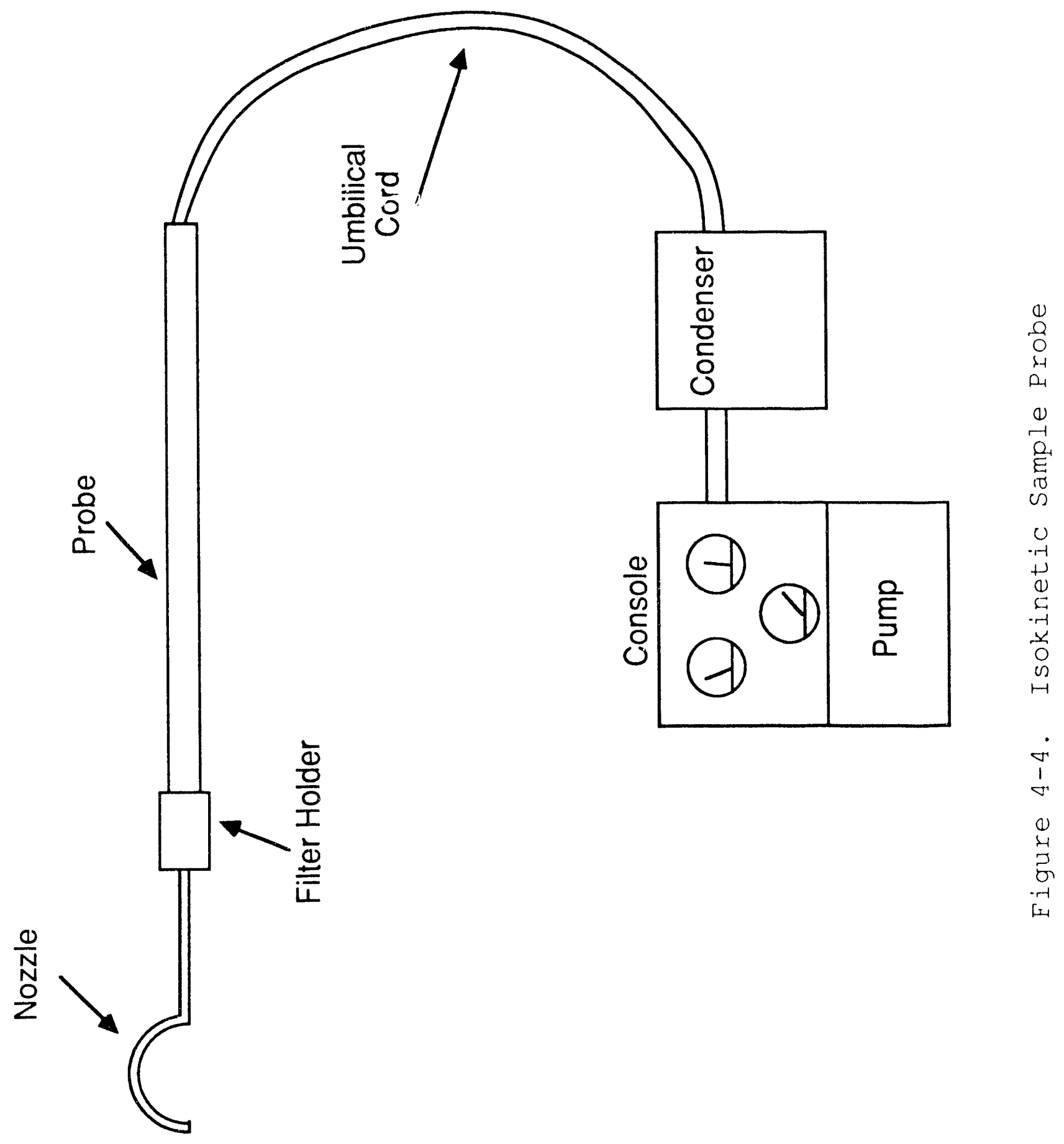


outside wall to the centerline of the combustion chamber, for a total traverse distance of 10'2". The probes are watercooled and were originally developed by 'TVA and EPRI for use in the analysis of a bubbling bed combustor freeboard. The current probe has been modified to incorporate site specific conditions of the Nucla CFB.

Table 4-4

ISOKINETIC SAMPLING REPEATABILITY TEST RESULTS

Location: Air Heater Exit

\begin{tabular}{lcc}
\hline Date & $1 / 3 / 89$ & $1 / 3 / 89$ \\
Start Time & $12: 00$ & $14: 30$ \\
Flue Gas Moisture, \% & 7.29 & 7.3 \\
Velocity, ft/sec DSFM & 33.69 & 34.43 \\
Volumetric Flow, DSCFM & 147,268 & 149,874 \\
Particulate Loading, gr/dscf & 10.31 & 10.44 \\
Particulate Mass Flow, 1b/hr & 13,645 & 13,412 \\
Percent Isokinetic & 100.6 & 100.5 \\
\hline
\end{tabular}

The probe has a water-cooled outside shell and an electrically heated gas sample tube which is connected to the gas analyzers (described in section 4.2.2) via a heated sample line. Suction is provided by the gas sample pump in the gas analyzer cabinet and pulls the combustion gasses from the combustion chamber. An air aspirated knife gate isolates the penetration through the water walls at the two locations.

In operation, the combustion gasses first pass through an unheated quench tube where the gas temperature is reduced to less than $400^{\circ} \mathrm{F}$, the maximum operating temperature of the sample line. The electrically heated sample line then maintains the sample temperature above the acid dew point of the gas (set point is $350^{\circ} \mathrm{F}$ ) to minimize condensation and corrosion of the sample line. The gas is sampled at a flow rate of approximately 7 liters/min. The sample passes through a cyclone separator and a fabric filter to remove any entrained solids. Both filters are contained within a heated cabinet. The gas sample then passes through another heated sample line to the gas analyzers.

A cooling water flow rate of between five and twenty gpm is required to maintain internal temperatures below $175^{\circ} \mathrm{F}$. Seven thermocouples are included in the system to allow the sampling team to monitor the operating conditions inside the probe. Cooling water passes through the length of the probe and returns to the outlet nozzle before being disposed of in the plant drain system. Water flow control is maintained by a manual control valve on the cooling water inlet line.

Initial use of the FGAS probes met with some difficulty due to plugging of the probe. This was traced to two separate 
causes. The first was a buildup of particles in the diaphragm valve located in the sample line. This was resolved by moving the valve downstream of the cyclone separator where the particulates are significantly lower. The second problem was caused by blockage of the line by a single large particle. This was solved by adding an orifice at the inlet and by replacing some of the teflon tubing with stainless tubing. With these modifications, the FGAS probe was capable of operating for over two hours without plugging, which is the time needed to complete a traverse.

Results of the FGAS traverses are contained in section 9 of this report.

\subsubsection{Economizer Exit Gas Analysis System (EGAS)}

The economizer exit gas sample is an average of sixteen sample points which are mechanically interconnected in a heated valve averaging enclosure which is located between the two inlet ducts to the tubular air heater at an elevation of 94'. The two inlet ducts to the air heater are divided into eight $2 ' x 4^{\prime}$ grids with a gas sample point located in the center of each grid. The samples are withdrawn by heated lines that terminate in the sample averaging cabinet. The EGAS averaging cabinet, and all of the sample lines, are heated to prevent acid dew point formation in the sample train. A single heat-traced line carries the gas sample to the gas analyzers.

Gas sample flow rates through each of the 16 probes are equalized by matching the vacuum on each sample line with a Hastelloy needle valve. The system also allows any individual probe, or any combination of probes to be sampled. For "split" combustor tests described in section 6, gas samples were collected separately for each air heater inlet duct, i.e. each sample was the average of 8 probes.

Each of the sixteen gas sample points also has a thermocouple installed next to the sample probe. The eight temperatures in each duct are averaged locally in a thermocouple averaging box. The two averages are available as separate values on the DCS. The outlet of the tubular air heater contains eighteen thermocouples arrayed in a similar configuration to the inlet temperature grid. The two average temperatures are also available on the DCS.

\subsubsection{Gas Analyzers}

The gas analyzer equipment is located at elevation 24 ' on the turbine deck. The equipment includes a gas conditioning cabinet, and an air conditioned cabinet that contains the gas analyzers and a six pen strip chart recorder. An electrical output signal from each analyzer corresponding to the gas 
concentration is sent to the DCS. The strip chart recorder also displays the outputs from the analyzers. Other output signals are available for alarms and range settings of the various analyzers. The gas analyzers used in this installation are listed below along with their measurement method. The instruments are listed for the purposes of providing complete information regarding the test program and do not necessarily represent an endorsement of this equipment by CUEA or the DOE.

- oxygen Beckman Industrial Corporation Model 755 Paramagnetic measurement system.

- Carbon Monoxide and Carbon Dioxide Beckman Industrial Corporation Model 864 Infrared absorption measurement system.

- $\mathrm{NO}_{\mathrm{Y}}$ Beckman Industrial Corporation Model 951A Chemiluminescence measurement system.

- Sulfur Dioxide Western Research Model 721A Energy absorption by a sample cell.

Calibration of the gas analyzers is performed by flowing premixed calibration gasses through the sample system at regular intervals. The calibration gasses are stored in high pressure cylinders and are connected to the analyzers by a manifold provided with the equipment. Five gas cylinders are required to store all of the required gas mixtures. Table 45 lists the calibration gas mixtures.

\subsubsection{Solid Sampling system}

For the performance calculations, all of the solid streams entering and leaving the boiler were sampled and analyzed. In order to sample these streams, either full-cut or fullcross sampling devices were used except for limestone sampling. 
Table 4-5. E/FGAS Analyzer Calibration Gasjes

\begin{tabular}{|c|c|c|}
\hline Bottle & Gas & Range \\
\hline 1 & $\mathrm{~N}_{2}$ for zero reference & $\mathrm{N}_{2}>99.8 \%$ \\
\hline 2 & Low span $\mathrm{O}_{2}, \mathrm{CO}, \mathrm{CO}_{2}$ & $\begin{array}{l}\mathrm{O}_{2} 8 \% \\
\mathrm{CO} 400 \mathrm{ppm} \\
\mathrm{CO}_{2} 4 \frac{\circ}{5} \\
\text { Balance } \mathrm{N}_{2}\end{array}$ \\
\hline 3 & $\mathrm{High}$ span $\mathrm{O}_{2}, \mathrm{CO}, \mathrm{CO}_{2}$ & 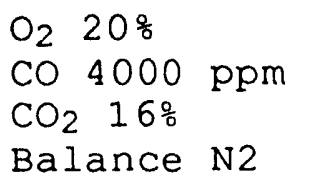 \\
\hline 4 & Low $\operatorname{span} \mathrm{SO}_{2}, \mathrm{NO}_{\mathrm{x}}$ & $\begin{array}{lll}\mathrm{SO}_{2} 400 & \mathrm{ppm} \\
\mathrm{NO}_{\mathrm{x}} 400 & \mathrm{ppm} \\
\text { Balance } & \mathrm{N}_{2}\end{array}$ \\
\hline 5 & $\mathrm{High}$ span $\mathrm{SO}_{2}, \mathrm{NO}_{\mathrm{X}}$ & $\begin{array}{l}\mathrm{SO}_{2} 1200 \mathrm{ppm} \\
\mathrm{NO}_{\mathrm{x}} 800 \mathrm{ppm} \\
\mathrm{Balance} \mathrm{N}_{2}\end{array}$ \\
\hline
\end{tabular}

Coal is sampled using full-cut flow diverters installed on the front of each of the six weigh belt feeders. Initial operation of the full-cut diverter sampler revealed some problems associated with fines accumulation in the sample line and with fine loss due to the dust suppression system. These problems were solved by the addition of close clearance seals on the sample valve, and an air actuated damper on the dust suppression vacuum line to isolate the feeder being sampled.

Limestone is sampled using two thief samplers that withdraw a sample from the limestone weigh bins. The sample point was originally located near the bottom of the weigh bins. However, problems with pressurization of the weigh bins caused the sample points to be relocated near the top of the weigh bins.

Bed ash is sampled using thief probes located below each of the four bottom ash coolers. No major problems were experienced with these sample points.

The fly ash sampler was described in section 4.1 .5 of this report. The continuous sampler has been found to give a reliable, representative sample of the fly ash. 


\subsubsection{Sample Preparation Laboratory}

In order to measure the performance of a fluidized bed boiler, a number of solid samples need to be taken during the performance tests. These samples include:

- Coal

- Limestone

- Bed ash

- Ely ash

Section 4.2.3 described the manner in which the solid samples are withdrawn from the boiler during the performance tests. In this section, the steps taken to prepare and analyze the solid samples will be discussed.

In order to minimize the cost of the sample laboratory at Nucla, it was decided that most $0:$ the chemical analyses required by the performance calculations would be performed at an off-site laboratory. Nevertheless, several steps were needed to insure that a representative sample reached the chemical laboratory. The Chemical Analysis Report and the Physical Analysis Report contained in Table 4-6 of Section 4.2.5.1 lists the chemical and physical analyses required by the performance calculations. The sample preparation laboratory at Nucla performs the analyses for:

- Size distribution

- Air dry moisture

- Bulk density

- Particle density

- Sulfur

The remainder of the analyses listed in Table 4-6 are performed by an outside analytical laboratory. Sulfur is also determined by the outside laboratory.

\subsubsection{Ceal Preparation}

Figure 4-6 shows the coal preparation flow sheet. Coal is sampled from the six coal feeders at Nucla. Approximately 5 gallons of coal are sampled from each feeder. All six samples taken at the same time are composited to form one coal sample for the test period. The sample is then riffled down to form a 20 pound analytical sample and a 5 pound physical analysis sample.

The 20 pound analytical sample is crushed to minus 30 mesh. Five pounds of this sample are then allowed to air dry at $40^{\circ} \mathrm{C}$ for six hours. Next the air dried analytical sample is riffled and one quart is stored in a sealed, labeled container as an archive sample. The remaining 200-300 grams are pulverized to minus 200 mesh and blended. A small amount 


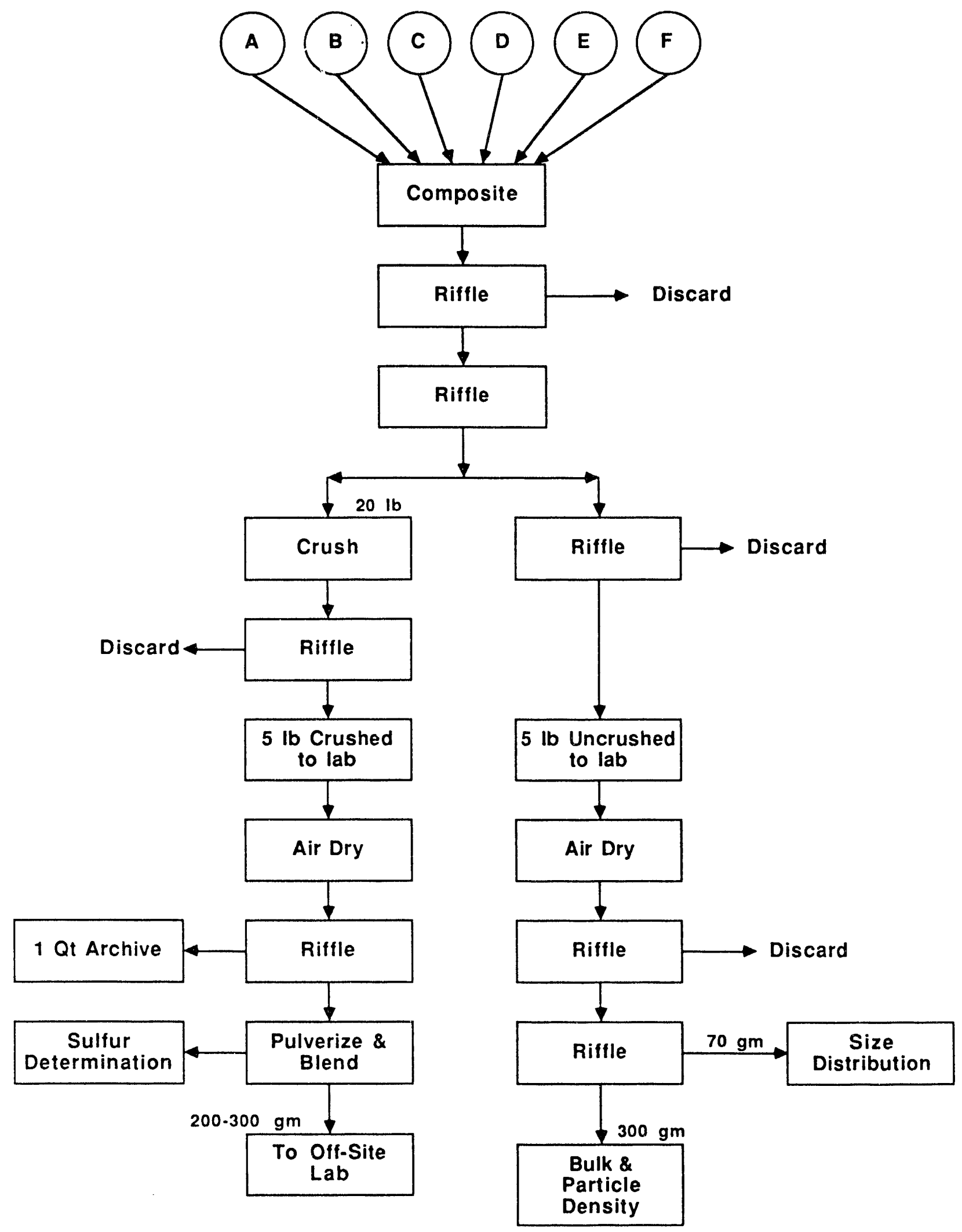

Eigure 4-5. Coal Preparation Flow sheet 
of this sample is periodically analyzed in a Leco sulfur analyzer. The remainder of the sample is shipped to the analytical laboratory in a sealed container.

The five pound physical analysis sample is weighed and air dried for 6 hours at $40^{\circ} \mathrm{C}$. The air dried sample is then reweighed and the air dry moisture is determined. Next the sample is riffled to give a 70 gram sample that is analyzed for size distribution and a 300 gram sample that is used for bulk and particle density determinations.

\subsubsection{Iimestone Preparation}

Figure 4-6 shows the flow sheet for the laboratory preparation of the limestone sample. Approximately five pounds of limestone are withdrawn from each of the two limestone feeders. These two samples are composited to give the limestone gross composite sample for the time period. The ten pound sample is then oven dried to determine the total moisture of the limestone.

Next the limestone sample is passed through a series of riffles to produce a 1 quart archive sample, a 300 gram sample for particle and bulk density determination, a 70 gram sample for size distribution analysis, and a 200 to 300 gram analytical sample. The analytical sample is pulverized to minus 200 mesh, blended, and sent to the outside laboratory for analysis.

\subsubsection{Bottom Ash Preparation}

Figure 4-7 shows the flow sheet for the preparation of the bottom ash sample. Five pound samples are withdrawn from each of the four bed ash discharge points. These four samples are composited to form the sross composite bottom ash sample for the sampling period. The gross composite sample is riffled to give about 400 grams of material for the physical analyses. The remainder of the bottom ash sample is crushed to minus 30 mesh. The crushed sample is then riffled to yield a 1 quart archive sample and a 200-300 gram analytical sample. The 200-300 gram analytical sample is pulverized to minus 200 mesh. Some of this material is analyzed in the Leco sulfur analyzer at Nucla, and the rest is sent off site for chemical analysis.

\subsubsection{Ely Ash Preparation}

Figure 4-8 shows the flow sheet for the preparation of the fly ash sample. A single fly ash sample is obtained from the continuous fly ash sampler during a sample time period. This sample is riffled to yield a 1 quart archive sample, a 300 gram sample for bulk and particle density determination, and a 200-300 gram analytical sample. The analytical sample is 


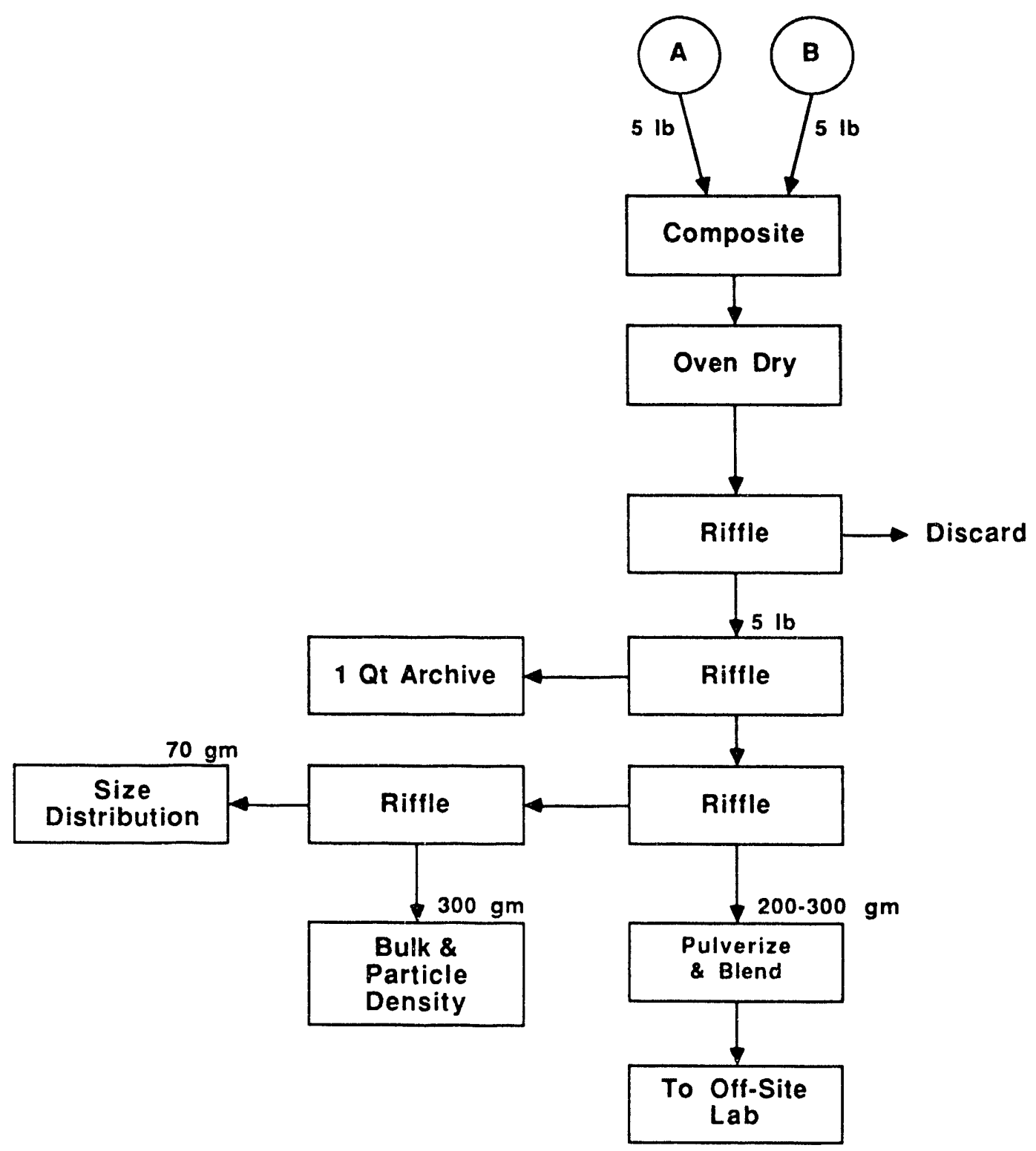

Figure 4-6. Limestone Preparation Flow sheet 


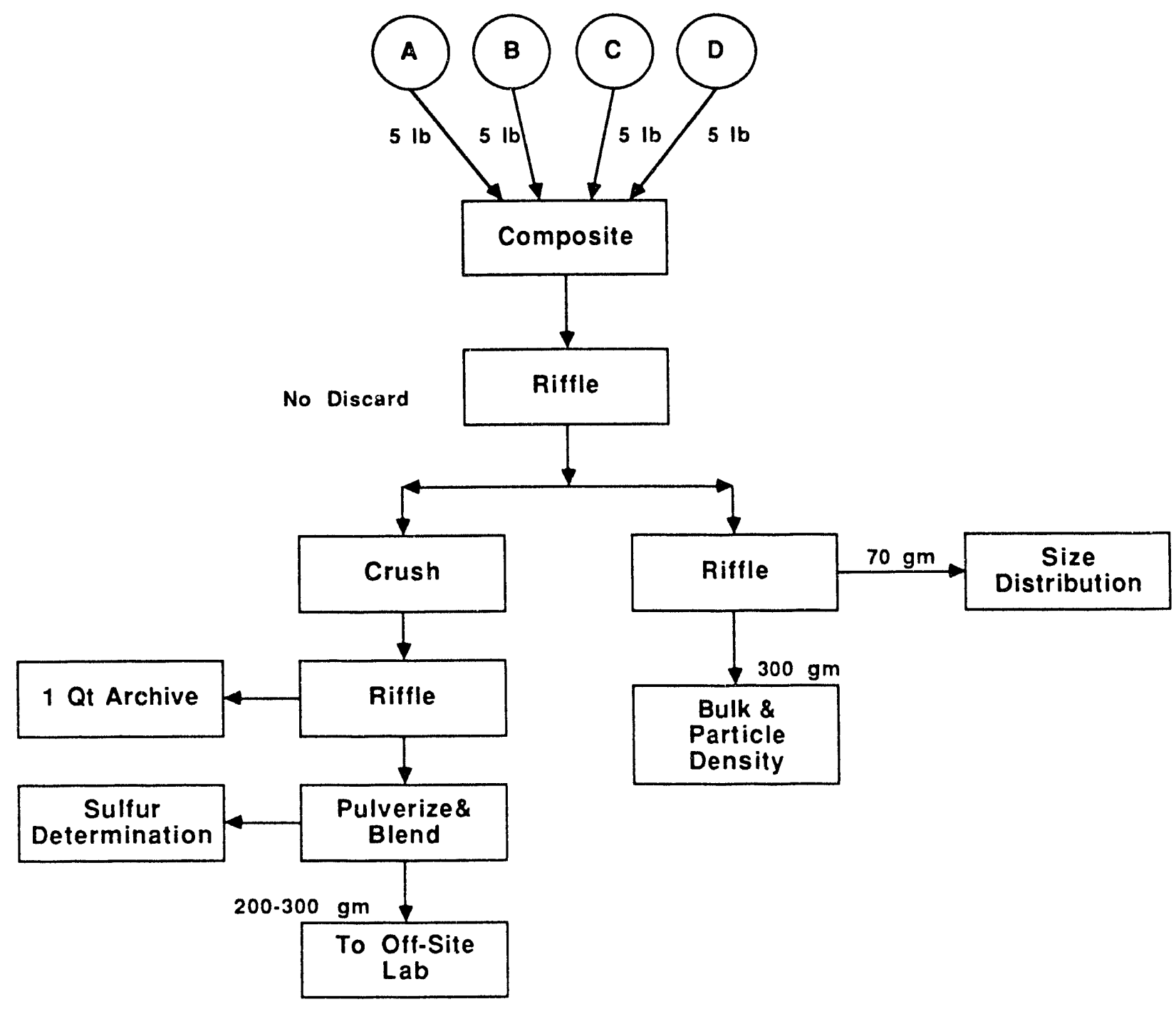

Figure 4-7. Bottom Ash Preparation Flow Sheet 


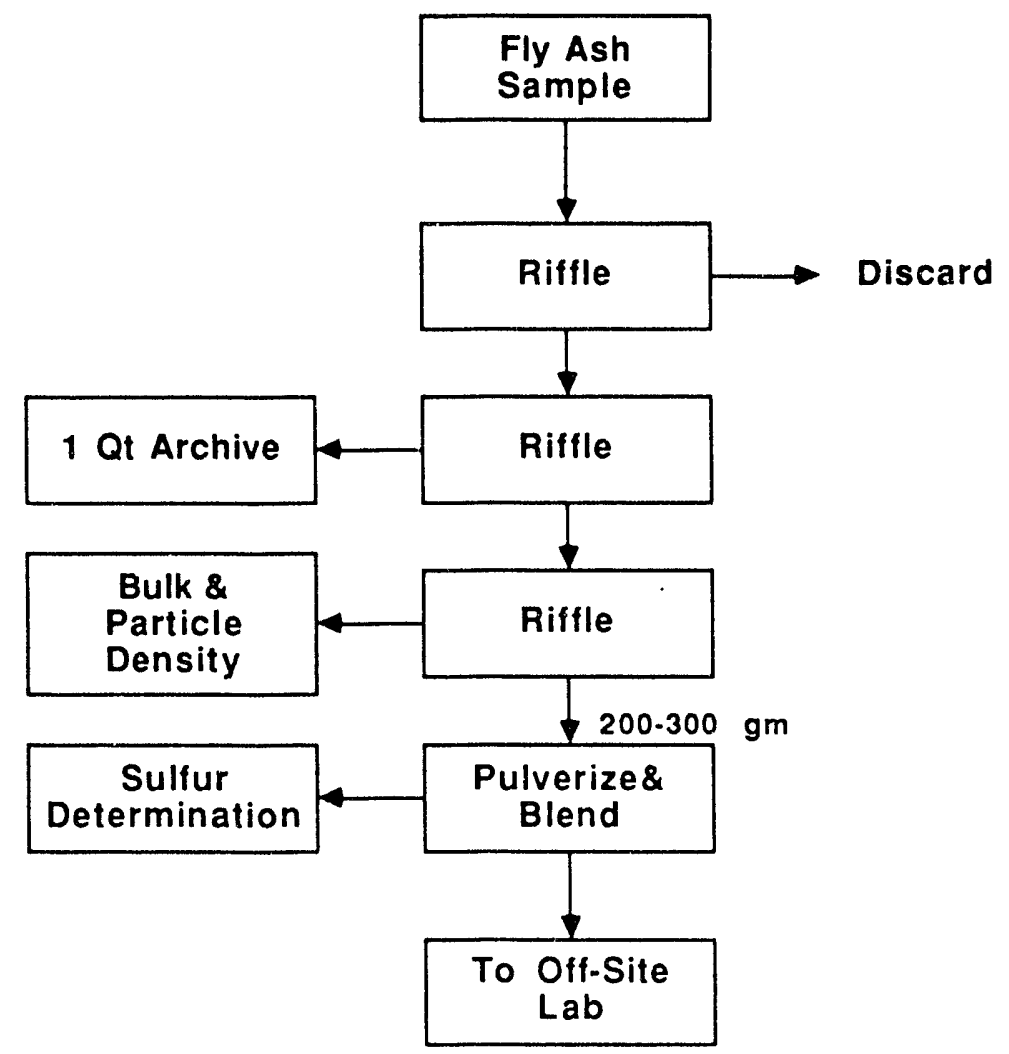

Figure 4-8. Fly Ash Preparation Flow Sheet 
pulverized to minus 200 mesh. Part of this sample is analyzed in the Leco sulfur analyzer at Nucla. The remainder is sent to the off-site laboratory for chemical analysis.

\subsubsection{5 euality control}

The Nucla laboratory personnel developed a rigorous program to insure quality control in the preparation and analysis of the solid samples. For each performance test, one of the samples sent to the laboratory was a duplicate of another sample. In addition, several tests were conducted to determine the division of analysis variance. Duplicate samples were also sent to other laboratories on a roundrobbin basis to serve as a check on the outside laboratory's procedures. Careful record keeping was also employed.

\subsubsection{VAX Computer}

The data acquisition system used for the test program was a Digital Equipment Corporation (DEC) V7: 8200 computer with eight megabytes of Random Access Memory. Specialized software was developed for real-time and historical data monitoring on this system. The VAX computer reads plant data directly off the plant's Westinghouse digital control system. The software then averages and stores the data for retrieval and analysis. Software can produce historical trend plots, run the performance calculations anc uncertainty analysis for performance tests, and other file mairtenance procedures from a menu driven master program. Both laser and graphics printers are attached to the VAX for hard copy output.

The VAX computer is connected to IBM PC's and the Macintosh computers via a serial cable. Files can be transferred to or from the VAX using the Kermit protocol.

The historical data storage and retrieval programs of the VAX are far superior to the capabilities of the plant distributed control system. As such, the VAX was beneficial to the plant in evaluating process upsets and trips, and to the test program for management of test conditions during the performance tests. Measurement points accessed by the VAX computer are listed in Appendix A along with calibration information for the transmitters.

\subsubsection{Performance Calculations}

The performance calculations for the test program are carried out on the VAX computer. The algorithms to perform the calculations were developed by EPRI and their contractors. The calculations include an implementation of PTC 4.1, the ASME boiler test code, heat and material balances around the boiler envelope, calculations of Ca/s molar ratio, calcium utilization, superficial velocities, and particle sizes of 
the various solid streams. Details of the performance calculations are contained in the 1988 Annual Report.

The performance calculations were checked extensively by EPRI and their contractors. The calculation results were checked against an Excel spread sheet calculation developed by the test team.

Results of the performance calculations are printed out on eight summary sheets. These summary sheets contain all of the relevant data obtained during a performance test. The eight summary sheets for test PS17 are shown in Table 4-6.

\subsubsection{Uncertainty Analysis}

ASME PTC 19.1 provides guidelines for determining the measurement uncertainty of the various plant measurements that feed the performance calculation program. PTC 19.1 also provides guidelines for propagating these uncertainties throughout the performance calculations.

The procedure for calculating the uncertainty of the results of a given calculation can be summarized as follows:

1. Determine the average values of the independent parameters $\left(\bar{P}_{i}\right)$ that enter into the result $(r)$ of the calculation.

2. Determine the precision index of the average value $\left(\mathrm{S}_{\overline{\mathrm{P}}}\right)$ for each $\overline{\mathrm{P}}_{i}$.

3. Determine the bias limit for each of the measured parameters $\left(B \overline{\mathrm{P}}_{i}\right)$.

4. Determine the degrees of freedom associated with each $\bar{P}_{i}\left(\sqrt{P}_{i}\right)$.

5. Use the perturbation method to determine the bias limit of the result $\left(B_{r}\right)$.

6 . Use the perturbation method to determine the precision index of the result $\left(S_{r}\right)$.

7. Calculate the degrees of freedom of the result $\left(v_{r}\right)$.

8. Find the Student's $t$ factor ( $t$ ) corresponding to $v_{r}$.

9. Calculate the total uncertainty of the result by the root-sum-square method (UrRSS). 
Table 4-6. Summary sheets for Test PSI7

PROCESS OPERATING SUMMARY REPORT

\author{
TEST : PS17 \\ Start....10/11/90 9:0:0 \\ End.......10/11/90 15: 0:0 \\ Printed.....17-JAN-1991 14:16:57.00
}

Combustor $\dot{A}$

Combustor B

Unit

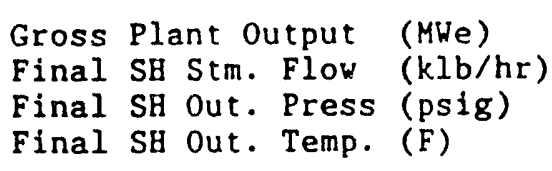

55.69

490.83

1451.47

971.16

$\begin{array}{ll}\text { Coal Rate Frnt-Wst } & (k l b / h r) \\ \text { Coal Rate Frnt-Est } & (k l b / h r) \\ \text { Coal Rate Rear } & (k l b / h r) \\ \text { Total } & (k l b / h r)\end{array}$

9.98

9.72

11.33

Limestone Rate (klb/hr)

1.40

Bed Drain Rate (klb/hr)

2.13

Flyash Flow (klb/hr)

Calculated
Superficial Velocity ( $\mathrm{ft} / \mathrm{sec}$ )
Distritutor Plate (Inl Air)
Freeboard (Inlet Air)
Dist. Plate (02 Method)
Freeboard (02 Method)

6.99

10.05

6.73

9.75

1546.54

1525.81

1462.37
62.77

$1.02 \quad 2.42$

$1.02 \quad 2.42$

1.97

4.10

11.71

9.40

10.63

31.74

11.71

7.20

10.16

6.94

9.85

1501.40

1514.90

1487.11

Wet Flue Gas Flow

- 02 Method (kIb/hr)

696.59

Flue Gas Composition (AH Inlet)

$02(\mathrm{v} \%)$

$\mathrm{CO} 2(\mathrm{v} \%)$

CO (ppmv)

NOX (ppmv)

( 1 bs $/ 10^{-6}$ btu)

SO2 (ppmv)

( $1 \mathrm{bs} / 10^{\circ} 6 \mathrm{btu}$ )

6.33

13.00

98.36

40.77

0.07

102.23

0.23

Total Air Flow (klb/hr)

647.62

Primary Air Flow (klb/hr)

388.28

sec. Air Flow (klb/hr)

259.34

SA/PA Ratio

() 6 ; 
Table 4-6. (Cont't)

PROCESS OPERATING SUMMARY REPORT

TEST : PS17

Start.....10/11/90 9:0:0

End.......10/11/90 15: 0: 0

Printed.....17-JAN-1991 14:16:57.00

Combustor A

Combustor B
Unit

0.00

51.65

46.48

31.78

46.59

31.88

42.56

23.59

$-0.34$

41.91

20.88

$-0.22$

$-2.71$

0.00

0.53

3.22

$-6.59$

$-12.78$

ID Fan In. Press. (in WG)

Cyclone In. Temp. (F)

Cyclone Out. Temp. (F)

Loop Seal Solids Temp.

(F)

1387.82

1405.95

1464.26

1386.31

1402.59

1500.24

$501.2 \epsilon$

504.85

288.48

286.01

384.70

387.58

413.27

410.06

139.34

175.85

469.21

21.92

0.71

1504.93

Drum Press. (Psig)

Ambient Temp. (F)

Baro. Press. (In $\mathrm{Hg}$ )

Rel. Humidity (\%)
117.25

24.59

11.17 
Table $4-6 . \quad$ (Cont't)

PERFORMANCE SUMMARY REPORT

TEST : PS17

Start....10/11/90 9: 0:0

End.......10/11/90 15: 0: 0

Printed....17-JAN-1991 14:17:10.00

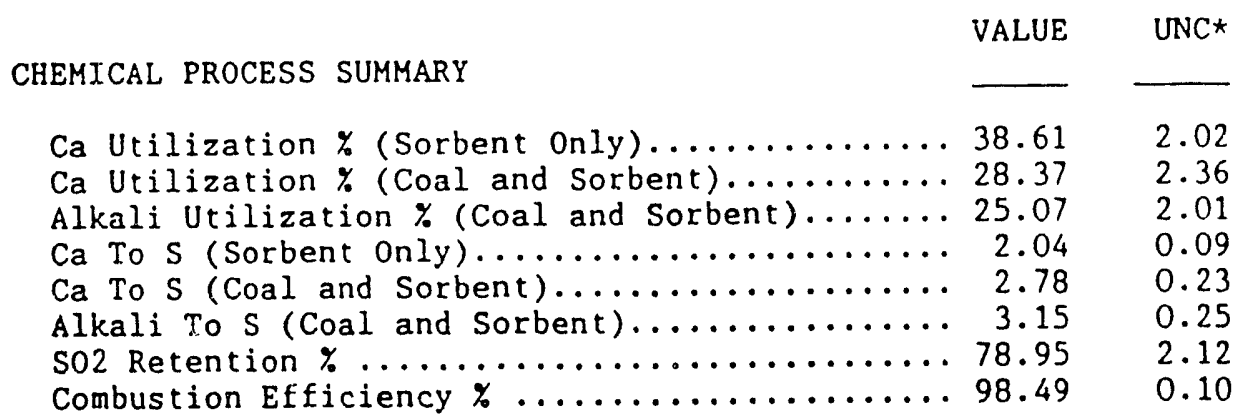

BOILER PERFORMANCE SUMMARY

Boller Efficiency (Loss Method) $\% \ldots \ldots \ldots \ldots .86 .72 \quad 0.32$

Boller Efficiency (I/0 Method) \% .........85.81 3.03

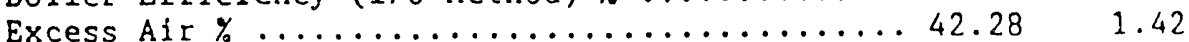

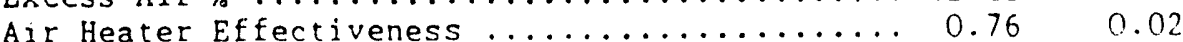

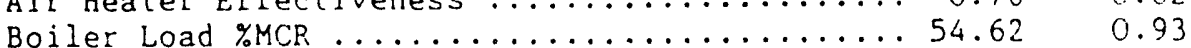

Wet flue gas flow - 02 Method (klbs/hr) ....696.59 18.28

M:TE. IAL BALANCE

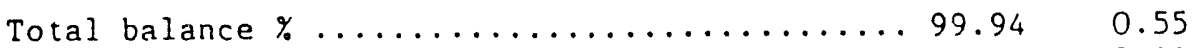

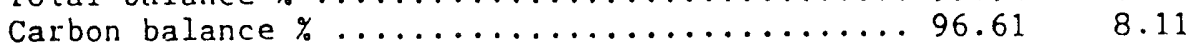

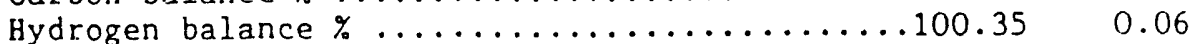

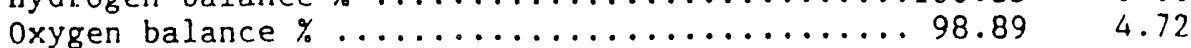

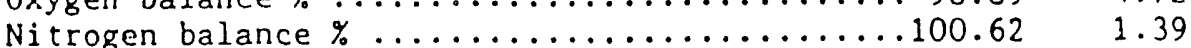

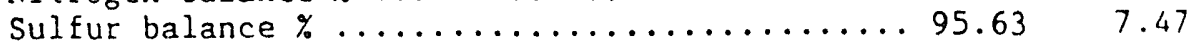

Calcium balance $\% \ldots \ldots \ldots \ldots \ldots \ldots \ldots \ldots \ldots \ldots 117 .{ }_{1} \quad 11.10$

UNIT HEAT RATE

Gross Heat Rate (btu/kwhr) ....................... 27547 .

Net Heat Rate (btu/kwhr) ............... 332236.

* Uncertainty, +/ - in same units as variable. 
Table 4-6. (Cont't)

MATERIAL BALANCE REPORT (02 METHOD) -...-

TEST : PS17

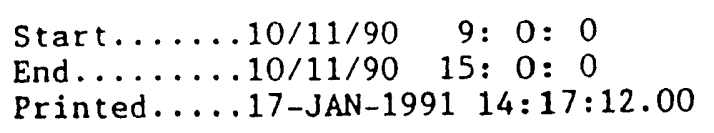

METHOD "A" MEASURED AIR FLOUS
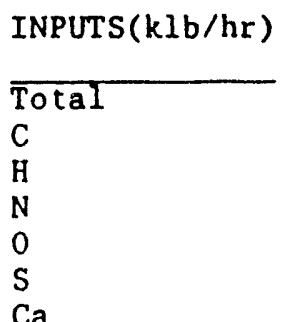

OUTPUTS(klb/hr)

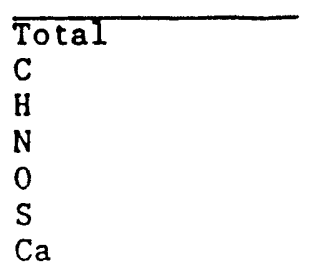

$\mathrm{Ca}$

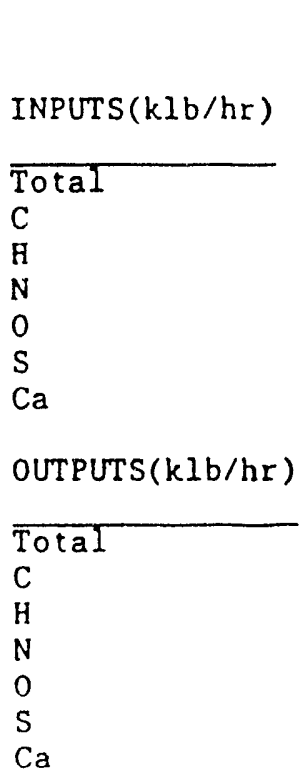

\begin{tabular}{rr}
\multicolumn{1}{c}{ Coal } & Sorbent \\
\cline { 2 - 2 } 62.77 & 2.42 \\
35.87 & 0.28 \\
2.69 & 0.00 \\
0.22 & \\
10.55 & 1.12 \\
0.34 & 0.00 \\
0.32 & 0.87
\end{tabular}

Flue Gas

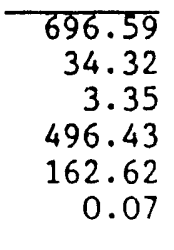

Fly Ash

11.71
0.55
0.01

0.60
0.14
0.83

Bed Drain

4.10
0.05
0.00
0.43
0.12
0.57

Total Output

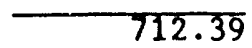

34.92

3.36

496.43

163.64

0.33

1.40

539.99

168.41

0.57
METHOD "B" CALCULATED AIR FLOW

\begin{tabular}{r}
\multicolumn{1}{c}{ Coal } \\
\hline 62.77 \\
35.87 \\
2.69 \\
0.22 \\
10.55 \\
0.34 \\
0.32
\end{tabular}

Sorbent

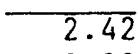

0.28

0.00

1.12

0.00

0.87

Flue Gas Fly Ash Bed Drain

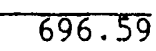

34.32

3.35

496.43

162.62

0.07

\begin{tabular}{rr}
\hline 11.71 & 4.10 \\
0.55 & 0.05 \\
0.01 & 0.00 \\
& \\
0.60 & 0.43 \\
0.14 & 0.12 \\
0.83 & 0.57
\end{tabular}

\begin{tabular}{r}
\multicolumn{1}{c}{ Air } \\
\hline 647.62 \\
0.66 \\
493.16 \\
153.80
\end{tabular}

Total Output

712.39

34.92

3.36

496.43

163.64

0.33

1.40
Total Input

36.15

3.41

540.21

180.09

0.34

1.19

\% AcC For

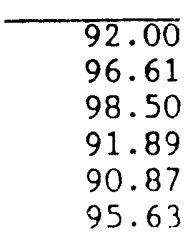

117.82 
Table $4-6$. (Cont't)

TEST : PS17

Start.....10/11/90 9:0:0

End........10/11/90 15: 0:0

Printed....17-JAN-1991 14:17:14.00

\begin{tabular}{|c|c|c|c|c|}
\hline & Coal & Sorbent & Fly Ash & Bed Drain Matl \\
\hline $\begin{array}{l}\text { HHV (Btu/lb) } \\
\text { Total Moisture (\%) } \\
\text { Air Dry Loss }(\%) \\
\text { Blk Den (\#/cft) } \\
\text { Volatiles }(\%) \\
\text { Fixed C }(\boldsymbol{z}) \\
\text { Ash }(\boldsymbol{z})\end{array}$ & $\begin{array}{r}9711.67 \\
8.87 \\
3.39 \\
0.00 \\
31.57 \\
38.70 \\
20.86\end{array}$ & 0.08 & & \\
\hline \multicolumn{5}{|l|}{ CONSTITUENTS $(\%)$} \\
\hline $\mathrm{C}$ & 57.15 & & 4.68 & 1.23 \\
\hline $\mathrm{H}$ & 3.29 & 0.00 & 0.06 & 0.10 \\
\hline 0 & 8.93 & & & \\
\hline iv & $0.3=$ & & & \\
\hline s & 0.55 & 0.00 & 1.17 & 2.89 \\
\hline $\mathrm{Ca}$ & 0.50 & 36.13 & 7.09 & 13.94 \\
\hline $\mathrm{Mg}$ & 0.13 & 0.44 & 0.57 & 0.56 \\
\hline $\mathrm{Fe}$ & 0.34 & 0.19 & 1.61 & 0.96 \\
\hline $\mathrm{CO} 2$ & & 42.43 & 0.69 & 0.82 \\
\hline
\end{tabular}

NOTE: Only constituents used in the Performance Calculations are reported. 
Table 4-6. (Cont't)

PHYSICAL ANALYSIS REPORT

TEST : PS17

Start....10/11/90 9: 0:0

End.......10/11/90 15: 0: 0

Printed....17-JAN-1991 14:17:17.00

Percentage Less Than

\begin{tabular}{|c|c|}
\hline Mesh & $\begin{array}{l}\text { Actual } \\
\text { Microns }\end{array}$ \\
\hline 1.50 & 37500 \\
\hline 1.00 & 25000 \\
\hline 0.75 & 19000 \\
\hline 0.50 & 12500 \\
\hline 0.25 & 6300 \\
\hline 4 & 4750 \\
\hline 6 & 3350 \\
\hline 8 & 2360 \\
\hline 10 & 1700 \\
\hline 14 & 1180 \\
\hline 20 & 850 \\
\hline 28 & 600 \\
\hline 48 & 300 \\
\hline 100 & 150 \\
\hline 150 & 106 \\
\hline 200 & 75 \\
\hline 325 & 45 \\
\hline 400 & 38 \\
\hline
\end{tabular}

Median diameter

1649.05

61.10

661.34 
Table 4-6. (Cont't)

HEAT BALANCE REPORT

TEST : PS17

Start....10/11/90 9:0:0

End.......10/11/90 15: 0: 0

Printed....17-JAN-1991 14:17:19.00

BOILER EFFICIENCY (\%)(LOSSES METHOD)

86.72

\begin{tabular}{|c|c|c|}
\hline & Value (KBtu/hr) & $\%$ of total \\
\hline CHEMICAL HEAT INPUT OF THE COAL: & 61.0127 .06 & 97.22 \\
\hline I. CREDITS & & \\
\hline $\begin{array}{l}\text { 1. Heat credit for sensible } \\
\text { heat in entering moist air }\end{array}$ & 12255.75 & 1.95 \\
\hline $\begin{array}{l}\text { 2. Sensible heat in entering } \\
\text { as-fired coal }\end{array}$ & -153.28 & -0.02 \\
\hline $\begin{array}{l}\text { 3. Sensible heat in entering } \\
\text { wet sorbent }\end{array}$ & 11.72 & 0.00 \\
\hline $\begin{array}{l}\text { 4. Heat credit for sulfation } \\
\text { reaction }\end{array}$ & 1817.15 & 0.29 \\
\hline 5. Bottom ash cooling water input & 3518.03 & 0.56 \\
\hline 6. Sootblowing steam & 0.00 & 0.00 \\
\hline
\end{tabular}

II. LOSSES

1. Beat loss from unburned coal

$8921.83 \quad 1.42$

2. Heat loss from sensible heat in dry flue gas

34104.66

5.43

3. Heat loss due to moisture in

6377.08

1.02 as-fired fuel and sorbent

21121.05

3.37

4. Latent heat loss due to moisture from burning of hydrogen

* Total equals: Chemical input of coal plus credits 
Table $4-6 . \quad$ (cont't)

HEAT BALANCE REPORT $\ldots . . . . . . . . .$.

TEST : PS17

Start.....10/11/90 9:0:0

End.......10/11/90 15: 0:0

Printed.....17-JAN-1991 14:17:19.00

\begin{tabular}{|c|c|c|c|}
\hline & Value $(\mathrm{KBtu} / \mathrm{hr})$ & $\%$ of & total \\
\hline II. LOSSES (CONT) & & & \\
\hline $\begin{array}{l}\text { 5. Latent heat loss due to } \\
\text { moisture in the air }\end{array}$ & 563.30 & & 0.09 \\
\hline $\begin{array}{l}\text { 6. Heat loss due to calcination } \\
\text { of sorbent }\end{array}$ & 1497.00 & & 0.24 \\
\hline $\begin{array}{l}\text { 7. Heat loss due to formation } \\
\text { of } \mathrm{CO}\end{array}$ & 262.86 & & 0.04 \\
\hline $\begin{array}{l}\text { 8. Heat loss due to unburned } \\
\text { hydrocarbons in flue gas }\end{array}$ & 0.00 & & 0.00 \\
\hline $\begin{array}{l}\text { 9. Heat loss due to } \\
\text { radiation and convection }\end{array}$ & 5000.00 & & 0.80 \\
\hline $\begin{array}{l}\text { 10. Heat loss due to } \\
\text { sensible heat in flue dust }\end{array}$ & 492.27 & & 0.08 \\
\hline $\begin{array}{l}\text { 11. Heat loss due to } \\
\text { ser ible heat in bod drai. }\end{array}$ & 252.80 & & 0.04 \\
\hline $\begin{array}{l}\text { 12. Heat loss due to sootblower } \\
\text { steam }\end{array}$ & 0.00 & & 0.00 \\
\hline $\begin{array}{l}\text { 13. Heat loss to bottom, ash cooler } \\
\text { cooling water }\end{array}$ & 4778.28 & & 0.76 \\
\hline
\end{tabular}

SUM OF LOSSES TERMS

83371.13

13.28

* Total equals: Chemical input of coal plus credits 
A more detailed description follows.

STEP 1: Find $\overline{\mathrm{P}} \mathrm{i}$

The average value for each of the inputs is given by:

$$
\overline{\mathrm{P}}_{i}=\frac{1}{\mathrm{~N}} \sum_{\mathrm{k}=1}^{\mathrm{N}} \mathrm{P}_{\mathrm{i}-\mathrm{k}}
$$

Where: $P_{i-k}=$ the $k$ th measurement of the ith input variable.

$\mathrm{N}=$ the number of repeat measurements

\section{STEP 2: Find $\mathrm{S}_{\mathrm{P}}$}

The precision error, or random error, for a given input parameter is assumed to be made up entirely of the precision index of the average of the measurements of that parameter. As described in PTC 19.1, the precision index, $S$, is an estimate of the standard deviation and is defined as:

$$
S=\left\{\frac{\sum_{k=1}^{N}\left(P_{i-k}-\bar{P}_{i}\right)^{2}}{(N-1)}\right\}^{.5}
$$

The quantity $S$ is a measure of the error that can be expected if any one measurement, $P_{i-k}$, is used to estimate the true average of the population sampled. However, if the average value, $\overline{\mathrm{P}}_{i}$, is used, the precision index of the average is defined as:

$$
S \overline{\mathrm{P}}_{i}=\frac{S}{\sqrt{\mathrm{N}}}
$$

Thus the precision error is reduced by using the average instead of any of the individual measurements. Equations 4-2 and 4-3 are used to determine the precision index of the average chemical analyses.

For the data points taken from the data highway, a slightly different procedure is required. Points on the data highway are stored as average values over a short time period,

usually 15 minute averages, $\overline{\mathrm{P}}_{i-j}$, along with a standard deviation, $S_{i-j}$, calculated for that average time period. 
When the test period is defined, the $M$ values of $\bar{P}_{i-j}$ are averaged to obtain $\overline{\mathrm{P}}_{i}$. The estimate of the pooled precision index for the individual $\overline{\mathrm{P}}_{i-j}$ 's is given by:

$$
\text { Spooled }=\left\{\frac{\sum_{j=1}^{M} s_{i-j^{2}}}{M}\right\}^{.5}
$$

The precision index of the grand average $\bar{P}_{i}$ is then given by:

$$
S_{\bar{P}}=\frac{S_{p o o l e d}}{\sqrt{H * M}}
$$

Where $\mathrm{H}$ is the number of measurements that are averaged to give $\overline{\mathrm{P}}_{i-j}$ and $\mathrm{M}$ is the number of stored readings that are averaged to give $\overline{\mathrm{P}}_{i}$.

\section{STEP 3: Determine $B \bar{P}_{i}$}

Bias limits for the input parameters are estimated from the manufacturers' performance specifications. There are six main types of measurements that are used as inputs to the performance calculations:

- Pressure (or differential pressure)

- Temperature

- Fluid flow rate

- Solid flow rate

- Gas chemical analysis

- Solid chemical analysis

The bias limits for the pressure and pressure differential measurements are obtained from the calibration data and the amount of drift observed between calibrations. Bias limits for temperatures are available from the vendors' catalogs. Bias limits on the air heater exit gas temperature thermocouples were determined by inserting each thermocouple into boiling water, and measuring the difference between the reading and $212^{\circ} \mathrm{F}$. No bias error is assumed to be associated with the location of the thermocouples.

Fluid flow measurements, such as those for feed water, steam, and air are based on the output from differential pressure $(\Delta \mathrm{P})$ instruments. These instruments measure the $\Delta \mathrm{P}$ across and orifice plate or other similar flow device. The signal 
from the $\Delta \mathrm{P}$ transmitter is processed through a square-root extractor, which puts out a signal that is proportional to the square root of the signal entering it. This square-root extractor output signal is then a linear function of the flo rate. Because of this, the bias limit on the fluid flow rat measurements are not only a function of the bias limit on th $\Delta \mathrm{P}$ reading, but also a function of flow rate as well. The bias limits for these instruments were obtained from the calibration data.

The bias limit for the solid flow rate measurements is obtained from the calibration data of each instrument. The bias limits for the gas analyzers are also obtained from the calibration data. The gas analyzers were calibrated on a regular schedule to eliminate any other sources of bias error. Chemical analyses biases were obtained from the calibration data obtained from the laboratory.

STEP 4: Determine $\sqrt{\bar{P}}_{\dot{1}}$

The degrees of freedom associated with the calculation of each $\mathrm{S}_{\overline{\mathrm{P}}}$ is given by

$$
\sqrt{\mathrm{P}}_{\mathrm{i}}=\mathrm{N}-1
$$

Where $\mathrm{N}$ is the total number of measurements that went into the average value ( $N$ is equal to $H^{\star} M$ for values on the data highway).

STEP 5: Calculate $\mathrm{Br}$

The bias limit of the result $\mathrm{Br}$ is the uncertainty of the result that is due to the bias limits of the input parameters. The value of $\mathrm{Br}$ is given by:

$$
\mathrm{Br}=\left[\sum_{i=1}^{\mathrm{N}}\left(\theta_{i} \quad \mathrm{~B} \overline{\mathrm{P}}_{i}\right)^{2}\right]^{.5}
$$

Where $\theta_{i}$ is the relative sensitivity coefficient for the $i$ th parameter. $\theta i$ is defined in PTC 19.1 as follows:

$$
\theta_{i}=\frac{\partial r}{\partial \overline{\mathrm{P}}_{i}}
$$

$\theta_{i}$ is the partial derivative of the result with respect to the $i^{\text {th }}$ input parameter. The value of $\theta_{i}$ can be calculated 
by taking the partial derivatives of all of the mathematical expressions used to calculate the result. This method is called the analytical method. A simpler way to determine the partial derivatives is to use the perturbation method, where

the value of $\overline{\mathrm{P}}_{i}$. is replaced in the calculation with $\left(\overline{\mathrm{P}}_{i}+\right.$ $\Delta \overline{\mathrm{P}}_{i}$ ), where $\Delta \overline{\mathrm{P}}_{i}$ is a small increment of $\overline{\mathrm{P}}_{i}$ (usually $1 \%$ of $\left.\overline{\mathrm{P}}_{i}\right)$, and a value of $r\left(\overline{\mathrm{P}}_{i}+\Delta \overline{\mathrm{P}}_{i}\right)$ is calculated. The value of $\theta_{i}$ is then given by:

$$
\theta_{i}=\frac{r\left(\overline{\mathrm{P}}_{i}+\Delta \overline{\mathrm{P}}_{i}\right)-r}{\Delta \overline{\mathrm{P}}_{i}}
$$

for each input parameter. This calculation has been found to give the same result as the analytical method, and while it requires considerably more calculations, is much easier to implement on the VAX computer than the analytical method.

STEP 6: Calculate $S_{r}$

The precision index of the calculated result, $S_{r}$, is the uncertainty of the result that is due to the precision indexes of the input parameters. The calculation of $S_{r}$ is identical to $\mathrm{B}_{r}$, except that $S \overline{\mathrm{P}}_{i}$ is substituted for $B \overline{\mathrm{P}}_{i}$ in equation $4-7$.

STEP 7: Calculate $v_{r}$

The degrees of freedom of the calculated result is a function of the precision index of the result, the precision index of the input variables, and the degrees of freedom of the input variables. The Welch-Satterwaite formula given in PTC 19.1 is used to calculate $v r$ as follows:

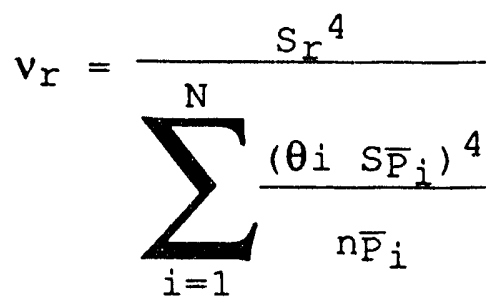

The perturbation results for $\theta i$ are used in both equations 47 and $4-10$. 
STEP 8: Find the Student's $t$ value

The precision index of the result, $\mathrm{Sr}$, is related to the precision error of the calculated result by a factor known as Student's $t$ value. The precision error of the calculated result is $\left(t * S_{r}\right)$. The value of $t$ is a function of the number of degrees of freedom and the probability that the true value of $r$ will be inside of the range of $r \pm t \star S_{r}$. The value of $t$ was evaluated at a probability interval of 95\%. Table 4-7 lists values of $t$ for the $95 \%$ probability interval as a function of $v$ degrees of freedom.

STEP 9: Calculate UrRSS

The last step in the calculation of the uncertainty of the result is to combine the values of $B_{r}$ and $S_{r}$ to obtain UrRSS. PTC 19.1 recommends using the root-sum-square model for combining the bias error and the precision error. The equation for the overall uncertainty is:

$$
\mathrm{U}_{\mathrm{rRSS}}=\left[\mathrm{Br}^{2}+\left(t \mathrm{~S}_{\mathrm{r}}\right)^{2}\right] \cdot 5
$$

Using the values of $t$ from Table 4-7 gives an uncertainty interval of $95 \%$. The final result can be expressed with its uncertainty interval as:

$$
r \pm U_{\text {RSS }}
$$

Table 4-7. Student's $t$ Values at the 95\% Probability Level

\begin{tabular}{cccc}
\hline$n$ & $t$ & $n$ & $t$ \\
\hline 1 & 12.71 & 16 & 1.120 \\
2 & 4.303 & 17 & 2.110 \\
3 & 3.182 & 18 & 2.101 \\
4 & 2.776 & 19 & 2.093 \\
5 & 2.571 & 20 & 2.086 \\
6 & 2.447 & 21 & 2.080 \\
7 & 2.365 & 22 & 2.074 \\
8 & 2.306 & 23 & 2.069 \\
9 & 2.262 & 24 & 2.064 \\
10 & 2.228 & 25 & 2.060 \\
11 & 2.201 & 26 & 2.056 \\
12 & 2.179 & 27 & 2.052 \\
13 & 2.160 & 28 & 2.048 \\
14 & 2.145 & 29 & 2.045 \\
15 & 2.131 & 30 & 2.042 \\
& & 40 & 2.021 \\
& & 60 & 2.000 \\
& & 120 & 1.980 \\
& & $\infty$ & 1.960 \\
\hline
\end{tabular}




\title{
Section 5
}

\author{
HOT-MODE SHAKEDOWN
}

The purpose of hot-mode testing is to establish the conduct for future steady-state performance testing as discussed in section 6. Specifically, the test plan is designed to establish 1) the required times to reach steady-state conditions following changes in unit load and bed chemistry, 2) the quantity of solids samples and process data required to assure acceptable accuracy in calculated results, and 3) the required duration for each performance test. These tests were conducted from March 6 to 18, 1989.

Prior to these tests, a one week series of operational tests were conducted to establish "design" operating conditions for the boiler by which the hot-mode tests would be conducted. These tests were termed pre-hot-mode tests. In particular, bed temperatures and pressures, ash cooler fluidizing velocities, and primary to secondary air ratios were established for the hot-mode test plan. In addition, the pre-hot-mode tests provided a run-in calibration and training period prior to the start of the hot-mode test plan.

\subsection{PRE-HOT-MODE TEST RESULTS}

During a one week period prior to hot-mode testing, all solids feed and disposal systems were calibrated, including the six coal feeders, two limestone feeders, two bottom ash weigh bins, and the fly ash weigh bin. The calibrations were performed according to procedures developed during the cold mode shakedown period described in section 4. Due to difficulties calibrating the fly ash flow meter, a methodology was developed for calculating the flow rate based on a mass balance of inerts in the input coal and limestone streams and the output bottom ash stream. This method was used for the remainder of all performance testing described in section 6 .

In addition, all solids sampling hardware was tested and a partial set of solids samples were withdrawn from the boiler according to the sampling scenario established for the hotmode test plan. These samples were prepared in the on-site solids preparation laboratory as a final check on all equipment, procedures, and manpower availability.

The operational tests designed to establish "design" operating conditions for the hot-mode test plan revealed the following: 
1. The ability to pre-set combustor operating temperatures was not possible. Temperatures were found to vary with load, excess air, and bed pressures. The latter are measured along each of three walls in the lower combustion chambers approximately one foot above the air distributor plate. The value is an indication of the solids inventory in the bed.

2. At similar loads, excess air levels, and bed pressures, the operating temperatures between combustion chambers could be significantly different. Temperatures could also vary within the same combustion chamber between repeat tests under seemingly identical operating conditions. This suggested that solids distribution in the upper freeboard region of the combustion chambers may be different between the two combustors and between duplicate tests. This distribution of solids is not indicated by the measurement of bed pressure at the one foot level in the combustor. However, the pressure profile is measured at 10 foot intervals along the rear wall of combustor B. Data from these pressure taps suggested differences in profiles under nearly identical operating conditions.

3. Ash cooler fluidizing velocities did little to affect changes in combustor operating temperatures. The original intent of this design was to classify bed material and return the finer size fraction to the combustion process while removing the larger material from the boiler as bottom ash. Although size data did indicate that higher fluidizing velocities in the ash coolers produced a coarser bed drain, this change had little impact on the overall solids distribution in the boiler and hence, on operating temperatures.

4. Changes in primary to secondary air ratio had no immediate impact on combustor operating temperatures. Changes in bed temperatures over 4 to 8 hour periods following these changes were consistent with the normal drift observed during the unit operational period prior to these tests. No definite conclusions could be made regarding the impact of $\mathrm{PA} / \mathrm{SA}$ ratio of temperature.

5. Increasing excess air at constant load decreased combustor operating temperatures, as expected. This is caused by the increase in combustor stoichiometry and the associated reduction in adiabatic flame temperature. However, excess air adjustments are limited due to the requirement at half load to maintain a minimum underbed air flow to each combustion chamber to reduce backsifting into the windbox, and at full load by primary air fan limitations.

Based on results from these tests, only unit load and excess air were determined to be significant controllable parameters affecting operating temperatures and hence, test results. To establish repeatability of test results, setpoints for the 
following operating variables were established prior to testing:

- Unit load

- Excess air at 3.3 vol. o 02

- PA/SA ratio as established at a given load by the design flow curves provided by the boiler vendor

- Bed pressures set to 18 in wg. average in each chamber

- Ash cooler velocities set to $6 \mathrm{ft} / \mathrm{s}$

- All coal and limestone feeders in service

Also based on results from these tests, an effort was undertaken to develop a correlation for predicting combustor operating temperatures based on measured controllable and uncontrollable operating parameters. This resulted in the installation of pressure taps on each combustion chamber to measure the differential pressure along the water walls between the lower combustor refractory/water-wall interface and the top of the combustion chamber. This led to a relatively accurate correlation, as discussed in greater detail in section 10. Combustor operating temperatures are predicted based on the differential pressure measurement, which is uncontrollable, and unit load and excess air.

\subsection{OBJECTIVES AND PROCEDURES FOR HOT-MODE TESTING}

The hot-mode test plan consisted of a series of five special tests designed to:

- Determine the number of solids samples which must be taken during a performance test to achieve a desired degree of output accuracy.

- Establish the duration for steady-state performance testing.

- Demonstrate the accuracy of solids preparation procedures according to ASTM standards.

- Determine the times required for the boiler to reach chemical equilibrium after a step change in Ca/s ratio and to reach thermal equilibrium following a step change in load.

\subsubsection{Determination of the Number of Solids Samples Required}

ASTM procedures outline a method for determining the number of samples required to achieve a specified accuracy in an output variable, based on the uncertainty of a single input variable. Since feed and waste streams are not uniform throughout a test, the chemical composition of solids streams is expected to vary over the course of a test run. Therefore, it is necessary to collect and analyze several samples to accurately represent the chemical composition of each stream. Because fewer solids samples can be collected relative to the number of readings that can be recorded from on-line instrumentation, the solids data have a much greater 
effect on performance calculation result uncertainties than data from the data highway.

The uncertainty analysis software subroutine, incorporated into the performance calculations in the second quarter of 1988, calculates the uncertainty in each of the outputs from the performance calculations, given the uncertainty in each of the measurements used as inputs to the performance calculations. This was discussed in more detail in section 4.2.5.2. The uncertainties depend upon the actual values, standard deviations (precision errors), and bias errors associated with the input variables to the performance calculations. The original algorithm used for calculating uncertainties involved taking partial derivatives of each performance equation. This required that the uncertainty analysis code be changed every time a change was made to the performance calculation code. To avoid this, the test team developed a "perturbation method" to calculate the uncertainty in test results based on the uncertainty of all input measurements. The contributions to the uncertainty in the result by the uncertainty of the input parameter is found by perturbing each input parameter value by the amount of the input uncertainty and evaluating the result at the new value of the input parameter. Thus, there is no need to change the uncertainty calculations to match revisions in the performance calculations. This method establishes the total uncertainty of all calculated results for a test run based on the contributions of precision and bias errors of all input variables. The uncertainty analysis can also be used to establish output variable sensitivity (sensitivity analysis) to changes in input variables. Sensitivity analysis is helpful in highlighting critical process instrumentation and for establishing required instrument accuracy (i.e., calibration frequency).

To determine the number of samples required, the test team performed the uncertainty analysis on hot-mode test SDl for various 2-hour increments. Each additional 2-hour increment adds one additional set of coal, limestone, fly ash and bottom ash samples. The variance of other process variables, such as temperature and pressure measurements, also change as the duration of the test run increases. As the number of samples included in a test run increases, the uncertainty in the results is expected to decrease. Target accuracies for calculated test results were established during cold mode shakedown testing. For example, four of these target accuracies for calculated results are:

- Boiler efficiency $\pm 0.5 \frac{0}{\circ}$

- Calcium balance $\pm 10 \%$

- Combustion efficiency $\pm 0.2 \%$

- Sulfur retention $\pm 5 \%$ 
It is possible to choose the number of solids samples required to achieve these target uncertainties. This, in turn, establishes the test duration, since it is difficult to collect a set of solids samples more frequently than once every 2 hours.

\subsubsection{Determination of the Accuracy of Solids Preparation Procedures}

The validation process for the solids sampling, preparation, and analysis procedures began during cold-mode shakedown, when an extensive review of the sampling locations and procedures was performed to identify and eliminate any sources of systematic bias. Quantification of the error due to preparation and analysis was completed during the hot-mode test sequence by measuring the variance of the analytical results of four identically prepared samples, each derived from a single initial sample. The variance of the results is called the division and analysis variance ( $\left.\mathrm{s}_{\mathrm{da}}{ }^{2}\right)$, and is a measure of the random error introduced by preparing and analyzing samples.

ASTM procedures provide guidelines for determining the acceptability of the division and analysis variance. The acceptability depends upon two criteria. First, the variance should not change when measured repeatedly. Statistical tests are used to determine if a change in the variance is real (i.e., caused by problems with the preparation procedures or the result of measurement inaccuracies).

To determine $\mathrm{S}_{\mathrm{da}}{ }^{2}$, a single sample is collected according to normal sampling procedures. The sample is then split into four subsamples. Each of these subsamples is reduced according to standard procedures to a lab sample which is then analyzed. The variance of the four analyses is then calculated and reported as $\mathrm{S}_{\mathrm{da}}{ }^{2}$.

The number of samples called for by the ASTM procedure was modified to use 8 samples requiring 32 analyses. This modified plan was used for coal and bottom ash samples, and greatly reduced the cost of the procedure without compromising results.

The second criterion for determining acceptability is that the variance of division and analysis should not be more than 20 percent of the overall variance $\left(S_{O}{ }^{2}\right)$. The overall variance includes the variability of the material as well as the preparation and analysis variability. The first step in determining $\mathrm{S}_{\circ}{ }^{2}$ involves collecting an incremental sample, which is one acquired through a single operation of the sampling device. This sample is not composited with other increments but is prepared as a separate lab sample. The 
ASTM plan was modified so that 42 incremental samples were collected for coal and 40 were collected for bottom ash during the 48 hours allotted for the test.

To calculate $\mathrm{S}_{0}{ }^{2}$, the analytical results were divided into two groups, and a variance was calculated for each group. The variances of the two groups were averaged and then multiplied by an "F" factor from statistical tables to calculate a "probable maximum" value of $\mathrm{S}_{O}{ }^{2}$. This is the number upon which ASTM requirements are based.

\subsubsection{Determination of the Time Required to Steady State}

The time requirement to steady state is defined as the time period over which the plant must operate at constant conditions to ensure chemical and thermal equilibrium with all reacting variables. This information is valuable for test scheduling in that it indicates the time required between tests for the plant to reach equilibrium at the new conditions. For this test plan, major first-order transient times were determined by making changes in the boiler load and the $\mathrm{Ca} / \mathrm{S}$ ratio. Boiler load for the $\mathrm{Ca} / \mathrm{S}$ ratio transient test was $100 \% \mathrm{MCR}$. The $\mathrm{Ca} / \mathrm{S}$ ratio transient was introduced by shutting off the limestone feeders. After 12 hours of operation, the limestone feed rate was returned to twice its initial setting. Operation was observed for another 12 hours prior to proceeding to the load change transients.

For the load ramp test, main turbine load was adjusted down in a controlled ramp (not less than $1 \frac{\circ}{0}$ per minute and not more than the maximum rate of load reduction which had been demonstrated from an initial value of $100 \% \mathrm{MCR}$ down to the minimum load at which all turbine/generators remained in service. After 24 hours, load was increased in a controlled ramp back to the initial $100 \%$ MCR value.

\subsection{TEST MATRIX}

The test matrix for the hot-mode-shakedown tests is as shown below:

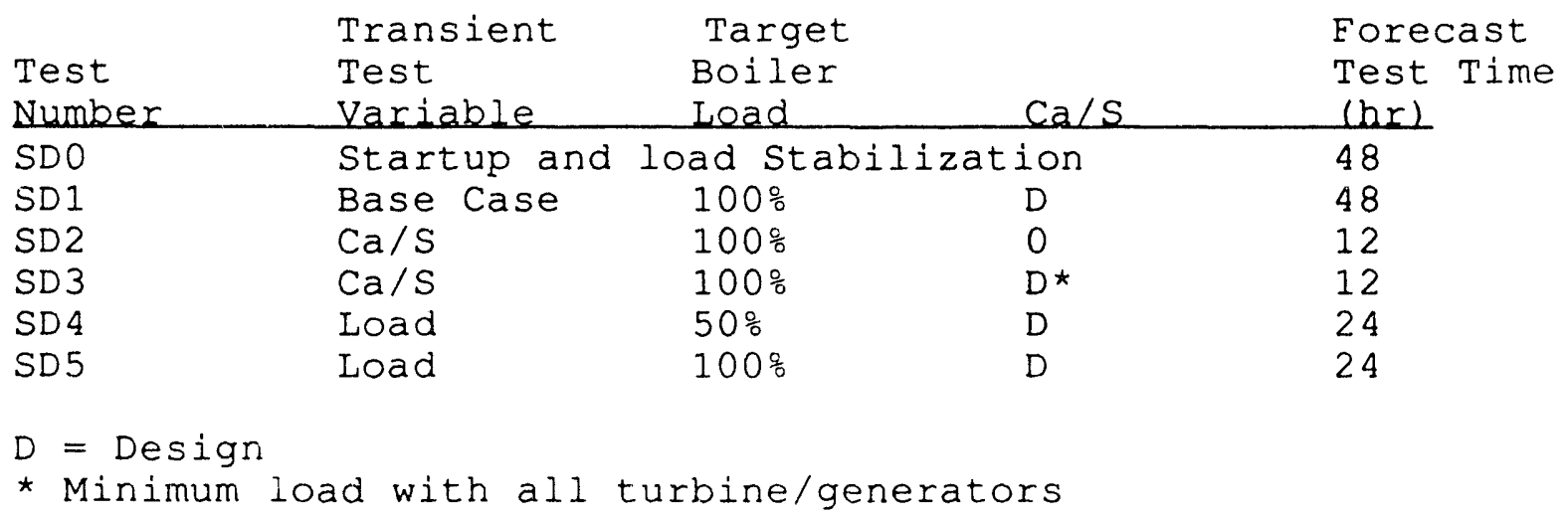


Hot-mode tests SD0 through SD5 were performed from 08:00 on March 12 through 10:00 on March 18. The unit switched from Peabody coal to the test coal, salt Creek, one day prior to the initiation of test SDO. Test SDO was actually a 24-hour hold period at steady-state conditions prior to the start of solids sampling. Test SDI was a baseline performance test whose primary objective was to determine the minimum test duration required to achieve an acceptable level of uncertainty in performance calculation results. Tests SD2 and SD3 determined the response time of $\mathrm{SO}_{2}$ emissions following a complete stoppage of limestone flow into the boiler, and after resumption of limestone feed at twice the previous rate. Tests SD4 and SD5 measured the plant response to a load change.

The plant was operated at steady-state at close to full load (105 MWe) from 08:00 on March 13, 1989 to 08:00 on March 15, 1989. During this time, instrument readings from the plant control system data highway were recorded by the data acquisition system every 30 seconds and solids samples were collected every 2 to 4 hours.

\subsection{HOT-MODE TEST RESULTS}

\subsubsection{Determination of the Number of Solids Samples Required}

There are four solids streams to consider in uncertainty analyses: coal and limestone entering the boiler and bottom ash and fly ash exiting the boiler. Plots in the 1987-1988 Annual Report graphically show the variation in the composition of the four solids streams over the duration of the test. Generally, solids analyses from test SDI indicate that salt Creek coal has a low composition variability. Plots of scatter in solids analysis can also be useful in troubleshooting the solids sampling and preparation procedures; for example, unusually high readings of carbon content in some bottom ash samples led to the realization that samples had been prepared in a crusher that had not been rinsed with bottom ash prior to use.

The six main types of measurements used as inputs to the performance calculations are:

- Pressure (or pressure difference)

- Temperature

- Fluid flow rate

- Solid flow rate

- Gas chemical analysis

- Solid chemical analysis

The uncertainty in a measured variable has two components - a precision component and a bias component. Precision error is 
a function of the number of readings and the scatter in those readings. A larger number of readings during a steadier process will generally lead to a smaller precision error. Bias error is that component of the uncertainty which is fixed from one reading to the next. Also known as systematic error, it is a function of instrument accuracy and is estimated using equipment specifications and engineering judgement. See section 4.2.5.2 for more information on measurement uncertainty.

Shown in Table 5-1 are the major contributors to uncertainty in the calculation of boiler efficiency by the losses method. Figure 5-1 shows how the uncertainty in boiler efficiency (loss method) decreases with time.

In Table 5-1, the input variables for a given result are shown in the order of maximum contribution for the results calculated over the 48-hour run period. The numbers shown for the contribution are equivalent to the terms $\mathrm{Br}^{2}$ (bias limit of the result) and $\operatorname{srr}^{2}$ (Student $t$ factor multiplied by the precision index of the result) as described in section 3.2.5.2. Contributions shown are those whose values are greater than one percent. of the value of the maximum contribution. The total uncertainty (shown near the top of the table) is the square root of the sum of all the contributions.

The major. contributors to uncertainty in six other important performance calculation results are shown in Tables 5-2 through 5-7 and the corresponding plots of the uncertainty of results with time are shown in Figures 5-2 through 5-7. The tables and plots are shown for the following performance calculation results:

- Boiler efficiency (I/O method)

- Ca/s molar ratio

- $\mathrm{SO}_{2}$ retention ( $\left.\frac{\circ}{5}\right)$

- Ca utilization

- Net heat rate

- Combustion efficiency

In Tables 5-1 through 5-7, a bias error is always the largest contributor to the uncertainty for the period. The only precision errors that appear are those associated with solids analysis, and a larger number of readings will generally lead to a smaller precision error. This leads to the conclusion that results uncertainties are reduced by increasing the number of solids samples. Also, the uncertainty obtained by taking 16 solids samples over a 48-hour steady-state period can be replicated by taking 16 solids samples over a shorter period of time. However, factors such as manpower, sample processing equipment requirements, and residence time of material in the boiler impose practical limitations on the 
Table 5-1

BOILER EEFICIENCY (LOSS METHOD)

\begin{tabular}{|c|c|c|c|c|c|c|c|c|c|c|c|c|c|}
\hline Deecripilon & $\begin{array}{l}\text { ERROA } \\
\text { TYPEE }\end{array}$ & $4 \mathrm{HR}$ & |RANK| & 8 HA & RANK & $10 \mathrm{HR}$ & |AANK| & $12 \mathrm{HR}$ & |RANK| & $24 \mathrm{HA}$ & RANK & $18 \mathrm{HA}$ & PANK \\
\hline MEAN VALUE & & 88.17 & & 88.04 & & 88.09 & & 8811 & & 8827 & & 8838 & \\
\hline TOTAL UNCERTAINTY & & 0.77 & & 0.38 & & 0.33 & & 029 & & 0.26 & & 0.23 & \\
\hline UNC CONTAIBUTIONS & & & & & & & & & & & & & \\
\hline & & & & & & & & & & & & & \\
\hline O2 Q oconmlxer llue gas oullel & BuS & 0.012 & 5 & 0.0125 & 3 & 0.0125 & 2 & 0.0124 & $\underline{2}$ & 0.0119 & 2 & 0.0119 & 1 \\
\hline HHV of tuel AF boels & P.E. & 0.419 & 1 & 0.0725 & 1 & 0.0415 & 1 & 00304 & 1 & 0.014 & 1 & 0.0079 & 2 \\
\hline Hydrogen in conl AF baele & Bus & 0.0063 & 6 & 0.00633 & 5 & 0.00633 & 5 & 0.00631 & 4 & 0.00623 & 3 & 00062 & 3 \\
\hline Cerbon in tly ash & Bus & 0.00445 & 7 & 0.00449 & 7 & 000448 & 7 & 0.00456 & 6 & 0.0045 & 5 & 00043 & 4 \\
\hline Hydrogen In fly ash & Bus & - & & 0.00405 & 8 & 000407 & 9 & 0.00414 & 7 & 0.00408 & 6 & 00039 & 5 \\
\hline Hydrogen In coel AF besis & $P E$ & 0.0182 & 4 & 0.00566 & 6 & 0.00426 & 8 & 0.00316 & 9 & 0.00466 & 4 & 0.0033 & 6 \\
\hline Cerbon In fly esh & P.E. & . & & $\cdot$ & & 0.0111 & 3 & 0.00733 & 3 & 0.00251 & 9 & 00030 & $?$ \\
\hline HHV of tuel AF basle & Bus & $\therefore$ & & 0.0032 & 9 & 0.00316 & 10 & 0.00314 & 10 & 0.00305 & 7 & 0.0030 & 8 \\
\hline Radient and convectlve losses & Bus & $\cdot$ & & 0.00211 & 10 & 00021 & 11 & 0.0021 & 11 & 0.0021 & 11 & 00021 & 9 \\
\hline Carbon in coal AF bas lo & P.E. & 0.0406 & 3 & 0.00913 & 4 & 0.00533 & 6 & 0.00365 & 8 & 000268 & 8 & 00015 & 10 \\
\hline Ash in coul AF beslo & BIAS & $\cdot$ & & 0.00165 & 11 & 0.00156 & 12 & 0.00154 & 12 & 0.00153 & 12 & 00014 & 11 \\
\hline Molsture in tuel AF besle & BuAS &. & & 0.00107 & 12 & 0.00106 & 13 & 0.00106 & 13 & 0.00105 & 13 & 0.0011 & 12 \\
\hline Ash in cool AF bosle & $P E$ & 0.0653 & 2 & 0.0135 & 2 & 0.00724 & 4 & 0.00494 & 5 & 0.00244 & 10 & 0.0010 & 13 \\
\hline
\end{tabular}

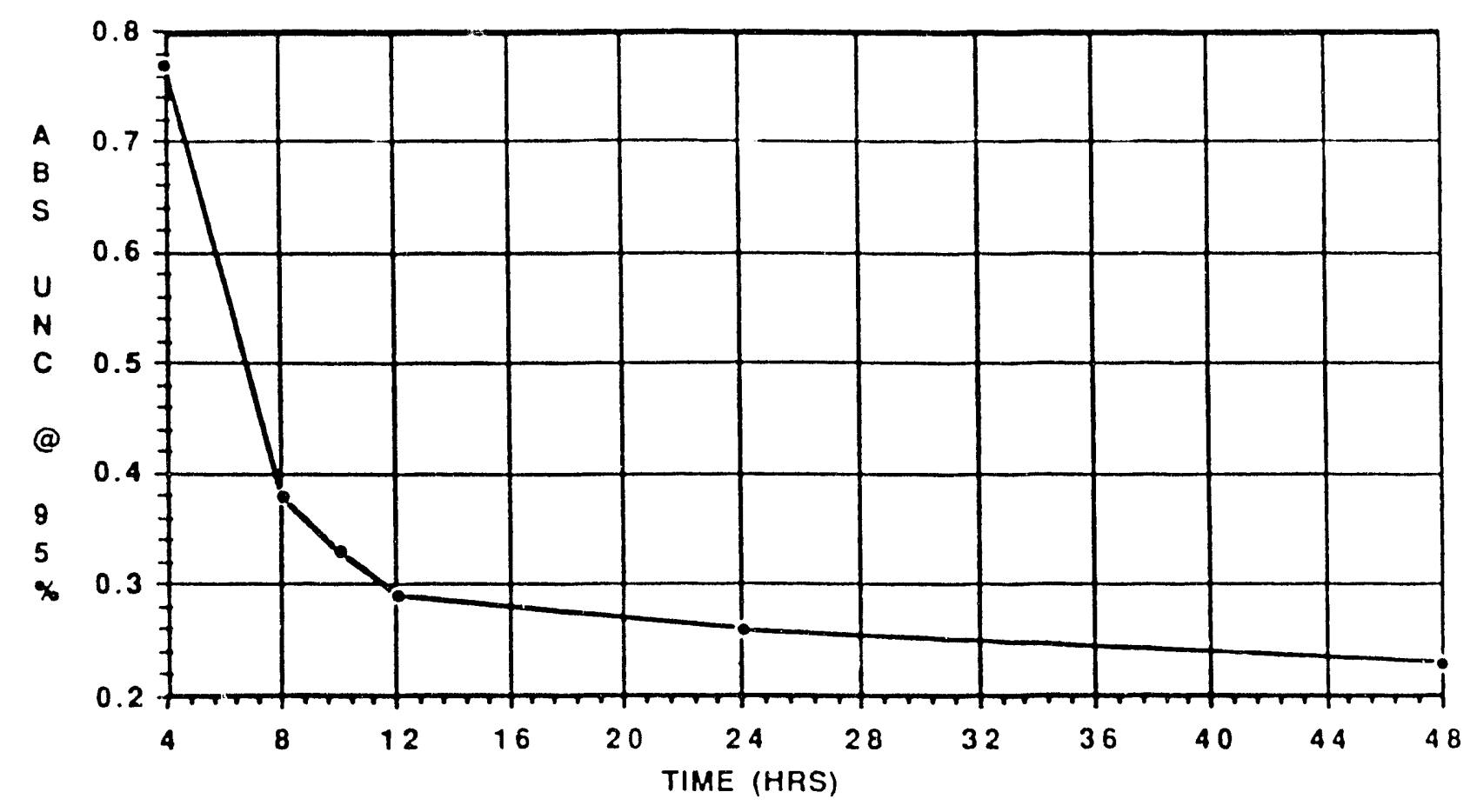

Figure 5-1. Absolute Uncertaing in poilex feficienoy (Loss Method) va. Tine. 
Table $5-2$

BOILER EFFICIENCY (I/O METHOD)

\begin{tabular}{|c|c|c|c|c|c|c|c|c|c|c|c|c|c|}
\hline Deecriplion & $\begin{array}{l}\text { EAROA } \\
\text { TYPE }\end{array}$ & 4 HA & IRAMK & - MR & |RANK & $10 \mathrm{HA}$ & |AANK & $12 \mathrm{HR}$ & |RANK & $24 \mathrm{HA}$ & |FANK & $48 \mathrm{HA}$ & RANK \\
\hline MEAN VALUE & & 86.39 & & 06.12 & & 8601 & & 8595 & & 86.07 & & 8614 & \\
\hline TOTAL UNCERTAINTY & & 6.87 & & 3.34 & & 299 & & 283 & & 2.62 & & 2.54 & \\
\hline UNC CONTAIBUTIONS & & & & & & & & & & & & & \\
\hline Foedwater llow GMP CMP & Qus & $499 \mathrm{E}+00$ & 2 & 4 & 2 & 9945,00 & 7 & 4 & & 4005,00 & 1 & $109 \mathrm{~F} \cdot 00$ & \\
\hline HHV of luol AF baele & P.E. & $4.09 E+01$ & $\frac{i}{1}$ & $5.18 E+00$ & $\frac{2}{1}$ & $301 E .00$ & 2 & $210 \varepsilon+00$ & $\frac{1}{2}$ & \begin{tabular}{|l|}
$9.22 \mathrm{E} \cdot 01$ \\
\end{tabular} & $\frac{1}{2}$ & $\frac{9.991 .00}{4.90 E .01}$ & $\frac{1}{2}$ \\
\hline SH llB allemperator flom & BAS & & & $191 \mathrm{E} .01$ & 3 & $1.90 E \cdot 01$ & 3 & $190 \mathrm{E} \cdot 01$ & 3 & $1.91 E \cdot 01$ & 3 & $1.92 \mathrm{E} \cdot 01$ & 3 \\
\hline HHV of tual AF bosels & BUS & & & $1.66 E \cdot 01$ & 4 & $165 E .01$ & 4 & $1.64 \mathrm{E} \cdot 01$ & 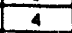 & $1.64 E \cdot 01$ & 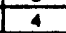 & $165 \mathrm{E} .01$ & 4 \\
\hline Caol llow cmb a, rear wall(4D) & BIAS & & & $847 E-02$ & 5 & $8.45 E \cdot 02$ & 5 & $8.46 E .02$ & 5 & $8.50 E .02$ & 5 & $8.55 E \cdot 0 ?$ & 5 \\
\hline 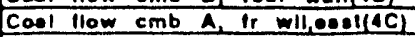 & Bus & & & $8.43 E \cdot 02$ & 6 & $811 E .02$ & 6 & $841 E .02$ & $\frac{7}{7}$ & $844 E-02$ & $\frac{5}{6}$ & $849 E .02$ & $\frac{5}{6}$ \\
\hline Cool llow cmb A rear woll (AA) & BIAS & & & $827 E .02$ & 8 & $826 \mathrm{E} \cdot 02$ & 7 & $8.26 \mathrm{E} .02$ & 8 & $8.29 \mathrm{E} .02$ & 7 & $8.32 \mathrm{E} .02$ & $\frac{5}{7}$ \\
\hline Cool llow cmb B, Ir wll,onell(4E) & BIAS & & & $8.24 E \cdot 02$ & 9 & $823 E \cdot 02$ & 8 & $8.23 E .02$ & 9 & $8.26 \mathrm{E} \cdot 02$ & 8 & $8.30 \mathrm{E} .02$ & 8 \\
\hline Casl llow cmb $A_{1}$ It wil, wo:1(4B) & BIAS & & & $0.12 E \cdot 02$ & 10 & $8.10 E .02$ & 9 & $8.10 E .02$ & $\frac{10}{10}$ & B.15E.02 & $\frac{9}{9}$ & $820 E \cdot 01$ & 9 \\
\hline Cool llow cmb B, It wll,wostl(ff) & BIAS & & & B.08E.02 & 11 & $806 \mathrm{E} \cdot 02$ & 10 & $806 E .02$ & 11 & $810 E \cdot 02$ & 10 & $814 E \cdot 02$ & 10 \\
\hline Foodwalef Tomp & Bus & & & $841 E .02$ & 7 & $699 \mathrm{E} \cdot 02$ & 11 & 8.44 .02 & 6 & $5.87 \mathrm{E} .02$ & 11 & $638 E \cdot 0$ & 11 \\
\hline
\end{tabular}

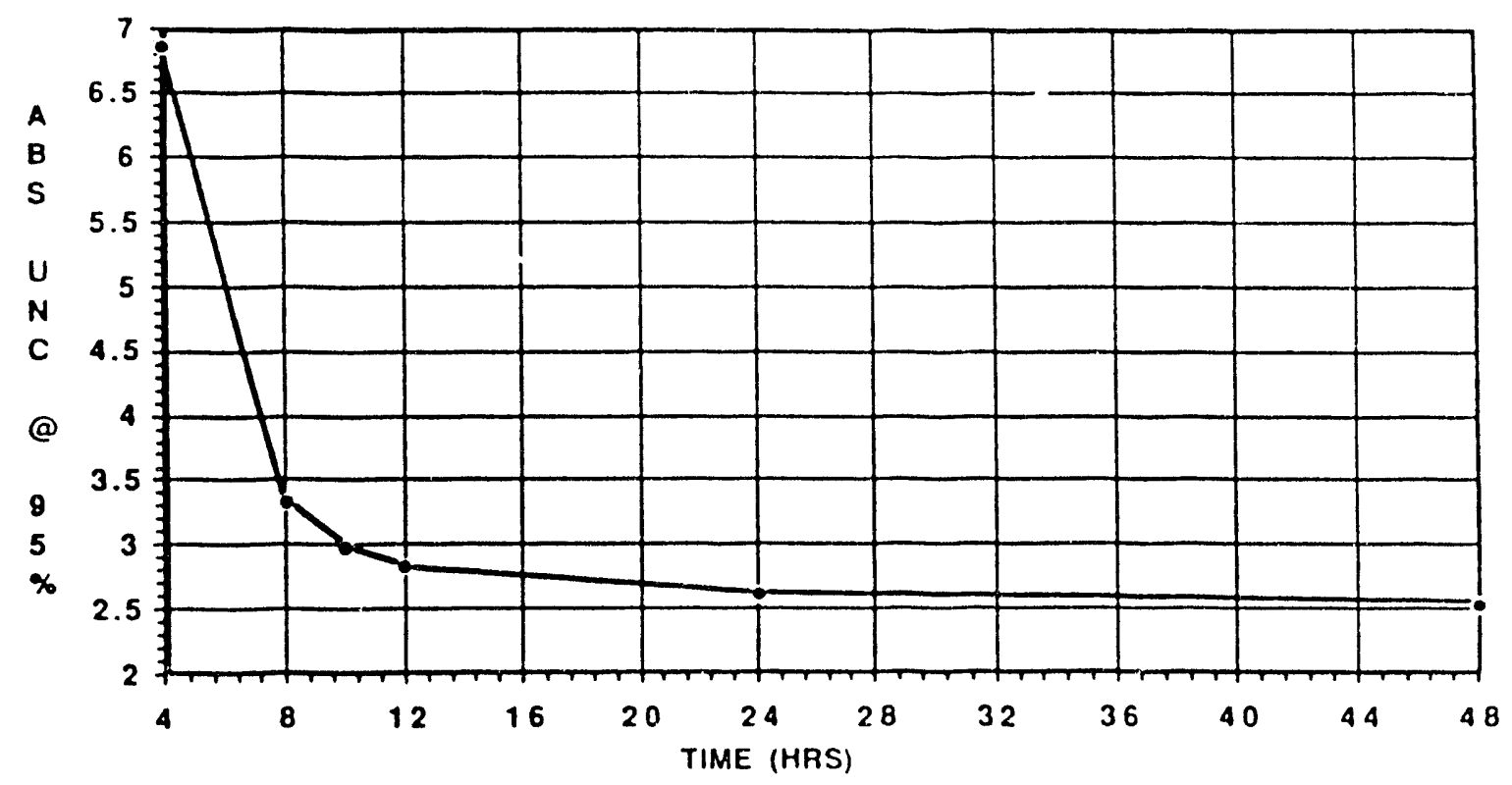

Figure 5-2. Absolute Uncertainty in Boiler Efficiency (I/O Method) vs. Time. 
Table 5-3

Ca/S MOLAR RATIO (SORBENT ONLY)

\begin{tabular}{|c|c|c|c|c|c|c|c|c|c|c|c|c|c|}
\hline Descriplion & $\begin{array}{l}\text { ERPOF } \\
\text { TYPE }\end{array}$ & $\triangle M A$ & IRANK & $B$ HR & RANK & $10 \mathrm{HA}$ & RANK & $12 \mathrm{HA}$ & |AANK & $24 \mathrm{HA}$ & PANK & $18 \mathrm{HA}$ & RANK \\
\hline MEAN VALUE & & 1.4 & & 138 & & 139 & & 141 & & 141 & & 148 & \\
\hline TOTAL UNCERTAINTY & & 044 & & 022 & & 019 & & 018 & & 017 & & 017 & \\
\hline \multirow{2}{*}{\multicolumn{14}{|c|}{ UNC CONTAIBUTIONS }} \\
\hline & & & & & & & & & & & & & \\
\hline & & & & & & & & & & & & & \\
\hline Sullur in conl af besis & BAS & $196 E .02$ & 2 & $194 \mathrm{E} \cdot 02$ & 2 & $1.97 \mathrm{E} \cdot 02$ & 1 & $205 E \quad 02$ & 1 & 209502 & 1 & $231 E .02$ & 1 \\
\hline Sullur In cosl af besis & $P E$ & $169 E .01$ & 1 & $236 E .02$ & 1 & $1.41 \mathrm{E} .02$ & 2 & $962 \mathrm{E} .03$ & 2 & $433 E \cdot 03$ & 2 & $219 E \cdot 03$ & 2 \\
\hline Sortuent lood rale CMB AA & BIAS & 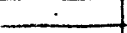 & & $124 E .03$ & 3 & $1.27 E .03$ & 3 & $130 E-03$ & 3 & $130 E .03$ & 3 & $144 \mathrm{E} .03$ & 3 \\
\hline Sorbenl lood rale CMB $1 \mathrm{~B}$ & BNAS & $\therefore$ & & $118 E .03$ & 4 & $1.17 \mathrm{E} .03$ & 4 & $119 E .03$ & 4 & $120 E .03$ & 4 & $134 E .03$ & 4 \\
\hline Colctum in lime AF basis & $P E$ & - & & $648 E .04$ & 5 & $586 \mathrm{E} .04$ & 5 & $983 \mathrm{E} 04$ & 5 & $445 E \cdot 04$ & 5 & $234 E \cdot 04$ & 5 \\
\hline
\end{tabular}

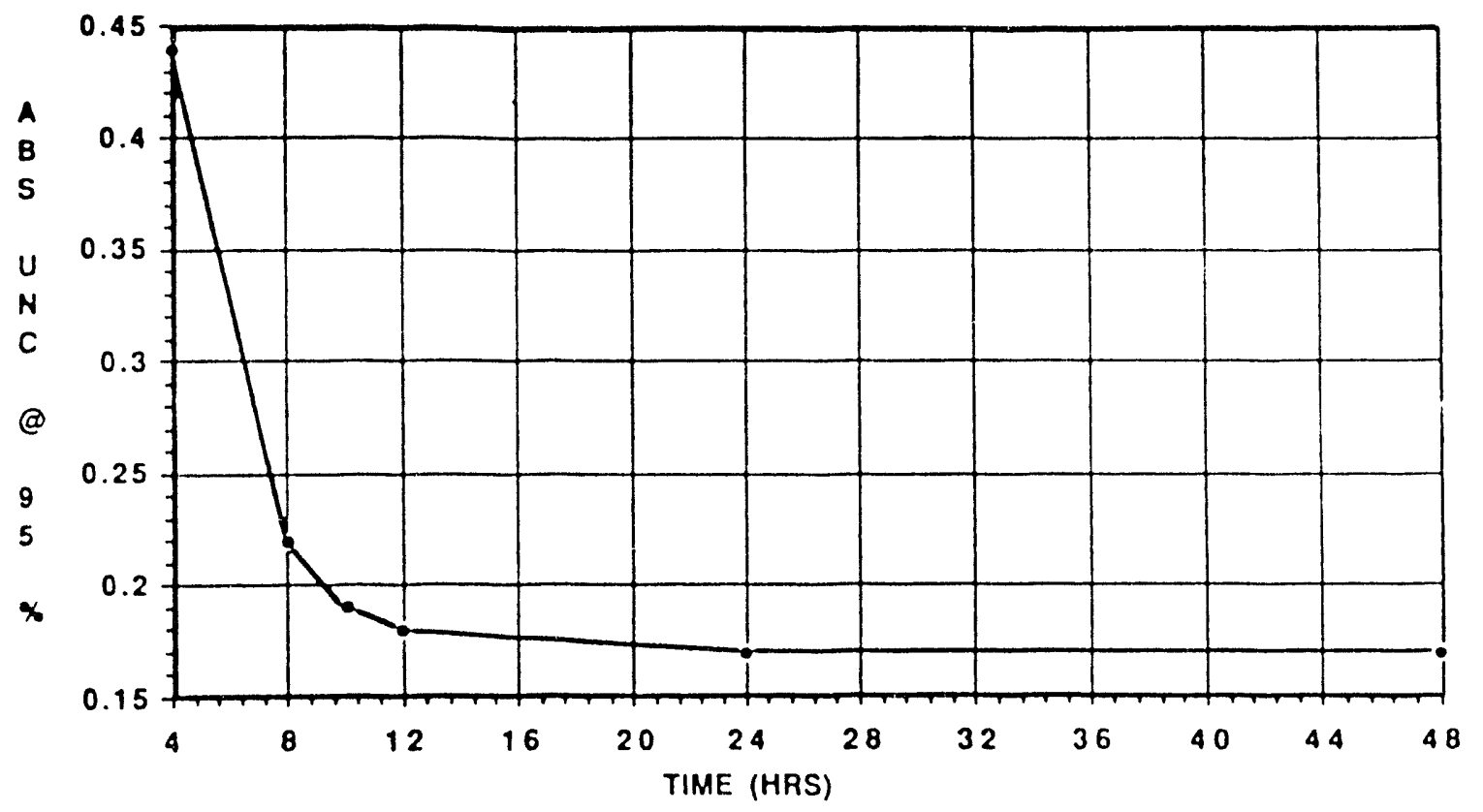

Figure 5-3. Absolute Uncertainty in Ca/S Molar Ratio (Sorbent) vs. Time. 
Table 5-4

SULFUR DIOXIDE RETENTION PERCENT

\begin{tabular}{|c|c|c|c|c|c|c|c|c|c|c|c|c|c|}
\hline Descripllon & $\begin{array}{l}\text { ERROF } \\
\text { TYPE }\end{array}$ & $4 M R$ & JRANK & - $\mathrm{ma}$ & IRANK & $10 \mathrm{HA}$ & |AANK & $12 \mathrm{HR}$ & |RANK & $24 \mathrm{HA}$ & JRANK & $48 \mathrm{HA}$ & JRANK \\
\hline MEAN VALUE & & 702 & & 69.28 & & 6913 & & 6883 & & 6866 & & 6848 & \\
\hline TOTAL UNCEAIAINTY & & 9.62 & & 5.23 & & 4.76 & & 459 & & 431 & & 418 & \\
\hline UNC CONTAIQUTIONS & & & & & & & & & & & & & \\
\hline & & & & & & & & & & & & & \\
\hline Sullur in caal aF basle & Bus & $8.69 E+00$ & 2 & $9.49 E+00$ & 2 & $9.65 E+00$ & 1 & $9.98 E .00$ & 1 & $1.03 E+01$ & 1 & $1.04 E+01$ & 1 \\
\hline SO2 L LO/ Q econ fluo ges & ous & $4.92 \mathrm{E}+00$ & 3 & $5.13 E+00$ & 3 & $5.15 E+00$ & 3 & $5.22 E .00$ & 2 & $535 E \cdot 00$ & 2 & $5.39 E+00$ & 2 \\
\hline Sullur in coel AF baele & F.E & $7.51 \mathrm{E}+01$ & 1 & $1.16 E+01$ & 1 & $6.90 E+00$ & $\frac{2}{2}$ & $502 E+00$ & 3 & $2,18 E \cdot 00$ & 3 & $989 \mathrm{E} .01$ & 3 \\
\hline O2 al econ llue gat oullol & BUS & & & $5.43 \mathrm{E} \cdot 01$ & 5 & $5.18 E .01$ & 4 & $5.58 E .01$ & 4 & $5.65 \mathrm{E}-01$ & 4 & $574 E \cdot 01$ & 4 \\
\hline Carbon in coal AF opele & P.E & $3.19 E+00$ & 4 & $5.53 \mathrm{E} \cdot 01$ & 4 & $3.29 \mathrm{E} \cdot 01$ & 5 & $219 \mathrm{E} .01$ & 5 & $1.52 \mathrm{E} \cdot 01$ & 5 & & \\
\hline
\end{tabular}

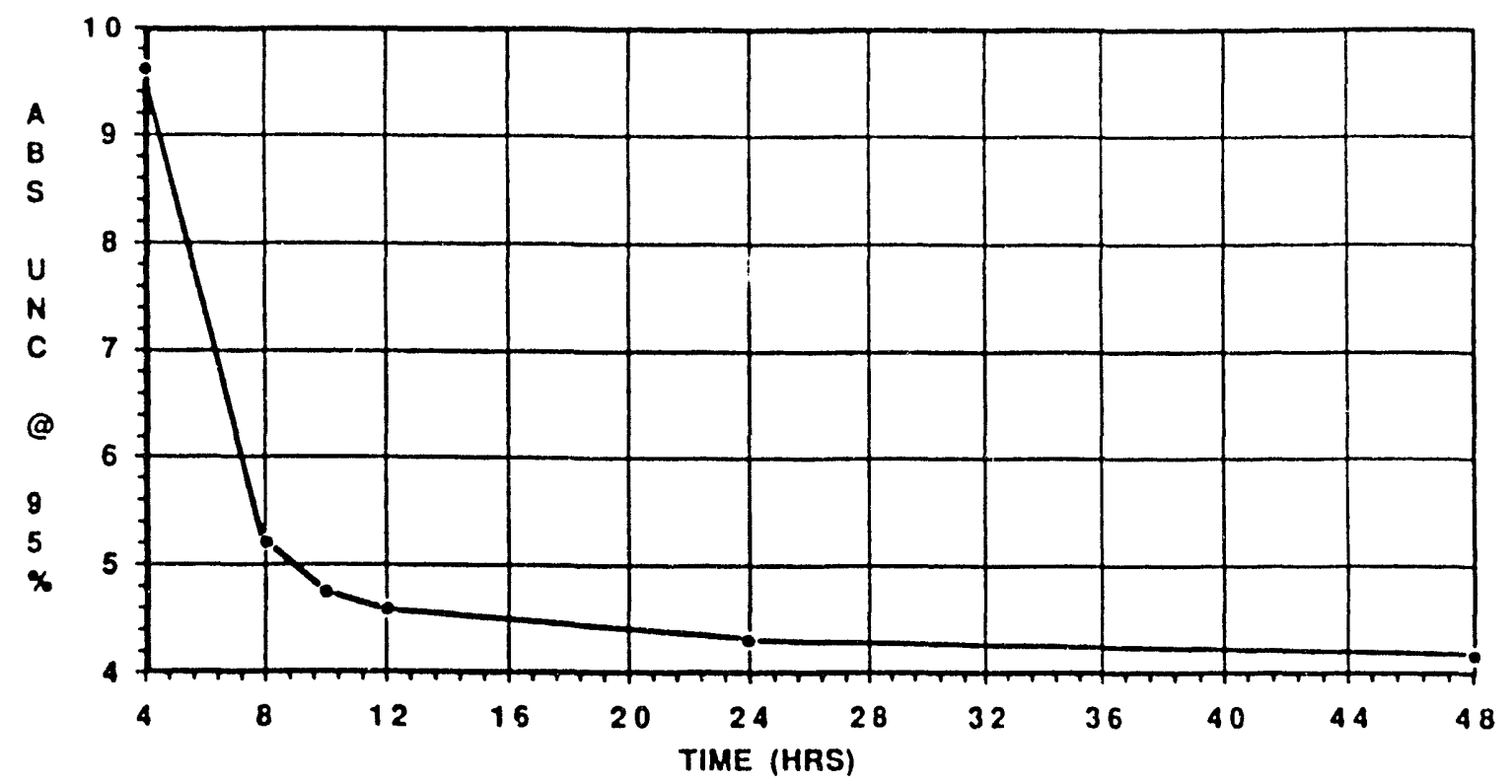

Eigure 5-4. Absolute Uncertainty in Sulfur Dioxide Retention vs. Time. 
Table 5-5

CALCIUM UTILIZATION (SORBENT ONLY)

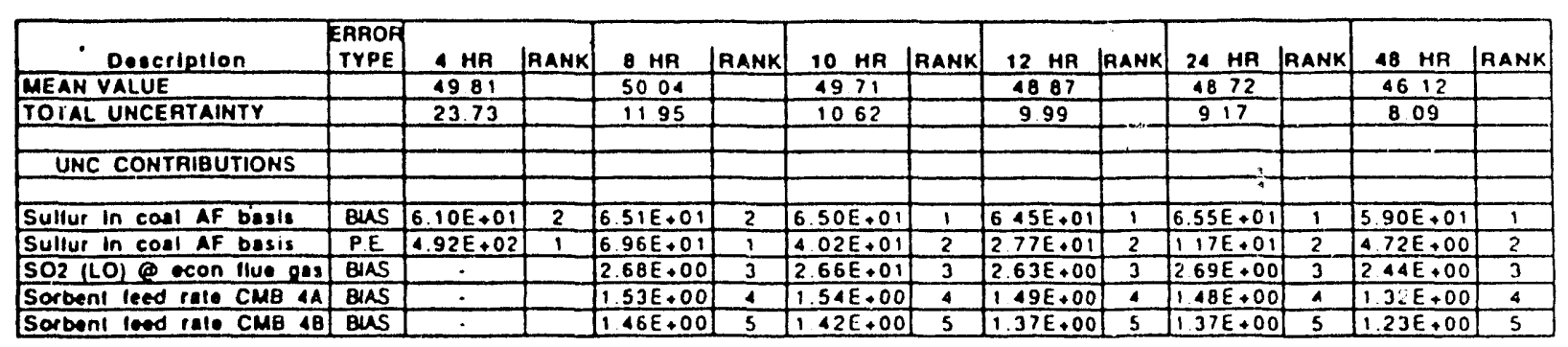

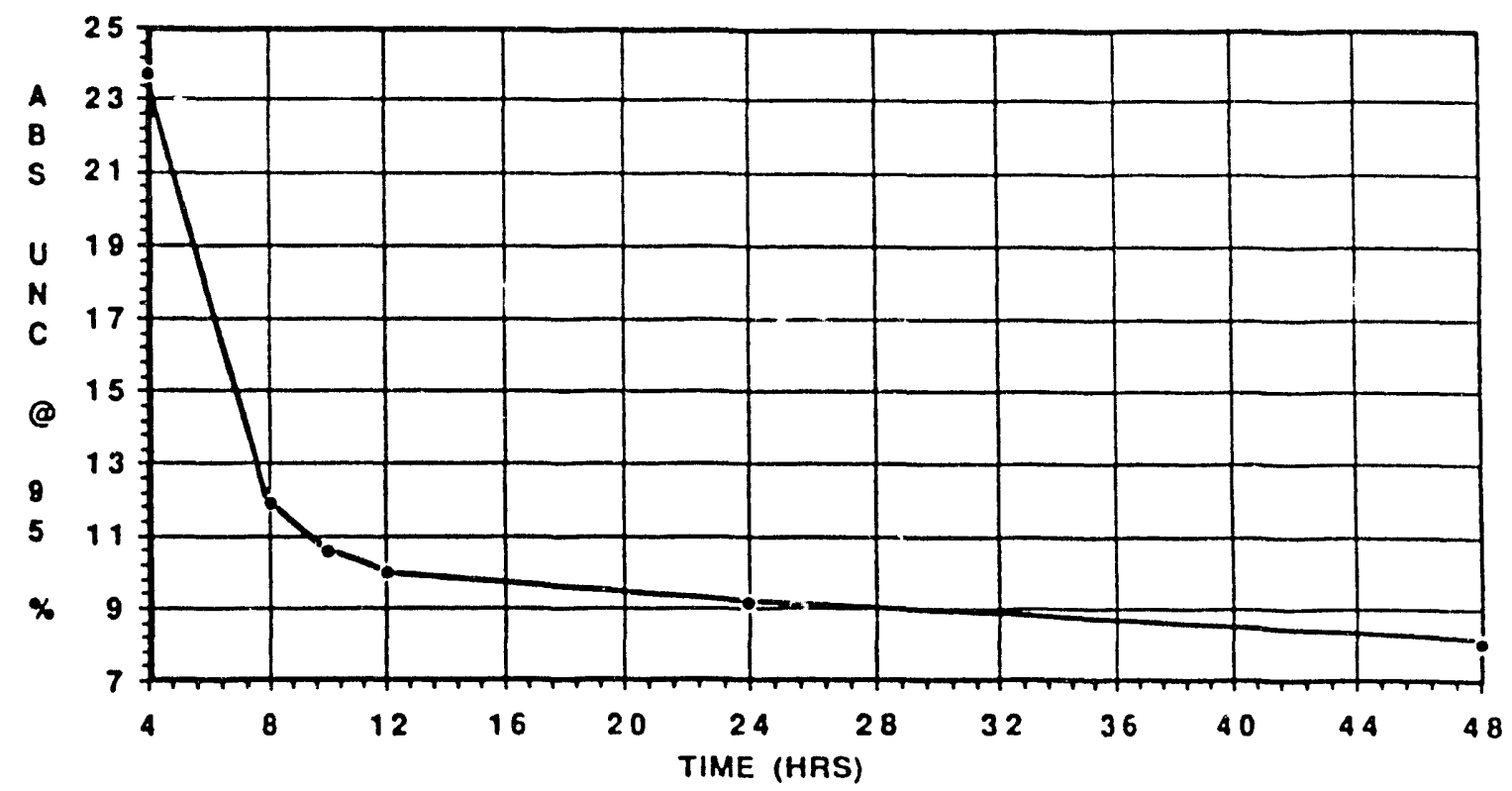

Figure 5-5. Absolute Uncertainty in Calcium Utilization (Sorbent) vs. Time. 
Tabie $5-6$

NET PLANT HEAT RATE

\begin{tabular}{|c|c|c|c|c|c|c|c|c|c|c|c|c|c|}
\hline Descripllon & $\begin{array}{l}\text { ERROA } \\
\text { TYPE }\end{array}$ & $4 \mathrm{HR}$ & |RANK| & HR & |RANK| & $10 \mathrm{MA}$ & |RANK| & $12 \mathrm{HR}$ & |RANK & $24 \mathrm{MP}$ & |RANK| & $48 \mathrm{HR}$ & JRANK \\
\hline MEAN VALUE & & 112605 & & 113015 & & 113141 & & 113252 & & 112977 & & 112565 & \\
\hline TOTAL UNCERTAINTY & & 878 & & 351 & & 291 & & 260 & & 214 & & 194 & \\
\hline & & & & & & & & & & & & & \\
\hline UNC CONTAIBUTIONS & & & & & & & & & & & & & \\
\hline & & & & & & & & & & & & & \\
\hline Tolel lood in MW $1,2,3,4$ & ens & 17200 & 2 & $1.74 E \cdot 04$ & 2 & $1.74 E \cdot 04$ & 2 & $175 E+04$ & 2 & $173 E \cdot 04$ & 1 & $171 E .04$ & 1 \\
\hline HHV of tuel AF bosls & P.E. & 73900 & 1 & $935 E \cdot 04$ & 1 & $546 E \cdot 04$ & 1 & $380 E \cdot 04$ & 1 & $1.64 E+04$ & 2 & $862 \mathrm{E} .03$ & 2 \\
\hline HHV of fuel AF beals & Bus & - & & $2.97 \mathrm{E} .03$ & 3 & $297 E \cdot 03$ & 3 & $296 \mathrm{E} .03$ & 3 & $293 \mathrm{E} \cdot 03$ & 3 & $2.91 E .03$ & $\frac{2}{3}$ \\
\hline Coal llow cmb 8 , reer woll $(40)$ & Bus & $\therefore$ & & $1.47 E .03$ & 4 & $147 \mathrm{E} .03$ & 1 & $148 E \cdot 03$ & 4 & $1.47 E .03$ & 4 & ISIE.03 & 8 \\
\hline Cosl flow cmb A if wll, $1,1 /(4 C)$ & BUS & $\overline{-}$ & & $146 E .03$ & 5 & $146 E .03$ & 5 & $1.7 E .03$ & 5 & $1.6 E .00$ & 5 & $146 E .03$ & 7 \\
\hline Cosl llow cmb A reat wall $(A A)$ & BuS & & & $143 E .03$ & 6 & $144 \mathrm{E} .03$ & 6 & $144 E .03$ & 6 & $144 E \cdot 00$ & 6 & $143 E+03$ & $\epsilon$ \\
\hline Cosl flow cmb B If wll,ess!(4E) & BLAS & $\dot{-}$ & & $143 E .03$ & 7 & $143 E .03$ & 7 & $144 E .03$ & 7 & $143 E \cdot 03$ & 7 & $142 \mathrm{E} .03$ & 5 \\
\hline Call flow cmt A, If wll,west(48) & BuS & $\cdot$ & & $140 E \cdot 03$ & 8 & $141 E .03$ & 8 & $1.1 E+03$ & $B$ & $1+1 E+03$ & 8 & $141 E \cdot 03$ & 4 \\
\hline Coul llow cmb B, ir wll,wesl(4f) & Bus & & & $1.0 E \cdot 03$ & 9 & $140 E .03$ & 9 & $111 E .03$ & 9 & $140 E \cdot 03$ & 9 & $140 E .03$ & 3 \\
\hline Unll ouslliory Irenslormer uW & Bus & & & & & $578 E .02$ & 10 & $579 E .02$ & 10 & $572 \mathrm{E} .02$ & 10 & $566 E .02$ & 10 \\
\hline
\end{tabular}

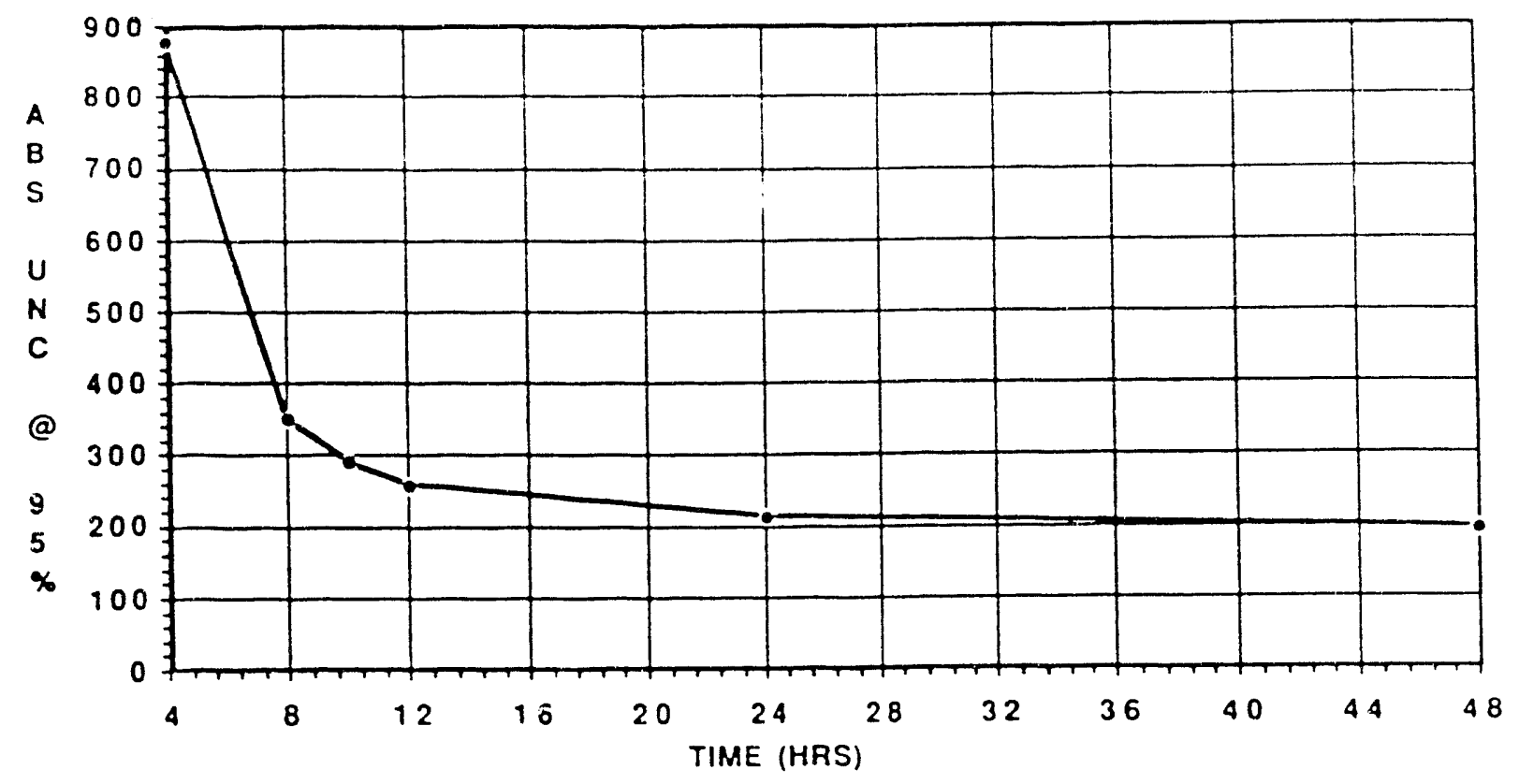

Eigure 5-6. Absolute Uncertainty in Net Plant Heat Rate vs. Time. 
Table 5-7

COMBUSTION EFEICIENCY

\begin{tabular}{|c|c|c|c|c|c|c|c|c|c|c|c|c|c|}
\hline Description & $\begin{array}{l}\text { ERPOF } \\
\text { YYPE }\end{array}$ & $4 \mathrm{HR}$ & |RANK| & $8 \mathrm{HR}$ & |RANK & $10 \mathrm{HA}$ & |RANK & $12 \mathrm{HR}$ & IRANK. & $24 M R$ & RANK & $48 \mathrm{MR}$ & LANK \\
\hline MEAN VALUE & & 98.04 & & 9804 & & 98.08 & & 98.07 & & 9809 & & 9818 & \\
\hline \multirow[t]{2}{*}{ TOTAL UNCERTAINTY } & & 0.32 & & 018 & & 0.19 & & 017 & & 0.14 & & 013 & \\
\hline & & & & & & & & & & & & & \\
\hline \multicolumn{14}{|l|}{ UNC CONTRIBUTIONS } \\
\hline & & & & & & & & & & & & & \\
\hline Carbon in llyash & BUAS & 9.04E.03 & 3 & $5.10 E \cdot 03$ & 2 & $5.10 \mathrm{E} \cdot 03$ & 3 & $519 E \cdot 03$ & 3 & $5.08 \mathrm{E} \cdot 03$ & 1 & $484 E \cdot 03$ & 1 \\
\hline Hydrogen in flyesh & BLAS & $4.11 E \cdot 03$ & 4 & $4.16 E .03$ & 3 & $4.18 E \cdot 03$ & 4 & $426 E .03$ & 4 & $417 E .03$ & 2 & $400 E \cdot 03$ & 2 \\
\hline Cerbon In llyash & P.E & $1.71 \mathrm{E} \cdot 03$ & 8 & $7.67 \mathrm{E} \cdot 04$ & 7 & $3.60 \mathrm{E} \cdot 02$ & 1 & $8.72 \mathrm{E} .03$ & 1 & $2.90 E \cdot 03$ & 3 & $365 E .03$ & 3 \\
\hline Ash In cosl AF besis & BLAS & $1.79 E \cdot 03$ & 7 & $1.78 E .03$ & 5 & $1.68 \mathrm{E} \cdot 03$ & 5 & $1.67 \mathrm{E}-03$ & 5 & $1.64 E .03$ & 5 & $153 \mathrm{E} \cdot 03$ & 4 \\
\hline Ash In cool AF besls & $P E$ & $7.06 E \cdot 02$ & 1 & $1.56 E \cdot 02$ & 1 & $8.44 E \cdot 03$ & 2 & $5.58 E .03$ & 2 & $268 \mathrm{BE} \cdot 03$ & 4 & $114 \mathrm{E} .03$ & 5 \\
\hline Bed druin rolo CMB 48 & BLAS & $\cdot$ & & $5.52 \mathrm{E} \cdot 04$ & 9 & $4.94 E .04$ & 7 & $4.11 E \cdot 04$ & 7 & $410 E-04$ & 6 & $449 E-04$ & 6 \\
\hline Carbon in bed drain & BLAS & $\therefore$ & & $2.49 E .04$ & 11 & $2.37 \mathrm{E} \cdot 04$ & 10 & $218 E \cdot 04$ & 11 & $2.12 E \cdot 04$ & 9 & $242 E .04$ & 7 \\
\hline Bed drain rale CMB $1 \mathrm{~A}$ & BLAS & & & $2.51 E .04$ & 10 & $2.36 E .04$ & 11 & $2.30 E \cdot 04$ & 10 & $2.19 E .04$ & 8 & $2.30 E \cdot 04$ & 8 \\
\hline HHV of luel AF basis & $P E$ & $1.18 E .02$ & 2 & $2.15 E .03$ & 4 & $119 E .03$ & 6 & $8.63 E-04$ & 6 & $3.87 \mathrm{E} .04$ & 7 & $205 E .04$ & 9 \\
\hline Hydrogen in bed drain & BLAS & $\cdot$ & & $2.05 E .04$ & 12 & $1.80 \mathrm{E} \cdot 04$ & 12 & $1.80 E .04$ & 12 & $175 E .04$ & 10 & $2.02 \mathrm{E} \cdot 04$ & 10 \\
\hline CO2 in llyash & BLAS & 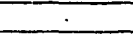 & & $1.67 E .04$ & 13 & $1.75 E .04$ & 13 & $175 E \cdot 04$ & 13 & $17 ? \mathrm{E} \cdot 04$ & 12 & $169 E .04$ & 11 \\
\hline Hydrogen in llyash & $P E$ & $340 E \cdot 03$ & 5 & $8.79 E .04$ & 6 & $4.63 E \cdot 04$ & 8 & $2.96 E \cdot 04$ & 8 & $1.5: E .04$ & 13 & $100 E \cdot 04$ & 12 \\
\hline Carbon in bed drain & $P E$ & $252 E .03$ & 6 & $576 E \cdot 04$ & 8 & $3.68 E \cdot 04$ & 9 & $280 E \cdot 04$ & 9 & $173 E .04$ & 11 & $945 E \cdot 05$ & 13 \\
\hline HHV of fuel AF basis & BLAS & 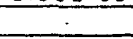 & & 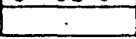 & & & & & & $826 E \cdot 05$ & 14 & $745 E .05$ & 14 \\
\hline
\end{tabular}

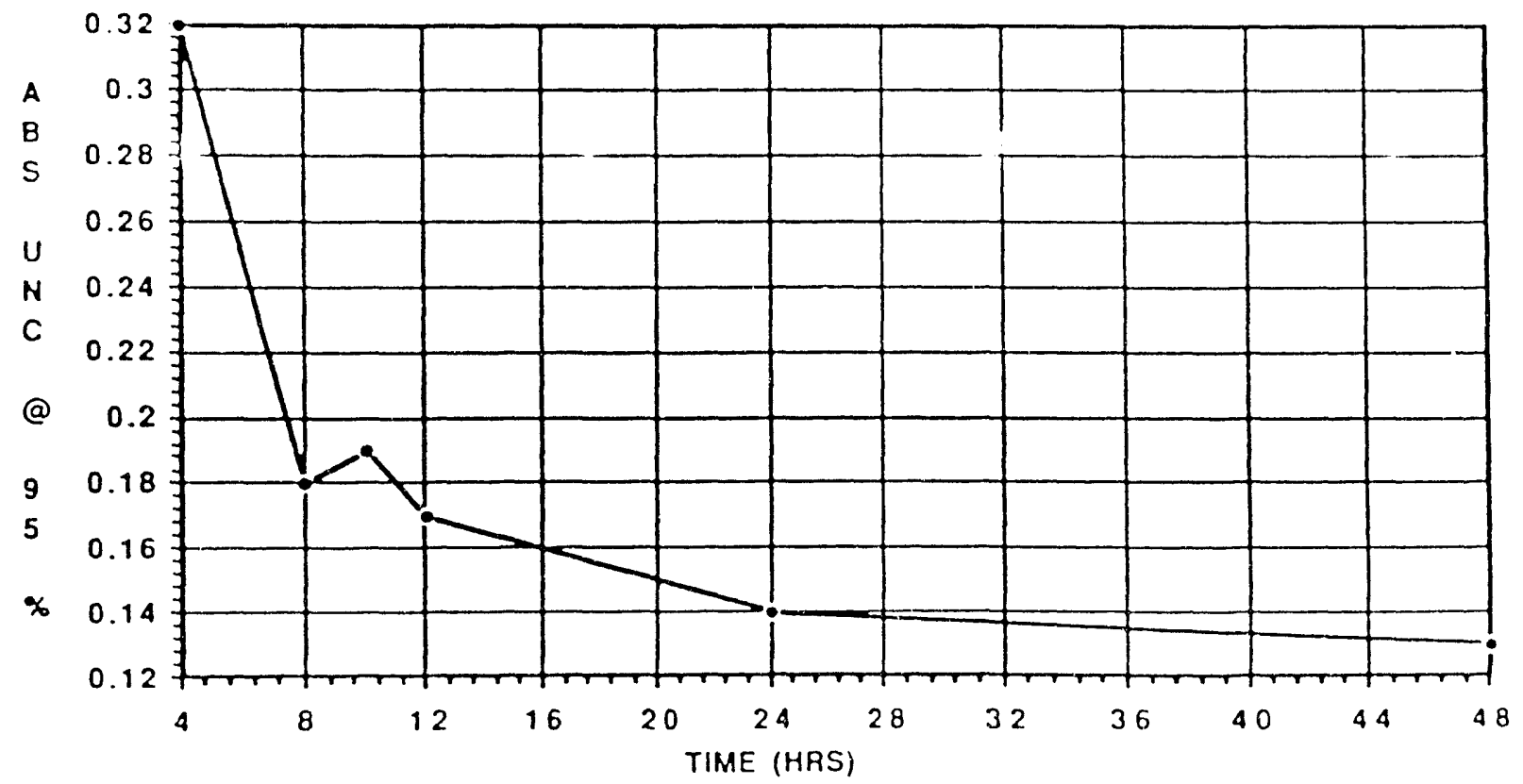

Eigure 5-7. Absolute Uncertainty in Combustion Efficiency vs. Time. 
feasible increases in sampling frequency and corresponding decreases in test duration.

For four out of the seven major calculated results, (Ca/S ratio, $\mathrm{SO}_{2}$ retention, calcium utilization, and boiler efficiency (I/O method)) the contribution of the largest precision error was reduced below that of the largest bias error after 10 hours (six solids samples) for test SD1. Therefore, for those variables, the point of diminishing returns has been reached with regard to minimizing uncertainty from increasing the number of samples. For combustion efficiency and net heat rate, this point is reached after 24 hours of sampling ( 10 samples). For boiler efficiency by loss method, it takes 48 hours ( 16 samples). However, since the uncertainties associated with these results are acceptably low after only 10 hours of sampling, it is not necessary to increase the number of solids samples taken to achieve a further reduction in uncertainty.

In Figures 5-2 through 5-7, it can be seen that a point of diminishing returns for uncertainty minimization is reached when a bias error becomes the top ranking contributor to the uncertainty in a given result. To further reduce the uncertainty, reduction in this top ranking bias error is required.

\subsubsection{Accuracy of Solids Preparation Procedures}

Concerning the accuracy of solids preparation procedures, three tests are available for determining the acceptability of the variance of division and analysis, $\mathrm{Sda}^{2}$ : excessive variation, division and analysis variance limit (from ASTM procedures), and high uncertainties in performance analysis results (from ASME PTC 19.1).

With respect to meeting the first criteria, values obtained during repeated determinations of $\mathrm{S}_{\mathrm{da}}{ }^{2}$ may not vary excessively. Whether the amount of variation is excessive is based on the statistical "F" test, which limits the amount of the ratio of each individual measurement of $\mathrm{S}_{\mathrm{da}}{ }^{2}$ to the average of all the measurements within the group. Another check is provided by comparing the average value of each group to the overall average again using the statistical "F" factors.

Table 5-8 shows the results of the variance ratio tests for coal and bottom ash for each of the eight samples, which were divided into two groups of 4 samples each. 
Table 5-8. Results of Variance Analysis Coal Variance

Bottom Ash Variance

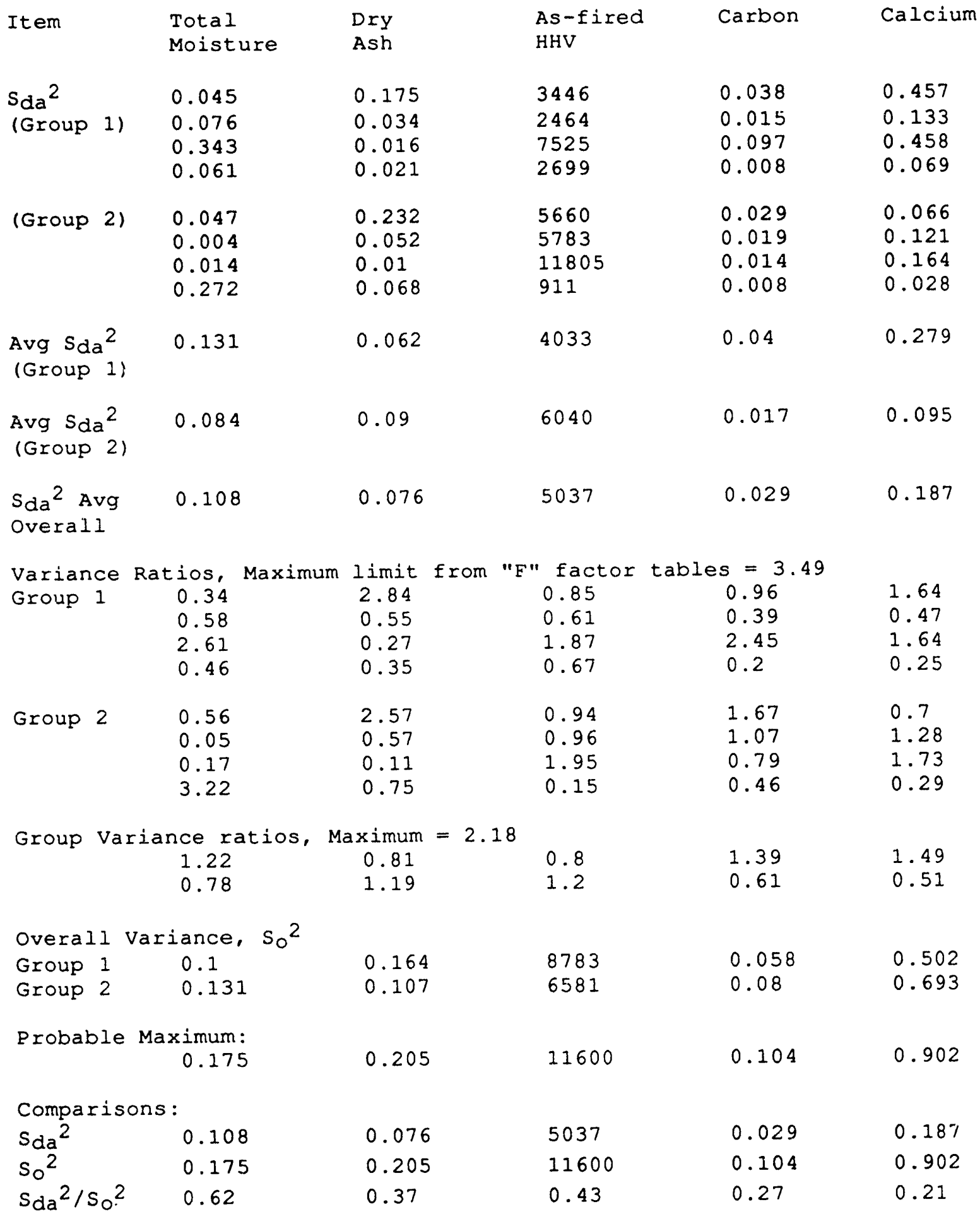


The ratio of each individual $\mathrm{S}_{\mathrm{da}}{ }^{2}$ to the average of the group of four must not exceed 3.49 (from "F" factor tables); none of the ratios exceed this limit. The ratio of each group average to the overall average must not exceed 2.18 ; none of the ratios exceed this limit, either. If any of the ratio tests fail the "F" factor criteria, ASTM methodology would have required that the techniques of preparation and analysis be improved.

The division/analysis variance limit test requires that the division and analysis variance be no more than $20 \%$ of the overall variance. The probable maximum value of $\mathrm{s}_{0}{ }^{2}$, which is used for comparison of $\mathrm{S}_{\mathrm{O}}{ }^{2}$ and $\mathrm{S}_{\mathrm{da}}{ }^{2}$, is shown. From the table, the division and analysis variance exceeds $20 \%$ of the overall variance in all instances. Since the value for $\mathrm{s}_{\mathrm{da}}{ }^{2}$ represents a precision error for solids sampling and analysis, the $20 \%$ criteria set by ASTM code becomes more difficult to achieve as the coal properties become more uniform. Improving the precision error may require mors sample increments, larger sample lot sizes, and/or sample crushing at earlier stages of preparation.

\subsubsection{Determination of the Time to Steady State}

Concerning transient tests, tests SD2 and SD3 determined the response time of $\mathrm{SO}_{2}$ emissions following a complete stoppage of limestone flow into the boiler, and after resumption of limestone feed at twice the previous rate. Results are shown in Figures 5-8 through 5-10.

Tests SD4 and SD5 measured the plant response to a fairly rapid load change. Of primary concern is the rate of change in refractory temperatures. These represent the longest lag time to thermal equilibrium of any variable. A representative cyclone refractory temperature is displayed for the load decrease and increase, respectively, in Figures 5-11 through 5-13. A noticeable difference in the response time for decreasing and increasing loads was observed. This represents the effect of higher heat transfer coefficients at higher loads.

\subsection{CONCLUSIONS}

Ultimately, the overall uncertainty in the final performance results dictates requirements for precision error for all input parameters. The uncertainty analysis program used on the test results ties the uncertainties of all input parameters to the uncertainties in the results. 


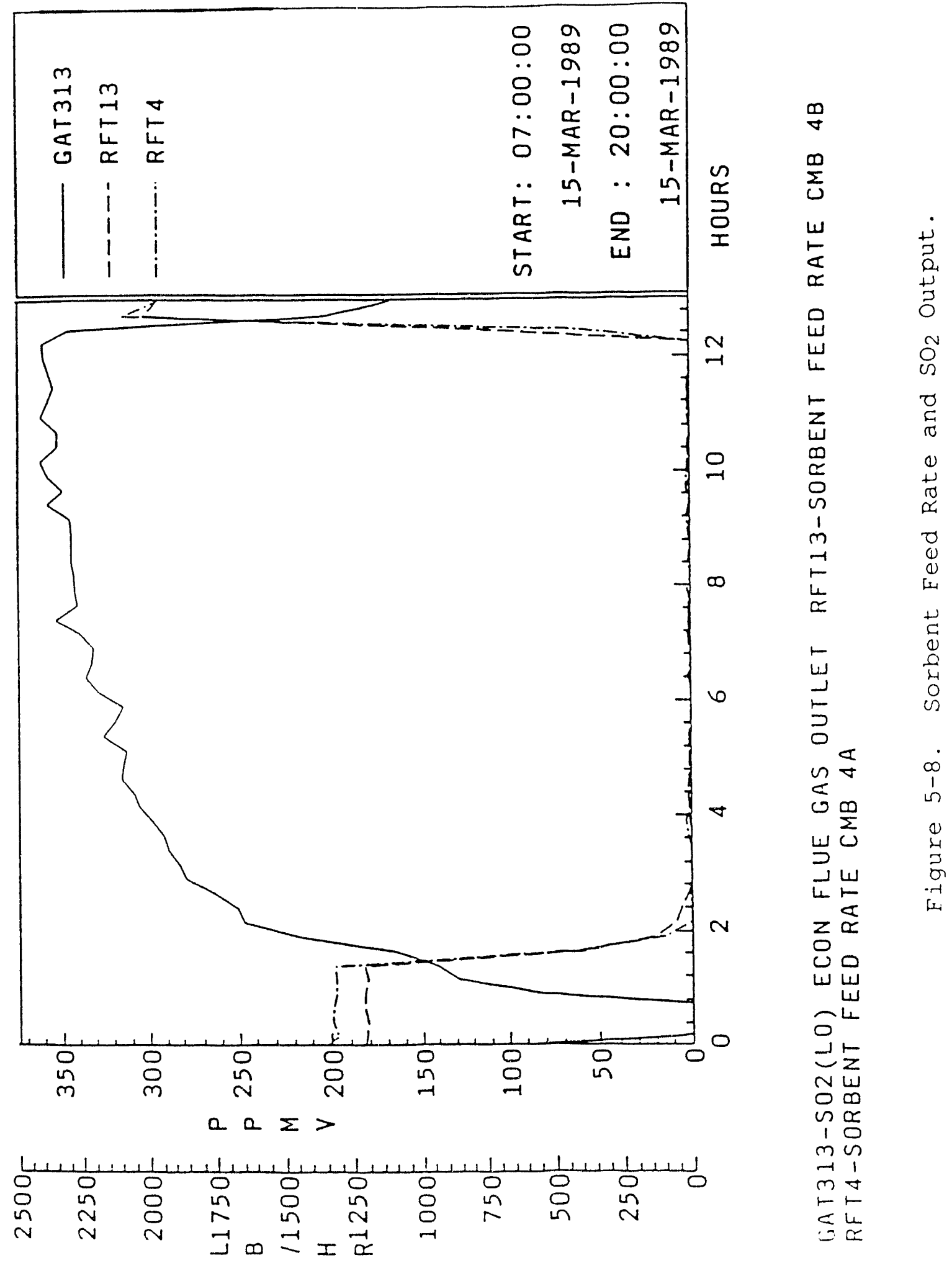




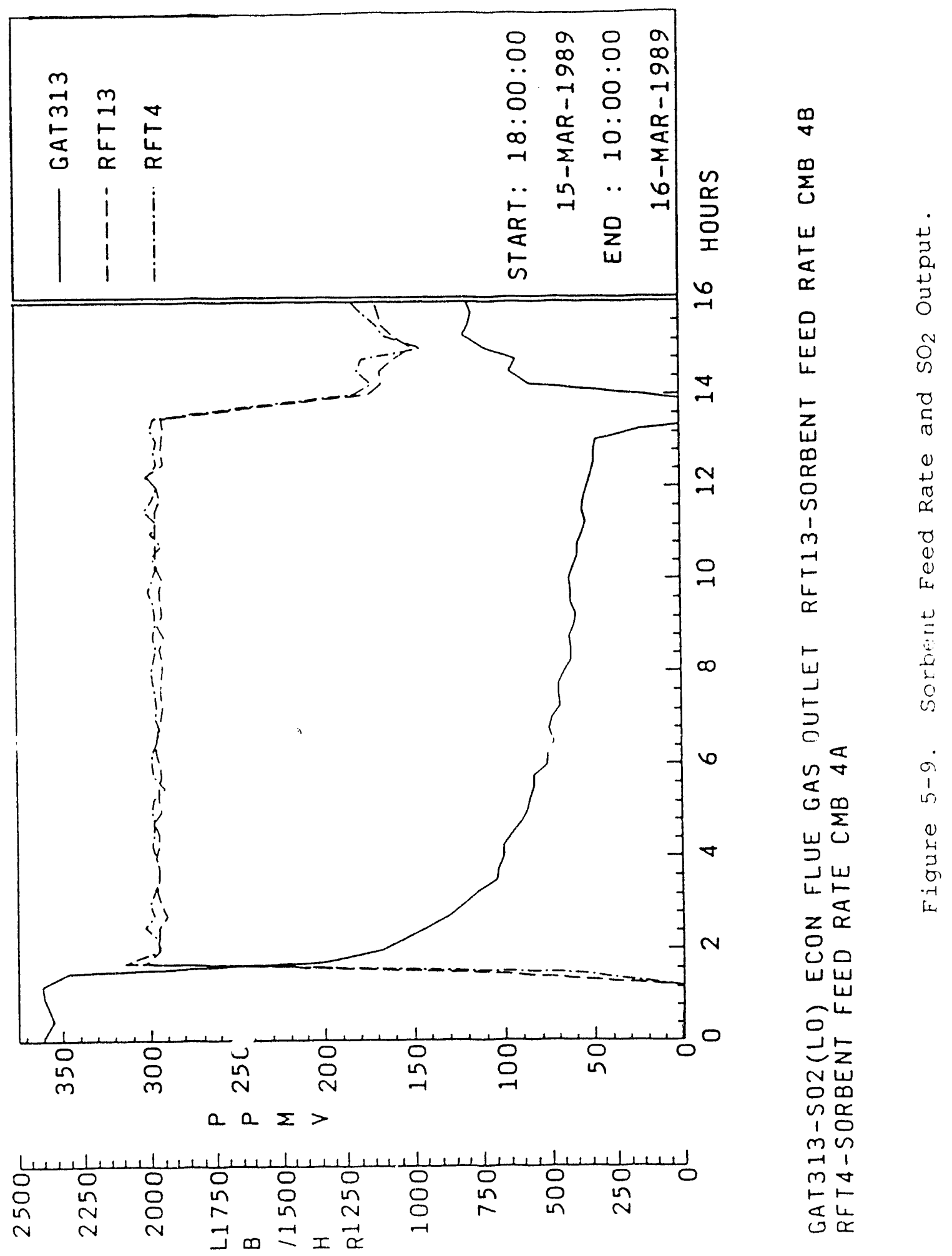




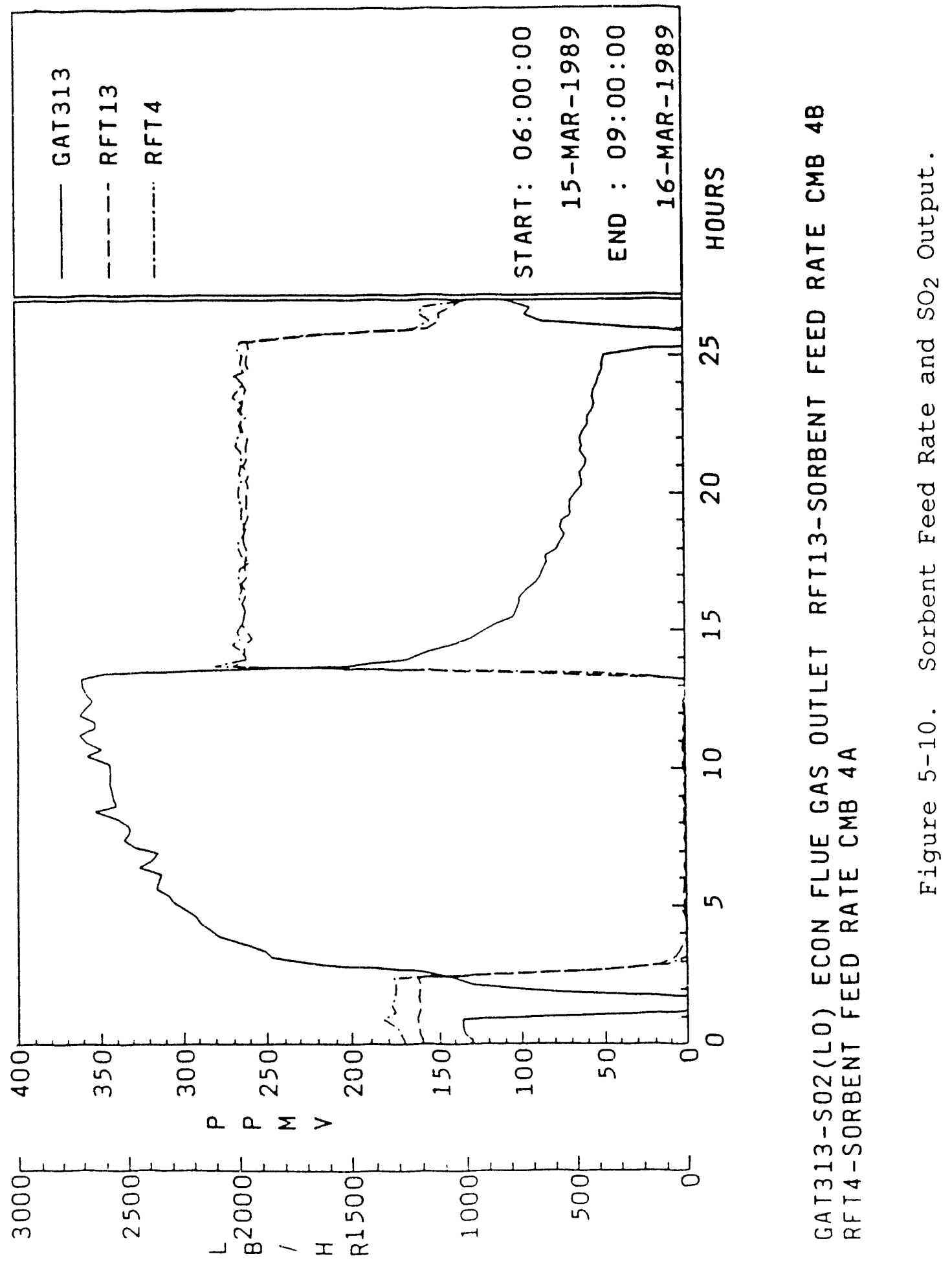




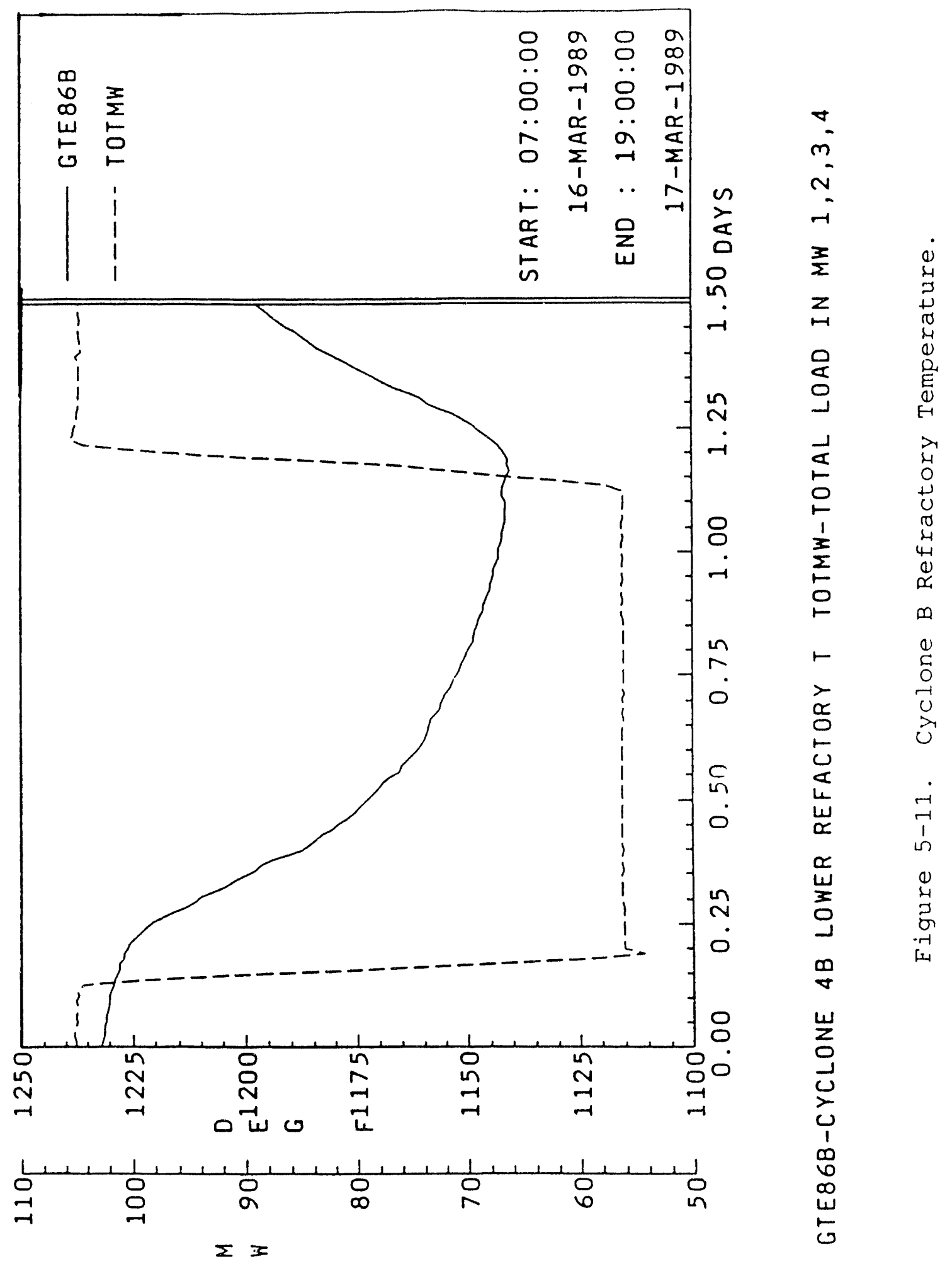




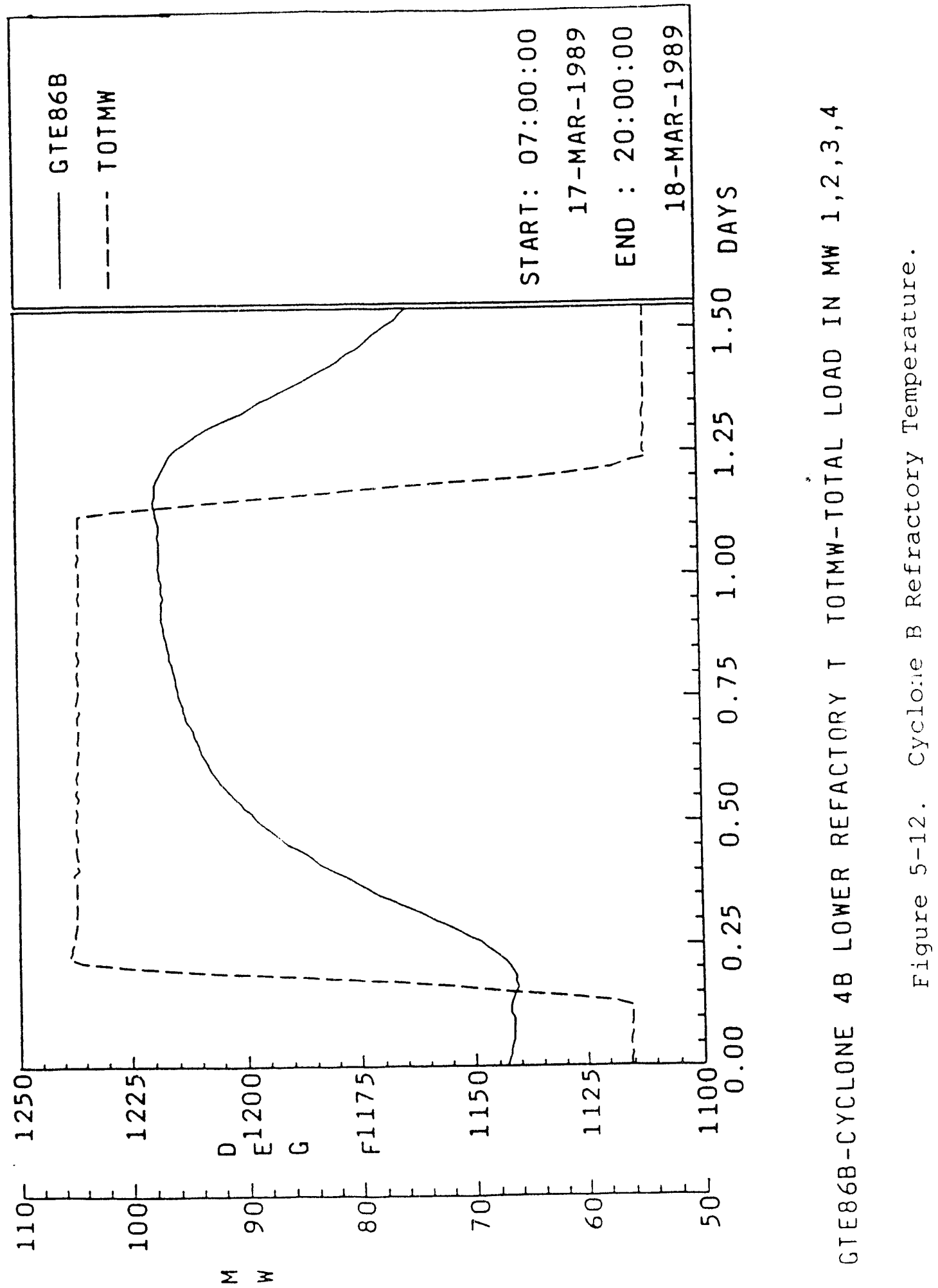




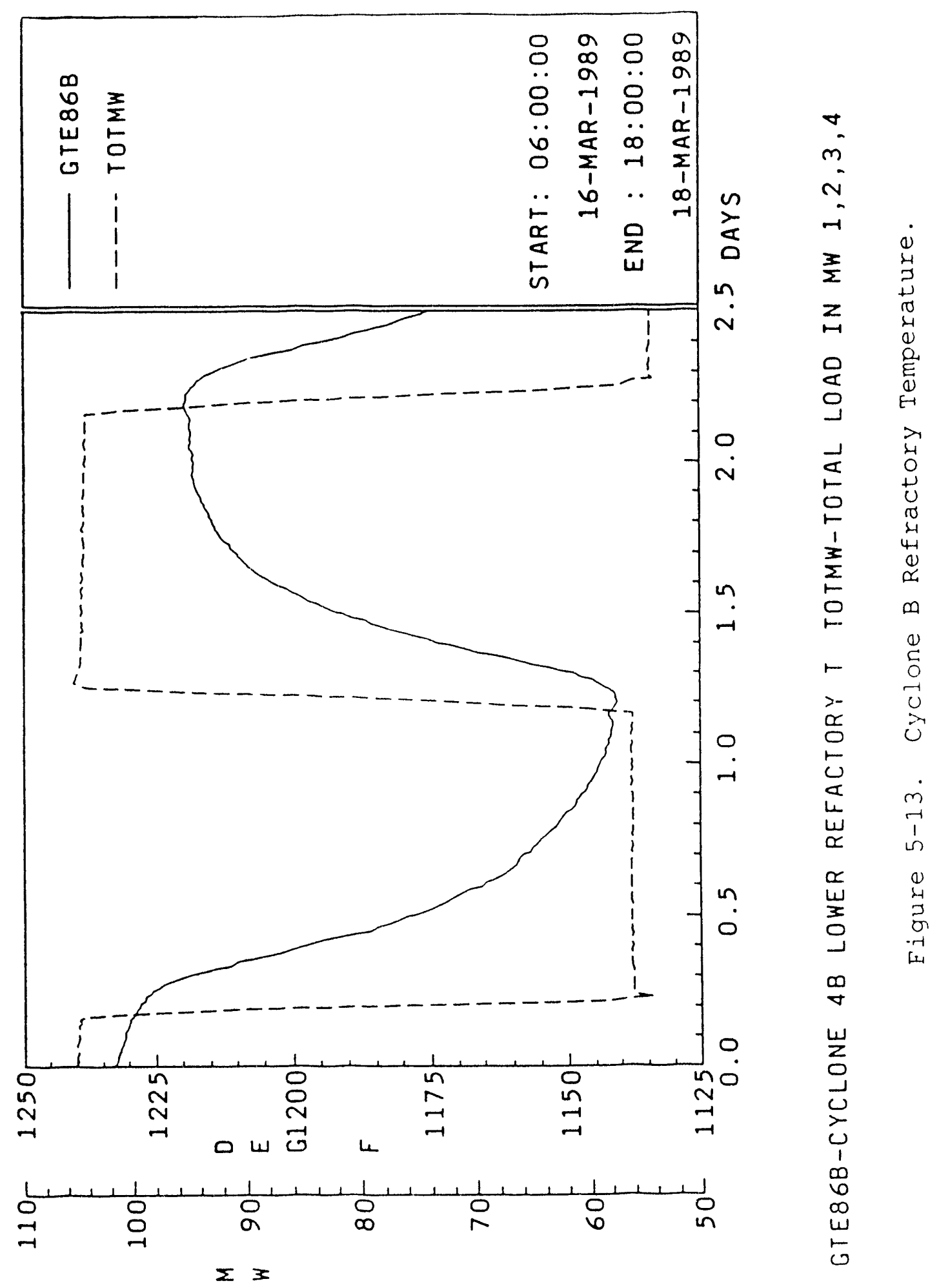


After test SD1, uncertainty analysis was used by the test team to establish the numbers of solids samples required to minimize the uncertainties of important results. These were determined to be six samples each of coal, fly ash, limestone, and bottom ash. The test duration required to physically collect these samples is 10 hours. Better estimates of bias exror also became available and were included in the uncertainty analysis. Solids sampling requirements were updated with the bias errors.

In addition, the test team chose to target minimum uncertainty rather than targeting a specific uncertainty. In addition, calcium balance was replaced by calcium to sulfur ratio as a key performance result. Minimum uncertainty is defined as that obtained when a reduction in measurement precision errors has a negligible impact on the total results uncertainties.

As performance test results were evaluated, a better understanding developed of what measurements contributed the most to results uncertainty. Four of the most important are identified here:

1. Solids sample chemical data

2. Coal feed rates

3. Limestone feed rates

4. Gas analyzer data

The bias error values used originally for solids chemical data were overestimated for most of the chemical species. Discussion with the off-site laboratory resulted in the revised values currently in use. These are shown in the 1990 Annual Report.

The bias determined from 10 coal feed calibrations agreed well with the original bias estimate. A $1 \%$ span error and a $0.3 \mathrm{Klb} / \mathrm{hr}$ zero error are used.

The bias determined from calibration data for limestone feed rates was much larger than the original estimate, as shown in below:

\section{Limestone feeder bias estimates}

\begin{tabular}{lllll} 
Combustor & \multicolumn{2}{c}{ Original } & \multicolumn{2}{c}{ Revised } \\
Span error, $\frac{8}{8}$ & $4 \mathrm{~A}$ & $4 \mathrm{~B}$ & $\mathrm{~A}$ & $4 \mathrm{~B}$ \\
Zero error, lb/hr & 50 & 5 & 20 & 12 \\
& 50 & 50 & 50 & 50
\end{tabular}

The bias estimates for $\mathrm{NO}_{\mathrm{X}}, \mathrm{CO}$, and $\mathrm{SO}_{2}$ gas analyzers remained at the originally estimated $10 \mathrm{ppmv}$. The 02 estimated bias was reduced to $0.15 \%$ from $0.40 \%$, and the $\mathrm{CO} 2$ bias was increased from $0.40 \%$ to $1.1 \%$. A temperature-related drift is responsible for the higher $\mathrm{CO}_{2}$ bias. 
Impact of revised bias error estimates: The revisions made to the bias estimates did not have a substantial impact on the performance results uncertainties. Increases in some bias estimates were offset by decreases in others. The effect on each of the four key results uncertainties after changes in the bias estimates after test SD1 is shown below:

calculated result

Boiler efficiency

Combustion efficiency

$\mathrm{Ca} / \mathrm{S}$

Sulfur retention
Original

Test Plan Unc, 8

\pm 0.5
\pm 0.2
\pm 10
\pm 5

Revised Uncertainty, $\frac{q}{8}$

$\pm 0.3$

$\pm 0.2$

$\pm 14$

$\pm 5$

In conjunction with the revised bias estimates, the solids sampling requirements were reassessed. The solids sampling requirements for dial and split combustor tests were determined as follows:

Split combustor tests:

Fly ash samples are taken at a point that is common to both combustors. Since a difference in fly ash carbon is expected between the combustors, combustion and boiler efficiency results for a single combustor are not valid. $\mathrm{Ca} / \mathrm{S}$ and sulfur retention are the remaining key results uncertainties and will determine the number of solids samples required.

With only $\mathrm{Ca} / \mathrm{S}$ and sulfur retention uncertainty to contend with, sulfur in the coal becomes the most significant precision error. By varying the number of coal samples included in completed test uncertainty analyses, it was determined that four samples will yield minimum results uncertainty for most of the tests completed to date. Only two each of limestone, fly ash, and bottom ash samples are required.

Combined combustor tests:

For combined combustor tests the boiler and combustion efficiency can be evaluated. To minimize the uncertainty in these results, coal ash and fly ash carbon precision errors must be kept low. Analyses have shown that five coal and six fly ash samples consistently minimized uncertainty in these results for performance tests completed to date. Again, only two limestone and two bottom ash samples are required per test. The five coal samples required for minimum boiler and combustion efficiency uncertainty exceed the four samples necessary to minimize $\mathrm{Ca} / \mathrm{S}$ uncertainty and sulfur retention uncertainty.

Expected uncertainties for the four key results with the present bias estimates and with five coal samples, six fly 
ash samples, two limestone samples, and two bottom ash samples are:

Rerformance Result

Boiler efficiency

Combustion efficiency

$\mathrm{Ca} / \mathrm{S}$

Sulfur retention
Uncertainty, 8

$$
\begin{aligned}
& \pm 0.3 \\
& \pm 0.1 \\
& \pm 5 \\
& \pm 3
\end{aligned}
$$

Concerning the time to chemical or thermal equilibrium after step changes in $\mathrm{Ca} / \mathrm{S}$ ratio or load, respectively, due to scheduling and coal supply constraints, the tests were not run long enough to reach full equilibrium. Initially, this was deemed sufficient as it was assumed that extrapolations could be made from collected data yielding equilibrium values and times to steady state. However, this was not the case and analyses showed that the time required for the plant to reach equilibrium after a step change in limestone flow rate is longer than 12 hours. To ensure equilibrium conditions, at least one day of operation at the new Ca/S setting should be scheduled before testing after a step change in limestone feed rate.

Analysis of the transient effects of step changes in loar. also lead to the conclusion that at least one day of unit operation is required for process stabilization between steady-state performance tests at different loads.

For both types of transient responses, a longer period of time than 24 hours is recommended before the start of testing following significant changes in load and/or Ca/s ratio. 
Section 6

PERFORMANCE TEST RESULTS

Performance calculations were run for a total of 72 steady-state tests over the course of the Phase I and Phase II test programs. The baseline fuel for both test phases was Salt Creek coal. Tests were run on two alternate fuels, Peabody coal and Dorchester coal.

Because of the large operating temperature differential that exists between combustors at full load, tests run at these conditions were conducted as split combustor tests, in which each combustion chamber is tested separately. In addition, some tests were run as split combustor tests due to limestone feeder problems that resulted in different feed configurations for the two combustors. Three data sets are produced for each split combustor test. One data set provides combustion and boiler efficiency results for the entire boiler, while each of the other two data sets provide emissions data for an individual combustor.

Therefore, performance calculations were run for a total of 124 data sets. A listing of these data sets is shown in Table 6-1, along with the associated dates and important unit operating parameters. Summary reports for all data sets analyzed to date appear in the in the volume of performance summary reports.

In this section, emissions data and boiler and combustion efficiencies obtained from the performance tests are described. The effects of the following plant parameters were investigated:

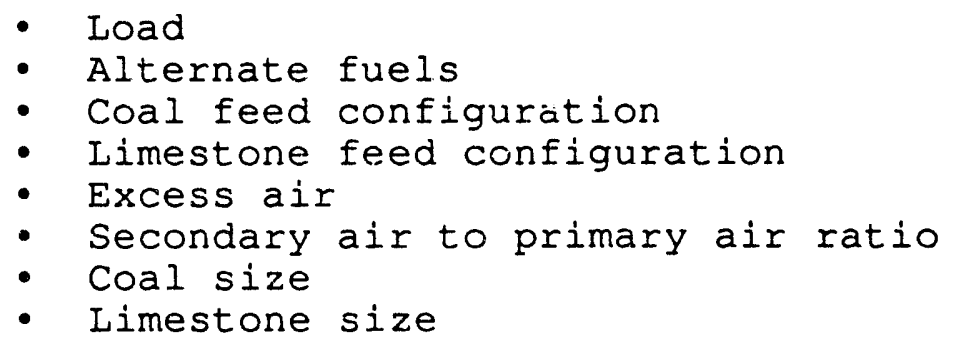

Over the range of operating parameters at which testing was performed at Nucla, bed temperature was found to be the most influential operating parameter. With the possible exceptions of coal feed configuration and excess air at elevated temperatures, it is the only parameter which had a measurable impart on emissions or efficiencies. Emissions of $\mathrm{SO}_{2}$ and $\mathrm{NO}_{\mathbf{x}}$ were found to increase with increased combustor temperatures while $C O$ emissions decreased with increasing temperature. Combustion efficiency also improved as the temperature was increased. No means for effective control of bed temperature were found during the course of 


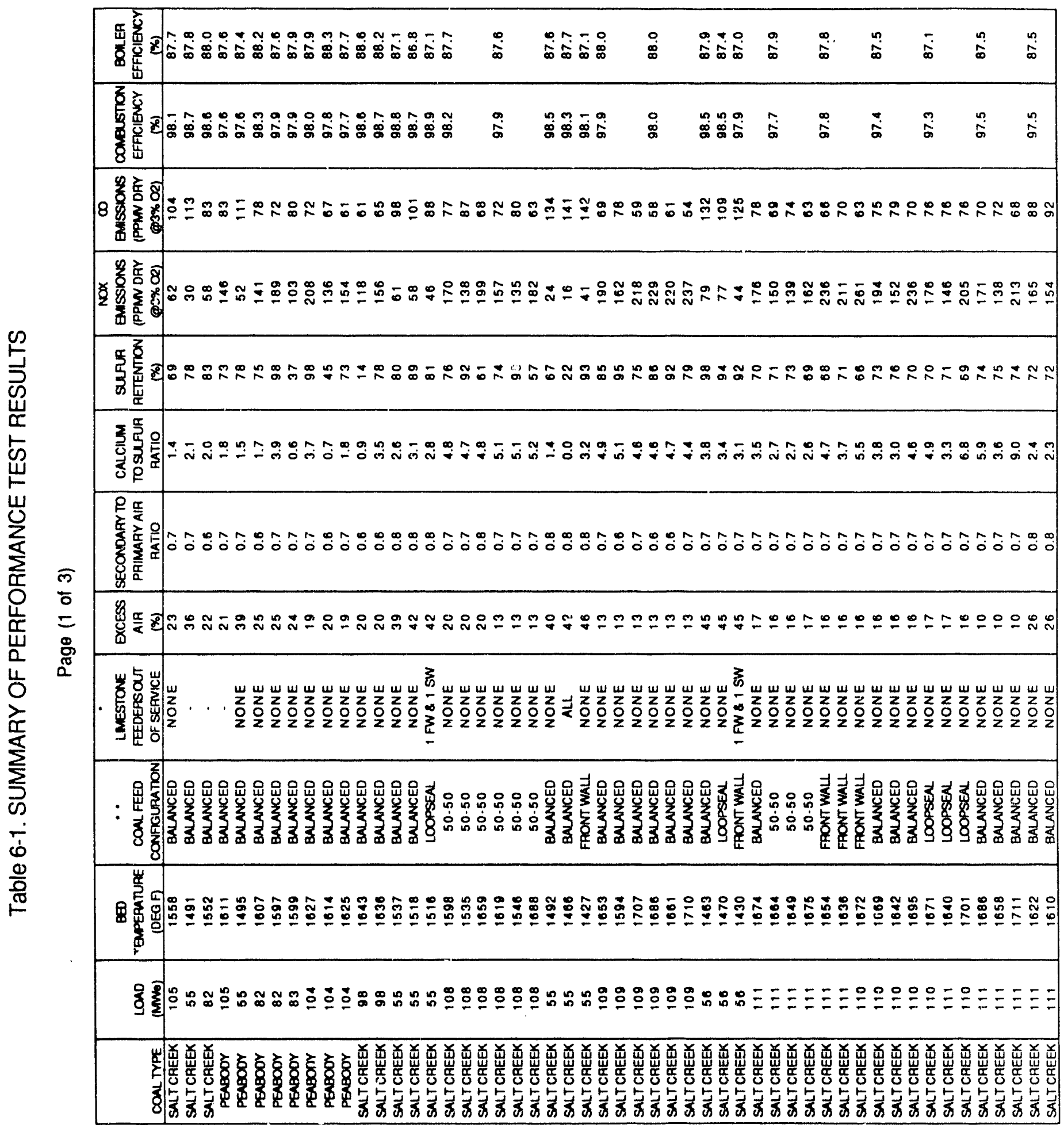




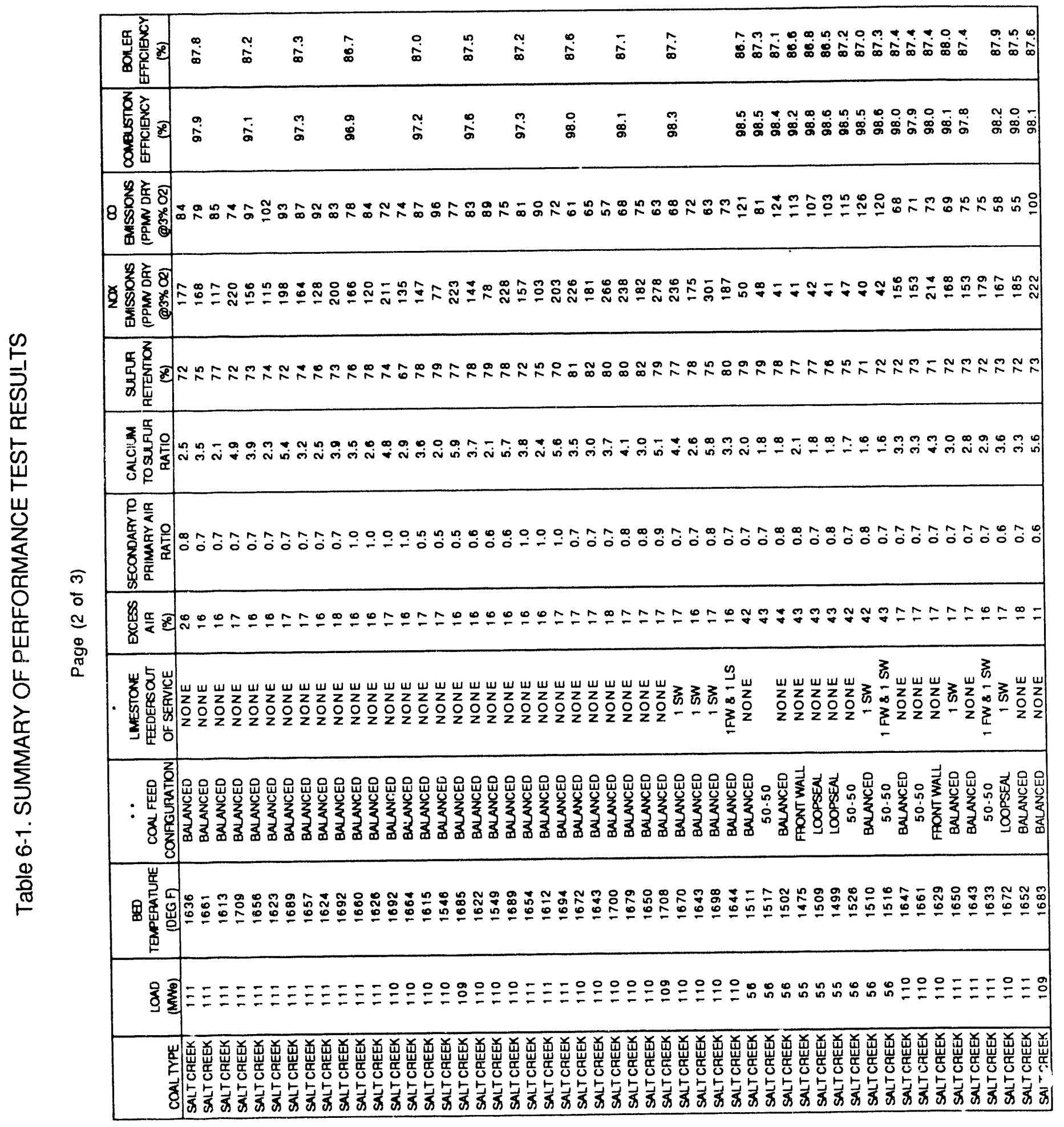




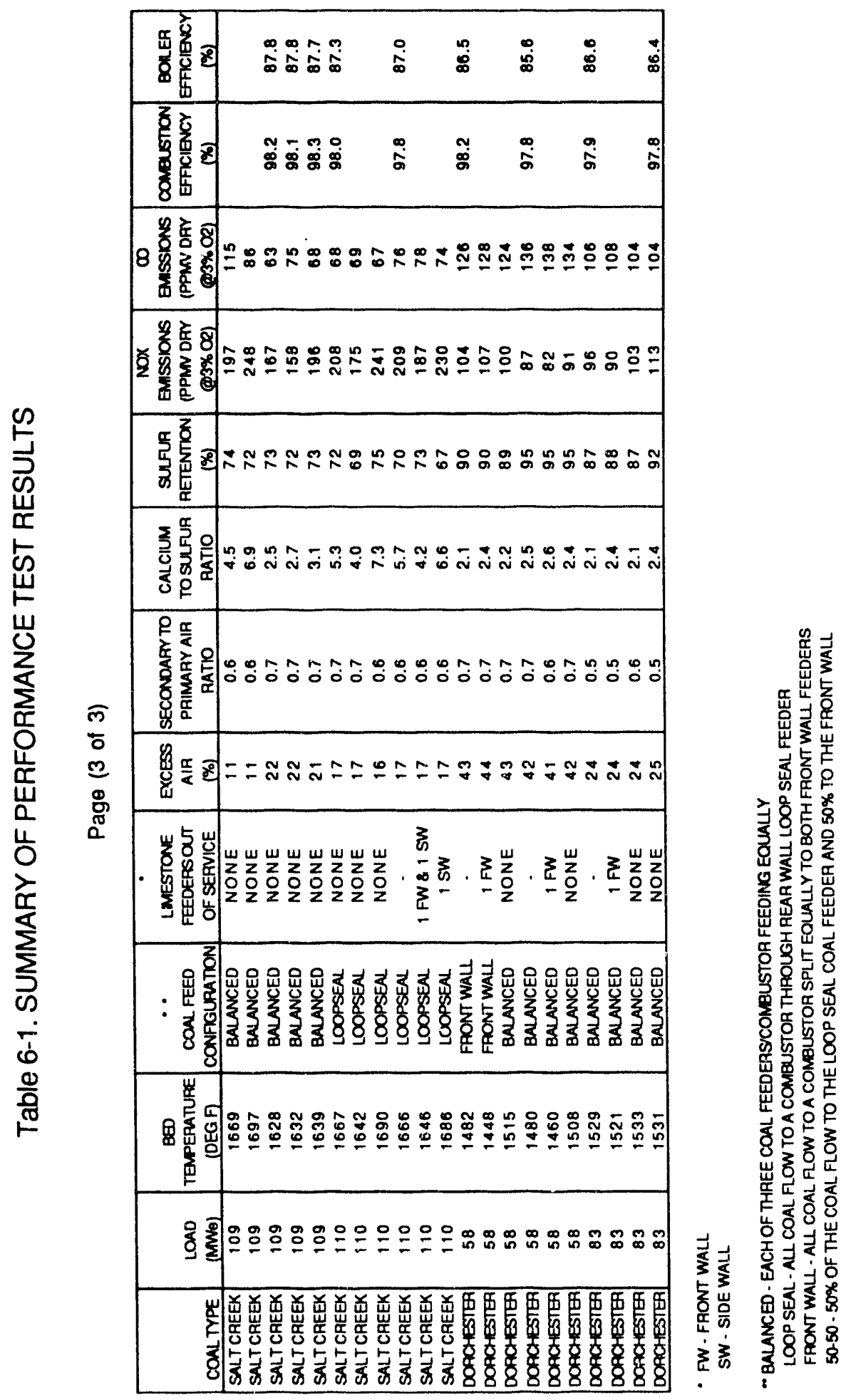


performance testing. This is discussed in more detail in section 10 of this report.

Tests to examine the effects of coal and limestone size were limited at Nucla. This is because the existing equipment for sizing this material was not flexible enough to vary the size appreciably.

\subsection{EMISSIONS DATA SUMMARY}

Flue gas emissions data and associated operating parameters were tabulated for a total of 72 Phase I and Phase II tests and analyzed to establish trends and correlations. As two sets of emissions data can be obtained from each split combustor test, the 72 performance tests provide 98 sets of emissions data. Table 6-2 tabulates the results of the analyses performed on the emissions data obtained from these tests. Mean bed temperatures shown are the average of all thermocouple readings in the refractory-lined lower combustor section.

Since plant stack emissions data are readily available from the continuous emissions monitors (CEM), they are included in Table 63 as verification of the emissions data measured by the test program instrumentation at the air heater inlet. Table 6-4 presents additional data related to sulfur capture.

Analyses of the effects of various operating parameters on the emissions are presented in separate sub-sections for $\mathrm{SO}_{2}, \mathrm{NO}_{\mathbf{x}}$, and $\mathrm{CO}$.

\section{$6.1 .1 \quad$ Sulfur Retention}

Figure $6-1$ is a plot of $\mathrm{SO}_{2}$ retention versus $\mathrm{Ca} / \mathrm{S}$ molar ratio for all data points taken at mean bed temperatures lower than $1620^{\circ} \mathrm{F}$. $\mathrm{Ca} / \mathrm{S}$ ratio requirements for a given sulfur retention are fairly consistent below $1620^{\circ} \mathrm{F}$, but increase rapidly with temperature above this point. The calculated uncertainty band-widths are displayed along with the points. Ca/S molar ratios were calculated based on the calcium content of the sorbent only and do not account for the calcium content of the coal.

Also shown in the figure is a curve which represents a correlation based on the points shown. The equation for the curve is:

$$
\text { Sulfur Retention }=100 *\left(1-e^{-0.803 * \mathrm{Ca} / \mathrm{s}}\right)
$$

In this figure, a Ca/S molar ratio of 1.5 to 2.0 is required for $75 \%$ sulfur retention and a ratio of between 4.0 and 5.0 is required for $95 \%$ retention.

The $1620^{\circ} \mathrm{F}$ bed temperature limit was determined by plotting adjusted $\mathrm{Ca} / \mathrm{S}$ molar ratios against bed temperature for tests with sulfur retentions between $65 \frac{\circ}{\circ}$ and $85 \%$. The $\mathrm{Ca} / \mathrm{S}$ molar ratios were 


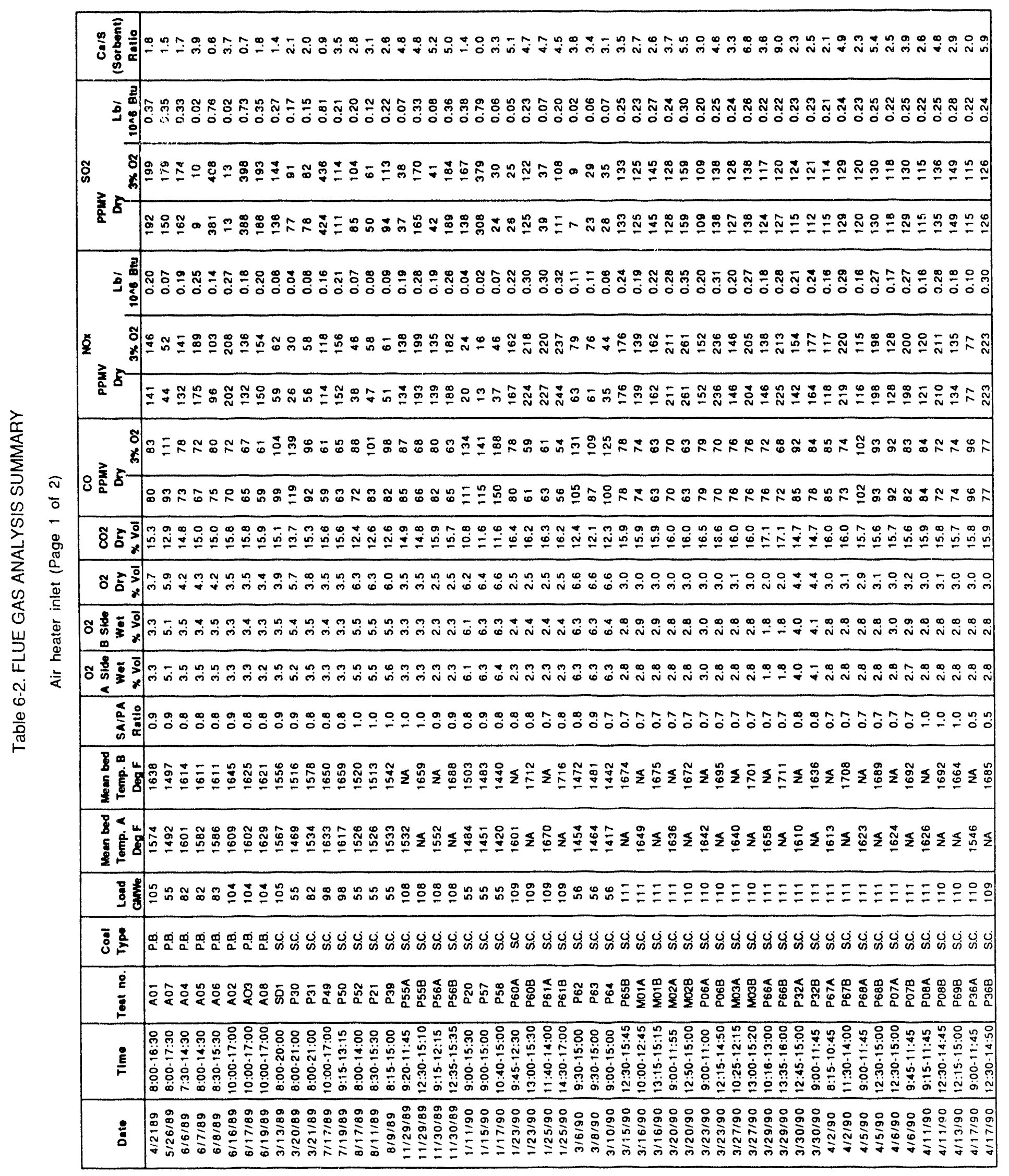




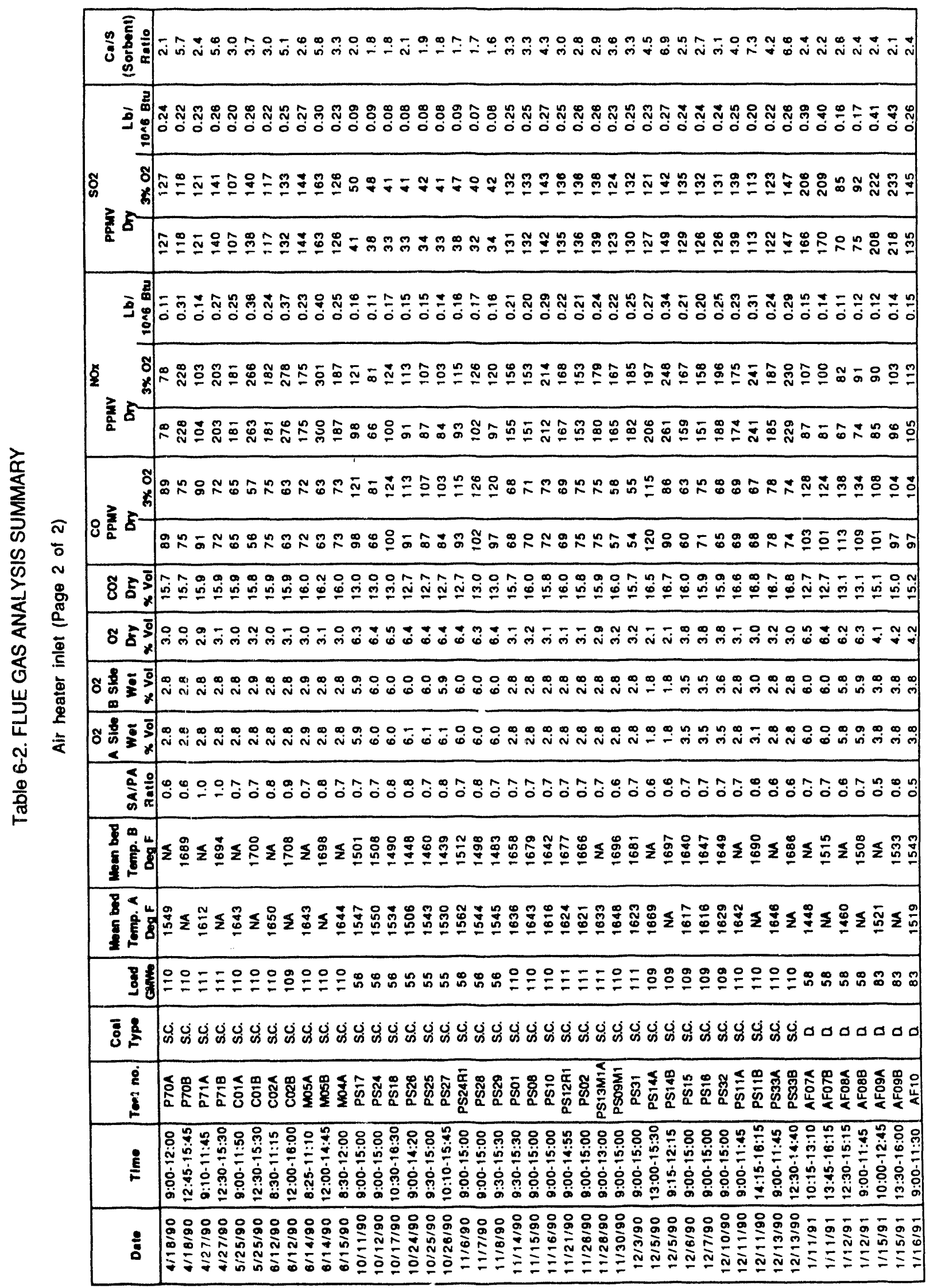


Table 6-3. PLANT STACK EMISSION SUMMARY

(Page 1 of 2)

\begin{tabular}{|c|c|c|c|c|c|c|c|c|c|c|}
\hline Daie & Time & Toet No. & $\begin{array}{c}\text { Typo } \\
\text { of coal }\end{array}$ & $\begin{array}{l}\text { Load } \\
\text { GMWe }\end{array}$ & $\begin{array}{c}\text { Nox } \\
\text { Lb/ } \\
\text { 10^6Btu } \\
\end{array}$ & $\begin{array}{c}\text { SO2 } \\
\text { PPMV }\end{array}$ & $\begin{array}{c}802 \\
\text { LBI } \\
10 \wedge 68+4 \\
\end{array}$ & $\begin{array}{c}\text { SO2 } \\
\text { A side } \\
\text { ppMV } \\
\end{array}$ & $\begin{array}{c}\text { SO2 } \\
\text { B slde } \\
\text { PPMV } \\
\end{array}$ & $\begin{array}{c}\text { Opacity } \\
\% \\
\end{array}$ \\
\hline $3 / 13 / 89$ & $8: 00-20: 00$ & SD1 & S.C. & 105.3 & 0.08 & 117 & 0.25 & 101 & 14 & 4 \\
\hline $3 / 20 / 89$ & $08: 00.21: 00$ & P30 & S.C. & 55.2 & 0.04 & 63 & 0.15 & 65 & 126 & 3 \\
\hline $3 / 21 / 89$ & $08: 00-21: 00$ & P31 & S.C. & 82.3 & 0.08 & 65 & 0.15 & 51 & 97 & 4 \\
\hline $4 / 2189$ & $8: 00-16: 30$ & A01 & PB. & 105.2 & 0.20 & 174 & 0.39 & 170 & 67 & 0 \\
\hline $5 / 26 / 89$ & $8: 00-17: 30$ & A07 & PB. & 54.9 & 0.07 & 141 & 0.35 & 137 & 107 & 3 \\
\hline $6 / 6 / 89$ & $7: 30-14: 30$ & $\mathrm{AO} 4$ & P.B. & 82.4 & 0.18 & 151 & 0.30 & 135 & 125 & 6 \\
\hline $6 / 7 / 89$ & $8: 00-14: 30$ & A05 & PB. & 82.4 & 0.26 & 9 & 0.02 & 4 & 10 & 9 \\
\hline $6 / 8 / 89$ & $8: 30-15: 30$ & A06 & PB. & 82.6 & 0.14 & 355 & 0.84 & 322 & 313 & 10 \\
\hline $6 / 16 / 89$ & $10: 00-17: 00$ & $\mathrm{AO2}$ & PB. & 103.6 & 0.28 & 3 & 0.00 & 4 & 9 & 7 \\
\hline $6 / 17 / 89$ & $10: 00-17: 00$ & $\mathrm{AO3}$ & PB. & 103.8 & 0.18 & 367 & 0.79 & 302 & 299 & 7 \\
\hline $6 / 19 / 89$ & $10: 00-17: 00$ & $A 08$ & PB. & 104 & 0.20 & 175 & 0.36 & 167 & 122 & 8 \\
\hline $7 / 17 / 89$ & $10: 00-17: 00$ & $P 49$ & S.C. & 98.2 & 0.17 & 395 & 0.83 & 389 & 321 & 8 \\
\hline $7 / 19 / 89$ & $9: 15-13: 15$ & P50 & S.C. & 98.2 & 0.22 & 98 & 0.21 & 99 & 82 & 8 \\
\hline $8 / 17 / 89$ & $8: 00-14: 00$ & P52 & S.C. & 55.4 & 0.07 & 70 & 0.19 & 67 & 64 & 7 \\
\hline $8 / 11 / 89$ & $8: 30-15: 30$ & P21 & s.c. & 55.4 & 0.08 & 37 & 0.09 & 36 & 33 & 7 \\
\hline $8 / 9 / 89$ & $8: 15-15: 00$ & P39 & S.C. & 55.4 & 0.08 & 76 & 0.19 & 68 & 74 & 7 \\
\hline $11 / 29 / 89$ & $9: 20-11: 45$ & P55A & S.C. & 107.7 & 0.24 & 84 & 0.18 & 22 & 116 & 9 \\
\hline $11 / 29 / 89$ & $12: 30-15: 10$ & P55B & S.C. & 107.8 & 0.23 & 85 & 0.18 & 21 & 116 & 9 \\
\hline $11 / 30 / 89$ & $9: 15-12: 15$ & P56A & S.C. & 108.2 & 0.21 & 101 & 0.21 & 27 & 142 & 9 \\
\hline $11 / 30 / 89$ & $12: 35-15: 35$ & P56B & S.c. & 108.3 & 0.21 & 99 & 0.20 & 26 & 136 & 9 \\
\hline $1 / 11 / 90$ & $9: 00-15: 30$ & P20 & S.c. & 55.3 & 0.03 & 119 & 0.32 & 105 & 116 & 6 \\
\hline $1 / 15 / 90$ & $9: 00-15: 00$ & P57 & S.C. & 55.1 & 0.01 & 289 & 0.83 & 261 & 240 & 5 \\
\hline $1 / 17 / 90$ & $10: 40 \cdot 15: 00$ & P58 & S.C. & 55.4 & 0.06 & 17 & 0.04 & 17 & 10 & 4 \\
\hline $1 / 23 / 90$ & $9: 45-12: 30$ & P60A & S.C & 108.6 & 0.27 & 58 & 0.11 & 16 & 75 & 6 \\
\hline $1 / 23 / 90$ & $13: 00-15: 30$ & P60B & S.C. & 108.5 & 0.27 & 63 & 0.13 & 16 & 80 & 6 \\
\hline $1 / 25 / 90$ & $11: 40-14: 00$ & P61A & S.C. & 108.7 & 0.32 & 65 & 0.12 & 24 & 69 & 7 \\
\hline $1 / 25 / 90$ & $14: 30-17: 00$ & P61B & S.C. & 108.8 & 0.31 & 65 & 0.13 & 27 & 68 & 7 \\
\hline $3 / 6 / 90$ & $9: 30-15: 00$ & P62 & S.C. & 55.6 & 0.11 & 0 & 0.00 & 0 & 13 & 3 \\
\hline $3 / 8 / 90$ & $9: 30-15: 00$ & P63 & S.C. & 55.7 & 0.10 & 10 & 0.02 & 8 & 26 & 4 \\
\hline $3 / 10 / 90$ & $9: 00-15: 00$ & $F 64$ & S.C. & 55.7 & 0.06 & 15 & 0.03 & 22 & 23 & 3 \\
\hline $3 / 15 / 90$ & $12: 30-15: 45$ & P65B & S.C. & 110.7 & 0.15 & 70 & 0.12 & 88 & 89 & 4 \\
\hline $3 / 16 / 90$ & $10: 00-12: 45$ & MOIA & S.C. & 110.9 & 0.20 & 109 & 0.22 & 99 & 101 & 4 \\
\hline $3 / 16 / 90$ & $13: 15-15: 15$ & Mo1B & S.c. & 110.9 & 0.19 & 121 & 0.25 & 102 & 109 & 4 \\
\hline $3 / 20 / 90$ & $9: 00-11: 55$ & M02A & S.C. & 110.7 & 0.30 & 128 & 0.26 & 95 & 96 & 3 \\
\hline $3 / 20 / 90$ & $12: 50-15: 00$ & $\mathrm{MO2B}$ & S.C. & 110.4 & 0.31 & 129 & 0.26 & 95 & 99 & 3 \\
\hline $3 / 23 / 90$ & $9: 00.11: 00$ & P06A & s.c. & 110 & 0.26 & 109 & 0.23 & 83 & 83 & 3 \\
\hline $3 / 23 / 90$ & $12: 15-14: 50$ & P06B & S.C. & 110.1 & 0.25 & 109 & 0.23 & 84 & 83 & 3 \\
\hline $3 / 27 / 90$ & $10: 25-12: 15$ & MO3A & S.c. & 110.6 & 0.23 & 122 & 0.26 & 94 & 95 & 5 \\
\hline $3 / 27 / 90$ & $13: 00-15: 20$ & MO3B & S.C. & 110.4 & 0.23 & 109 & 0.23 & 89 & 81 & 6 \\
\hline $3 / 29 / 90$ & $10: 16-13: 00$ & P66A & S.C. & 110.7 & 0.22 & 114 & 0.23 & 89 & 85 & 3 \\
\hline $3 / 29 / 90$ & $13: 35-16: 00$ & P66B & S.C. & 110.6 & 0.23 & 104 & 0.21 & 89 & 71 & 3 \\
\hline $3 / 30 / 90$ & $12: 45-15: 00$ & P32A & S.C. & 110.8 & 0.22 & 94 & 0.21 & 82 & 64 & 5 \\
\hline $3 / 30 / 90$ & $9: 00-11: 45$ & P32B & S.c. & 110.8 & 0.23 & 94 & 0.21 & 79 & 62 & 4 \\
\hline $4 / 2 / 90$ & $8: 15-10: 45$ & P67A & S.C. & 111.1 & 0.22 & 107 & 0.21 & 88 & 70 & 4 \\
\hline $4 / 2 / 90$ & $11: 30-14: 00$ & P67B & S.C. & 110.8 & 0.21 & 108 & 0.22 & 88 & 70 & 3 \\
\hline $4 / 5 / 90$ & $9: 00-11: 45$ & P68A & S.c. & 111.0 & 0.20 & 105 & 0.22 & 89 & 71 & 3 \\
\hline $4 / 5 / 80$ & $12: 30-15: 00$ & P68B & S.C. & 110.5 & 0.20 & 106 & 0.22 & 89 & 70 & 3 \\
\hline $4 / 6 / 90$ & $12: 30-15: 00$ & P07A & S.C. & 110.7 & 0.22 & 107 & 0.22 & 88 & 71 & 4 \\
\hline $4 / 6 / 90$ & $8: 45-11: 45$ & Po7B & S.C. & 110.9 & 0.20 & 108 & 0.22 & 89 & 69 & 4 \\
\hline $4 / 11 / 80$ & $9: 15-11: 45$ & POBA & S.c. & 110.9 & 0.21 & 122 & 0.24 & 110 & 0 & 4 \\
\hline $4 / 11 / 90$ & $12: 30-14: 45$ & P08B & S.C. & 110.3 & 0.21 & 110 & 0.22 & 88 & 206 & 4 \\
\hline $4 / 13 / 90$ & $12: 15-15: 00$ & P69B & S.C. & 110.3 & 0.11 & 108 & 0.23 & 80 & 66 & 6 \\
\hline $4 / 17 / 90$ & $9: 00-11: 45$ & P36A & S.C. & 109.7 & 0.20 & 107 & 0.23 & 86 & 174 & 5 \\
\hline $4 / 17190$ & $12: 30-14: 50$ & P36B & S.C. & 109.4 & 0.20 & 95 & 0.21 & 81 & 78 & 3 \\
\hline
\end{tabular}


Table 6-3. PLANT STACK EMISSION SUMMARY

(Page 2 of 2)

\begin{tabular}{|c|c|c|c|c|c|c|c|c|c|c|}
\hline Date & Time & Test No. & $\begin{array}{c}\text { Typo } \\
\text { of coal }\end{array}$ & $\begin{array}{l}\text { Load } \\
\text { GMWe }\end{array}$ & $\begin{array}{c}\text { NOX } \\
\text { Lb/ } \\
\text { 10^6Btu }\end{array}$ & $\begin{array}{c}\mathrm{SO} 2 \\
\text { PPMV }\end{array}$ & \begin{tabular}{|c|}
$\mathrm{SO} 2$ \\
$\mathrm{LB} /$ \\
10^8Btu \\
\end{tabular} & $\begin{array}{c}\text { SO2 } \\
\text { A SIde } \\
\text { PPMV }\end{array}$ & $\begin{array}{l}\text { SO2 } \\
\text { B Side } \\
\text { PPMV }\end{array}$ & $\begin{array}{c}\text { Opacity } \\
\%\end{array}$ \\
\hline $4 / 18 / 90$ & $9: 00-12: 00$ & P70A & S.C. & 109.8 & 0.21 & 104 & 0.22 & 93 & 139 & 4 \\
\hline $4 / 18 / 90$ & $12: 45 \cdot 15: 45$ & P70B & S.C. & 109.7 & 0.21 & 103 & 0.22 & 94 & 133 & 4 \\
\hline $4 / 27 / 90$ & $9: 10-11: 45$ & P71A & S.C. & 110.7 & 0.20 & 105 & 0.21 & 88 & 95 & 5 \\
\hline $4 / 27 / 90$ & $12: 30-15: 30$ & P71B & S.C. & 110.7 & 0.20 & 106 & 0.22 & 87 & 91 & 4 \\
\hline $5 / 25 / 90$ & $9: 00-11: 50$ & $\operatorname{Co1A}$ & s.c. & 109.9 & 0.31 & 98 & 0.21 & 84 & 101 & 6 \\
\hline $5 / 25 / 90$ & $12: 30-15: 30$ & Co1B & S.c. & 109.6 & 0.29 & 106 & 0.24 & 91 & 104 & 6 \\
\hline $6 / 12 / 90$ & $8: 30 \cdot 11: 15$ & $\mathrm{CO} 2 \mathrm{~A}$ & S.c. & 109.6 & 0.30 & 104 & 0.22 & 90 & 80 & 5 \\
\hline $6 / 12 / 90$ & $12: 00-16: 00$ & $\mathrm{CO} 2 \mathrm{~B}$ & S.C. & 109.5 & 0.32 & 102 & 0.22 & 89 & 82 & 5 \\
\hline $6 / 14 / 90$ & $8: 25-11: 10$ & M05A & s.c. & 109.8 & 0.31 & 131 & 0.27 & 113 & 103 & 4 \\
\hline $6 / 14 / 90$ & $12: 00-14: 45$ & MO5B & S.C. & 109.6 & 0.31 & 124 & 0.26 & 98 & 104 & 4 \\
\hline $6 / 15 / 90$ & $8: 30 \cdot 12: 00$ & MO4A & S.c. & 110.1 & 0.33 & 119 & 0.25 & 96 & 97 & 5 \\
\hline $10 / 11 / 90$ & $9: 00 \cdot 15: 00$ & PS17 & S.c. & 55.7 & 0.07 & 87 & 0.24 & 79 & 82 & 3 \\
\hline $10 / 12 / 90$ & $9: 00-15: 00$ & PS24 & S.c. & 55.8 & 0.06 & 84 & 0.22 & 79 & 89 & 3 \\
\hline $10 / 17 / 90$ & $10: 30-16: 30$ & PS18 & S.c. & 56.2 & 0.05 & 86 & 0.22 & 86 & 88 & 4 \\
\hline $10 / 24 / 90$ & $9: 00-14: 20$ & PS26 & S.C. & 55.4 & 0.06 & 104 & 0.30 & 92 & 95 & 4 \\
\hline $10 / 25 / 90$ & $9: 30-15: 00$ & PS25 & S.c. & 55.2 & 0.06 & 93 & 0.23 & 91 & 95 & 3 \\
\hline $10 / 26 / 90$ & $10: 10-15: 45$ & PS27 & S.C. & 55.1 & 0.06 & 92 & 0.23 & 90 & 95 & 3 \\
\hline $11 / 6 / 90$ & $9: 00-15: 00$ & PS24R1 & S.c. & 55.7 & 0.06 & 96 & 0.24 & 86 & 76 & 3 \\
\hline $11 / 7 / 90$ & $9: 00 \cdot 15: 00$ & PS28 & S.C. & 55.8 & 0.05 & 103 & 0.25 & 92 & 82 & 3 \\
\hline $11 / 8 / 90$ & $9: 30 \cdot 15: 30$ & PS29 & S.c. & 55.8 & 0.06 & 80 & 0.20 & 98 & 50 & 4 \\
\hline $11 / 14 / 90$ & $9: 30-15: 30$ & PSO1 & S.C. & 110.3 & 0.19 & 120 & 0.24 & 110 & 50 & 3 \\
\hline $11 / 15 / 90$ & 9:00-15:00 & PSOB & S.C. & 110.3 & 0.19 & 118 & 0.24 & 110 & 50 & 3 \\
\hline $11 / 16 / 90$ & $9: 00-15: 00$ & PS10 & S.C. & 110.4 & 0.27 & 127 & 0.26 & 110 & 50 & 3 \\
\hline $11 / 21 / 90$ & $9: 00-14: 55$ & PS12R1 & s.c. & 110.9 & 0.20 & 123 & 0.24 & 110 & 57 & 4 \\
\hline $11 / 26 / 90$ & 9:00-15:00 & PSO2 & S.C. & 110.7 & 0.19 & 118 & 0.24 & 110 & 57 & 3 \\
\hline $11 / 28 / 90$ & 9:00-13:00 & PS13M1A & S.c. & 111.4 & 0.27 & 107 & 0.21 & 109 & 67 & 3 \\
\hline $11 / 30 / 90$ & $9: 00 \cdot 15: 00$ & PSO9M1 & S.C. & 110.2 & 0.21 & 115 & 0.25 & 102 & 96 & 3 \\
\hline $12 / 3 / 90$ & 9:00-15:00 & PS31 & S.C. & 110.6 & 0.23 & 119 & 0.24 & 102 & 102 & 4 \\
\hline $12 / 5 / 90$ & $13: 00-15: 30$ & PS14A & S.C. & 109.0 & 0.29 & 128 & 0.24 & 102 & $1: 2$ & 4 \\
\hline $12 / 5 / 90$ & $9: 15-12: 15$ & PS14B & S.c. & 109.0 & 0.29 & 126 & 0.23 & 102 & 110 & 4 \\
\hline $12 / 6 / 90$ & $9: 00-15: 00$ & PS15 & S.C. & 109.3 & 0.21 & 118 & 0.25 & 102 & 101 & 4 \\
\hline $12 / 7 / 90$ & 9:00-15:00 & PS16 & S.c. & 109.4 & 0.20 & 115 & 0.24 & 102 & 102 & 4 \\
\hline $12 / 10 / 90$ & $9: 00-15: 00$ & PS32 & S.c. & 109.3 & 0.25 & 113 & 0.25 & 98 & 100 & 3 \\
\hline $12 / 11 / 90$ & $9: 00-11: 45$ & PS11A & S.C. & 110.5 & 0.24 & 134 & 0.28 & 109 & 118 & 3 \\
\hline $12 / 11 / 90$ & $14: 15-16: 15$ & PS11B & s.c. & 110.0 & 0.28 & 93 & 0.19 & 101 & 105 & 3 \\
\hline $12 / 13 / 90$ & $9: 00-11: 45$ & PS33A & S.c. & 109.9 & 0.13 & 110 & 0.22 & 96 & 83 & 3 \\
\hline $12 / 13 / 90$ & $12: 30-14: 40$ & PS33B & S.C. & 109.8 & 0.11 & 119 & 0.25 & 95 & 97 & 3 \\
\hline $1 / 11 / 91$ & $10: 15-13: 10$ & AF07A & D. & 58 & 0.15 & 166 & 0.39 & 136 & 125 & 3 \\
\hline $1 / 11 / 81$ & $13: 45-16: 15$ & AF07B & D. & 58 & 0.14 & 170 & 0.40 & 134 & 127 & 2 \\
\hline $1 / 12 / 91$ & $12: 30-15: 15$ & AF08A & D & 58 & 0.11 & 70 & 0.16 & 55 & 51 & 3 \\
\hline $1 / 12 / 91$ & $9: 00 \cdot 11: 45$ & AFO $8 B$ & D. & 58 & 0.12 & 75 & 0.17 & 51 & 52 & 2 \\
\hline $1 / 15 / 91$ & $10: 00-12: 45$ & AF09A & D. & 83 & 0.12 & 208 & 0.41 & 163 & 161 & 3 \\
\hline $1 / 15 / 91$ & $13: 30-16: 00$ & AF09B & D. & 83 & 0.14 & 218 & 0.43 & 146 & 161 & 3 \\
\hline $1 / 16 / 91$ & $9: 00 \cdot 11: 30$ & AF 10 & D. & 83 & 0.15 & 135 & 0.26 & 99 & 104 & $\underline{2}$ \\
\hline
\end{tabular}




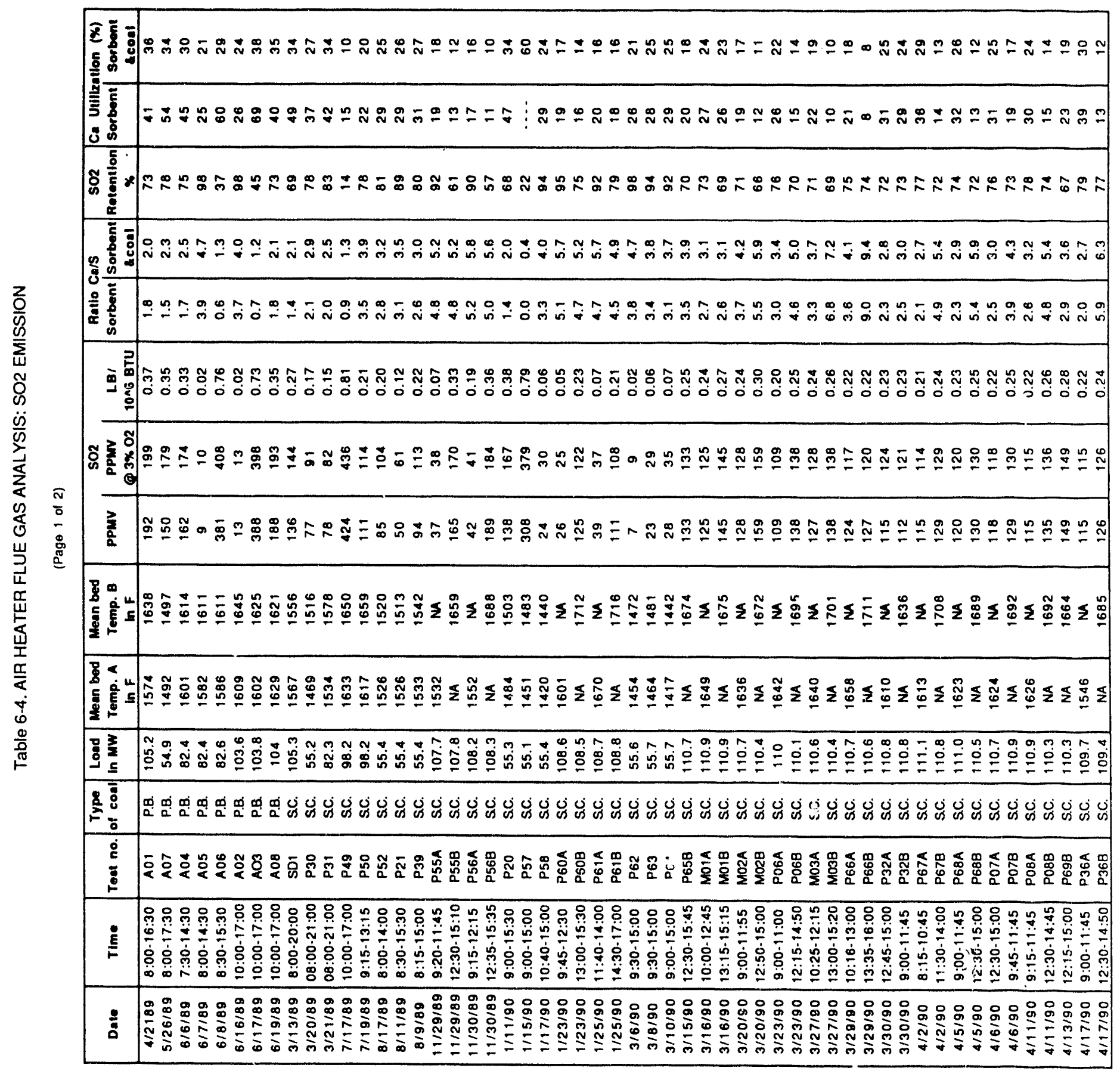




\begin{tabular}{|c|c|c|}
\hline \multirow{15}{*}{ 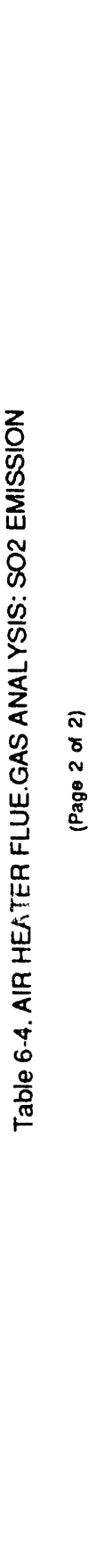 } & 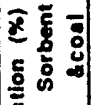 & న エ \\
\hline & 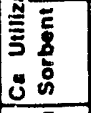 & 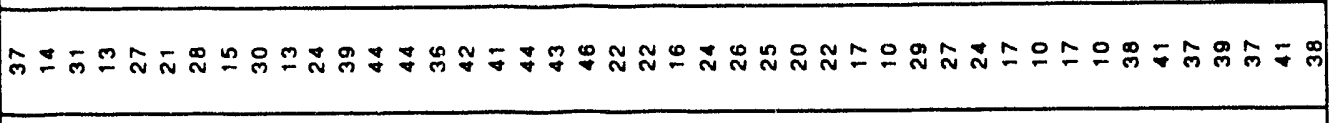 \\
\hline & 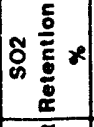 & 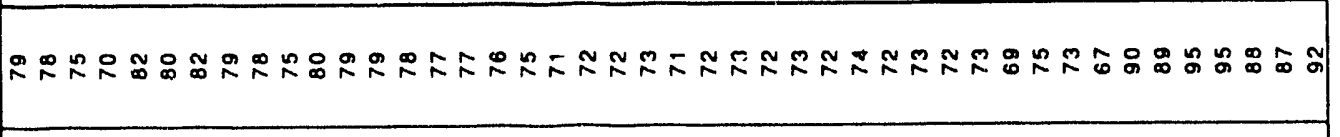 \\
\hline & 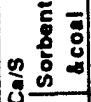 & 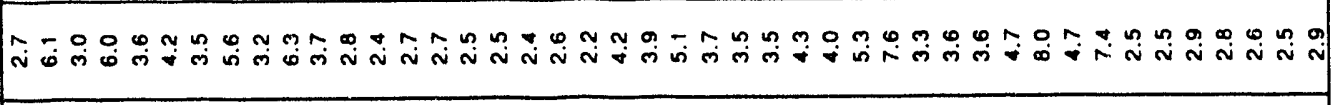 \\
\hline & 望 & 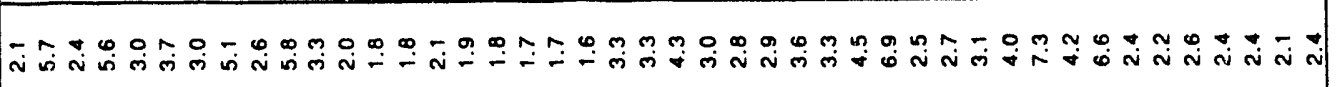 \\
\hline & 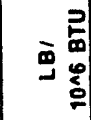 & 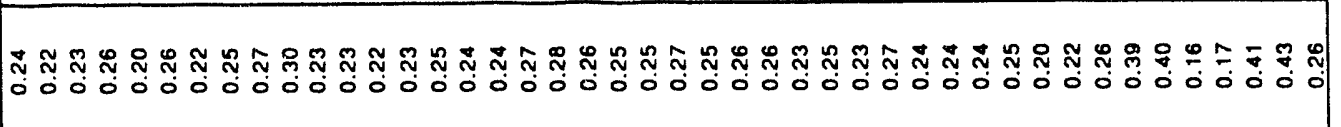 \\
\hline & 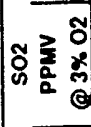 & 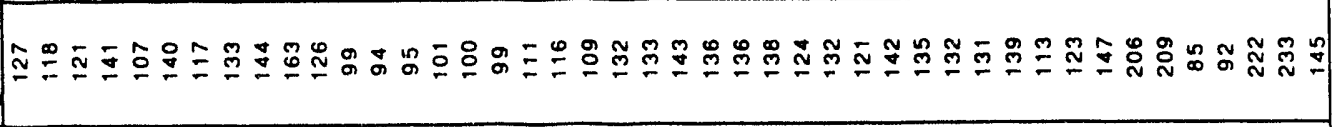 \\
\hline & $\frac{3}{a}$ & 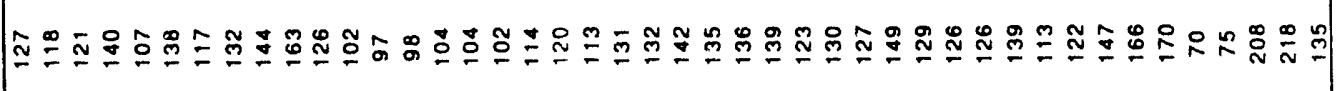 \\
\hline & 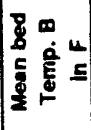 & 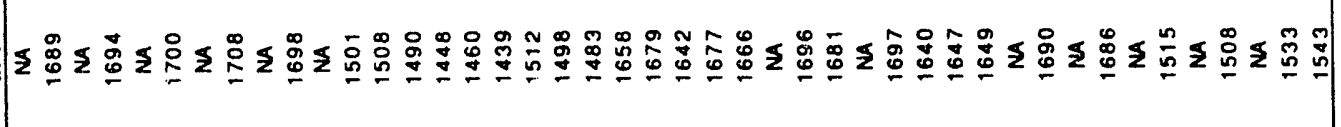 \\
\hline & 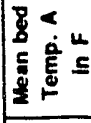 & 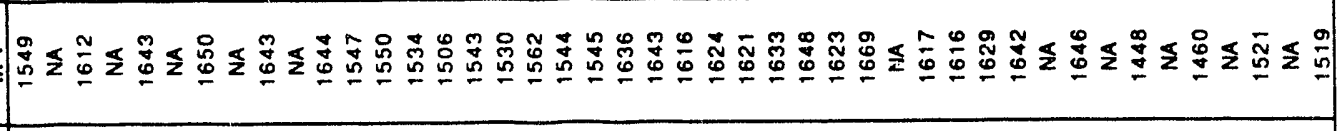 \\
\hline & 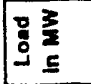 & 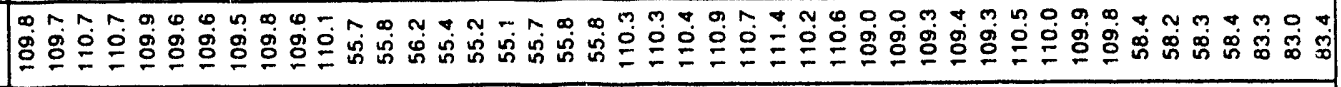 \\
\hline & $\frac{1}{8} \bar{c}$ & 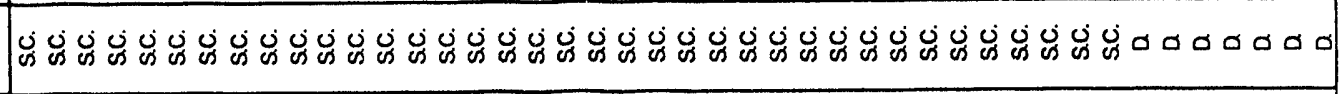 \\
\hline & $\stackrel{\dot{\varepsilon}}{\dot{E}}$ & 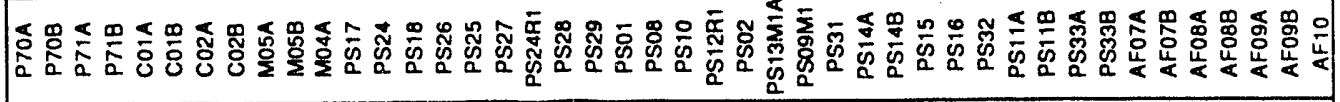 \\
\hline & $\underline{\underline{E}}$ & 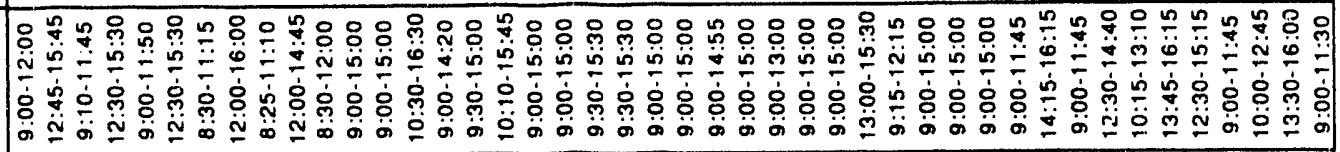 \\
\hline & 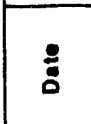 & 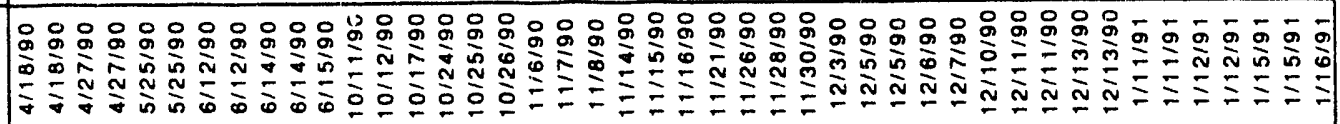 \\
\hline
\end{tabular}




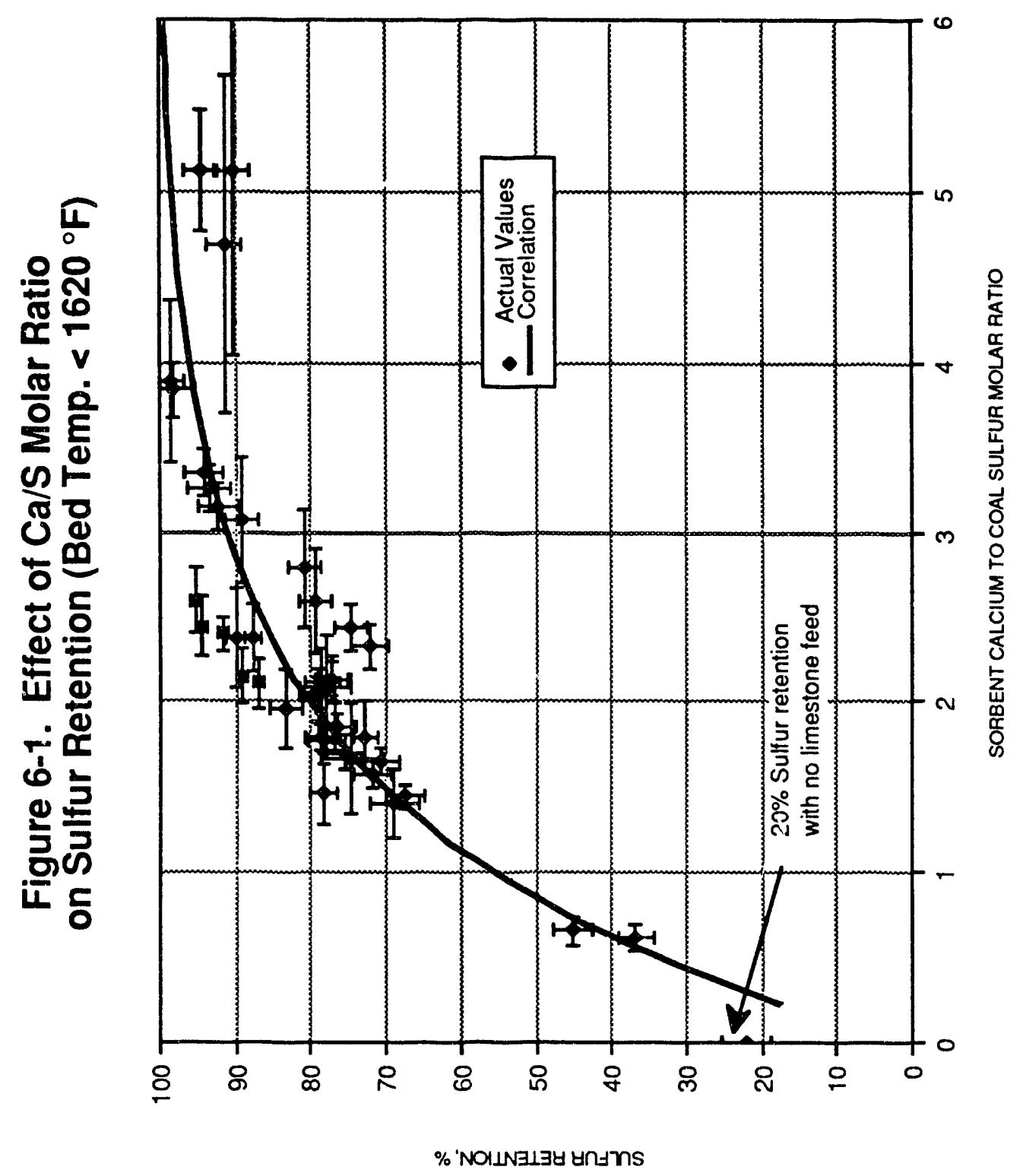


adjusted to $75 \%$ retention to compensate for the fact that $\mathrm{Ca} / \mathrm{S}$ requirements vary with sulfur retention. The equation used to adjust the $\mathrm{Ca} / \mathrm{S}$ parameter for $75 \%$ retention follows:

$$
\text { Adjusted } \mathrm{Ca} / \mathrm{S}=\mathrm{Ca} / \mathrm{S} * \frac{(-1.386)}{\ln (1-\text { sulfur retention/100) }}
$$

The plot of adjusted $\mathrm{Ca} / \mathrm{S}$ molar ratios versus average bed temperature is illustrated in Figure 6-2. Included in the figure is a best fit curve, which was developed using the points shown. The equation for the best fit curve is:

$$
\mathrm{Ca} / \mathrm{S}=1.8+\mathrm{e}^{(\mathrm{T}-1627) \star 0.0184}
$$

where

$$
\begin{array}{ll}
\mathrm{Ca} / \mathrm{S} & =\mathrm{Ca} / \mathrm{S} \text { molar ratio, adjusted to } 75 \% \text { retention } \\
\mathrm{T} & =\text { Average bed temperature, }{ }^{\circ} \mathrm{F}
\end{array}
$$

From the figure, it can be seen that the $\mathrm{Ca} / \mathrm{S}$ molar requirement for $75 \%$ retention increases considerably above $1620^{\circ} \mathrm{F}$. Below $1620{ }^{\circ} \mathrm{F}$, a Ca/S ratio of approximately 1.5 to 2.0 is required for $75 \%$ retention.

Figure 6-3 shows the $\mathrm{Ca} / \mathrm{S}$ requirements for various sulfur retentions for tests run on Peabody, Salt Creek, and Dorchester coals at temperatures below $1620^{\circ} \mathrm{F}$. It can be seen that there is no detectable difference between the Peabody and Salt creek coals, while the Dorchester coal appears to have slightly lower $\mathrm{Ca} / \mathrm{S}$ requirements for a given retention. This is most likely due to the higher sulfur content of the Dorchester coal (ranging from $1.4 \frac{\circ}{6}$ to $1.8 \%$ ) which is 2 to 3 times that of the Peabody and salt Creek coals $(0.4 \%$ to $0.8 \%)$.

In Figure 6-4, the effect of load on tests run at bed temperatures less than $1620^{\circ} \mathrm{F}$ on Salt Creek and Peabody Coal is shown. It appears from the figure that higher load tests are more Iikely to result in higher $\mathrm{Ca} / \mathrm{S}$ requirements. However, these points were all split combustor tests where the other combustor was operating at a temperature well over $1620^{\circ} \mathrm{F}$. Thus, these $\mathrm{SO}_{2}$ measurements may have been biased upwards by high $\mathrm{SO}_{2}$ emissions from the other combustor. For example, in test $\mathrm{P} 60 \mathrm{~A}, \mathrm{SO}_{2}$ emissions from combustor A measured $25 \mathrm{ppm} \mathrm{SO} 2$ at $3 \% \mathrm{O}_{2}$, while $\mathrm{SO}_{2}$ emissions from combustor $\mathrm{B}$ measured $122 \mathrm{ppm} \mathrm{SO} 2$ at $3 \% \mathrm{O}_{2}$. A small amount of flue gas mixing between the two combustors at the measurement location would have resulted in a higher $\mathrm{SO}_{2}$ reading for combustor $\mathrm{A}$. Since the split combustor measurements are taken at the air heater inlet where some gas mixing is possible, these points are most likely biased in the direction of lower sulfur capture.

The effect of coal feed configuration on Ca/S requirements for full-load tests can be seen in Figure 6-5. For these tests, the data shows that balanced (33\% feed to each of the three feeders in 


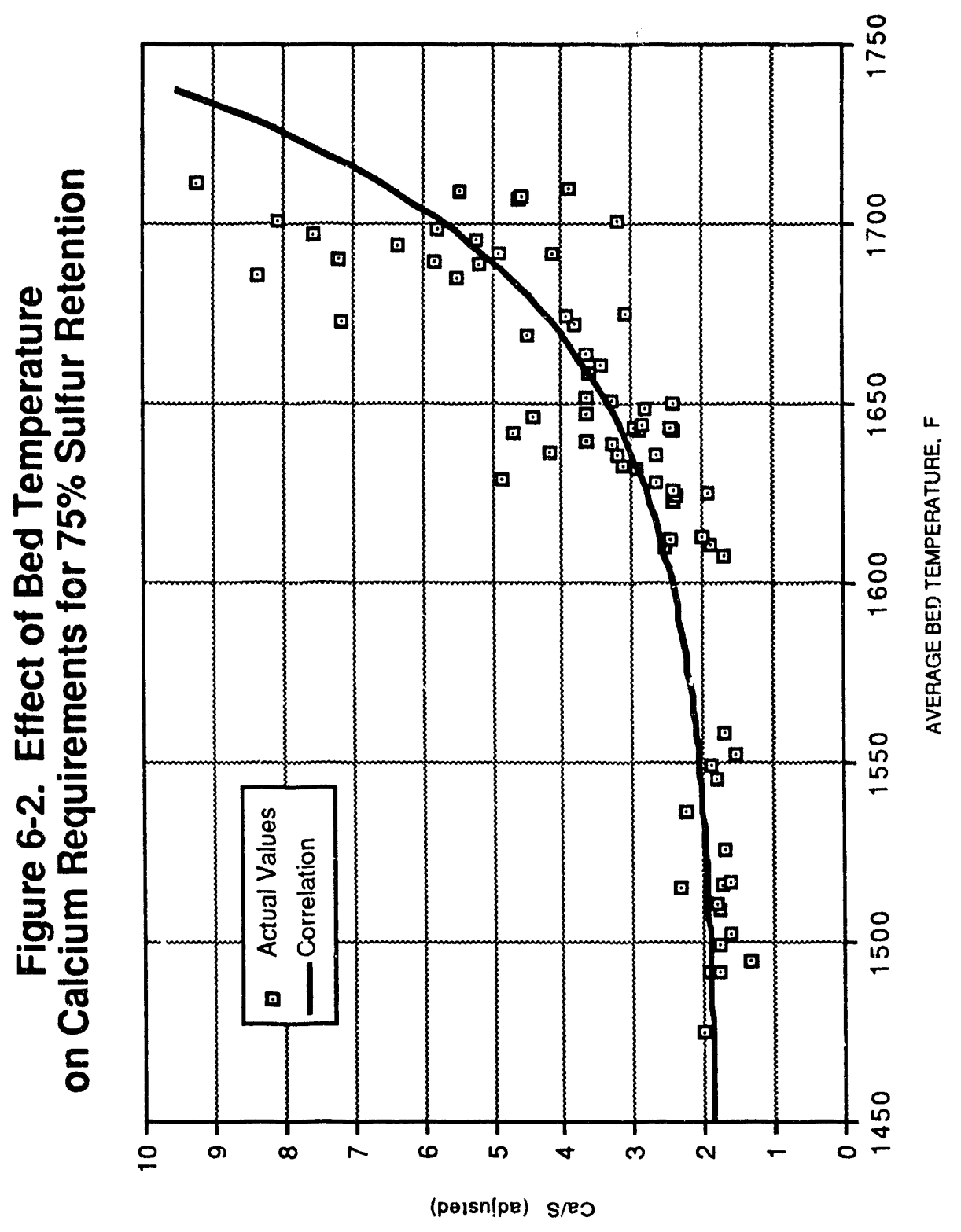




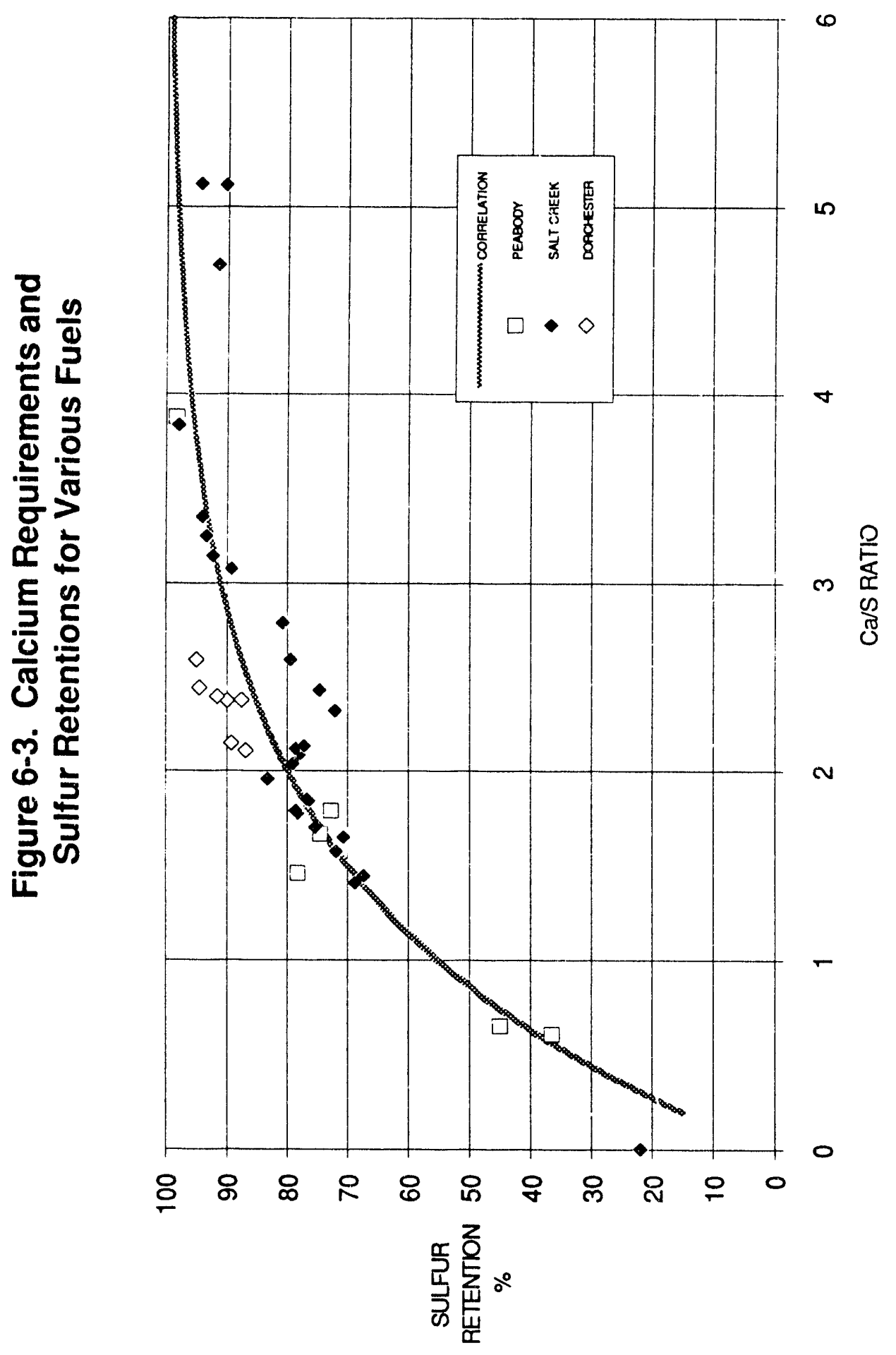

6-15 


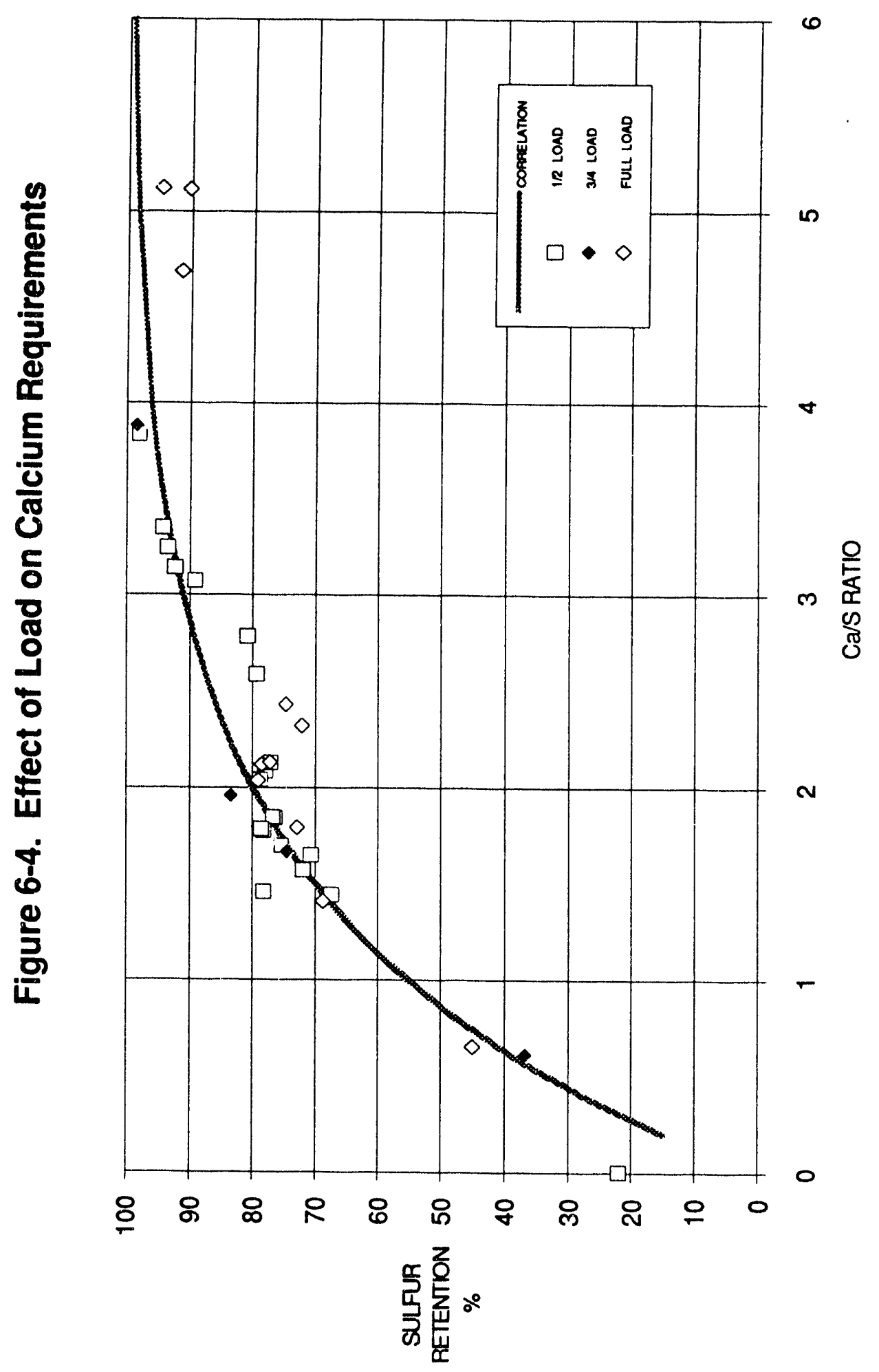

6-16 


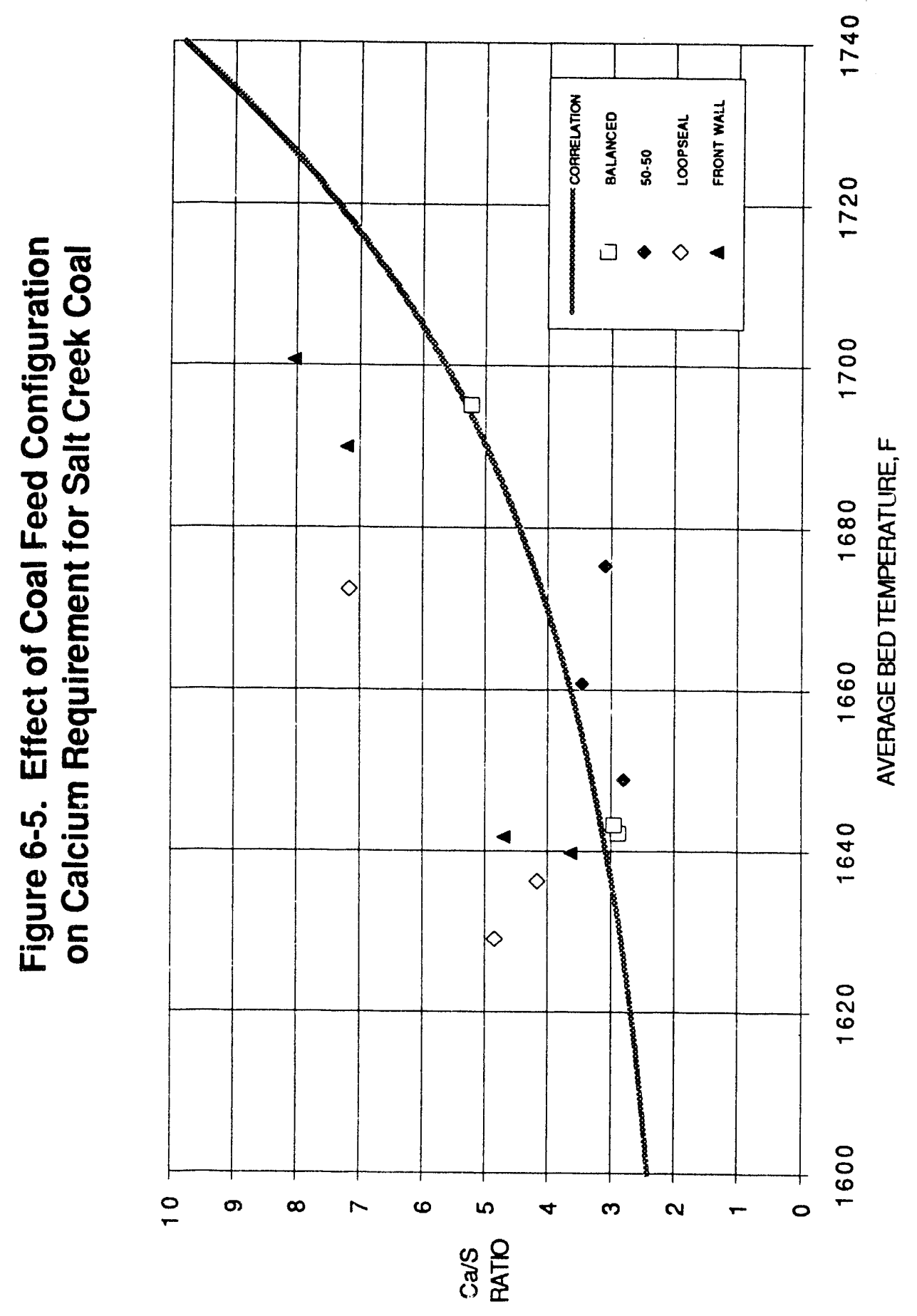


each combustor) and 50-50 (25\% to each of the front wall feeders and $50 \%$ to the loop seal coal feeder) coal feed distributions yield lower $\mathrm{Ca} / \mathrm{S}$ requirements. This effect becomes more pronounced at elevated bed temperatures. No effect of coal feed distribution on $\mathrm{Ca} / \mathrm{S}$ requirements was found at half load.

As can be seen in Figure 6-6, results from testing indicate that calcium requirements are insensitive to changes in limestone feed configuration at full load. At lower loads, no indication of calcium requirement sensitivity to limestone feed configuration was found. The number of these configuration tests are limited due to mechanical limitations to the limestone feed system.

The results, shown in Figure 6-7, show the effect of excess air and temperature on the $\mathrm{Ca} / \mathrm{S}$ ratio. At bed temperatures below 1680 ${ }^{\circ} \mathrm{F}$, excess air does not appear to influence calcium requirements. Above this point, the data indicate that decreased excess air may have a negative impact on $\mathrm{Ca} / \mathrm{S}$ requirements. The data above 1680 ${ }^{\circ} \mathrm{F}$ indicate that the $10 \%$ excess air points deviate from the correlation curve as the temperature increases, while the points above 13\% excess air do not.

Attempts to determine the effect of $\mathrm{SA} / \mathrm{PA}$ ratio on calcium requirements are documented in Figure 6-8. As is apparent from the figure, no effect can be seen when SA/PA ratio is varied over its full range $(0.5$ to 1.0$)$ during full load operation. Also, no effect due to changes in the $S A / P A$ ratio was found during half load testing.

It has been suggested that $C O$ concentration may affect calcium requirements. This was investigated, and no relationship between flue gas air heater inlet $C O$ concentrations and calcium requirements was found in data from the tests run at Nucla.

\section{$6.1 .2 \mathrm{NO}_{\mathrm{x}}$ Emissions}

$\mathrm{NO}_{\mathrm{x}}$ emissions for all tests completed have been less than 0.34 Ib/MMBtu (as measured by the CUEA stack emissions monitoring system), which is well within the emission limit of $0.50 \mathrm{lb} / \mathrm{MMBtu}$. The average level of $\mathrm{NO}_{\mathrm{x}}$ emissions for all tests is $0.18 \mathrm{lb} / \mathrm{MMBtu}$. For fluidized bed boilers operating well below the thermal $\mathrm{NO}_{\mathbf{x}}$ formation temperature of approximately $2500^{\circ} \mathrm{F}$, it is believed that $\mathrm{NO}_{\mathrm{x}}$ emissions result from fuel-bound nitrcgen being converted to $\mathrm{NO}_{x}$ followed by the destruction of the $\mathrm{NO}_{x}$ in the combustor. Mechanisms and reactions that lead to $\mathrm{NO}_{x}$ formation in fluidized bed combustion systems are complicated, and for a given coal and limestone, may be influenced by a number of factors.

Bec temperature is one of the most influential factors affecting $\mathrm{NO}_{x}$ emissions. The effect of this parameter on $\mathrm{NO}_{\mathrm{x}}$ emissions has been well researched and documented. In general, $\mathrm{NO}_{\mathrm{x}}$ emissions have been shown to increase with increasing bed temperature. A 


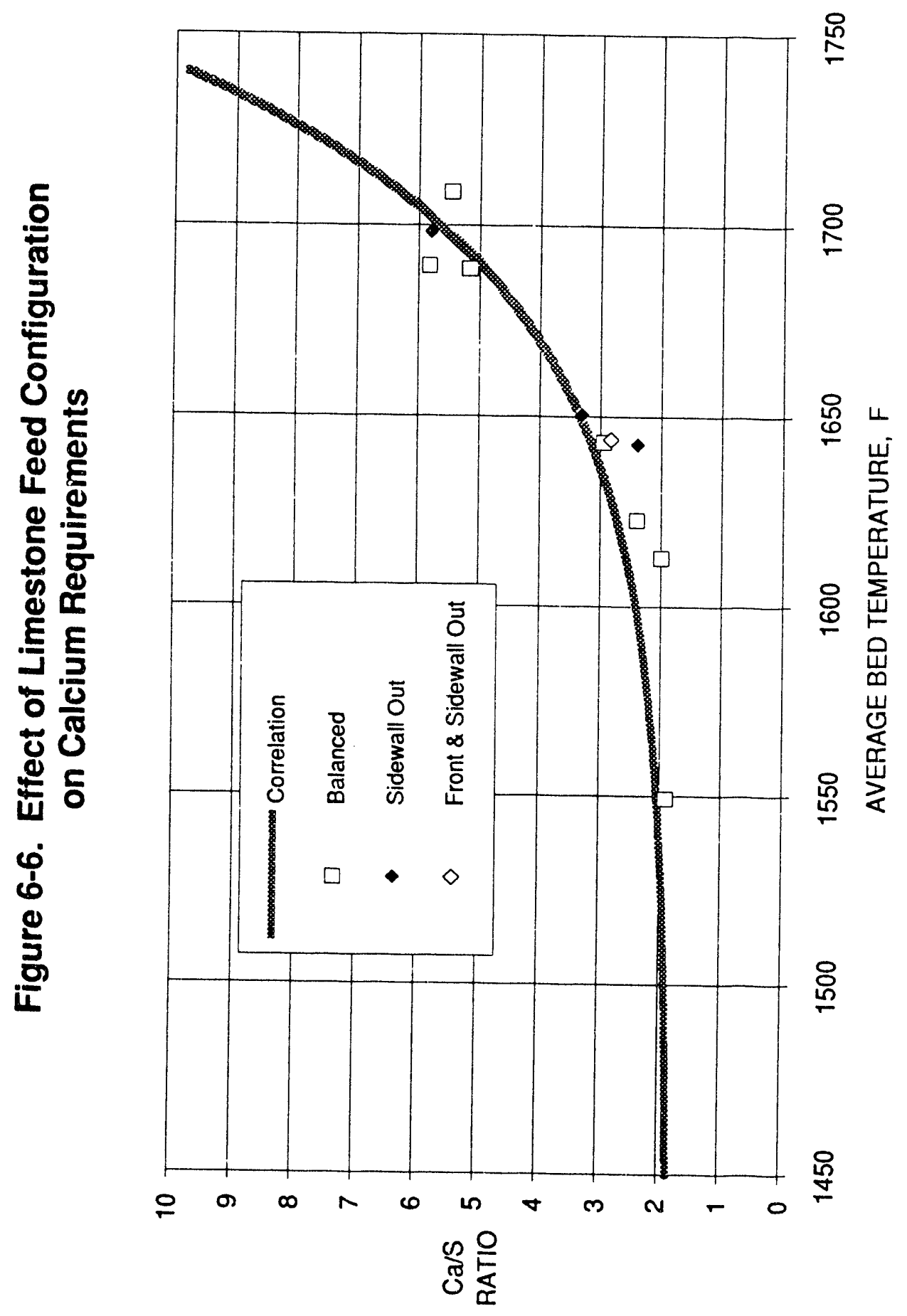




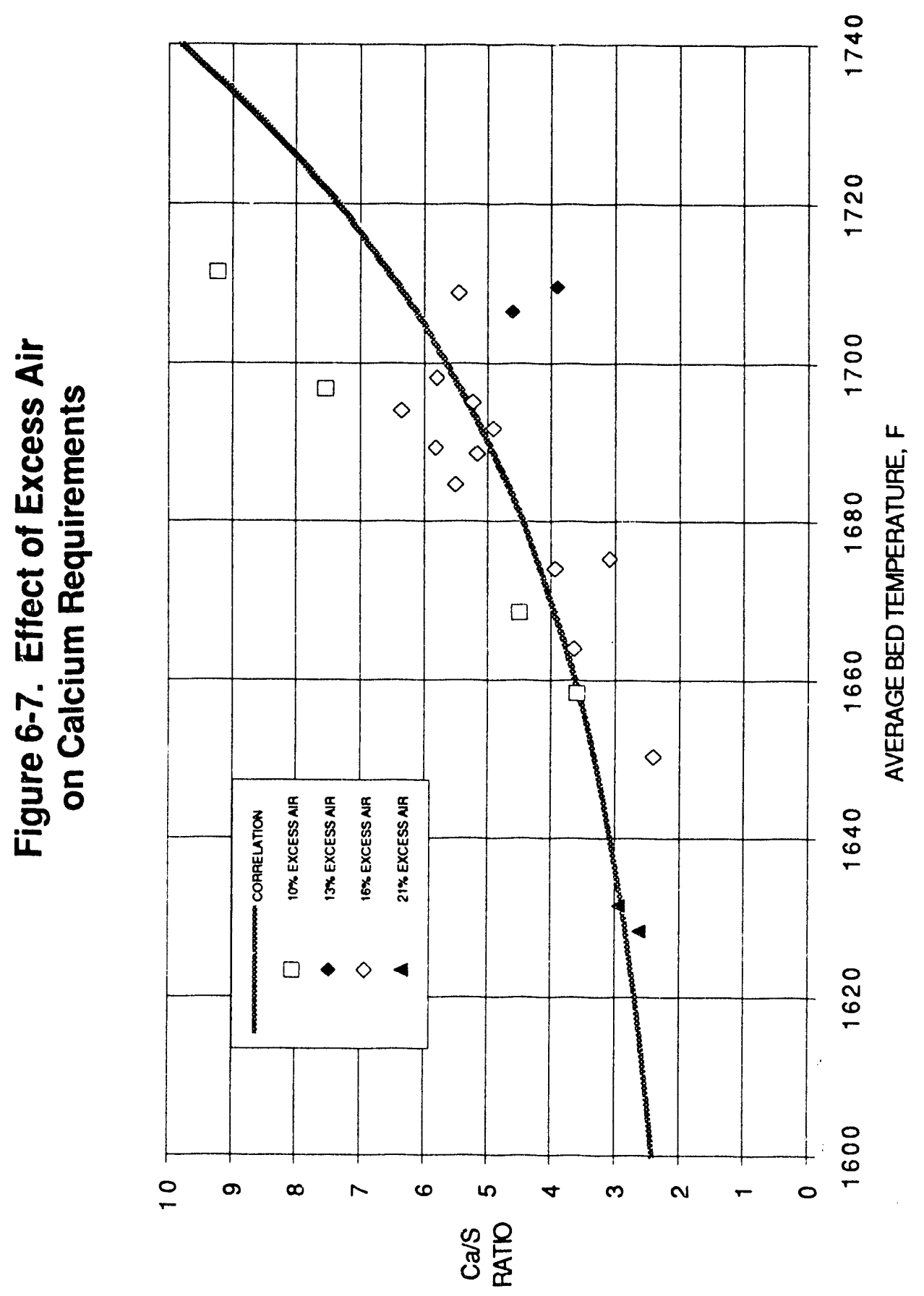




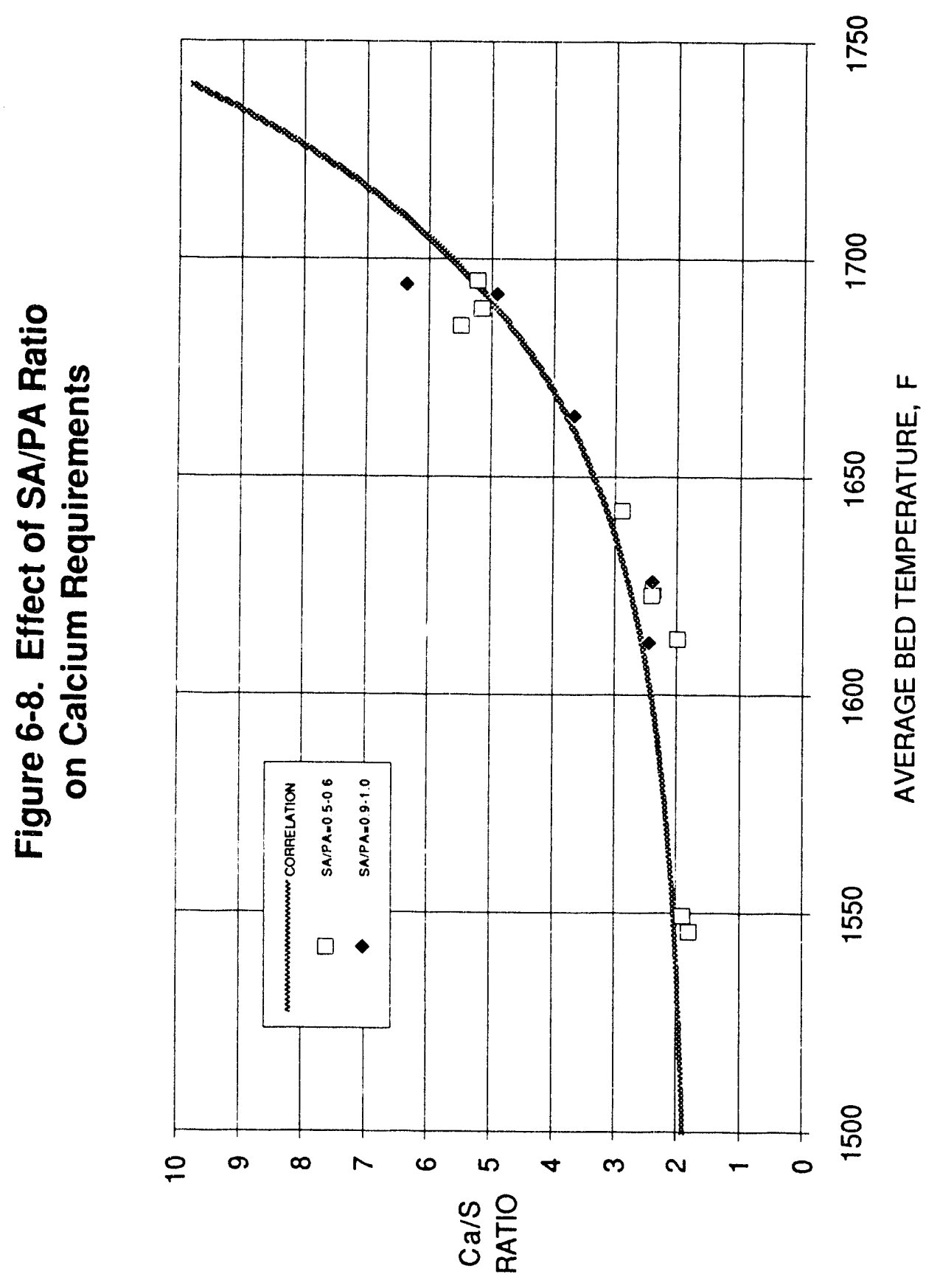


plot showing this relationship for the Nucla CFB boiler is included here as Figure 6-9.

A second order polynomial relationship was used to fit a curve to the data points. This curve is also shown in Figure 6-9. The equation for the curve is:

$$
\left[\mathrm{NO}_{\mathrm{X}}\right]=4139-5.867 * \mathrm{~T}+2.1 \mathrm{E}-3 \star \mathrm{T}^{2}
$$

where:

$$
\begin{array}{ll}
{\left[\mathrm{NO}_{\mathbf{x}}\right]} & =\mathrm{NO}_{\mathbf{x}} \text { concentration corrected to } 3 \% \mathrm{O}_{2} \text {, ppmv } \\
\mathrm{T} & =\text { Mean bed temperature, }{ }^{\circ} \mathrm{F}
\end{array}
$$

An attempt to explain the scatter in the $\mathrm{NO}_{\mathbf{x}}$ versus bed temperature plot for all balanced coal feed configuration tests identified Iimestone feed rate as another variable affecting $\mathrm{NO}_{\mathrm{x}}$. Figure $6-10$ shows $\mathrm{NO}_{\mathrm{x}}$ plotted against bed temperature for different $\mathrm{Ca} / \mathrm{N}$ weight ratios. $\mathrm{Ca} / \mathrm{N}$ weight ratio serves as a measure of limestone feed normalized to the nitrogen input of the coal. Table 6-5 contains all data relevant to the development of Figure 6-10.

$\mathrm{CaO}$ has been known to influence both $\mathrm{NO}_{\mathbf{x}}$ formation and reduction. Oxidation of volatile nitrogen, present in the form of $\mathrm{NH}_{3}$, is catalyzed by CaO. This may explain why higher $\mathrm{NO}_{\mathrm{x}}$ emissions result from increasing $\mathrm{Ca} / \mathrm{N}$ weight ratios.

Figure 6-11 shows how the $\mathrm{NO}_{\mathbf{x}}$ emissions varied with the use of alternate fuels. As shown in the figure, emissions during operation on Dorchester coal were consistently higher than the correlated values. This is most likely due to the fact that the sulfur content, and therefore limestone feed rate (and $\mathrm{Ca} / \mathrm{N}$ ratio), was higher when operating on this fuel.

The effect of coal feed configuration on $\mathrm{NO}_{\mathrm{x}}$ during full load operation is shown in Figure 6-12. It appears that feeding coal through the front wall only may lead to higher $\mathrm{NO}_{\mathrm{x}}$ emissions. As was the case with the Dorchester coal, higher limestone feed requirements with front wall only coal feed lead to higher limestone feed rates, which increases the $\mathrm{Ca} / \mathrm{N}$ ratio. It is significant to note that while coal feed to the loop seal feed point only results in higher $\mathrm{Ca} / \mathrm{S}$ ratios, it does not appear to lead to higher $\mathrm{NO}_{\mathrm{x}}$ emissions. No effect of coal feed configuration was found at lower temperatures and loads.

The influence of excess air on $\mathrm{NO}_{\mathbf{x}}$ emissions was investigated, and the results of that investigaiion are shown in Figure 6-13. As the figure shows, excess air did not appear to have a significant effect on the emissions of $\mathrm{NO}_{\mathbf{x}}$ over the range tested. This result is somewhat surprising as most researchers believe that increased excess air will lead to increased $\mathrm{NO}_{\mathrm{x}}$ emissions. However, the range of excess air studied in these tests was somewhat limited. 


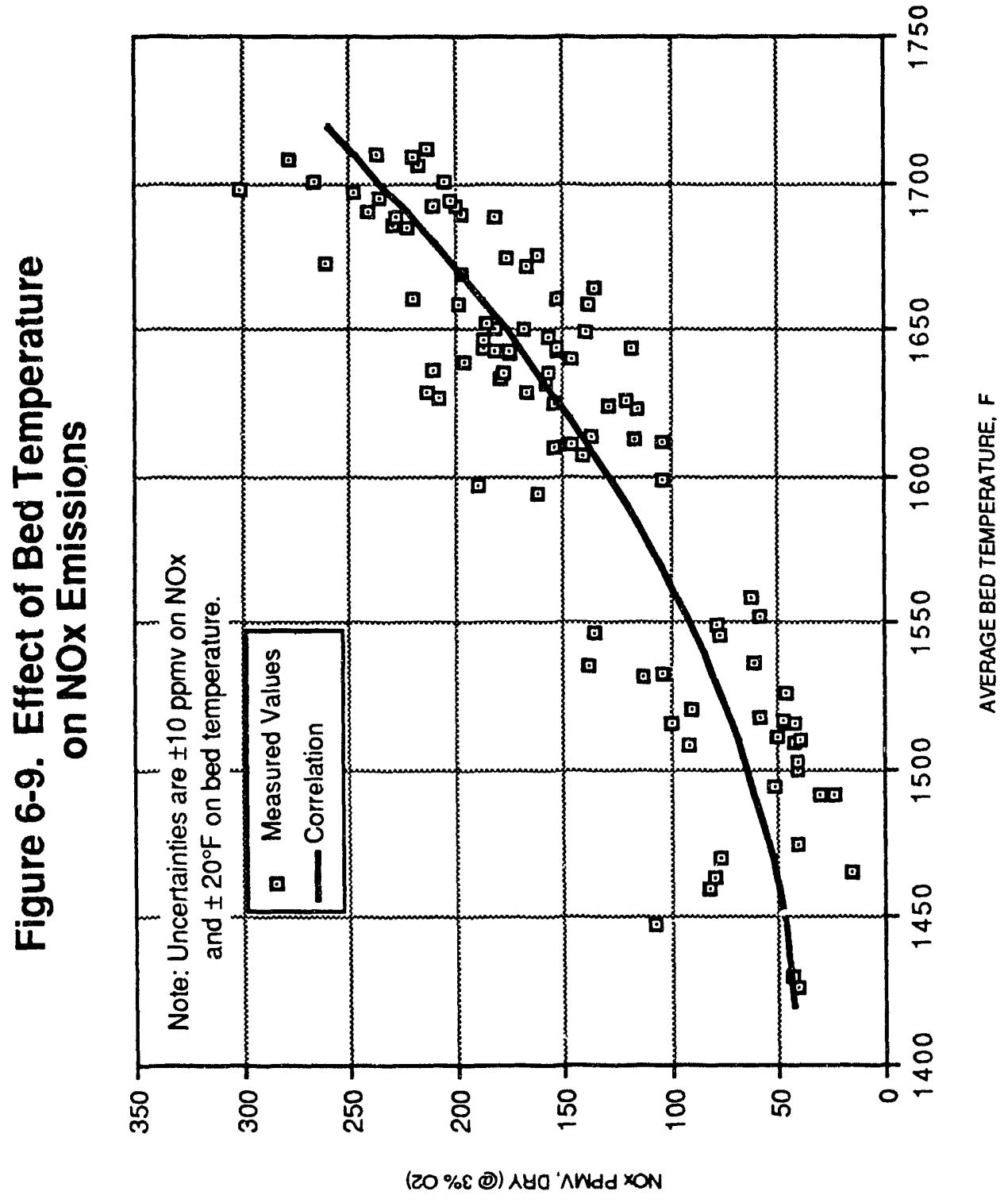


Table 6-5. EFFECT OF LIMESTONE FEED ON NOX EMISSIONS

(Page 1 of 2)

\begin{tabular}{|c|c|c|c|c|c|c|c|c|}
\hline Test No. & $\begin{array}{c}\text { NOx } \\
\text { PPMV } \\
\text { @3\% O2 } \\
\end{array}$ & $\begin{array}{c}\text { Mean Bed } \\
\text { Tomp. } \\
\text { deg F }\end{array}$ & $\begin{array}{c}O 2 \\
\% \text { Vol. }\end{array}$ & $\begin{array}{l}\text { Nitrogen } \\
\text { contont } \\
\text { of coal } \\
\end{array}$ & $\begin{array}{c}\text { Coal foed } \\
\text { rete } \\
\text { KIb/hr }\end{array}$ & $\begin{array}{c}\text { Limestone } \\
\text { feed rate } \\
\mathrm{K} / \mathrm{b} / \mathrm{hr}\end{array}$ & $\begin{array}{c}\text { Ca/N wolght } \\
\text { retlo }\end{array}$ & $\begin{array}{l}\text { Volatlle } \\
\text { content } \\
\text { of coal } \\
\end{array}$ \\
\hline P57 & 16 & 1467 & 6.4 & 0.43 & 61 & 0.0 & 0.0 & 31.3 \\
\hline$P 49$ & 118 & 1642 & 3.5 & 1.29 & 95 & 1.5 & 0.4 & 33.5 \\
\hline SD1 & 62 & 1562 & 3.9 & 1.53 & 103 & 2.3 & 0.5 & 31.3 \\
\hline A06 & 103 & 1599 & 4.2 & 0.94 & 85 & 1.2 & 0.5 & 28.1 \\
\hline $\mathrm{AO3}$ & 136 & 1614 & 3.5 & 1.06 & 107 & 1.7 & 0.5 & 29.0 \\
\hline PS29 & 120 & 1500 & 6.4 & 1.25 & 59 & 1.5 & 0.7 & 34.4 \\
\hline PS28 & 126 & 1502 & 6.3 & 1.32 & 60 & 1.7 & 0.8 & 34.6 \\
\hline P68A & 115 & 1623 & 2.9 & 1.47 & 54 & 2.0 & 0.9 & 32.9 \\
\hline PS24R1 & 115 & 1518 & 6.4 & 1.22 & 60 & 1.8 & 0.9 & 32.6 \\
\hline PS13M1A & 179 & 1633 & 2.9 & 1.91 & 53 & 2.6 & 0.9 & 33.9 \\
\hline PS18 & 124 & 1496 & 6.5 & 1.27 & 61 & 2.0 & 0.9 & 32.5 \\
\hline PS15 & 167 & 1628 & 3.8 & 1.56 & 110 & 4.7 & 1.0 & 32.1 \\
\hline PS27 & 103 & 1483 & 6.4 & 1.25 & 58 & 1.9 & 1.0 & 31.3 \\
\hline P36A & 77 & 1546 & 3.0 & 1.31 & 55 & 2.0 & 1.0 & 32.3 \\
\hline P30 & 30 & 1493 & 5.7 & 1.03 & 58 & 1.7 & 1.0 & 31.7 \\
\hline PS25 & 107 & 1495 & 6.4 & 1.21 & 57 & 2.0 & 1.0 & 32.3 \\
\hline PSO9M1 & 167 & 1672 & 3.2 & 1.93 & 105 & 5.9 & 1.0 & 33.4 \\
\hline P07A & 128 & 1624 & 3.0 & 1.42 & 53 & 2.2 & 1.1 & 32.8 \\
\hline M01B & 162 & 1675 & 3.0 & 1.23 & 57 & 2.1 & 1.1 & 32.1 \\
\hline P67A & 117 & 1613 & 3.0 & 1.21 & 55 & 1.9 & 1.1 & 32.5 \\
\hline PS16 & 158 & 1632 & 3.8 & 1.44 & 105 & 4.4 & 1.1 & 32.9 \\
\hline P71A & 103 & 1612 & 2.9 & 1.23 & 57 & 2.1 & 1.1 & 32.5 \\
\hline M01A & 139 & 1649 & 3.0 & 1.31 & 56 & 2.3 & 1.1 & 32.6 \\
\hline P32A & 154 & 1610 & 4.4 & 1.12 & 54 & 1.9 & 1.1 & 32.6 \\
\hline PS31 & 185 & 1652 & 3.2 & 1.63 & 109 & 5.9 & 1.2 & 32.8 \\
\hline P70A & 78 & 1549 & 3.0 & 1.24 & 55 & 2.2 & 1.2 & 31.6 \\
\hline PS26 & 113 & 1465 & 6.4 & 1.23 & 61 & 2.4 & 1.2 & 32.3 \\
\hline P32B & 177 & 1636 & 4.4 & 1.12 & 54 & 2.0 & 1.2 & 32.4 \\
\hline P08A & 120 & 1626 & 3.0 & 1.28 & 55 & 2.4 & 1.2 & 32.2 \\
\hline P69B & 135 & 1664 & 3.0 & 1.30 & 56 & 2.5 & 1.2 & 31.9 \\
\hline P52 & 46 & 1523 & 6.3 & 1.50 & 54 & 2.9 & 1.3 & 33.6 \\
\hline P64 & 44 & 1430 & 6.6 & 1.29 & 61 & 2.9 & 1.3 & 32.9 \\
\hline PS12R1 & 168 & 1650 & 3.1 & 1.34 & 110 & 5.6 & 1.3 & 31.9 \\
\hline P65B & 176 & 1674 & 3.0 & 1.38 & 56 & 2.9 & 1.3 & 32.7 \\
\hline P31 & $5 \varepsilon$ & 1556 & 3.8 & 0.84 & 80 & 2.6 & 1.4 & 33.7 \\
\hline PS32 & 196 & 1639 & 3.8 & 1.30 & 108 & 5.5 & 1.4 & 32.0 \\
\hline P50 & 156 & 1638 & 3.5 & 1.64 & 94 & 6.2 & 1.4 & 30.8 \\
\hline P58 & 46 & 1430 & 6.6 & 1.16 & 63 & 2.9 & 1.4 & 30.8 \\
\hline P06A & 152 & 1642 & 3.0 & 1.13 & 54 & 2.5 & 1.5 & 32.6 \\
\hline P63 & 76 & 1473 & 6.6 & 1.25 & 58 & 3.0 & 1.5 & 31.7 \\
\hline MO2A & 211 & 1636 & 3.0 & 1.32 & 56 & 3.1 & 1.5 & 30.4 \\
\hline A07 & 52 & 1495 & 5.9 & 0.93 & 59 & 2.3 & 1.5 & 28.8 \\
\hline М०3А & 146 & 1640 & 3.1 & 1.19 & 52 & 2.6 & 1.5 & 32.6 \\
\hline P39 & 61 & 1538 & 6.0 & 1.13 & 58 & 2.9 & 1.6 & 28.8 \\
\hline P20 & 24 & 1494 & 6.2 & 0.52 & 64 & 1.5 & 1.6 & 33.3 \\
\hline PSO1 & 156 & 1647 & 3.1 & 1.18 & 109 & 5.6 & 1.6 & 33.4 \\
\hline PS11A & 175 & 1642 & 3.1 & 1.38 & 52 & 3.3 & 1.6 & 32.0 \\
\hline P62 & 79 & 1463 & 6.3 & 1.30 & 58 & 3.5 & 1.6 & 31.9 \\
\hline PS14A & 197 & 1669 & 2.1 & 1.52 & 55 & 3.9 & 1.7 & 32.7 \\
\hline P07B & 200 & 1692 & 3.2 & 1.35 & 54 & 3.5 & 1.7 & 32.9 \\
\hline MO5A & 175 & 1643 & 3.0 & 1.24 & 55 & 3.3 & 1.7 & 33.8 \\
\hline
\end{tabular}


Table 6-5. EFFECT OF LIMESTONE FEED ON NOX EMISSIONS

(Page 2 of 2)

\begin{tabular}{|c|c|c|c|c|c|c|c|c|}
\hline Tost No. & $\begin{array}{c}\text { NOx } \\
\text { PPMV } \\
@ 3 \% 02\end{array}$ & $\begin{array}{l}\text { Moan Bed } \\
\text { Tomp. } \\
\text { deg F }\end{array}$ & $\begin{array}{c}02 \\
* \text { Vol. }\end{array}$ & $\begin{array}{l}\text { Nitrogen } \\
\text { contont } \\
\text { of coal }\end{array}$ & $\begin{array}{c}\text { Coal feod } \\
\text { rate } \\
\text { Klb/hr }\end{array}$ & $\begin{array}{c}\text { Limestone } \\
\text { feod rate } \\
\mathrm{K} / \mathrm{b} / \mathrm{hr}\end{array}$ & $\begin{array}{c}\text { Ca/N welght } \\
\text { ratlo }\end{array}$ & $\begin{array}{l}\text { Volatile } \\
\text { contont } \\
\text { of coal }\end{array}$ \\
\hline A04 & 141 & 1608 & 4.2 & 0.77 & 86 & 3.2 & 1.8 & 29.5 \\
\hline P66A & 138 & 1658 & 2.0 & 1.13 & 55 & 3.1 & 1.8 & 32.3 \\
\hline C01A & 181 & 1643 & 3.0 & 1.21 & 56 & 3.4 & 1.8 & 32.7 \\
\hline PS33A & 187 & 1646 & 3.2 & 1.35 & 51 & 3.5 & 1.8 & 32.6 \\
\hline P21 & 58 & 1520 & 6.3 & 1.23 & 57 & 3.6 & 1.8 & 32.8 \\
\hline PSO8 & 153 & 1661 & 3.2 & 0.99 & 110 & 5.7 & 1.9 & 32.5 \\
\hline CO2A & 182 & 1650 & 3.0 & 1.26 & 55 & 3.8 & 2.0 & 32.9 \\
\hline P55B & 199 & 1659 & 3.6 & 1.33 & 110 & 8.0 & 2.0 & 30.3 \\
\hline M04A & 187 & 1644 & 3.0 & 1.26 & 55 & 3.8 & 2.0 & 33.5 \\
\hline P68B & 198 & 1689 & 3.1 & 1.50 & 54 & 4.6 & 2.1 & 32.9 \\
\hline$A 08$ & 154 & 1625 & 3.4 & 0.81 & 100 & 4.6 & 2.1 & 30.6 \\
\hline P55A & 138 & 1532 & 3.5 & 1.26 & 108 & 7.9 & 2.1 & 30.7 \\
\hline A01 & 146 & 1606 & 3.7 & 0.82 & 98 & 4.6 & 2.1 & 30.2 \\
\hline P60B & 218 & 1712 & 2.5 & 1.24 & 114 & 8.4 & 2.1 & 32.4 \\
\hline P60A & 162 & 1601 & 2.5 & 1.24 & 112 & 8.5 & 2.2 & 32.8 \\
\hline P61A & 220 & 1670 & 2.5 & 1.21 & 112 & 8.3 & 2.2 & 30.7 \\
\hline P56A & 135 & 1552 & 2.5 & 1.22 & 111 & 8.3 & 2.2 & 27.8 \\
\hline P56B & 182 & 1688 & 2.5 & 1.17 & 112 & 8.1 & 2.2 & 30.1 \\
\hline P67B & 220 & 1708 & 3.1 & 1.25 & 54 & 4.1 & 2.2 & 32.8 \\
\hline P06B & 236 & 1695 & 3.0 & 1.15 & 55 & 4.0 & 2.3 & 31.9 \\
\hline P61B & 237 & 1716 & 2.5 & 1.24 & 113 & 8.8 & 2.3 & 32.6 \\
\hline PS24 & 81 & 1498 & 6.4 & 0.52 & 60 & 2.0 & 2.3 & 32.5 \\
\hline P08B & 211 & 1692 & 3.1 & 1.26 & 58 & 4.7 & 2.3 & 31.1 \\
\hline MO2B & 261 & 1672 & 3.0 & 1.29 & 56 & 4.8 & 2.4 & 31.0 \\
\hline PS148 & 248 & 1697 & 2.1 & 1.71 & 56 & 6.4 & 2.5 & 32.5 \\
\hline Co1B & 266 & 1700 & 3.2 & 1.17 & 58 & 4.7 & 2.5 & 31.6 \\
\hline P71B & 203 & 1694 & 3.1 & 1.23 & 57 & 4.8 & 2.5 & 32.2 \\
\hline PS33B & 230 & 1686 & 3.0 & 1.35 & 52 & 5.2 & 2.6 & 32.1 \\
\hline P7OB & 228 & 1689 & 3.0 & 1.26 & 55 & 5.5 & 2.8 & 32.0 \\
\hline P36B & 223 & 1685 & 3.0 & 1.31 & 55 & 5.8 & 2.9 & 32.3 \\
\hline PS11B & 241 & 1690 & 3.0 & 1.38 & 52 & 6.1 & 3.0 & 32.3 \\
\hline AFO9B & 103 & 1533 & 4.2 & 1.28 & 51 & 5.5 & 3.0 & 29.7 \\
\hline PSO2 & 153 & 1643 & 3.1 & 0.55 & 110 & 5.3 & 3.2 & 32.8 \\
\hline МозB & 205 & 1701 & 3.0 & 1.17 & 52 & 5.4 & 3.2 & 32.8 \\
\hline $\mathrm{CO} 28$ & 278 & 1708 & 3.1 & 1.27 & 56 & 6.6 & 3.4 & 33.0 \\
\hline A05 & 189 & 1597 & 4.3 & 0.88 & 85 & 7.0 & 3.4 & 31.7 \\
\hline AF09A & 90 & 1521 & 4.1 & 1.27 & 49 & 6.0 & 3.5 & 30.4 \\
\hline AF07B & 100 & 1515 & 6.4 & 1.26 & 37 & 4.5 & 3.5 & 31.9 \\
\hline $\mathrm{A} 02$ & 208 & 1627 & 3.5 & 0.94 & 99 & 9.5 & 3.6 & 32.9 \\
\hline AF 10 & 113 & 1531 & 4.2 & 1.15 & 100 & 12.0 & 3.7 & 29.7 \\
\hline AFOBB & 91 & 1508 & 6.3 & 1.19 & 36 & 4.4 & 3.7 & 30.6 \\
\hline MO5B & 301 & 1698 & 3.1 & 1.24 & $5 E$ & 7.2 & 3.8 & 33.3 \\
\hline PS17 & 121 & 1506 & 6.3 & 0.35 & 63 & 2.4 & 4.0 & 31.6 \\
\hline AFOBA & 82 & 1460 & 6.2 & 1.18 & 37 & 5.1 & 4.0 & 30.1 \\
\hline AF07A & 107 & 1448 & 6.5 & 1.24 & 38 & 5.5 & 4.2 & 30.5 \\
\hline P66B & 213 & 1711 & 2.0 & 1.11 & 55 & 7.6 & 4.5 & 32.0 \\
\hline PS10 & 214 & 1629 & 3.1 & 0.55 & 115 & 7.9 & 4.6 & 32.4 \\
\hline
\end{tabular}




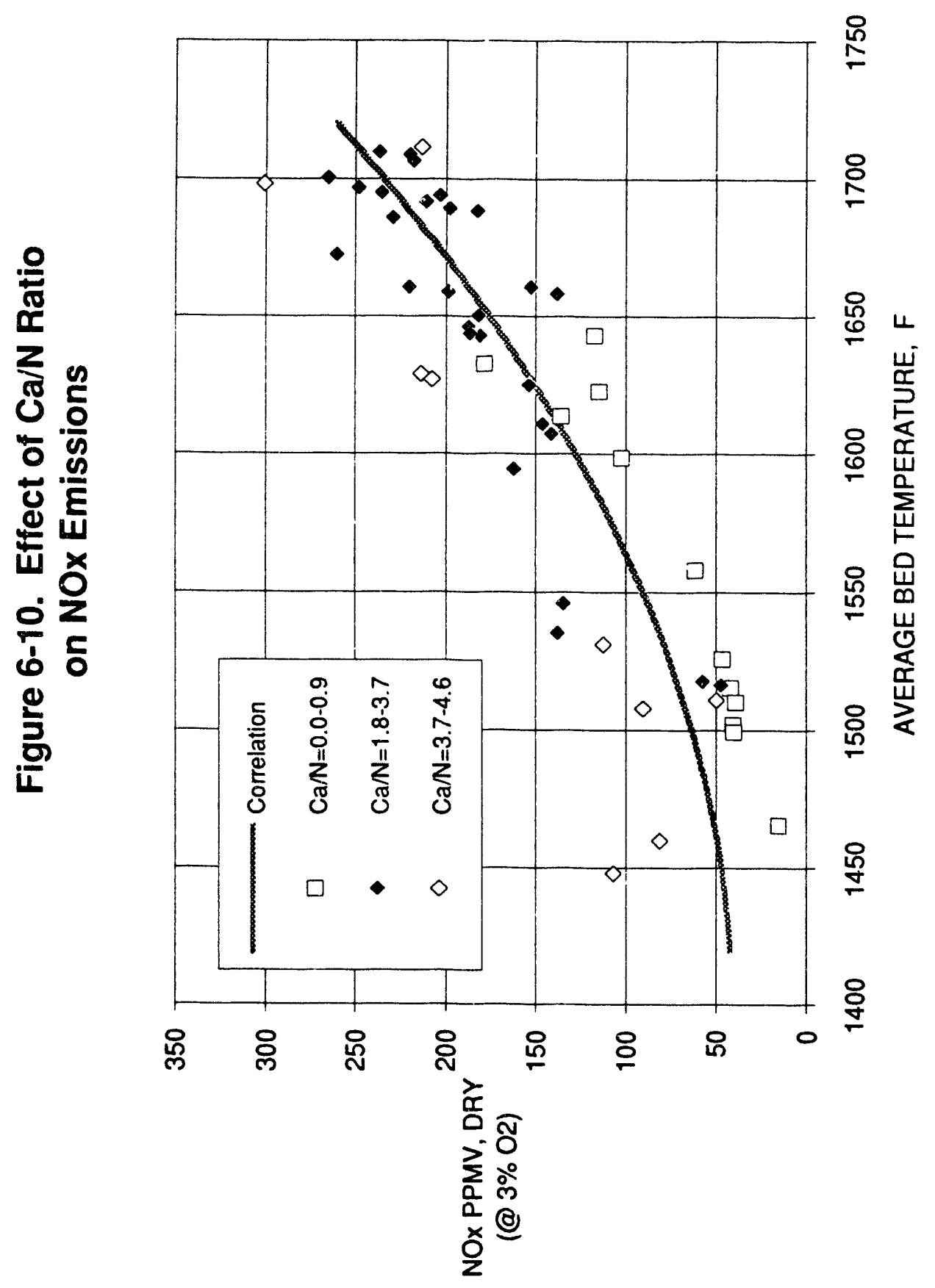




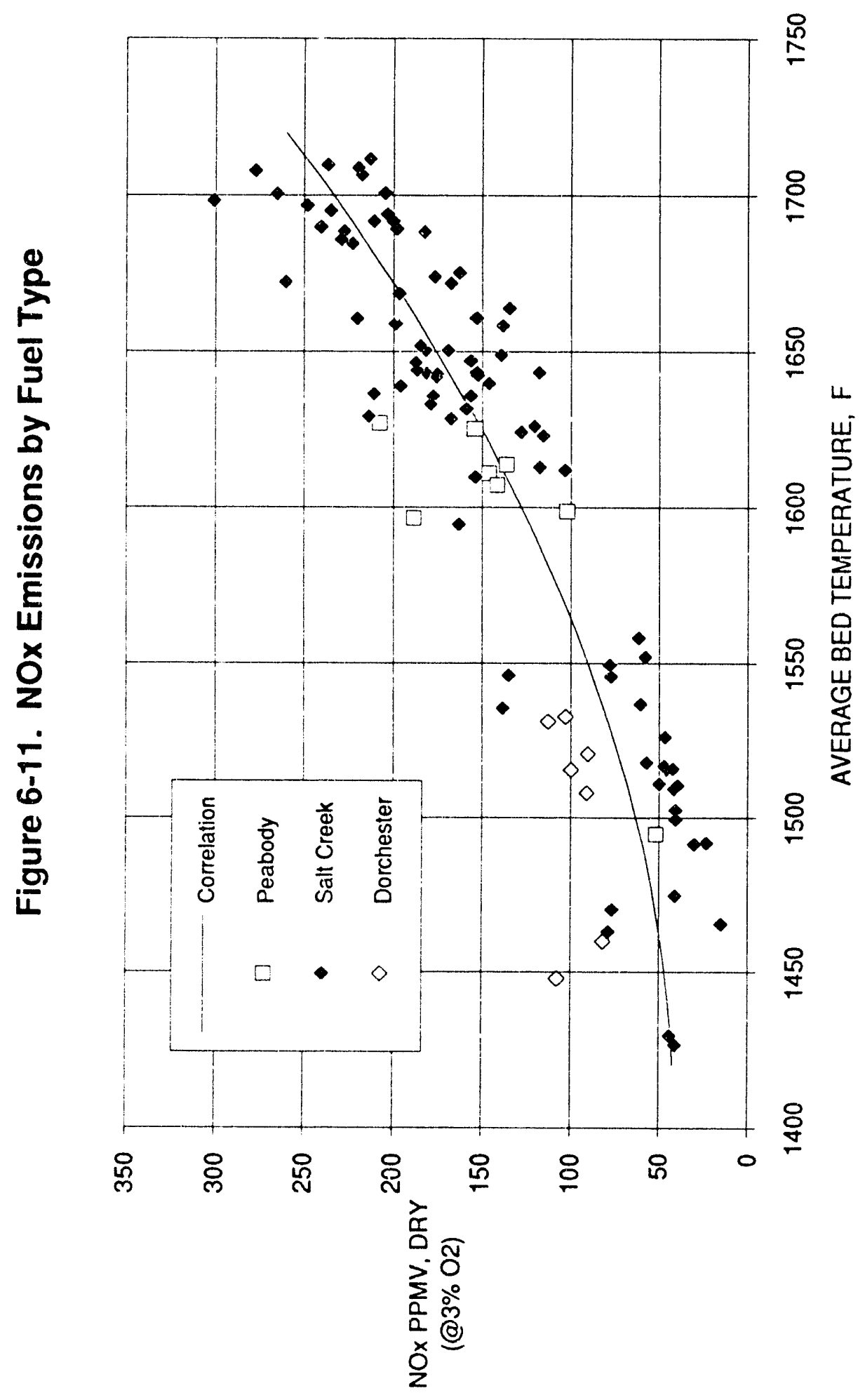




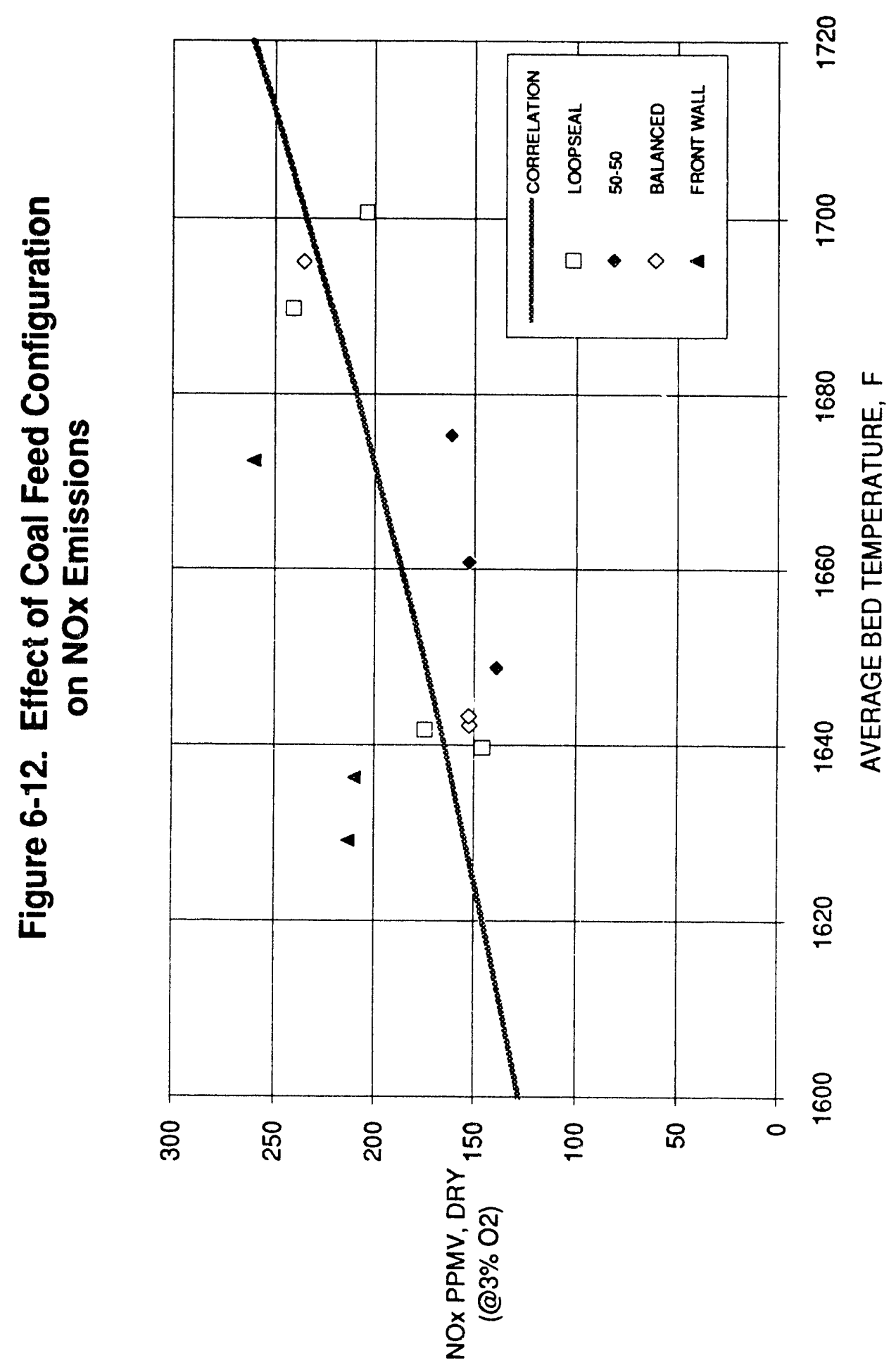




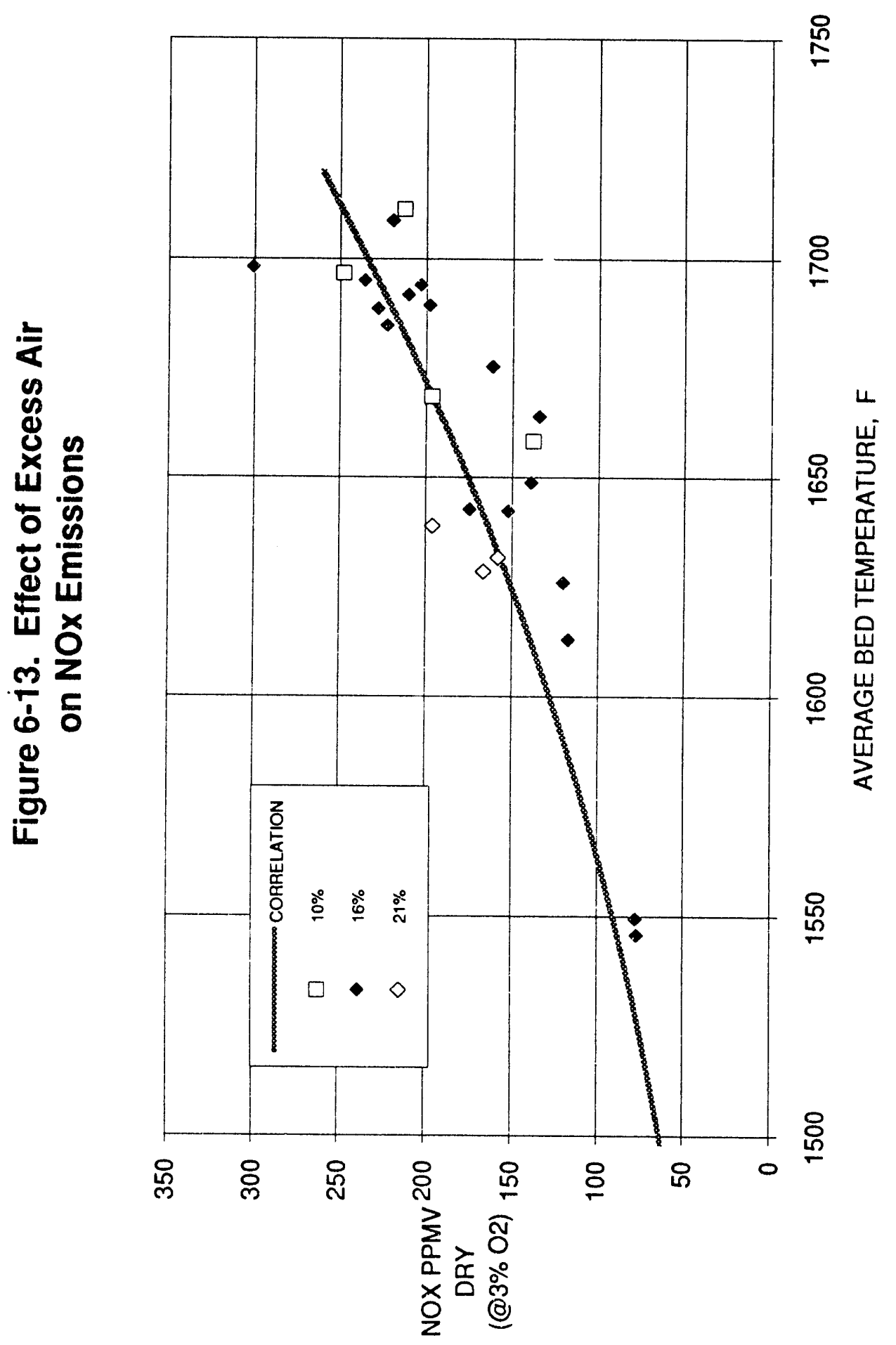


Limestone feed configuration, SA/PA ratio, and $C O$ concentration were found to have no measurable effect on $\mathrm{NO}_{\mathrm{x}}$ emissions over the range of testing that was conducted at Nucla. In addition, other than the effect due to increased temperature with increasing load, no effect of load on $\mathrm{NO}_{\mathbf{x}}$ emissions was found.

\subsubsection{Carbon Monoxide Emissions}

Figure 6-14 is a plot of $\mathrm{CO}$ emissions, corrected to 3 percent $\mathrm{O}_{2}$ in the dry flue gas, against mean bed temperature for all test runs completed during the Phase I and Phase II test programs. It can be seen that, in general, $C O$ emissions decrease as mean bed temperature increases. A second order polynomial was used to curve-fit the data points. The equation for the correlation is:

$$
[\mathrm{CO}]=2542-2.858 * \mathrm{~T}+8.253 \mathrm{E}-4 * \mathrm{~T}^{2}
$$

where

$$
\begin{array}{ll}
{[\mathrm{CO}]} & =\mathrm{CO} \text { concentration corrected to } 3 \% \mathrm{O}_{2}, \mathrm{ppmv} \\
\mathrm{T} & =\text { Mean bed temperature, }{ }_{\mathrm{F}}
\end{array}
$$

Eigure 6-15 is a plot showing the CO emissions performance during operation of the boiler on the three different fuels used at Nucla. It can be seen that the use of Peabody coal leads to emissions of $C O$ that are ccnsistently at or below the correlated values, while nearly all CO emission values for tests run on Dorchester coal feli above the correlation curve.

The effect of coal feed configuration on CO emissions on Salt creek coal at full load is shown in Figure 6-16. This figure shows that, as was the case with $\mathrm{NO}_{\mathrm{x}}$, emissions of $\mathrm{CO}$ drop when the front wall only coal feed configuration is used. No effect was seen at lower loads.

The effect of excess air on $c 0$ emissions was investigated at full load on Salt Creek coal. The results are shown in Figure 6-17. Excess air appears to have a slight impact on $\mathrm{CO}$, however, the difference is within the uncertainty band of the measurements. It should be noted, however, that the highest co emission shown in Figure 6-17 corresponds to the lowest value of excess air for any test run, 10.1\%. This suggests that when excess air is reduced to low values, $\mathrm{CO}$ emissions begin to increase.

As with $\mathrm{Ca} / \mathrm{S}$ requirements and emissions, SA/PA ratio had no influence on $\mathrm{CO}$ emissions over the range tested.

\subsection{COMBUSTION EFFICIENCY}

In this section, combustion efficiency is discussed from 68 performance tests for which this parameter was calculated. The values obtained for combustion efficiency range from $96.9 \%$ to 


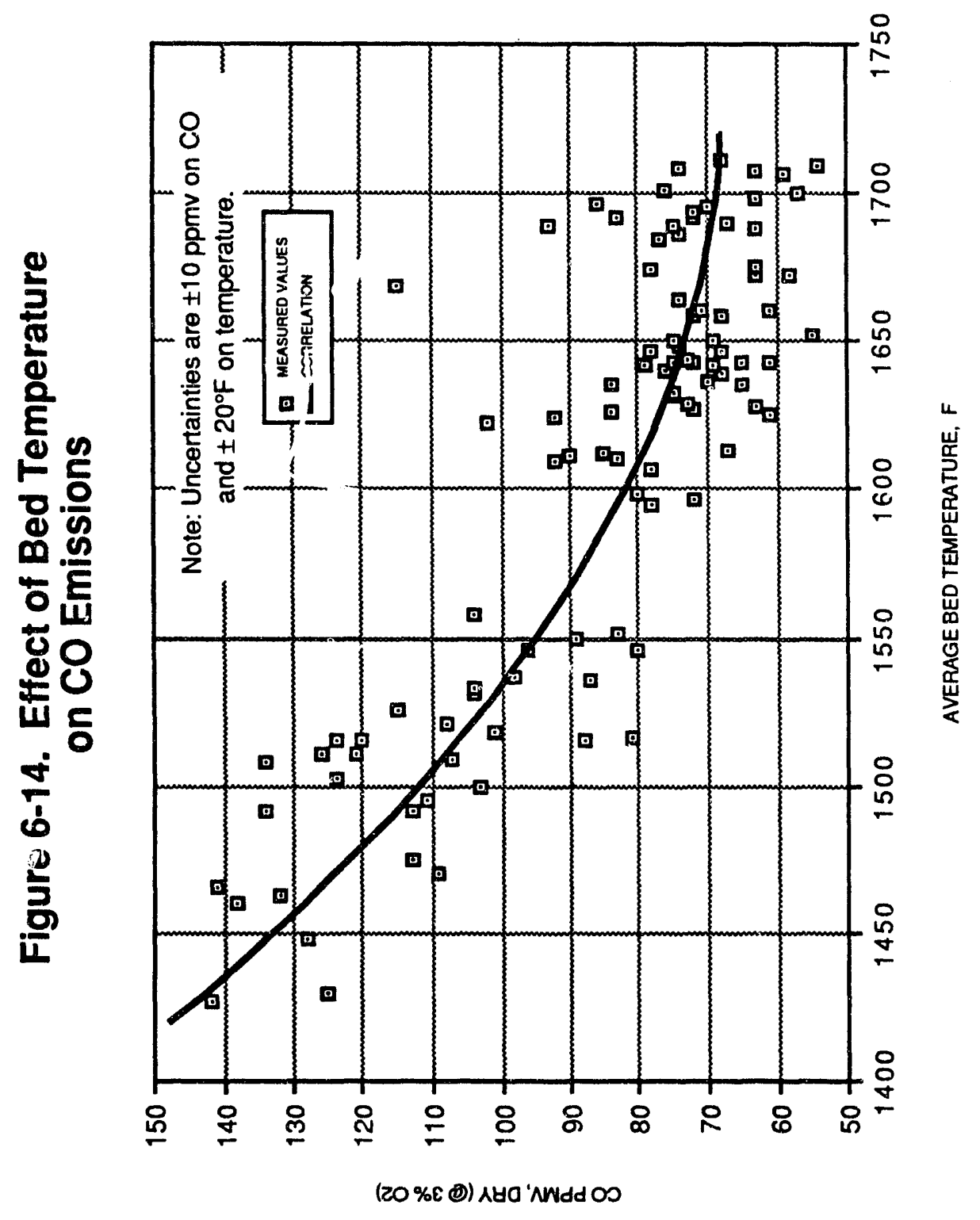




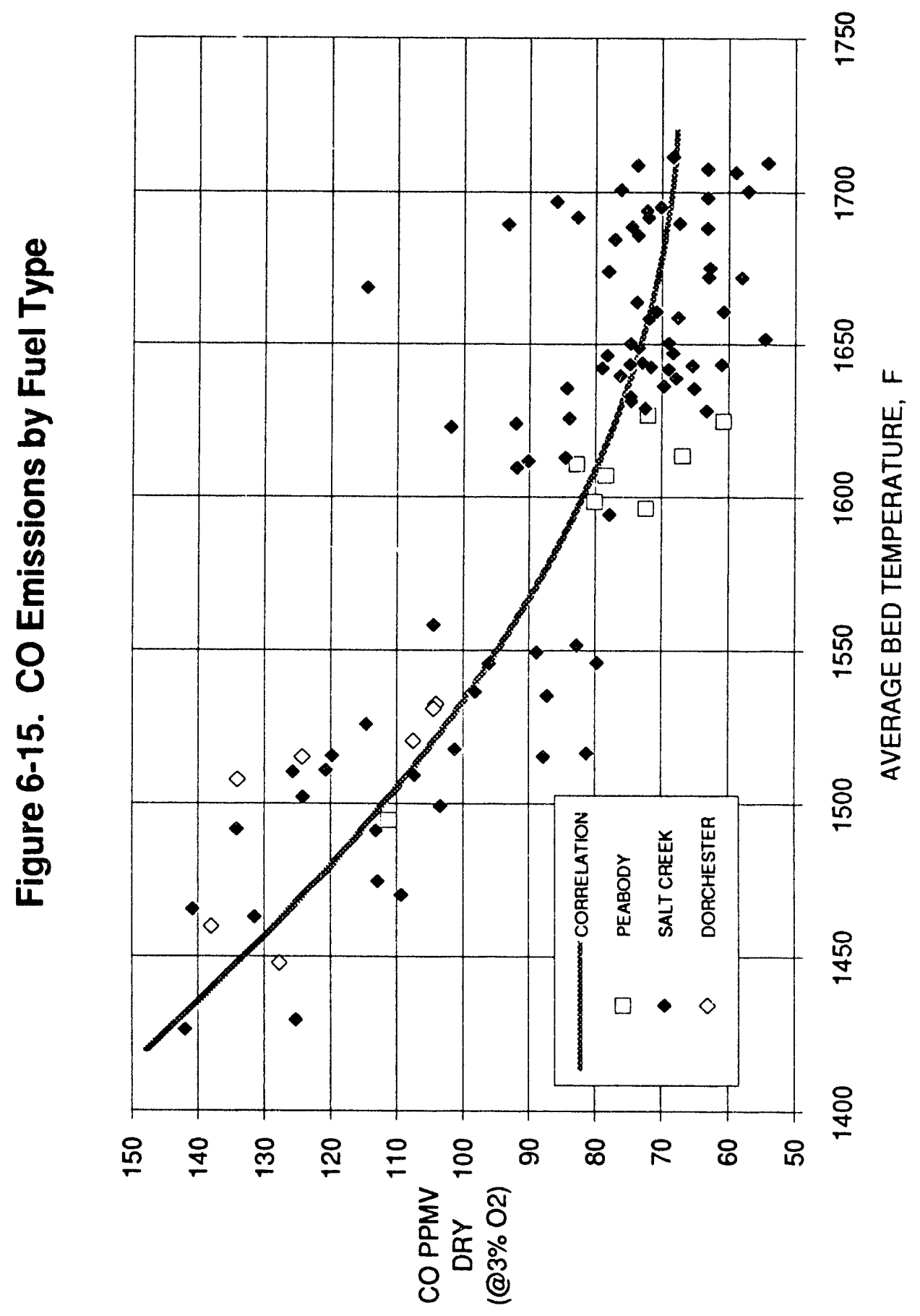




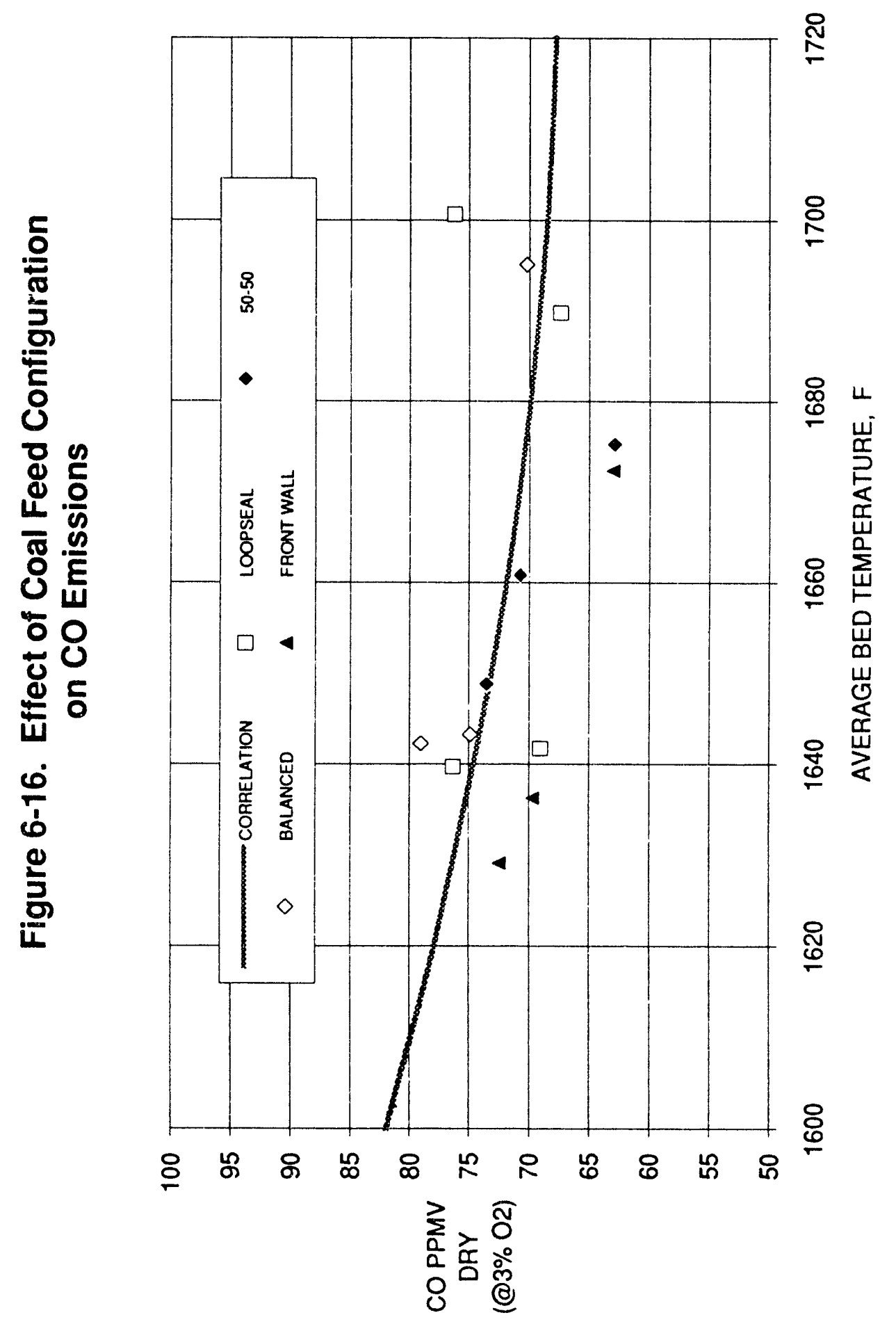

$6-33$ 


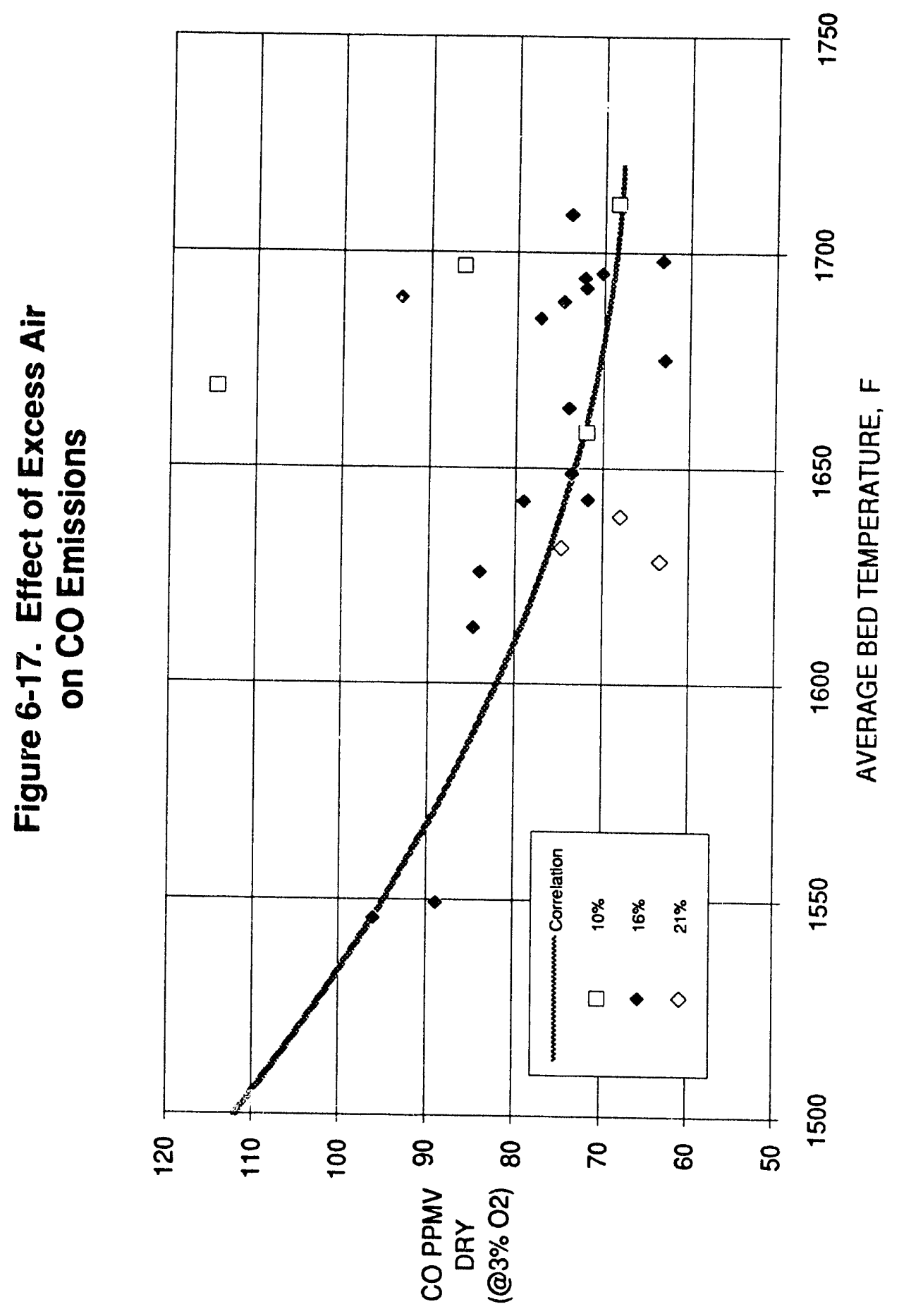


98.9\%. Combustion data are summarized in Table 6-6. No significant differences between the Salt Creek and Peabody coals were found, and no single process parameter (e.g., bed temperature, SA/PA ratio, coal feeder configuration, etc.) appeared to affect the results over the full range of operating conditions.

Combustion efficiency is a measure of the quantity of carbon that leaves the boiler before being fully oxidized to $\mathrm{CO}_{2}$. There are four sources of incompletely burned carbon:

- Carbon in the fly ash

- Carbon in the bottom ash

- Carbon monoxide in the flue gas

- Hydrocarbons in the flue gas

Carbon in the fly ash is the largest source of heat loss from incomplete combustion of carbon at Nucla. For tests conducted to date, this stream averaged about $93 \%$ of the incompletely burned carbon leaving the boiler. Another 5\% is contained in the bottom ash stream. In addition to having a lower carbon content, the flow rate of bottom ash averages only $15 \frac{0}{\circ}$ of the fly ash flow rate. The contribution from carbon monoxide in the flue gas averages $2 \%$. Hydrocarbons in the flue gas were measured during one full load baseline test and were found to be negligible.

Figure 6-18 shows that combustion efficiencies for Dorchester and Peabody coals are generally less than for Salt Creek coal when bed temperatures are below $1550{ }^{\circ} \mathrm{F}$. Above $1550{ }^{\circ} \mathrm{F}$, combustion efficiencies for tests run on Peabody coal fall in the middle of the range of the Salt creek coal tests. It can also be seen that while bed temperatures do not seem to correlate well to combustion efficiency at higher temperatures, for tests run on salt Creek coal, it does correlate rather well below $1550^{\circ} \mathrm{F}$. Further discussion of this behavior can be found in section 6.3 of this report. Section 6.3 is devoted to boiler efficiency, and the behavior of unburned carbon loss (which is essentially the complement of combustion efficiency) is covered there in more detail.

6.3

BOILER EFEICIENCY

In this section, the results of the analysis of boiler gross efficiency by the losses method are presented for 68 performance tests for which this parameter was calculated. Efficiencies for these tests vary from $85.6 \%$ to $88.6 \%$. This range (3.0\%) is significant relative to the uncertainty band of $\pm 0.3 \%$ that has been calculated for these values because it represents $10 \%$ of the total.

Tables $6-7,6-8$ and $6-9$ show the averages and ranges of values for the various contributions to heat loss calculated for the tests run on Peabody, Salt Creek, and Dorchester coals, respectively. 


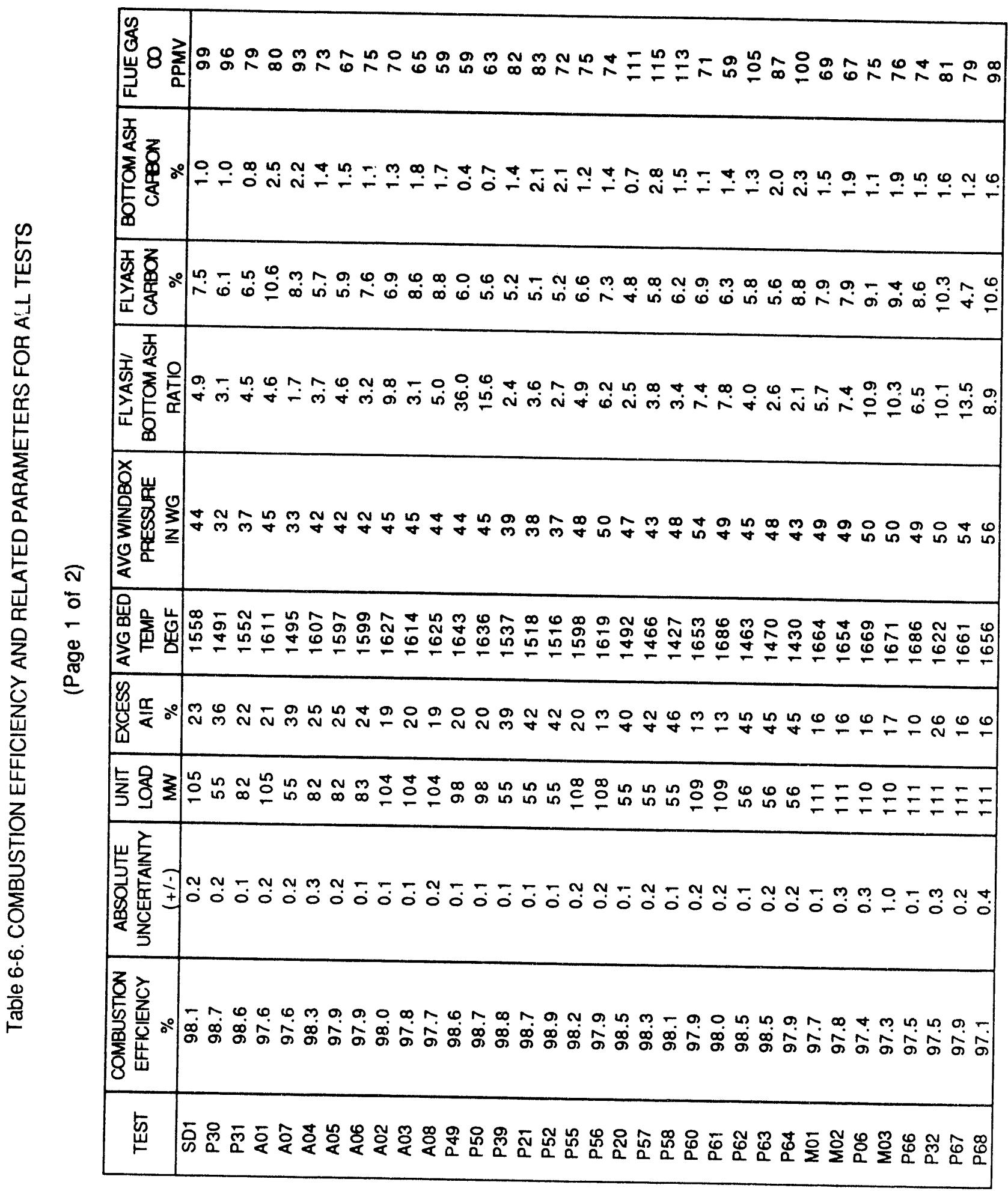




\begin{tabular}{|c|c|}
\hline 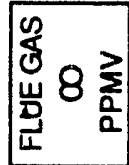 & 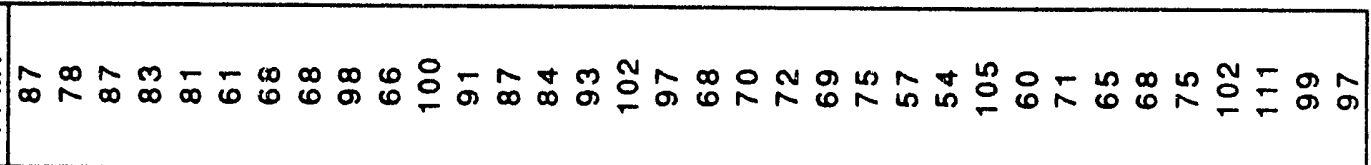 \\
\hline 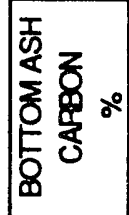 & 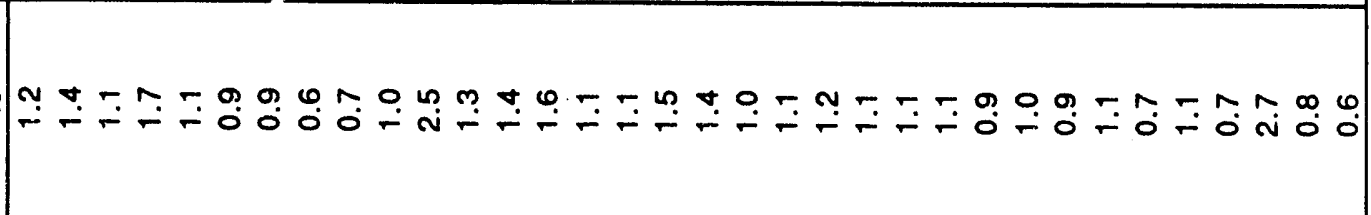 \\
\hline 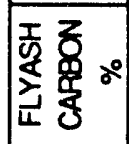 & 番 \\
\hline 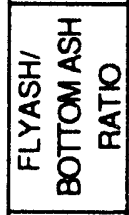 & 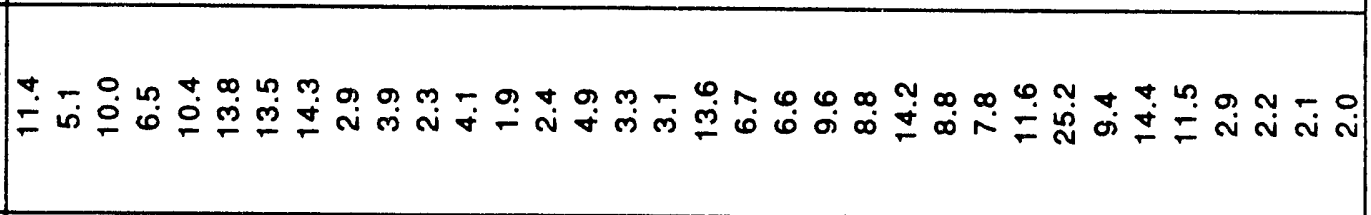 \\
\hline 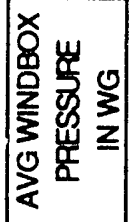 & 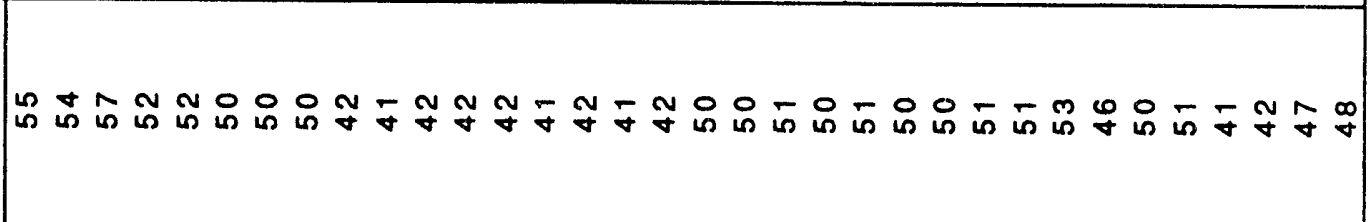 \\
\hline $\begin{array}{l} \\
\end{array}$ & 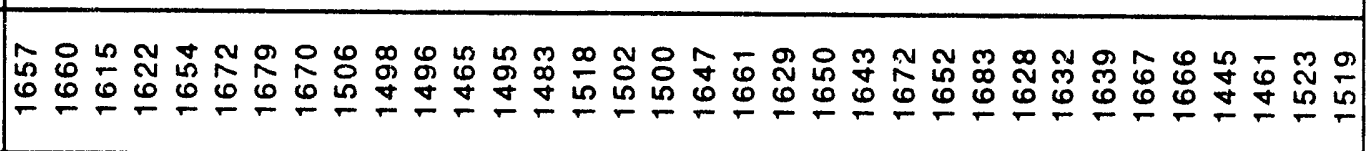 \\
\hline 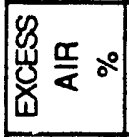 & กำำำ \\
\hline 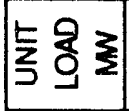 & 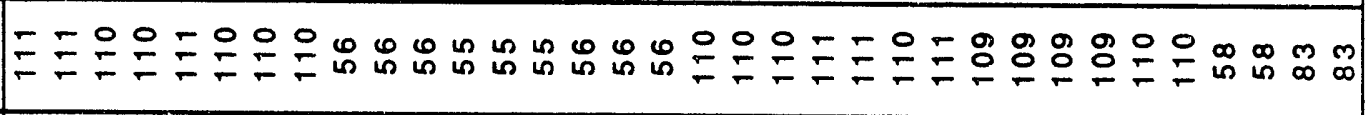 \\
\hline 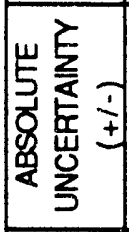 & 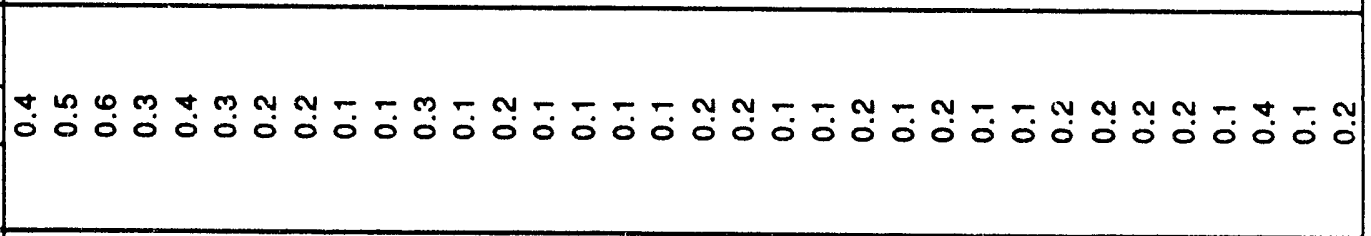 \\
\hline 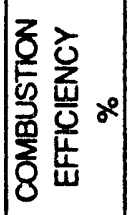 & 垈 \\
\hline 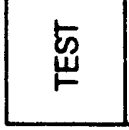 & 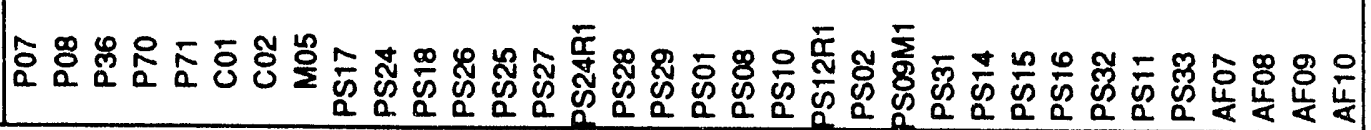 \\
\hline
\end{tabular}




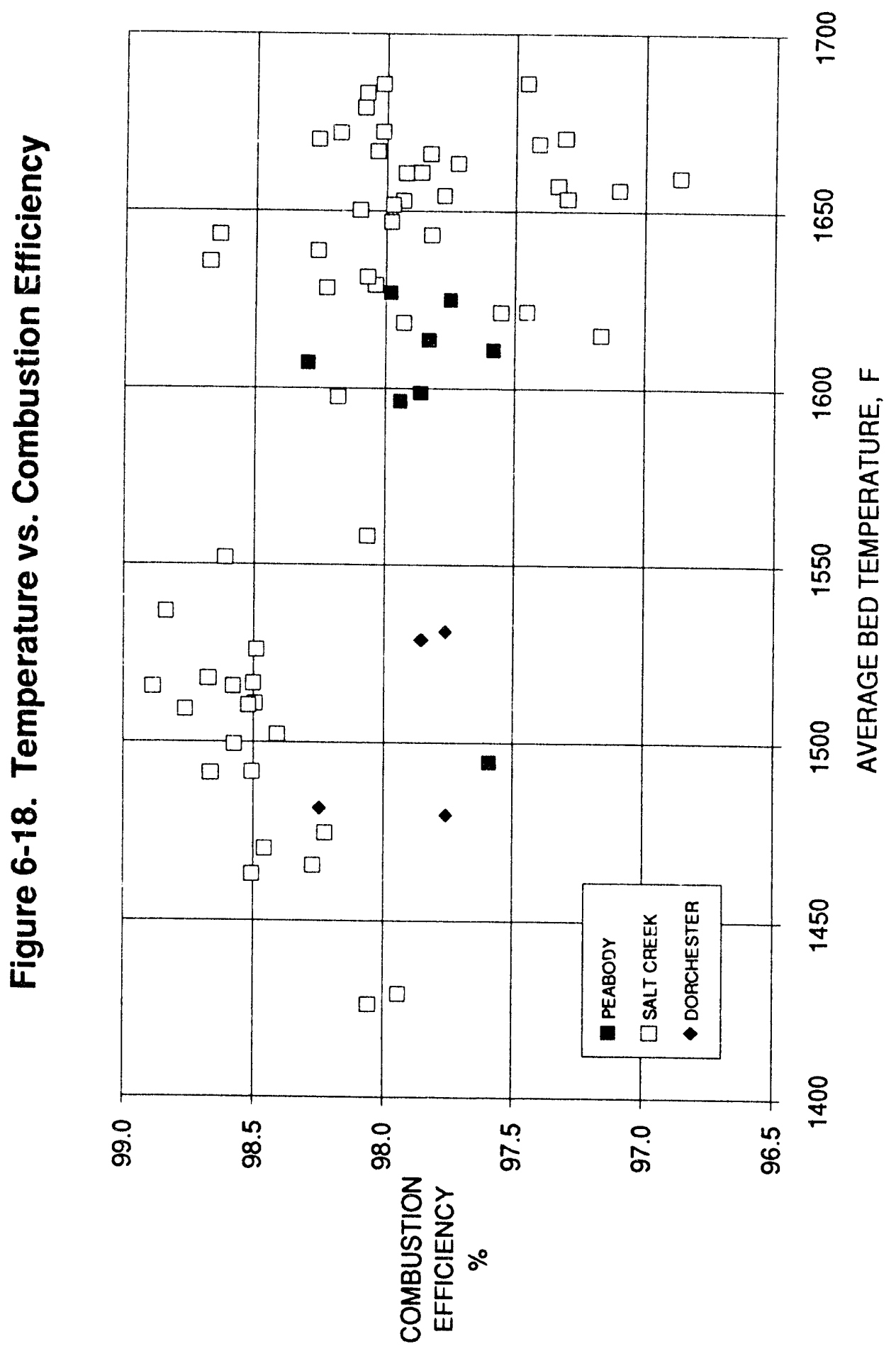




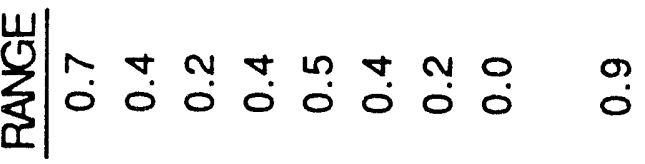

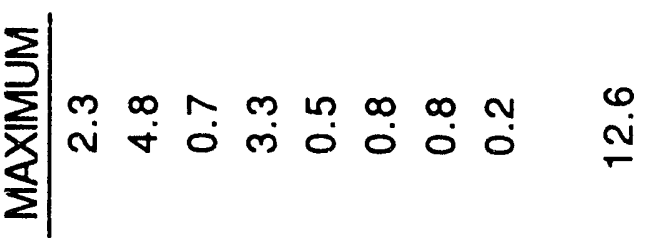

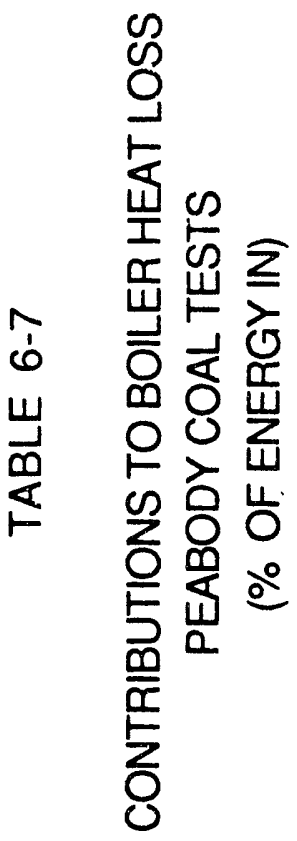

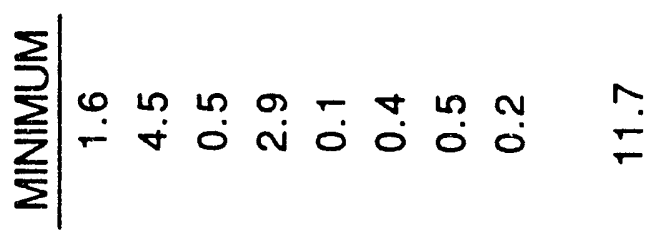

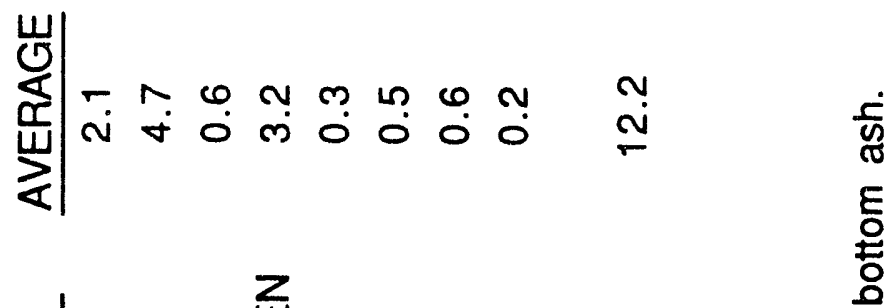

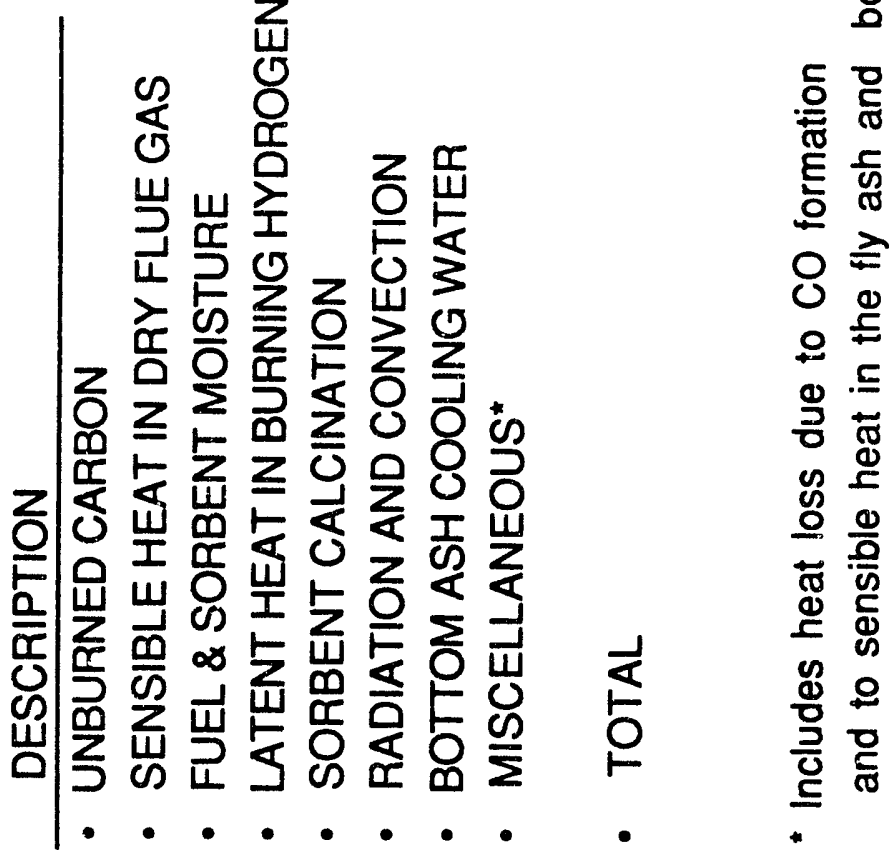




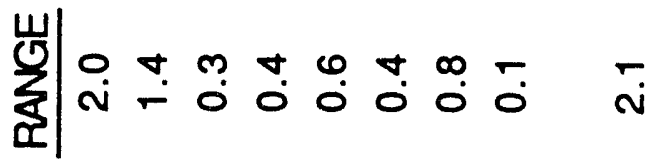

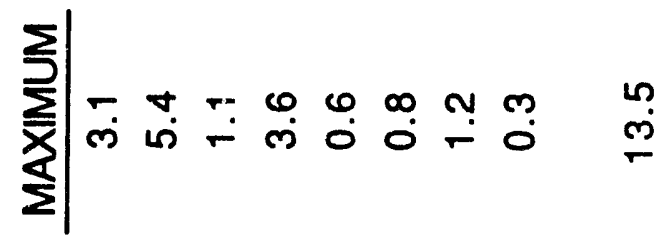

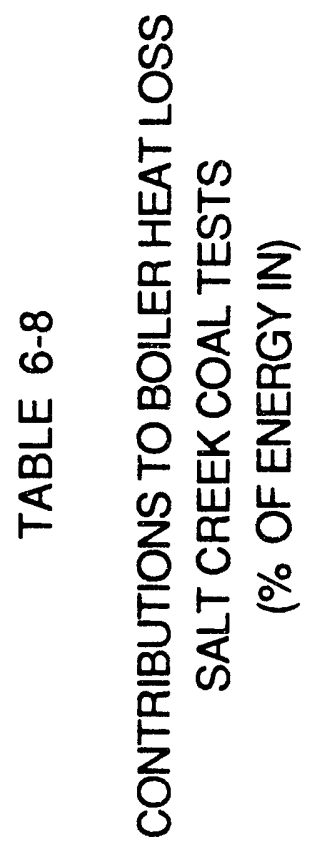

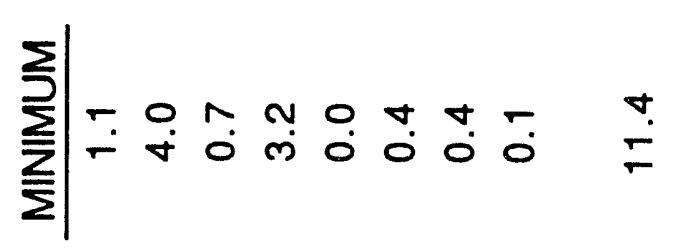

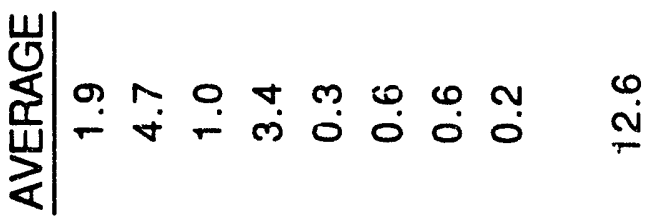

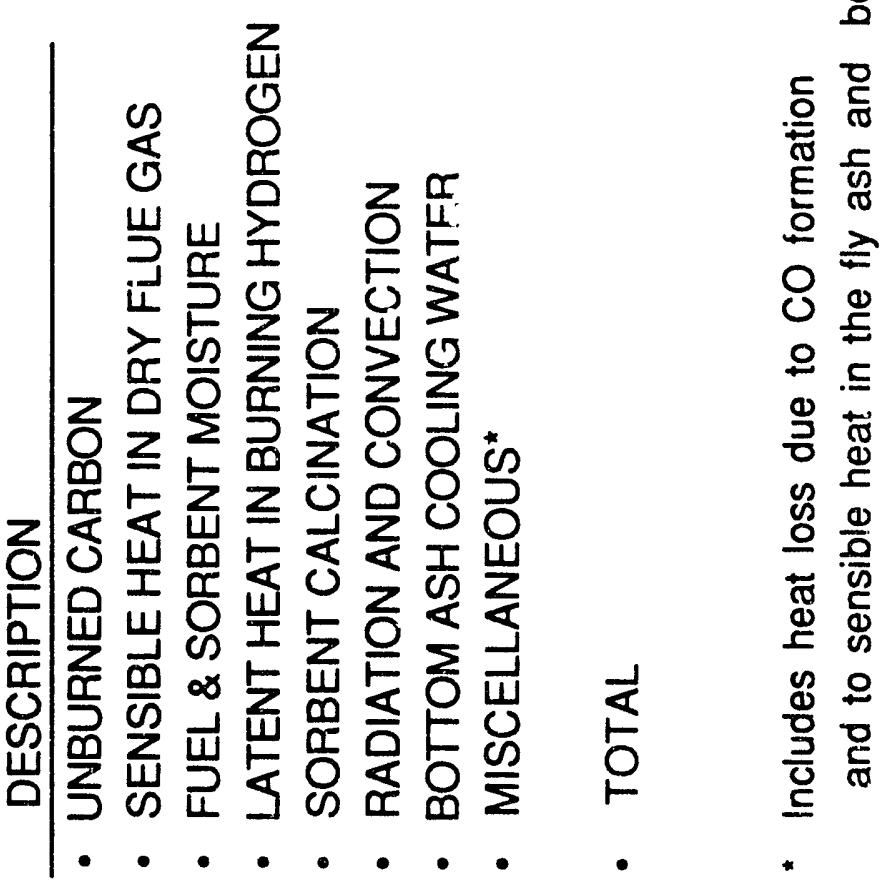




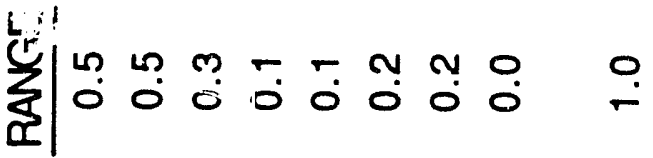

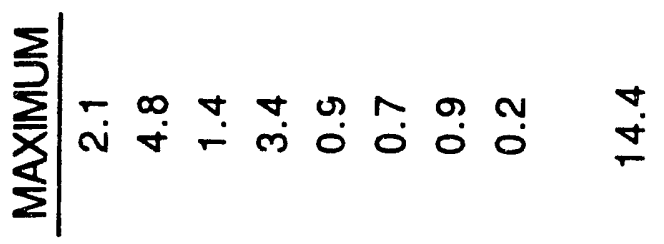

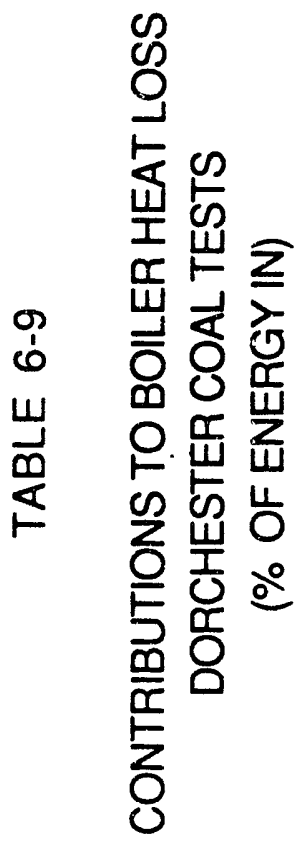

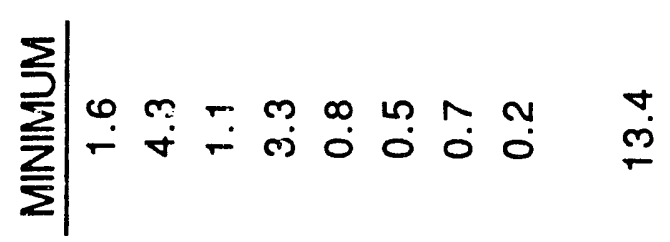

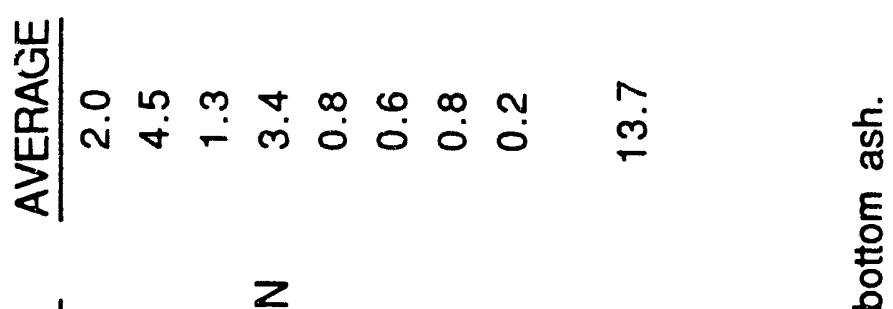

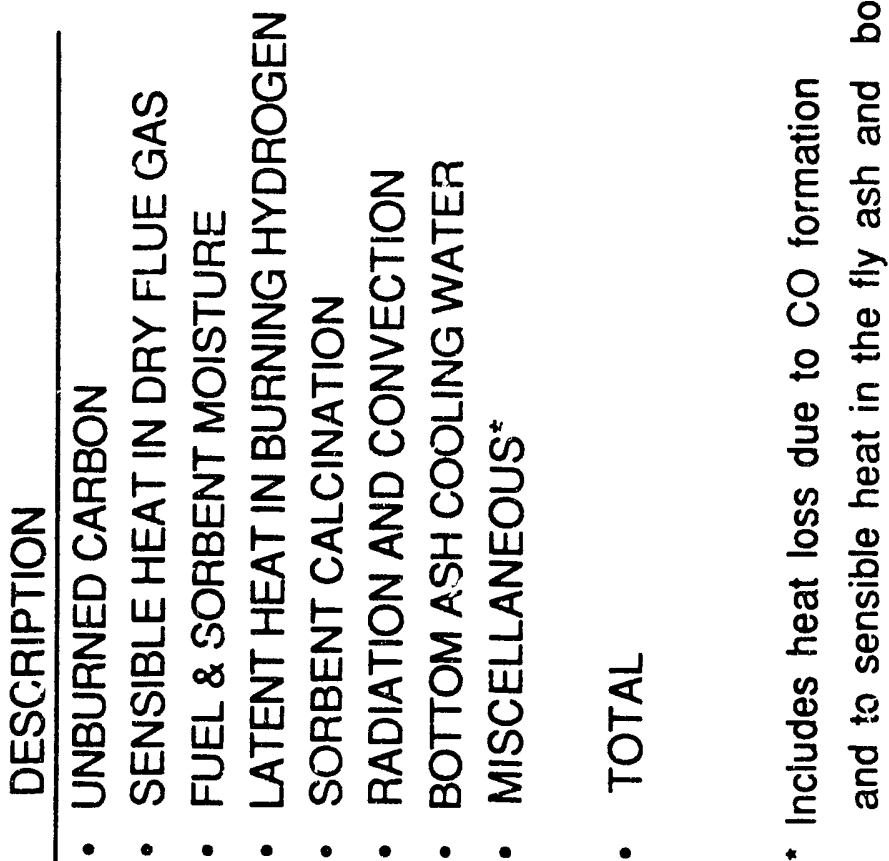


These tables show that tests run on Peabody coal had the highest average efficiency ( $87.8 \%)$, efficiencies for Salt Creek coal tests were slightly lower (average of $87.4 \%$ ), and tests on Dorchester coal averaged significantly lower $(86.3 \%)$. It can be seen that the primary reason for the higher efficiencies with Peabody coal was the lower losses due to fuel and sorbent moisture. There were two main contributors to the lower Dorchester efficiencies, which were fuel and sorbent moisture and sorbent calcination losses. The Dorchester coal had a higher level of moisture than either of the other two coals, and a much higher sulfur content, resulting in higher limestone feed rates and therefore higher calcination losses.

Sensible heat in the flue gas and burning hydrogen are the largest contributors to the total heat loss from the boiler. However, sensible heat of the dry flue gas and unburned carbon losses have the largest range of values. In addition, these are the only two losses that might be affected by controllable combustion process parameters (e.g., excess air, coal feed configuration, etc.). The other major contributors to boiler heat loss are dependent upon feed stock properties and plant design parameters. Moisture in the feed stocks and burning hydrogen in the coal are properties of the fuel and sorbent. The quantity of energy absorbed by the calcination reaction is dependent entirely upon the calcium flow rate, which is in turn determined by the quantity of sulfur in the coal and the calcium to sulfur ratio for the required $\mathrm{SO}_{2}$ emission level. The bottom ash cooling water heat loss is controlled by the design of the bottom ash coolers and the temperature of the cooling water entering the control volume. The heat loss due to radiation and convection depends upon the design of the boiler, ambient temperature, and load.

The most useful correlations are therefore those that are tied to analyses of the flue gas and unburned carbon losses. It can be seen that flue gas exit losses (adjusted for air inlet temperature) increase as excess air increases (Figure 6-19).

Unburned carbon loss is shown plotted against freeboard gas velocity in Figure 6-20. In this figure, it appears that this loss stays at a fairly low level to about $16 \mathrm{ft} / \mathrm{s}$, then increases. One possible explanation for this behavior is that the residence time of the burning coal particles is reduced at these higher velocities, such that there is insufficient residence time to completely burn before exiting the cyclone.

Figure 6-21 shows how temperature affects the unburned carbon loss. It can be seen that from about $1430{ }^{\circ} \mathrm{F}$ to $1500{ }^{\circ} \mathrm{F}$, this loss goes down steadily with temperature. Above $1550{ }^{\circ} \mathrm{F}$, however, it begins to increase with temperature. Below $1500^{\circ} \mathrm{F}$, increasing operating temperatures result in faster reaction times, leading to a lower loss. 


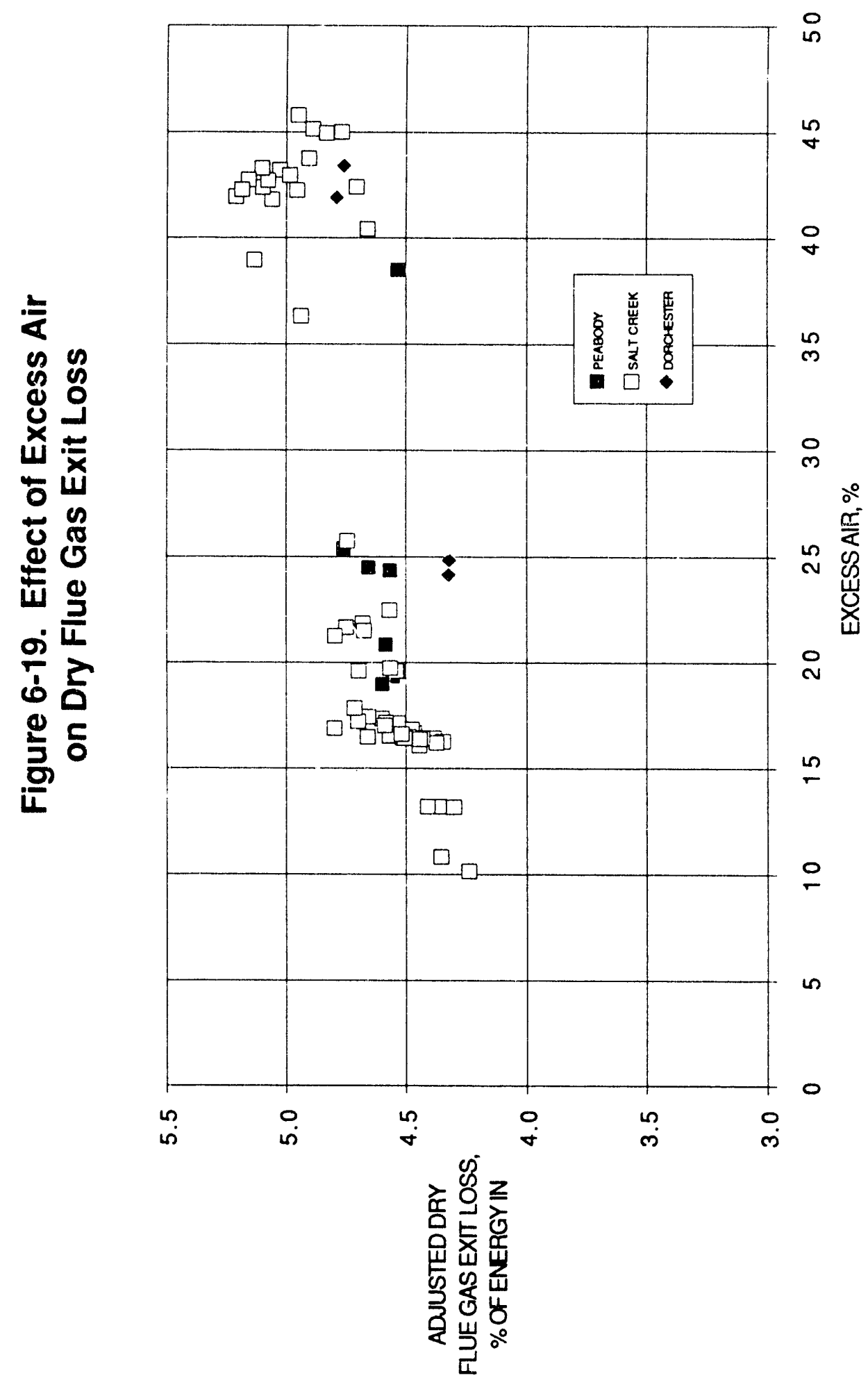




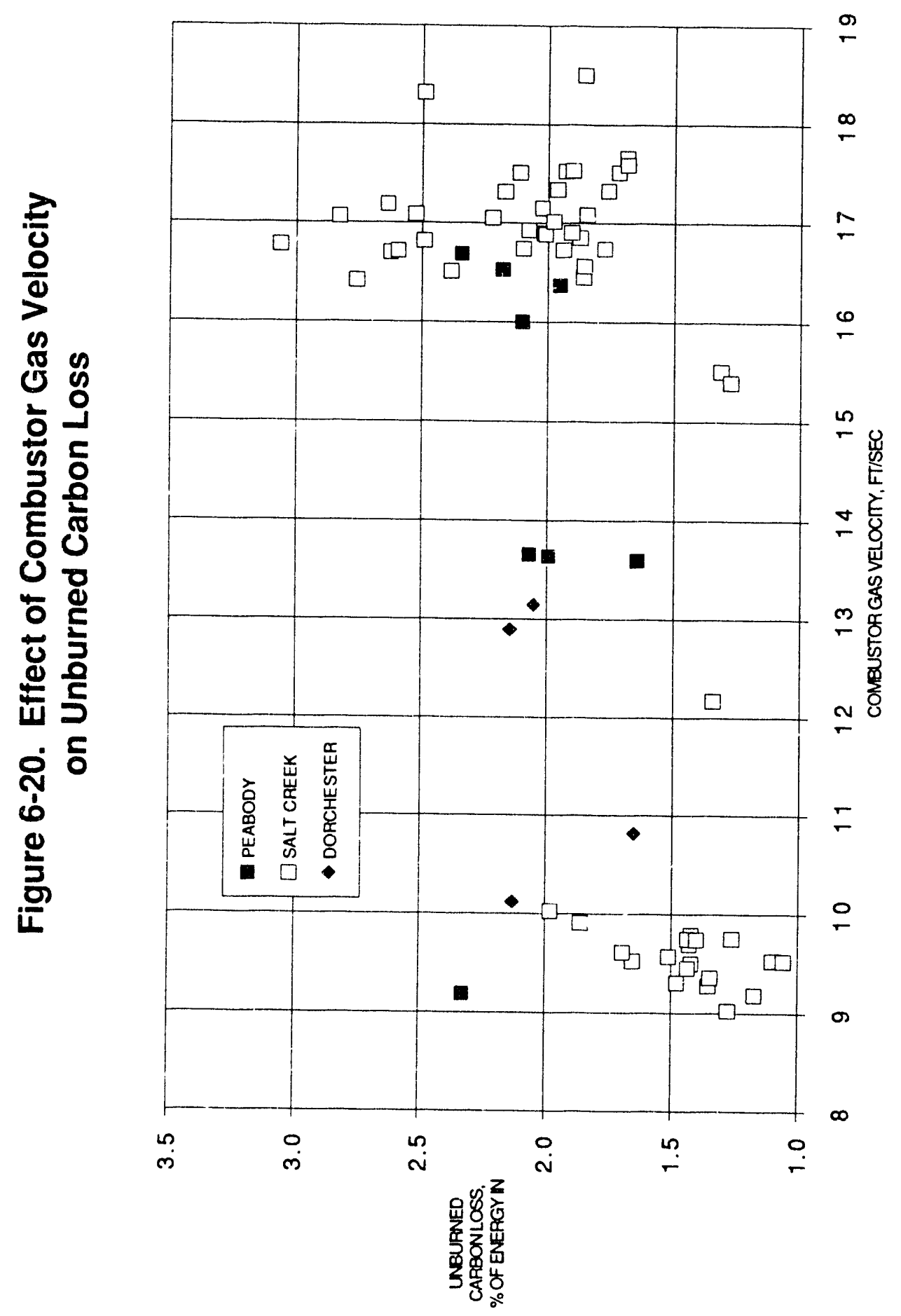




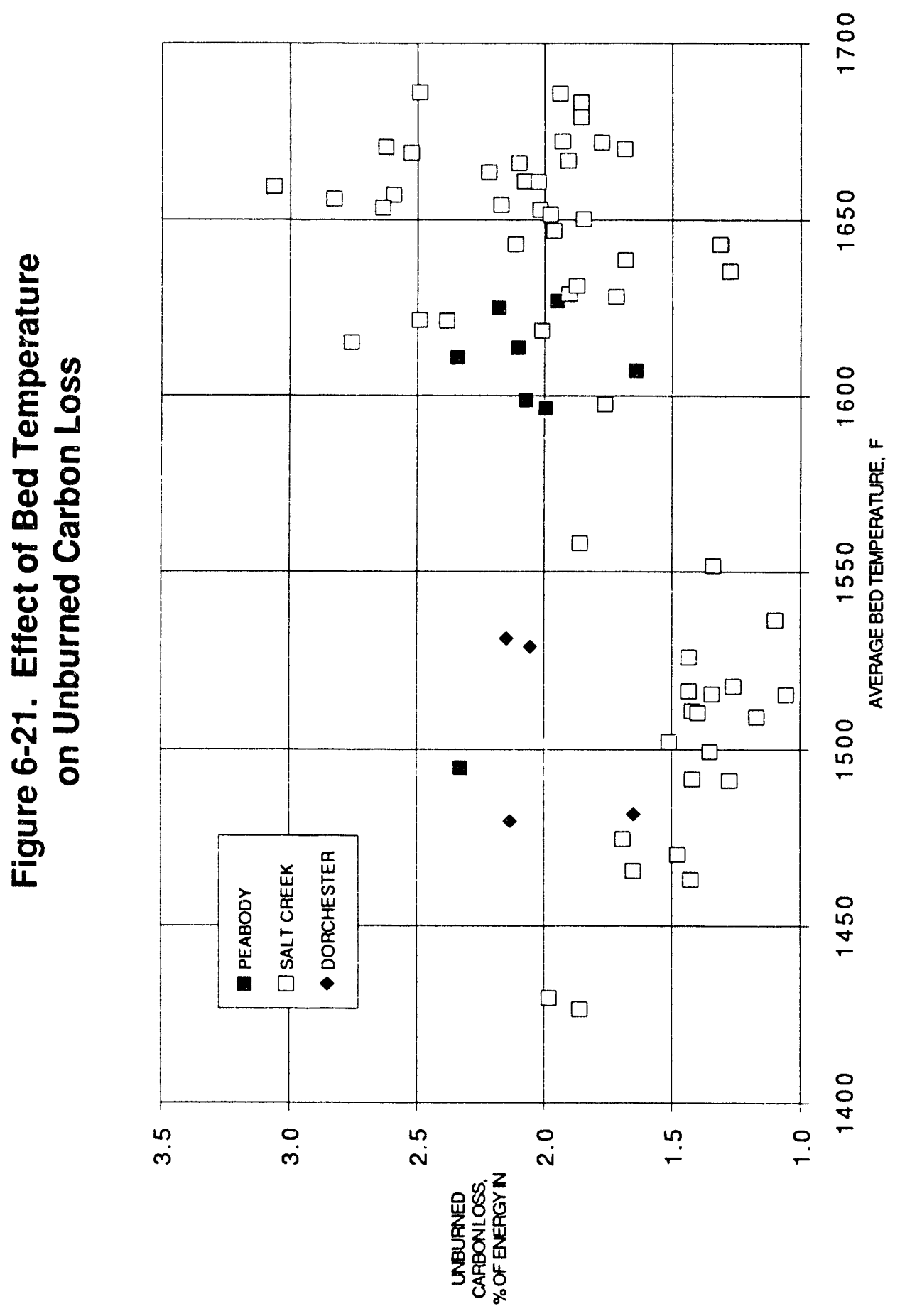


At Nucla, the freeboard velocity, temperature, and excess air are all strongly dependent on load. 'From half load to full load, excess air decreases, while temperature and freeboard velocity increase. It is not possible to vary these parameters independently over a wide range at Nucla. As a result, dry flue gas losses can be seen to go down as load increases, while unburned carbon losses go up. This phenomenon is shown for all Salt Creek coal tests in Figure 6-22. The net result is a cancelling effect such that boiler efficiency at Nucla is independent of load.

Neither coal feed configuration or SA/PA ratio were found to influence dry flue gas or unburned carbon losses. Heat balance summary reports showing the heat loss breakdowns for each of the tests analyzed during the test program can be found in the volume of performance summary reports. 


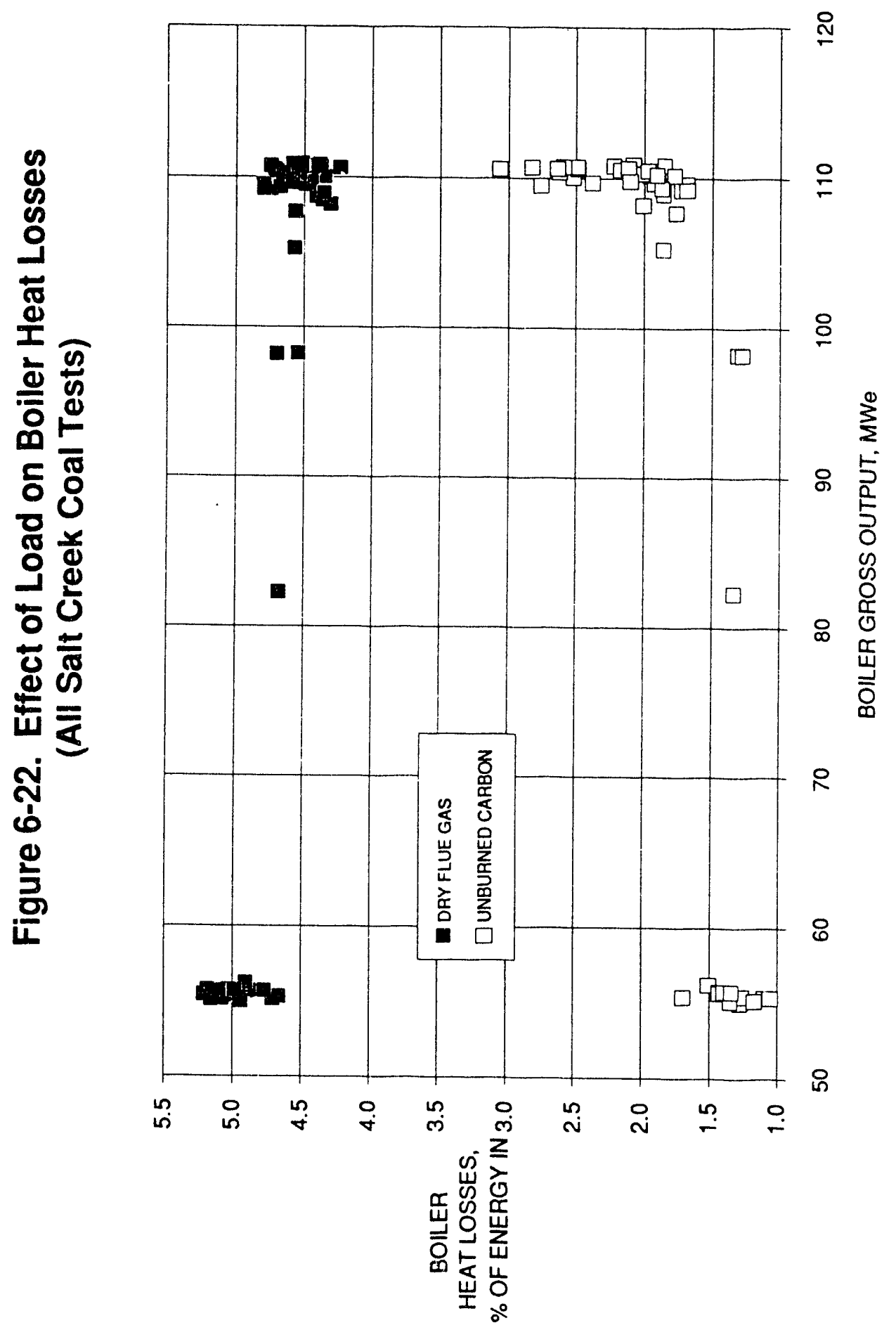




\section{Section 7 \\ START-UP, COLD AND HOT RESTART CHARACTERISTICS}

This Test $\mathrm{Plan}$ investigated the response characteristics of the CFB boiler and its auxiliary systems during start-up and restart after various time periods of unit shutdown. Data from representative cold, hot, and warm restarts were analyzed and are presented below. The annual reports contain additional data for start-ups analyzed during the corresponding reporting period.

\subsection{SUMMARY OF RESULTS}

Ultimately, it is the plant owner's objective to raise steam conditions and put energy onto the grid as quickly as possible using start-up procedures that maximize safety and equipment life.

Cold start-up times at Nucla are governed by the time required to, 1) achieve $100^{\circ} \mathrm{F}$ of superheat prior to turbine roll without exceeding the manufacturer's recommended drum metal temperature ramp rates of $100^{\circ} \mathrm{F} / \mathrm{h}, 2$ ) heat soak the turbine prior to generator synchronization, and 3 ) synchronize the generator and raise unit load. The data suggests that drum metal temperature rates are more critical in the first five to six hours of start-up than bulk refractory temperatures, which also have a manufacturer's recommended limit of $100^{\circ} \mathrm{F} / \mathrm{h}$. However, refractory components located near the surface of hot solids and gas streams, which have been prone to pinch spalling and failure near the surface, may have temperature rates which exceed the $100^{\circ} \mathrm{F} / \mathrm{h}$ criteria. The ability of refractory materials to perform in a cycling environment with an economical life expectancy is the best test of this CFB component.

Warm and hot restart times are governed by how quickly, 1) plant operators can isolate the turbine and maintain steam conditions during the shutdown and, 2) fans can be isolated to preserve bed temperature. Gas firing durations during restarts will be determined by the time required to reestablish $100^{\circ} \mathrm{F}$ superheat temperatures or by the time to reestablish $950^{\circ} \mathrm{F}$ bed temperatures necessary for the initiation of coal feed. Changes to boiler purge methodologies may reduce the impact of the latter on restart times. 


\subsection{OBJECTIVES AND APPROACH}

The following objectives were defined in the Detailed Test Plan and are addressed in this section:

- Times to full power operation, starting from cold conditions and from various intervals of unit downtime.

- The component of the boiler system that limits the rate at which it can be restarted.

- Characteristics of the boiler or its auxiliary components that limit the capability to match the steam turbine conditions.

- Start-up fuel (propane) requirements.

- Potential improvements in the start-up procedures that may lead to operational and economic advantages.

Data were collected for start-ups and restarts after various outage durations during the normal course of unit operation (i.e., restart tests were not pre-planned). Table 7-1 summarizes the start-ups analyzed indicating the date, outage duration, test classification, and other pertinent information including start-up gas requirements. Based on the results of this test plan, a revised start-up procedure was developed and is included in Appendix B.

\subsection{COLD START-UPS}

Cold start-ups are defined here as those which occur following a shutdown interval during which all boiler components, particularly those made up of refractory, have essentially reached ambient temperature. Following a unit trip, this can be achieved in approximately 48 hours with fans in service to cool the bed and refractory components.

Data from a cold start-up on $10 / 09 / 89$ are shown in Figures 71 through 7-10. This particular start-up is somewhat unique in that the economizer was deliberately emptied prior to gas firing in an effort to reduce drum level instability during the first six hours of gas firing. A detailed discussion of this test is included in the 1990 Annual Report. This did not affect start-up times or procedures and the trend plots shown in Figures 7-1 through 7-10 are representative of a normal cold start-up. The steps involved in a cold start are marked on the figures and are summarized as follows:

1. Fans are started and air flow is initiated through the windbox and air distribution grid. In Figure 7-3, only the air flow and bed temperatures are shown on combustor A since data are similar on combustor B. Following a five minute air purge, the duct burners 


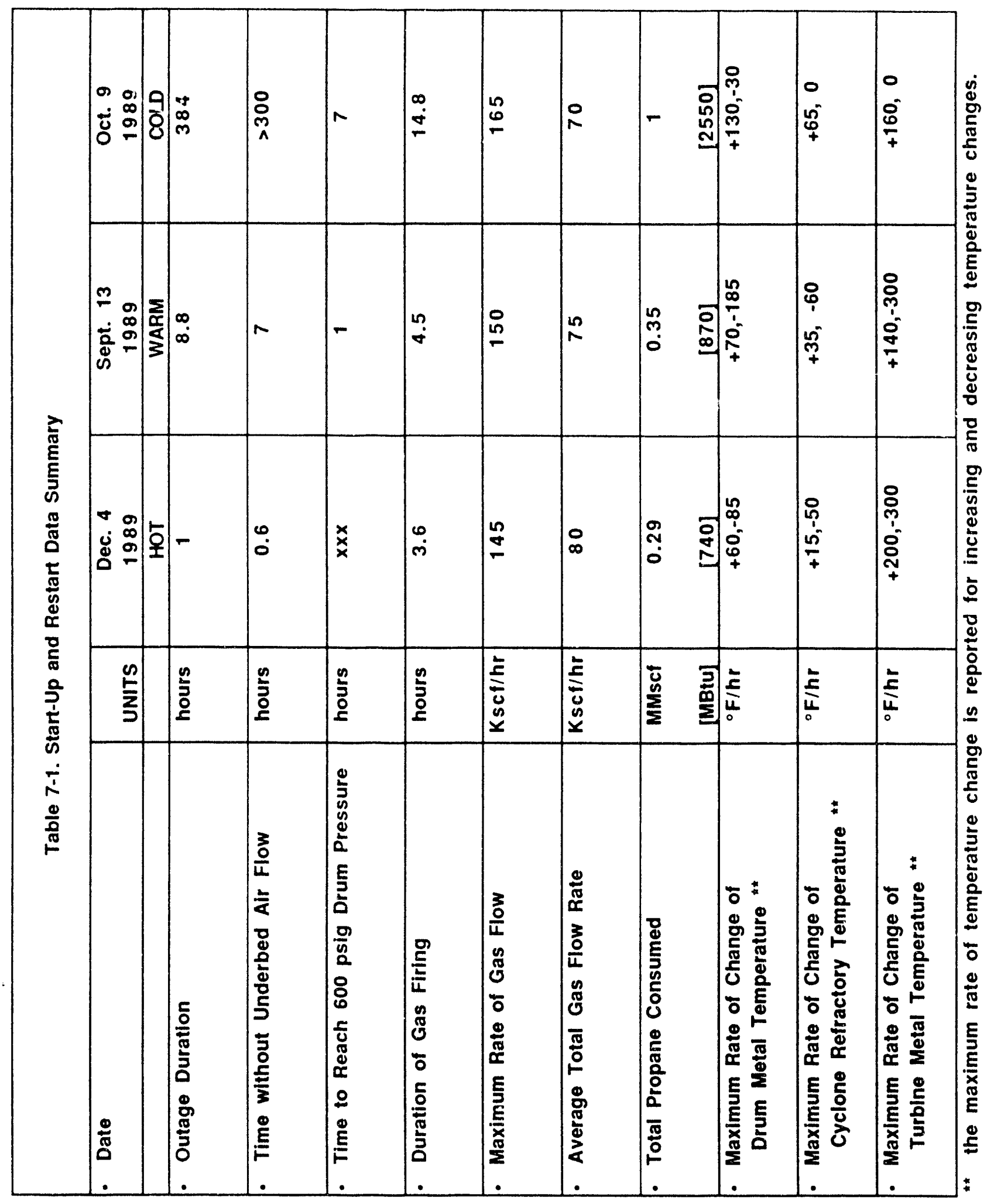




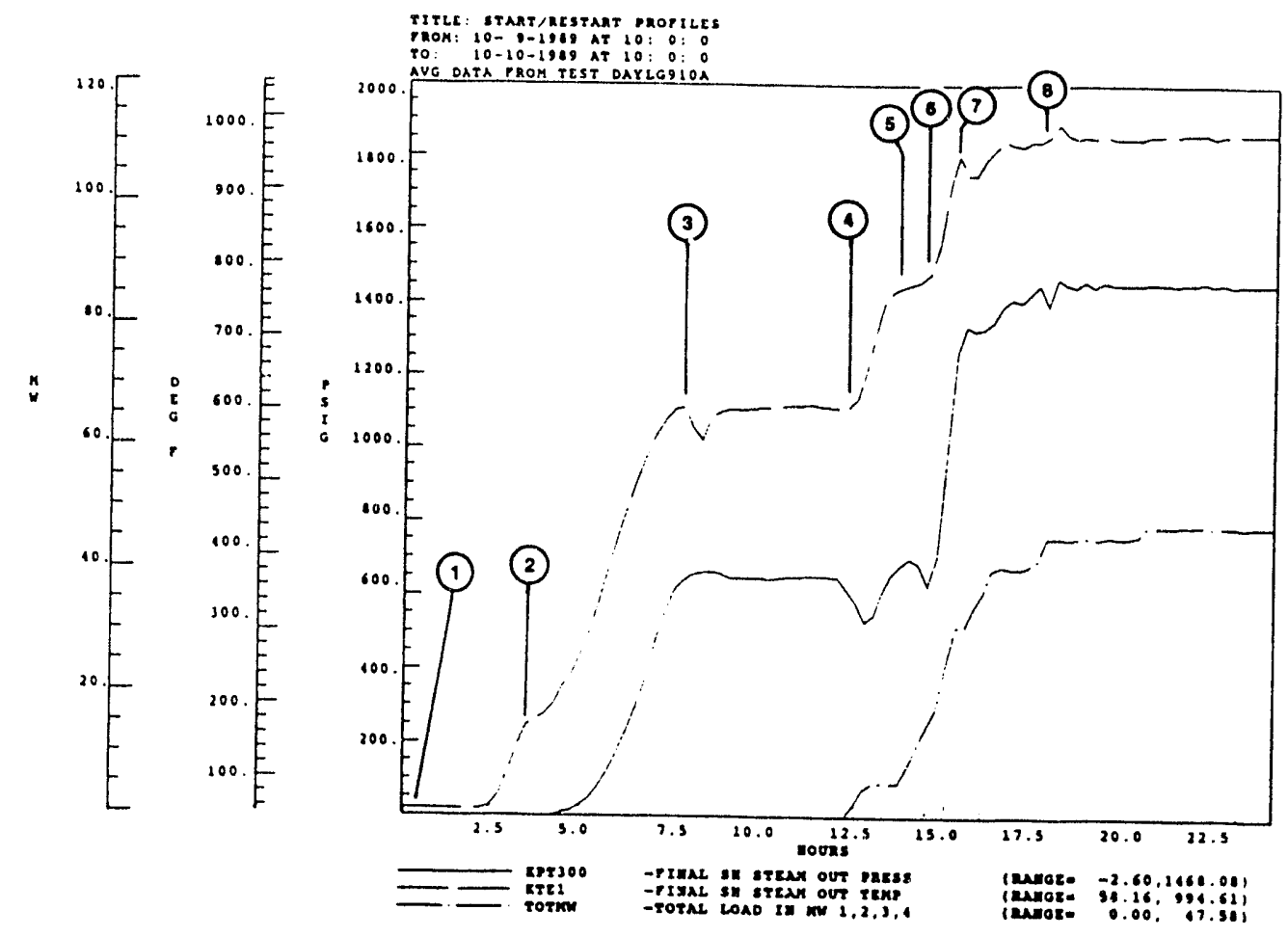

Figure 7-1. Load \& Steam Conditions for Cold Start-up.

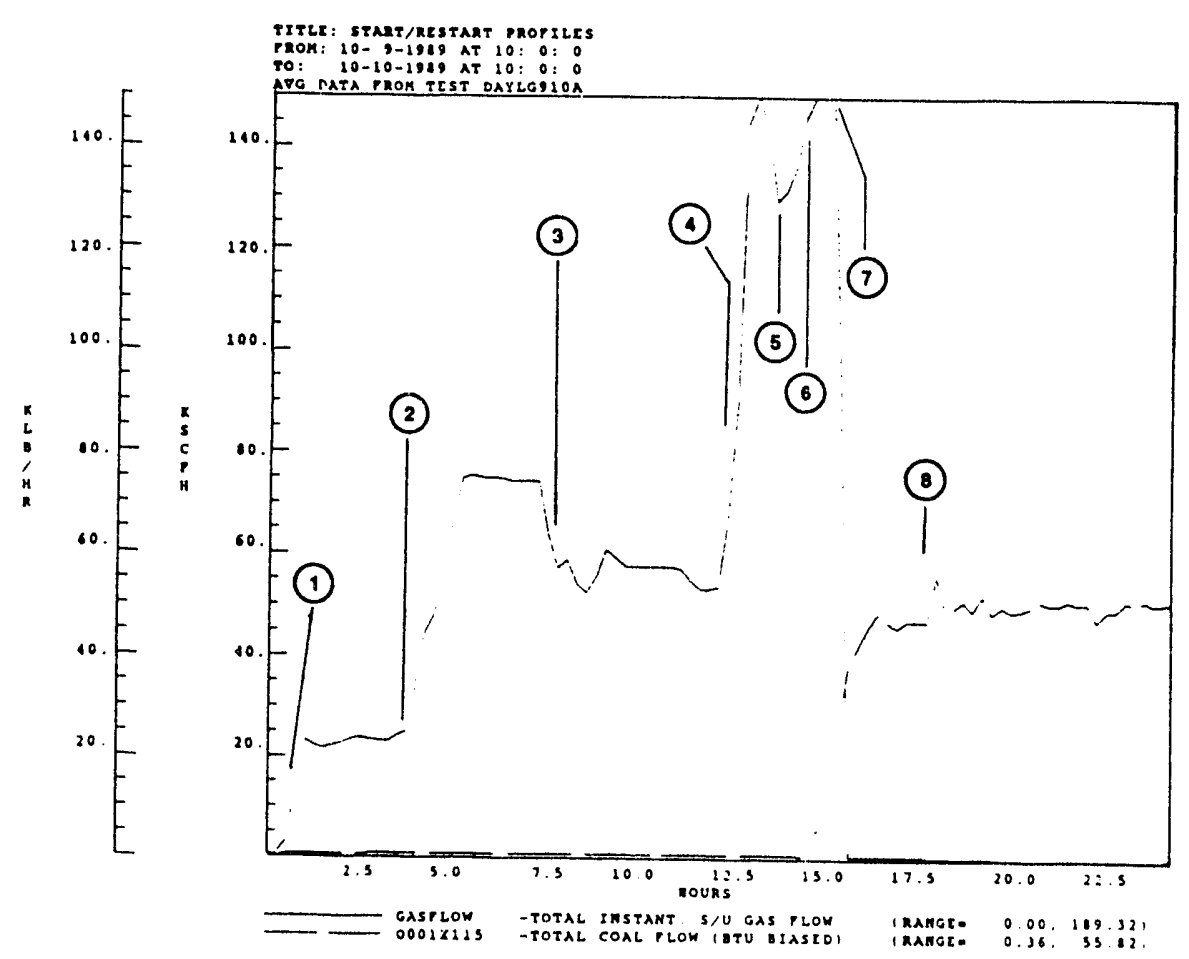

Figure 7-2. Coal and Gas Flow for Cold Start-up. 


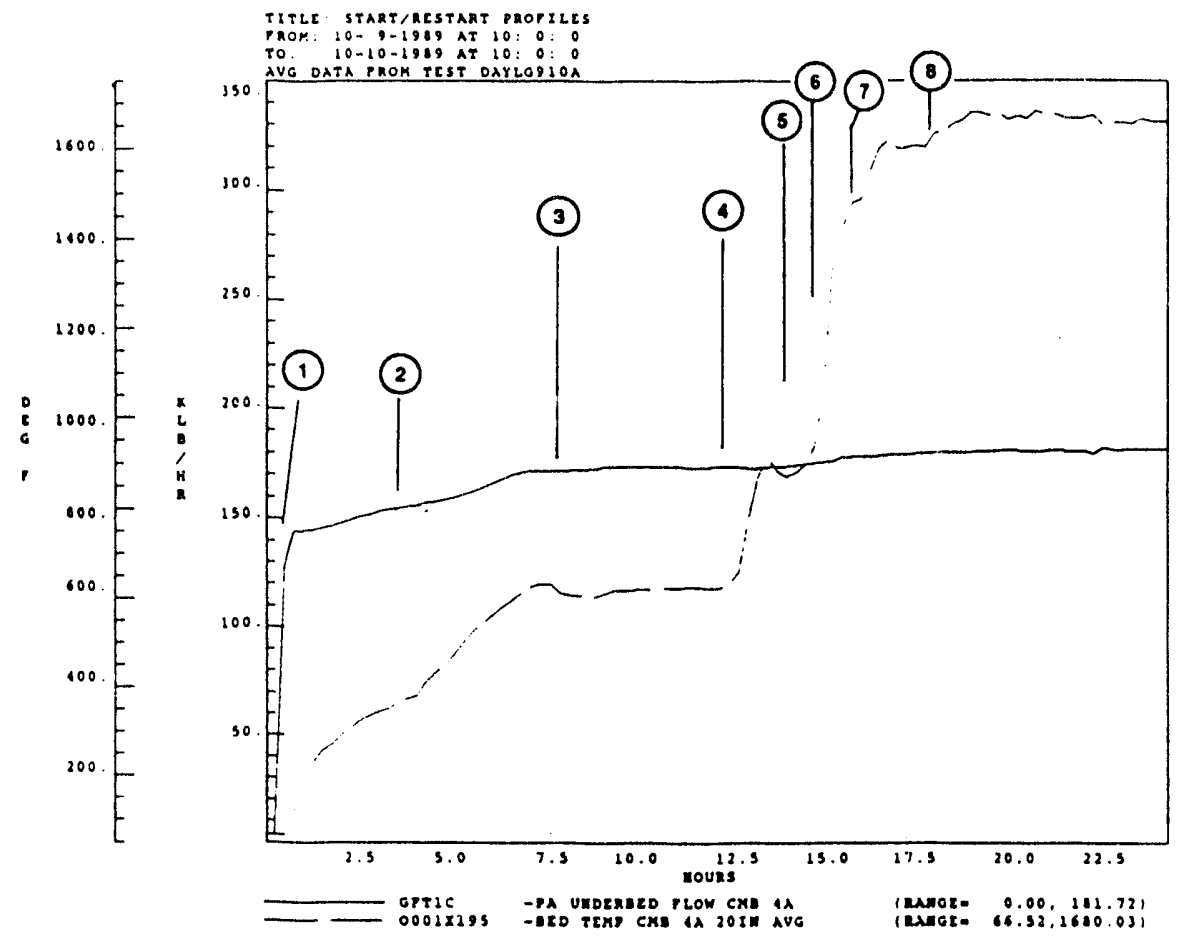

Figure 7-3. Air Flow \& Bed Temps. for Cold Start-up.

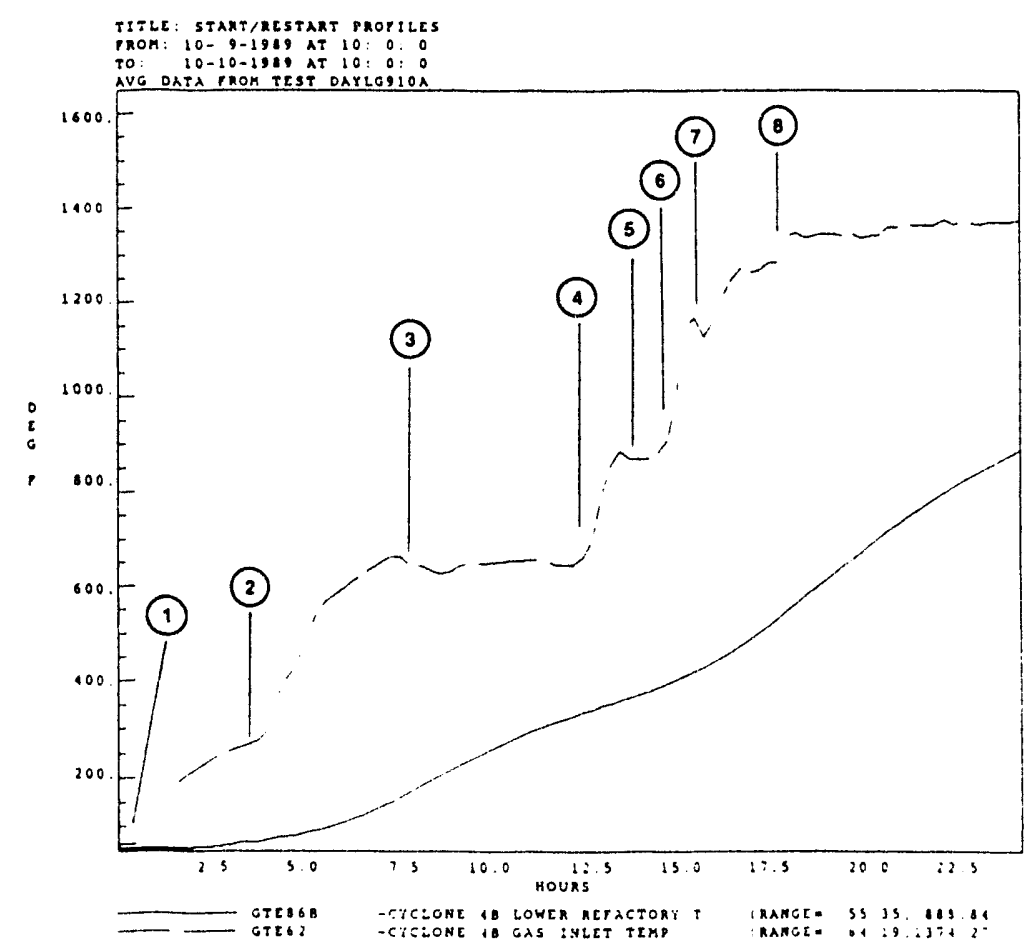

Figure 7-4. Cyclone Refractory Temps. for Cold Start-up. 


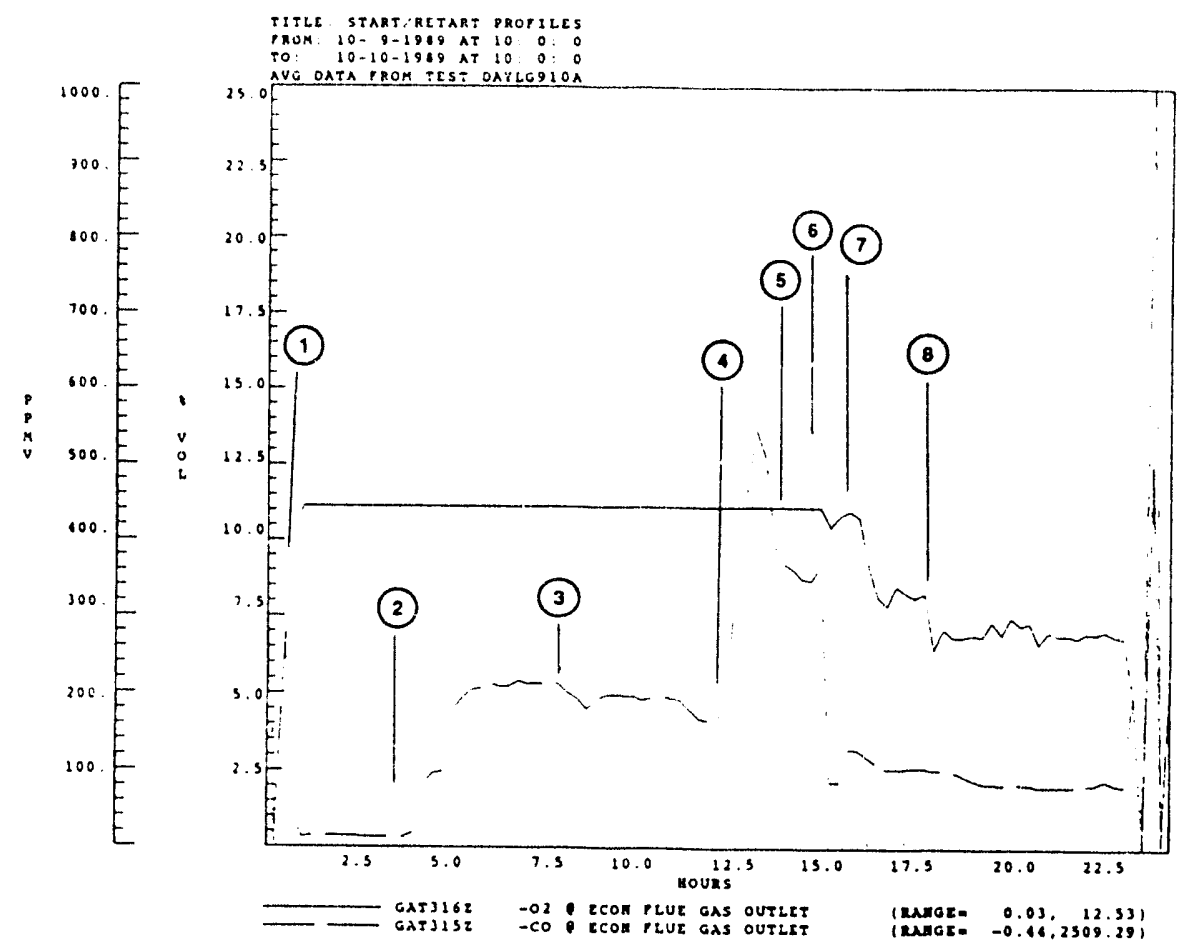

Figure 7-5. $\mathrm{O}_{2}$ and CO Emissions During Cold Start-up.

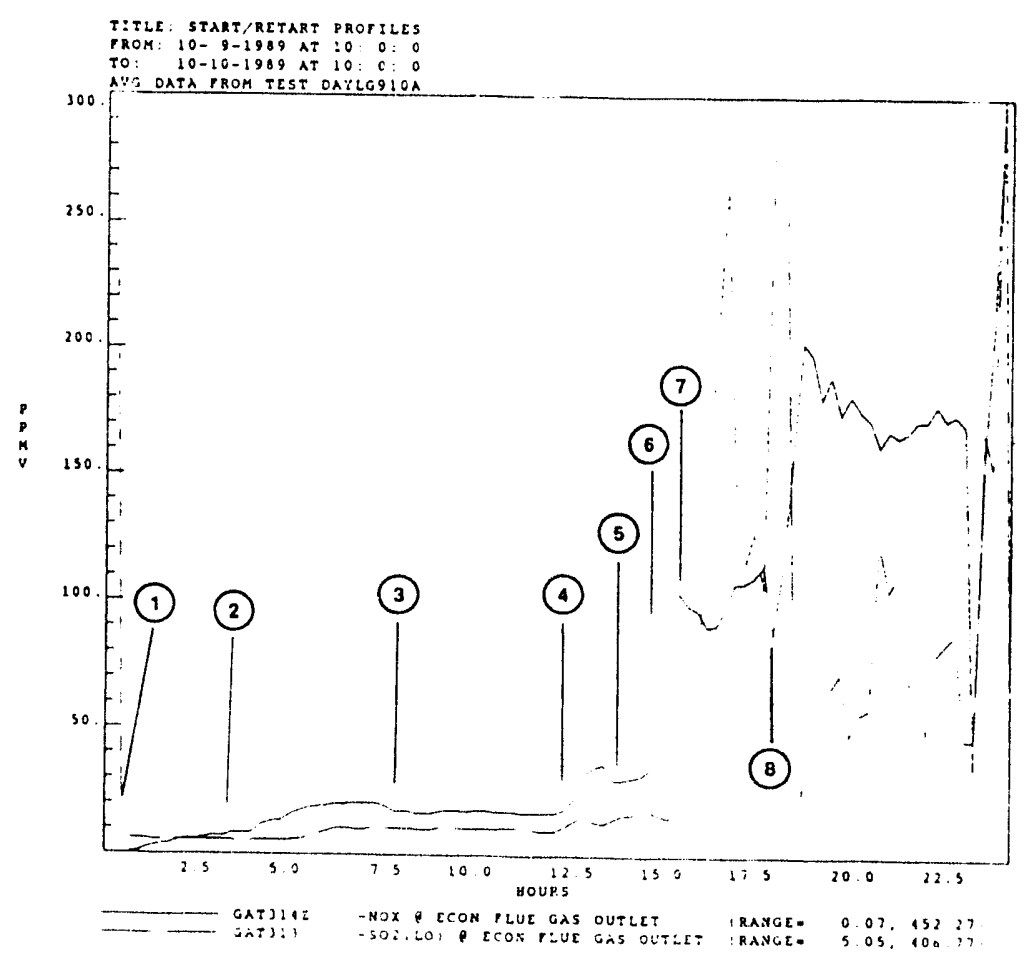

Eigure 7-6. NOX and 502 Emissions During Cold start-up. 


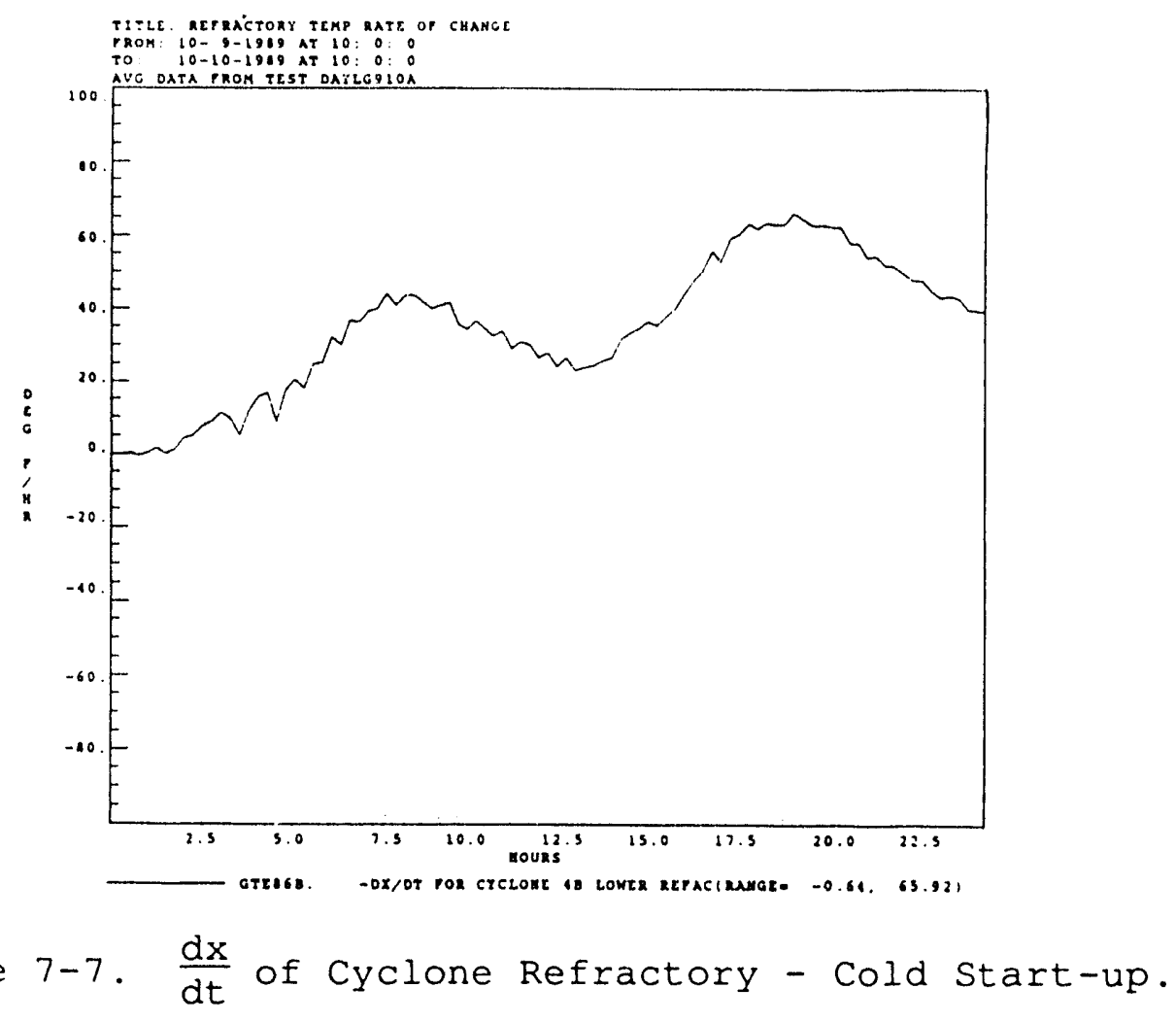

Figure 7-7. $\frac{d x}{d t}$ of Cyclone Refractory - Cold Start-up.

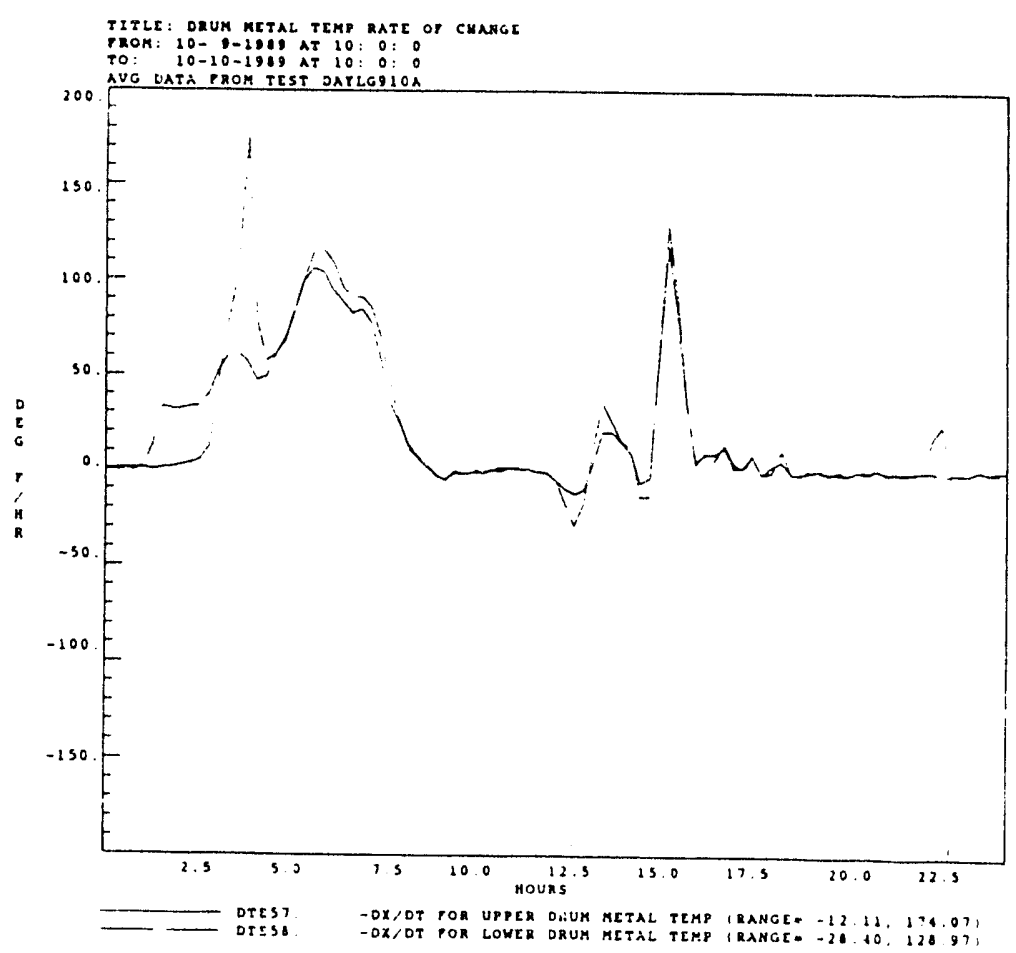

Eigure 7-8. $\frac{d x}{d t}$ of Drum Metal Temp. - Cold Start-up. 


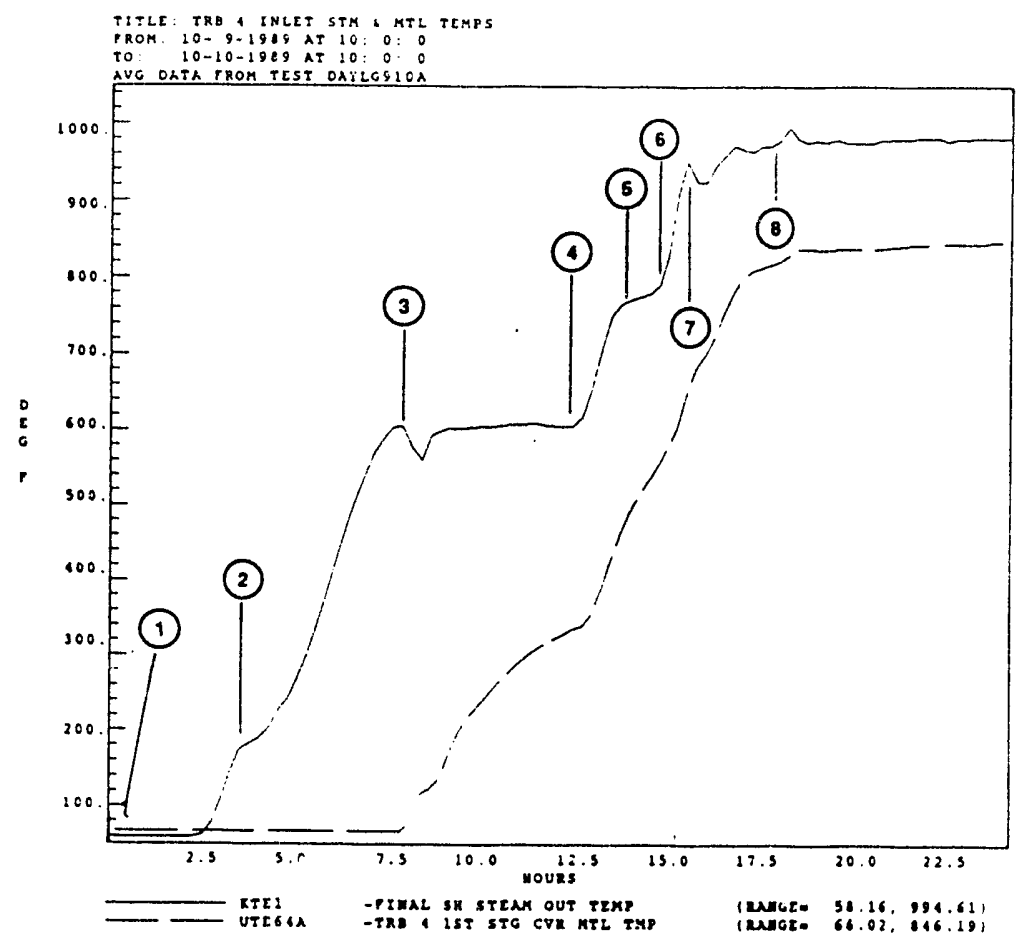

Figure 7-9. Steam \& Turbine Metal Temps. - Cold Start-up.

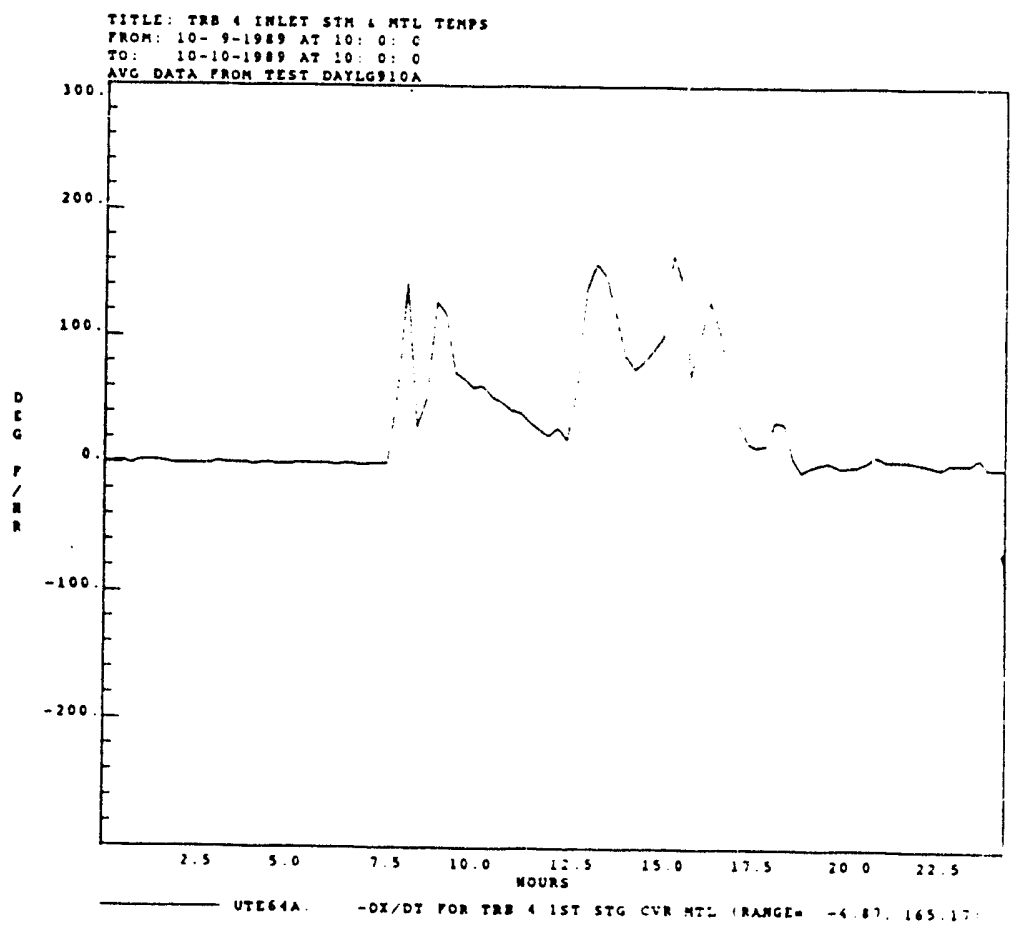

Eigure 7-10. $\frac{d x}{d t}$ of Turbine Metal Temps. - Cold Start-up. 
(located immediately upstream of the windbox) are started on both combustors. In this example, duct burners are operated for approximately 3 hours until a drum pressure of $25 \mathrm{psig}$ is reached. At this time, all boiler vents and drains are closed except for the main steam lead drains.

2. One in-bed start-up burner is fired in each combustion chamber, raising the total gas flow from approximately 10 to $20 \mathrm{kscfh}$ per combustor. Thirty minutes later, an additional start-up burner is fired in each combustor, bringing the total gas flow to approximately $38 \mathrm{kscfh}$ (per combustor). The propane firing rate during this period is based on drum metal and refractory temperature restrictions of $100^{\circ} \mathrm{F} / \mathrm{h}$ and control of drum level. At this point, one duct burner and two of the three in-bed start-up burners are in service on each combustion chamber.

3. Turbine roll is initiated once $100^{\circ} \mathrm{F}$ of superheat is reached. This occurs at approximately 600 psig and 600 ${ }^{\circ} \mathrm{E}$ steam conditions. Turbine roll lasts for approximately 5 hours in this example, although 3 hours is recommended by the turbine manufacturer as adequate. As seen in Figure 7-2, propane firing rate is reduced to approximately $30 \mathrm{kscfh}$ per combustor during turbine roll.

4. Once the turbine heat soak period is complete, the generator is synchronized and load is increased to 5 MWe gross output and held at this level for one hour to stabilize. A third in-bed start-up burner is placed in service on each combustor and the total propane firing rate is increased.

5. Following stabilization at 5 MWe, propane firing rates are increased to $70 \mathrm{kscfh}$ per combustor and bed temperatures are increased to $950{ }^{\circ} \mathrm{F}$, required for the initiation of coal feed. Gross unit output has increased during this period to approximately 20-25 MWe on propane only.

5. Coal flow is initiated once bed temperatures increase to $950^{\circ} \mathrm{F}$, required for light-off. Load is increased as coal flow is established.

7. Start-up burners are shut off once bed temperatures have reached $1400^{\circ} \mathrm{F}$.

8. Gross unit output is increased to approximately 45 MWe on the new turbine/generator set. Although not shown on the figures, each of the three 12.5 MWe generator sets are then sequentially placed into service and overall load is increased to 110 MWe gross output. 
In this example, the time required from initial light-off to turbine roll was 7 hours, turbine roll (heat soak) was approximately 5 hours, synchronization and a stabilization period at 5 MWe takes approximately 2 hours, and the time required to reach 45 MWe was 3 hours. The overall time required to place the generator on-line from cold conditions was 12 hours and the total time to reach 45 MWe was 17 hours.

Figure 7-1 indicates final steam conditions and shows that seven hours were required to reach $100{ }^{\circ} \mathrm{F}$ superheat temperatures (step 3) prior to turbine roll. Figure 7-2 shows the propane and coal feed rates during start-up. Figure 7-3 indicates underbed air flow and the increase in bed temperature in combustor $A$. Data are overlapping for combustor $B$ and have been omitted for clarity. Coal flow is initiated at step 6 once bed temperatures have reached approximately $950^{\circ} \mathrm{F}$.

Figure 7-4 shows the increase in cyclone inlet gas temperature and the corresponding rise in refractory temperature. Refractory temperatures are measured at various locations in cyclone $B$. Thermocouples are inserted at various depths in the one foot thickness of refractory insulation. The value plotted in Figure 7-4 represents a point in the conical section of the cyclone. Figure 7-7 shows a maximum rate of change of refractory temperature for this measurement of $65^{\circ} \mathrm{F} / \mathrm{h}$. The manufacturer's recommended limit is $100{ }^{\circ} \mathrm{F} / \mathrm{h}$. Although this thermocouple may not be representative of all temperatures within the cyclone refractory, particularly those facing the hot solids and gases near the refractory surface, it does indicate that bulk temperatures during a cold start-up are not exceeding recommended rate limitations and, therefore, are not imposing a restriction on start-up.

Gaseous emissions data are presented in Figures 7-5 and 7-6. CO emissions are in excess of 500 ppmv during the interval when propane firing rates are high following the completion of the turbine heat soak, and when coal flow is first initiated and bed temperatures have not reached $1250^{\circ} \mathrm{F}$. Above this temperature (minimum CO ignition temperature is $\left.1128^{\circ} \mathrm{F}\right)$, CO emissions drop to less than $150 \mathrm{ppmv}$. NOX emissions increase to as high as 200 ppmv as coal is first introduced and load is increased to $45 \mathrm{MWe} . \mathrm{SO}_{2}$ emissions showed two brief spikes to 250-300 ppmv as coal is first introduced and load in increased. As limestone feed is initiated, emissions are restored to compliance levels. It may be possible to remain in $\mathrm{SO}_{2}$ compliance throughout a cold unit start-up by charging the bed with limestone prior to initiating coal flow. 
Figure 7-8 shows the rate of change of drum metal temperatures throughout the start-up. Note that prior to turbine roll, a $100{ }^{\circ} \mathrm{F} / \mathrm{h}$ rate of increase is reached, which is the manufacturer's recommended limit. Propane firing (energy input) cannot proceed at a faster rate or this criteria will be exceeded. At a minimum, the time required to raise $100^{\circ} \mathrm{F}$ of superheat temperature $\left(600^{\circ} \mathrm{F}\right.$ at $\left.600 \mathrm{psig}\right)$ is 5 hours, which corresponds to $100^{\circ} \mathrm{F} / \mathrm{h}$ increase in drum metal temperature. In this example, drum metal temperatures did not exceed $50{ }^{\circ} \mathrm{F} / \mathrm{h}$ during the first three hours of startup. This is because the propane firing rate (heat input) is restricted during this interval to prevent upsets in drum level. Once boiler vents and drains are closed and the drum pressure is in excess of 25 psig, drum level fluctuations diminish in magnitude but must be monitored until a drum pressure of 300 psig is reached. From this point, the restriction on the rate of increase in pressure part metal temperatures dictates the time to turbine roll.

Figure 7-9 shows the final steam temperature along with the turbine first stage cover metal temperature. The rate of change in the latter temperature is shown in Figure 7-10, which exceeds $150{ }^{\circ} \mathrm{F} / \mathrm{h}$ for short intervals when $600^{\circ} \mathrm{F}$ steam is first introduced to the turbine, and again as the generator is synchronized and steam flow is increased. It is not certain if this differs from a start-up of a pulverized coal fired unit or if these short intervals at $150^{\circ} \mathrm{F} / \mathrm{h}$ are hazardous to turbine life.

Under optimum conditions with a turbine rated at 110 MWe, full load from cold conditions could be reached in approximately ten hours. This includes five hours to raise $100^{\circ} \mathrm{F}$ superheat temperatures, a three hour turbine soak, a one hour hold at 5 MWe to stabilize, and one hour to full load. Achieving full load from 45 MWe is complicated at Nucla because of the 74 MWe turbine with controlled extraction to three 12.5 MWe turbine, and the time required to bring each of these systems on-line.

\subsection{WARM RESTART}

Data are presented for a warm restart following a unit trip and a seven hour period with the turbine-generator off-line. The unit trip was initiated by a secondary air (SA) fan trip which caused a unit trip. All fans were out of service for a seven hour period immediately following the trip. This shutdown/restart sequence simulates a condition where the unit is taken off-line during a period of low load demand

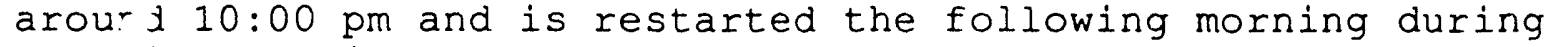
a period of high demand. The shutdown and restart sequence is numbered on Figures 7-11 through 7-20 according to the following sequence: 


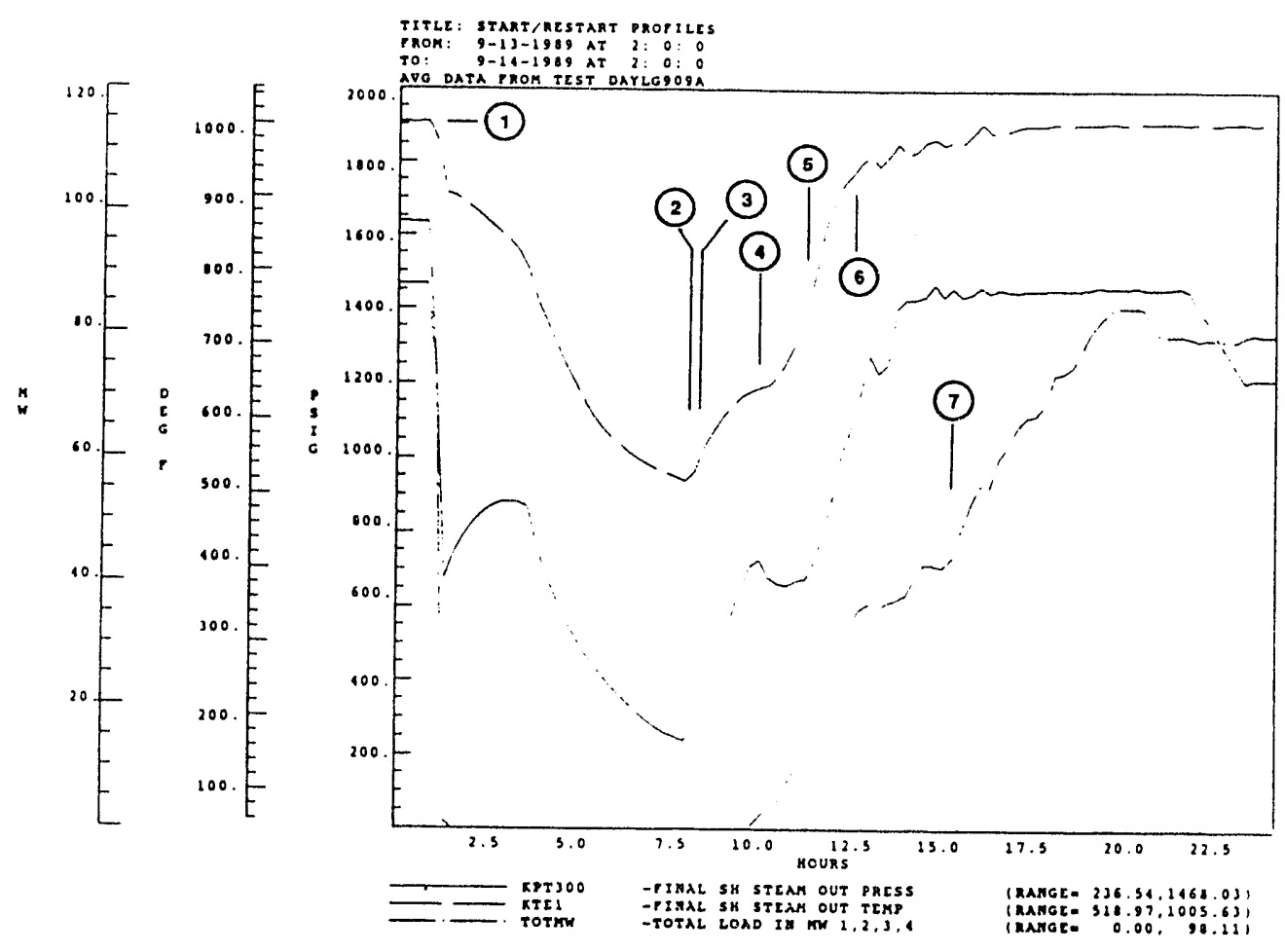

Figure 7-11. Load \& Steam Conditions for Warm Restart.

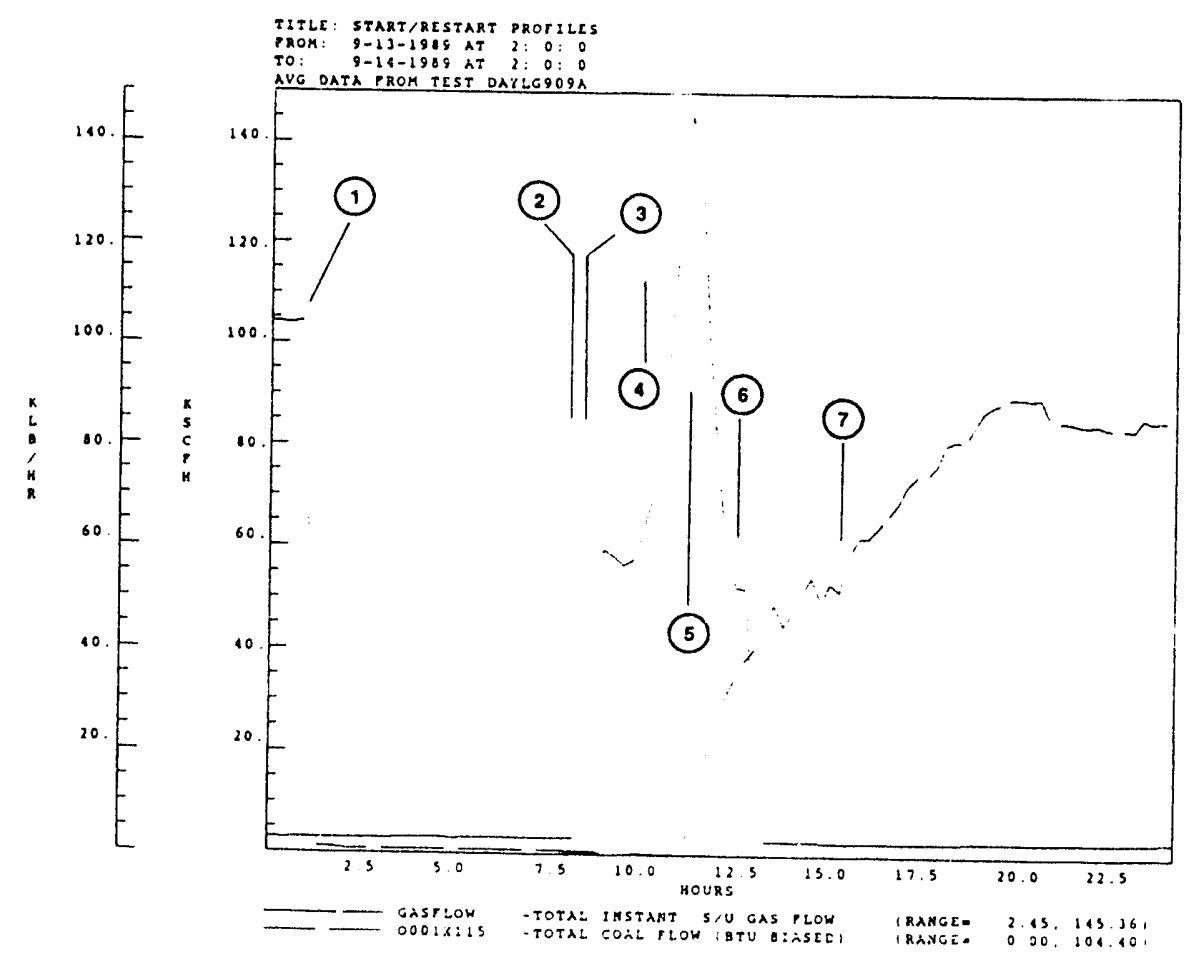

Eigure 7-12. Coal and Gas Flow for Warm Restart. 


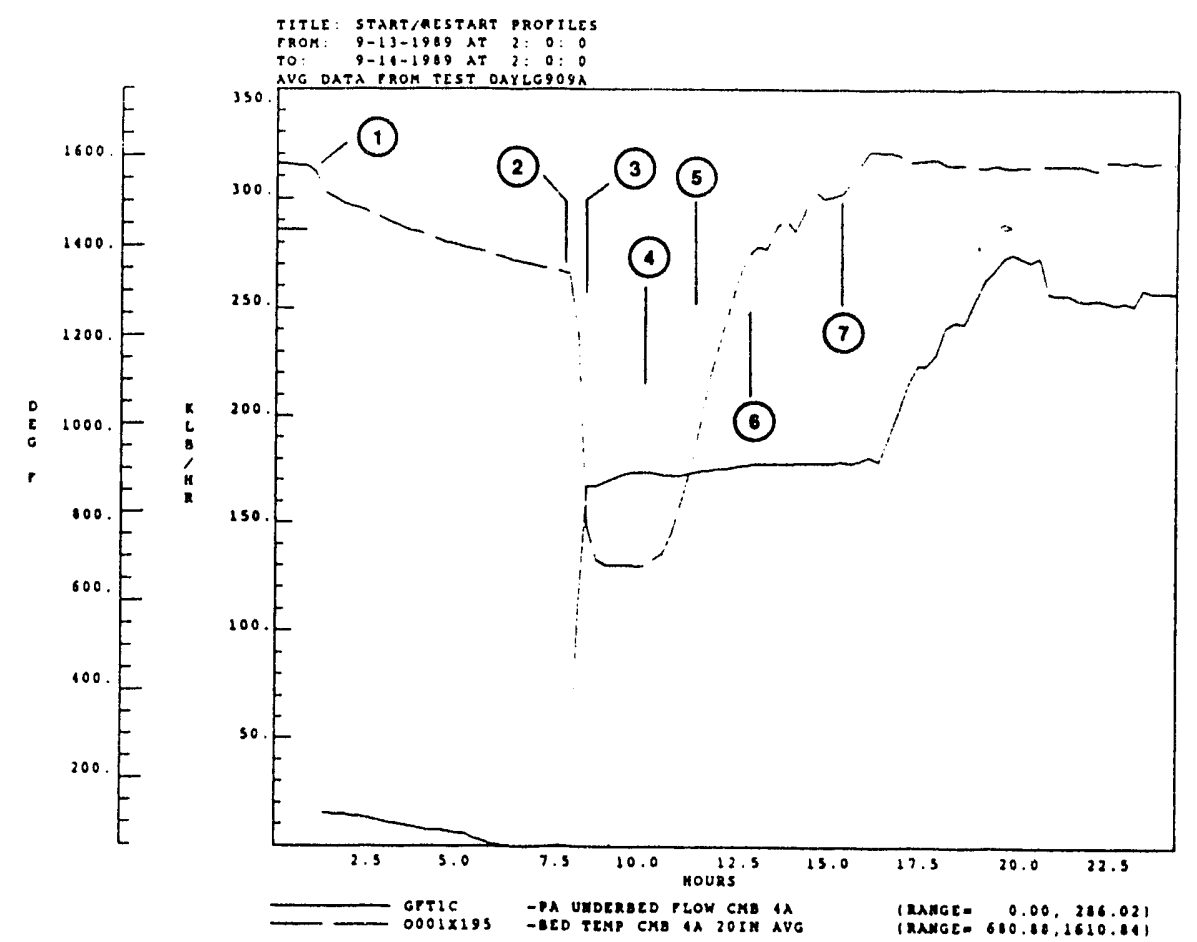

Figure 7-13. Air Flow \& Bed Temps. for Warm Restart.

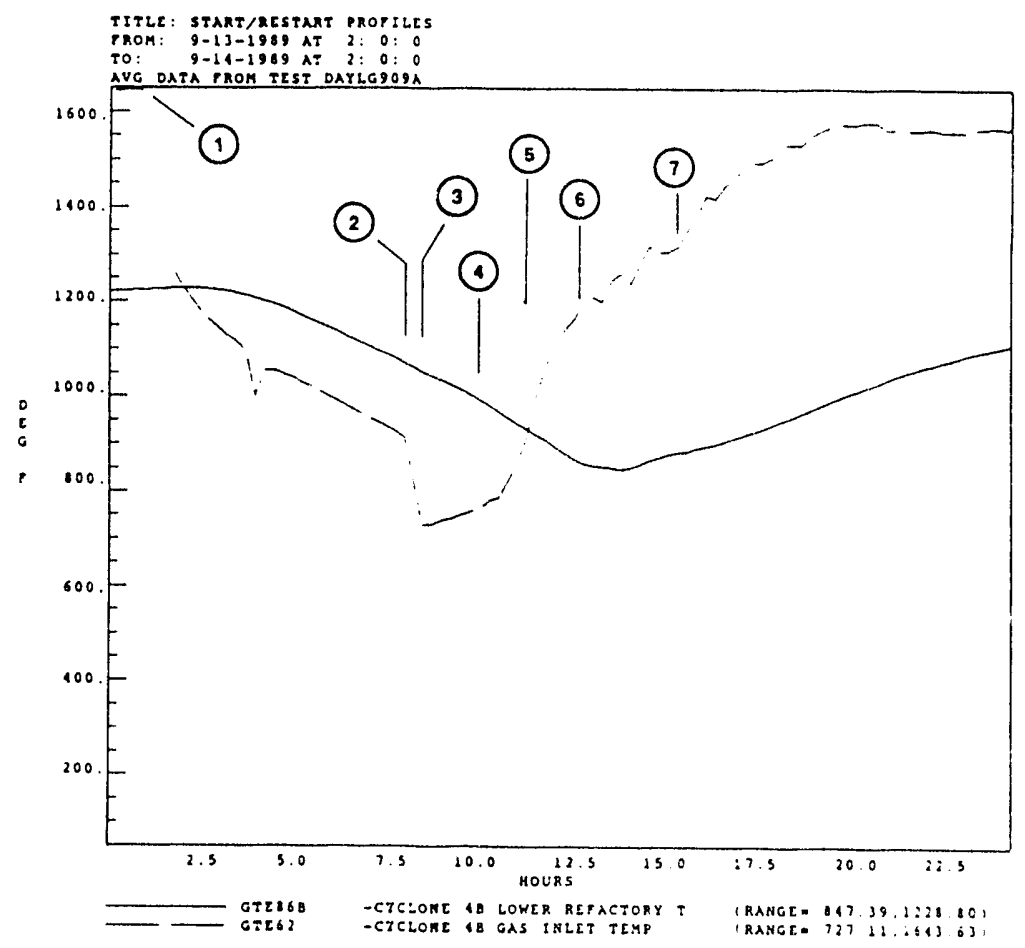

Eigure 7-14. Cyclone Refractory Temps. for Warm Restart. 


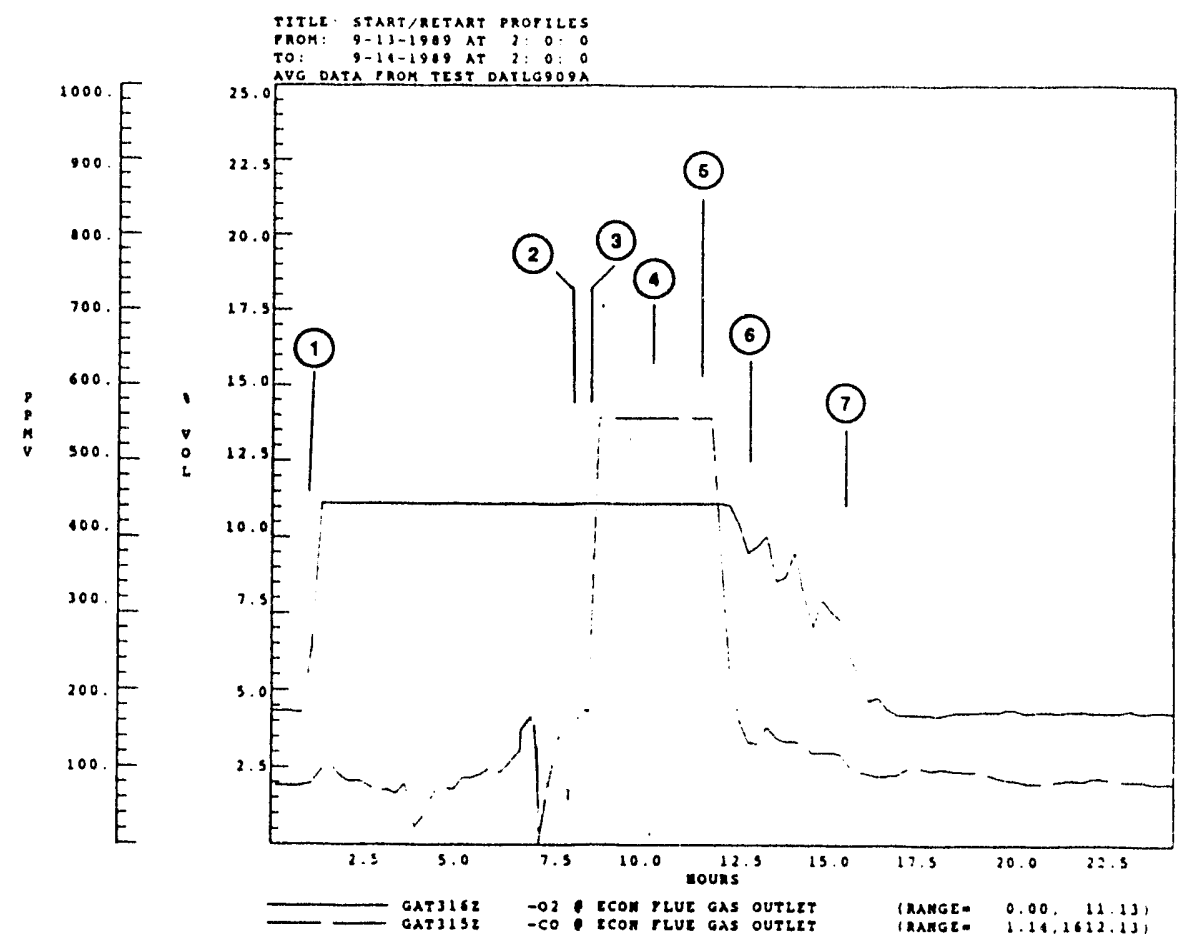

Figure 7-15. $\mathrm{O}_{2}$ and $\mathrm{CO}$ Emissions During Warm Restart.

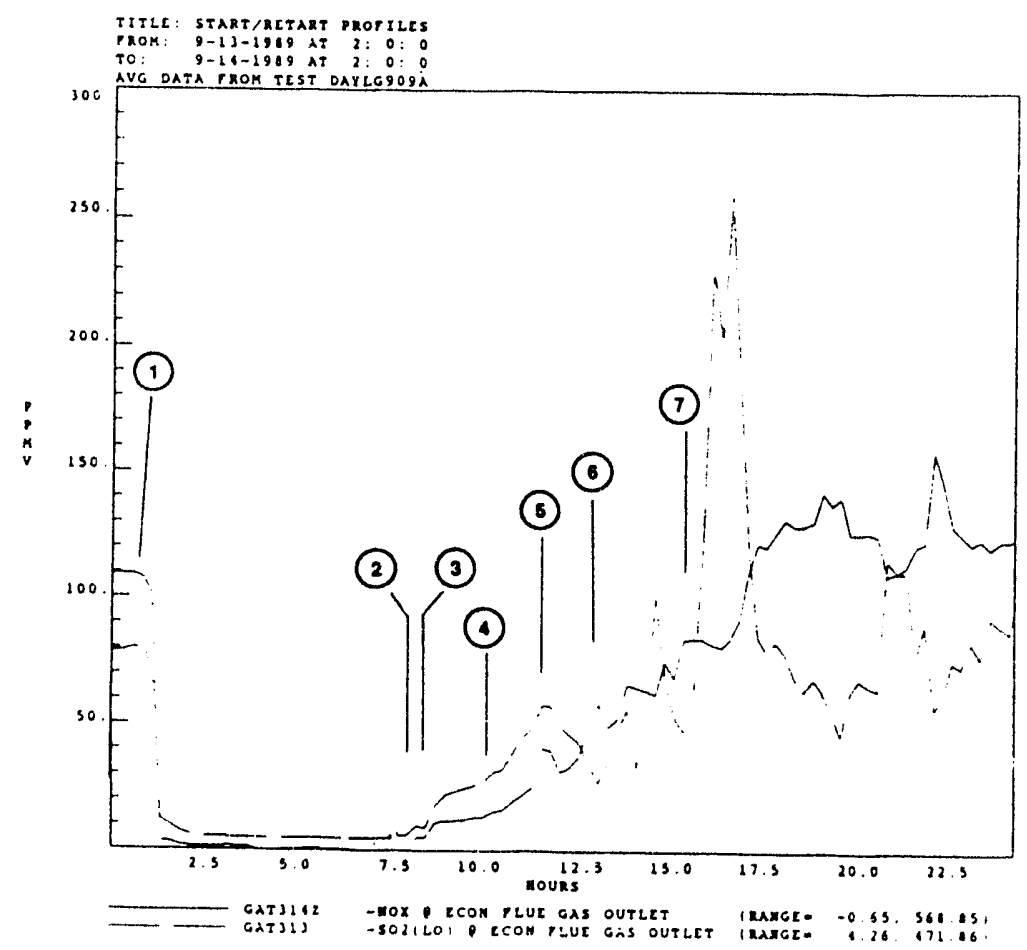

Figure 7-16. $\mathrm{NOX}$ and $\mathrm{SO}_{2}$ Emissions During Warm kestart. 


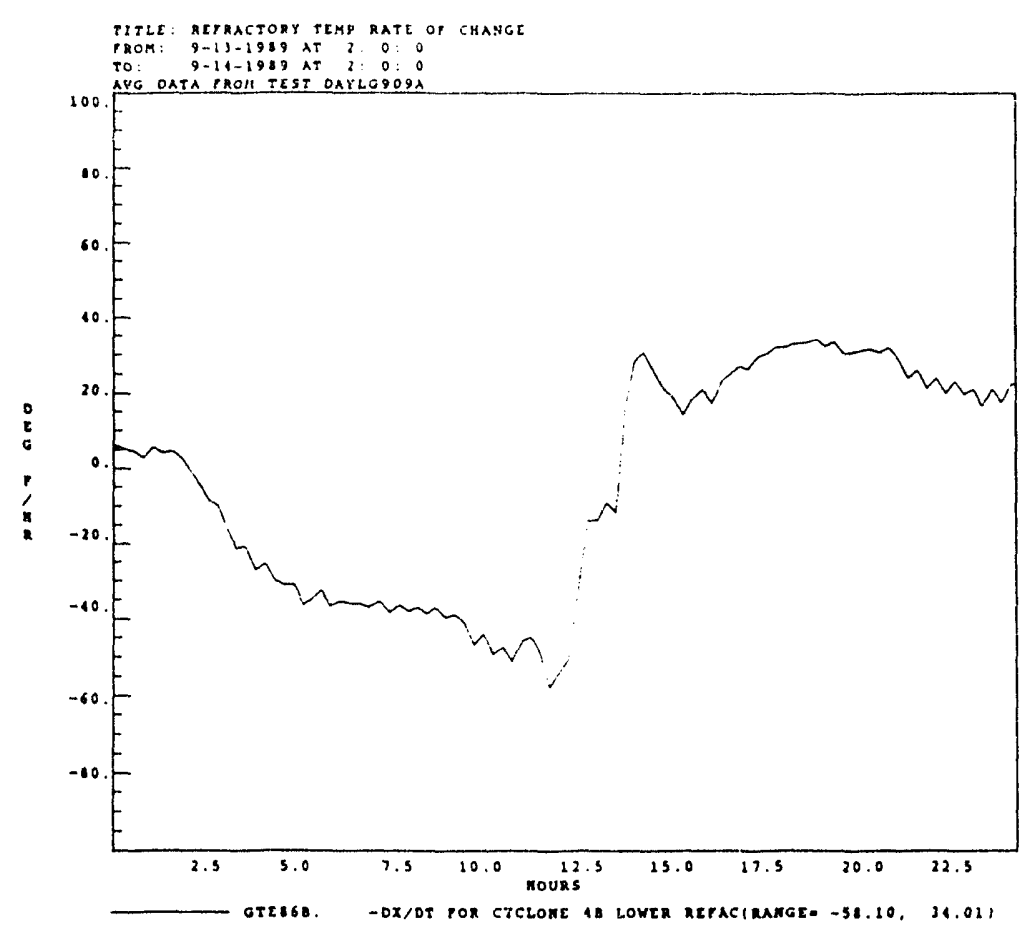

Figure 7-17. $\frac{d x}{d t}$ of Cyclone Refractory - Warm Restart.

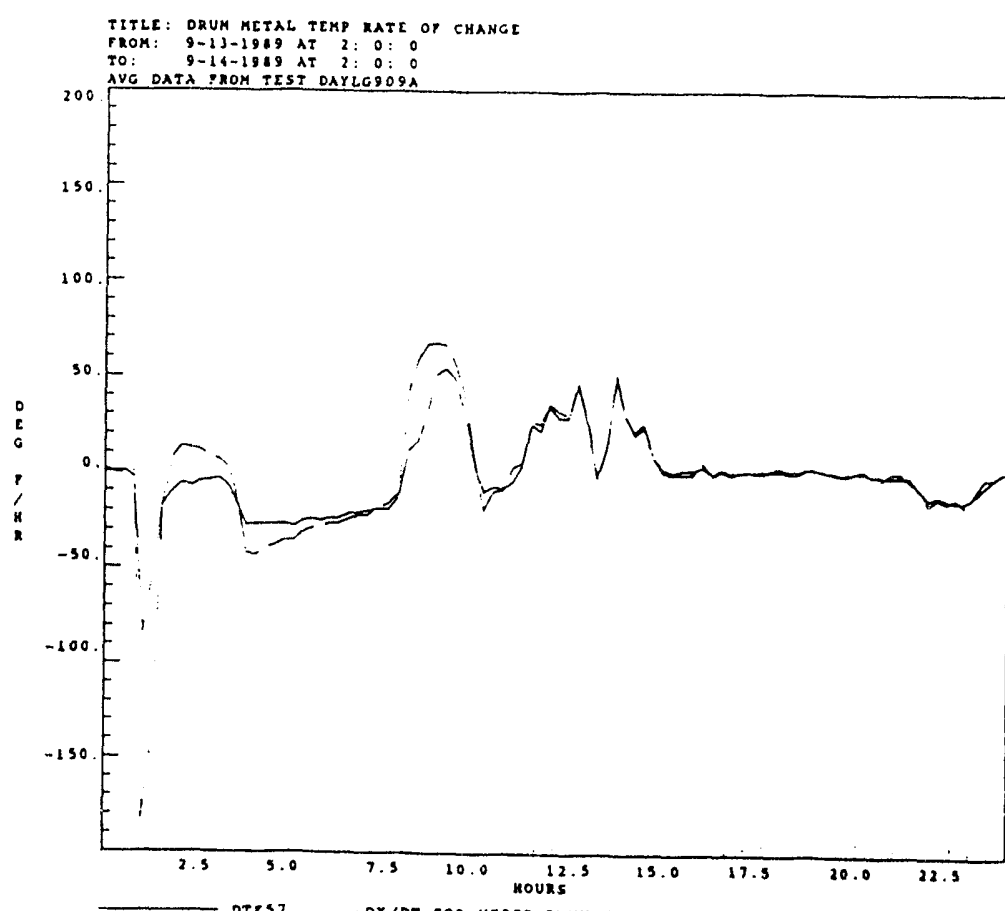

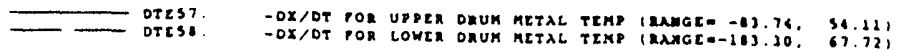

Figure 7-18. $\frac{d x}{d t}$ of Drum Metal Temp. - Warm Restart. 


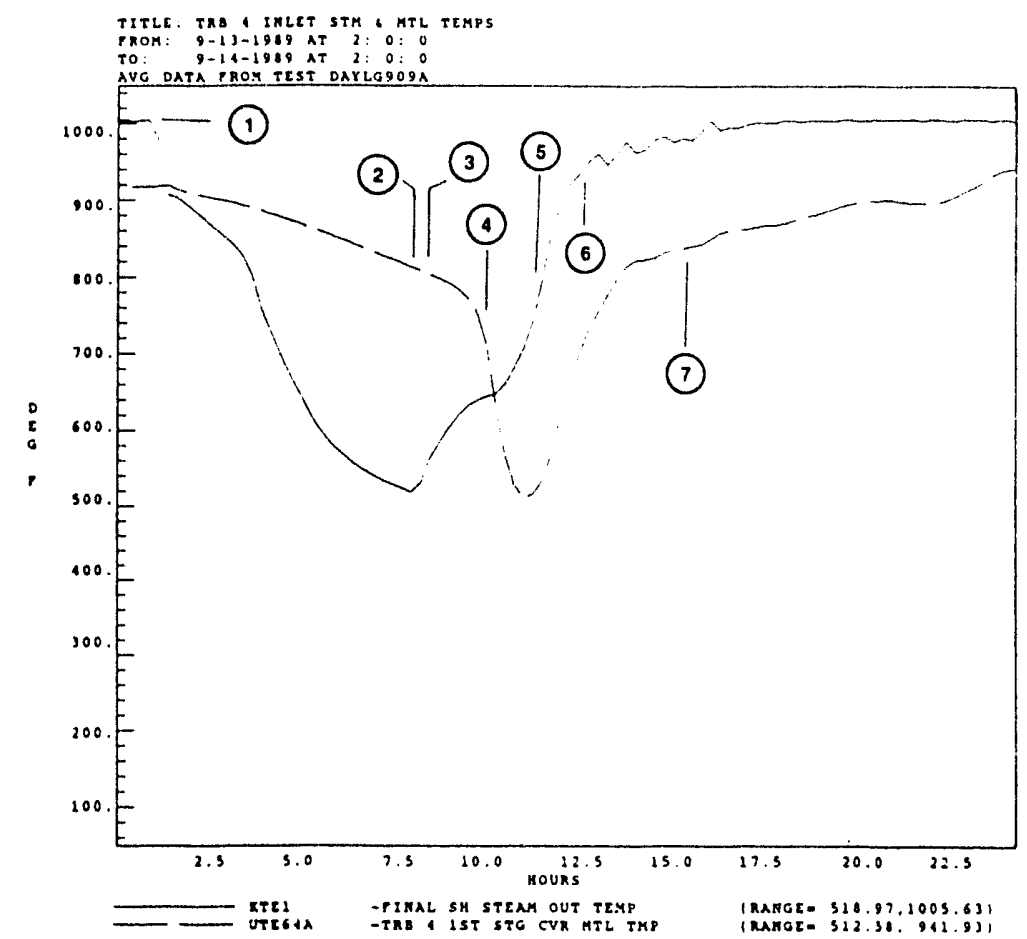

Eigure 7-19. Steam \& Turbine Metal Temps. - Warm Restart.

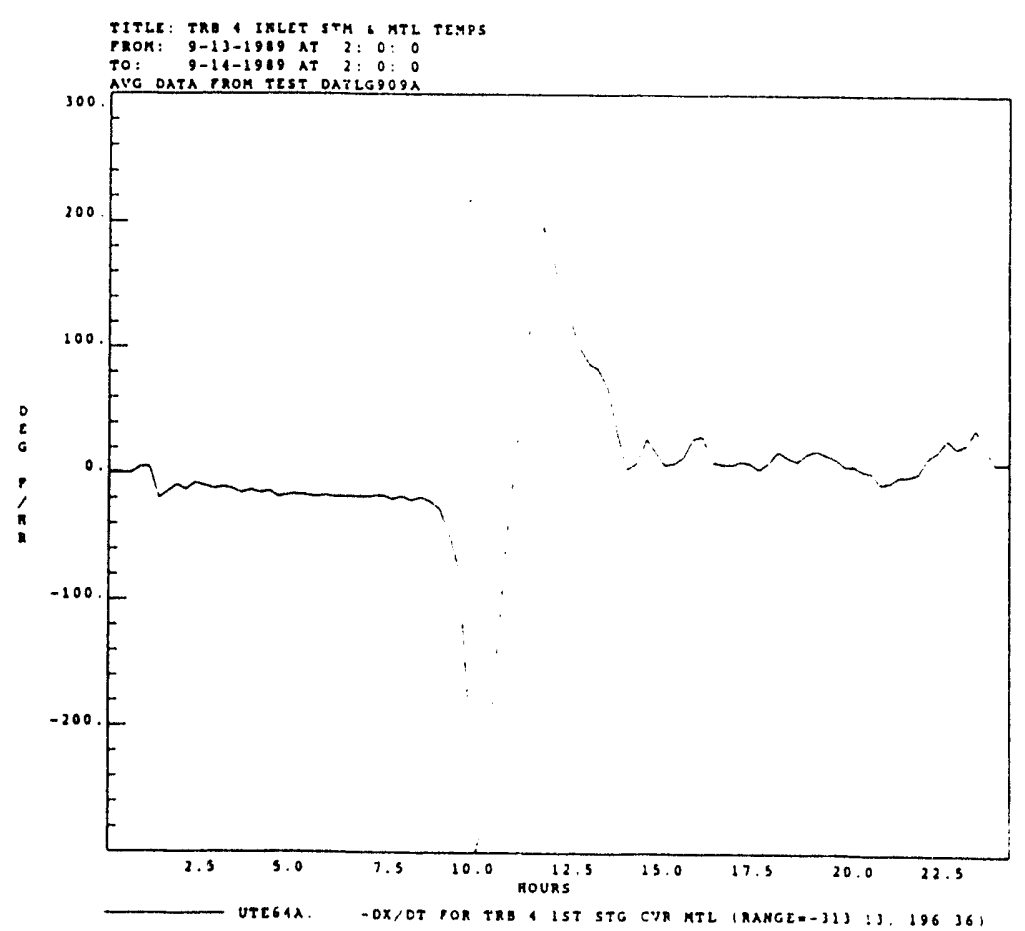

Figure 7-20. $\frac{d x}{d t}$ of Turbine Metal Temps. - Warm Restart. 
1. Unit trip from 95 MWe gross output at approximately 03:00 as the result of a secondary air fan trip. Power to all fans is off and the fan rotors are in wind-down. Final steam pressure drops to 700 psig as load is reduced on the 74 MWe generator before it is taken offline (the old 12.5 MWe turbines trip immediately).

2. Fans are restarted at approximately 09:50.

3. Once all fans and the high pressure blower have been started and powered up, a duct burner and two in-bed start-up burners are fired on each combustor following a five minute air purge.

4. With $100^{\circ} \mathrm{F}$ of superheat established at $600^{\circ} \mathrm{F}$ and 600 psig final steam conditions, the generator is synchronized and load is increased to $5 \mathrm{MWe}$ gross. The third in-bed start-up burner is fired in each combustion chamber and propane firing is increased to both combustors.

5. Coal flow is introduced once bed temperatures increase to above $950^{\circ} \mathrm{F}$. Generator output is increased during this period. Propane flow is reduced as coal feed is increased.

6. Start-up burners are shut off once bed temperatures have increased above $1400^{\circ} \mathrm{F}$.

7. Load is increased to 45 MWe gross output on the new 74 MWe turbine. Overall load is slowly increased to approximately 80 MWe as the 12.5 MWe units are brought on-line.

The figures and formats for data presentation are identical to those presented for the cold start-up. Figure 7-11 shows the drop in steam pressure from 1450 to 700 psig and steam temperature from $1000^{\circ} \mathrm{F}$ to $525^{\circ} \mathrm{F}$ during the seven hour interval following the unit trip and prior to the start of fans and gas burners. The drop in steam pressure results from maintaining steam flow to the 74 MWe turbine for a 15 to 20 minute interval following the trip. This also results in a $100^{\circ} \mathrm{F}$ drop in final steam temperature. The additional decrease in steam temperature from $900^{\circ} \mathrm{F}$ to $525^{\circ} \mathrm{F}$ over 6 hours represents unit cool-down without fans in service.

Figure 7-13 shows a decline in bed temperature of $175^{\circ} \mathrm{F}$ over 6 hours without fans in service, or approximately $30^{\circ} \mathrm{F} / \mathrm{h}$. With fans in service and air flow through the air distributor plate, bed temperatures decrease at a rate approaching $200^{\circ} \mathrm{F}$ in 5 minutes, which is the time required for a unit purge. This is an important factor in establishing restart times, since a bed temperature of $950{ }^{\circ} \mathrm{F}$ is required prior to the initiation of coal feed. In this example, bed temperatures 
decreased only $175^{\circ} \mathrm{F}$ over a 6 hour period. Although this demonstrates the ability of a CFB to effectively store energy for fast restarts without the use of start-up burners, the time required to restart fans and complete the boiler purge cycle reduces bed temperatures to just above $600{ }^{\circ} \mathrm{F}$, well below that required for the initiation of coal feed. This could be circumvented by closing off dampers to the air distributor grid during fan start-up and completing the boiler purge cycle through ports located above the hot, slumped bed. Although the latter is not permitted by code, this modified procedure is currently under review by the National Fire Prevention Association (NFPA).

Figures $7-14$ and $7-17$ show the rate of change of refractory temperature during the warm restart. A maximum rate of change of $50^{\circ} \mathrm{F} / \mathrm{h}$ was reached for a two hour interval immediately following the re-establishment of coal flow to the boiler. This is well under the recommended limit of 100 ${ }^{\circ} \mathrm{F} / \mathrm{h}$.

Figures 7-15 and 7-16 indicate emissions during the restart. Again, CO emissions are in excess of 500 ppmv during the period when start-up burners are fired and coal flow is initiated to the point where bed temperatures increase above $1250{ }^{\circ} \mathrm{F} . \mathrm{SO}_{2}$ emissions remain in compliance except for a brief one hour period when coal flow is first introduced. This may be preventable by initiating limestone feed in advance of coal feed. $\mathrm{NO}_{\mathrm{X}}$ emissions remain in compliance throughout the period.

Figures 7-18 and 7-20 show the rate of change for drum metal and turbine first stage metal cover temperatures during the restart. Both remain within recommended margins, except for a three hour period when steam flow is initiated to the turbine and first stage metal cover temperatures go through a -300 to $+200^{\circ} \mathrm{F} / \mathrm{h}$ transient.

\subsection{HOT RESTART}

Data are presented for a hot restart following a unit trip and a one hour period with the turbine-generator off-line. the unit trip was initiated by a turbine control system trip which also tripped unit fans for approximately a 20 to 30 minute period. The shutdown and start-up sequence is similar to a warm restart. The numbering sequence on Figures 7-21 through 7-30 corresponds to the following numbered descriptions :

1. Unit trip at 110 MWe gross output at approximately $10: 15$ as the result of a turbine control trip. The combustion air fans and high pressure blower also trip and are in wind-down. Final steam pressure remains at 


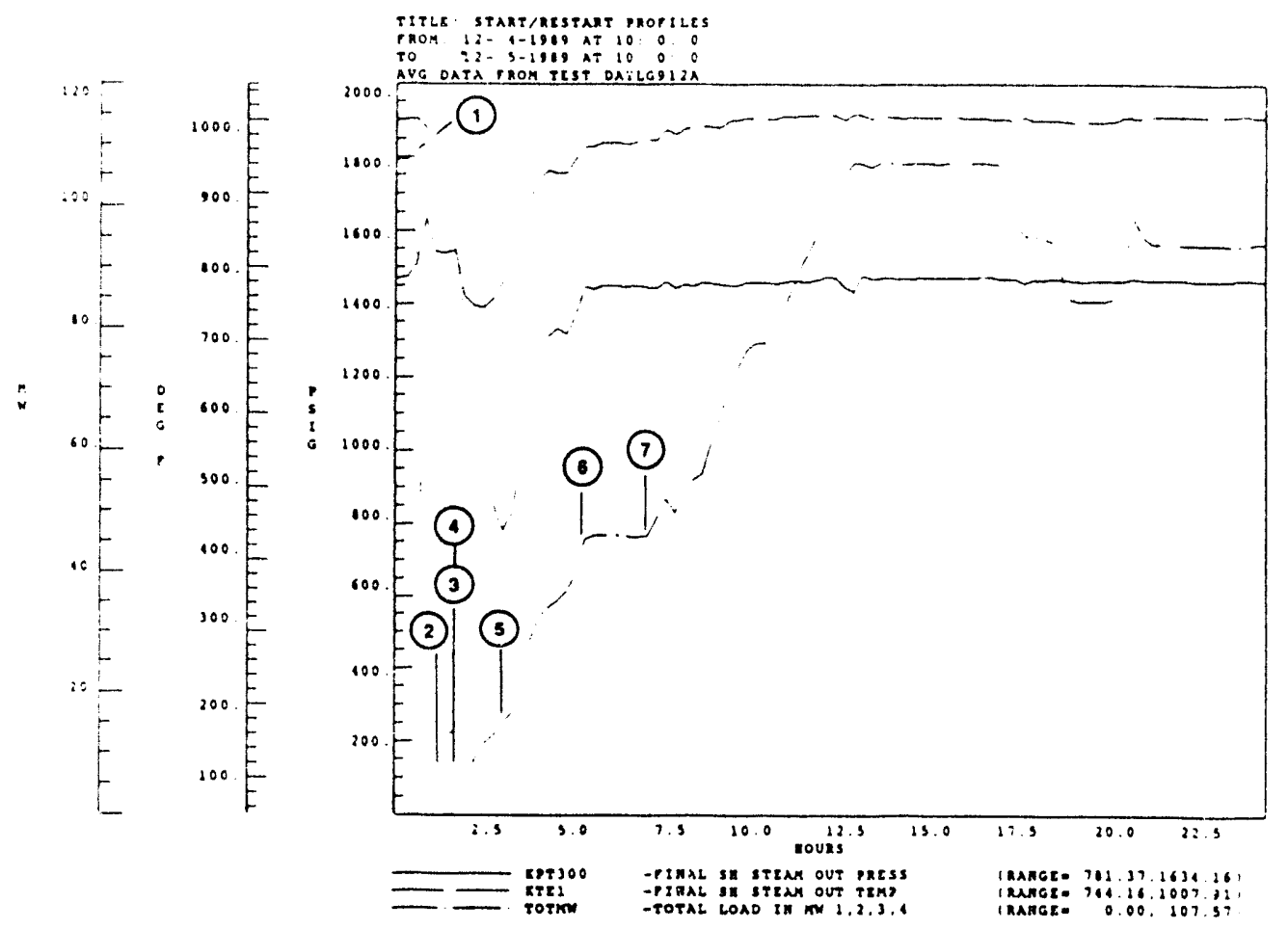

Figure 7-21. Load \& Steam Conditions for Hot Restart.

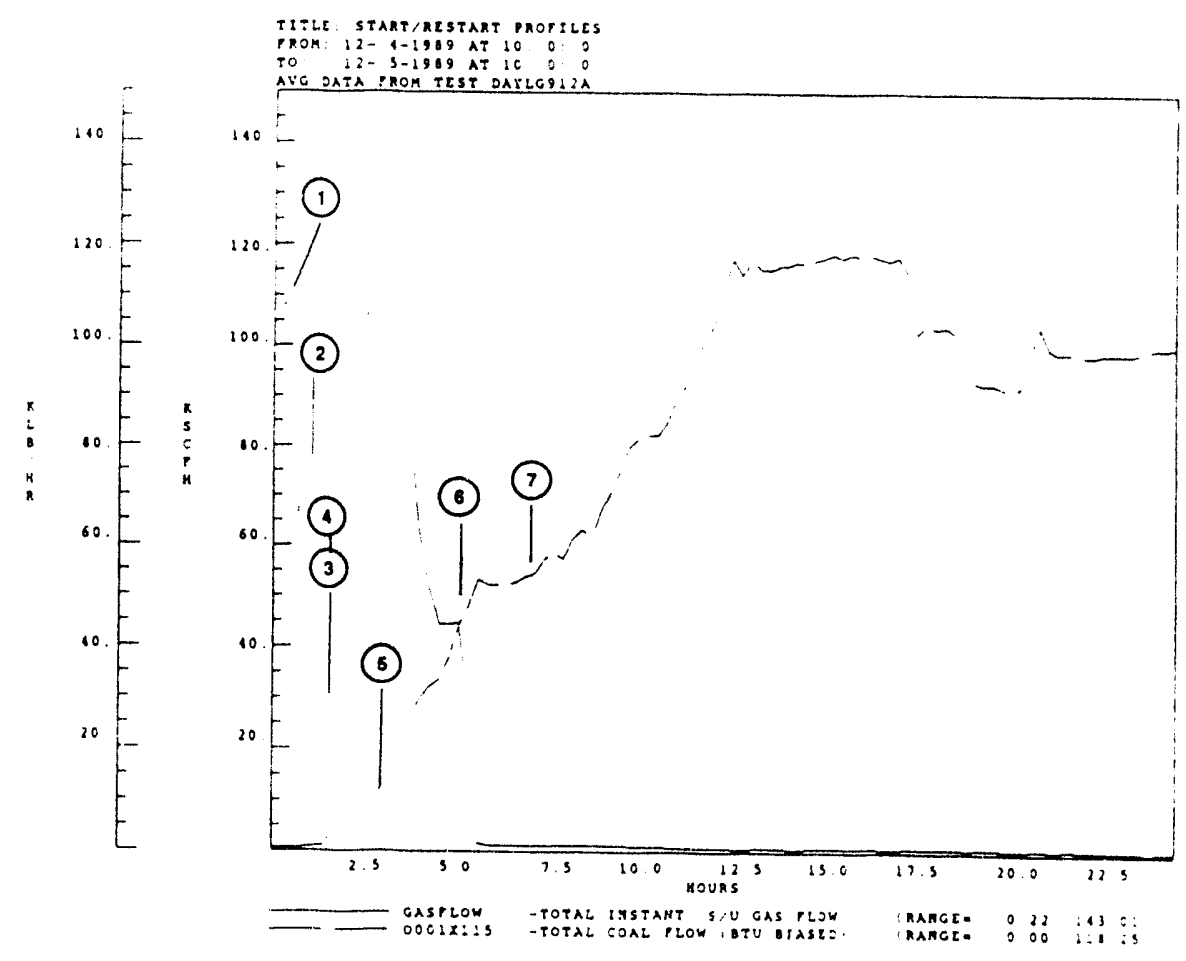

Eigure 7-22. Coal and Gas Flow for Hot Restart. 


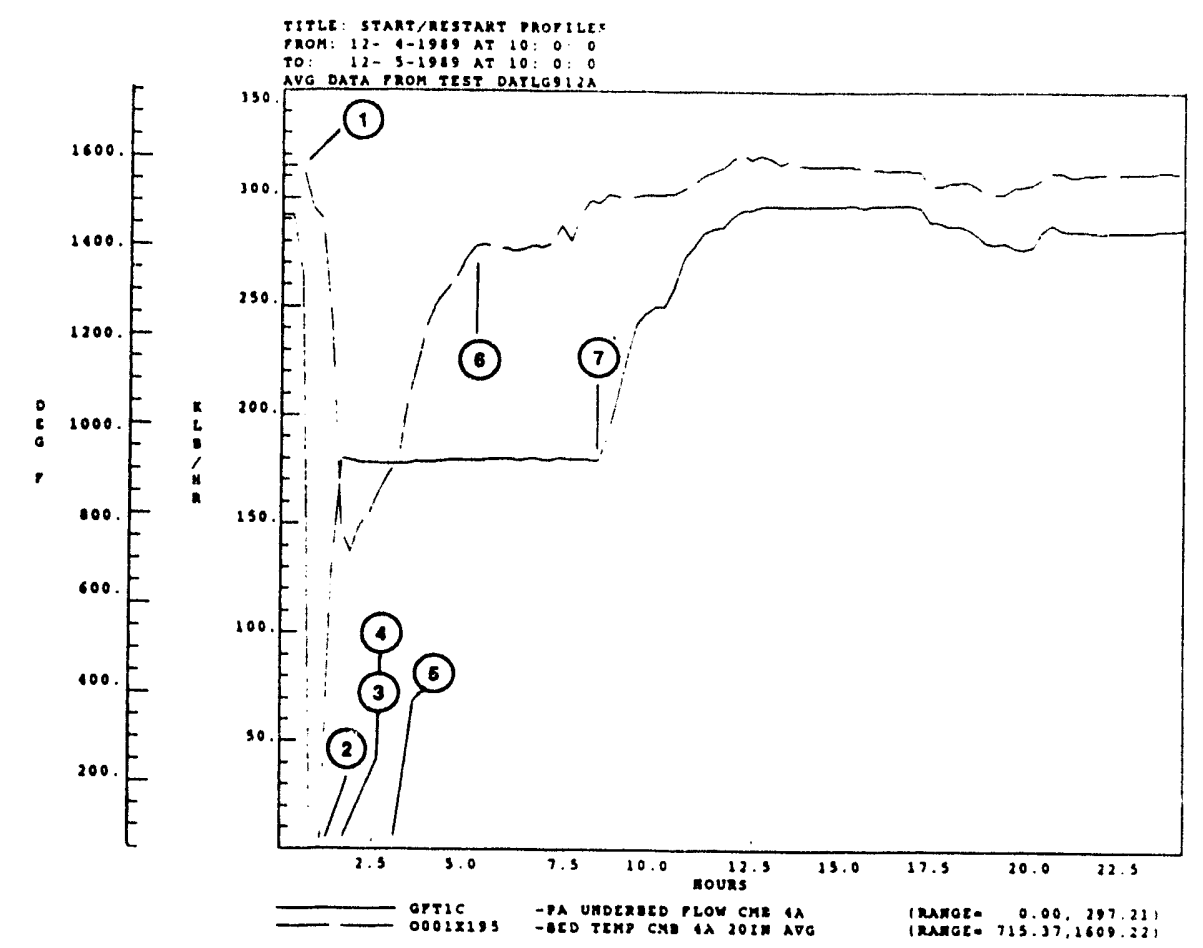

Figure 7-23. Air Flow \& Bed Temps. for Hot Restart.

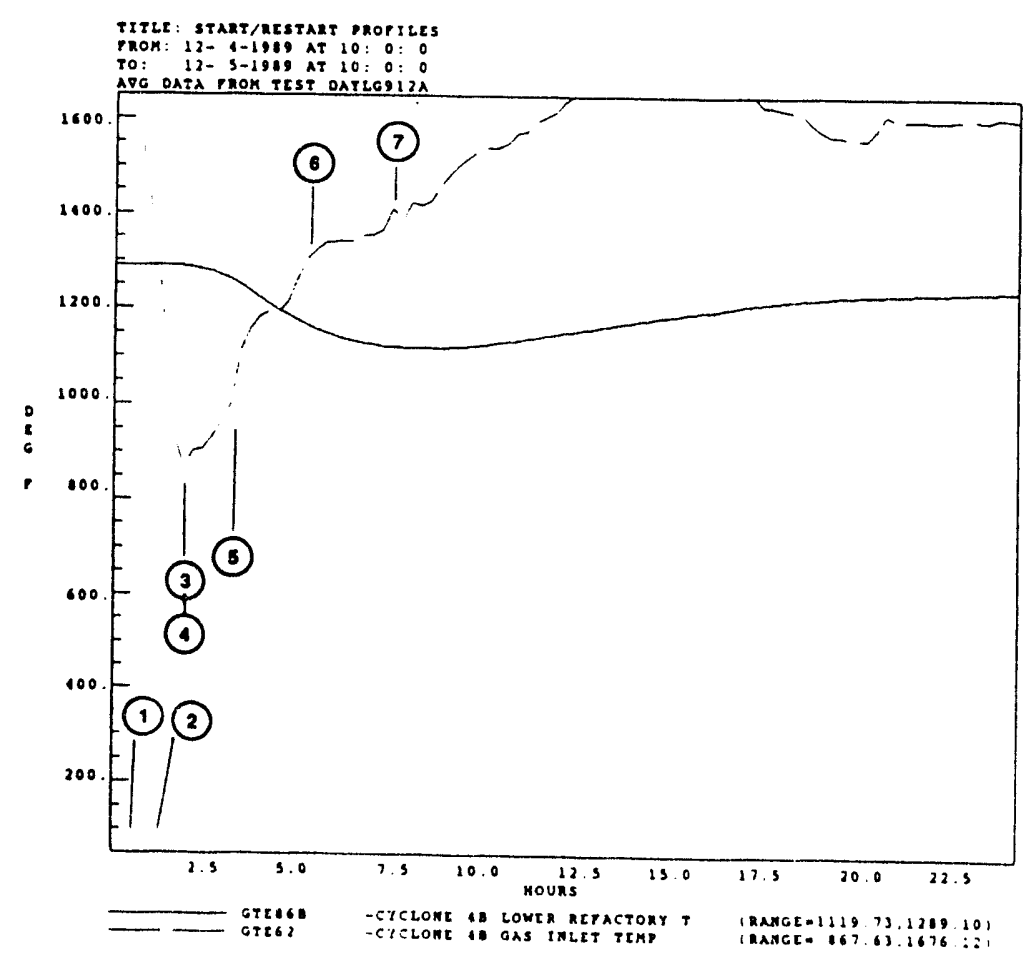

Figure 7-24. Cyclone Refractory Temps. for Hot Restart. 


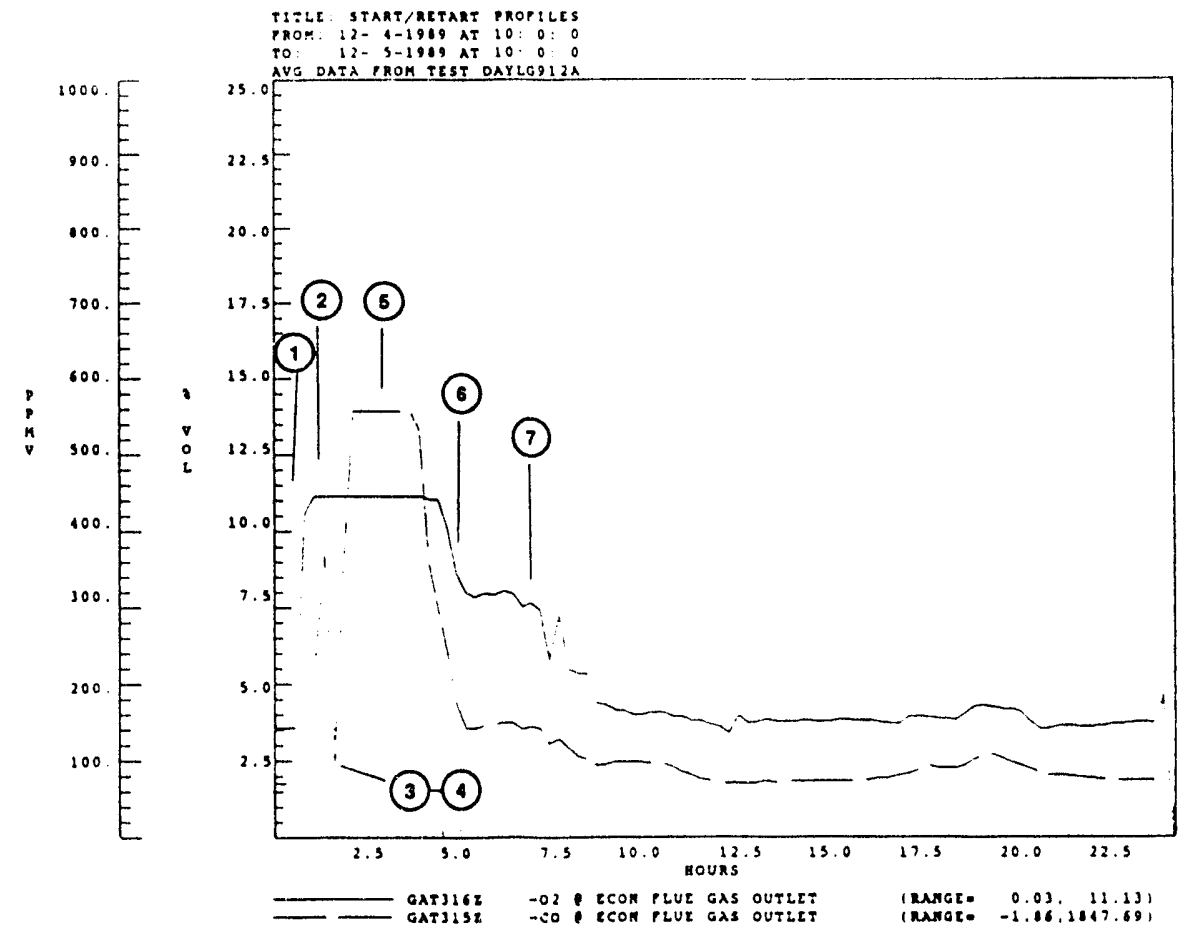

Figure 7-25. $\mathrm{O}_{2}$ and $\mathrm{CO}$ Emissions During Hot Restart.

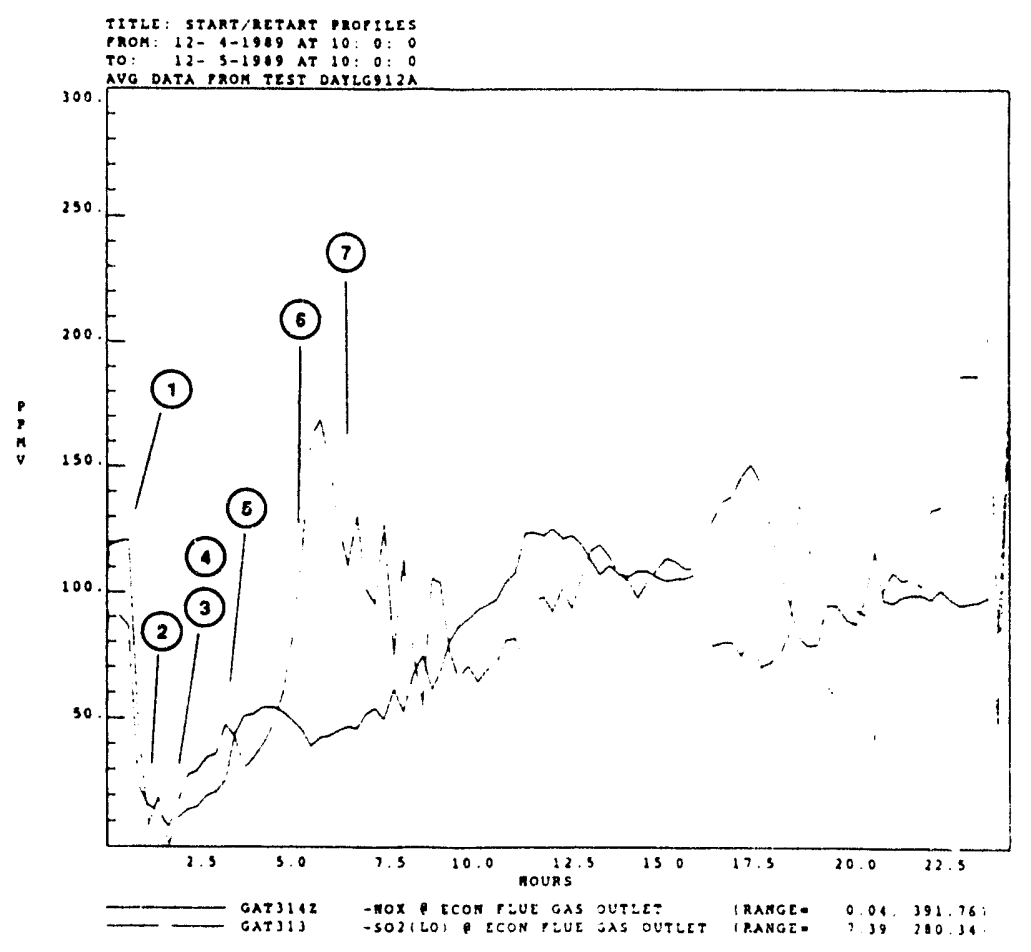

Eigure 7-26. $\mathrm{NOX}$ and $\mathrm{SO}_{2}$ Emissions During Hot Restart. 


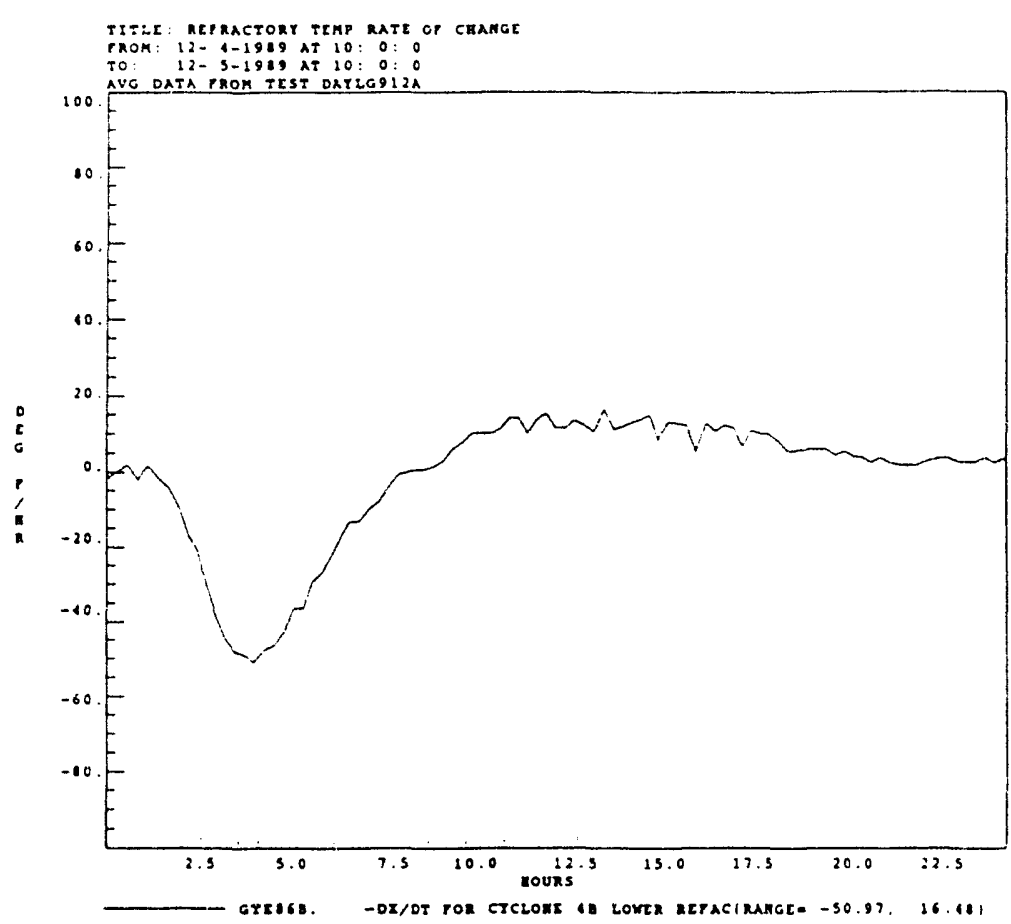

Figure 7-27. $\frac{d x}{d t}$ of Cyclone Refractory - Hot Restart.

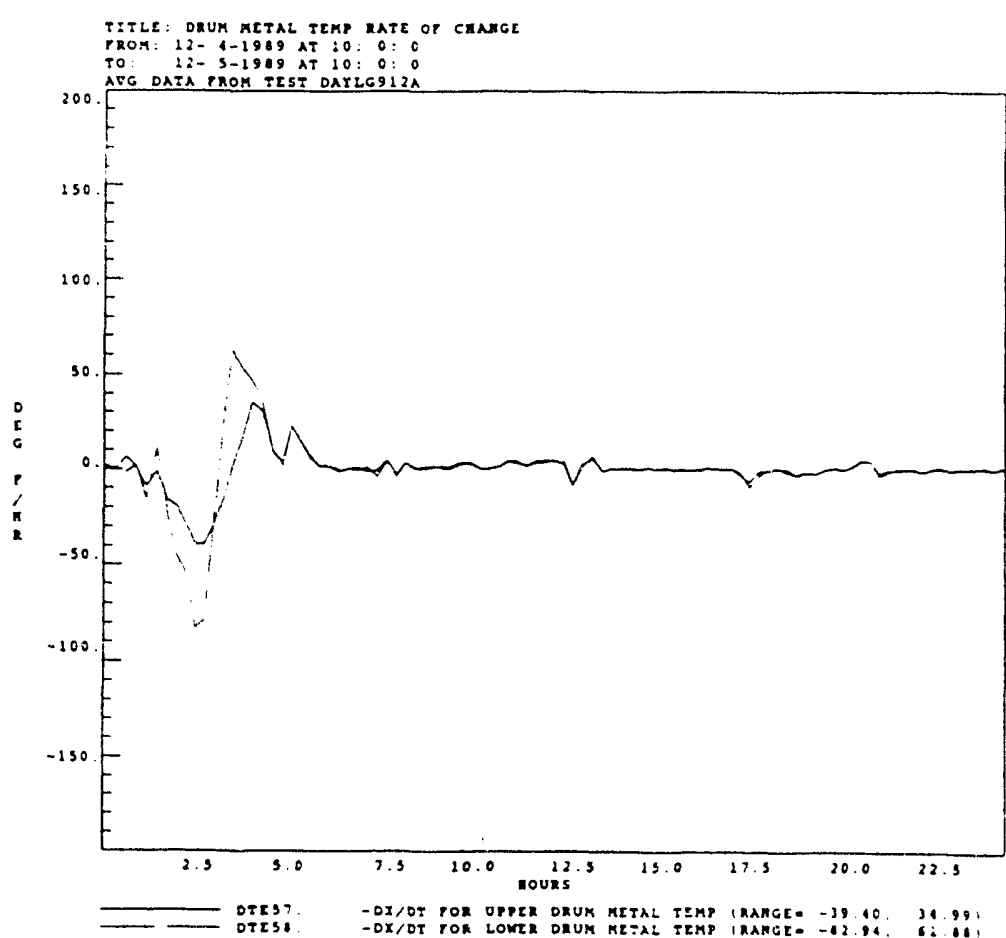

Figure 7-28. $\frac{d x}{d t}$ of Drum Metal Temp. - Hot Restart. 


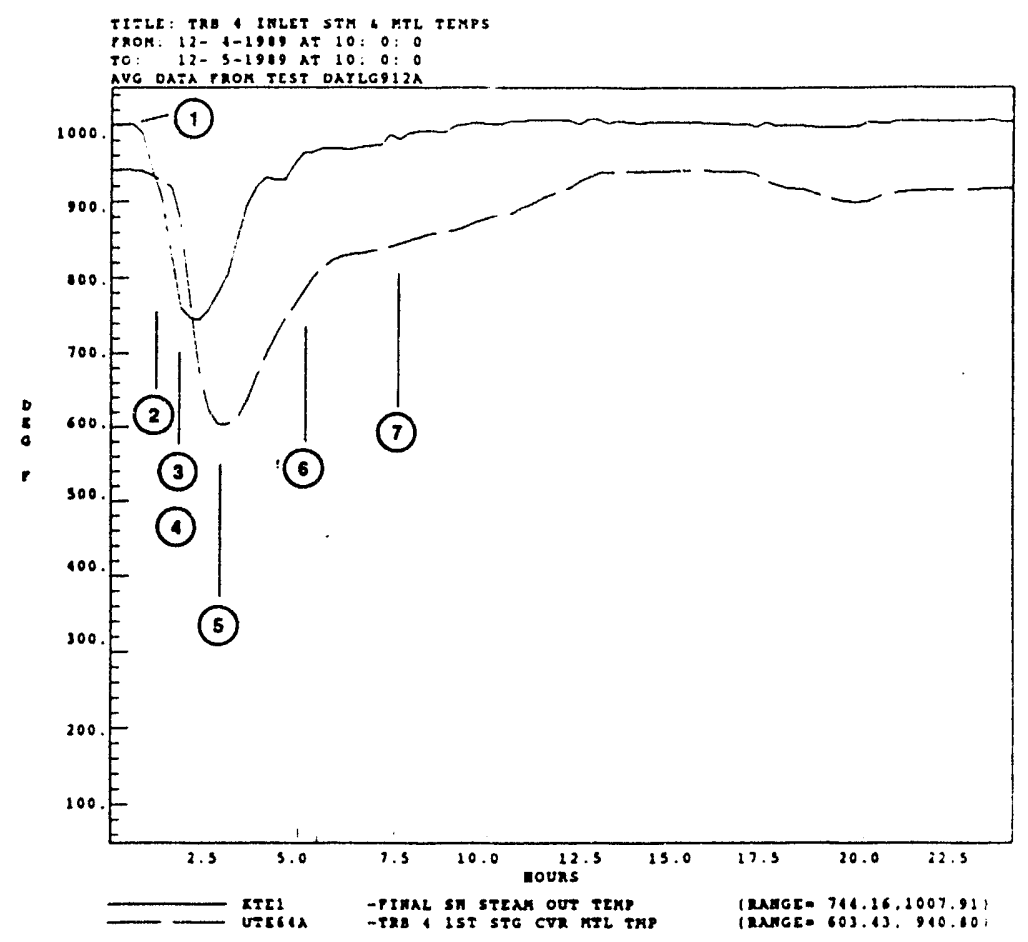

Figure 7-29. Steam \& Turbine Metal Temps. - Hot Restart.

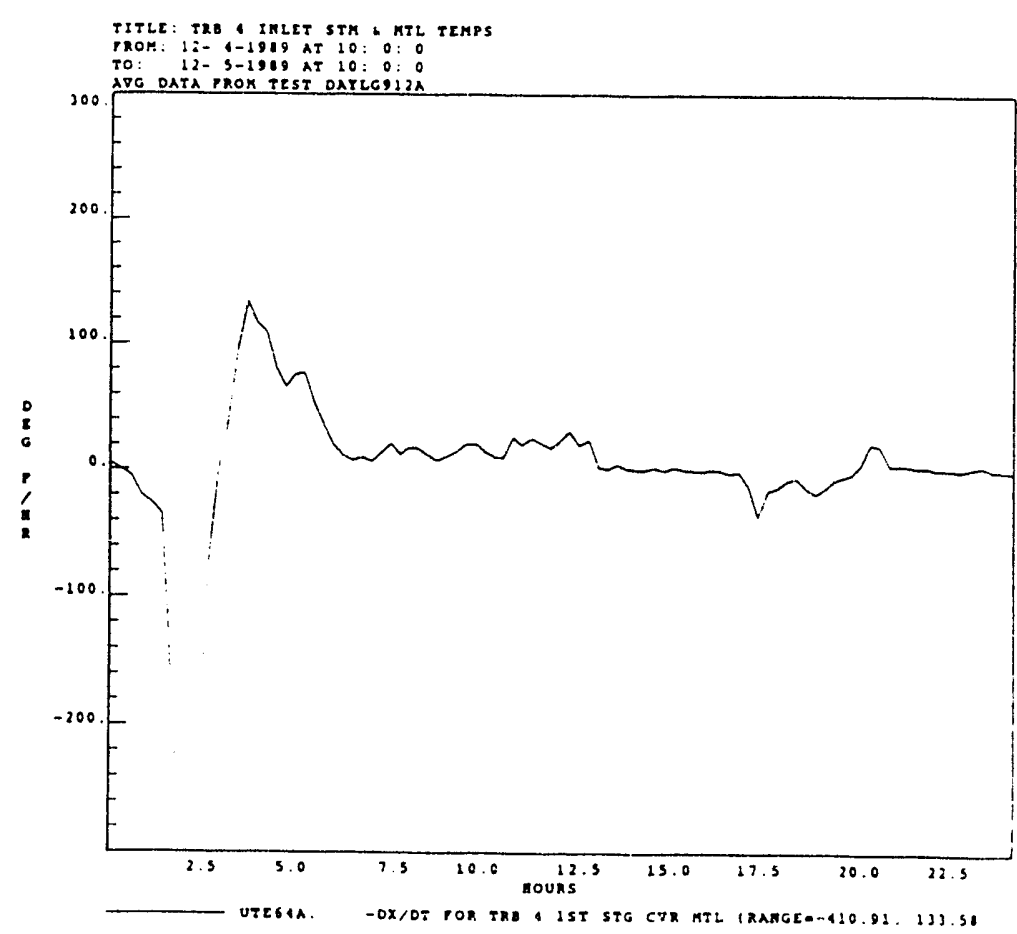

Figure 7-30. $\frac{d x}{d t}$ of Turbine Metal Temps. - Hot Restart. 
1450 psig since the turbine is broughc off-line immediately.

2. Fans are restarted at approximately 11:05.

3. Once all fans and the high pressure blower have been started and powered up, the duct burner and three start-up burners in each combustor are placed into service and total propane firing rate on both combustors is increased to $140 \mathrm{kscfh}$.

4. Since $100^{\circ} \mathrm{F}$ of superheat is maintained following the unit trip, the 74 MWe generator is synchronized at approximately $11: 35$ and load is increased.

5. Coal flow is introduced at approximately 12:50 once bed temperatures reach approximately $950^{\circ} \mathrm{F}$. Generator output is increased during this period. Propane flow is reduced as coal feed is increased.

6. Start-up burners are shut off once bed temperatures have increased above $1400^{\circ} \mathrm{F}$.

7. Load is increased to 45 MWe gross output for a two hour period after which the three 12.5 MWe turbinegenerators are sequentially placed into service as gross output is restored to 110 MWe.

Again, the figures and formats for data presentation are similar to those presented for cold and warm start-ups. Figure 7-21 shows a slight increase in steam pressure following the turbine trip because steam flow is immediately terminated while some energy is still being released in the boiler as the fans wind down. Steam temperature drops approximately $100^{\circ} \mathrm{F}$ during the 20 to 30 minute interval when fans are out of service. Figure 7-22 shows the start times and flow rates for propane and coal feed as well the shutdown time for propane flow.

Figure 7-23 shows a minimal drop in bed temperature during the interval with fans out of service, but a large decline of $750{ }^{\circ} \mathrm{F}$ during the period when fans are restarted and the boiler purge cycle is completed. As mentioned, this temperature drop could be reduced if air flow were directed through overbed ports during fan start-up and boiler purge. This would reduce the time required on propane to raise bed temperatures back to $950^{\circ} \mathrm{F}$. Supplemental propane is required by current boiler operating logic when the unit is operating on coal and bed temperatures are less than $1400^{\circ} \mathrm{F}$.

Eigures 7-24 and 7-27 show the rate of change of refractory temperature during the hot restart. A maximum rate of change of $50^{\circ} \mathrm{F} / \mathrm{h}$ was reached for a two hour interval following the 
restart of fans and the introduction of coal feed. This is similar to results for a warm restart.

Figures 7-25 and 7-26 show emissions performance during the hot restart. As was shown for the cold and warm starts, CO emissions are in excess of 500 ppmv during the period when start-up burners are fired and coal flow is initiated until $1250{ }^{\circ} \mathrm{F}$ bed temperatures are reached. $\mathrm{SO}_{2}$ spiked to $175 \mathrm{ppmv}$ during a one hour interval when coal feed is first introduced but remain in compliance thereafter. $\mathrm{NO}_{\mathrm{x}}$ emissions are in compliance throughout the start-up.

Figures 7-28 and 7-30 show the rate of change for drum metal and turbine first stage metal cover temperatures during the hot restart. The former remains within recommended limits while turbine metal cover temperatures go through a transient similar to that reported during a warm restart when steam flow is first initiated to the turbine. It is not certain what effects this brief temperature transient has on turbine life. 
Section 8

LOAD FOLLOWING AND RATE OF LOAD CHANGE

This section summarizes results from a series of 16 dynamic response tests. During these tests, the output of the new 74 MWe turbine-generator was ramped at various rates of load change. These changes were made in both directions (i.e., increasing and decreasing load) over two magnitudes of total load change. The intent of this testing was to identify rate limiting factors in CFB boiler response to turbine load changes. Results indicated limitations at 7 MWe/min for some tests due to drum level control. Part of this limitation is believed to be correctable with improved accuracy of the final steam flow measurement used in three-element drum level control. No $\mathrm{CFB}$-related ramp rate limitations were evident at $7 \mathrm{MWe} / \mathrm{min}$.

\subsection{OBJECTIVES AND APPROACH}

The objectives of this plan were to test the dynamic response characteristics of the Nucla CFB to determine its capability to respond to changes in steam flow requirements demanded by load following operating modes. In particular, the intent was to define any rate limiting factors to load response that may be CFB-related or unique to the Nucla CFB design. Of particular concern at the outset of testing was the large thermal mass of a CFB boiler in both the refractory and circulating bed material. During load changes, fluidizing velocities change in the boiler, which affect solids recirculation and density profiles. This, in turn, alters heat transfer to the water walls and superheaters in the combustion chamber, and to superheater and economizer surface in the convection pass.

To accomplish the objectives of the Dynamic Test Plan, 16 tests were conducted at $\pm 1, \pm 3, \pm 5$, and $\pm 7 \mathrm{MWe} / \mathrm{min}$ ramp rates over 20 MWe and 40 MWe magnitude changes. Load changes were made on the new 74 MWe turbine only. Each of the three 12 MWe turbines were held at constant 36 MWe output for each of the tests. All downward ramps were initiated from 110 MWe and all upward ramps terminate at 110 MWe gross unit outpit.

Load ramps are accomplished by setting the final load setpoint and the desired rate of load change on the plant's distributed control system. Upon actuation of the control system to the new setpoints, the following occurs: 1) the MWe ramp generator begins to ramp toward the new load demand setting at a rate determined by the load ramp setpoint, 2) 
the turbine load controller drives the governor valves to a position where the unit load equals the output of the MWe ramp generator, and 3 ) the boiler master then adjusts fuel and air flows to maintain steam throttle pressure at 1450 psig. Aị flow is then trimmed to maintain 2.3 vol.\% $\mathrm{O}_{2}$ at the economizer outlet.

The maximum rate of load change suggested by the turbine manufacturer on the new 74 MWe turbine is $10 \%$ of rated capacity. This limits dynamic testing on the Nucla CFB to 7 MWe/min, which was the maximum rate tested.

\subsection{TEST MATRIX}

Table 8-1 summarizes the load response tests completed during the course of the Phase I and Phase II test programs. Data from tests at 1,3 , and $5 \mathrm{MWe} / \mathrm{min}$ ramp rates are presented in the Annual Reports. There were no rate limiting factors during these tests. Only data from tests conducted at 7 MWe/min are presented in this report.

Figure 8-1 shows a schematic of the turbine arrangement at the Nucla CFB. The new 74 MWe turbine is shown with controlled automatic extraction of 600 psig steam to the three existing 12.5 MWe turbines. The condensate from each of the 12.5 MWe turbines is forwarded through its own low pressure feed water heater and deaerator before being transferred to the new unit 4 deaerator storage tank. For a complete description of the unit design, see Report No. CA-C6.3, Detailed Public Design Report of the Nucla CFB.

\section{Table 8-1. Summary of Lهad Response Tests}

\begin{tabular}{|c|c|c|c|c|c|}
\hline Test \# & Date & Ramp Rate & Magnitude & Erom & Io \\
\hline D01 & $01 / 02 / 90$ & $1 \mathrm{MWe} / \mathrm{min}$ & -20 & 110 & 90 \\
\hline $\mathrm{DO} 2$ & $01 / 02 / 90$ & $1 \mathrm{MWe} / \mathrm{min}$ & +20 & 90 & 110 \\
\hline D03 & $01 / 03 / 90$ & $1 \mathrm{MWe} / \mathrm{min}$ & -40 & 110 & 70 \\
\hline D04 & $0.1 / 03 / 90$ & 1 MWe/min & +40 & 70 & 110 \\
\hline DO5 & $01 / 04 / 90$ & 3 MWe/min & -20 & 110 & 90 \\
\hline D0 6 & $01 / 04 / 90$ & $3 \mathrm{MWe} / \mathrm{min}$ & +20 & 90 & 110 \\
\hline D07 & $01 / 04 / 90$ & 3 MWe/min & -40 & 110 & 70 \\
\hline D08 & $01 / 04 / 90$ & 3 MWe/min & +40 & 70 & 110 \\
\hline D09 & $01 / 05 / 90$ & 5 MWe/min & -20 & 110 & 90 \\
\hline D10 & $01 / 05 / 90$ & $5 \mathrm{MWe} / \mathrm{min}$ & +20 & 90 & 110 \\
\hline D11 & $01 / 05 / 90$ & 5 MWe/min & -40 & 110 & 70 \\
\hline D12 & $01 / 05 / 90$ & 5 MWe/min & +40 & 70 & 110 \\
\hline LF 1 & $12 / 20 / 90$ & 7 MWe/min & -20 & 110 & 90 \\
\hline LF2 & $12 / 20 / 90$ & 7 MWe $/ \mathrm{min}$ & +20 & 90 & 110 \\
\hline $\operatorname{LF} 3$ * & $12 / 20 / 90$ & $7 \mathrm{MWe} / \mathrm{min}$ & -40 & 110 & 70 \\
\hline LF 4 & $12 / 20 / 90$ & $7 \mathrm{MWe} / \mathrm{min}$ & +40 & 70 & 110 \\
\hline
\end{tabular}




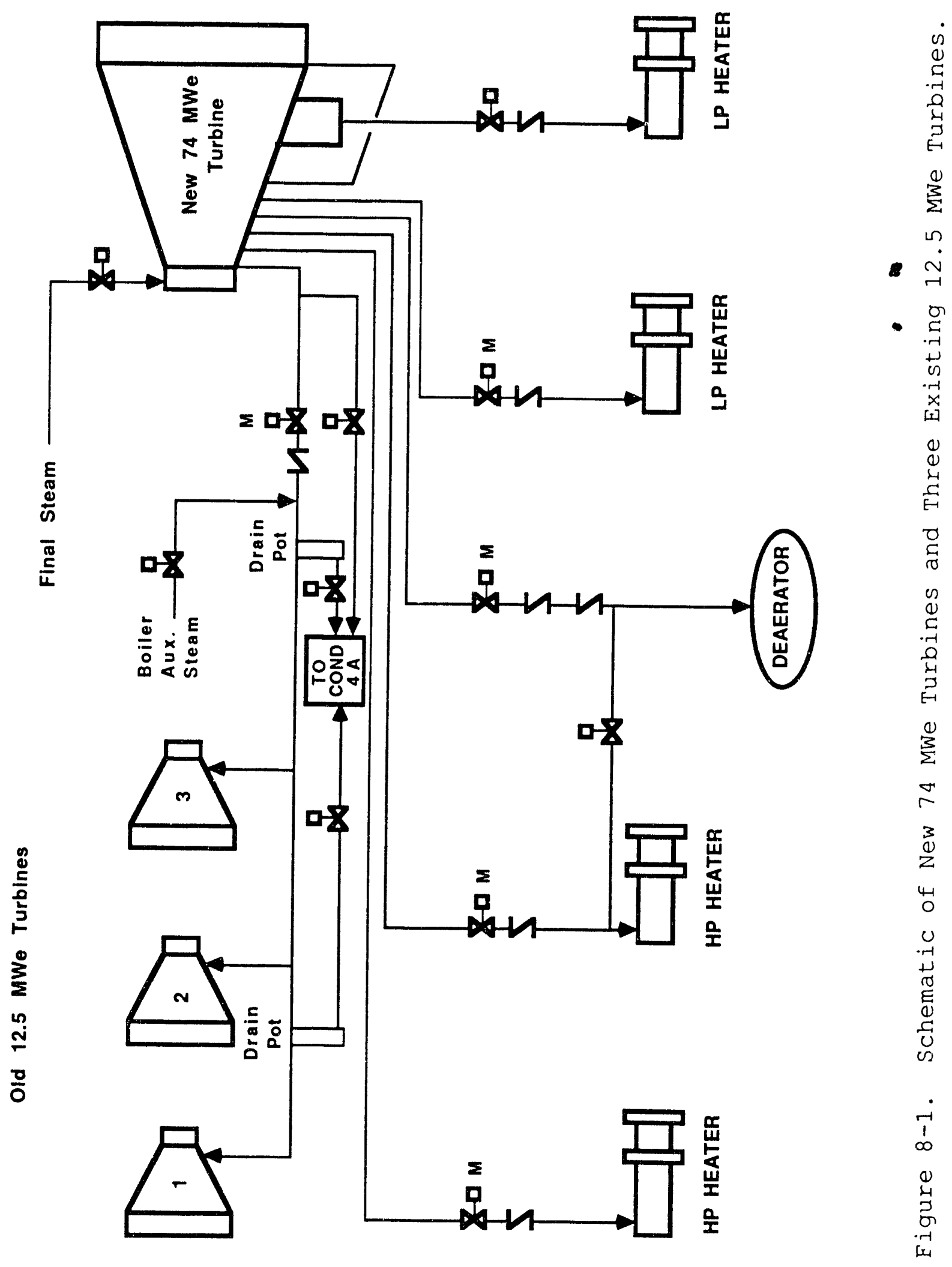


Note that it is not the intent of this section to provide a detailed analysis of the plant's control system. Rather, the intent is to identify rate limiting factors that may be CFBrelated.

\section{3 TEST RESULTS}

Figures 8-2 through 8-13 summarize real-time data for key operating variables during tests LF1, LF2, LF3, and LF4. Each of these four tests can be seen in these figures from data on 12/20/90. The curves represent raw data collected at 30 second intervals. The following is a summary of data presented in the figures:

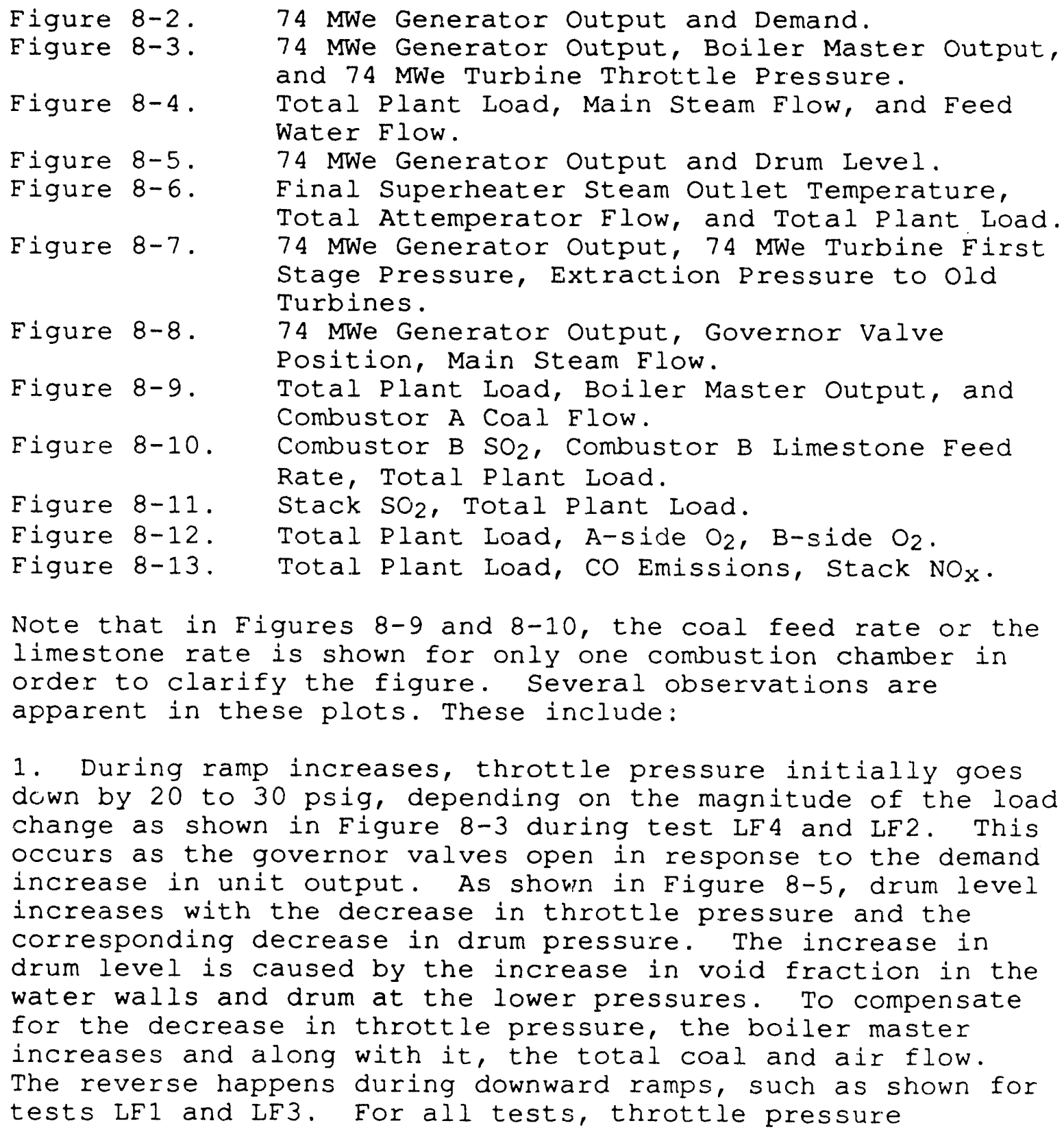

Note that in Figures $8-9$ and 8-10, the coal feed rate or the limestone rate is shown for only one combustion chamber in order to clarify the figure. Several observations are apparent in these plots. These include:

1. During ramp increases, throttle pressure initially goes down by 20 to 30 psig, depending on the magnitude of the load change as shown in Figure 8-3 during test LF4 and LF2. This occurs as the governor valves open in response to the demand increase in unit output. As shown in Figure 8-5, drum level increases with the decrease in throttle pressure and the corresponding decrease in drum pressure. The increase in drum level is caused by the increase in void fraction in the water walls and drum at the lower pressures. To compensate for the decrease in throttle pressure, the boiler master increases and along with it, the total coal and air flow. The reverse happens during downward ramps, such as shown for tests LF1 and LF3. For all tests, throttle pressure 


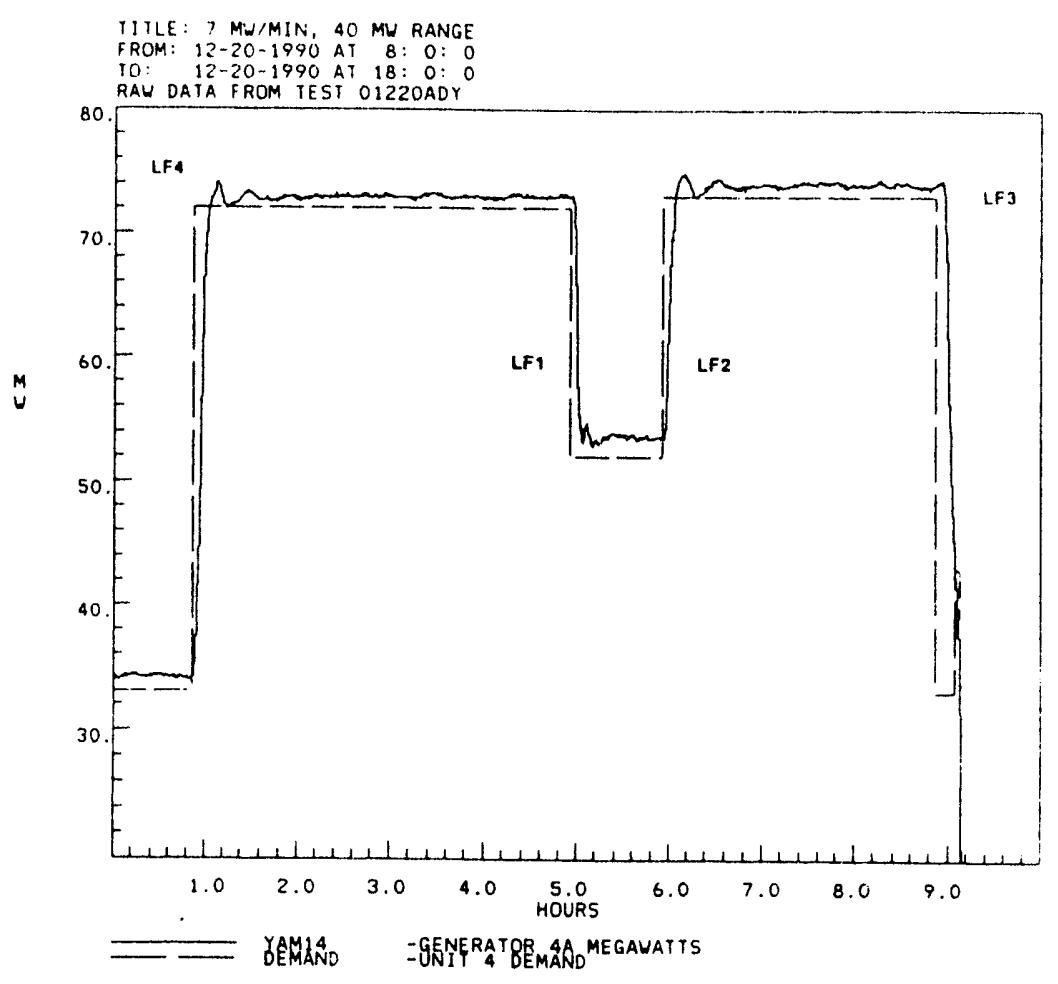

Figure 8-2. 74 MWe Generator Output and Demand.

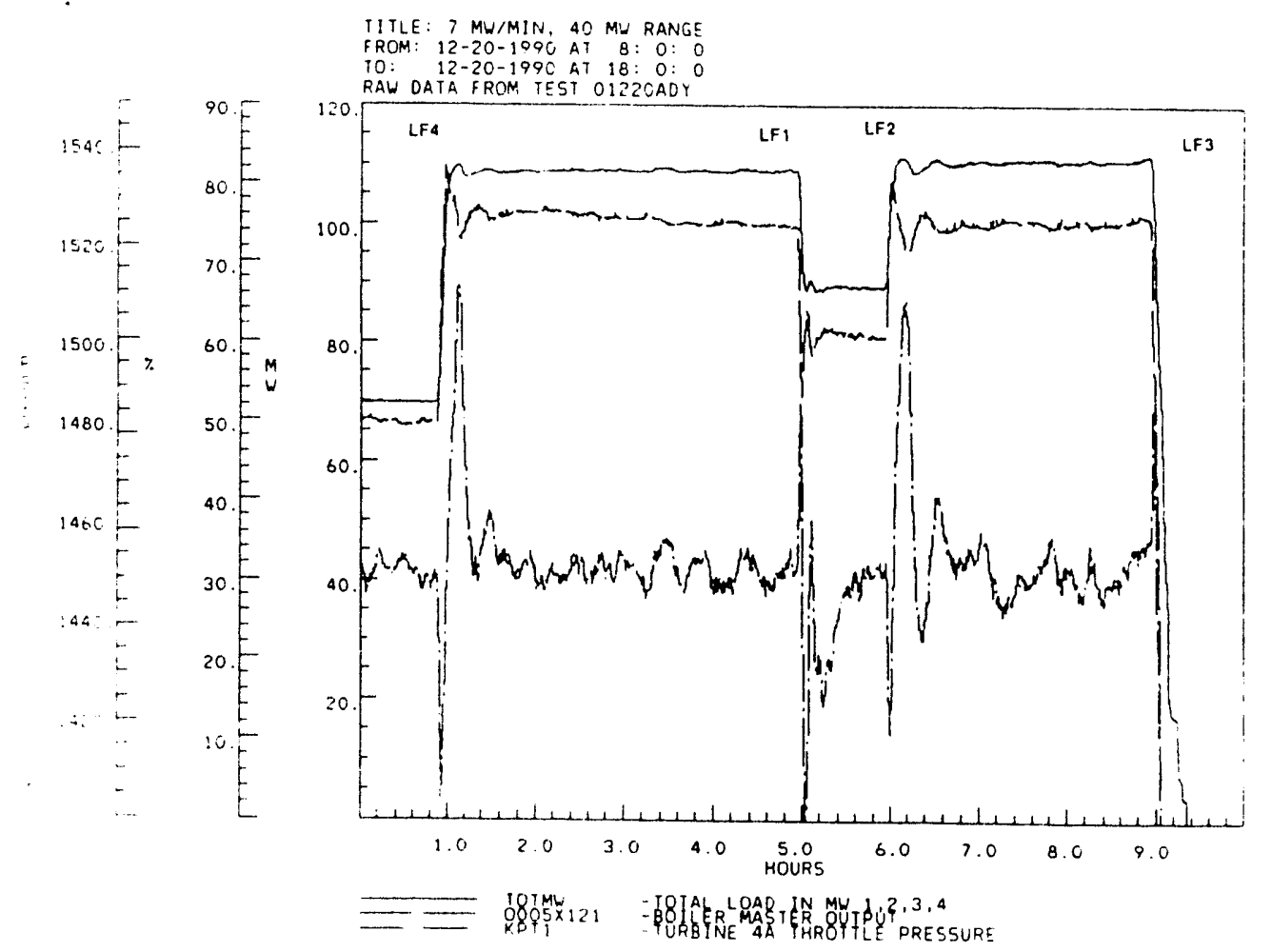

Eigure 8-3. 74 MWe Generator Output, Boiler Master Output, and Turbine Thrott $1 €$ Pressure. 


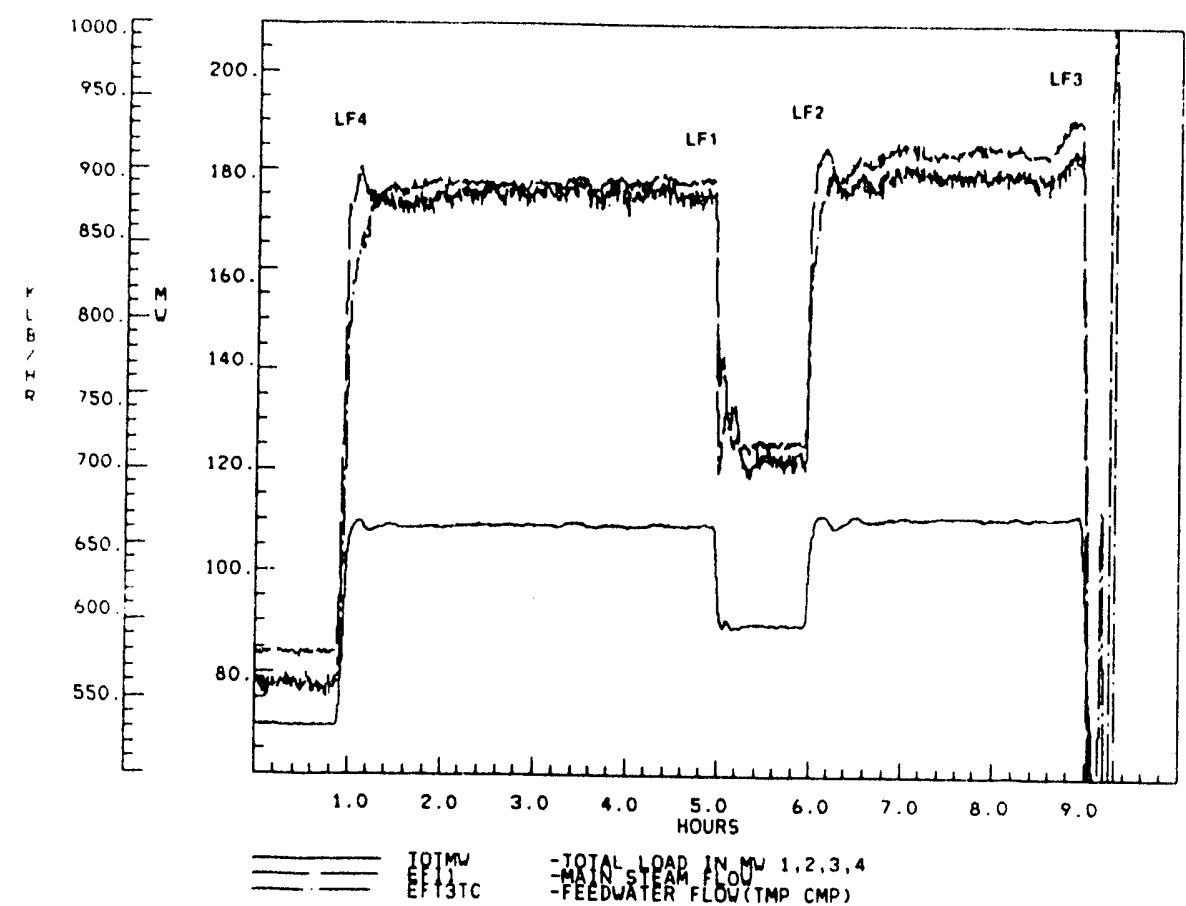

Figure 8-4. Total Plant Load, Main Steam Flow, and Feedwater Flow.

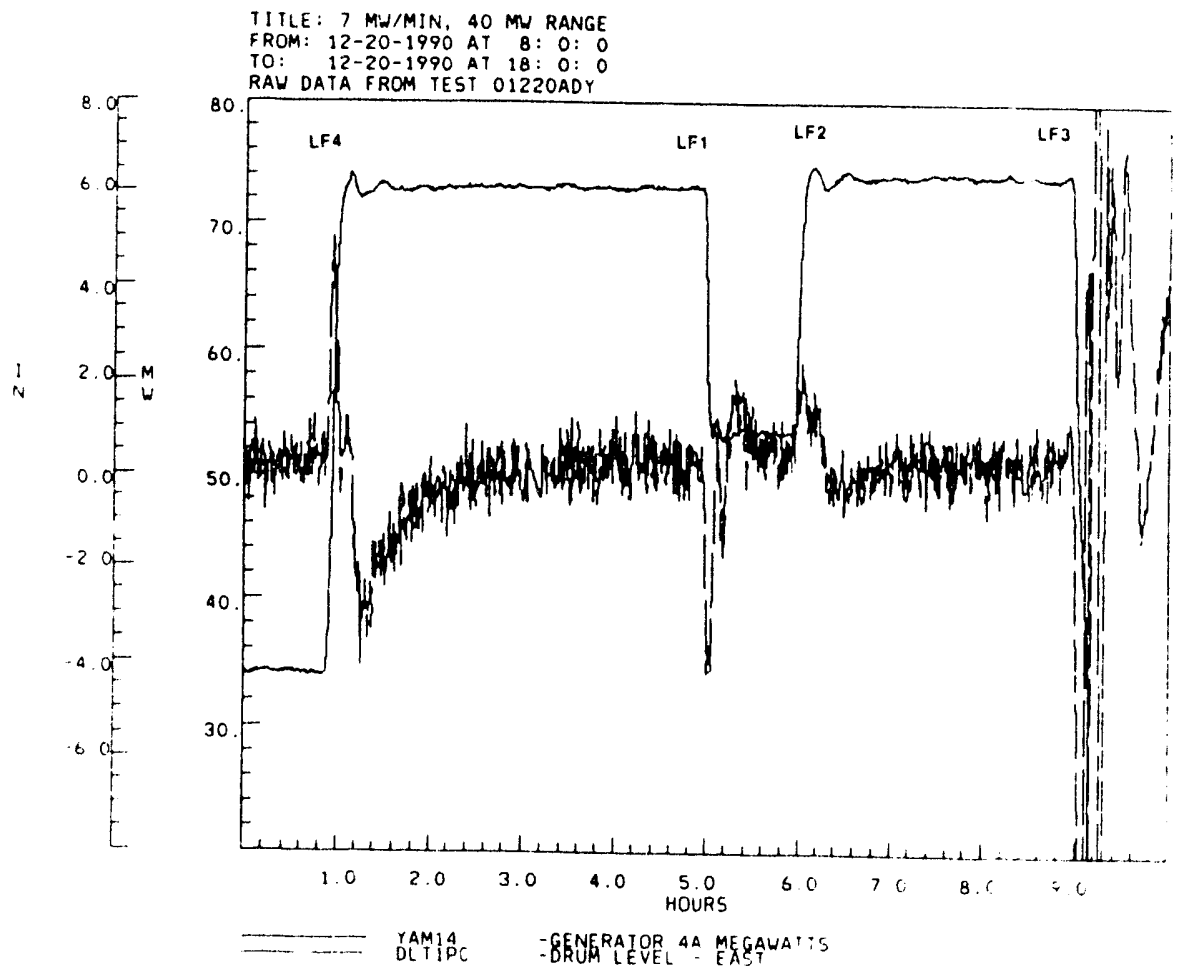

Figure 8-5. 74 MWe Generator output ard irumi level. 


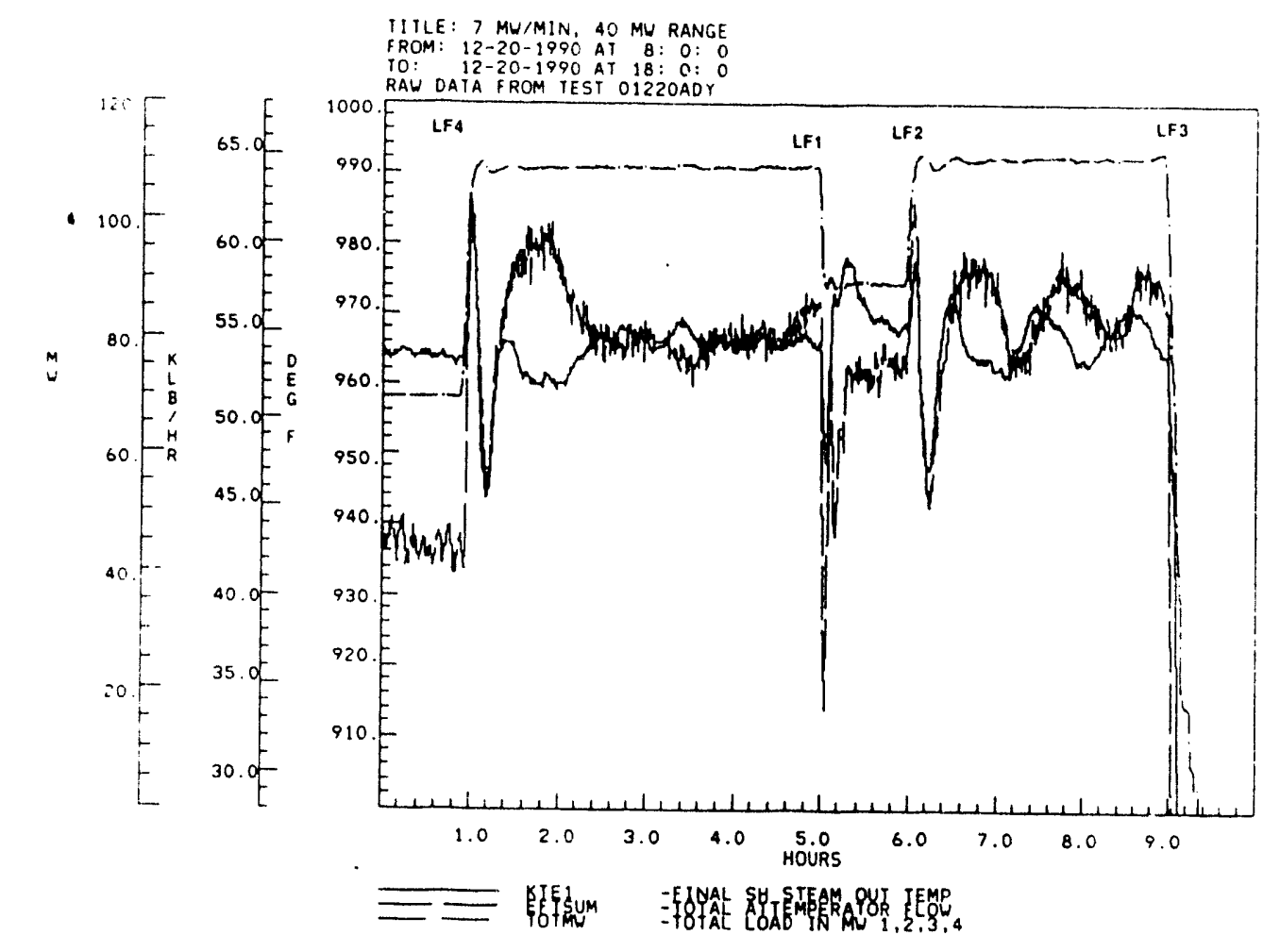
Figure 8-6. Final Superheater Steam Outlet Temp.,
Attemporator Flow, and Total Load.

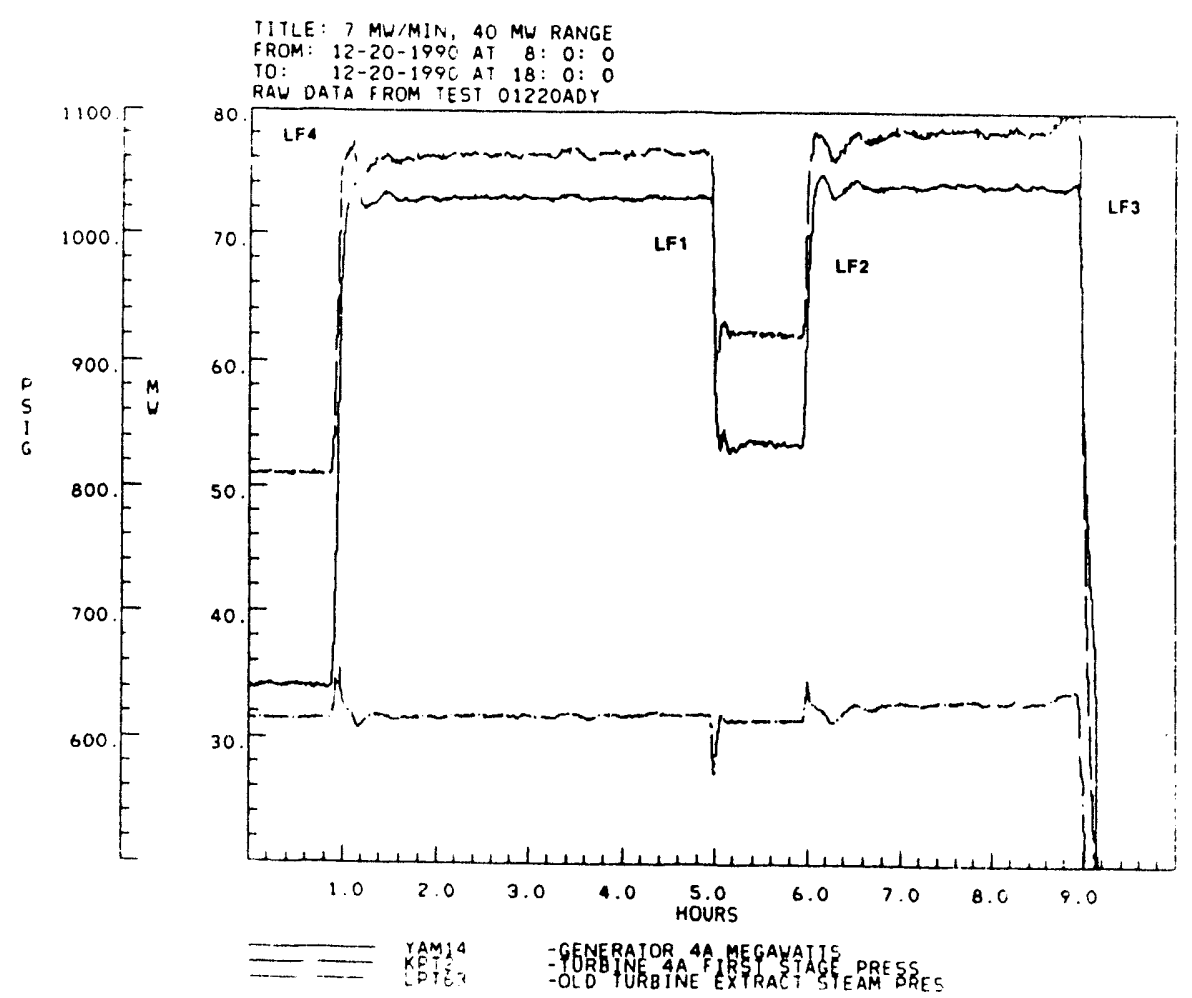

Figure 8-7. 74 MWe Generator Output, First stage Pressu Extraction Pressure to old Turbines. 


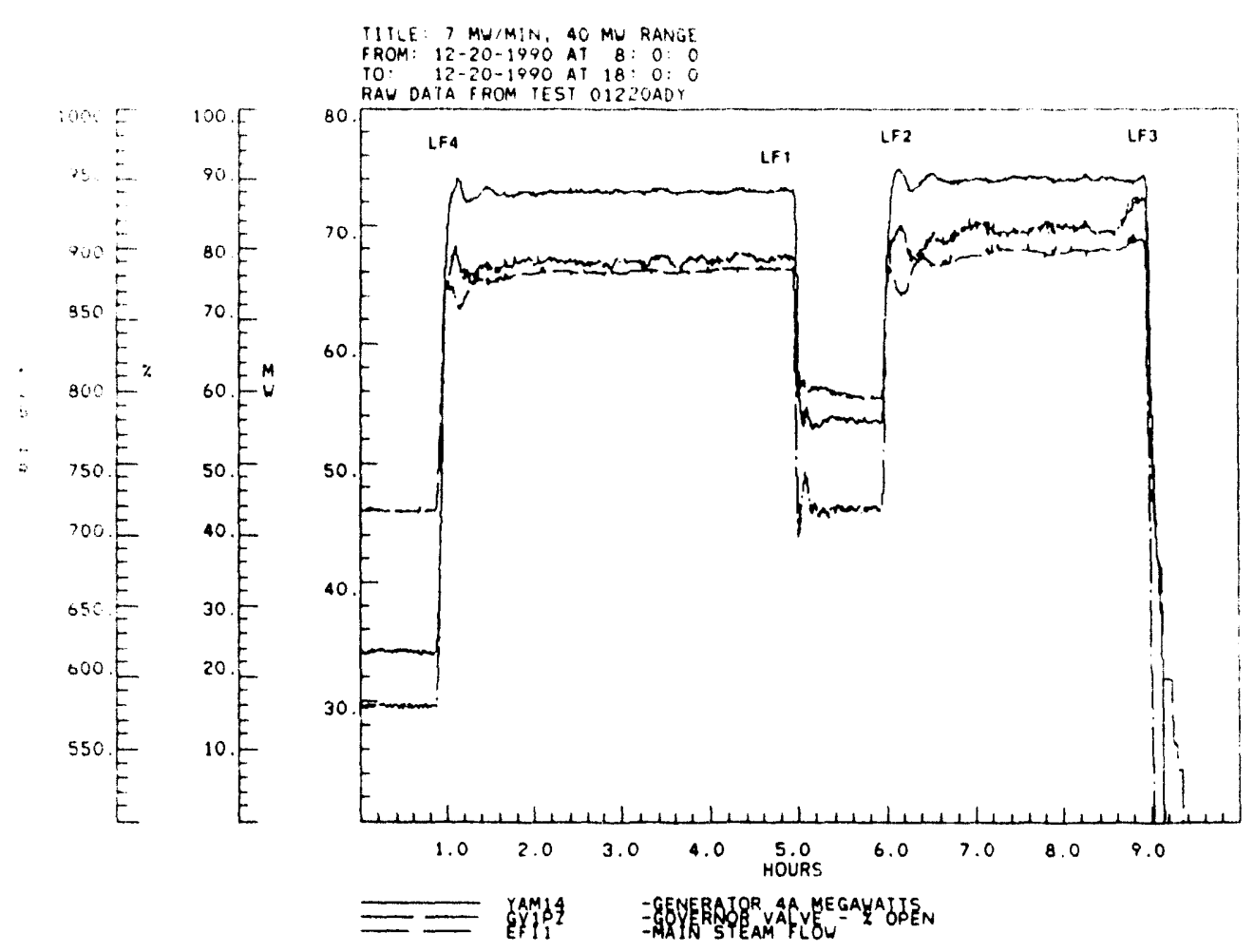

Figure 8-8. 74 MWe Generator Output, Governor Valve Position, Main steam Flow.

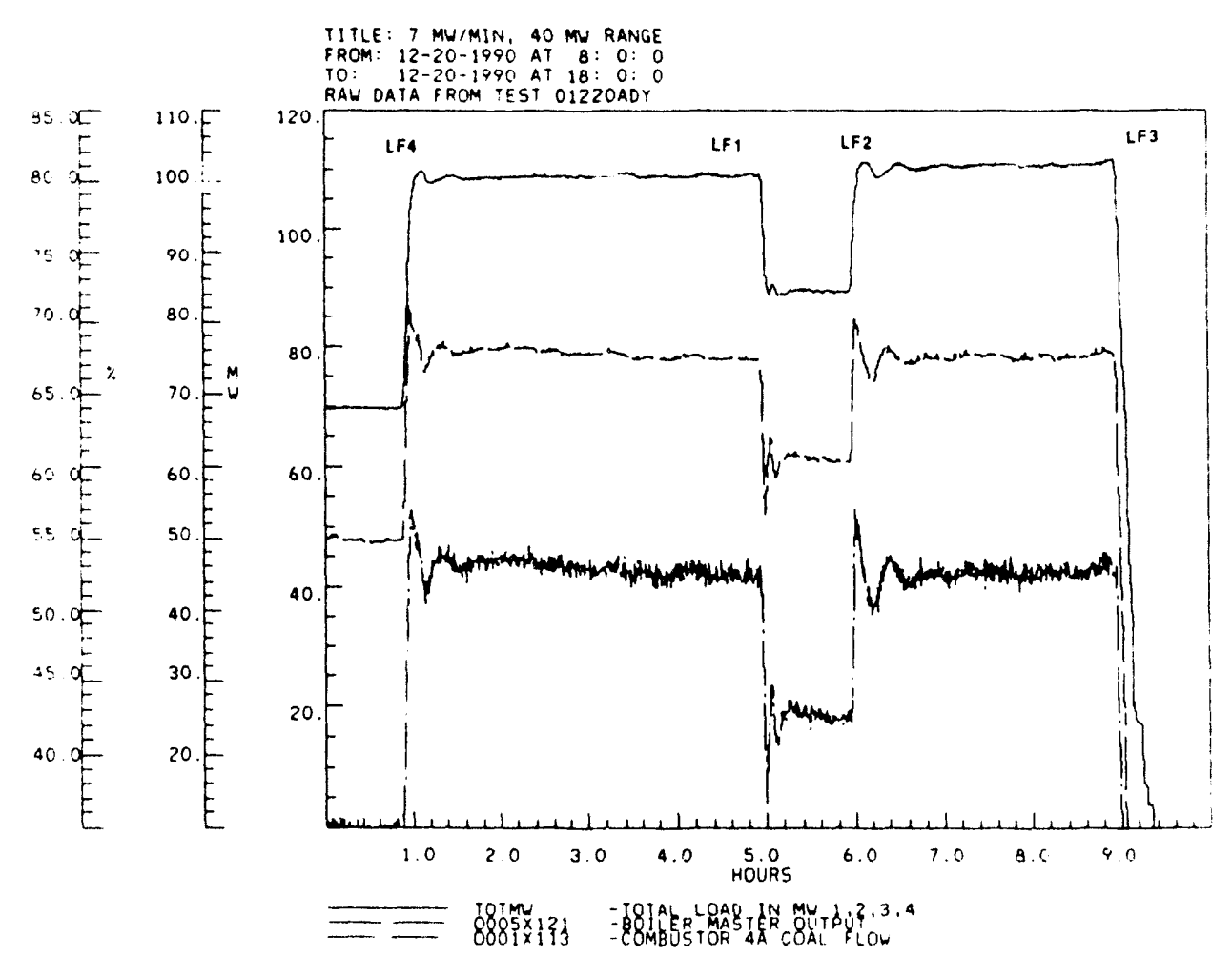

Figure 8-9. Total Plant Load, Boiler Master Output, and Combustor A Coal Flow. 


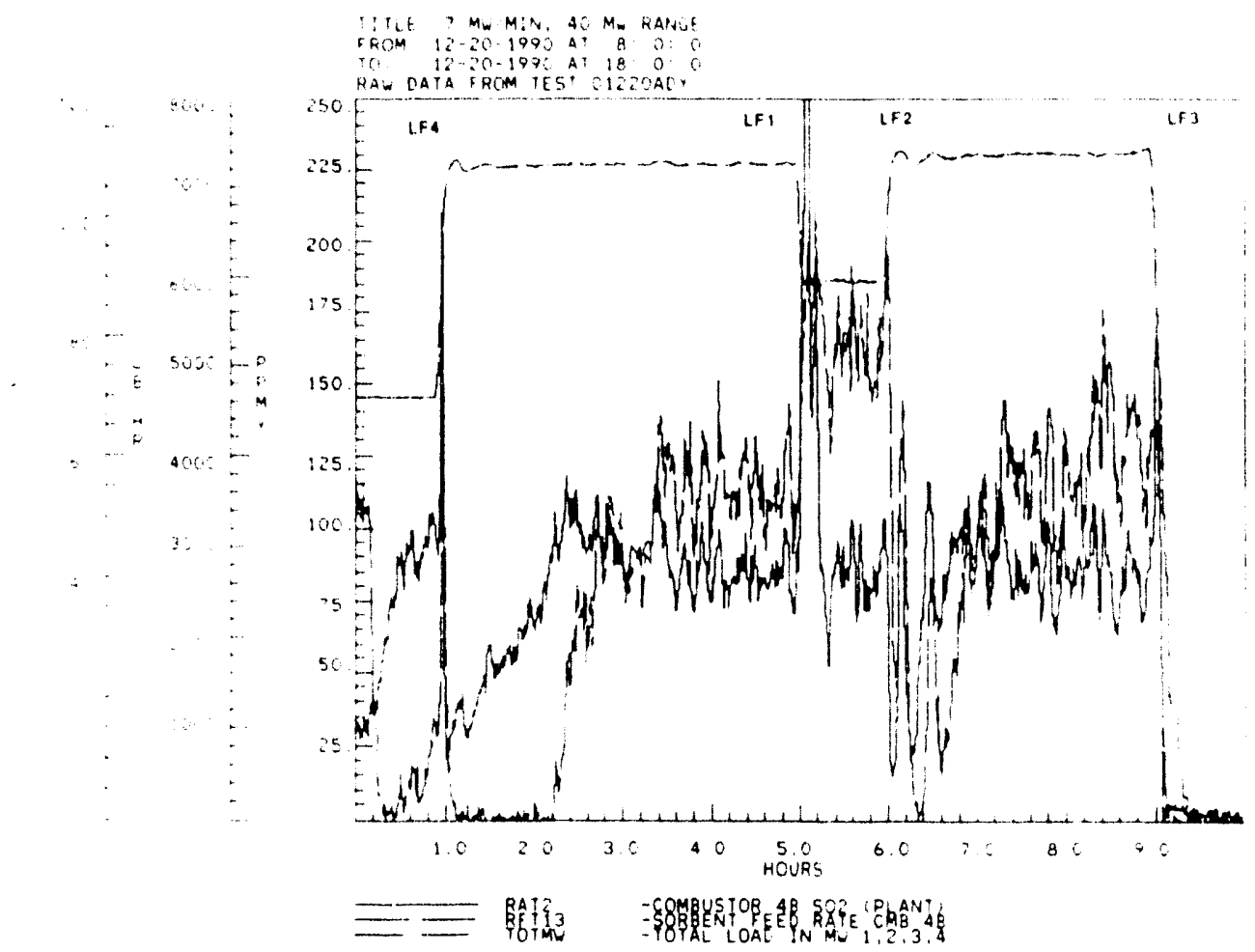

Eigure 8-10. Combustor $\mathrm{B} \mathrm{SO}_{2}$, Combustor $\mathrm{B}$ Limestone Feed Rate, Total Plant Load.

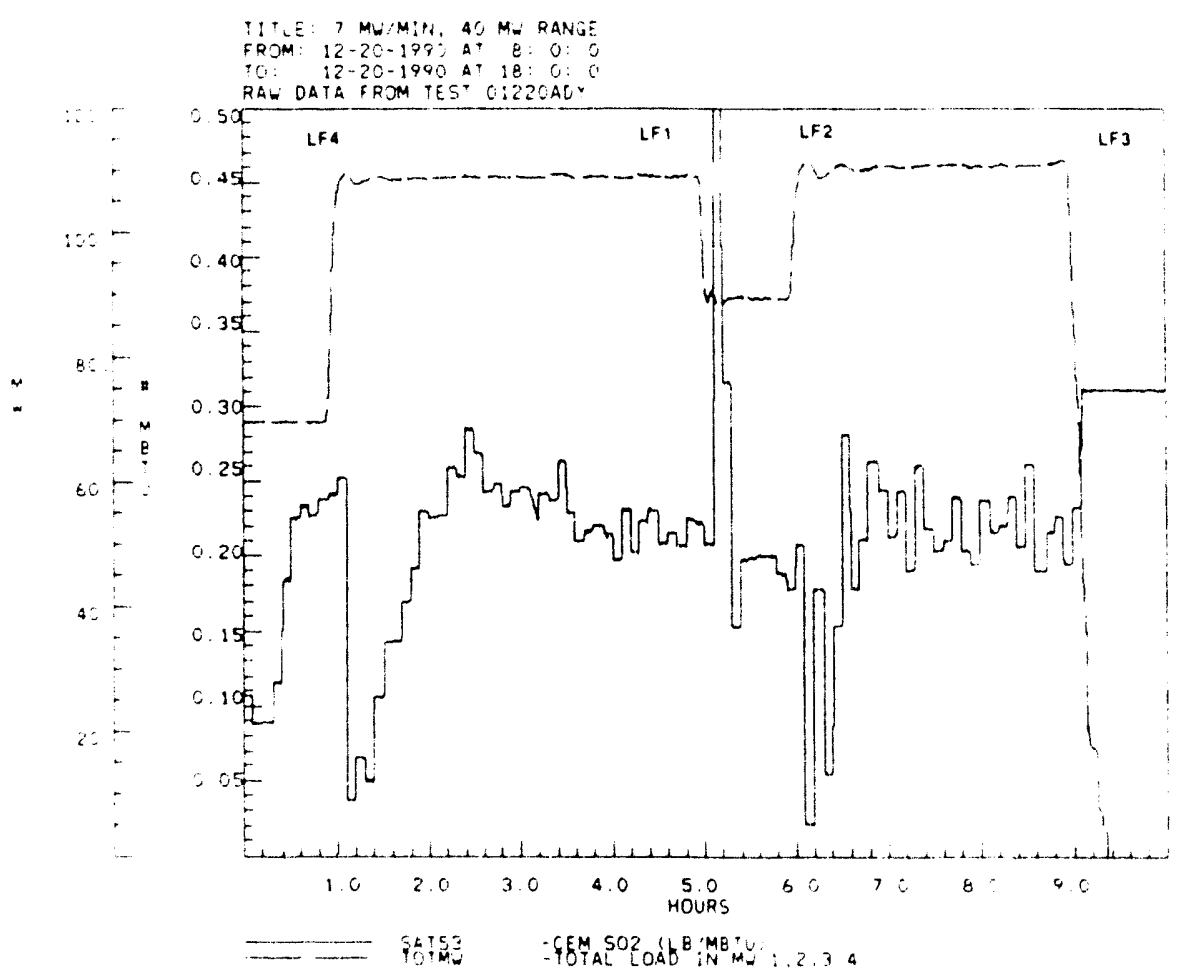

Figure 8-11. Stack 502, Total Plant Load. 


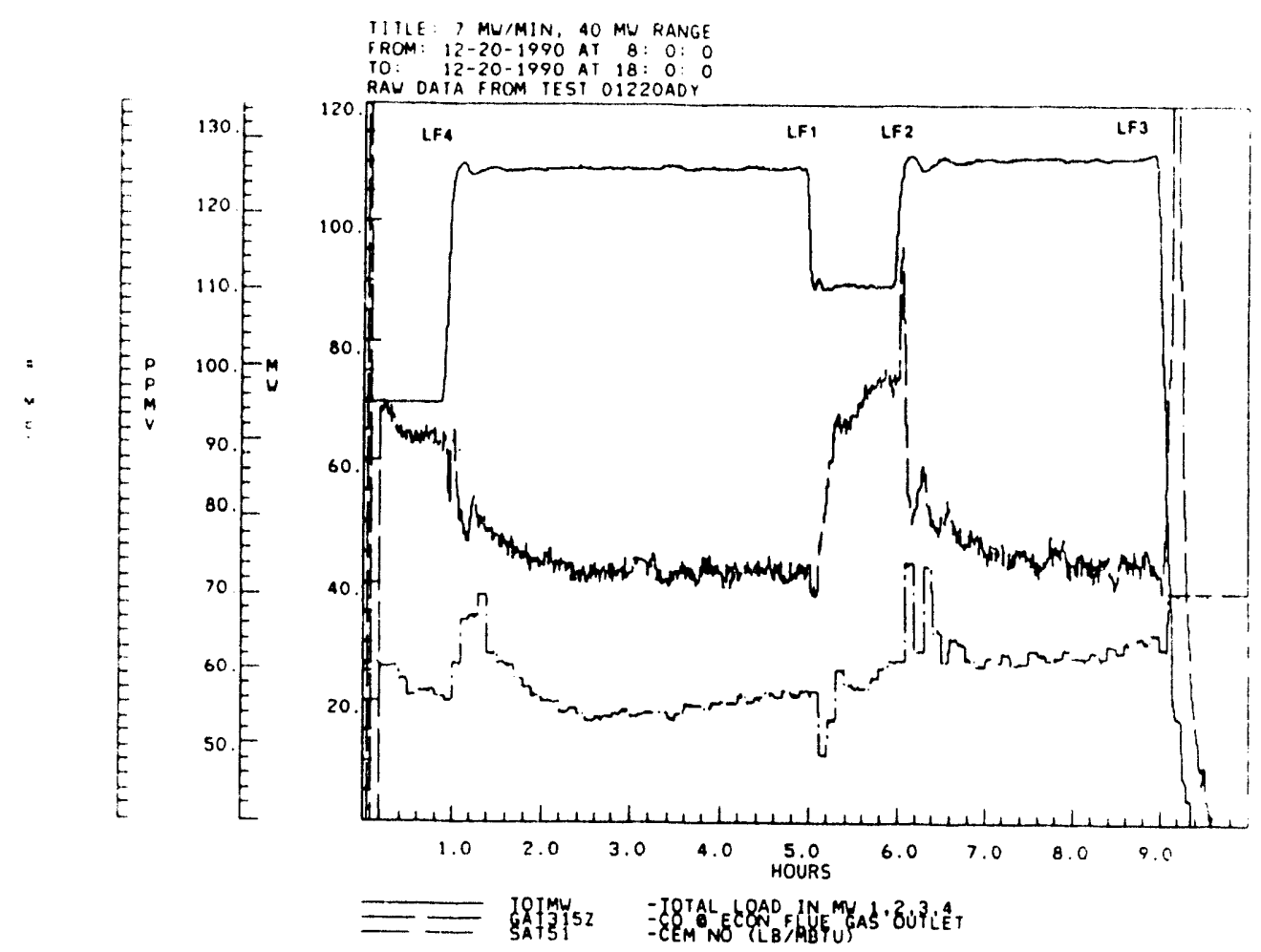

Figure 8-12. Total Plant Load, A-side $\mathrm{O}_{2}, \mathrm{~B}-$ side $\mathrm{O}_{2}$.

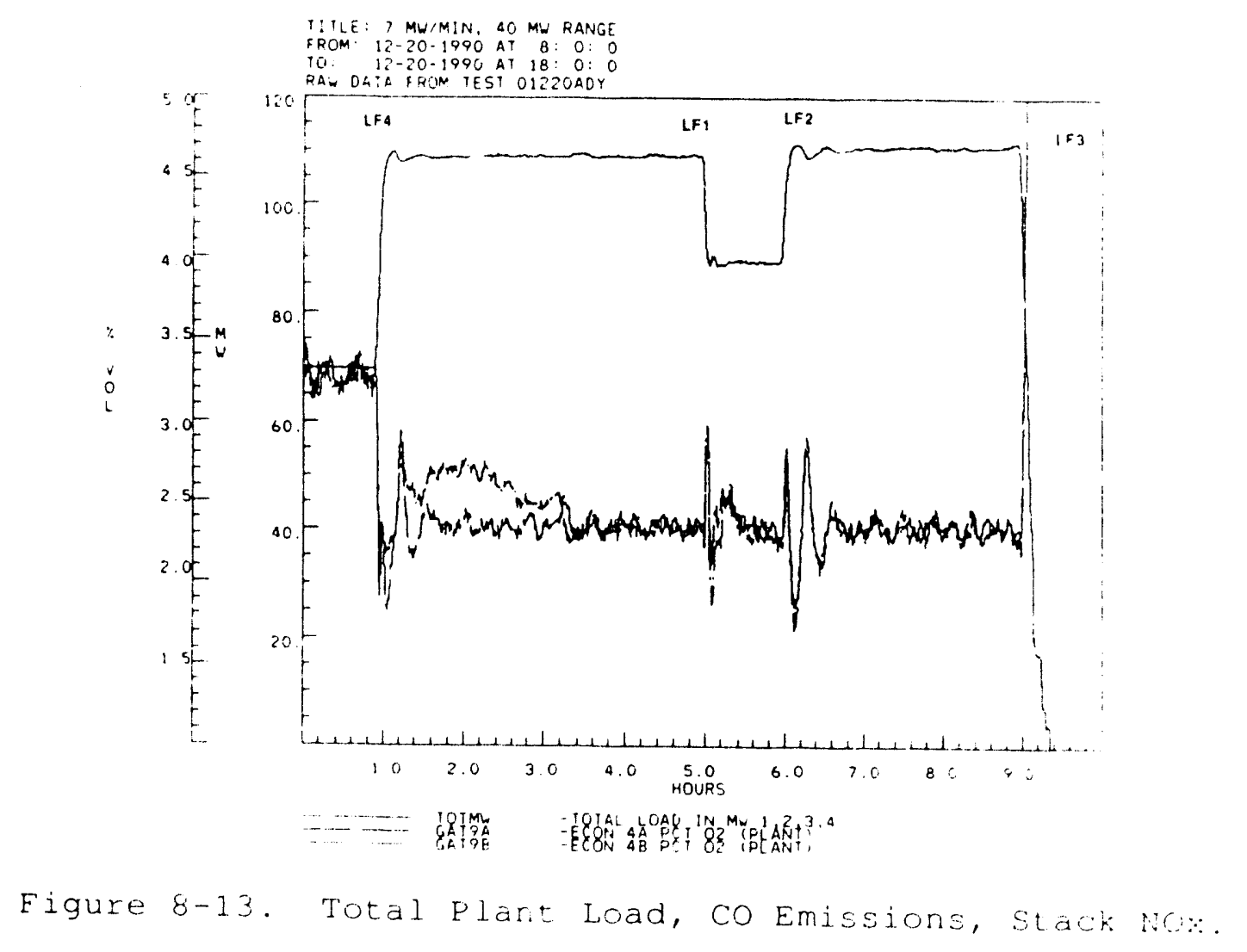


initially overshoots its target as the boiler master works towards returning it to $1450 \mathrm{psig.} \mathrm{Typically,} \mathrm{within} 30$ minutes of the initial load charge, oscillations in throttle pressure are dampened by the boiler master.

2. For these tests, the final steam temperature is approximately $960^{\circ} \mathrm{F}$. This is $40^{\circ} \mathrm{F}$ lower than the other load following tests as the result of increased attemperator spray flows. The change in attemperator spray flow logic was incorporated into the control system in october 1990 in order to lower secondary superheater metal temperatures and prevent tube failures associated with overheating, as discussed in Section 16. During load ramps upward; the final steam temperature increases as the boiler master increases firing rates to the combustors. As can be seen in Figure 8-6, attemperator spray flows also increase and then modulate to maintain secondary superheater outlet temperatures below 925 ${ }^{\circ} \bar{E}$.

3. In Figure 8-6, the first stage pressure on the 74 MWe turbine and the extraction pressure to the three existing 12.5 MWe turbines is shown for the four load response tests. During increases in load, the extraction pressure spikes upward approximately 30 psig for a 5 to 10 minute period before the auto-extraction valve dampens the oscillation back to the controlled setpoint of $600 \mathrm{psig}$. The reverse occurs during decreases in load. This fluctuation temporarily produces an erroneous steam flow indication, as will be discussed in section 8.4.

4. Figures $8-10$ and $8-11$ show the limestone feed rate to combustor $\mathrm{B}$, the in-plant $\mathrm{SO}_{2}$ measurement to combustor $\mathrm{B}$, and the $\mathrm{SO}_{2}$ measurement at the stack by the continuous emissions monitors. Note that following increases in load, $\mathrm{SO}_{2}$ emissions decrease significantly. Limestone feed rates also decrease since the $\mathrm{SO}_{2}$ measurement "trims" the feeder output to maintain emissions compliance. This functions in much the same way that the oxygen measurement trims the air flow dampers to maintain a pre-set excess air level.

This decrease in $\mathrm{SO}_{2}$ emissions is believed to result from the increased availability of stored calcium in the bed. At the higher fluidizing velocities accompanying the increase in load, this stored material becomes suspended higher in the combustion chanbers and is carried over to the cyclones, where the coarser material is captured and recirculated and the finer material escapes. During reductions in load, $\mathrm{SO}_{2}$ emissions tempurarily increase as the availability of suspended calcium-enriched bed material in the size range supported by the lower fluidizing velocities is now diminished. These temporary excursions in $\mathrm{SO}_{2}$ emissions could be eliminated by leading reductions in load with increased limestone feed. 
5. Co emissions, shown in Figure 8-13, increase during load reductions due to the decrease in combustor operating temperatures. NOx emissions, shown in the same figure, inc rease temporarily during load increases and exhibit the cpposite behavior during reductions in load. However, compliance is maintained during all load respunse tests.

Figure 8-14 represents the results from 40 MWe increases in: load for $1 \mathrm{MWe} / \mathrm{min}, 3 \mathrm{MWe} / \mathrm{min}, 5 \mathrm{MWe} / \mathrm{min}$, and $7 \mathrm{MWe} / \mathrm{min} \mathrm{ramp}$ tests. Note that from the initiation of the demand change in load to the first point of achieving the new setpoint, these tests averaged approximately $1.8,2.3,3.3$, and $3.9 \mathrm{MWe} / \mathrm{min}$, respectively. This is less than the ramp rate set point due to dampening effects of the control system on both ends of the overall load change. Taking the average slope in the middle portion of these curves, the ramp rates were approximately $2.2,3.2,5.6$, and $6.2 \mathrm{MWe} / \mathrm{min}$, respectively.

\subsection{MWe/MIN RAMP DECREASE OVER 40 MWe}

Figures 8-15 through 8-22 illustrate more detailed data from test LF3 compared to that presented above. Test LF3 was a downward ramp over 40 MWe from 110 MWe to 70 MWe at 7 MWe/min. During this test, the unit tripped on low drum level. Values in these figures represent data collected at 30 second intervals.

Figure 8-15. Test LF3 showing the 74 MWe Generator output
and Demand.

Figure 8-16. Test LF3 showing the Total Plant Output, Boiler Master output, and 74 MWe Turbine

Figure 8-17. Throttle Pressure.

Figure 8-17. Test LF3 showing the Total Plant Output, Main

Steam Flow, and Feed Water Flow.

Figure 8-18. Test LF3 showing the 74 MWe Generator Output

Figure 8-19. Test LF3 showing the 74 MWe Generator output, Governor Valve Posjtion, and the Main steam

Figure 8-20. Test LF3 showing the 74 MWe Generator Output, 74 MWe Turbine 1st Stage Pressure, and

Figure 8-21. Test LF3 showing the Combustor $\mathrm{A} \mathrm{SO}_{2}$ and

Figure 8-22. Limestone Feed Rate, and Total Plant Load. Final Steam Pressure and Temperature.

Following the change in load demand to. 70 MWe gross unit output and the initiation of the ramp rate at 7 MWe/min shown in Figure 8-i5, the governor valves begin to close as shown in Figure 8-19. As for other load reduction tests, this 


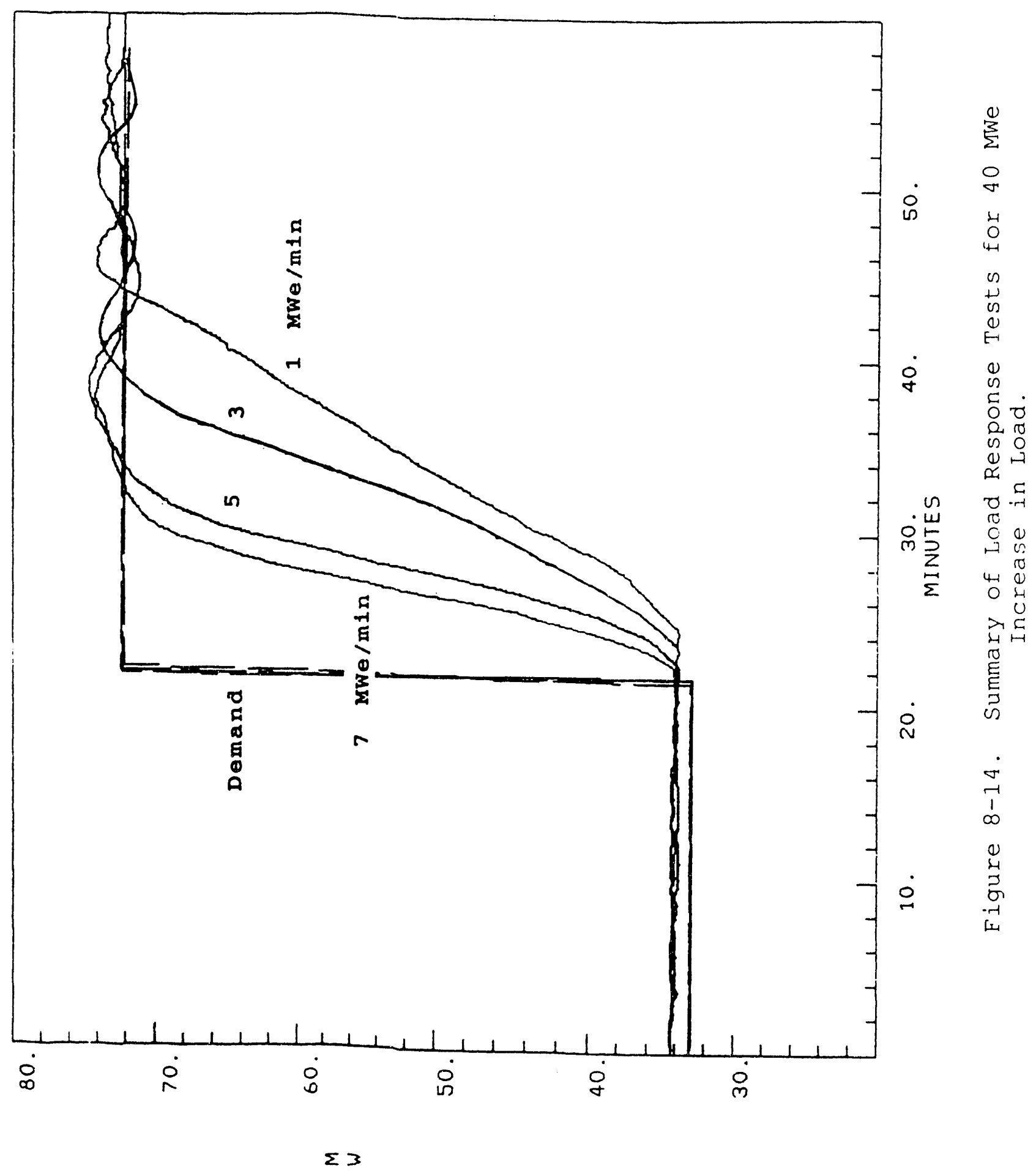




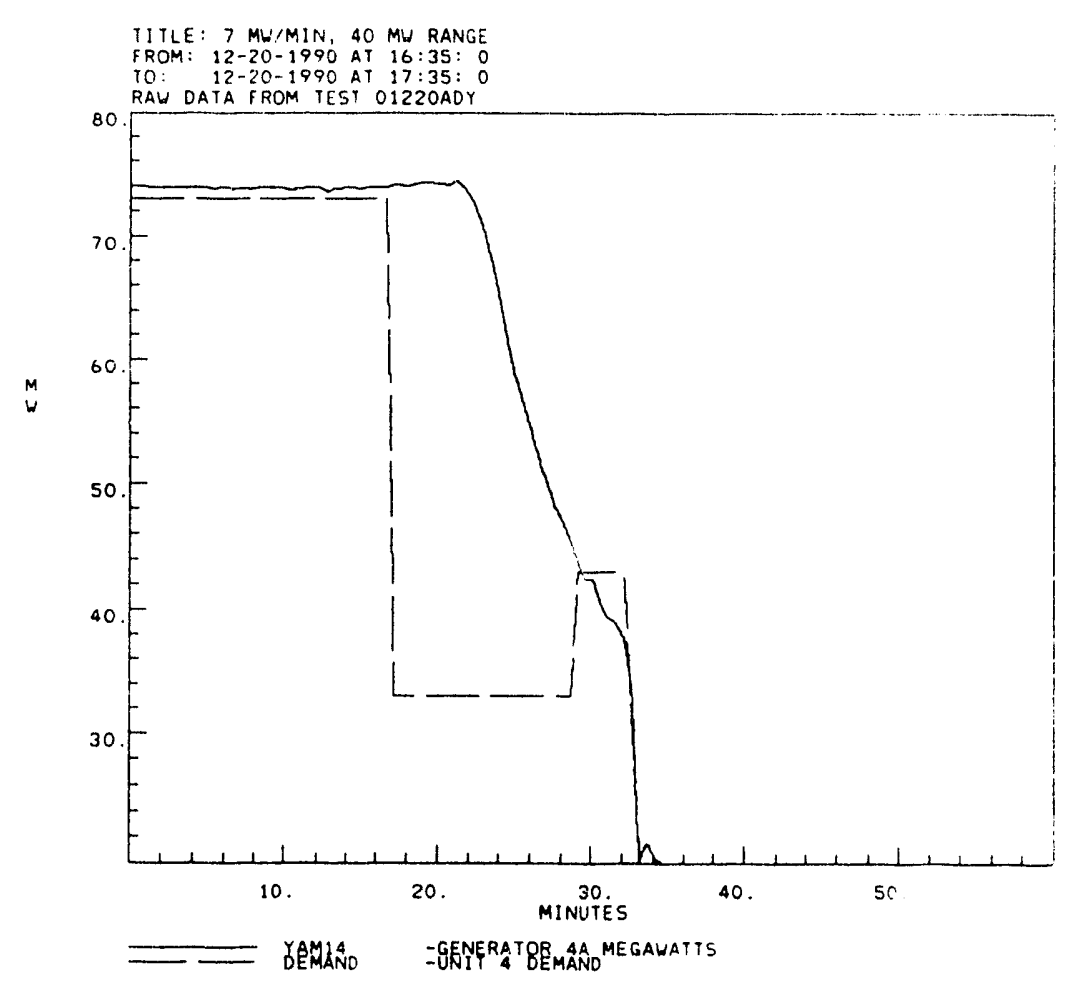

Figure 8-15. Test LF3: 74 MWe Generator Output and Demand.

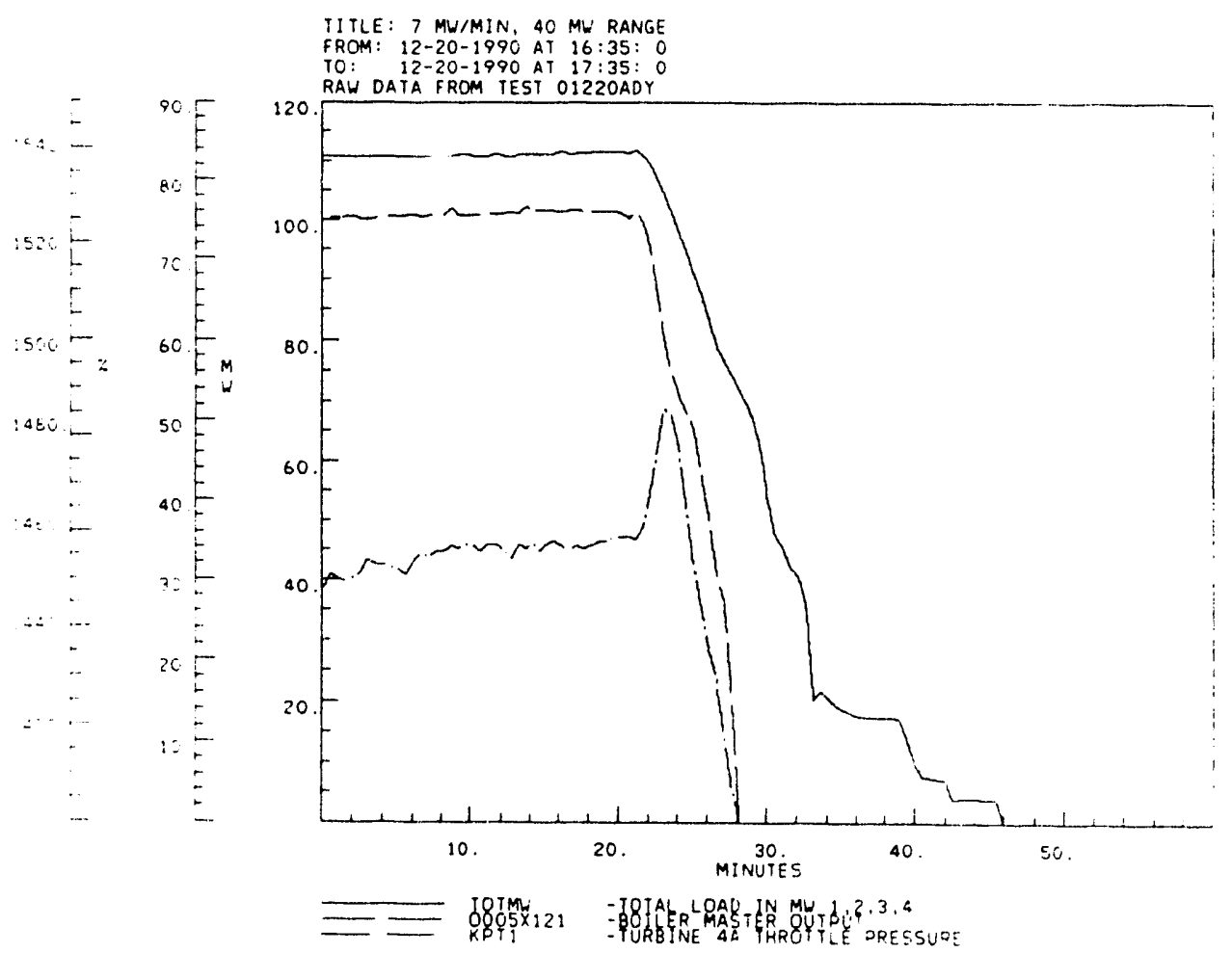

Figure 8-16. Test LF3: Total Plant Output, Boiler Master Output, and 74 MWe Turbine Thrott?e Eressire. 


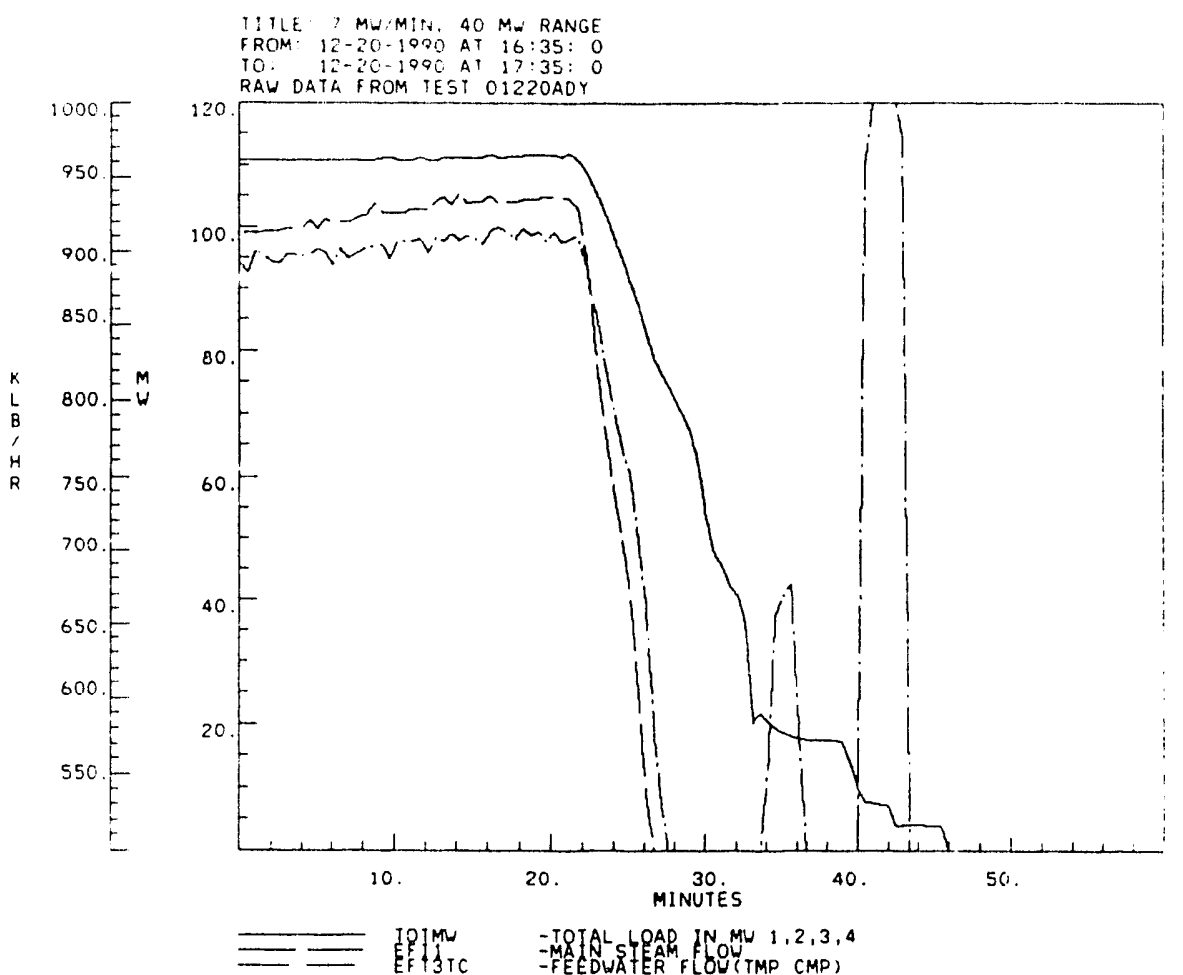

Figure 8-17. Test LF3: Total Plant Output, Main Steam Flow, and Feedwater Flow.

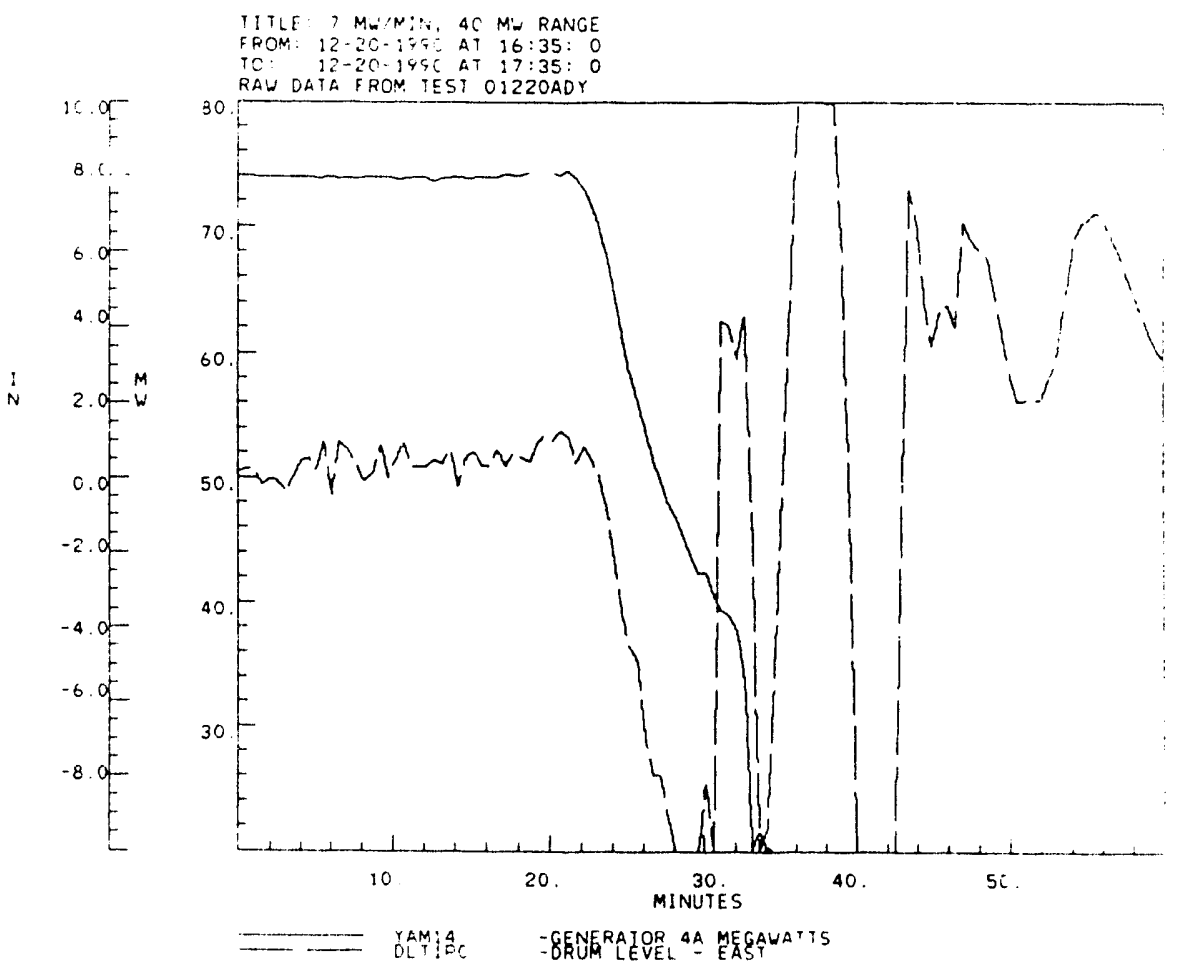

Figure 8-18. Test LF3: 74 MWe Generator Output and Drum Level. 


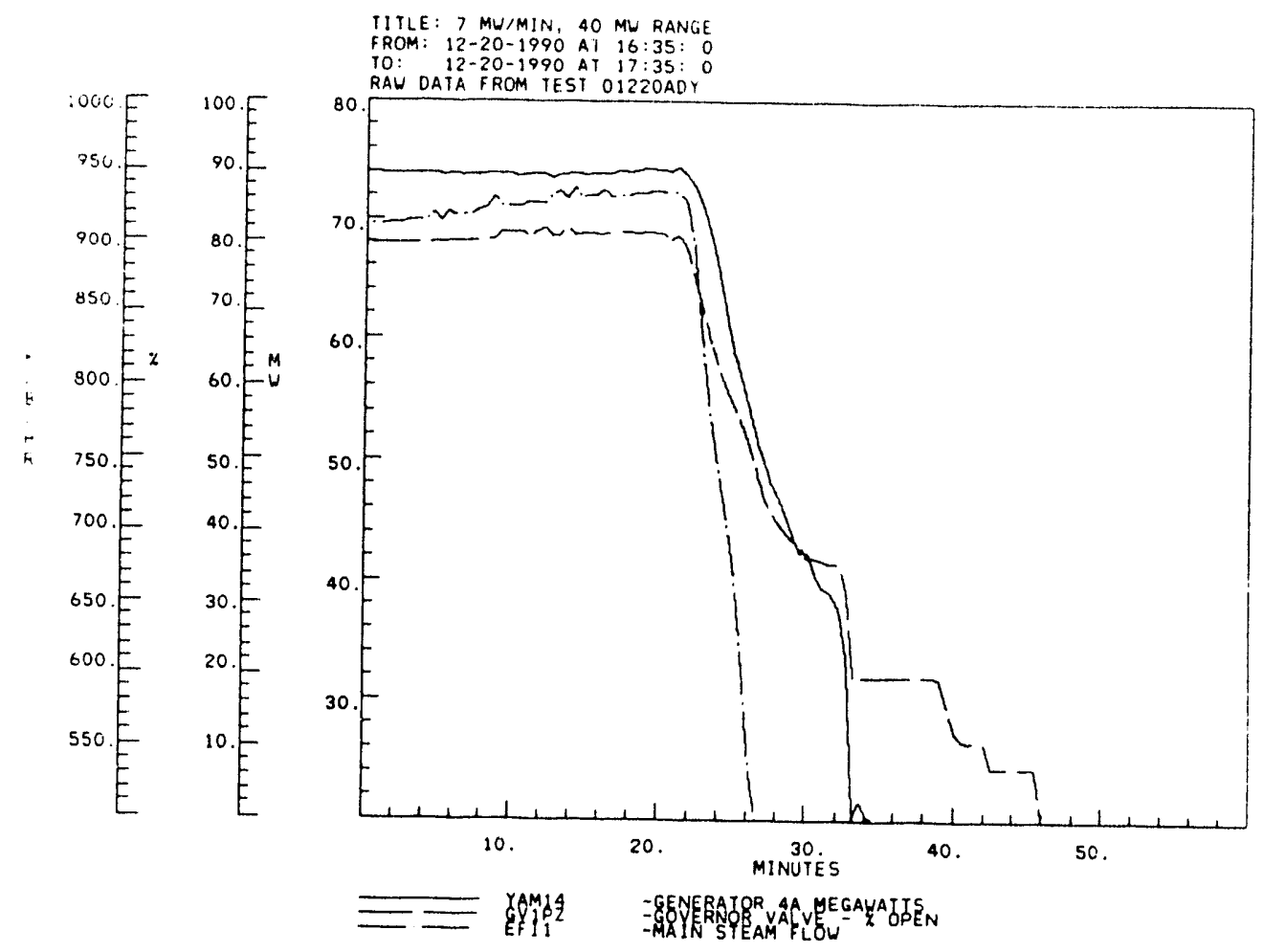

Figure 8-19. Test LF3: 74 MWe Generator Output, Governor Valve Position, and Main steam Flow.

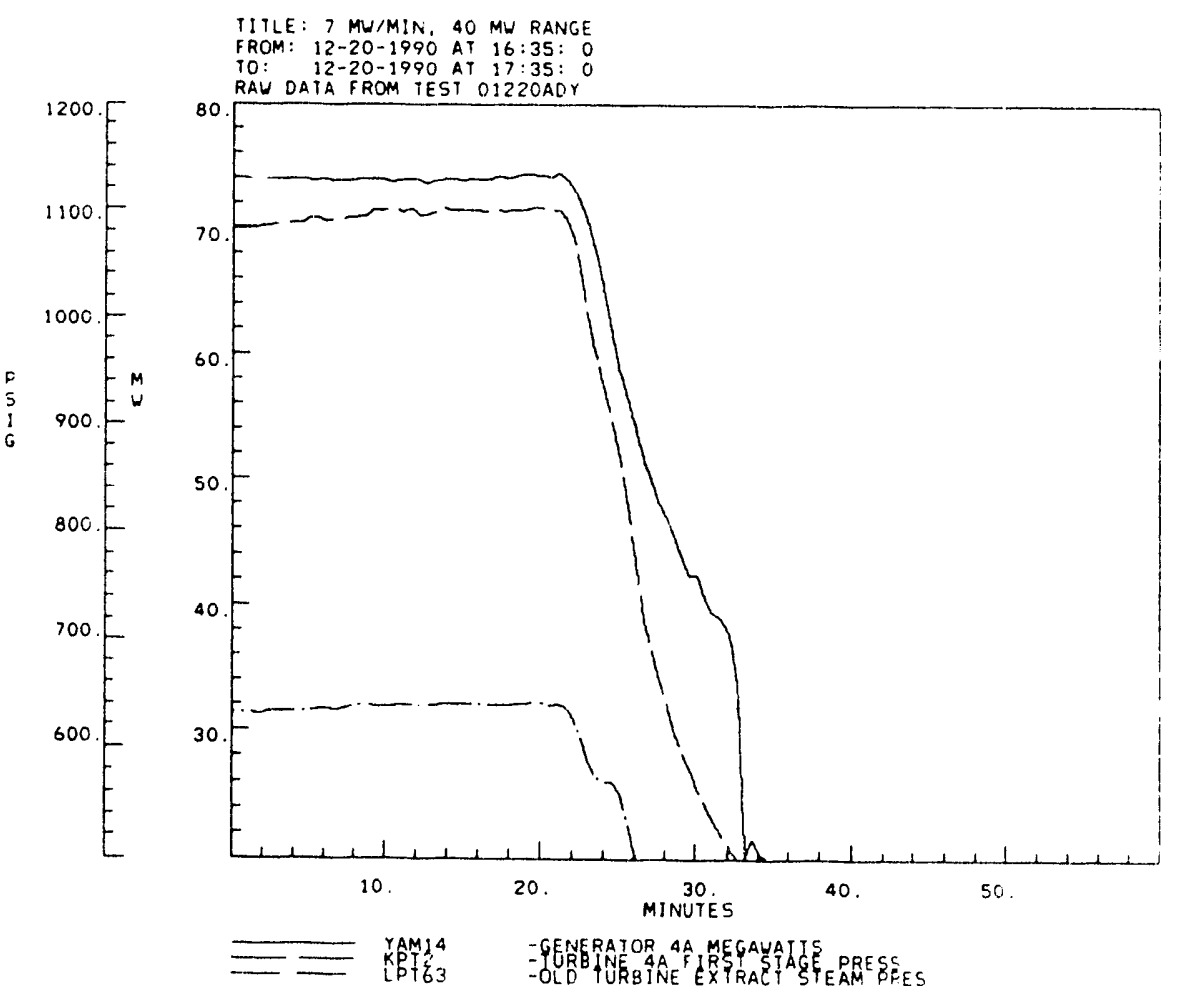

Figure 8-20. Test LF3: 74 MWe Generator output, 1st Stage Pressure, and Extraction Line Pressure. 


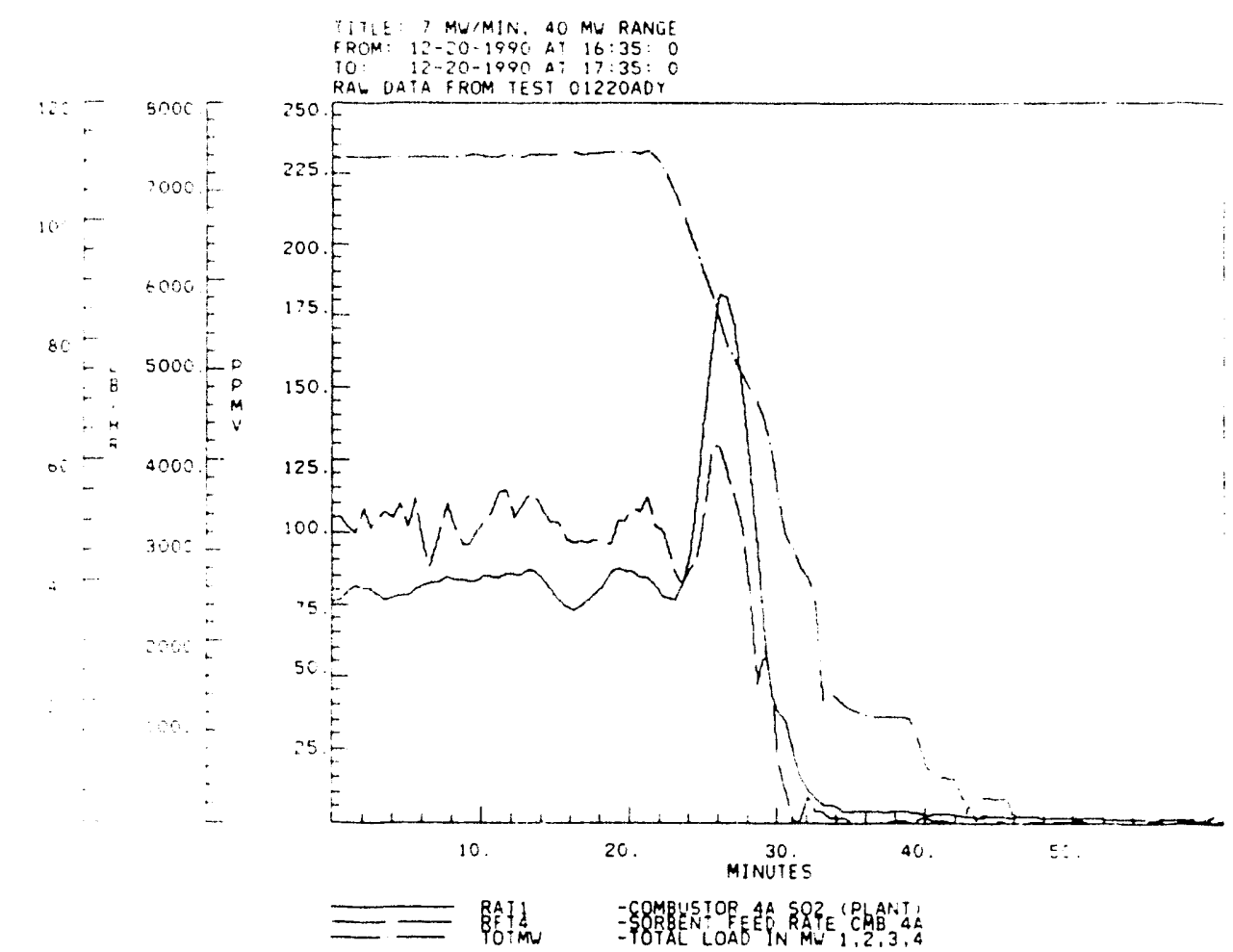

Figure 8-21. Test LF3: Combustor $\mathrm{A} \mathrm{SO}_{2}$ and Limestone Feed Rate, and Total plant Load.

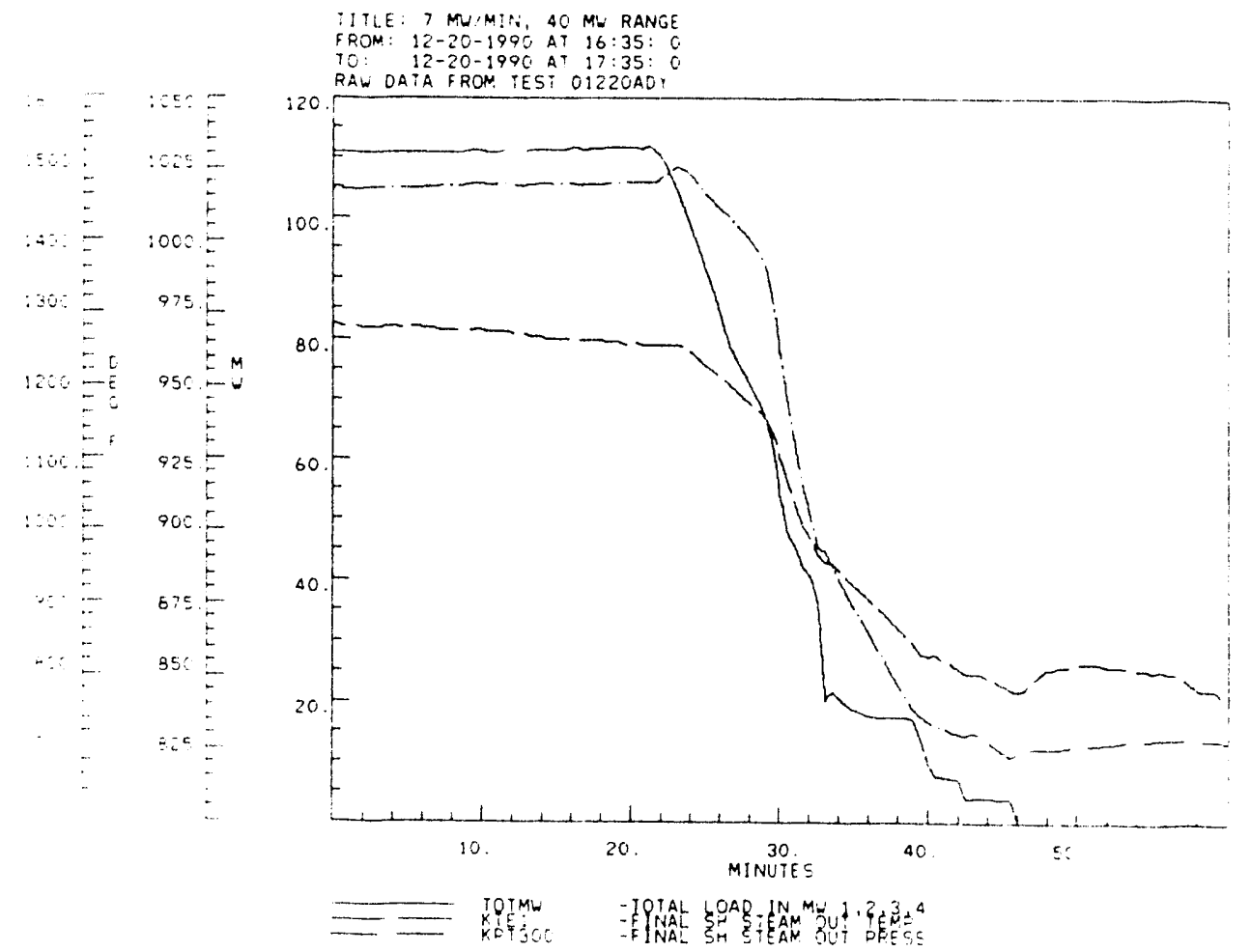

Figure 8-22. Test LF3: Total Plant Load, and Final Steam Pressure ard Temperature. 
results in an increase in throttle pressure shown in Figure 8-16 and a decrease in drum level shown in Figure 8-18.

Again, the corresponding increase in drum pressure results in collapsing steam voids in the drum and water walls. This void reduction causes an unavoidable drop in drum level.

Since the load to the three existing 12 MWe turbines remains constant at 36 MWe gross output, the same quantity of steam flow is taken at the controlled extraction point on the 74 MWe turbine. However, during a load reduction, the steam flow through the 74 MWe turbine downstream of the extraction valve decreases along with the corresponding pressure drop. During test LF3, the pressure drop through the back end of the 74 MWe turbine decreased to the point that the controlled extraction pressure could no longer be maintained and dropped below 600 psig (see Figure 8-20). This drop in extraction pressure affects the main steam flow calculation.

Final steam flow is calculated on the Nucla CFB using first stage pressure on the 74 MWe turbine. The calculation assumes a main steam pressure of 1464.7 psig, main steam temperature of $1005^{\circ} \mathrm{F}$, and an automatic extraction pressure of $640 \mathrm{psig.} \mathrm{Any} \mathrm{deviation} \mathrm{in} \mathrm{these} \mathrm{values} \mathrm{results} \mathrm{in} \mathrm{an}$ error in final steam flow measurement based on first stage pressure, particularly with the extraction pressure. This is shown in Figure 8-23, which indicates that a sudden decrease in extraction pressure from 640 psig to $560 \mathrm{psig}$, as is the case in Figure 8-20, results in an error in the steam flow calculation by approximately 6 percent.

The importance of this is the use of the calculated steam flow rate in 3 -element drum level control. This common control technique uses the steam flow rate as an anticipatory parameter to increase the feed water flow prior to any indicated change in drum level. The drum level indication is then used to "trim" the feed water flow. During drum level fluctuations with no indicated change in steam flow, the drum level takes over as the primary controller for feed water flow.

In test $L F 3$, as the governor valves close in response to the change in load demand, the actual steam flow decreases by less than that calculated based on 1st stage pressure alone. However, the 3 -element controller sees a larger reduction in steam flow by 6 percent, and reduces the feed water flow in excess of that required. This, coupled with the decrease in drum level due to the natural decrease in void fraction with increased drum pressure, results in a master fuel trip from low drum level.

Drum level control could be improved during load ramps by applying correction curves to the calculated steam flow for extraction pressure. Using the primary superheater 


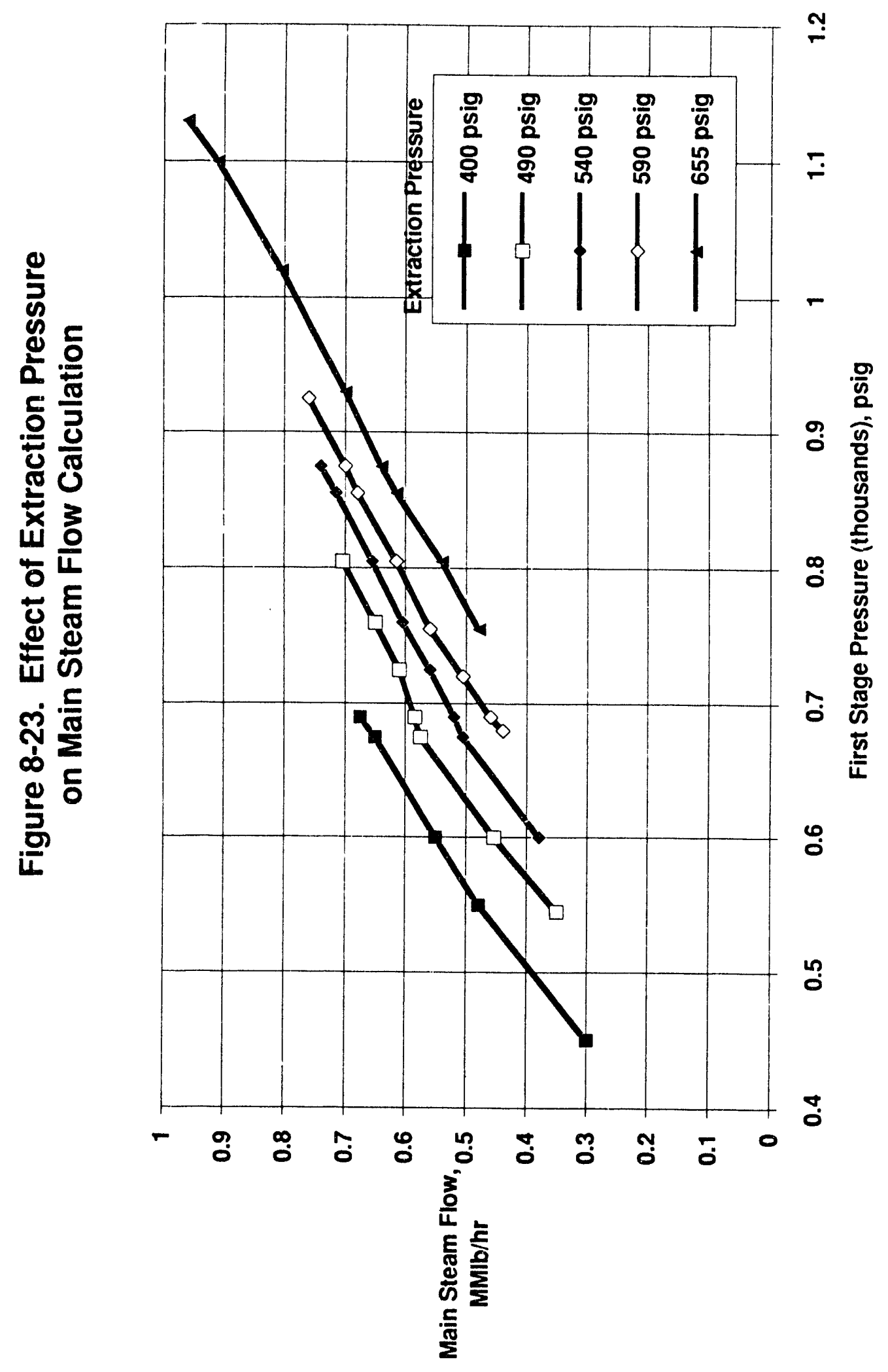


differential pressure as a measurement of the steam flow rate may provide another solution. 
Section 9

SOLIDS AND GAS MIXING

\subsection{OBJECTIVES AND APPROACH}

In an effort to study mixing in the upper combustor area of the CFB, the freeboard gas analysis system (FGAS) was used to conduct flue gas traverses at two elevations in combustor $B$ at Nucla during several performance tests. Tests were conducted at three loads with Peabody coal and at two loads with Salt Creek coal. In addition, traverses were also conducted with different coal feed and limestone feed configurations using Salt creek coal to study the impact of the feeder configurations on the gas profiles.

Table 9-1 lists the conditions of the tests along with the fuels tested and the feeder configurations.

\subsection{DESCRIPTION OF EQUIPMENT}

A description of the FGAS traversing probe is given in Section 4.2.1 of this report. Two retractable probes were used to extract gas samples. One was located at elevation $44^{\prime} 6^{\prime \prime}$ and the other was located at 86'6". For convenience these two traverse points are referred to as the $40 \mathrm{ft}$. and $80 \mathrm{ft}$. traverse points. The $40 \mathrm{ft}$. elevation is approximately $25 \mathrm{ft}$. above the air distributor plate and the $80 \mathrm{ft}$. elevation is approximately $65 \mathrm{ft}$. above the air distributor.

Gas samples are collected at $1 \mathrm{ft}$. intervals throughout the $10 \mathrm{ft}$. range of the probes. Figure 9-1 shows a plan view of the Nucla combustor $B$ and shows the relative locations of the coal feeders, limestone feeders, loop seal, secondary air ports, and traverse points. The loop seal enters the combustor approximately $2 \mathrm{ft}$. above the air distributor. One coal and one limestone feeder supply fuel and sorbent directly into the loop seal. The limestone feeders on the front wall and the outside wall are located about $5 \mathrm{ft}$. above the air distributor. The coal feeders on the front wall are approximately $7 \mathrm{ft}$. above the air distributor, as are the front and rear wall secondary air nozzles and the start-up burners. The secondary air nozzles along the outside and center.walls are located about $8 \mathrm{ft}$. above the air distributor. On the outside wall, two ash cooler air return lines are located approximately where the secondary air nozzles wolid normaliy be located. 


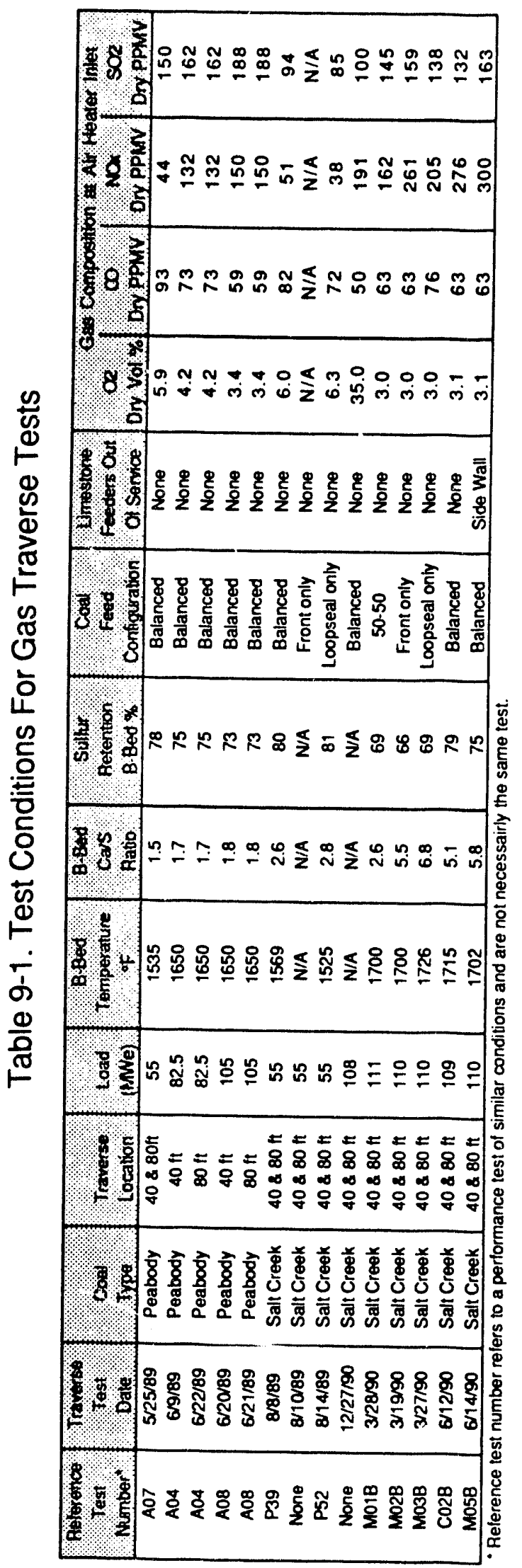




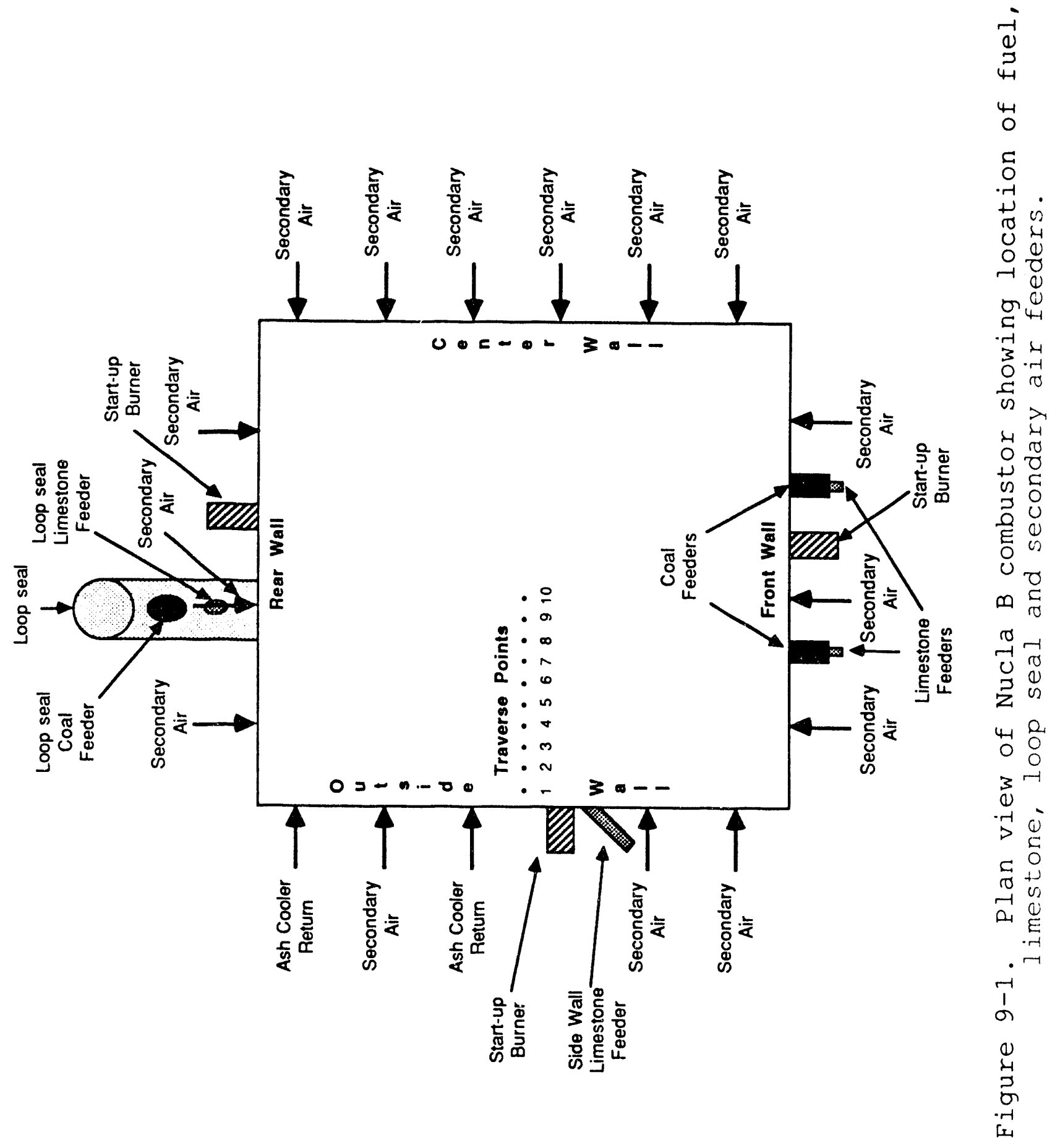


Ten points are sampled as the probe is moved into the furnace. Each point is sampled for 6 minutes. The gas concentrations are recorded on the VAX computer evexy 4 seconds throughout the duration of the traverse. Data collected during the periodic line purges are deleted from the traverse results. Once a traverse is complete, the data are reviewed carefully, and the purge periods are identified and eliminated. The remaining data are broken down into the 6-minute periods representing the ten traverse points, averaged, and then plotted against depth into the boiler. The resulting graphs illustrate the gas concentration profiles along a single axis at two elevations within the combustor.

There are two linitations to the gas traverse data that must be considered when analyzing the results. First, the data are taken along a single axis at each elevation. The traversing points are located directly above each other. However, the traverse location only represents the gas concentrations within a narrow band at each elevation. There is no information provided across the entire cross-section of the boiler. Second, aspirating air is required at the insertion point to prevent combustion gasses from escaping the boiler. This air may contaminate the gas sample taken at the 1-foot depth. However, there is no indication that this contamination is occurring.

\subsection{GAS TRAVERSE RESULTS}

\subsubsection{Effect of Load}

Fourteen gas traverse tests were conducted. Table 9-1 contains a list of the tests and the dates completed. The first five traverses listed in Table 9-1 were performed using Peabody coal. These tests were conducted at three loads with balanced feed to all three coal and four limestone feeders to study the effect of load on gas mixing. Furthermore, two sets of traverses were conducted using salt creek coal at two loads with balanced feed (55 MW on $8 / 8 / 89$ and 108 MWe on 12/27/89). Figures 9-2 through 9-5 show the effect of load for Peabody coal on $\mathrm{O}_{2}, \mathrm{CO}, \mathrm{NO}$, and $\mathrm{SO}_{2}$ traverses, respectively. Also shown on each figure is the concentration that was obtained at the air heater inlet. In order to allow comparisons of different graphs, all graphs for a gaseous component are drawn with the same Y-axis.

The $\mathrm{O}_{2}$ profiles shown in Figure 9-2 are relatively flat. The 55 MWe traverses indicate that there is a considerable amount of combustion occurring between the 40 and $80 \mathrm{ft}$. traverse planes, as evidenced by the decrease in $\mathrm{O}_{2}$ between these readings. The 82 and 105 MWe traverses seem to indicate that there is little, if any, combustion occurring between the two traverse planes near the center of the boiler, as evidenced 
O2Profile@55 MW

Pabody Coal - Balanced Feed

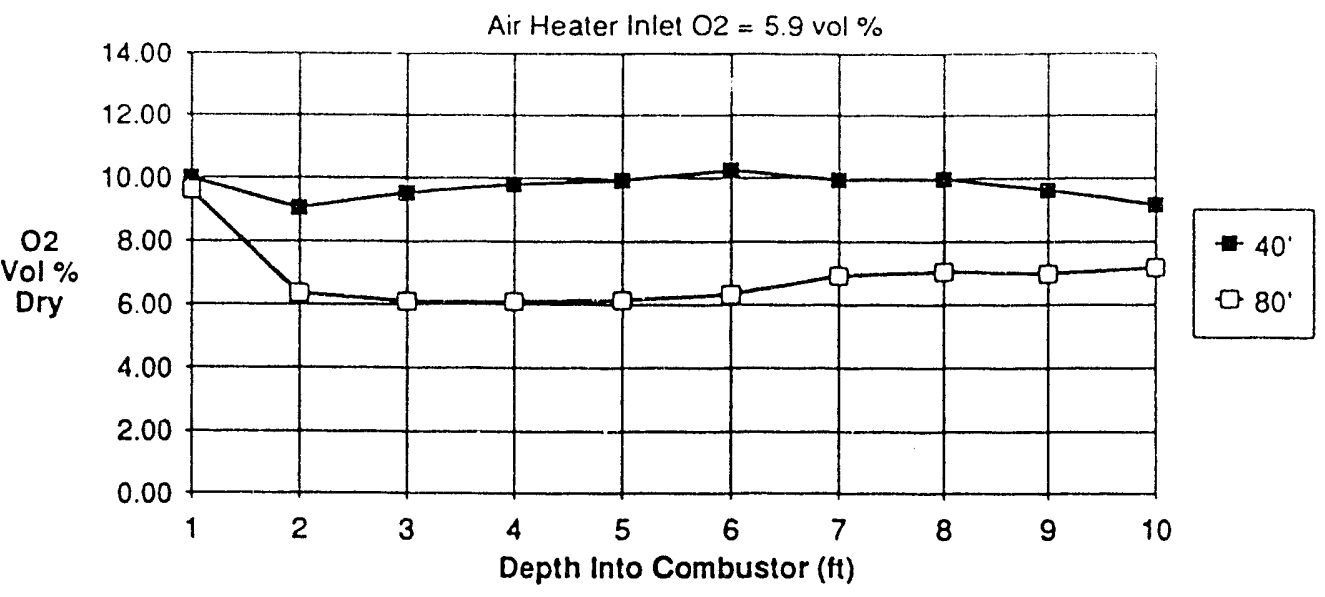

O2 Profile@105 MW

Peabody Coal - Balanced Feed

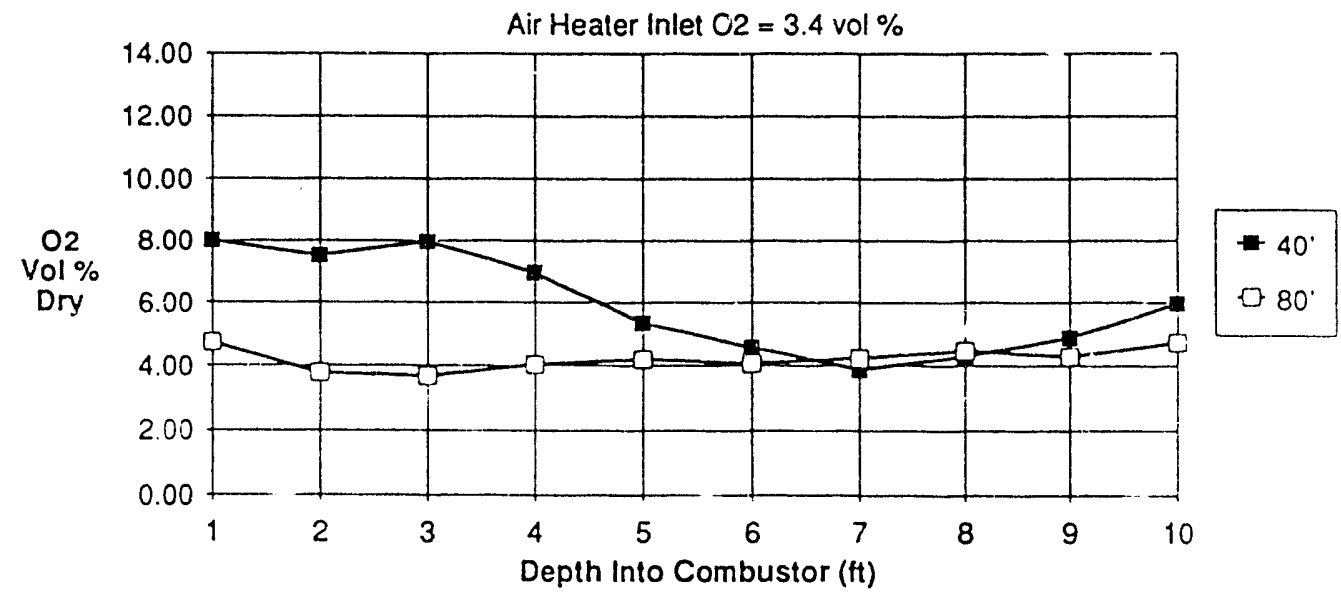

O2 Profile@82.5 MW

Peabody Coal - Balanced Feed.

Air Heater Inlet $\mathrm{O} 2=4.2$ vol $\%$

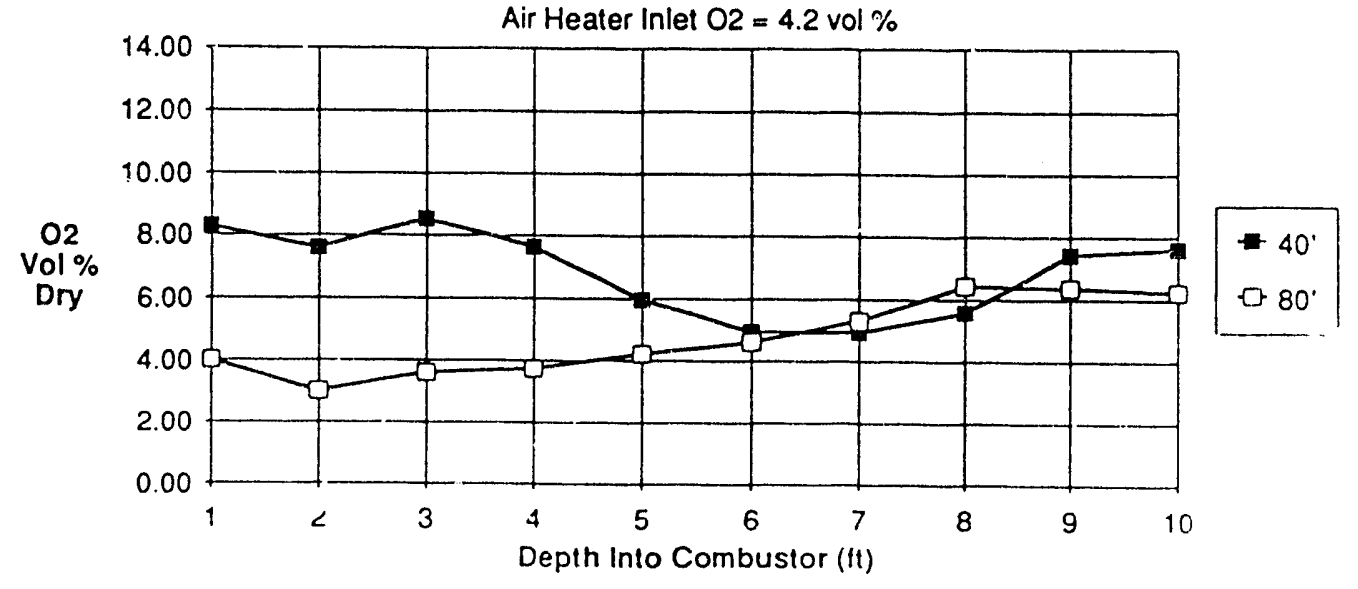

Figure 9-2. O2 traverses for Peabody coal at three loads. 


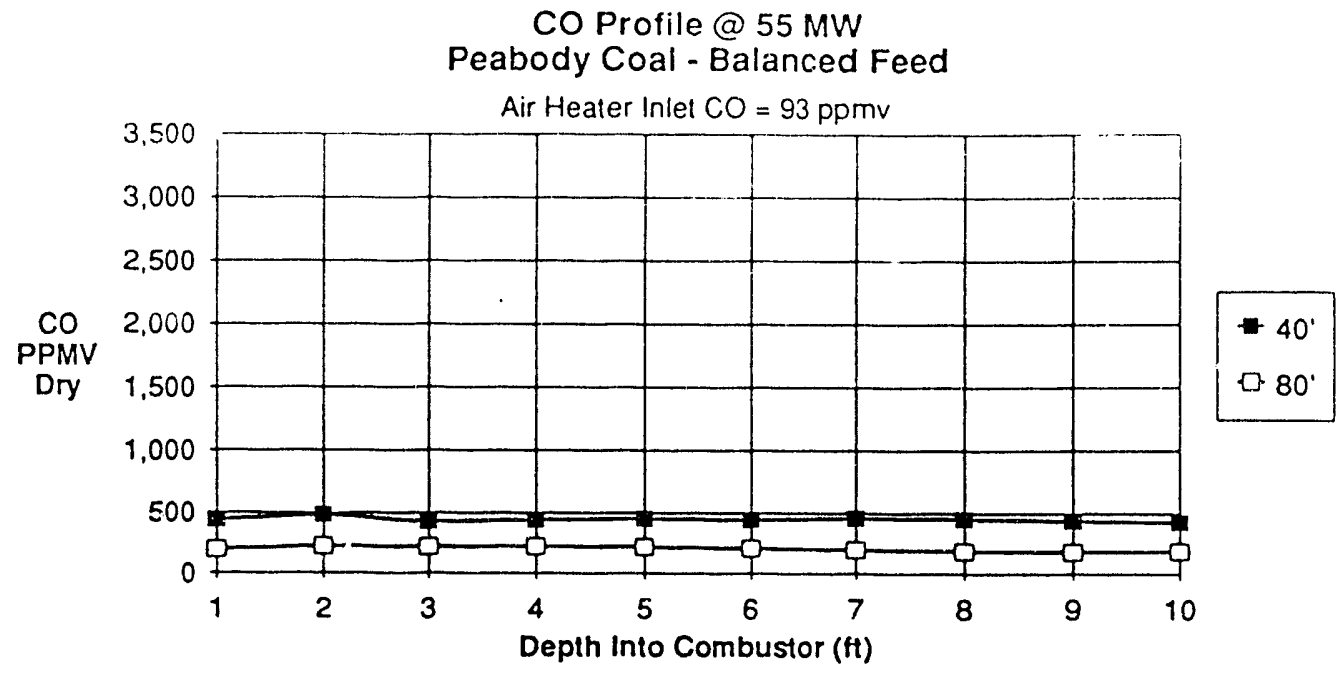

Co Profile @ $82.5 \mathrm{MW}$

Peabody Coal - Balanced Feed

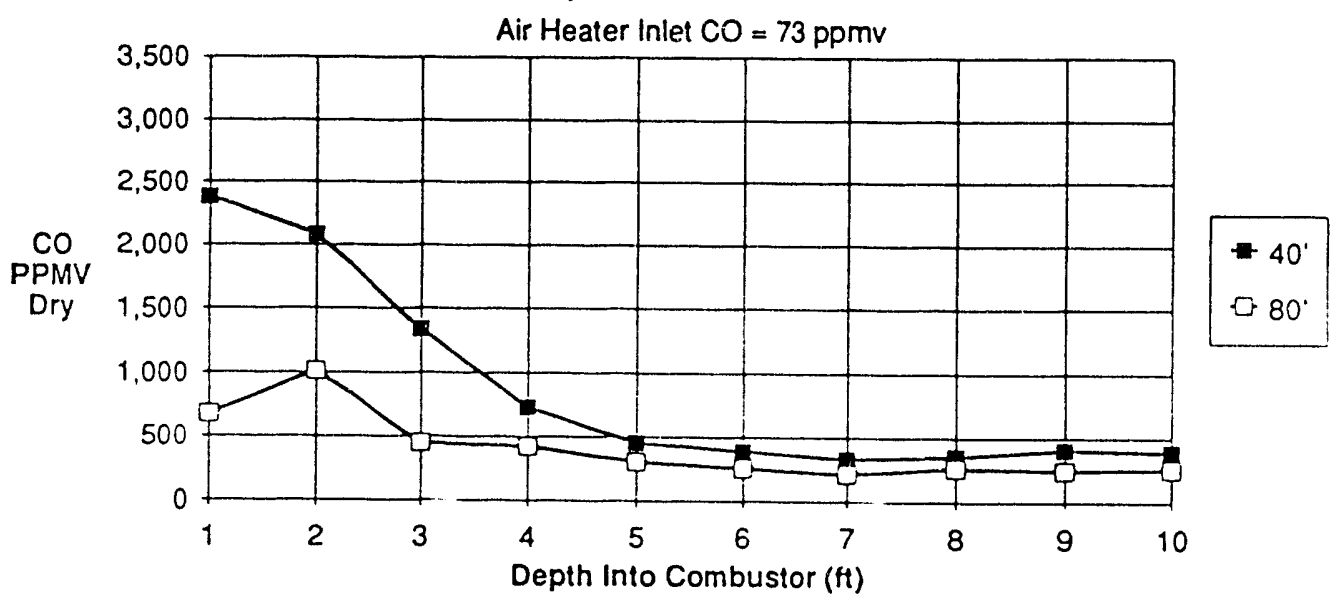

Co Profile @ 105 MW

Peabody Coal - Balanced Feed

Air Heater Inlet $\mathrm{CO}=59 \mathrm{ppmv}$

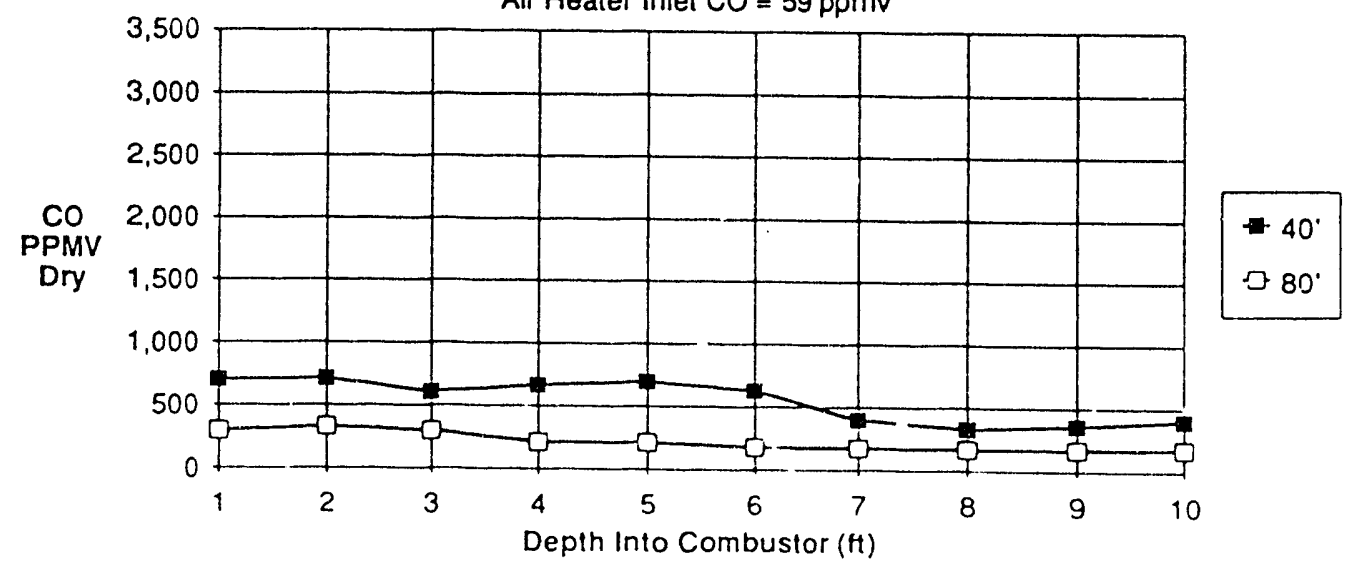

Figure 9-3. Co traverses for Feubody coa: at trree loads. 

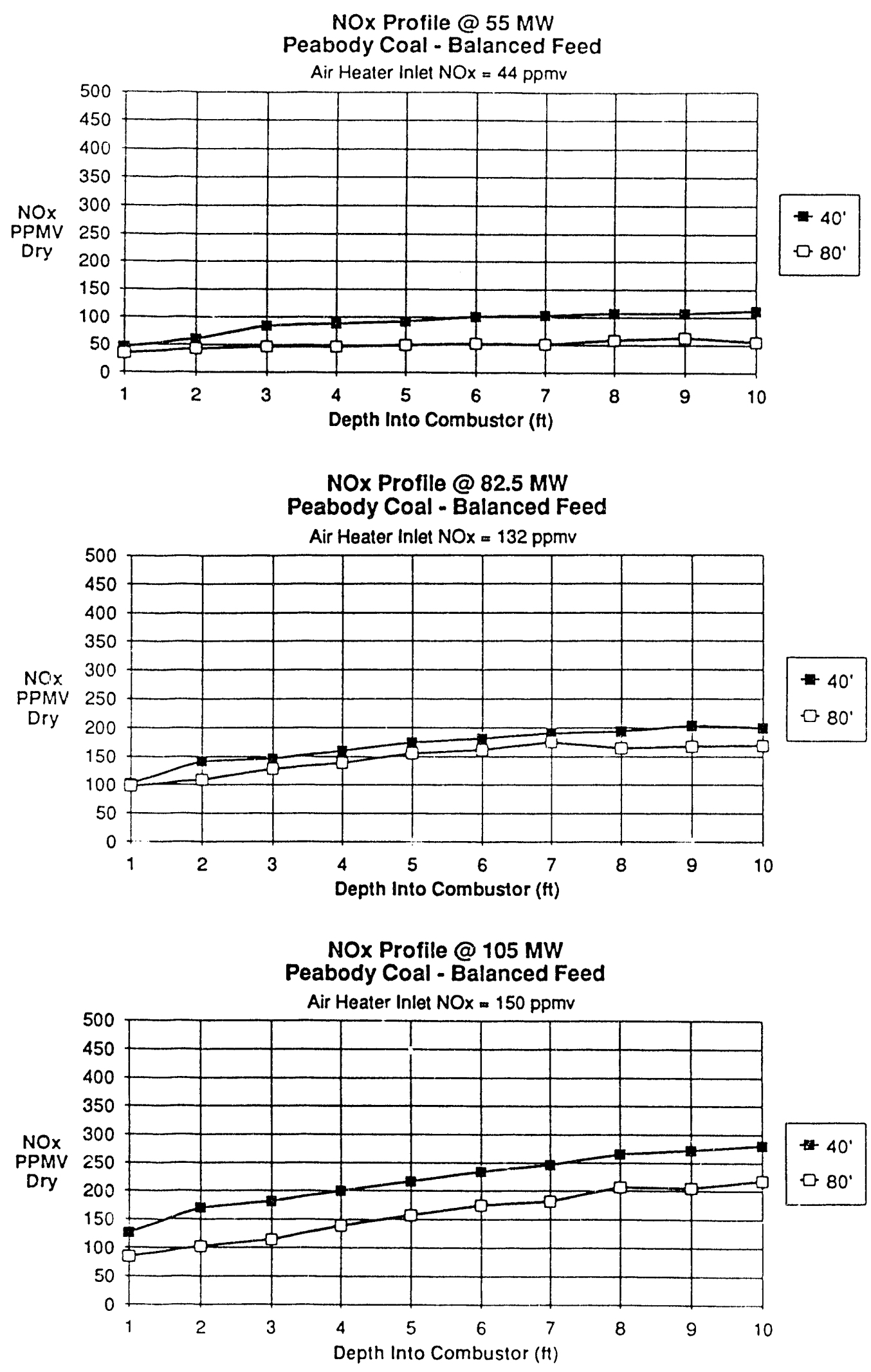

Eigure 9-4. Nox traverses for reabody cos at three doade. 

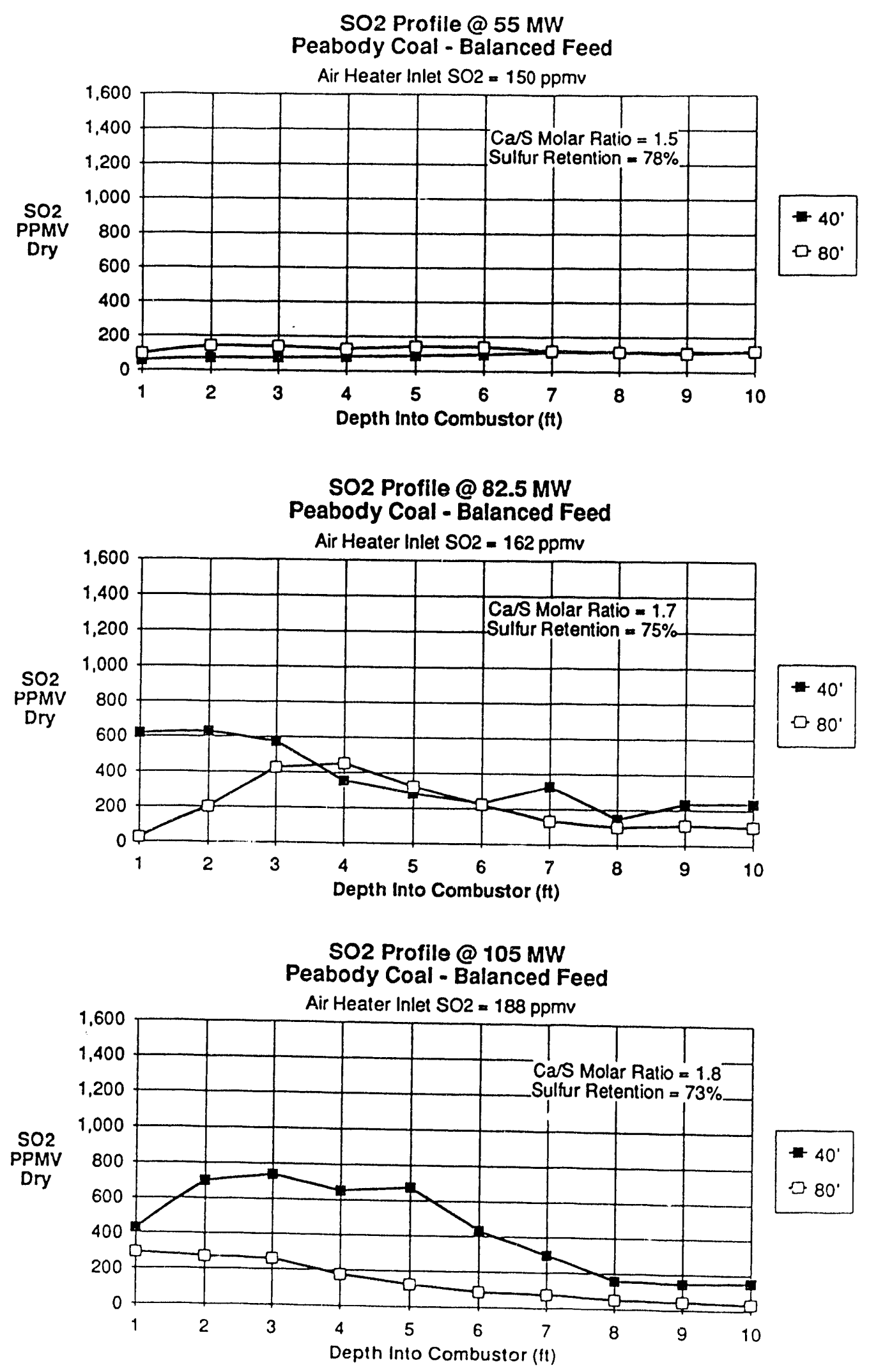

Eigure 9-5. Soz traverses for reabody coal
at thrte lojis. 
by the fact that the oxygen is not changing. At the walls, however, oxygen is still being consumed.

The CO profiles, shown in Figure 9-3, show little difference for the 55 and 105 MWe traverses. However the 82.5 MWe traverse shows rather large concentrations of $C O$ near the walls at the $40 \mathrm{ft}$. location. By the $80 \mathrm{ft}$. traverse, the CO levels have been reduced considerably. Note that the air heater inlet values show a trend of increasing $C O$ with decreasing load. This trend is believed to be due to the higher furnace temperatures at the higher loads.

The NOx profiles, shown in Figure 9-4, show a general trend of increasing values towards the center of the furnace. There is clear evidence of decreasing NOx with height in the combustor. Note also that there is little difference between the $80 \mathrm{ft}$. values and the air heater inlet value.

The $\mathrm{SO}_{2}$ profiles, shown in Figure 9-5, are relatively flat at 55 MWe with little change between the traverse planes and the air heater inlet. At 82.5 and 105 Mwe the trend is for increased $\mathrm{SO}_{2}$ near the wall. These traverses indicate that, for 82.5 and $105 \mathrm{MWe} ; \mathrm{SO}_{2}$ is being released high up in the combustor and near the wall. This observation is. corroborated by the $\mathrm{O}_{2}$ profiles that indicate combustion occurring between the two traverse planes. Also note that the $\mathrm{Ca} / \mathrm{S}$ ratio increased with increasing load. This may have been due to the higher bed temperatures, or it may have been due to the release of $\mathrm{SO}_{2}$ higher in the combustor. Note also that some sulfur capture must be occurring between the $80 \mathrm{ft}$. elevation and the air heater inlet.

\subsubsection{Effect of Coal Type}

Figures 9-6 through 9-9 show a comparison of traverses for Peabody and Salt Creek coals at half load and full load for $\mathrm{O}_{2}, \mathrm{CO}, \mathrm{NO}$, and $\mathrm{SO}_{2}$, respectively. Also shown on the plots are the values obtained at the air heater inlet during the traverses. These plots are shown to allow comparison of the gas traverses for the two fuels. The Peabody profiles are the same as those shown in Figures 9-2 through 9-5.

Table 9-2 shows the composition and size distribution for the coals used during these tests. The Salt Creek coal appears to have about $10 \%$ more fines ( $<600$ microns). Furthermore, the ratio of oxygen to fixed carbon is slightly higher for salt creek coal. The ratio of oxygen to fixed carbon (O/FC) has been found to be indicative of the reactivity of the char. Based on the O/FC ratios, the Salt Creek is about $14 \%$ more reartive than Peabody. The Salt Creek coal also has slightly higher volatiles and nitrogen contents than the Peabody coal. 

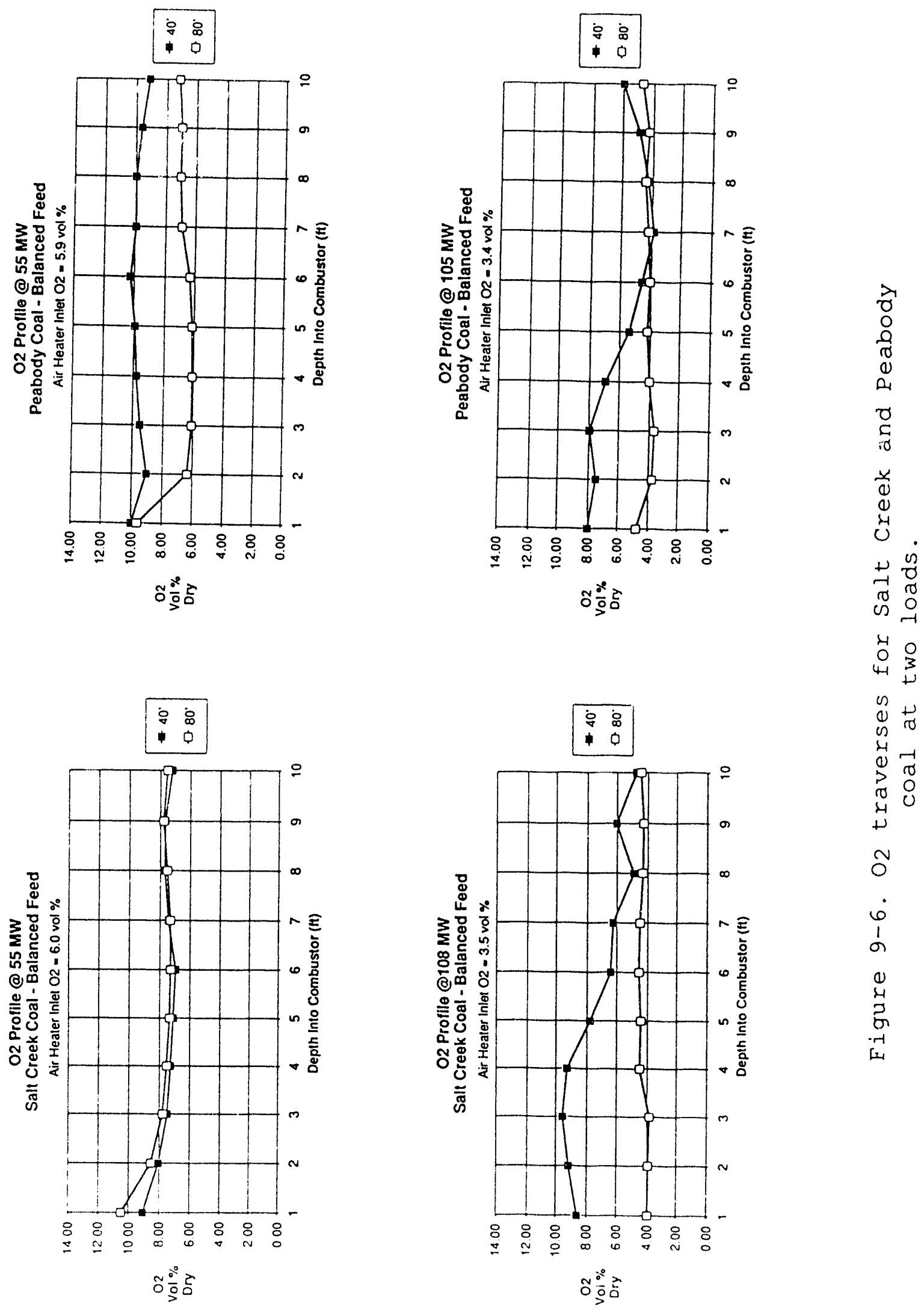

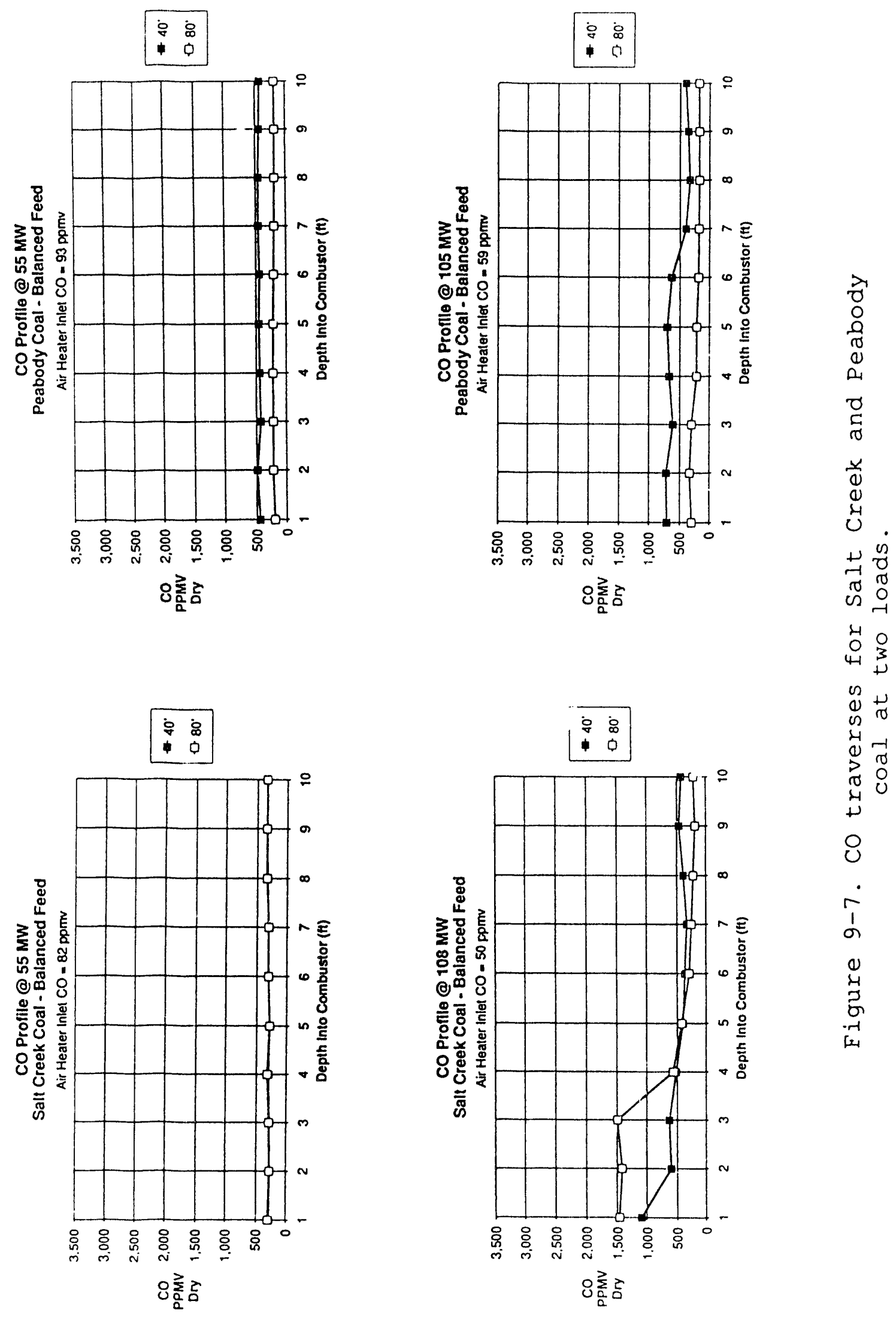

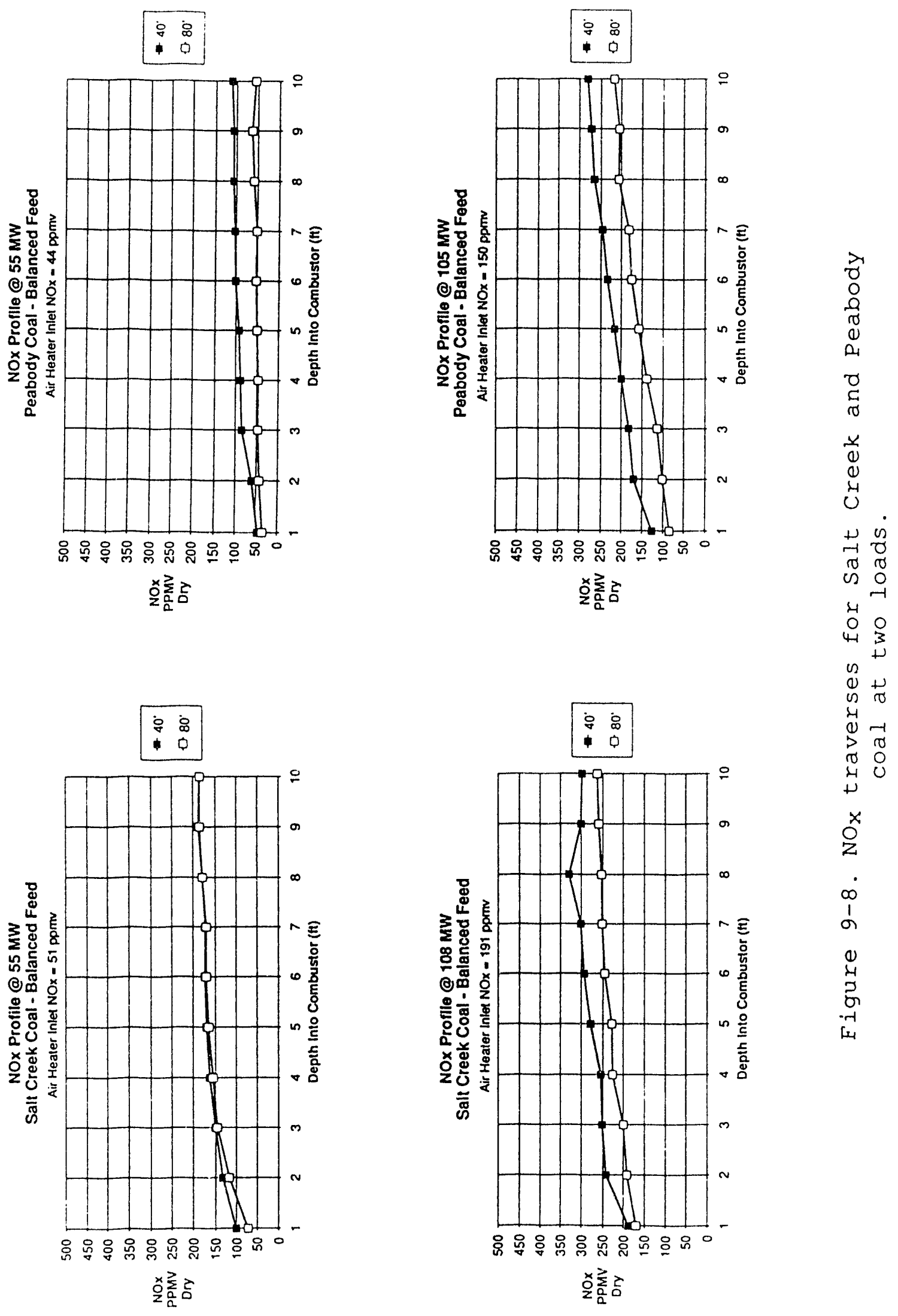

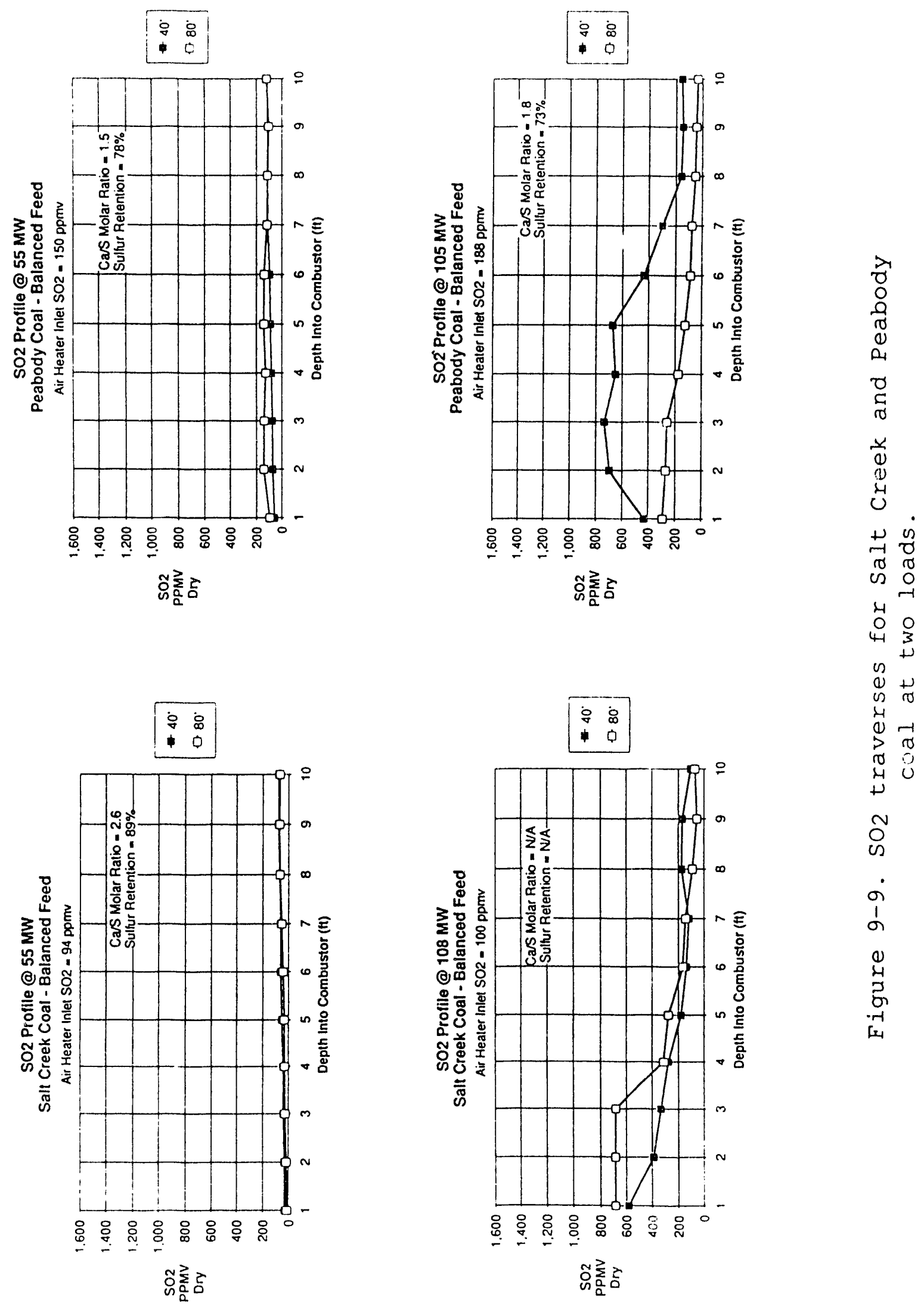
Table 9-2. Fuels Analyses for Traverse Tests

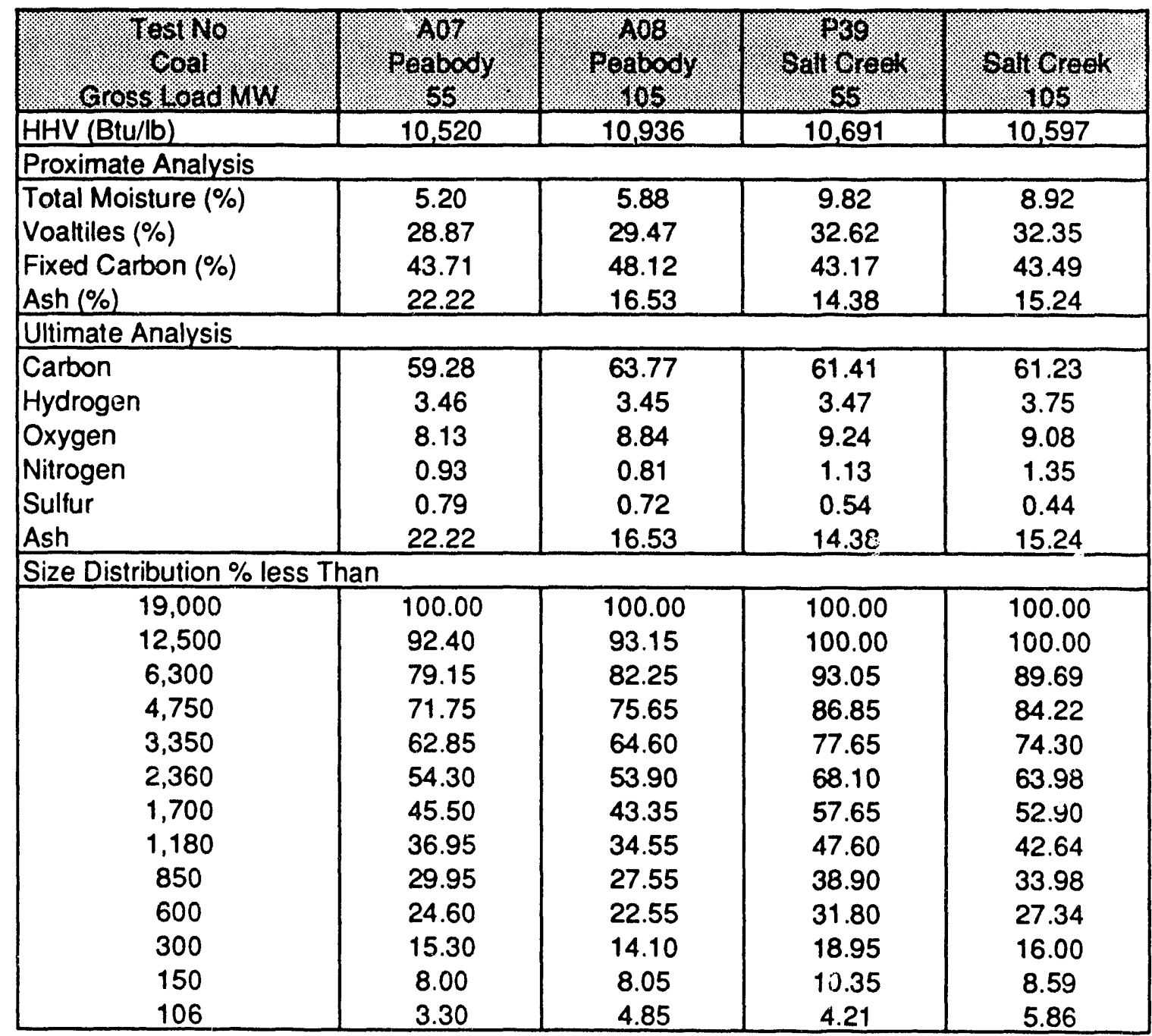


The $\mathrm{O}_{2}$ profiles are shown in Figure 9-6. For the 55 MWe traverses, the shape of the two profiles are similar. However, the Salt Creek coal shows little evidence of combustion between the 40 and $80 \mathrm{ft}$. traverse planes. This indicates that Salt creek coal burns lower in the furnace. This characteristic could be explained by the higher reactivity and higher volatile content of Salt Creek coal.

CO profiles are shown in Figure 9-7. With the exception of the 108 MWe salt Creek coal traverse, all of the traverses are relatively flat. The 108 MWe Salt Creek traverse shows increasing $C O$ near the wall. This trend was also observed in Figure 9-3 for the 82.5 MWe test on Peabody coal. Despite the high $C O$ readings (over 1400 ppmv near the wall for the 108 MWe Salt Creek traverse), the air heater readings remained low, indicating that $C O$ is burned above the $80 \mathrm{ft}$. elevation. This probably occurs in the cyclone where turbulence mixes the oxygen with the co.

Figure 9-8 shows the $\mathrm{NO}_{\mathrm{X}}$ profiles for Peabody and salt creek coals at the two loads. The NOx readings for salt Creek coal are consistently higher than the peabody coal readings. This may reflect the higher fuel nitrogen in the salt creek coal. In all cases, the $\mathrm{NO}_{\mathrm{X}}$ levels increase towards the center of the furnace.

Figure 9-9 shows the $\mathrm{SO}_{2}$ profiles for both coals at the two loads. The traverse profiles for the 55 MWe tests are quite similar, being relatively flat and near the air heater value. The full load tests show an interesting phenomenon. Near the wall, the Peabody coal $40 \mathrm{ft}$. traverse shows $\mathrm{SO}_{2}$ values above the $80 \mathrm{ft}$. traverse, while the Salt Creek coal $40 \mathrm{ft}$. traverse has $\mathrm{SO}_{2}$ values less than the $80 \mathrm{ft}$. traverse.

\subsubsection{Effect of Fuel Feed Location}

Another series of tests were performed to study the effect of fuel feed location on the gas traverses. These tests were conducted at 55 and $110 \mathrm{MW}$ with Salt Creek coal. Three fuel feed configurations are examined in this report. The three configurations are: 1) balanced coal, with 33\% coal feed to all three feeders; 2) front wall feed, with $50 \%$ of the coal feed to each of the front wall feeders; and 3) loop seal feed, with $100 \%$ coal feed to the loop seal coal feeder. An additional configuration of $25 \%$ coal to each of the front wall feeders and 50\% to the loop seal, termed the 50/50 feed configuration, was tested at 110 MWe only. This feed configuration will be discussed separately.

Figure 9-10 shows the $\mathrm{O}_{2}$ profiles for the two loads and the three feeder configurations. While the profile for the balanced feed is relatively flat, the two extreme feed conditions show opposite trends. The front wall feed 

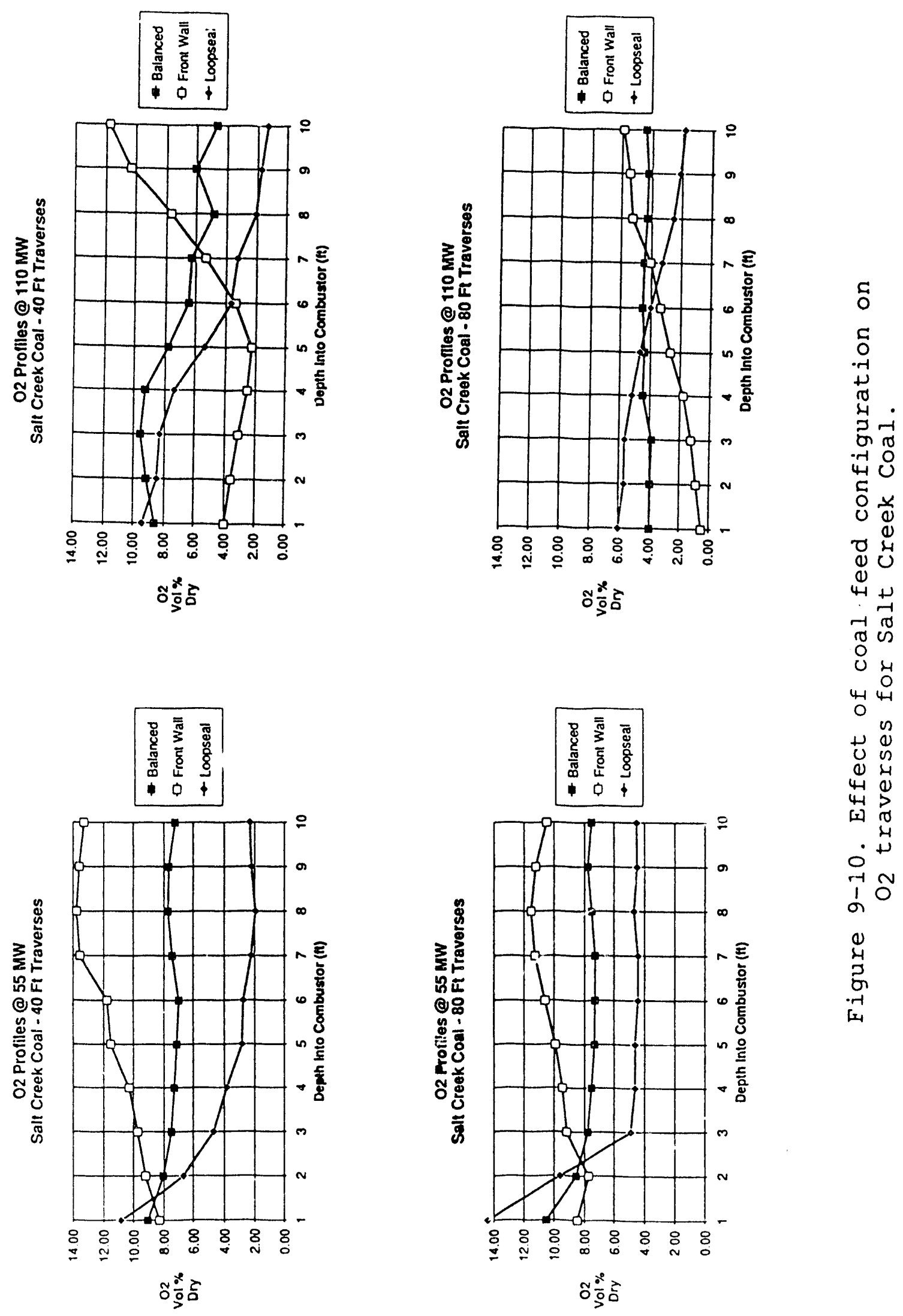
configuration shows the oxygen concentration increasing towards the center of the furnace. The loop seal feeder configuration shows oxygen concentrations increasing towards the wall. The trend is most visible at the 110 MWe loads. These curves indicate that coal fed through the loop seal is forced towards the center of the furnace while coal fed at the front wall feeders apparently burns more towards the wall.

Figure 9-11 shows the CO traverses for the three feed configurations at both loads. As with the oxygen, the co profiles indicate that the loop seal coal feed is burning towards the center of the furnace while the front wall feed burns towards the wall. Note also that, despite the extremely high $C O$ levels at the $80 \mathrm{ft}$. traverse plane, the co at the air heater was 63 ppmv for the front wall test and 76 ppmv for the loop seal test. This again indicates that $c 0$ is being burned downstream of the $80 \mathrm{ft}$. plane, probably in the cyclones.

Figure 9-12 shows the NOX traverses for the three feed configurations and the two loads. At $55 \mathrm{MWe}$, the balanced feed traverses showed the highest $\mathrm{NO}_{\mathrm{X}}$ readings, however this trend reverses at full load. Furthermore, while the front wall feeder at full load did not show any traverse points higher than the loop seal configuration, the front wall feeder gave the highest $N O x$ readings at the air heater inlet (261 ppmv NOX for the front wall, 205 ppmv for the loop seal, and 191 ppmv for the balanced). The loop seal feed configuration did not appear to have any impact on $\mathrm{NO}_{\mathrm{x}}$ at the air heater inlet, but did show increased values inside the furnace.

Figure 9-13 shows the $\mathrm{SO}_{2}$ traverses for the three feed configurations and the two loads. The 55 MWe traverses indicate that the lcop seal feed configuration had higher $\mathrm{SO}_{2}$ readings towards the center of the furnace than the other two configurations. This can be explained by the lower $\mathrm{O}_{2}$ readings in this region (see figure 9-10). However, the differences are small. At full load, the trend is for increased $\mathrm{SO}_{2}$ readings towards the center of the furnace for the loop seal feed configuration, and towards the walls for the front wall feeders. It should also be pointed out that both the front wall tests and the loop seal tests showed poorer sulfur capture efficiency than the balanced feed configuration, with the loop seal configuration being slightly worse than the front wall configuration.

Figures 9-14 through 9-17 compare the 50/50 feed distribution (25\% coal to each wall feeder and $50 \%$ to the loop seal) to the balanced feed configuration ( $33 \frac{\circ}{6}$ coal feed to all three feeders). The graphs for the 50/50 feed show similar trends to the balanced feed configuration. However, combustion 

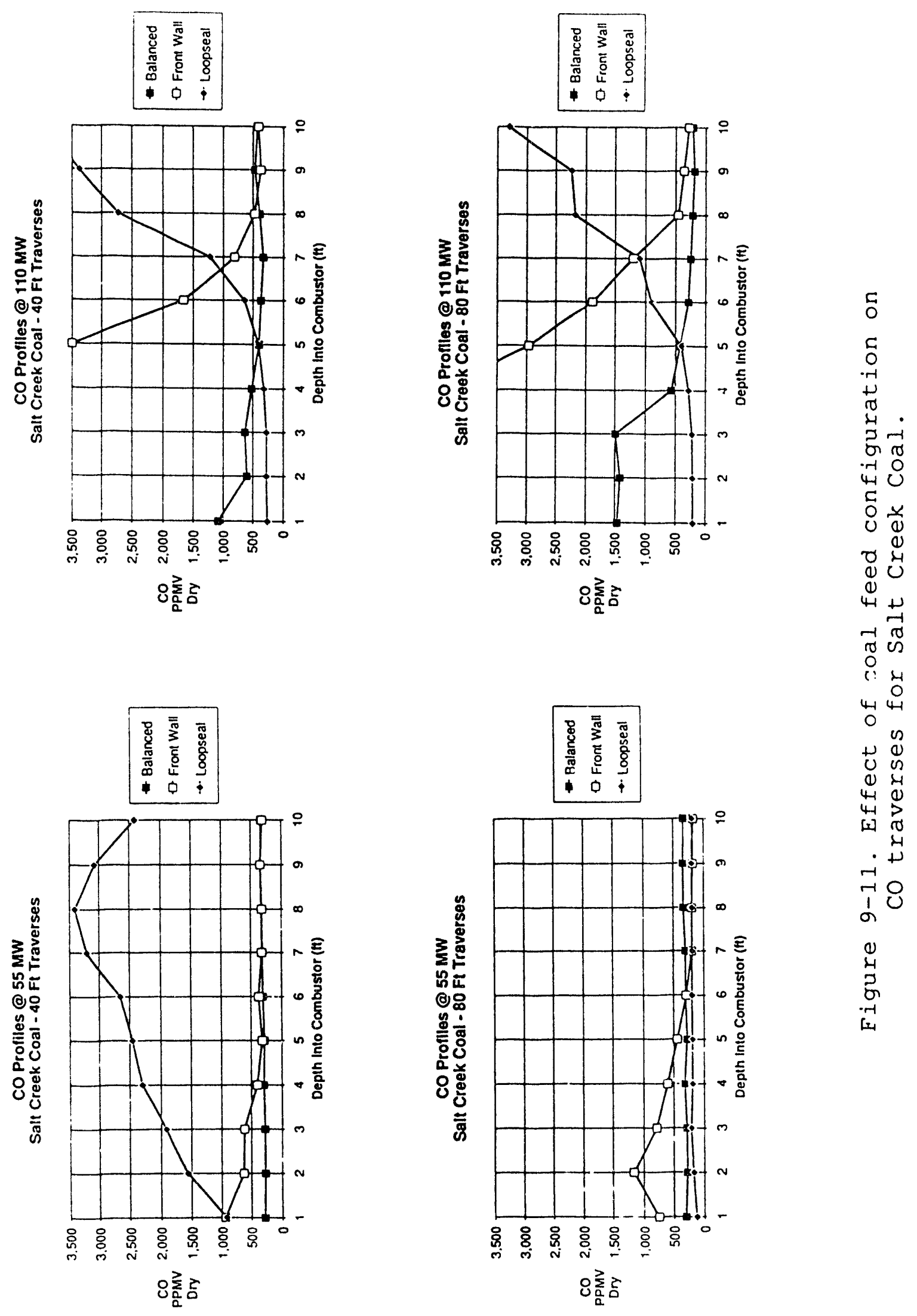

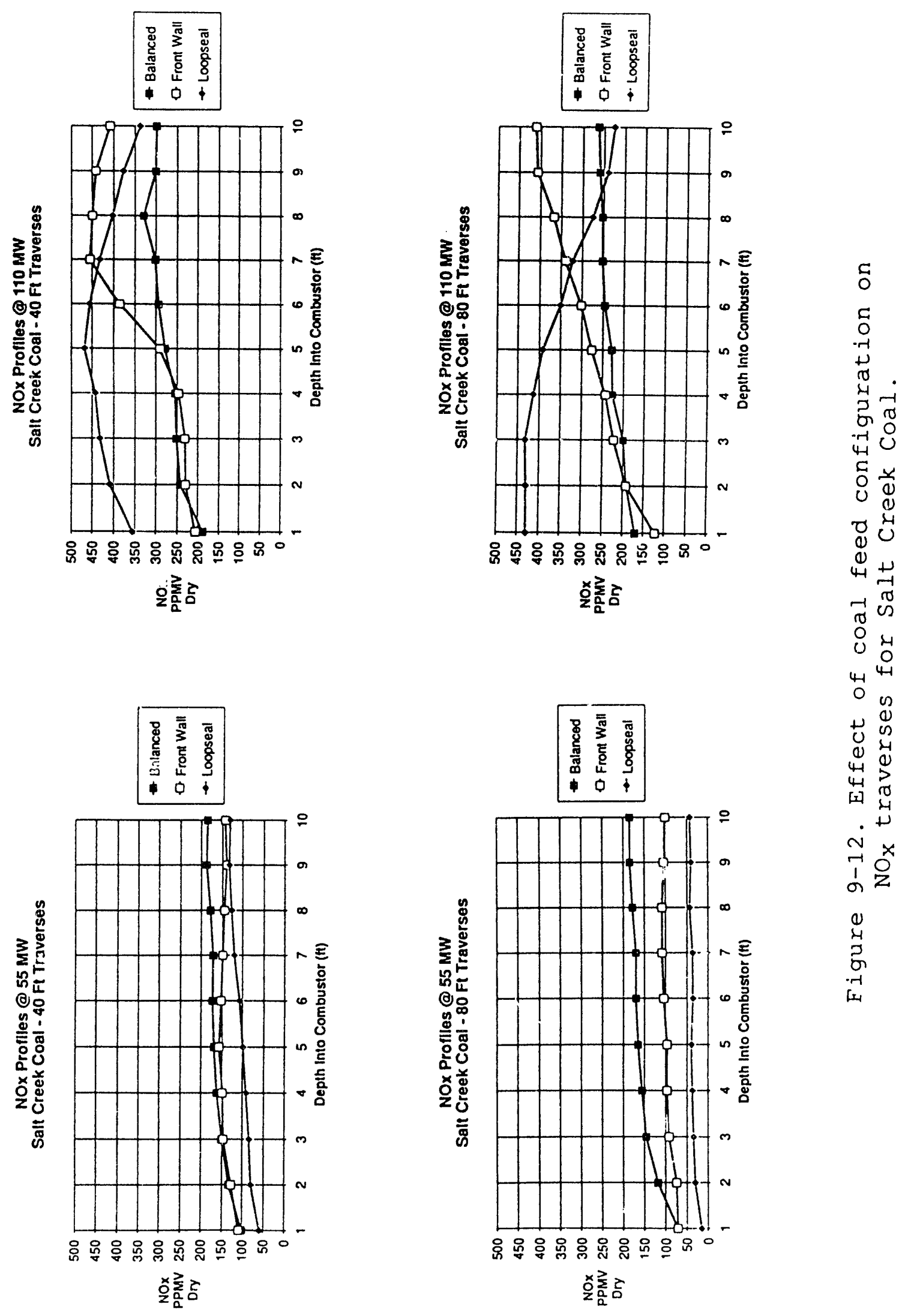

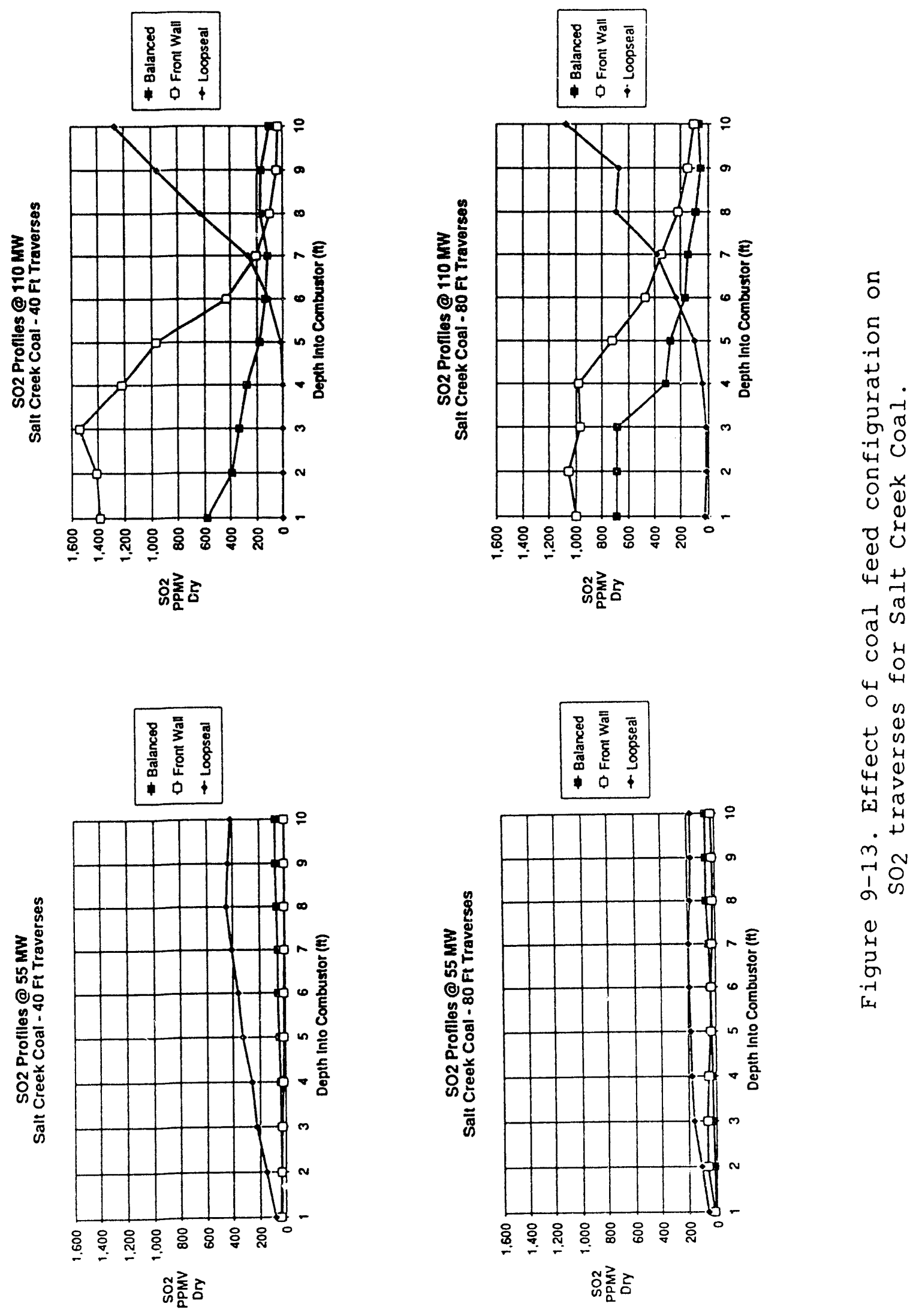

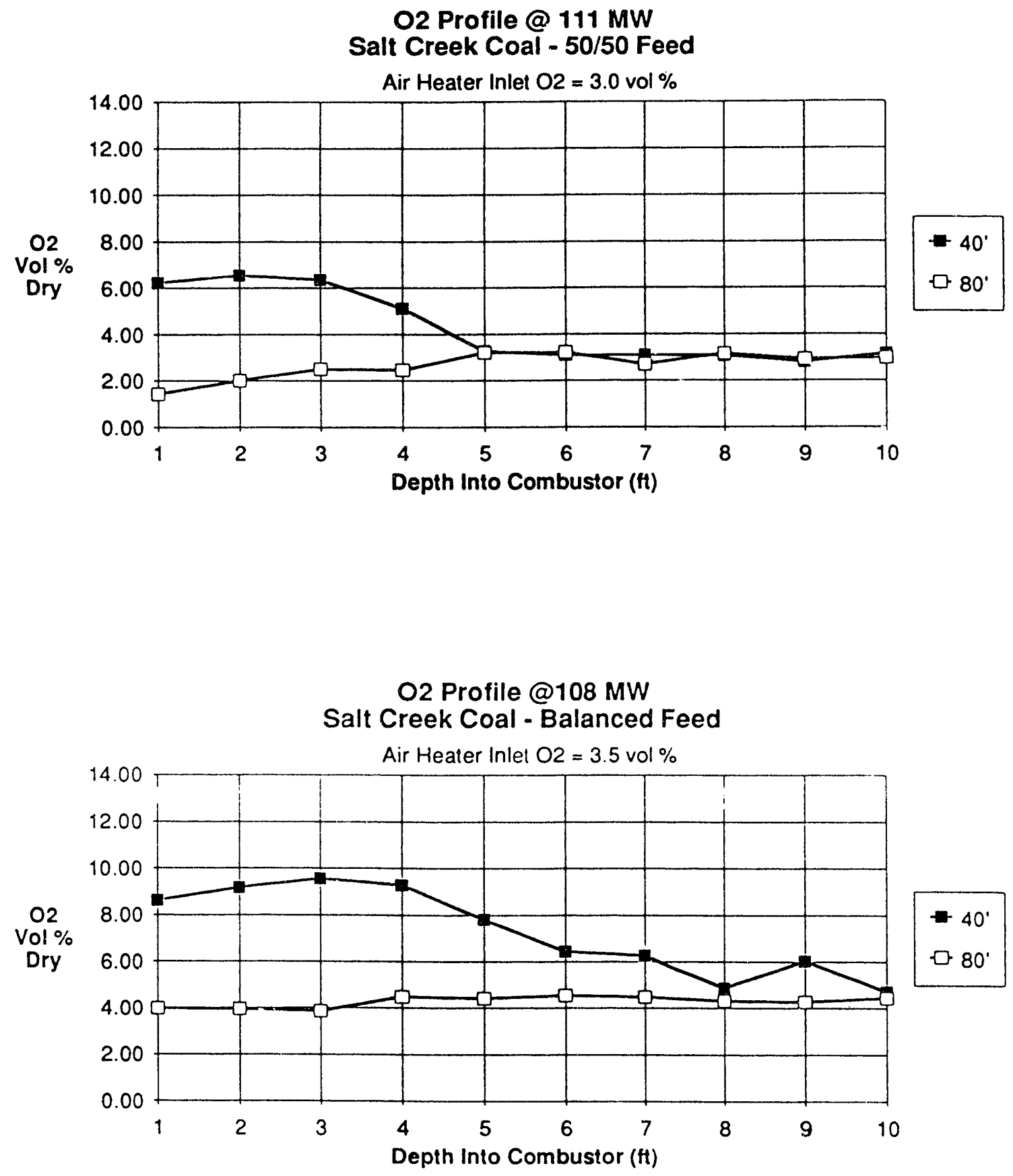

Figure 9-14. Comparjson of $\mathrm{O}_{2}$ traverses for $50 / 50$ coal feed and balanced coal feed. 

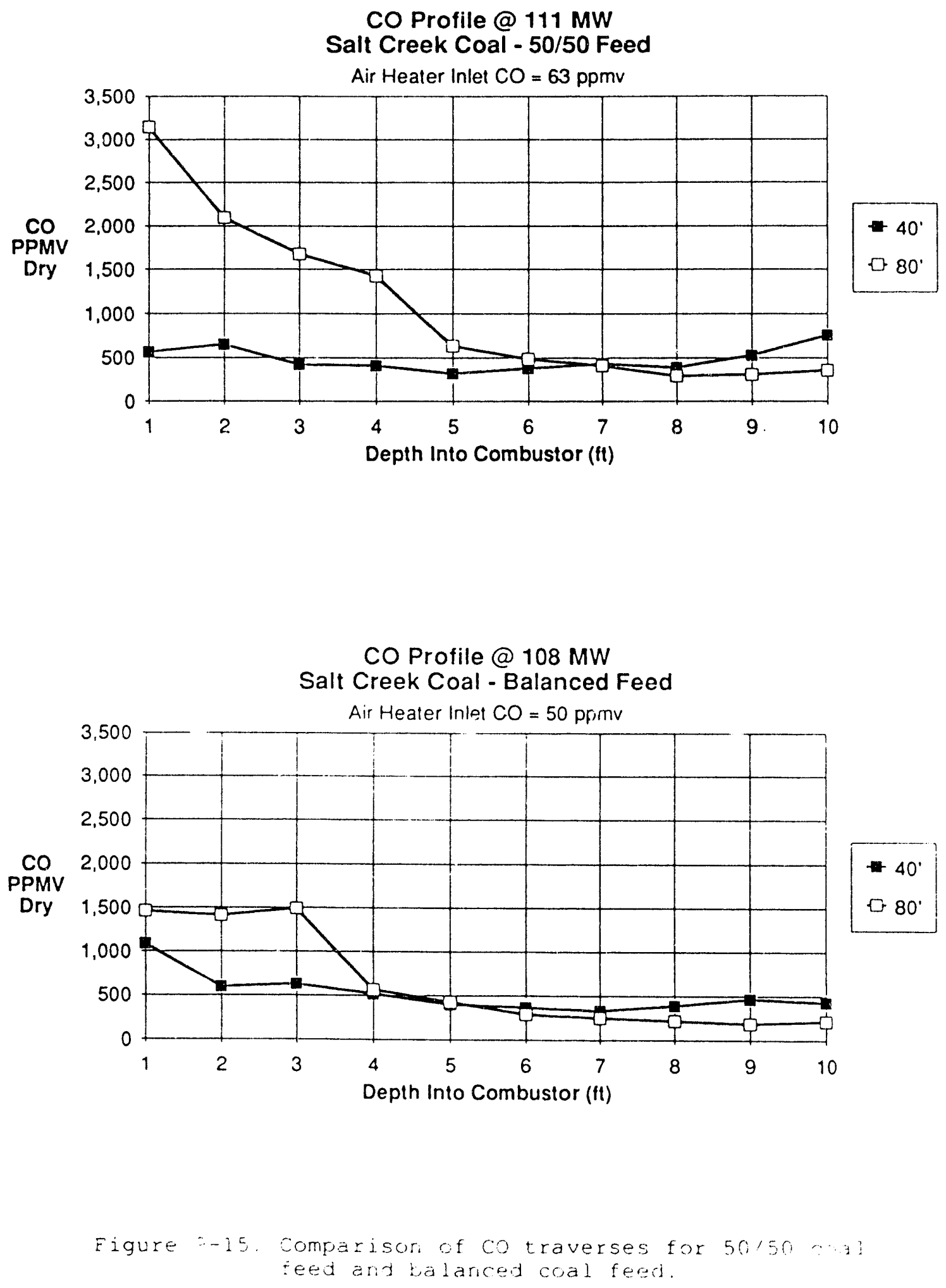

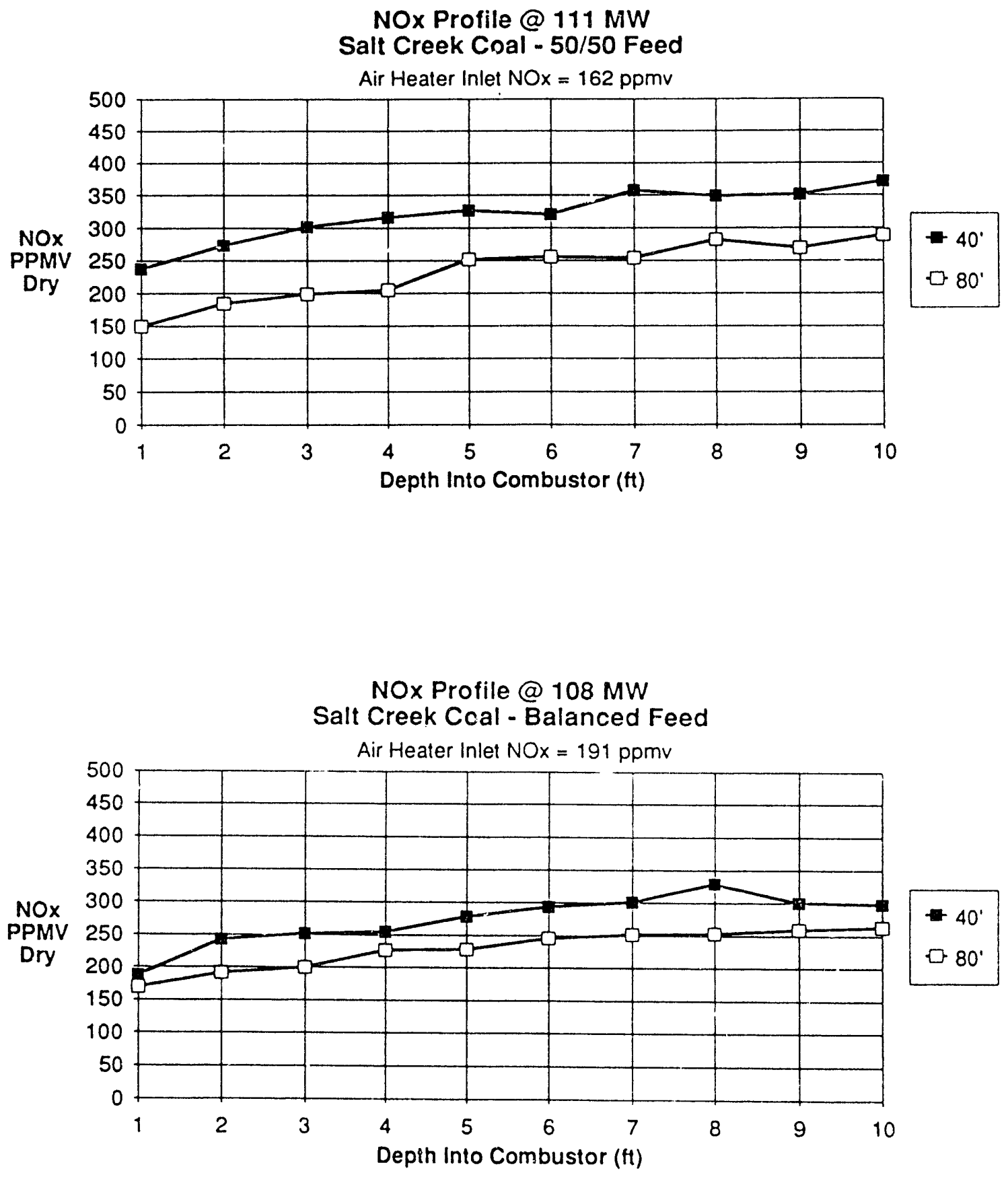

Figure 9-16. Comparison of NOx traverses for 50/50 coal feed and balanced coal feed. 

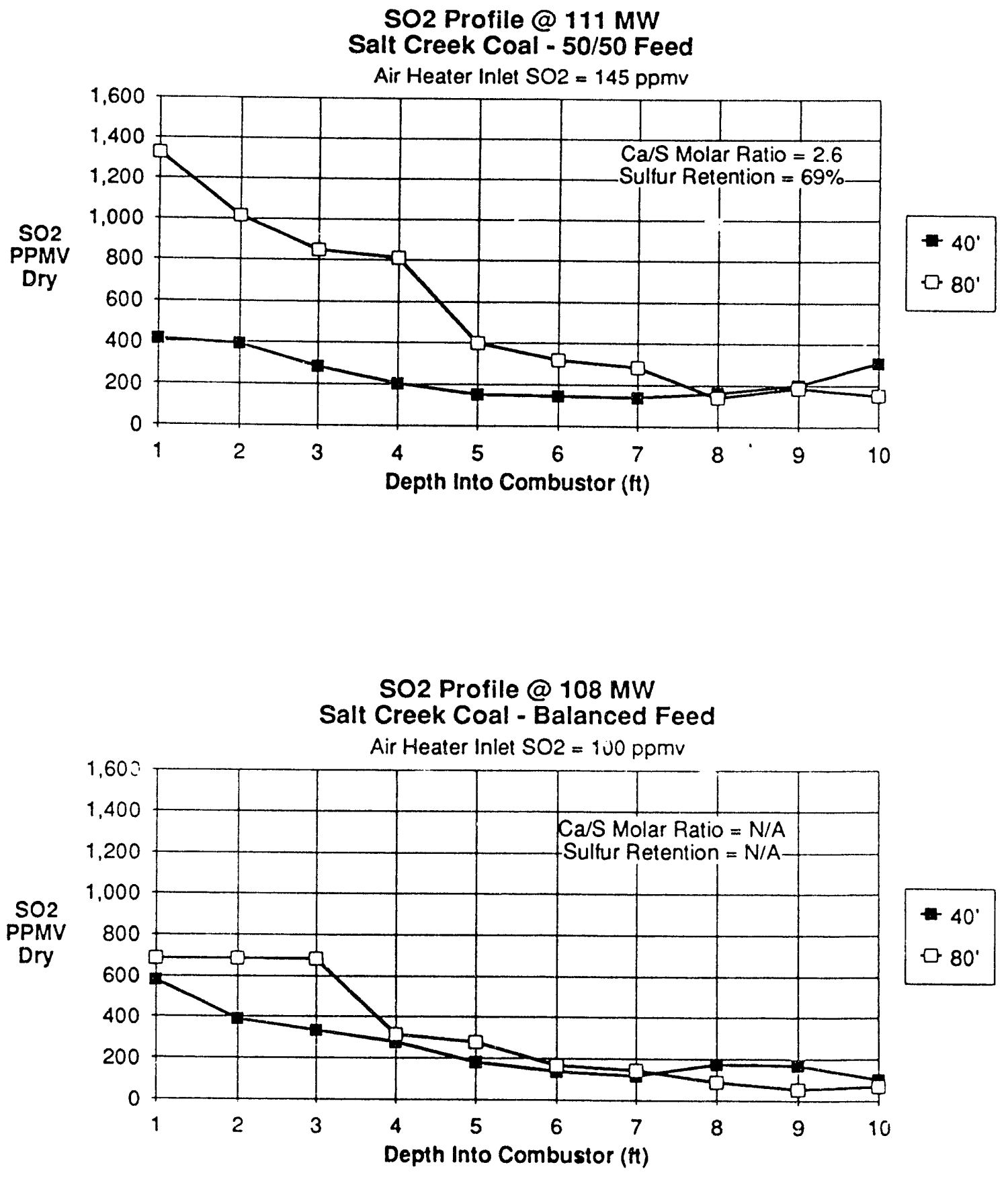

Figure 9-17. Comparison of $\mathrm{SO}_{2}$ travarses for $50 / 50$ coal feed and balanced coal feed. 
appears to be shifted slightly towards the walls for the $50 / 50$ feed distribution. These profiles are quite similar to the Peabody coal traverses at 105 MWe.

\subsection{DISCUSSION OF RESULTS}

The gas traverses tend to confirm the same conclusions regarding emissions that were reached in section 6. Namely, better distribution of the fuel inside the combustor results in improved emissions. The traverses also indicate that there is poor lateral mixing of gaseous products between the two traverse planes. This is evidenced by the fact that peaks in a gaseous component at the $40 \mathrm{ft}$. elevation also appear in approximately the same place in the $80 \mathrm{ft}$. elevation traverse.

The traverses also indicate that fuel distribution has an impact on the gaseous products all the way through the combustor. This observation is based on the loop seal and front wall feed configurations where $100 \%$ and $50 \%$ of the total fuel was fed at a single feed point. These traverses suggest that improved fuel distribution, in the form of more feed points, may improve the emissions from a CFB. However, the relatively flat profiles obtained for the balanced feed configuration indicate that suricient distribution may already be achieved.

The most intriguing result of these traverses is the apparent differences seen for the front wall feed and the loop seal feed configurations. These traverses indicate that coal fed to the loop seal tends to burn in the center of the furnace, while coal fed to the front wall feeder appears to burn near the walls. This result is surprising since the loop seal feeder is located about 9'6" ft. from the outside wall and the nearest front wall feeder is about 7'6" from the outside wall. While situated on opposite walls at the axis of the traverse, these two feed points are located almost the same distance from the traverse plane. Thus, even though the two feeders are relatively close to the center of the furnace, their impact on the gas traverses is dramatic.

One possible explanation for this observation could be due to the location of the feeders relative to the air distributor. The loop seal feeds the recycle and coal just above the air distributor, while the front wall feeders are located about 7 ft. above the air distributor. If there is a dense bed that is only a few feet deep on the air distributor, then the loop seal will be feeding into the dense bed while the front wall feeder.will be feeding over top of this bed. The outside and center walls of the combustors are sloped slightly, with the area of the air distributor being smaller than the area of the upper furnace. Bed material falling down these walls will cause the dense bed to move towards the center of the furnace, since material is being added at the walls. such 
motion would tend to force fuel fed in at the loop seal towards the center of the furnace. This hypothesis is also corroborated by the erosion pattern on the air distributor, shown in Figure 16-7, which indicates that the recycle material remains in a narrow channel along the center of the bed.

Fuel fed above the dense bed will be forced by the gas flow path, which follows the contours of the furnace walls, and will be forced toward the walls. Any material that reaches the dense bed will be carried by the bed movement toward the center of the furnace. However, the fuel fines and a good portion of the fuel volatiles will probably be carried with the gas toward the walls.

It was widely believed that the secondary air ports would completely mix the gaseous products and solid material as it leaves the primary combustion zone. Apparently this does not happen at Nucla to a great degree. It is possible that a better secondary air design involving more air nozzles and higher velocity jets could provide better mixing and, therefore, better emissions control.

The traverses taken at Nucla are only performed at two elevations and along a single traverse line into the center of the combustor. However, the furnaces are not symmetrical and it would be unwise to assume that the traverses shown represent the profiles across the entire boiler. Traverses along a line over a front wall coal feeder and a loop seal feeder would probably be quite different from the ones obtained in this study. Another problem with these traverses is that there is no measurement of the gas flow rate at each traverse point. Thus, in a region of low $\mathrm{O}_{2}$, there is no way of knowing the volume of gas that is rising at that point. This makes comparison of the traverse readings to the air heater inlet averages difficult. Nevertheless, despite these limitations, the gas traverses provided some new insight into the operations of the CFB furnace. 
Section 10

HEAT TRANSFER

\subsection{APPROACH AND METHODOLOGY}

In the Nucla CFB, heat transfer takes place between the water walls in the combustors and the recirculating solids that make up the bed material. Some additional heat transfer takes place between the circulating bed and the superheaters. The amount of heat transferred to the walls of the combustor ultimately determines the operating temperature of the combustur.

In this section, data from the Phase I and Phase II test programs will be used to develop correlations for the combustor temperature. The effects of load, excess air, superficial velocity, bed pressure drop, and suspension density on heat transfer and bed temperature will be studied. Correlations for bed temperature will be developed for Peabody and Salt Creek coals. Correlations will also be developed to relate the heat flux to the walls with the superficial velocity and the suspension density. Finally, these correlations will be used to discuss control options for the Nucla boiler.

\subsection{DESCRIPTION OF INSTRUMENTATION}

During testing at Nucla, data were taken to help provide a better understanding of the parameters that affect heat transfer. The data included pressure and temperature measurements. In addition to these measurements, chordal thermocouples were installed on the rear wall of combustor $B$ by EPRI during the Phase I testing to measure the heat flux at different elevations in the combustor. EPRI also installed pressure taps up the rear wall on combustor $B$. Table 10-1 shows the elevation above the air distributor for the chordal thermocouples and the pressure taps.

Actual details of the chordal thermocouples can be found in the Annual Reports. The data taken from these pressure taps and chordal thermocouples is proprietary to pyropower and cannot be reported here. However, averages over three zones in the combustor, the lower zone, the middle zone, and the upper zone, were available to be used to develop correlations. These zones are defined as follows:

Lower furnace: $20-40 \mathrm{ft}$. abor $\geq$ air distributor Middle furrace: $40-70 \mathrm{ft}$. above air distributor Upper furnace: 70-113 ft. above air distributor 
Table 10-1

Location of Pressure Taps and Chordal Thermocouples

\begin{tabular}{|c|c|}
\hline $\begin{array}{l}\text { Pressure } \\
\text { Transmitter }\end{array}$ & $\begin{array}{c}\text { Feet Above } \\
\text { Air Distributor }\end{array}$ \\
\hline $\begin{array}{l}\text { GPT300 } \\
\text { GPT301 } \\
\text { GPT302 } \\
\text { GPT303 } \\
\text { GPT304 } \\
\text { GPT305 } \\
\text { GPR306 } \\
\text { GPT307 } \\
\text { GPT308 } \\
\text { GPT309 } \\
\end{array}$ & $\begin{array}{l}12 \\
15 \\
18 \\
22 \\
28 \\
37 \\
49 \\
62 \\
75 \\
89 \\
\end{array}$ \\
\hline Chordal TC. & \\
\hline 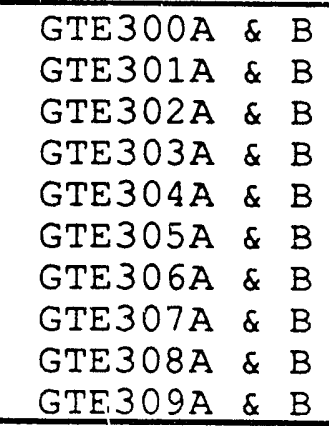 & $\begin{array}{r}15 \\
18 \\
23 \\
28 \\
37 \\
49 \\
62 \\
75 \\
89 \\
101\end{array}$ \\
\hline
\end{tabular}

The heat flux data averaged over these three zones are reported in this section, the suspension densities cannot be reported. Both are used to develop correlations for the heat transfer.

In addition to the pressure taps in combustor $B, \Delta P$ transmitters were installed on both combustors to measure the upper combustor pressure drop. These taps are located $12 \mathrm{ft}$. and $88 \mathrm{ft}$. above the air distributor and measure the pressure drop of the suspended bed material. The pressure drop data will be used to correlate bed temperatures.

\section{3 BED TEMPERATURE ANALYSIS}

At a given set of firing conditions (i.e. load, excess air, etc.) the bed temperature in a combustor is an indication of the amount of heat transfer taking place between the bed and the walls of the combustor. A heat balance taken around the Nucla boiler shows that approximately $65 \%$ of the lieat released in the furnace is absorbed by the water walls and superheater II. The remainder of the heat is removed from the furnace by the hot flue gas and is transferred to the 
convection pass surfaces. Tables $10-2$ and 10-3 show the actual distribution of heat absorption for Salt Creek and Peabody coals, respectively, at various loads. Also shown on these tables are the load, excess air, and average bed temperatures for sides $A$ and $B$ of the boiler. The percentage of heat absorption values are based on the following measuręments:

- Steam/water flow rate through the boiler component

- Boiler component inlet and outlet steam/water temperatures

- Boiler component inlet and outlet steam/water pressures

Table 10-2.

Boiler Heat Absorption for Salt Creek Coal

\begin{tabular}{|c|c|c|c|c|c|c|c|c|}
\hline $\begin{array}{l}\text { Test No. } \\
\text { Load MWe } \\
\text { Excess Air }{ }^{\circ} \\
\text { A Bed Temp }{ }^{\circ} \mathrm{F} \\
\text { B Bed Temp }{ }^{\circ} \mathrm{F}\end{array}$ & $\begin{array}{l}\text { SD1 } \\
105 \\
22.5 \\
1579 \\
1550 \\
\end{array}$ & $\begin{array}{l}\text { P30 } \\
55 \\
36.4 \\
1500 \\
1556 \\
\end{array}$ & $\begin{array}{l}\text { P31 } \\
82 \\
21.9 \\
1562 \\
1587 \\
\end{array}$ & $\begin{array}{l}\text { P49 } \\
98 \\
19.6 \\
1660 \\
1671 \\
\end{array}$ & $\begin{array}{l}\text { P } 50 \\
98 \\
19.6 \\
1641 \\
1677 \\
\end{array}$ & $\begin{array}{l}\text { P21 } \\
55 \\
42.0 \\
1552 \\
1540 \\
\end{array}$ & $\begin{array}{l}\text { P52 } \\
55 \\
41.8 \\
1551 \\
1525 \\
\end{array}$ & $\begin{array}{l}\text { P39 } \\
55 \\
39.0 \\
1559 \\
1569 \\
\end{array}$ \\
\hline \multicolumn{9}{|c|}{ Furnace $\frac{\circ}{\circ}$ of } \\
\hline $\begin{array}{l}\text { Combustor } \\
\text { SH2 }\end{array}$ & $\begin{array}{l}56.5 \\
11.5\end{array}$ & $\begin{array}{l}58.7 \\
10.0\end{array}$ & $\begin{array}{l}58.1 \\
11.0\end{array}$ & $\begin{array}{l}55.5 \\
11.0\end{array}$ & $\begin{array}{l}56.2 \\
11.1\end{array}$ & $\begin{array}{c}56.8 \\
9.8\end{array}$ & $\begin{array}{c}56.7 \\
9.4\end{array}$ & $\begin{array}{c}57.1 \\
9.9\end{array}$ \\
\hline Total & 68.0 & 68.7 & 69.1 & 66.5 & 67.3 & 66.6 & 66.1 & 67.0 \\
\hline \multicolumn{9}{|c|}{ Backpass of Heat Absorbed } \\
\hline $\begin{array}{l}\text { SH1 } \\
\text { SH3 } \\
\text { Eco \& Hanger } \\
\text { Conv Cage }\end{array}$ & $\begin{array}{l}13.9 \\
4.6 \\
10.6 \\
2.9\end{array}$ & $\begin{array}{l}12.1 \\
3.3 \\
12.4 \\
3.5\end{array}$ & $\begin{array}{c}12.9 \\
3.6 \\
11.1 \\
3.3\end{array}$ & $\begin{array}{l}14.1 \\
4.9 \\
11.0 \\
3.5\end{array}$ & $\begin{array}{c}14.0 \\
4.8 \\
10.7 \\
3.2\end{array}$ & $\begin{array}{l}13.8 \\
3.7 \\
12.4 \\
3.5\end{array}$ & $\begin{array}{l}14.1 \\
3.8 \\
12.5 \\
3.5\end{array}$ & $\begin{array}{c}13.5 \\
3.9 \\
12.2 \\
3.4\end{array}$ \\
\hline Total & 32.0 & 31.3 & 30.9 & 33.5 & 32.7 & 33.4 & 33.9 & 33.0 \\
\hline
\end{tabular}

Flow rates were directly measured except for main steam flow which was calculated based on feed water, total attemperator, and blowdown flows. Fluid temperatures at the inlet and outlet of each section were also directly measured. Steam pressures were only available at the steam drum inlet, the drum, and the outlet of superheater III. All other pressures were estimated based on design pressure drops.

Data show that the percentage of heat absorption in the furnace is relatively constant with load. There also appears to be little difference in the heat absorption of the furnace when firing the different fuels. In general, the heat 
absorption in the furnace increases slightly (0.5 to $\left.1 \frac{1}{6}\right)$ with load. This is most likely due to the fact that as the load is increased, the excess air is decreased.

Table $10-3$

Boiler Heat Absorption for Peabody Coal

\begin{tabular}{|c|c|c|c|c|c|c|c|c|}
\hline $\begin{array}{l}\text { Test No. } \\
\text { Load MWe } \\
\text { Excess Air }{ }^{\circ} \\
\text { A Bed Temp }{ }^{\circ} \mathrm{F} \\
\text { B Bed Temp }{ }^{\circ} \mathrm{F}\end{array}$ & $\begin{array}{l}\text { A01 } \\
100 \\
20.9 \\
1593 \\
1671 \\
\end{array}$ & $\begin{array}{l}\text { A02 } \\
104 \\
19.4 \\
1629 \\
1675 \\
\end{array}$ & $\begin{array}{l}\text { A03 } \\
104 \\
19.6 \\
1593 \\
1675 \\
\end{array}$ & $\begin{array}{c}\text { A04 } \\
82 \\
24.5 \\
1632 \\
1650 \\
\end{array}$ & $\begin{array}{r}\text { A05 } \\
82 \\
25.4 \\
1613 \\
1650 \\
\end{array}$ & $\begin{array}{c}A 06 \\
82 \\
24.4 \\
1617 \\
1648 \\
\end{array}$ & $\begin{array}{c}\text { A07 } \\
55 \\
38.5 \\
1533 \\
1535 \\
\end{array}$ & $\begin{array}{l}A 08 \\
104 \\
19.0 \\
1649 \\
1650 \\
\end{array}$ \\
\hline \multicolumn{9}{|c|}{ Furnace $\frac{\circ}{6}$ of Heat Absorbed } \\
\hline $\begin{array}{l}\text { Combustor } \\
\text { SH } 2\end{array}$ & $\begin{array}{l}55.2 \\
11.4\end{array}$ & $\begin{array}{l}55.6 \\
11.4\end{array}$ & $\begin{array}{l}55.9 \\
11.3\end{array}$ & $\begin{array}{l}55.5 \\
10.8\end{array}$ & $\begin{array}{l}55.3 \\
10.8\end{array}$ & $\begin{array}{l}55.8 \\
10.9\end{array}$ & $\begin{array}{c}57.0 \\
9.9\end{array}$ & $\begin{array}{l}55.7 \\
1.1 .5\end{array}$ \\
\hline Total & 66.6 & 67.0 & 67.2 & 66.3 & 66.1 & 66.7 & 66.9 & 67.2 \\
\hline \multicolumn{9}{|c|}{ Backpass $\frac{\circ}{\circ}$ of Heat Absorbed } \\
\hline $\begin{array}{l}\mathrm{SH} 1 \\
\mathrm{SH} 3 \\
\text { ECo \& Hanger } \\
\text { Conv Cage }\end{array}$ & $\begin{array}{c}14.2 \\
4.9 \\
11.0 \\
3.3\end{array}$ & $\begin{array}{l}14.2 \\
4.8 \\
11.0 \\
3.0\end{array}$ & $\begin{array}{c}14.3 \\
4.7 \\
10.6 \\
3.2\end{array}$ & $\begin{array}{l}14.2 \\
4.6 \\
11.2 \\
3.7\end{array}$ & $\begin{array}{l}14.4 \\
4.5 \\
11.5 \\
3.5\end{array}$ & $\begin{array}{l}14.3 \\
4.5 \\
10.9 \\
3.6\end{array}$ & $\begin{array}{c}13.1 \\
3.7 \\
12.3 \\
4.0\end{array}$ & $\begin{array}{l}14.3 \\
4.7 \\
10.6 \\
3.2\end{array}$ \\
\hline Total & 33.4 & 33.0 & 32.8 & 33.7 & 33.9 & 33.3 & 33.1 & 32.8 \\
\hline
\end{tabular}

Tables $10-2$ and $10-3$ also show a recurring problem experienced at Nucla, namely that the bed temperature in combustor $B$ is typically higher than the temperature in combustor $A$, except at low loads. Attempts to discover the cause of this difference revealed that the upper combustor flue gas pressure drop in combustor $B$ was generally operating at a lower level than in combustor $A$.

To further understand the effects of various operating parameters on the bed temperatures, data from combustor $B$ was analyzed when firing Peabody coal. It was found that the parameters that most affect bed temperature are load, flue gas oxygen, and upper combustor $\Delta P$ measured between the 24 and the $100 \mathrm{ft}$. pressure taps. These parameters are not entirely independent of each other, but were found to be effective in estimating operating temperatures. A correlation was developed for the bed temperature in combustor $B$ of the form: 


$$
T=T_{\text {Ref }}\left(\frac{\text { Load }}{\text { Load }_{\text {Ref }}}\right)^{\alpha}\left(\frac{O_{2}}{O_{2 \text { Ref }}}\right)^{\beta}\left(\frac{\Delta P}{\Delta P_{\text {Ref }}}\right)^{\gamma}
$$

Where: Load = Gross load in MWe

$\mathrm{O}_{2}=$ Flue gas oxygen at economizer outlet, Vol\%

$\Delta \mathrm{P}=$ Upper combustor pressure drop, in wg.

Test $A 08$ was chosen as the reference test. For this test $\mathrm{T}_{\text {Ref }}$ $=1620^{\circ} \mathrm{F}$, Load Ref $=104 \mathrm{MWe}, \mathrm{O}_{2 \text { Ref }}=3.32$ vol $\frac{\circ}{5}$, and $\Delta \mathrm{P}_{\text {Ref }}=6$ in wg. The correlation yielded the following exponents:

$$
\begin{aligned}
& \alpha=0.1697 \\
& \beta=-0.0823 \\
& \gamma=-0.2153
\end{aligned}
$$

Figure 10-1 shows the results of the correlation for the Peabody coal tests. These measurements and this correlation were developed during the Phase I testing. The standard deviation of the fit was $12^{\circ} \mathrm{F}$, which indicates that $68 \%$ of the bed temperature measurements fell within $\pm 12{ }^{\circ} \mathrm{F}$ of the calculated value.

During Phase II testing, the data from salt Creek coal was correlated for bed temperature. This time, data from both beds were used to develop the correlation. Furthermore, it was recognized that superficial velocity and load are somewhat analogous, although excess air has some impact on the differences between the two. Superficial velocity was used because the correlation was developed for both combustors, and velocity in each combustor is a better indication of the firing rate. The final form of the correlation chosen was:

$$
T=T_{\text {Ref }}\left(\frac{V_{S}}{V_{S R e f}}\right)^{\alpha}\left(\frac{O_{2}}{O_{2 R e f}}\right)^{\beta}\left(\frac{\Delta P}{\Delta P_{\text {Ref }}}\right)^{\gamma}
$$

Where: $V s=$ superficial velocity in each combustor.

For this correlation, it was desired to find one function that would fit both combustors. The following reference values were chosen: $\mathrm{T}_{\mathrm{Ref}}=1653^{\circ} \mathrm{F}, \mathrm{Vs}_{\mathrm{Ref}}=17.681 \mathrm{ft} / \mathrm{sec}, \mathrm{O}_{2 \mathrm{Ref}}$ $=3.132$ vol $\frac{5}{\circ}$, and $\Delta \mathrm{P}_{\text {Ref }}=6.145$ in wg. The correlation yielded the following exponents:

$$
\begin{aligned}
& \alpha=0.184 \\
& \beta=-0.085 \\
& \gamma=-0.100
\end{aligned}
$$




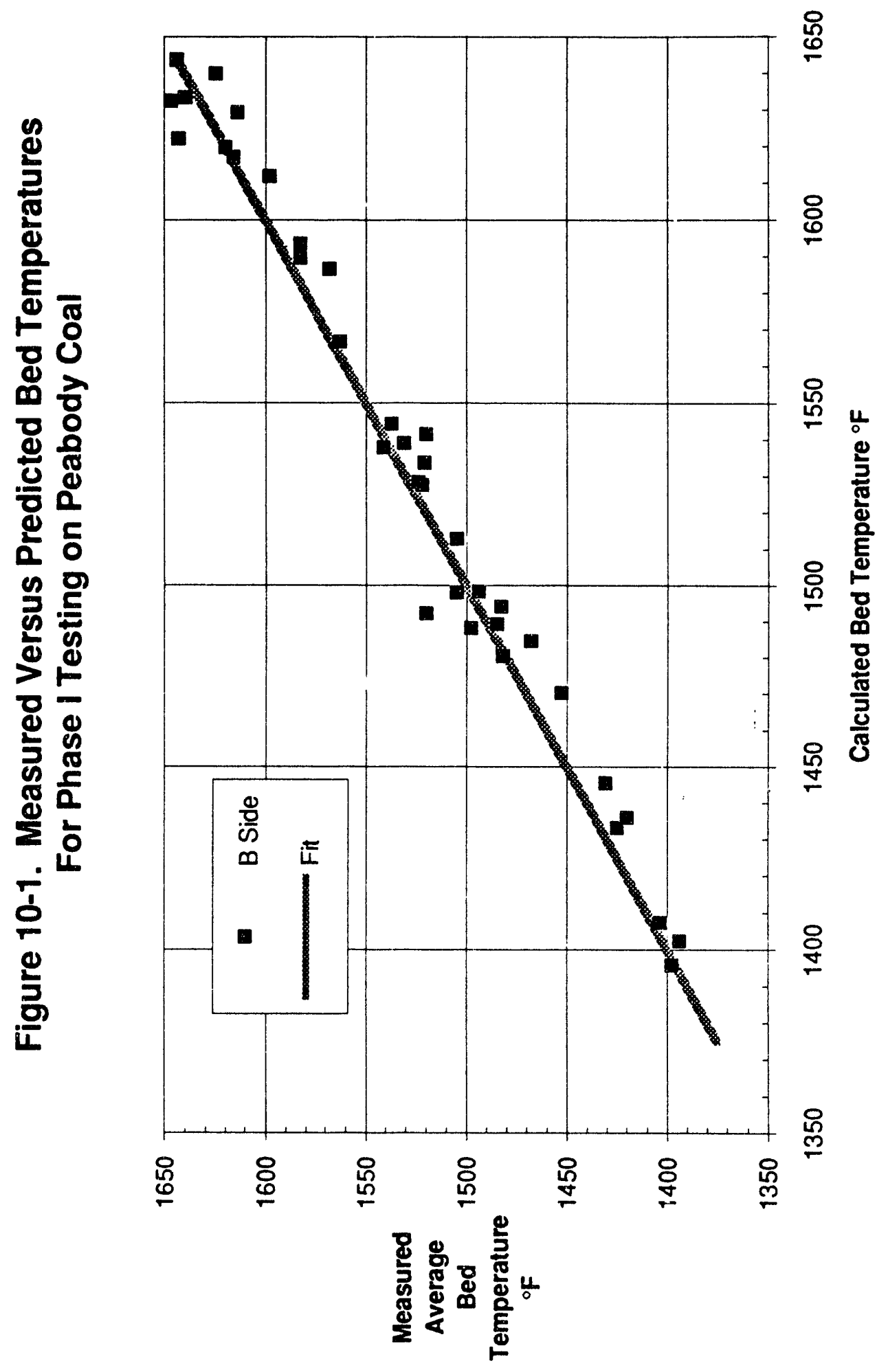

$10-6$ 
These values are similar to the ones obtained for the correlation for Peabody coal. Figure 10-2 shows the results of this correlation for the Phase II tests on Salt Creek coal. The standard deviation for this correlation was $15^{\circ} \mathrm{F}$. Note that this correlation fits both combustors. This indicates that there are no significant differences between the combustors to account for the temperature differences. Had there been differences, a single correlation would not have fit the data as well as this correlation.

Equation 2 sho is that a 1.5 inch differential in pressure between the two combustors accounts for about a $40^{\circ} \mathrm{F}$ differential in temperature. This is about the order of magnitude for both the differential pressure and operating temperature. This indicates that the different operating temperatures in the two combustors may be due to differences in the recirculation rates between the two combustors.

\section{4 HEAT FLUX CORRELATION}

The heat flux probes installed in the freeboard area were used to develop a correlation for the heat transfer in combustor B. Data used in the analysis were taken early during the Phase I test campaign. Shortly after the data were collected, some of the pressure taps were disconnected and the transmitters were used elsewhere in the plant. Table 10-4 shows the results of these heat flux measurements averaged over the three zones of the combustor.

The suspension density is the weight per unit volume of the bed. The bed is comprised of solid particles and void spaces. The suspension density is given by:

$$
\begin{aligned}
& \rho_{S}=(1-\varepsilon) \rho_{p} \\
& \text { Where: } \varepsilon=\text { bed voidage } \\
& \rho_{S}=\text { suspension density, } 1 \mathrm{~b} / \mathrm{ft}^{3} \\
& \rho_{\mathrm{p}}=\text { particle density, } 1 \mathrm{~b} / \mathrm{ft}^{3}
\end{aligned}
$$

The suspension density is calculated from the pressure profile in the combustor. The equation defining the suspension density is:

$$
\rho_{S}=-\frac{1}{g}\left(\frac{\Delta P}{\Delta h}\right)
$$

Where: $g$ = the gravitational constant $\mathrm{h}=$ height in $\mathrm{ft}$.

Combustor B at Nucla was equipped with 10 pressure taps and transmitters at various elevations up the rear wall of the 


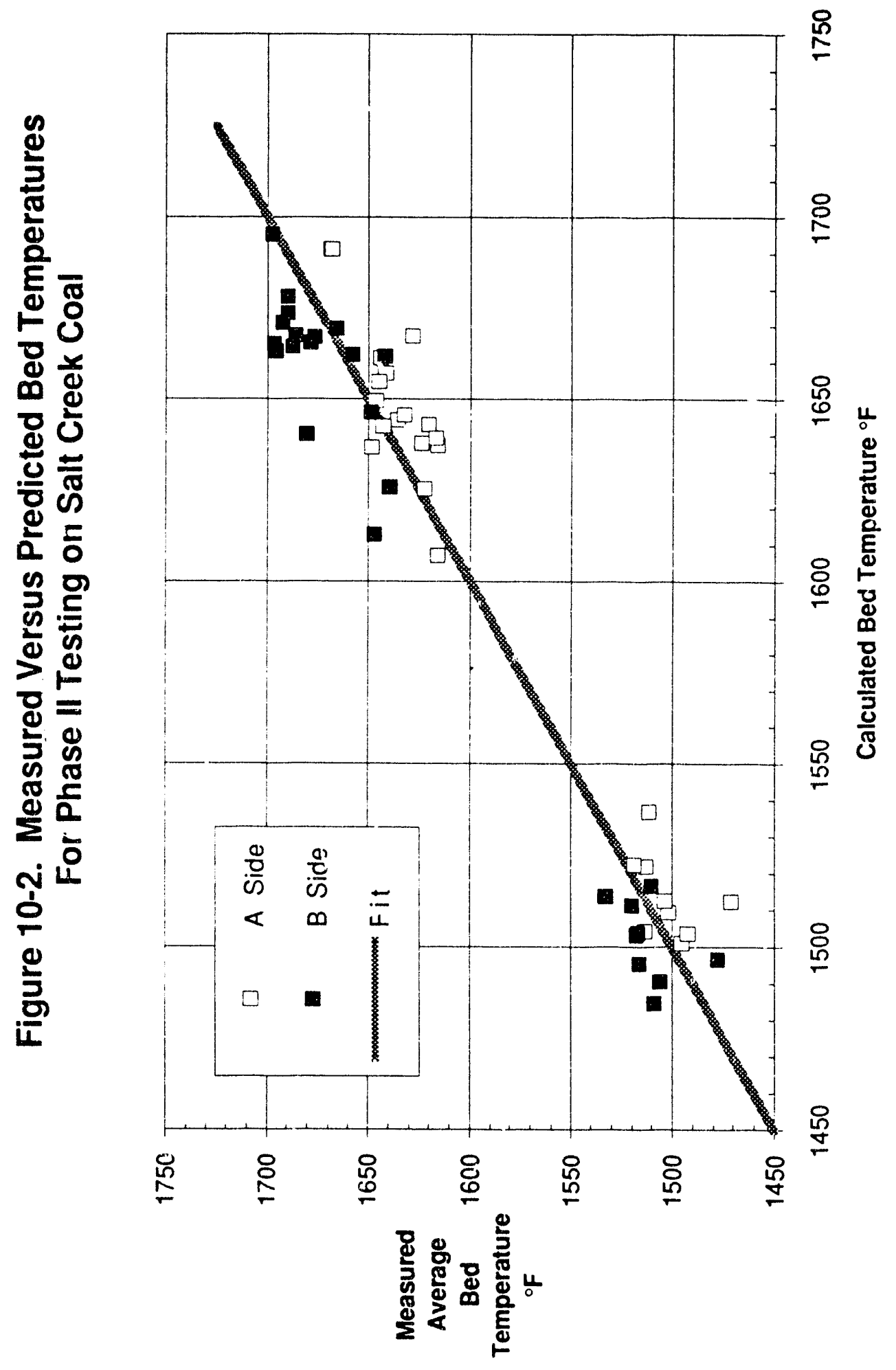




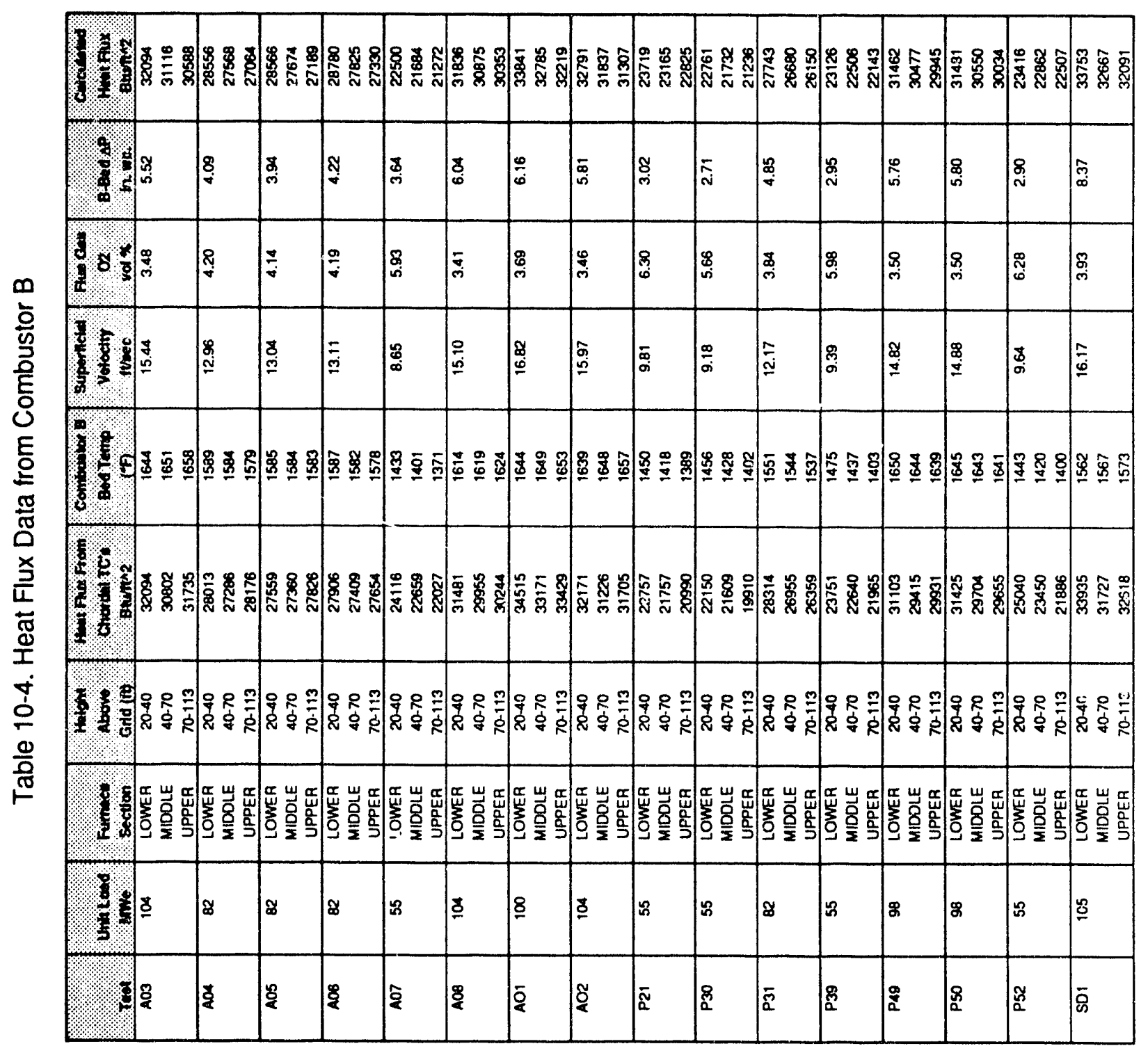


combustor. Taking the value of $\frac{\Delta p}{\Delta h}$ directly from the pressure tap readings proved difficult since the data were not always smooth. To improve the calcilation of the suspension density, a second order polynomial curve was fit to the absolute pressure readings versus the logarithmic height above the grid. This function was found to give a good fit of the pressure profile. Differentiating the curve fit with respect to height yielded the pressure gradient, which was then substituted into equation 4 above to give the suspension density as a function of height. The suspension densities were then averaged for the three zones.

Figure 10-3 shows the trend observed for the suspension density as a function of superficial velocity. Actual values for the suspension density cannot be shown. This curve shows that the suspension density is a relatively smooth function of velocity. Furthermore, the suspension density decreases with height in the combustor. Figure 10-4 shows the overall bed pressure drop versus superficial velocity. Note the similarity between this figure and the suspension density. Figure 10-5 shows the trend for the suspension density divided by the overall upper-bed $\Delta \mathrm{P}$ versus superficial velocity. This normalized suspension density was found to be constant over the range of velocities tested. This figure suggests that the pressure profile is similar at all loads and that the magnitude of the effect is determined by the overall pressure drop through the combustor.

Figure 10-6 shows the effect of superficial velocity on the heat flux measurements. Note that the heat flux is a strong function of velocity, particularly as velocity increases. Furthermore, there is only a slight difference in the heat fluxes between the lower furnace and the upper furnace. The difference between the upper and lower heat fluxes averaged $1200 \mathrm{Btu} / \mathrm{ft}^{2}$ and did not appear to be a function of velocity. Figure 10-7 shows the effect of suspension density on the heat flux. This figure shows that the suspension density does not strongly affect the heat flux, since the same heat flux can be obtained at densities that vary by as much as a factor of 2 .

To further examine the effect of velocity and suspension density on the heat flux, a correlation of the form:

$$
H F=H_{R e f}\left(V_{S}\right)^{\alpha}\left(\rho_{S}\right)^{\beta}
$$

was developed. The value of $\mathrm{HF}_{\text {Ref }}$ was $6948 \mathrm{Btu} / \mathrm{ft}^{2}$. The correlation yielded the following values for the exponents: 
Figure 10-3. Suspension Density Versus Superticial Velocity

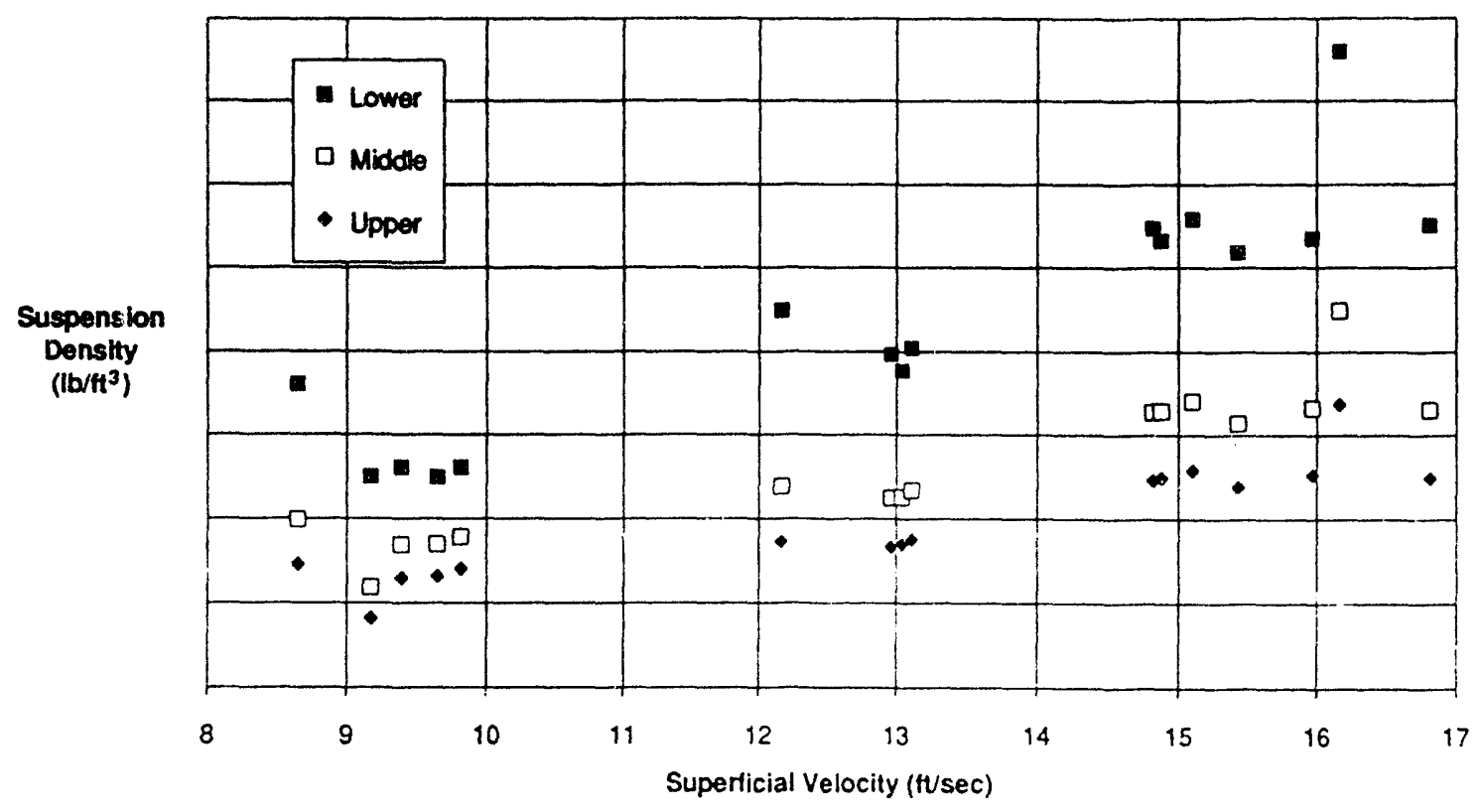

Flgure 10-4. Bed $\triangle P$ Versus Superficial Velocity For Combustor B

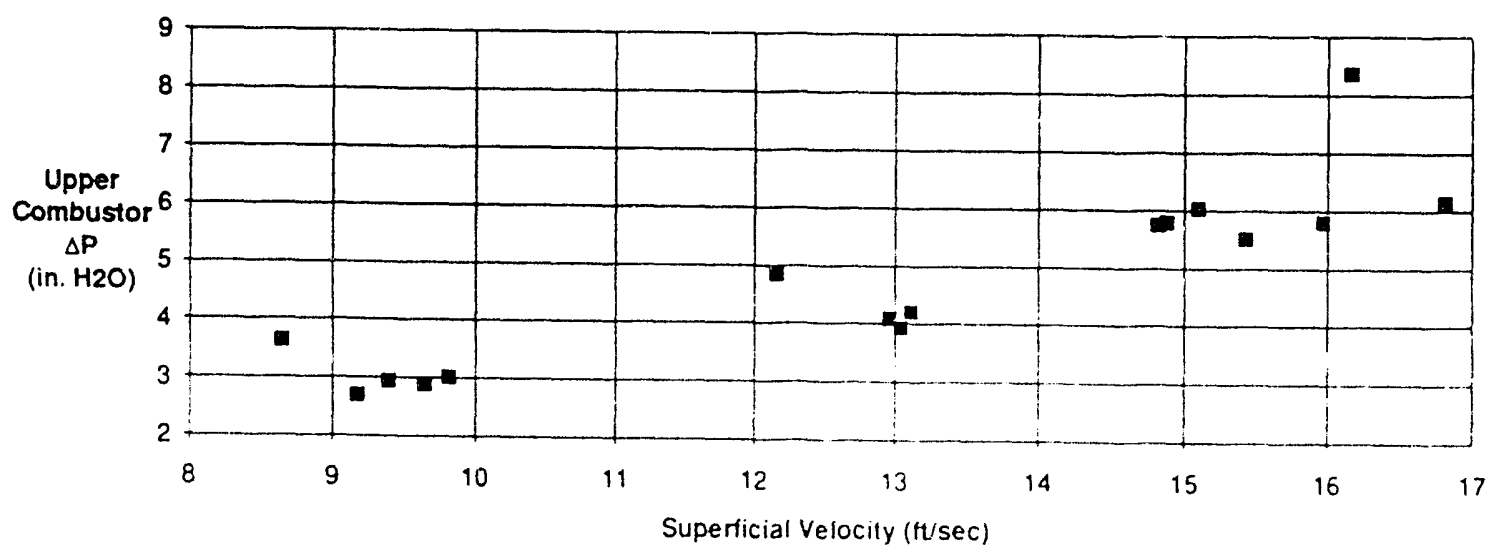


Figure 10-5. Normalized Suspension Density Versus Superficial Velocity

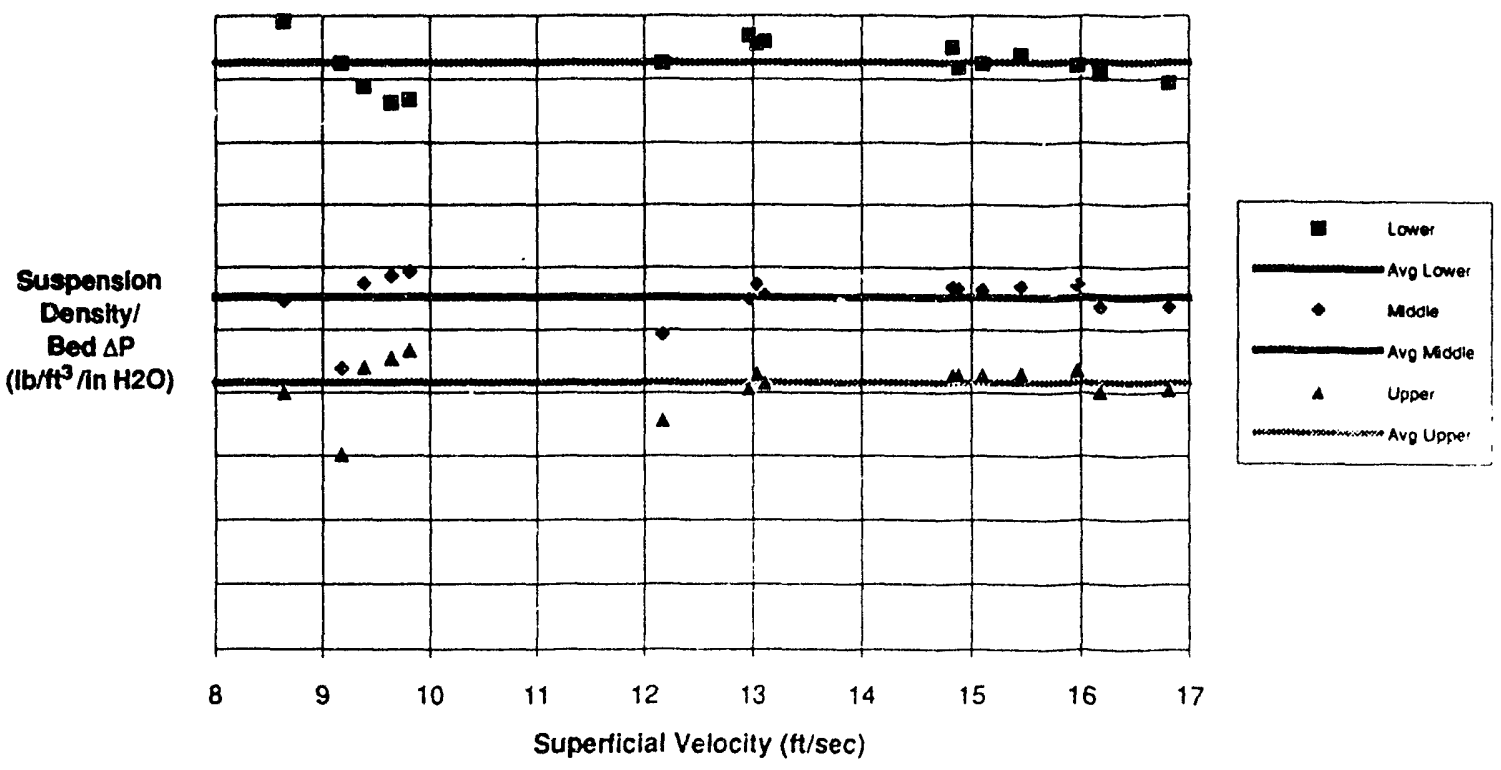

Figure 10-6. Heat Flux Versus Superficial Velocity

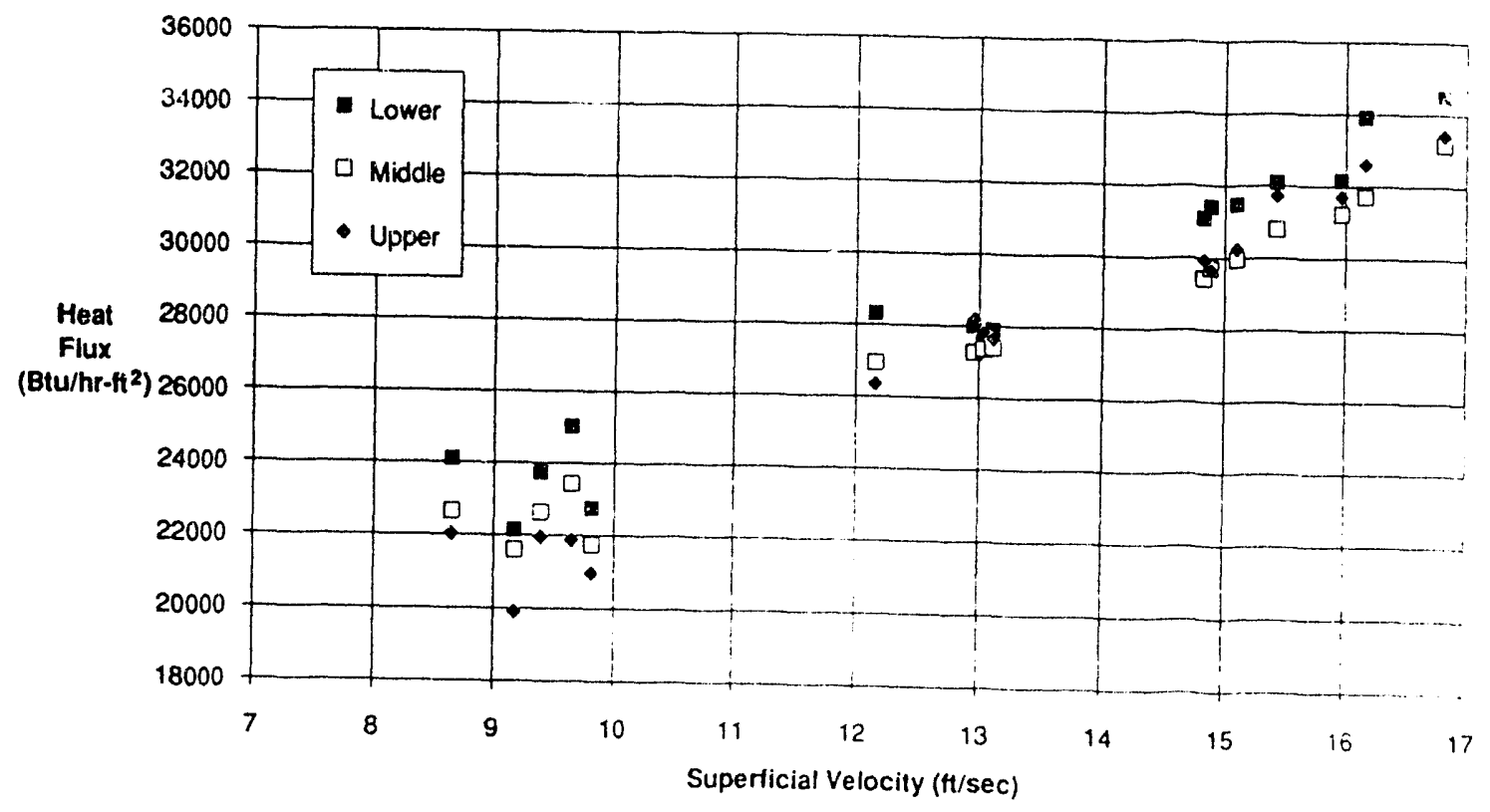


Figure 10-7. Heat Flux Versus Suspension Density

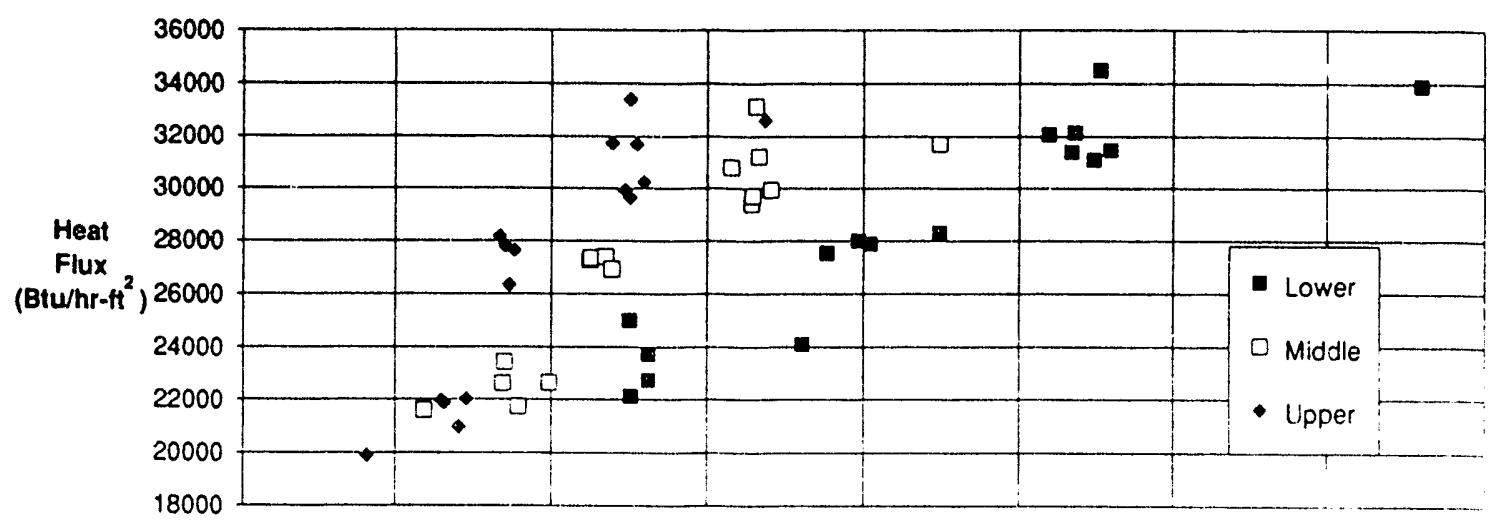

Suspension Density (Ib/t 3

Figure 10-8. Heat Flux Correlation

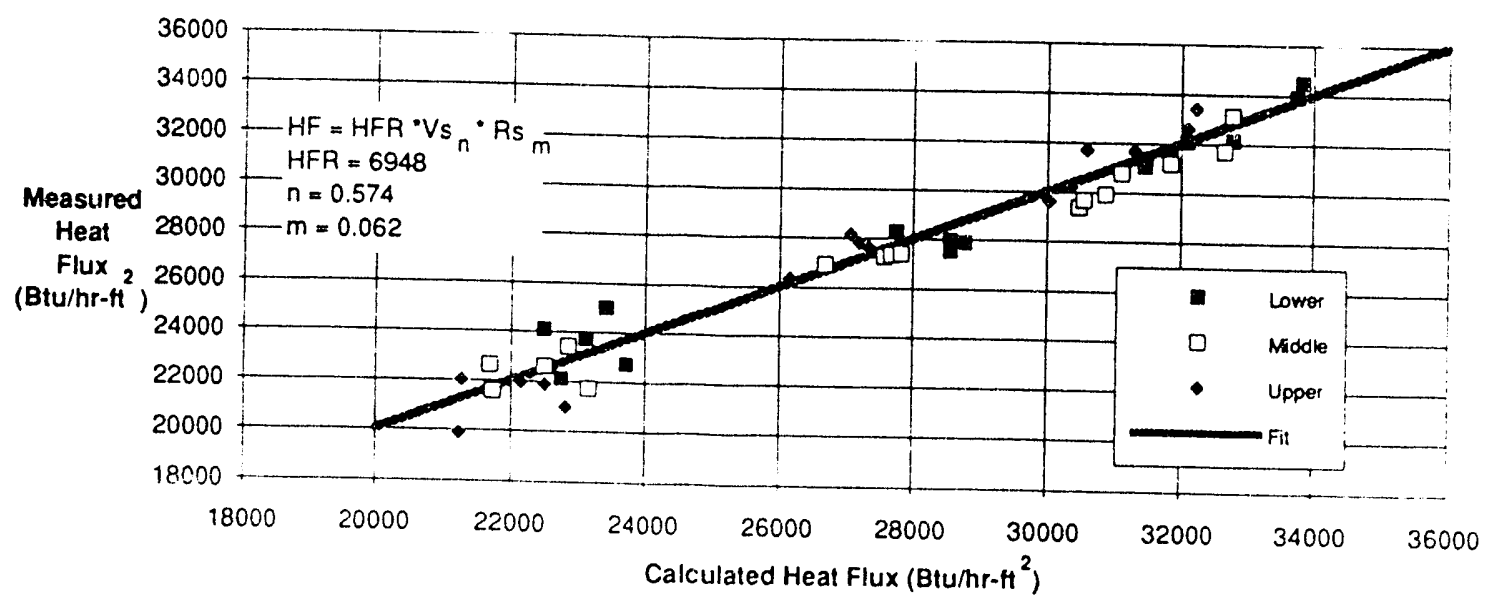




$$
\begin{aligned}
& \alpha=0.574 \\
& \beta=0.062
\end{aligned}
$$

Note that the low value for the exponent on the suspension density indicates a very weak influence on the heat transfer. Figure 10-8 shows the results of this correlation. The standard deviation on the calculated heat flux was 795 Btu/ft ${ }^{2}$.

The magnitude of the coefficients found in equation 5 indicates that the effect of suspension density is very minor relative to the effect of superficial velocity. The coefficient of 0.574 for the velocity term suggests a mechanism for heat transfer similar to gas convection, which has a velocity coefficient of 0.5 . However the overall magnitude of the heat transfer rate is approximately two to three times the value for simple gas convection with radiation.

\subsection{DISCUSSION OF RESULTS}

In the 1990 Annual Report, a number of observations were made regarding the temperature differential between the two combustors. Those observations are repeated here as a start of the discussion on heat transfer and boiler operations.

Observation 1. Combustor B generally has the higher operating bed temperature and cyclone inlet temperature.

Observation 2. Eurnace water-wall differential pressure is lowest in the combustor with the higher temperature. The differential fressure is a direct indication of solids loading and is generally lower in combustor B compared to combustor A.

Observation 3. Circulating material is consistently coarser in combustor $B$ as indicated by samples taken from each loop seal. At full load operation, this material generally gets coarser after three or four days following a start-up until an equilibrium is achieved.

Observation 4. Loop seal pressure measured at the bottom of the loop seal is lowest in the combustor with the higher temperature. In addition, loop seal differential pressure is lowest in the combustor with the higher temperature. These pressure measurements may indicate lower recycle rates in cyclone B. 
Observation 5 .

Observation 6 .

Observation 7 .

Observation 8 .

Observation 9.

Observation 10 .
Cyclone differential pressure (between the inlet and outlet) is lowest in the combustor with the highest temperature. Typically, this value is $2.8 \mathrm{in.} \mathrm{wg}$. in cyclone $A$ and 2.3 in.wg. in cyclone $B$ at full load.

The temperature in combustor $B$ was only moderately affected by bed inventory changes, SA/PA split, loop seal air flow changes or classification in the bottom ash cooler at any classification velocity. Combustor $A$ showed a better response to bed inventory and SA/PA split, but the temperature change effected was still only $30{ }^{\circ} \mathrm{F}$.

Changes in coal ash content have affected combustor temperature. An increase in ash content resulted in a lower combustor temperature as seen on June 1990 when the delivered Salt Creek coal ash content increased from $14 \%$ to $20 \%$.

Although the temperature differential has existed since initial start-up of the boiler, it appears to have become more prevalent since switching from Peabody coal to Salt Creek coal in July 1989. Unfortunately, periods of continuous full load operation with Peabody coal were infrequent. Therefore, the impact of coal type on the temperature differential is inconclusive. Peabody coal generally was several percent higher in ash content than Salt Creek coal.

Several upsets in furnace draft initiated by coal feeder trips have resulted in increased water-wall differential pressure and lower temperatures in combustor $B$. In every case, the improvement was short term and temperatures returned to their previous levels within hours of the event.

Load cycling of the boiler has demonstrated an interesting effect on the combustor $B$ water-wall differential pressure, and therefore, on combustor B temperature. Figures 10-9 and 10-10 illustrate a typical cycling behavior. During full load, steady-state operation, Combustor B waterwall differential pressure is lower than 
the corresponding pressure in combustor $A$. When load was decreased to $50 \%$ MCR, both watei. wall differential pressures dropped and then started to increase to reach final equilibrium values. However, the rate of increase was faster in combustor $B$ and within 36 hours, both water-wall differential pressures attained the same value. Consequently, the combustor temperatures became balanced. Upon return to full load, both water-wall differential pressures increased together to the previous full load value in combustor $A$, which was higher than the combustor $B$ water-wall differential pressure. The Combustor A water-wall differential pressure remained constant but the waterwall differential pressure in combustor $B$ started to decrease immediately, causing the bed temperatures to diverge.

The temperature differential prior to the load change in Figures 10-9 and 10-10 can be explained solely in terms of the water-wall pressure differential in the two combustors. Prior to the load change, the pressure differential in combustor A was $7.3 \mathrm{in.wg}$. and the pressure differential in combustor B was 5.5 in.wg. The correlations for bed temperature indicate that this pressure differential should result in approximately a $50^{\circ} \mathrm{F}$ temperature differential between the two beds, while the actual differential was 55 ${ }^{\circ} \mathrm{F}$.

Unfortunately, Observation 6 indicates that there is no way of controlling the water-wall pressure drop in either of the combustors. The bed classifier is not apparently capable of classifying the right size material in sufficient quantities to control the bed pressure differential. Therefore, the operation of the boiler at a given load is uncontrolied with respect to heat transfer, and the unit is dependent on the fuel ash content for temperature control.

The problem with the difference in water-wall pressure differentials between the two combustors appears to be due to a slight difference in the collection efficiency curves of the two cyclones. This is indicated by observation 3 and Observation 10. Observation 3 states that the recirculating material in the seal leg of combustor $B$ is coarser than the material from cyclone $A$. This indicates that $A$ cyclone is more efficient at collecting smaller particles than combustor B.

Only a small difference in the collection efficiencies is required to force large differences in size the distributions between the two cyclones. Because all material that is 


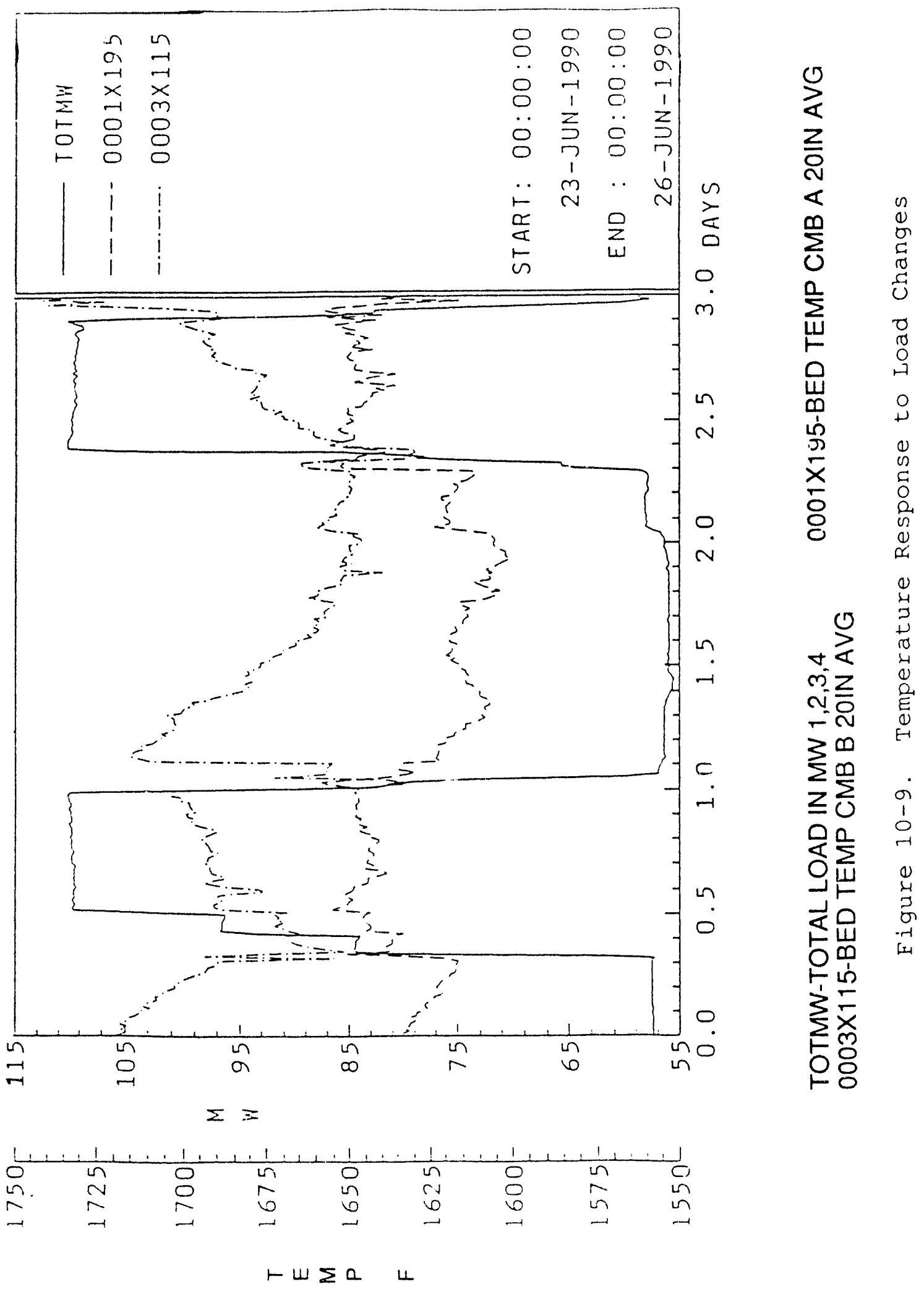




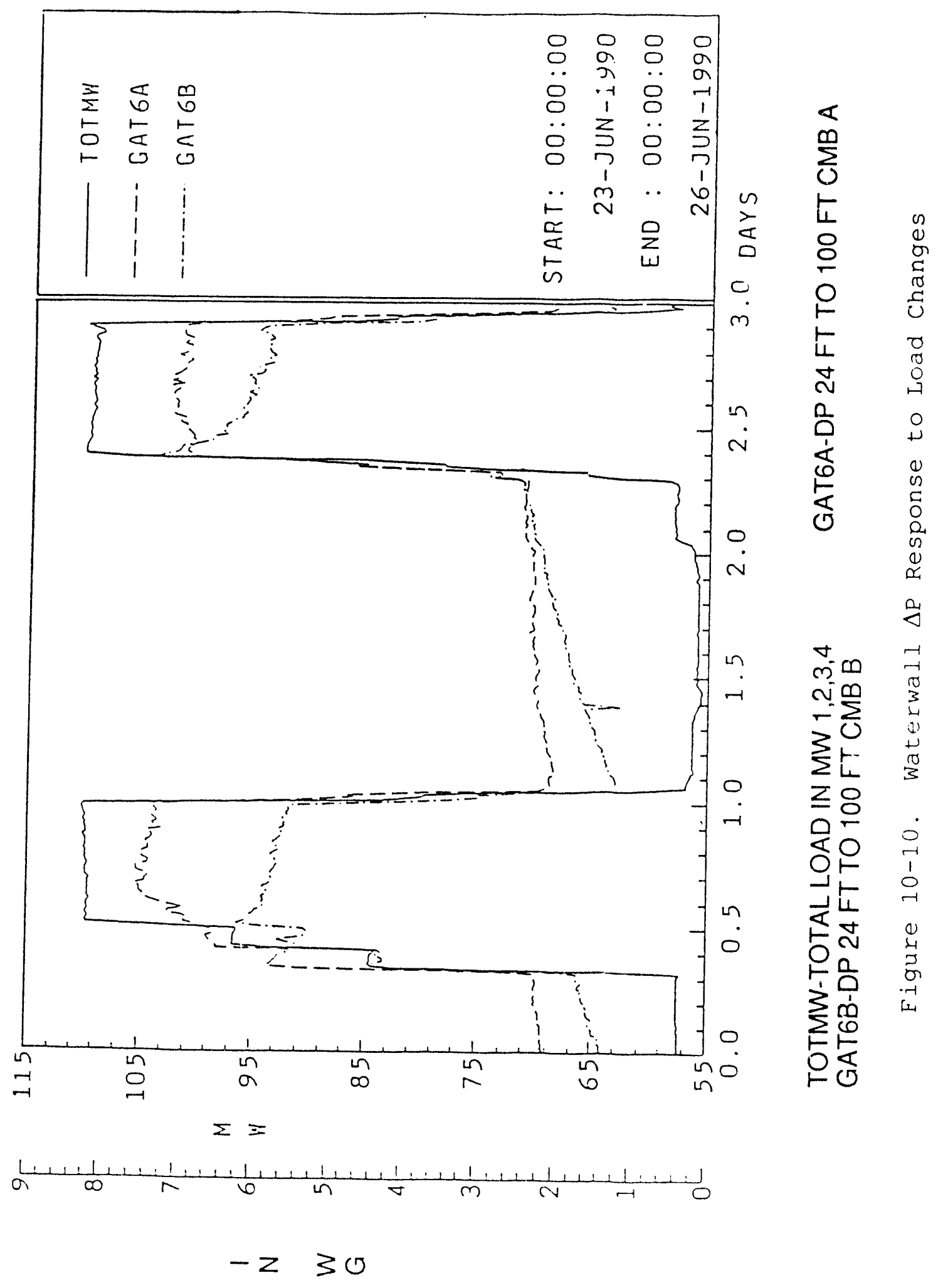


collected is reinjected, the weight of material in size cut $D_{i}$ is given by:

$$
\begin{aligned}
& W_{D i}=\frac{F r i}{\left(1-\frac{1}{\left.\eta_{i}\right)}\right.} \\
& \text { Where: } F_{D i}=\text { the amount of feed material in } \\
& \text { the size range } D_{i} \text { less the amount } \\
& \text { removed by the bed drain and attrition } \\
& \text { plus the amount added by attrition. } \\
& \eta_{i}=\text { the cyclone collection efficiency } \\
& \text { for particles of size } D_{i}
\end{aligned}
$$

At a fixed load, $F_{D i}$ is a constant value between both combustors. If, for example, the cyclone collection efficiency of a 180 micron particle is $98 \%$ in cyclone $A$ and only $96 \%$ in cyclone $B$, equation 6 predicts that the amount of 180 micron material circulating in combustor $A$ will be twice the amount of material in combustor $B$. Therefore, what amounts to an almost unmeasurable difference in cyclone collection efficiency can be magnified by the total recirculation system to become a very significant difference in the total recirculation rates between the two combustors.

Both the correlations for bed temperature and the correlation for heat flux show similar exponents for the $\Delta \mathrm{P}$ term 10.116 and 0.1 for the temperature correlations and 0.062 for the heat flux correlation). All of the correlations predict only a weak influence due to the water-wall $\Delta \mathrm{P}$. The pressure drops listed above ( $7.3 \mathrm{in.wg}$ for $A$ and 5.5 in. wg. for $B$ ) should make the heat flux in combustor $B$ be $1.7 \%$ less than the heat flux in combustor $A$. However, in order to operate either of the combustors at full load and $1550^{\circ} \mathrm{F}$, the waterwall $\Delta \mathrm{E}$ will have to be raised to over $13 \mathrm{in.wg}$., which is very difficult with the present cyclones.

Based on the heat transfer tests conducted at Nucla, it is apparent that the combustor temperatures are essentially uncontrollable. On a given day, there is no control element available to the operator to modify the temperature in either combustor except by excess air. In order for the combustor $B$ temperature to approximately equal that of combustor A, combustor $B$ would have to be operated at about 4.5 vol $\frac{0}{\circ} \mathrm{O}_{2}$, while combustor $A$ was operated at the normal amount of about $3 \mathrm{vol}: \mathrm{O}_{2}$. This type of operation would require about 5\% more air than the present operations. Since $\mathrm{SO}_{2}$ emissions have been found to increase dramatically above $1620{ }^{\circ} \mathrm{F}$, it is recommended that the unit cperate with enough excess air in each side of the combustor to maintain combustor temperatures below the $1620^{\circ} \mathrm{F}$ limit. 
Section 11

HOT CYCLONE PERFORMANCE

\subsection{APPROACH AND METHODOLOGY}

Proper performance of the hot cyclones of a CFB is vital to the proper operation of the unit. Data from Nucla have shown that maintenance of solids inventory in the furnace is essential for control of furnace temperatures. Therefore, it is important that the cyclones have a high collection efficiency in order to maintain the high solids loadings that are necessary.

The high solids loadings and the harsh environment in which these cyclones operate make direct measurement of the cyclone collection efficiency practically impossible. A plan had been developed to use samples of the seal leg and the fly ash to determine the cut point of the cyclones at Nucla and compare the measurements to model predictions. However, these tests were postponed indefinitely, at DOE's request, to concentrate CUEA's efforts on delivery of outstanding and final reports.

Temperature differences between the two combustors have indicated that there may be differences in the collection efficiency of the two cyclones at Nucla. In this report, data are presented from two direct measurements that were taken at the cyclone during the steady state performance tests. These measurements are cyclone pressure drop and temperature rise across the cyclone. The upper combustor pressure drop will also be used to evaluate the cyclone performance. These measurements will be examined to provide estimates of the different cyclone collection efficiencies.

\subsection{PRESSURE DROP}

The pressure drop across the cyclone is an important parameter both from a design and operational points of view. From a design standpoint, the cyclone pressure drop represents an energy loss that must be accounted for in the fan design. During operations, differences in the pressure drop readings under identical operating conditions may indicate a fuel change or a cyclone problem.

Figure 11-1 shows the cyclone pressure drop for both cyclones $A$ and $B$, as a function of the upper bed pressure drop, for both the Salt Creek and Dorchester coal tests conducted during the Phase II test program. This graph shows that Dorchester coal, with the higher ash content, has a 


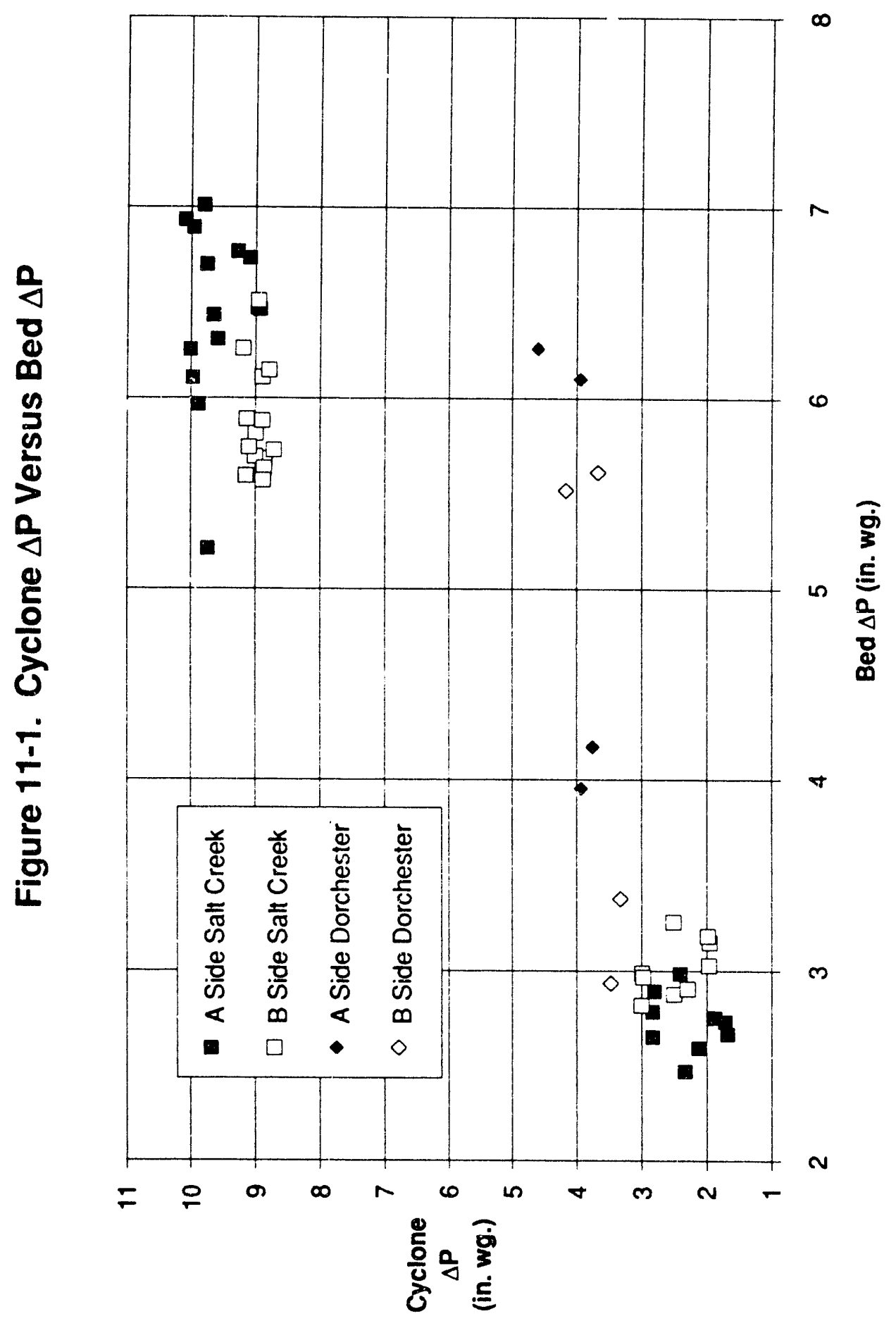


different pattern than the salt Creek coal. The bed pressure drop shown on the $\mathrm{x}$-axis of Figure $11-1$ is the pressure drop between the 24 and $100 \mathrm{ft}$ elevations. This value is believed to be proportional to the solids loading in the furnace, and therefore, to the inlet loading of the cyclone.

The pressure drop through a cyclone is essentially the sum of two components. The first is the pressure drop associated with the gas velocity. This term is proportional to the velocity squared. The second component of the pressure drop is that associated with the acceleration of solid particles in the cyclone. This term is proportional to the solids loading times the velocitj squared. Mathematically, the pressure drop can be expressed as:

$$
\begin{array}{ll}
\Delta \mathrm{P}_{\text {cyc }}=\mathrm{K}_{1} & \mathrm{~V}_{\mathrm{s}}^{2}+\mathrm{K}_{2} \rho_{\mathrm{s}} \mathrm{V}_{\mathrm{s}}^{2} \\
\text { Where: } & \mathrm{K}_{1} \& \mathrm{~K}_{2}=\text { proportionality constants } \\
& \mathrm{V}_{\mathrm{s}}=\text { superficial velocity in the combustor } \\
& \rho_{\mathrm{s}}=\text { solids density at the cyclone inlet. }
\end{array}
$$

The solids density at the combustor inlet can be approximated by the upper combustor $\Delta \mathrm{P}\left(\Delta \mathrm{P}_{\text {bed }}\right)$. Rearranging equation 1 and replacing $\rho_{\mathrm{s}}$ with $\Delta \mathrm{P}_{\text {bed }}$ gives:

$$
\frac{\Delta \mathrm{P}_{\mathrm{cyc}}}{\mathrm{V}_{\mathrm{S}}^{2}}=\mathrm{K}_{1}+\mathrm{K}_{2} \Delta \mathrm{P}_{\text {bed }}
$$

Equation 2 shows that a plot of $\frac{\Delta \mathrm{P}_{\mathrm{CYC}}}{\mathrm{V}_{\mathrm{s}}{ }^{2}}$ versus $\Delta \mathrm{P}_{\text {bed }}$ should yield a straight line of slope $K_{2}$ and intercept $K_{1}$. Figure 11-2 shows this plot for the Salt Creek coal and Dorchester coal tests. The lines represent the least. squares fit of the combustor $A$ and combustor $B$ data for Salt Creek coal. While there is a good amount of scatter in the data, the least squares fit did give slightly different values for $K_{1}$ and $K_{2}$ for the two cyclones.

Figure 11-3 shows a plot of the measured versus calculated cyclone $\Delta P$ using the values of $K_{1}$ and $K_{2}$ for the two cyclones. The correlation does a fair job of predicting the cyclone pressure drop, with all but one of the Dorchester coal tests falling within \pm 1 inch wg.

\subsection{COLLECTION EFEICIENCY ESTIMATE}

As was stated above, the upper bed pressure drop is an indication of the solids loading in the combustor. Figure 10-5, in the Heat Transfer section, showed that the average suspension density divided by the bed $\Delta \mathrm{P}$ was a constant that 


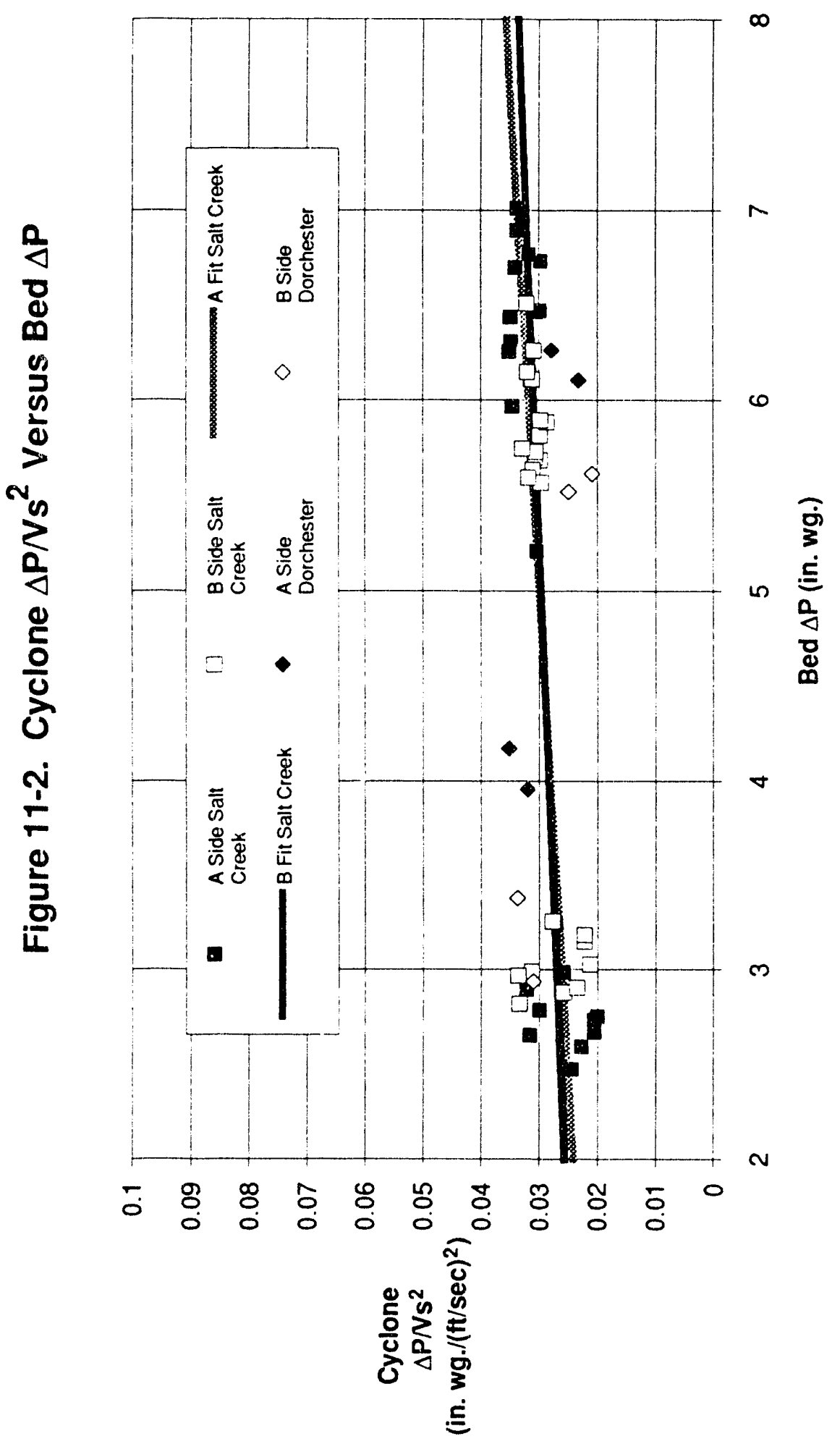




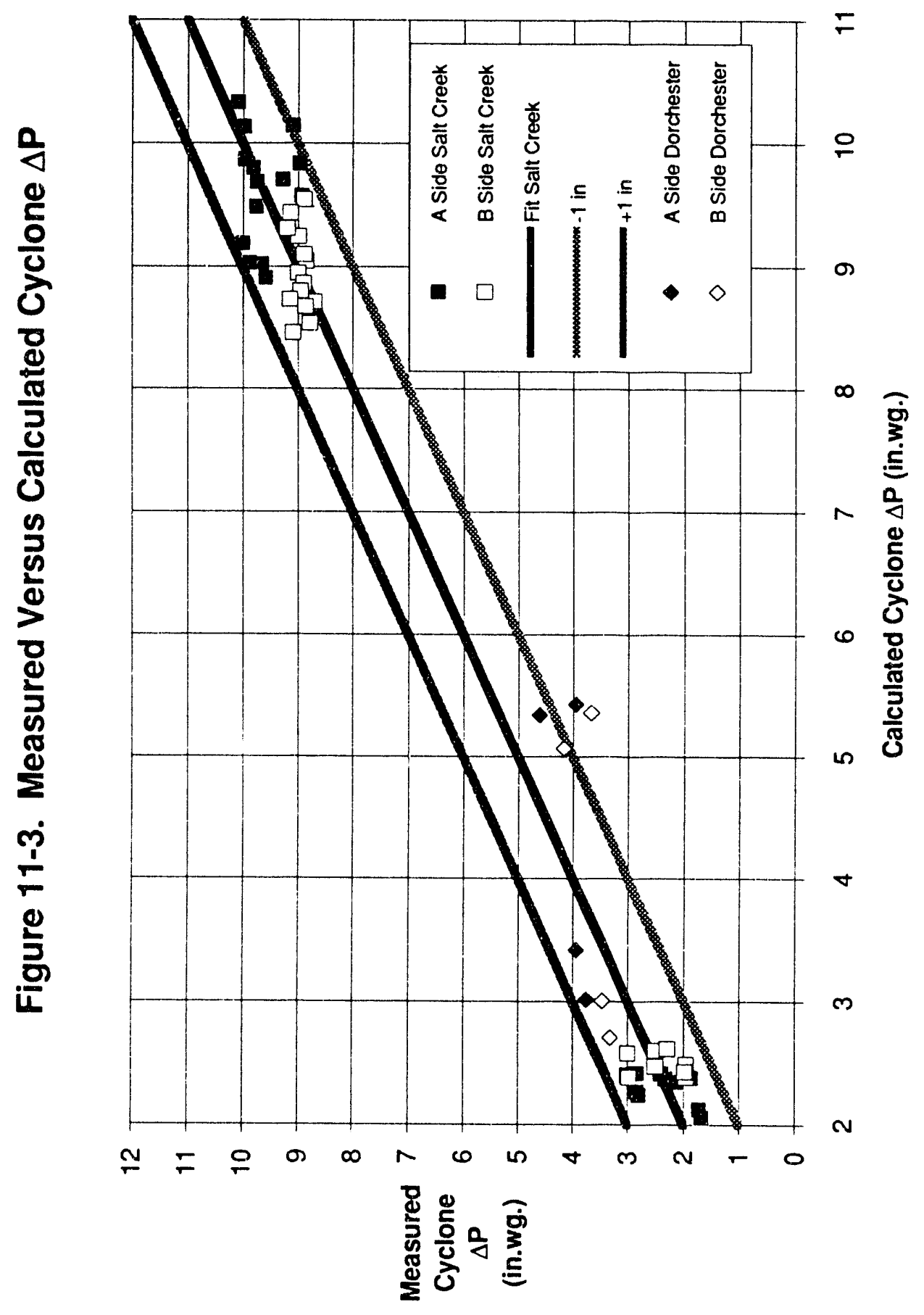


decreased exponentially with height up the combustor. Projecting this ratio of suspension density over bed $\Delta \mathrm{P}$ to the top of the combustor yields a value of 0.0333 lb/ft $3 /$ in.wg. Studies done with small scale CFB columns indicate that $80 \%$ of this pressure drop is due to the solids that are carried out of the furnace, while $20 \%$ of this pressure drop is caused by the forces needed to maintain the high solids loadings near the wall of the combustor. Therefore, the flow rate of solids out of the combustor and into the cyclone, $W_{C i n}$ is given by:

$$
\mathrm{W}_{\text {Cin }}=0.0333 \cdot 0.8 \cdot \Delta \mathrm{P}_{\text {bed }} \cdot \mathrm{V}_{\mathrm{S}} \cdot \mathrm{A}_{\text {bed }} \cdot 3600 \quad \mathrm{lb} / \mathrm{hr}
$$

Where: $\quad A_{\text {bed }}=$ bed cross sectional area $\mathrm{ft}^{2}$

The amount of fly ash leaving the combustor, WCout, can be found by performing an inerts balance around each combustor. The inerts balance is similar to the one used to calculate the fly ash flow rate leaving the boiler, and is described in section 4.1.5. The cyclone collection efficiency is then given by:

$$
\eta_{\text {cyc }}=100\left(1-\frac{W_{\text {Cout }}}{W_{\text {Cin }}}\right)
$$

Figure 11-4 shows the cyclone efficiencies for both cyclones calculated for Salt Creek and Dorchester coal tests as a function of the combustor superficial velocity. Note that for the full load tests, between 16 and $18 \mathrm{ft} / \mathrm{sec}$, the cyclone efficiency for cyclone $B$ is slightly less than the efficiency for cyclone $A$. Also note that at the half load tests, between 9 and $10 \mathrm{ft} / \mathrm{sec}$, this trend appears to reverse itself.

Figure 11-4 shows that the collection efficiency for the cyclones is quite high, ranging from $99.5 \%$ at half load to about 99.8\% at full load. At these cyclone efficiencies, the recycle rate of solids in the combustor is quite high.

Figure 11-5 shows the estimated recycle ratio, in lb fly ash/lb coal, versus the cyclone collection efficiency. For the full load tests, the recycle ratio ranged from 72 to 115 times the coal feed rate. Note that the combustor $B$ recycle rate ranged from 72 to 105 times the coal feed rate while the recycle rate on combustor A ranged from 80 to 115 times the coal feed rate. This clearly demonstrates how even a slight difference in the cyclone collection efficiencies can be magnified by the total recycle system.

Figure 11-6 shows the estimated recycle rate versus the superficial velocity in the bed. The most surprising result of this graph is the apparently linear relationship between the recycle rate and the superficial velocity. However, there is not sufficient data to confirm this conclusion, 

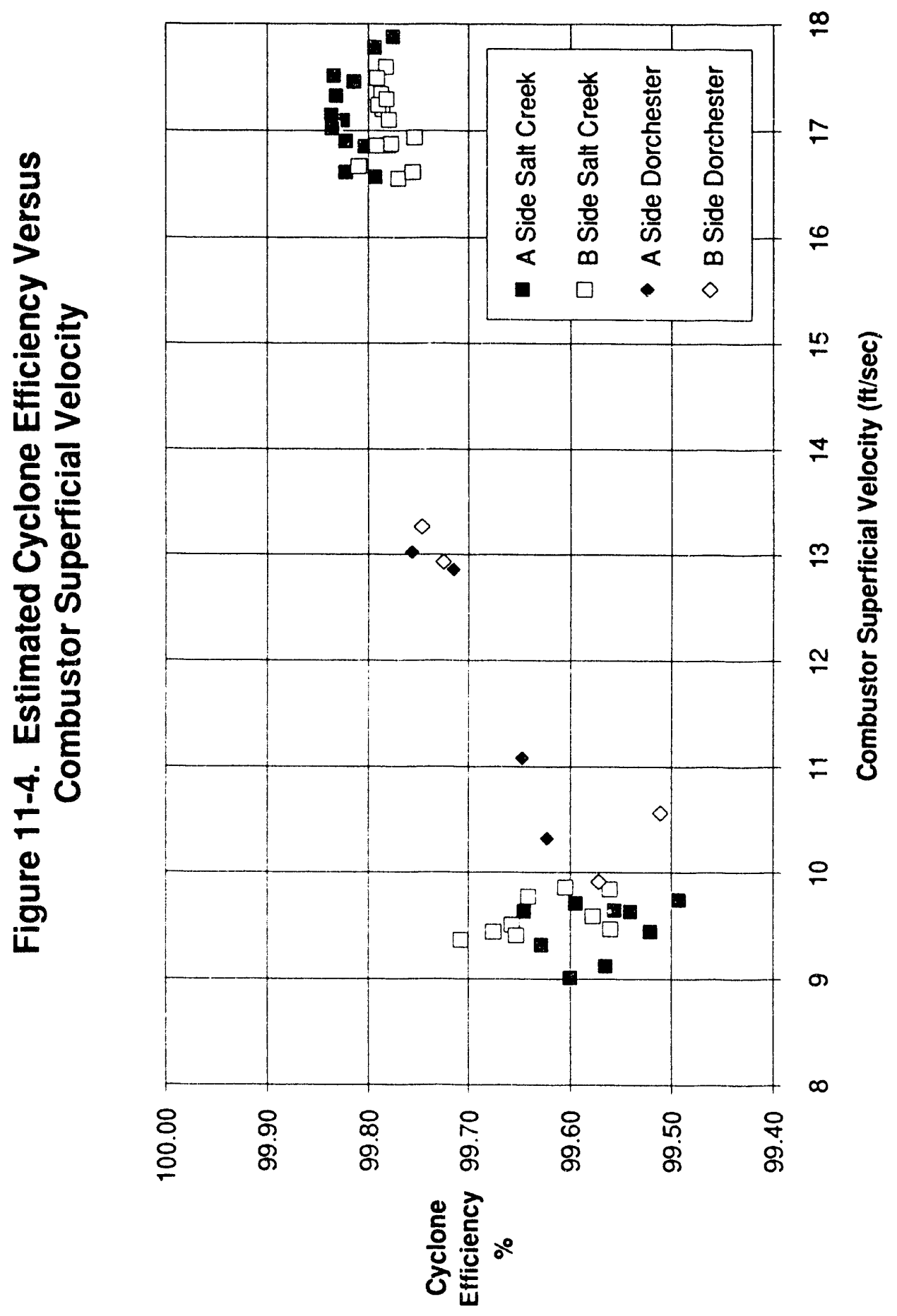


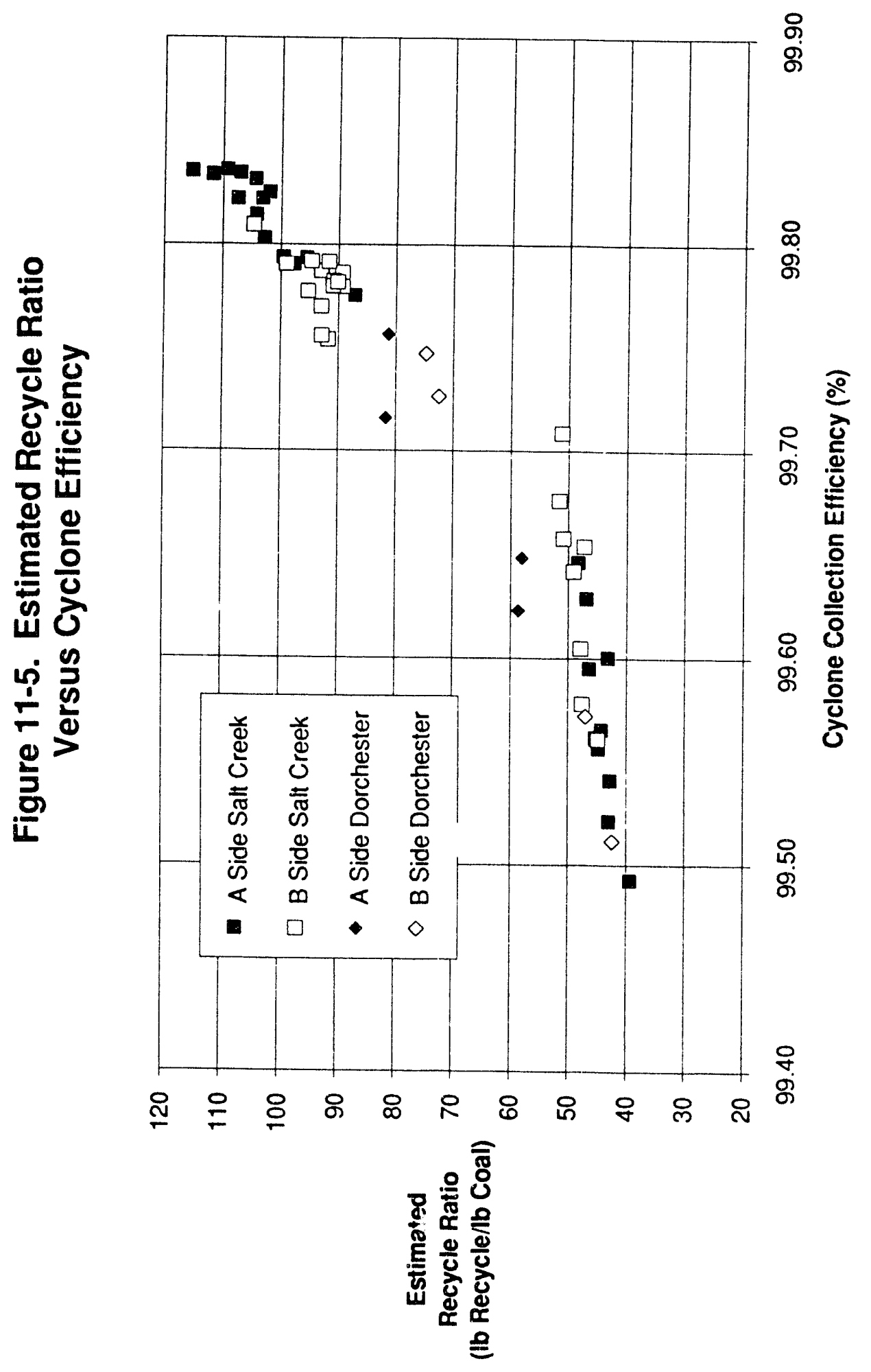



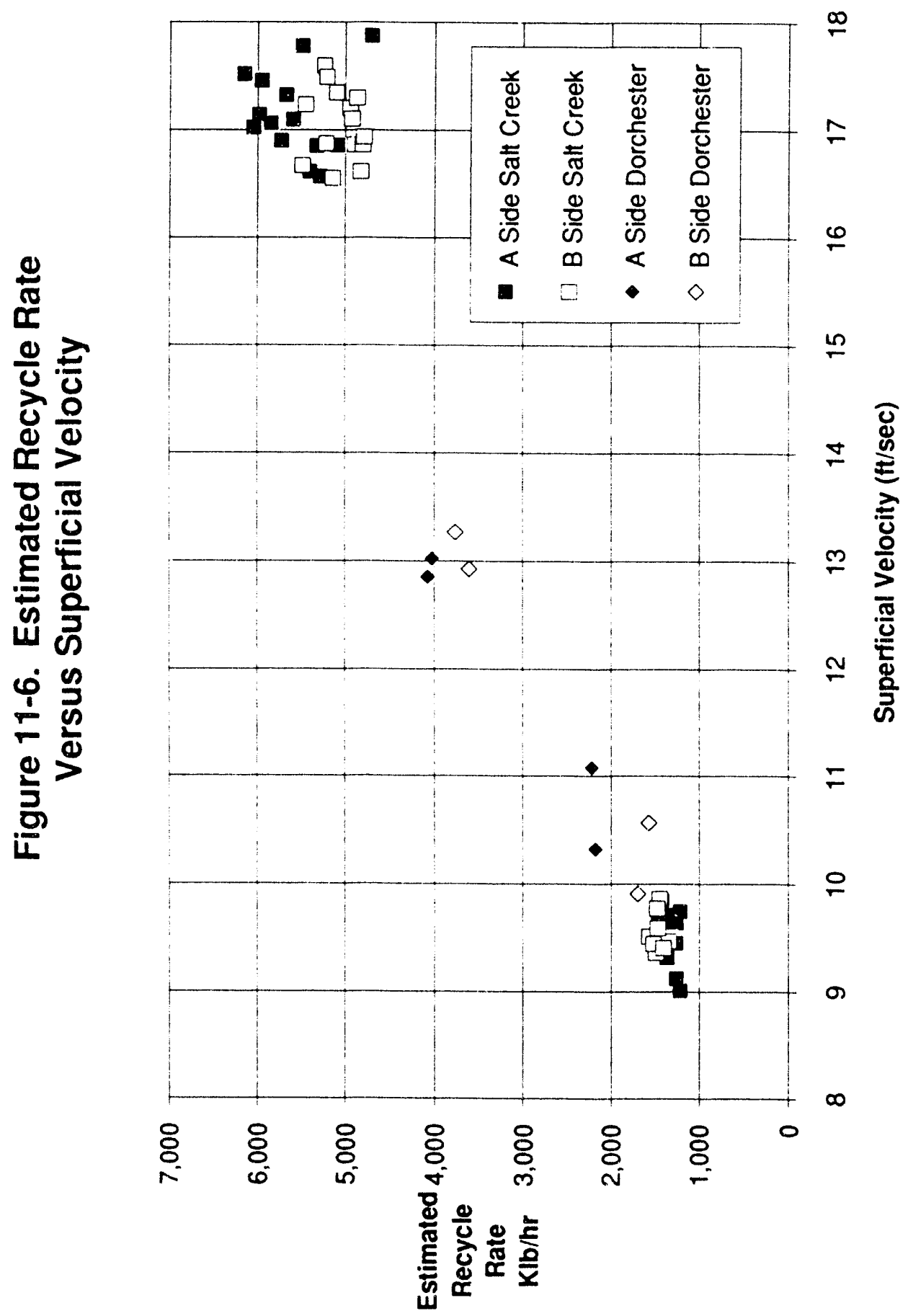
since the Salt creek tests were conducted at essentially two velocities as were the Dorchester coal tests. The data in this graph were taken during the phase II test program, when the pressure taps measuring the upper combustor pressure drop were in place. There were a few tests on salt creek coal conducted during phase I in the velocity range between 13 and $15 \mathrm{ft} / \mathrm{sec}$. Unfortunately, the pressure taps were not installed at that time. Therefore, it is not possible to draw any conclusions regarding the linear nature of this relationship.

\subsection{TEMPERATURE PROFILE}

The temperature rise across the cyclones at Nucla is shown versus the superficial velocity in Figure 11-7. This figure contains data from all of the performance tests conducted during both the Phase I and Phase II campaigns. All of the data show a linear relationship with the temperature rise across the cyclone being positive (the gas heats up) at low velocities and decreases with velocity becoming negative (the gas is cooled down) at velocities above $12 \mathrm{ft} / \mathrm{sec}$. This data is counter-intuitive, since the amount of combustion taking place in the cyclone is expected to increase with velocity in the bed.

Figure 6-22 showed that the carbon loss from the combustor increased with velocity, which would imply that more carbon, and therefore more combustion, is reaching the cyclones. However, the amount of carbon loss increased only slightly, while the amount of solids circulating increases dramatically. Nevertheless, this does not account for the gas cooling.

Figure 11-8 shows the seal leg solids temperature minus the cyclone inlet temperature. This data shows that, for most tests, there is a temperature increase for the solids. Thus, at full load the gas appears to be cooling at the same time the solids are heating. This suggests that something is cooling the flue gas after the solids are separated in the cyclone.

Figure 11-9 shows the gas temperature rise across the cyclone versus the $A / B$ cyclone outlet pressure. Note that as the pressure is lowered, the amount of cooling increases. This suggests that air in-leakage may be responsible for the observed flue gas temperature drop across the cyclone. One possible source of this air in-leakage is the vortex cooler, which draws ambient air into the cyclone to cool the vortex finder. However the measurements taken on this air is not sufficient to account for all of the cooling at full load. The measurements showed that the total air flow into the vortex cooler was about $7,100 \mathrm{lb} / \mathrm{hr}$, while the temperature drop at full load would require about $24,000 \mathrm{lb} / \mathrm{hr}$ of leakage. Furthermore, the measured air flow to the 

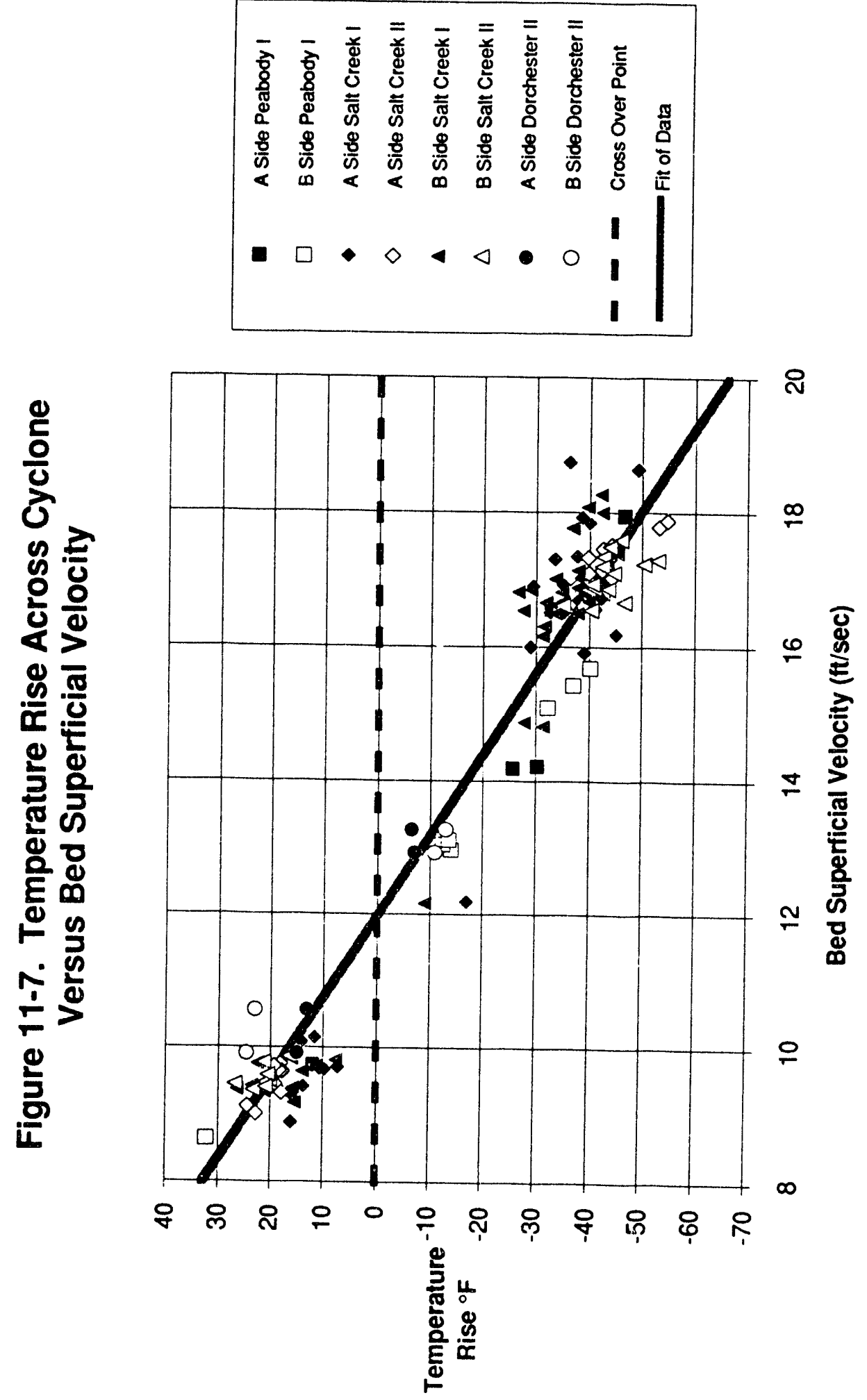

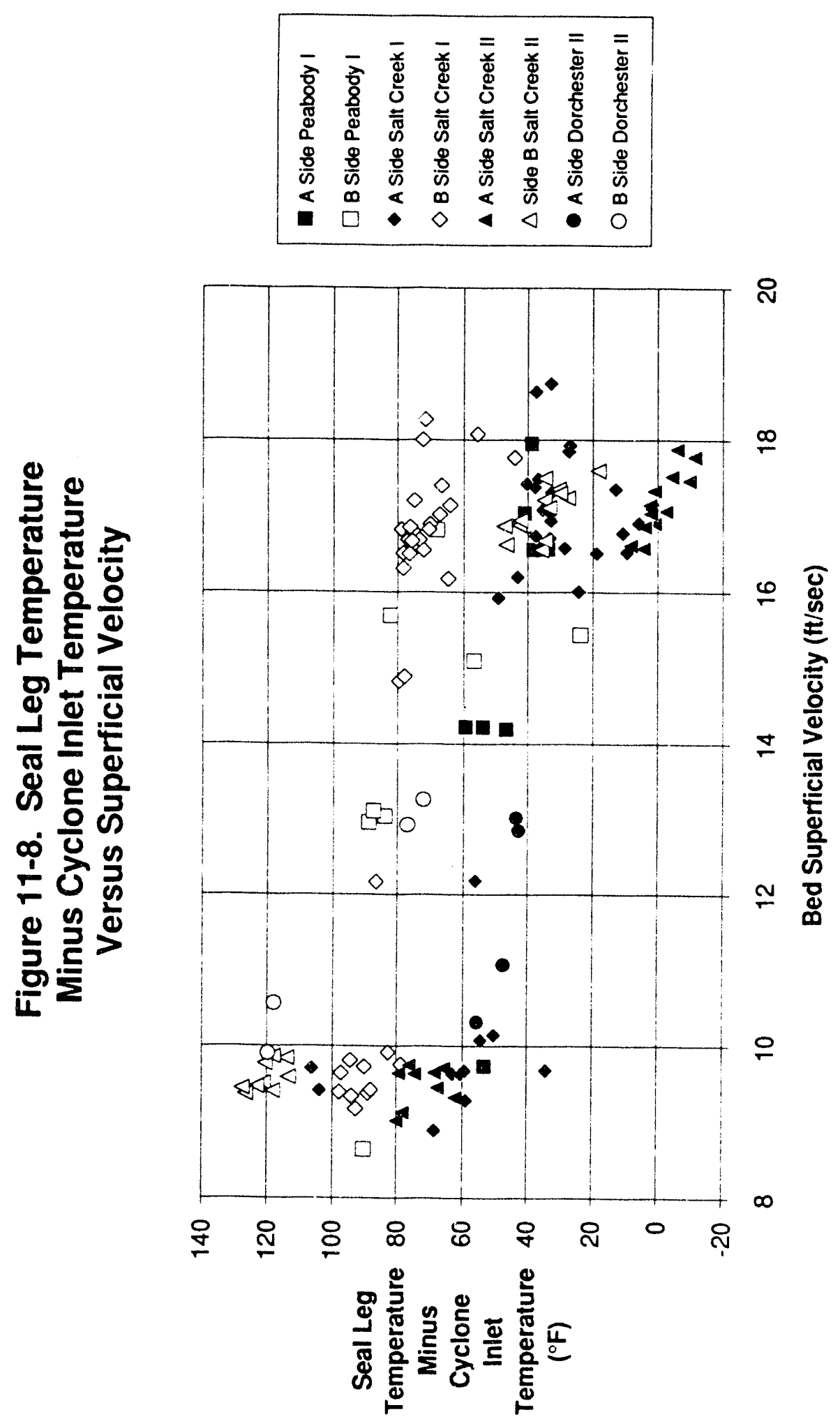

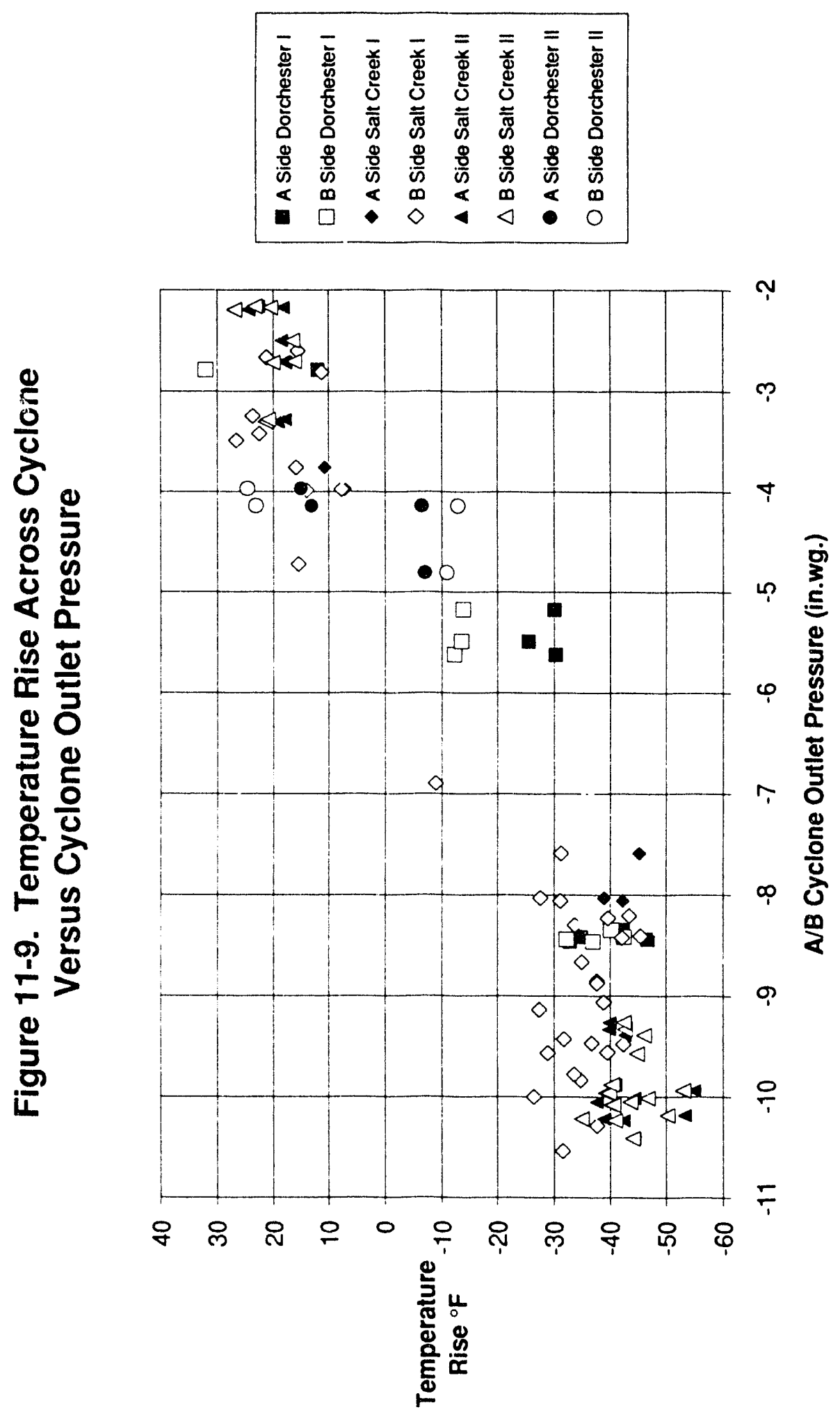
combustor, including the estimated $7,1001 \mathrm{~b} / \mathrm{hr}$ of the vortex cooling air, is consistently greater than the calculated air flow based on the flue gas oxygen for the full load tests. If additional air in-leakage were happening, then the calcu. ated air flow would be higher than the total of the measurements. Therefore, while the trend shown in Figure 117 is consistent for all coals and loads, the source of this cooling has not been identified. One possibility for this apparent cooling may be due to a measurement error at the outlet of the cyclone. Radiation between the unshielded thermocouple and the water-cooled convection pass screen tubes may be causing the thermocouple to read low values for the gas temperature. 
Section 12

COAL AND IIMESTONE PREPARATION AND HANDLING

\section{1 COAL PREPARATION AND HANDLING}

\subsubsection{System Description}

The existing, refurbished Nucla station coal system provides for coal receiving, two stages of crushing, weighing, sampling (as received), live storage/reclaim, and transfer into the plant building. The system is shown schematically in Figure 12-1 and is designed from existing and new equipment.

Raw run-of-mine coal is delivered from local coal mines to the plant by truck and is weighed and then dumped into an unloading hopper. Two half-capacity vibrating feeders deliver coal from the unloading hopper to the primary crusher where the coal is reduced in size to approximately $7 " \mathrm{x} 0$. The primary crusher discharges onto a belt conveyor to a secondary "granulator-type" crusher where it is reduced in size to approximately $3 / 4 " \times 0$. A single vibratory feeder delivers coal to the secondary crusher. From the secondary crusher, coal is delivered by a belt conveyor to a transfer house via an integral belt weigh scale.

In the transfer house, coal from conveyor A drops through a diversion gate that directs the coal flow to either storage via stack-out conveyor $B$, or into the power plant via conveyor C. A reclaiming hopper and vibratory feeder located beneath the "rocket" on the storage pile reclaims coal and feeds it onto plant conveyor $C$, which delivers coal to the main plant enclosure.

The discharge from conveyor $\mathrm{C}$ flows into a two-way diverter/splitter that directs coal onto either or both new en-masse inclined conveyors $A$ and $B$. Each of these drag chain type conveyors are rated at 127 tons/h. A new "asfired" coal sample system is located at the discharge of conveyor $\mathrm{C}$ at the base of these inclined conveyors. In the event of equipment problems, an 18 ton surge hopper has been installed just above the final crushers (at the discharge of the inclined conveyors) with capacity to store all coal on conveyor $C$ (see Figure 12-2).

At the outlet of the surge hopper, a two-way splitter/diverter gate transfers coal onto either of two vibratory feeders prior to the final crushers. Both crushers operate simultaneously to accept the full output of plant 


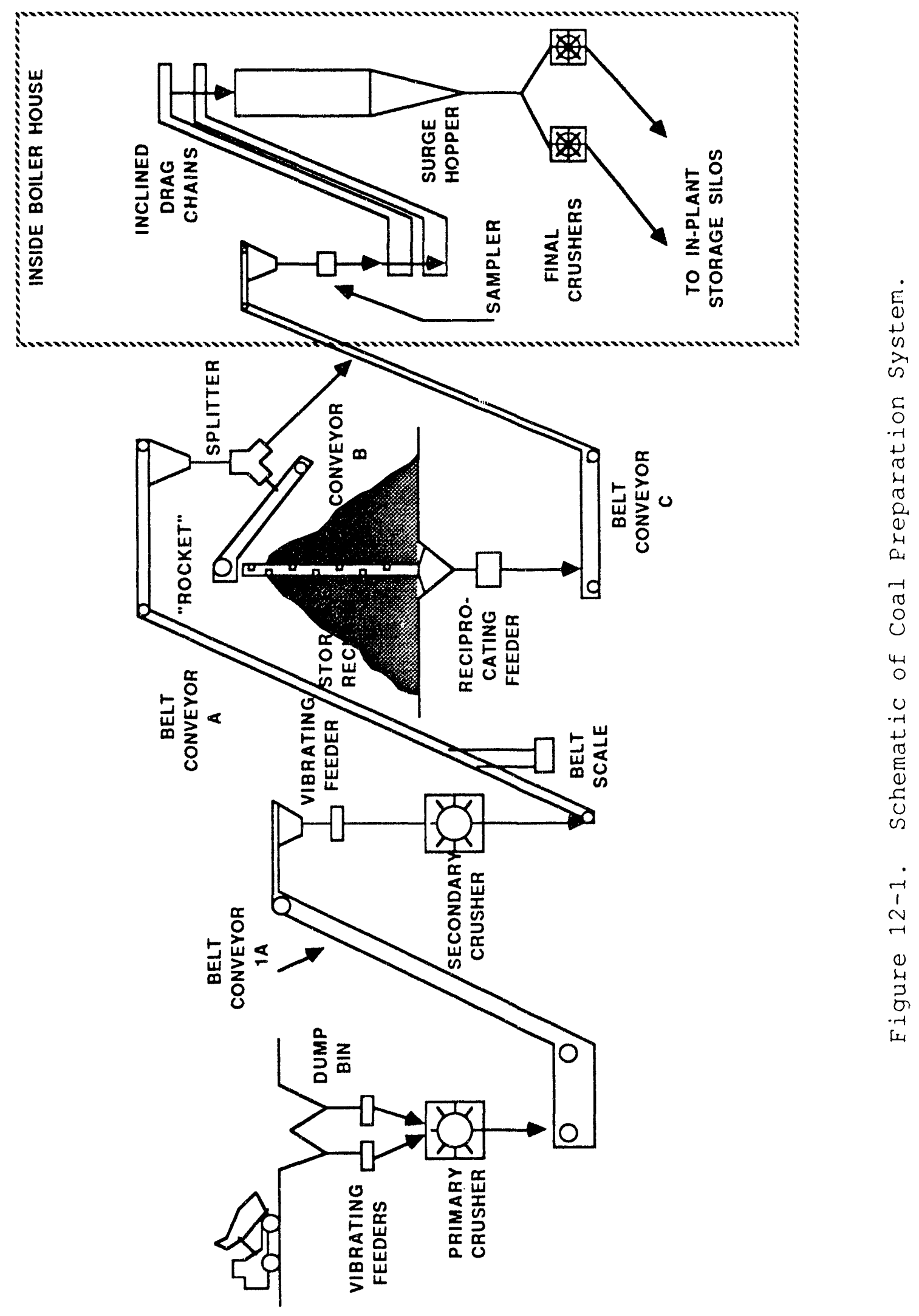




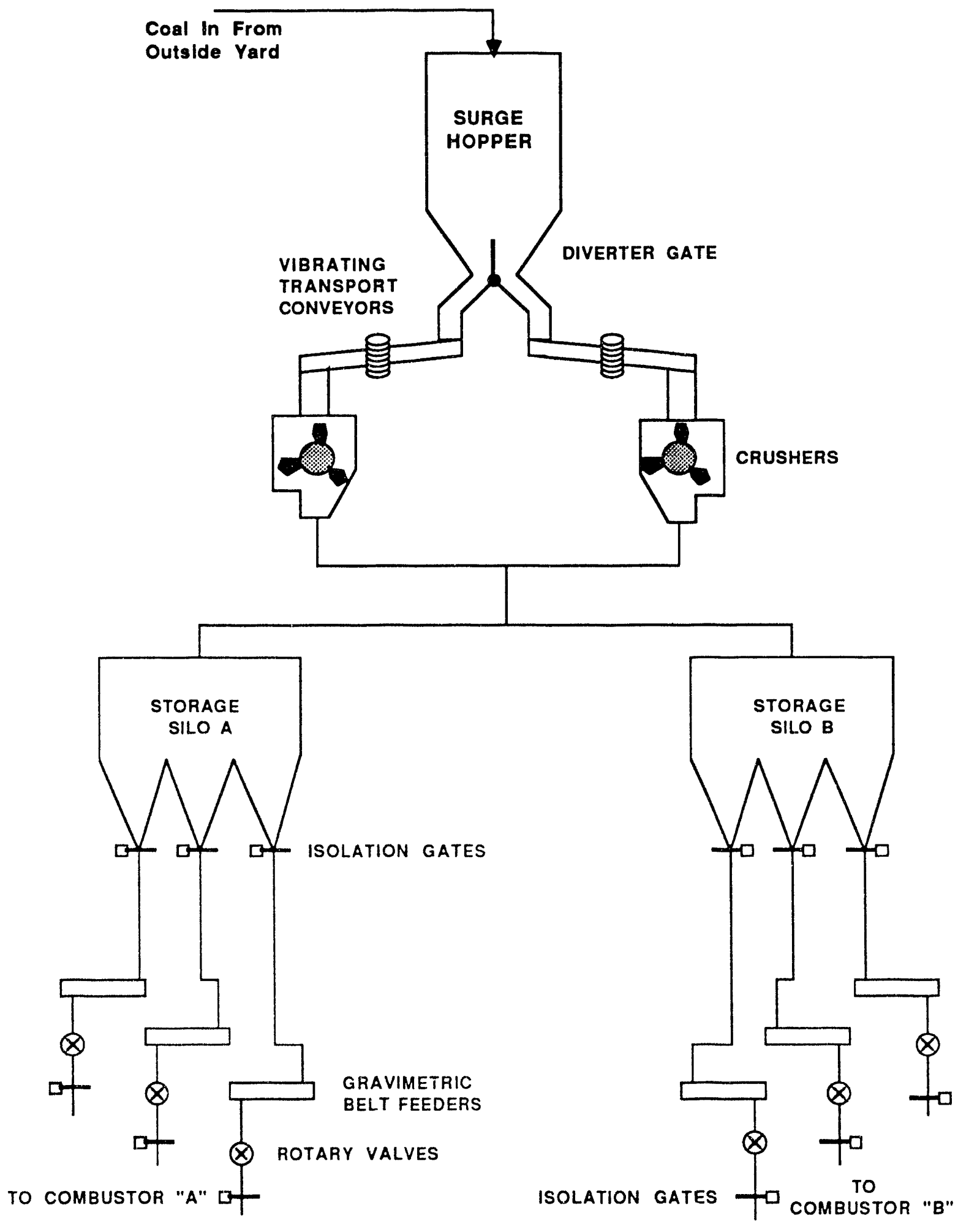

Eigure 12-2. Schematic of Coal Feed System. 
conveyor $C$. Both are reversible impact crushers which operate at a rate of 65 tons/h and reduce the coal size from $3 / 4 " \times 0$ to $1 / 4 " \times 0$, required for the CFB process. Since coal is normally delivered into the plant on conveyor $C$ on a two-shift per day basis, both coal crushers are usually in service when the plant is operating at full load.

At the outlet of the final crushers, two 54' long horizontal drag chains transfer the full output from each crusher to either or both of the in-plant coal storage silos. Three feed points are provided from each conveyor at the top of each silo to obtain a high percentage fill. The inlet openings to silo $A$ are equipped with remotely operated slidegates so that this silo can be bypassed (when full) to fill silo B. Silo B is equipped with manually operated slidegates.

Each coal silo has a capacity of 215 tons and is located in front of the front wall of the CFB boiler. This sizing provides an 8 hour storage capacity with the boiler operating at full load. Each silo has three discharge openings, designed to maintain mass flow movement to each of six boiler gravimetric feeders. Each silo discharge is equipped with a manual slide gate for isolation during maintenance on the gravimetric feeders (see Figure 12-3).

The gravimetric feeders discharge coal into the boiler via gravity and booster air flow. A motor actuated slide gate and rotary valve isolate the gravimetric feeders from the hot combustion products in the lower combustion chambers. One inclined and one horizontal drag chain-type conveyor is used to transfer coal from each of two gravimetric feeders situated along the front walls, around the side walls of each combustor, to the loop seal coal feed points.

\subsubsection{Summary of Coal system Operating Problems}

There have been no significant coal system equipment problems at the Nucla station. Most of the problems encountered have been maintenance related. These include rotary valve trips due to foreign matter entangled in the rotor, worn front wall coal chutes, and broken chain links and shear pins in the horizontal drag chain conveyor to the coal silos. For the most part, operation of this system has been trouble free and very reliable. Addressing these relatively minor problems more specifically:

- During operation on high moisture Dorchester coal, pluggage occurred in the outside preparation system at the inlets to the primary and secondary crushers and at the outside storage rocket (reclaim).

- Pluggage has occurred on occasion at the diverter gate on the in-plant surge hopper. 


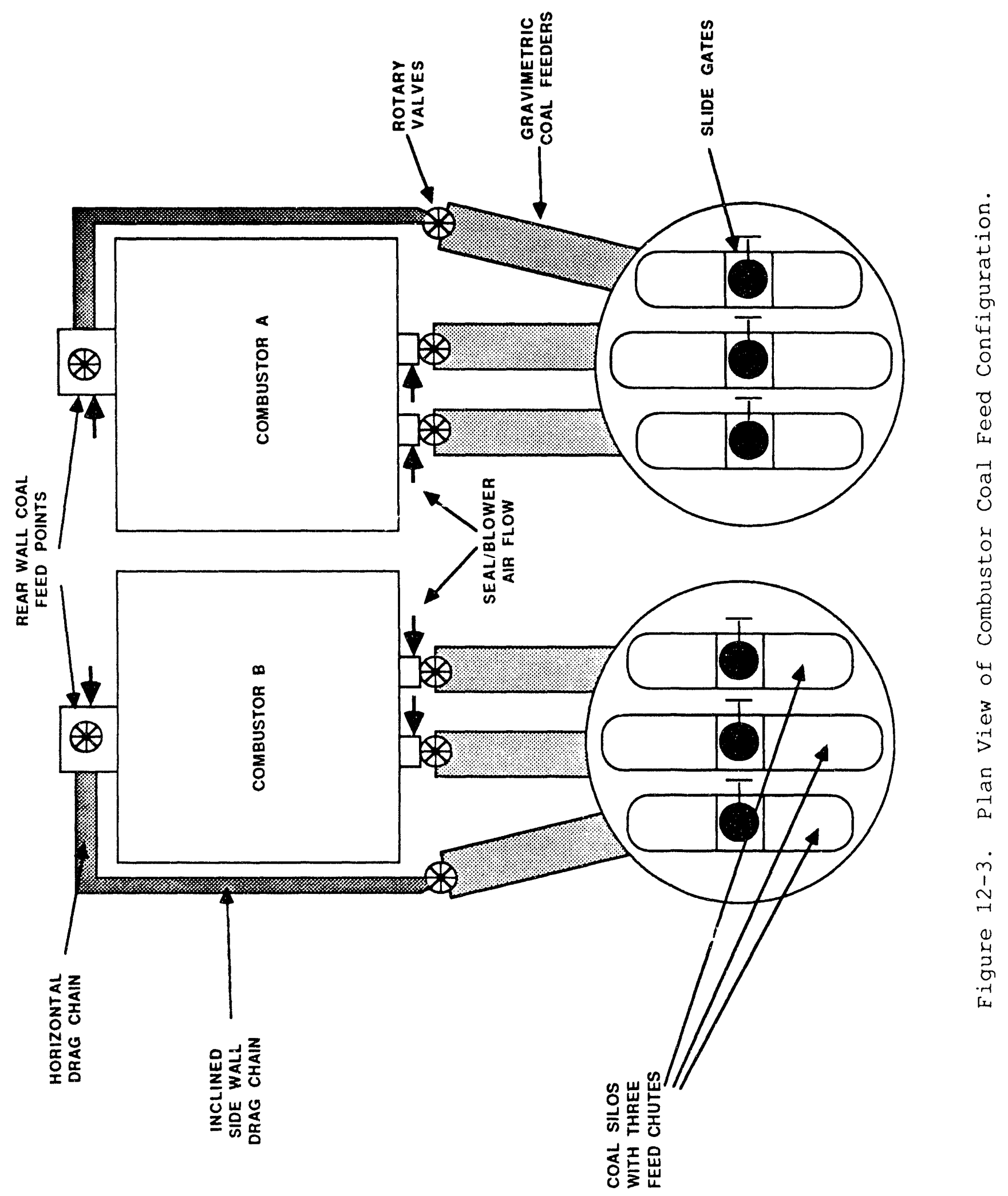


- Drag chains are loud and the vendor added teflon sheets to the base of the drag chain during acceptance testing. This reduced noise but did not fully resolve the problem. Fortunately, the chains are located on the tripper deck, which is isolated from the rest of the plant.

- Periodic blockage of the rotary valves under the coal feeders occurs from tramp material.

- The biggest problem with the coal feeders comes from belt misalignment. To correct this problem, operators adjust the belt tension which throws the feeder out of calibration. This is a problem with a twin combustion chamber design where it is desirable to balance temperatures on each side.

- Vibrating conveyors downstream of surge hoppers had a problem with structural supports which failed. This problem was corrected by reducing the length of the support cable.

\subsection{LIMESTONE PREPARATION AND HANDLING}

\subsubsection{System Description}

The limestone handling system provides for receiving, transferring, storing, and preparing the limestone before it is injected into the boiler. Schematics of the system are shown in Eigures $12-4$ and 12-5.

Raw limestone is delivered from a local quarry by truck and is dumped into a receiving hopper equipped with a pneumatic dust suppression system. A vibrating feeder delivers the limestone into a reversible hammermill that reduces the stone from roughly $10 " \mathrm{x} 0$ to $3 / 4 " \mathrm{x} 0$. A belt conveyor, with an integral weigh scale and magnetic separator, delivers the crushed product to a bucket elevator which transfers it to an outdoor storage silo. This portion of the system is rated at 68 tons/h. The silo has a storage capacity of 772 tons, which is equivalent to requirements for 70 hours of full load operation.

The storage silo transfers limestone to the pulverizer via a vibrating bin cone and vibrating feeder. The pulverizer is rated at 8.2 tons $/ \mathrm{h}$ and reduces the $3 / 4 " \times 0$ product to 150 micron average size. The pulverizer also contains a burner system, shown in Figure 12-5, that dries the product to less than 1\% moisture. The pulverizer is an air-swept pendulumtype roller mill. The pulverizer outlet limestone and air mixture are classified by a motor-driven spin separator that returns large size particles back to the pulverizer. Material that passes through the classifier is directed to a 


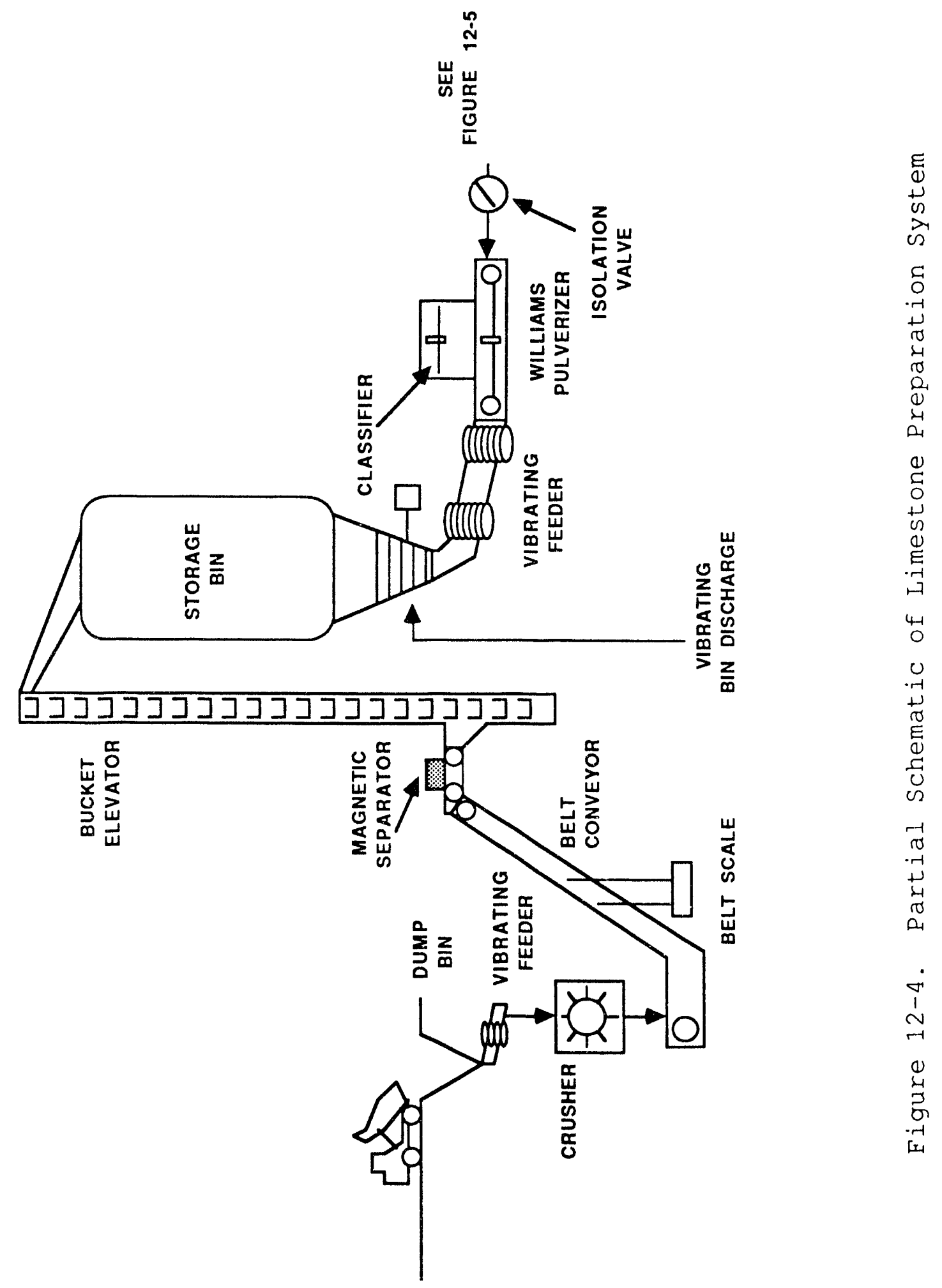




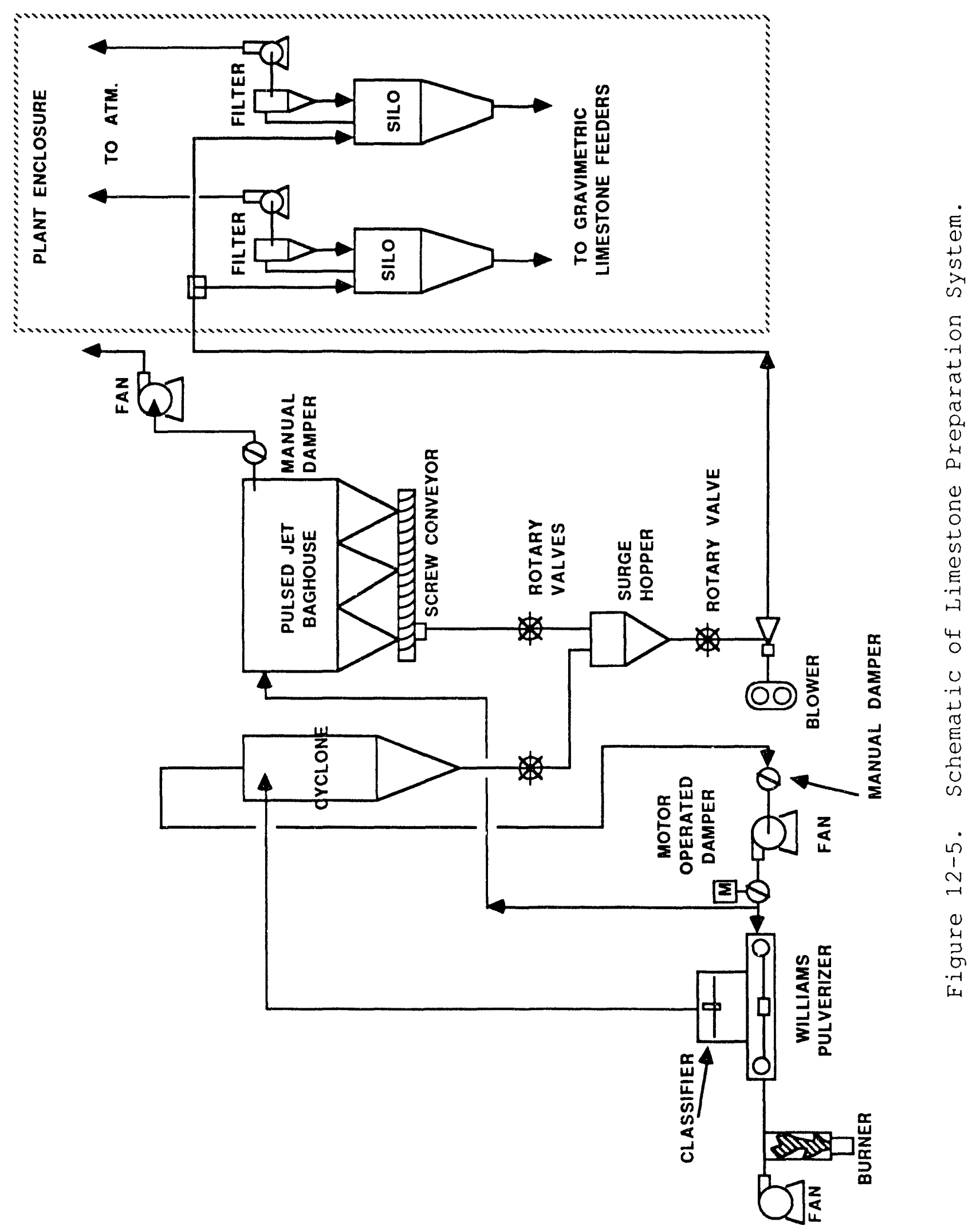




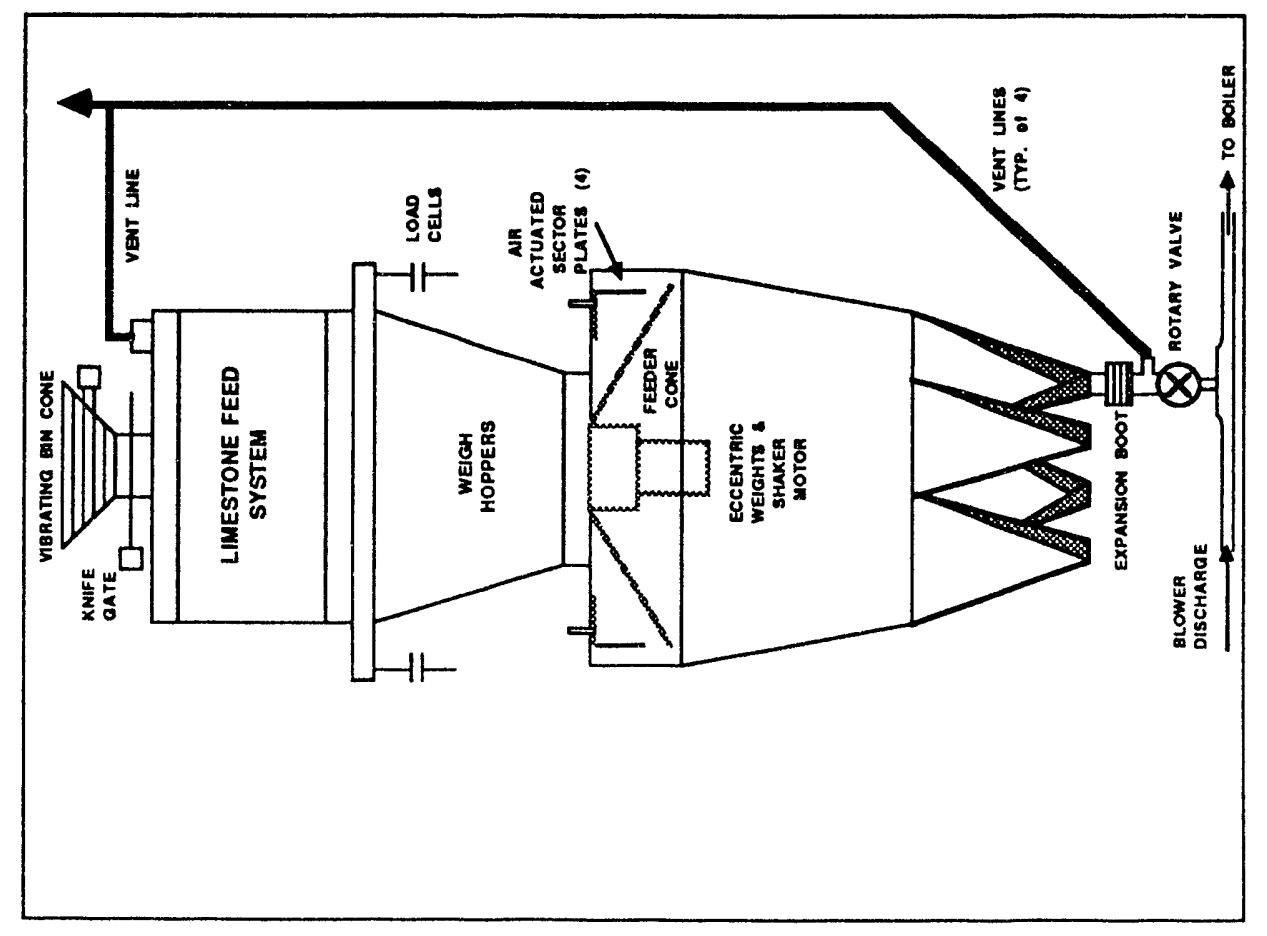

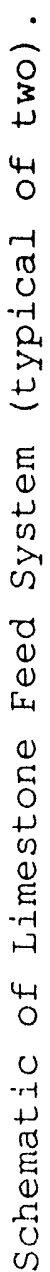

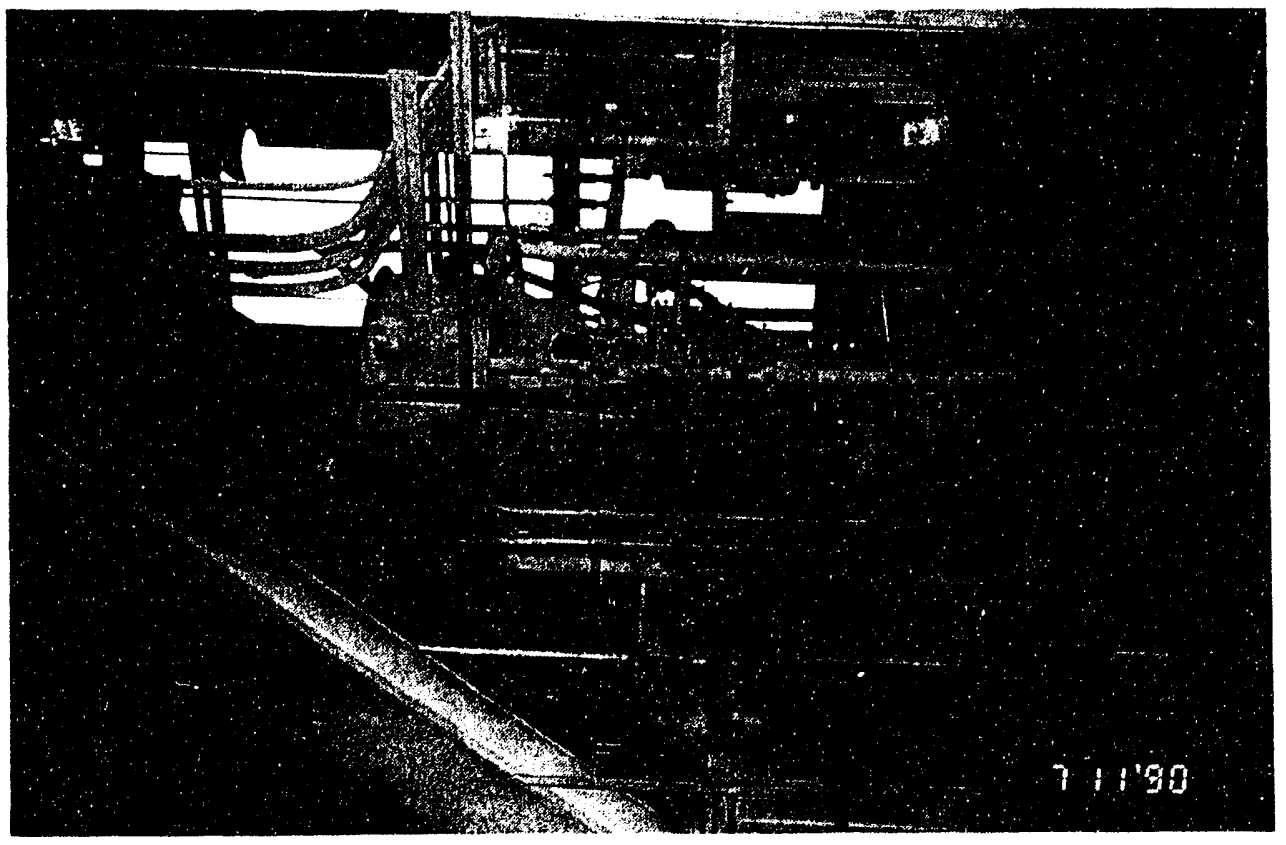


cyclone separator. The discharge from the cyclone returns to the inlet of the pulverizer fan which recirculates the air to the mill. Heated make-up air is provided by the fan and burner system. The separated limestone in the cyclone drops through a rotary feeder into a surge hopper (see Figure 12$5)$.

Transport air is bled from the pulverizer fan discharge to a fabric filter collector and exhaust fan. The entire limestone pulverizer system is maintained at a slightly negative pressure by the fabric filter exhaust fan. The fabric filter discharges collected limestone via a screw feeder and rotary valve to the surge hopper where it joins with the cyclone collection stream.

Pulverized limestone collected in the surge hopper is transported to the inside storage silos by a pressurized pneumatic conveying system at a rate of 8.2 tons/h. The pneumatic conveying line is isolated from the surge hopper by a rotary valve. Each of the two in-plant storage silos serves on combustion chamber and has an individual storage capacity of 123 tons. This size provides storage capacity sufficient to sustain 12 hours of full-load operation on design "A" coal. Each silo is equipped with a fabric filter for collection of entrained limestone in the limestone feeder vents and the pneumatic transport air.

Processed limestone passes through a vibrating bin on the bottom of the storage silo into a weigh hopper. A pistonactuated slide gate isolation valve separates the silo from the weigh hopper. The weigh hopper is mounted on load cells, as shown in Figure 12-6, and is filled by the storage silo at a preset weight. The load cell output is electronically monitored over a period of time to obtain an integrated rate of limestone feed. Each feeder is automatically adjusted in direct relation to combustion chamber coal flow and trimmed base on the flue gas $\mathrm{SO}_{2}$ concentration.

Limestone is fed from the weigh hopper to a second small hopper by a shaker cone that vibrates by eccentric weights attached to the shaker motor. Both of these are housed below the shaker cone in the lower storage hopper. Four piston actuated "sector" plates control the tolerance between the plates and the shaker cone, and therefore establish the rate of limestone feed to the lower hopper for a given shaker motor speed. Only opposite pairs of sector plates can be completely closed (if necessary) so that the shaker cone is still free to vibrate. From the lower hopper, limestone passes through four small conical hoppers each equipped with a rotary valve. These valves isolate the lower surge hopper from four pressurized pneumatic transport lines. Each of the four conical legs of the surge hopper has its own transport blower, transport line, and rotary valve. As mentioned, only 
opposite feed lines, as dictated by the relation of the conical leg to the sector plate location, can be isolated should system repairs be required. In addition, any individual feed system can be removed from service.

Each of the four feed lines on each limestone feed system transport limestone to the combustion chambers. A motoractuated valve isolates each feed line from the boiler should repairs or maintenance be required. Two limestone transport lines feed directly under the coal feed rorts along the front walls of the combustor. One transport line feeds to the side wall and one directly into the loop seal recycle return on the rear wall. The limestone feed locations are shown schematically in Figure 12-7.

\subsubsection{Summary of Iimestone System Operating Problems}

The feeding mechanism in the loss-in-weight feeder is a cone attached to an eccentrically loaded variable speed motor shaft. (shaker). The original design consisted of an unenclosed motor coupled to eccentric weights. During the first year and a half of operation, both feeders suffered multiple eccentric weight bearing failures and motor

burnouts. Because the shaker motor hangs suspended within the feeder in contact with limestone, a probable cause for failure was limestone leakage into the motor housing and bearings. The system was replaced with totally enclosed motors, integral bearings, and eccentric weights. The speed of the new assembly is $3600 \mathrm{rpm}$, as opposed to $1800 \mathrm{rpm}$ on the previous shaker motors. Since these replacements, there have been no additional failures.

Feeder stability has been poor due to pressurization of the charge hopper from transport air leaking past the rotary valves. In the second quarter of 1989, examination of rotary valve clearances indicated excessive wear had taken place since these clearances had last been set. The leakage resulting from wear to both the rotor tips and casing was estimated at nearly $50 \%$ of the transport blower flow rate. This, in turn, causes increased back pressure below the rotary valve, particularly at high conveying rates. Various venting configurations were tried with limited success.

Pocket vents in the casing of each rotary valve, installed to relieve rotor pocket pressure, were found to be ineffective because of pluggage. The vent located above the feeder cone was not sufficient to prevent pressure buildup throughout the system. The initial modification made to the feeder system was the removal of the pocket vents and the installation of an additional vent line located in the feeder bin below the feeder cone. This additional venting capacity increased the stable flow range up to $7000 \mathrm{lb} / \mathrm{h}$, but flow instability was still present at higher flow rates. 


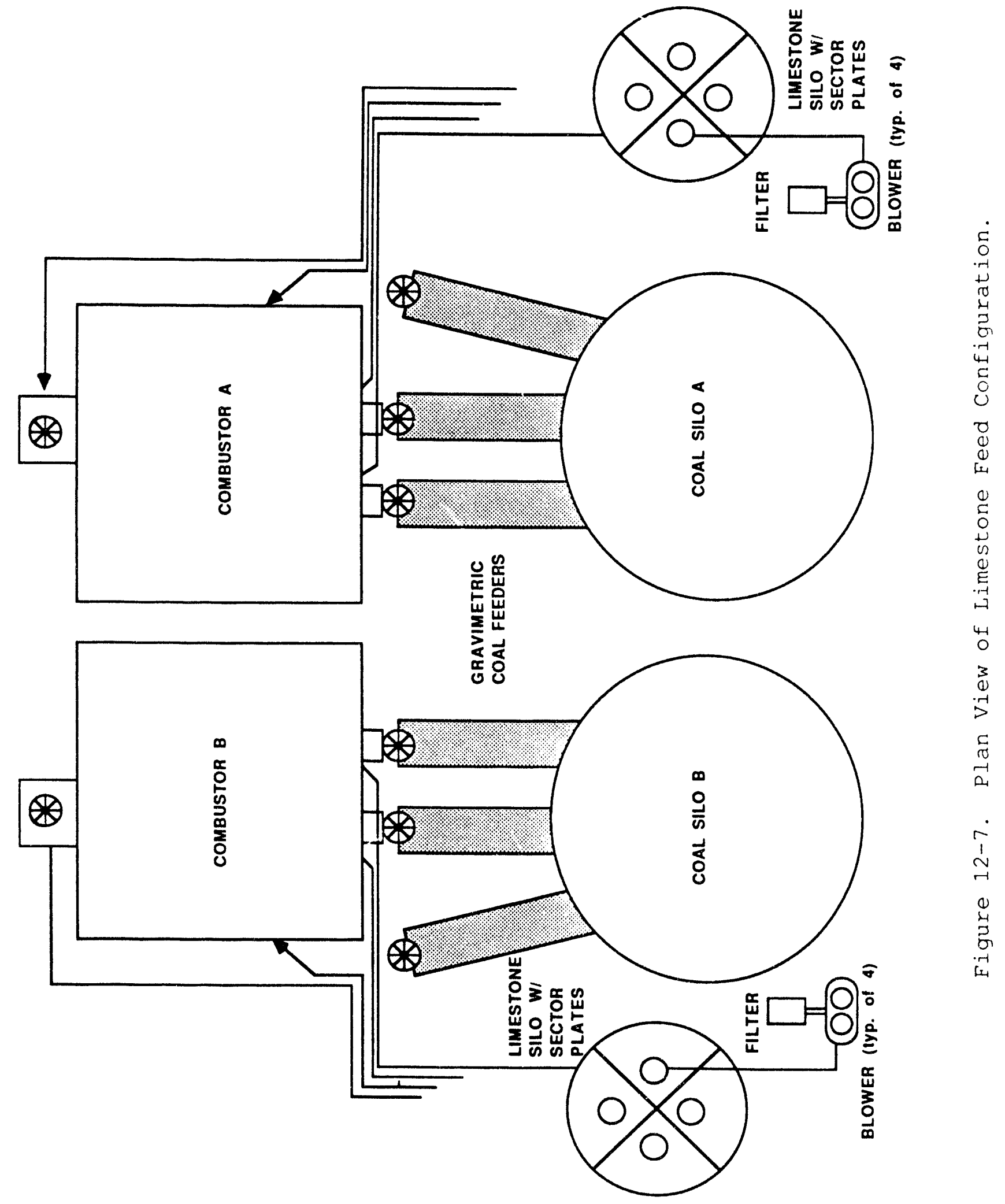


In addition to high pressure below the feeder cone, another characteristic of the flow instability was a high pressure drop across the feeder cone. Three pressure equalizing lines were added that connected the feeder bin volume, the volume just above the feeder cone, and the volume below the knife gate. Pressurized operation resulted in limestone leakage through flange connections. In addition, flushing occurred when the knife gate opened to fill the weigh hopper. This resulted in failure of the expansion boots above the rotary valves and loss of a significant amount of limestone to the plant.

In the next modification, the uppermost vent line was moved to the top of each coal silo. This isolated the feeder from the limestone preparation and provided a negative pressure (by way of the coal dust suppression system) for drawing the limestone fines through the vent. This modification improved feeder stability for limestone feed rates between 5000 and $80001 \mathrm{k} / \mathrm{h}$. At the conclusion of the test program, reliable operation at rated capacity $(12000 \mathrm{lb} / \mathrm{h})$ rad not been demonstrated. 
Section 13

\section{ASH HANDLING SYSTEM PERFORMANCE AND OPERATING EXPERIENCE}

\subsection{BOTTOM ASH REMOVAL AND DISPOSAL SYSTEM}

\subsubsection{System Description}

The bottom ash removal and disposal system provides for the classification, removal, cooling, transfer, storage and disposal of bottom ash from the boiler. The system also provides for reinjection of bottom ash from the storage silo back into the combustion chambers for boiler start-up. The system includes all equipment from the combustion chamber sidewall bottom ash ports to the truck filling facility and the reinjection equipment. A schematic of the system is shown in Figure 13-1.

As coal and limestone are fed into the combustion chambers, the inventory of bed ash particles increases. This causes a measurable increase in the pressure required to support and circulate the weight of the bed. The pressure, and consequently the bed inventory, are controlled by extracting bed ash through the bottom ash removal system. Hot $1600^{\circ} \mathrm{F}$ bottom ash is removed through bottom ash ports located on the outside walls of the lower combustion chambers.

Two 100 \% capacity fluid bed bottom ash coolers are used to cool and classify bottom ash before it is drained through rotary valves. One variable speed rotary valve is located under each ash cooler. The cooling mediums for the bottom ash coolers consist of water walls and air provided by an ash cooling fan. The water walls are included in a closed cooling water system which recovers heat from the bottom ash and transfers it to the low-pressure feed water system. A single fan provides air to the bottom ash coolers to cool and classify the ash.

Ash is admitted to the bottom ash coolers by means of inlet fluidizing nozzles which maintain a preset range of pressures in the ash coolers. The cooling air and classified bed material flow from the top of the bottom ash coolers to the combustion chambers via upper return ports. Bottom ash is removed from each cooler through a drain line containing a variable-speed rotary valve. The speed is regulated by the operator to control the inventory of bed material in the ash coolers. Two fluid bed ash coolers serve each combustion chamber and discharge into a single bottom ash surge hopper which is mounted on load cells. 


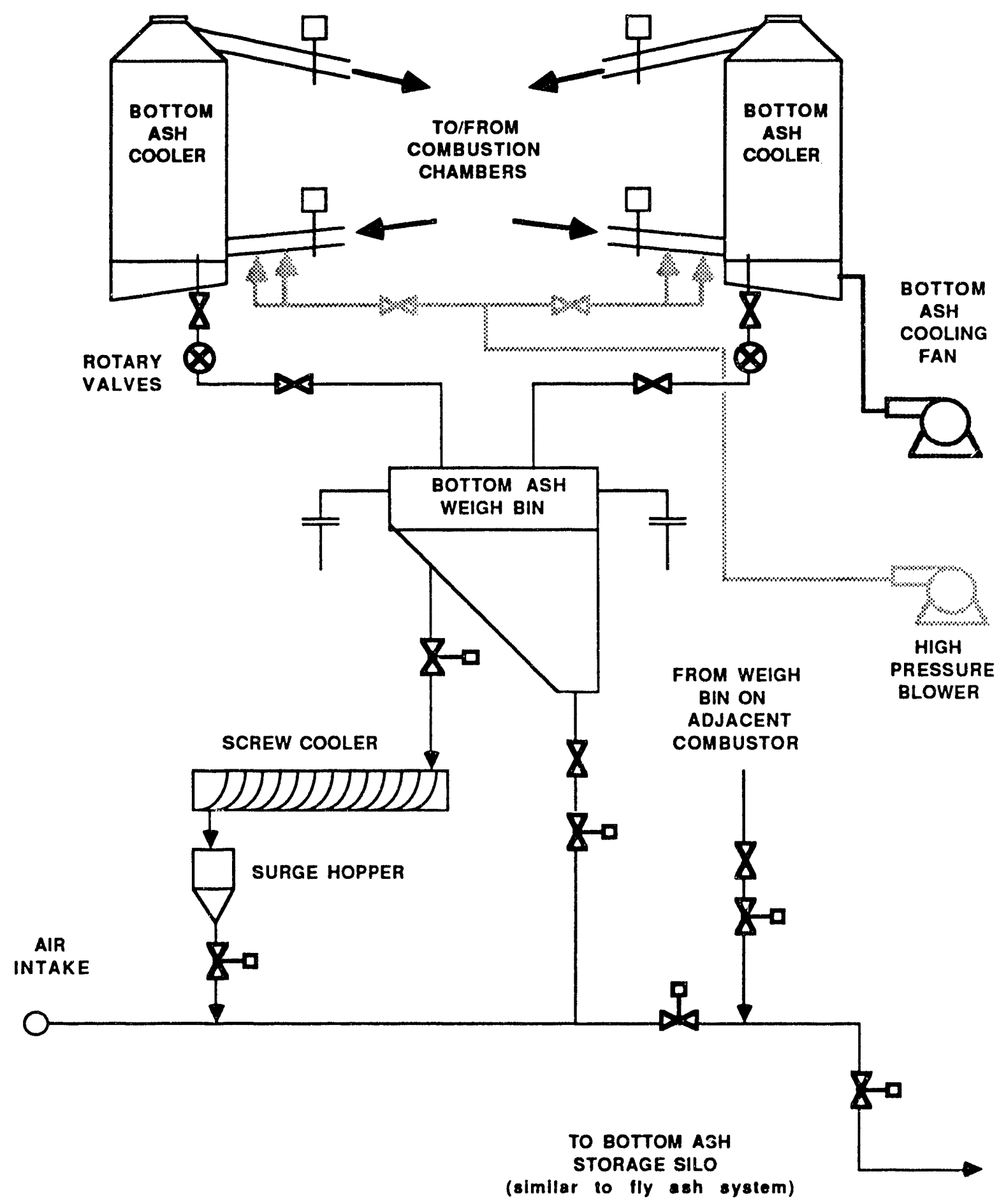

Figure 13-1. Schematic of Bottom Ash Remoral System (typical of two). 
When a single bottom ash cooler is operating on one combustion chamber, the expected ash exit temperature is approximately $450^{\circ} \mathrm{F}$ and the ash requires additional cooling. For this reason, a separate water-cooled screw conveyor is installed near the outlet of the surge hopper to provide additional cooling. During normal operation of the boiler, either both ash coolers or one ash cooler and the screw cooler on each combustion chamber are required. This arrangement provided the plant with redundancy should maintenance or repairs be necessary on one of the ash coolers. The heat removed from the screw coolers is also rejected to the closed cooling water system.

A 20 ton/h vacuum-type pneumatic conveying system is provided to transfer the bottom ash from the surge hoppers, or from the screw coolers, to the existing bottom ash storage silo. A continuously operating cyclone separator and pulsed-jet bag filter are installed on the silo roof to separate bottom ash from the conveying air. Two existing vacuum blowers, one operating and one spare, have been reconditioned and upgraded to provide the conveying motive force.

A pressurized ash reinjection subsystem is provided as part of the bottom ash handling system, which includes one gravity airlock feeder for transferring ash from the storage silo to a pressurized pneumatic conveying line. This pneumatic system conveys bottom ash back to each combustion chamber through a single reinjection port located in the loop seals on the rear wall of each combustion chamber. A single blower provides the pressurized conveying medium.

\subsubsection{Bottom Ash Handing System Operating Problems}

The bottom ash handling system has undergone several changes since the original installation. The general areas of these changes include amendment of the ash cooler to classifier, modifications to the ash cooler discharge lines and modifications to increase ash handing capacity.

Concerning amendment of the ash cooler to classifier, the initial design of the bottom ash cooler entrance was found to be inadequate to convey coarse bed material through the spout from the combustion chamber into the ash coolers. To facilitate coarse particle flow into the ash cooler, the following modifications were made:

- A high pressure air tube was installed at the inlet of each bottom ash spout, with the air passing through $1 / 8$ in: diameter holes, to facilitate conveying coarse materials into the ash cooler.

- The control logics were altered to regulate the total air flow rate to each cooler in order to maintain the classifying velocity at a preset value. Tiis was 
accomplished by adding motor-actuated butterfly dampers to each inlet air line. Air flow is measured in this line with an annubar. Classifying velocity in the ash coolers is determined based on the air flow rate, the cooler cross-sectional area, and the temperature and pressure in the ash cooler. Flow is then modulated to maintain a constant velocity. In the original control scheme, the air flow rate was held constant to each cooler and classifying velocity fluctuated with cooler operating temperatures and pressures.

- Refractory bricks were added to cover $34 \%$ of the ash cooler cross-sectional area at the grid level to increase air velocity for ash classification. At the same time, approximately $20 \%$ of the cooling tube surface area was covered by refractory. The resulting decrease in cooling capacity was within acceptable limits.

A minor modification was made in the ash cooler discharge line from the ash cooler to the bottom ash hopper to

facilitate removal of material that could potentially plug the discharge line upstream of the rotary valves. A door was installed in the line to allow inspection of the duct above the rotary valve and removal of any accumulated agglomerated bed material.

Concerning modifications to increase ash handing capacity, the bottom ash handling and conveying system removes bottom ash from the boiler at a rate sufficient to maintain constant solids inventory (and therefore constant bed pressure) in the combustor over the full operating range. The design removal rate capacity is $20 \mathrm{tph}$, which is the rate required for ash removal with high ash (35 wt. $\left.\frac{\circ}{2}\right)$ coal. Attempts to operate at full load with either the high ash or high sulfur coals were unsuccessful because of capacity limitations of approximately $8 \mathrm{tph}$.

After a thorough investigation by the bottom ash transport system vendor, major changes to the system were made. These included modifying/simplifying the piping layout, increasing pipe size, increasing transport flow from 3800 to 5000 ft $3 / \mathrm{min}$, and adding water sprays at the transport exhauster inlets.

Changes in piping layout and pipe size with the revised system were necessary to reduce friction losses in the ash transport line and to increase ash handling capacity. The piping arrangement within the ash pit was improved to form a single conveying line instead of two parallel lines to each combustion chamber. This eliminated the purge time and increased time for conveyance. For ease of mairitenance and reduced friction loss, the number of bends was reduced and $90^{\circ}$ elbows were replaced by more gradual bends. The size of the conveying line from the plant building to the top of the 
bottom ash silo was increased from 8 to 10 in. to reduce pressure drop at the higher conveying volume. Also, the air line from the separator to the exhausters was enlarged for the same purpose. All of these modifications were expected to reduce the friction loss by about 50 percent, and are shown in Figure 13-2.

To increase the volumetric capacity, the sheaves on the exhauster drive motor were replaced to increase the operating speed from 1500 to $1750 \mathrm{rpm}$. Also, to increase mass flow rate and efficiency, water sprays were added at the transport exhausters. The water injection provided a better seal and also lowered the temperature resulting in a higher vacuum.

The conveyor pickup velocity had been designed for 3800 $\mathrm{ft} 3 / \mathrm{min}$ after taking into account the actual sizing of the bottom ash generated at the Nucla unit. Of particular concern was the fraction of large size material not present during the pilot plant test burn. In addition to reducing system maintenance, these changes have eliminated the flow rate restriction in the transport line that limited full-load operation with high ash coal.

Demonstration of sustained operability on high ash coal was initially unsuccessful due to excessive temperatures of bed material discharging from the ash classifiers at full load. The temperatures were reduced to acceptable levels by operating both ash classifiers and the water-cooled screw cooler on each combustion chamber. The ash classifiers operate in parallel and the water-cooled screw cooler operates in series with either or both of the ash classifiers.

To reduce bed material drain temperatures from the ash classifiers under extreme operating conditions, two water sprays were added to each of the bottom ash cooler/classifiers. A water flow of $2 \mathrm{gpm}$ to each spray was sufficient to control ash temperature during sustained operation on high ash coal.

An additional change to the bottom ash removal system at Nucla included modifications to the bottom ash hoppers at the inlet to cooling screws. The inlet to the screw cooler was lowered and a bend was incorporated in the line to eliminate blockage of the inlet. This modification is shown in Figure $13-3$.

\subsubsection{Bottom Ash Cooler Inspections}

Generally, bottom ash cooler material performance has been good. However, inspections in June of 1989 revealed some relatively minor signs of wear in the firebrick linings, the refractory linings, and the water-wall tubes. Early failure 

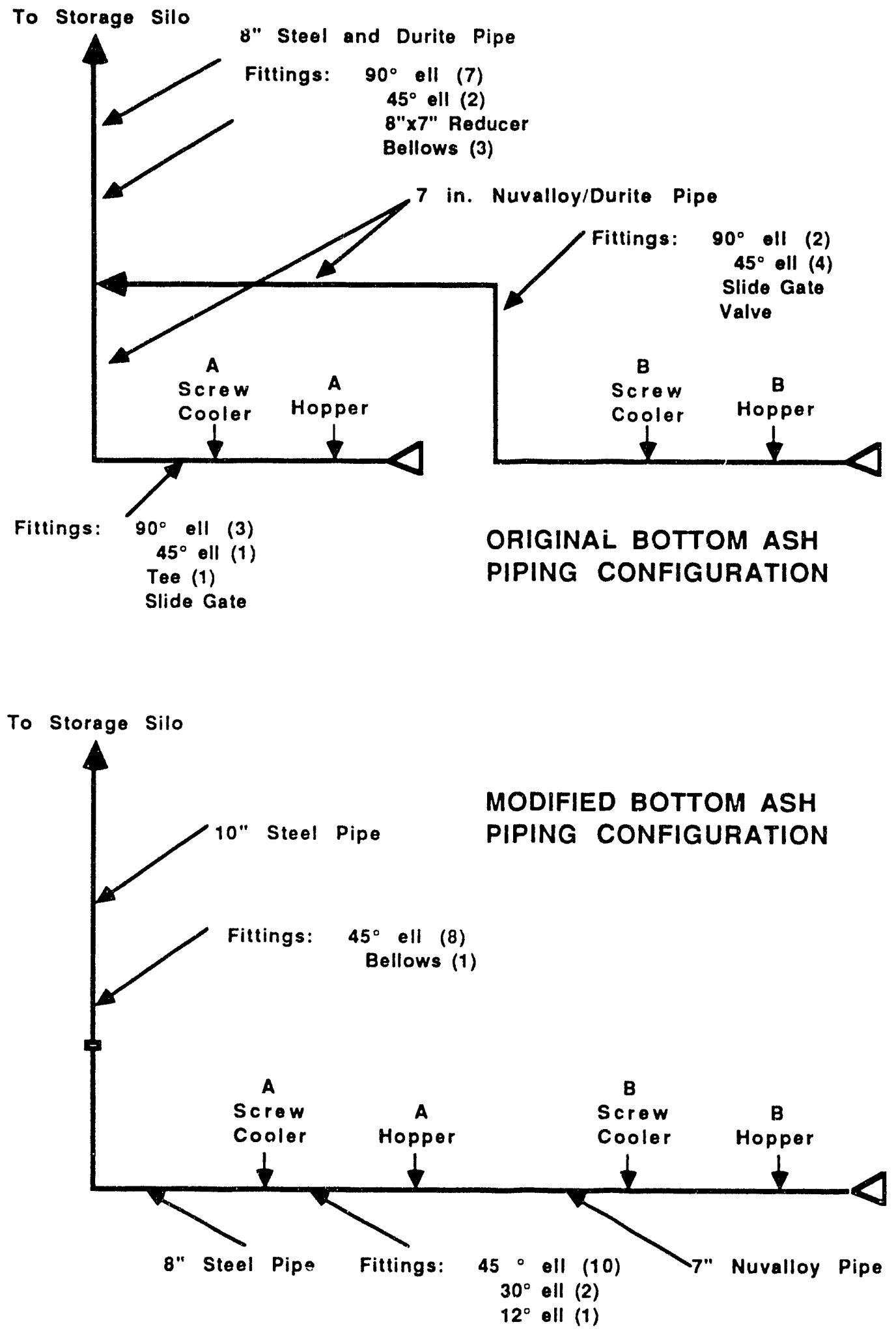

Figure 13-2. Bottom Ash Piping Modification. 

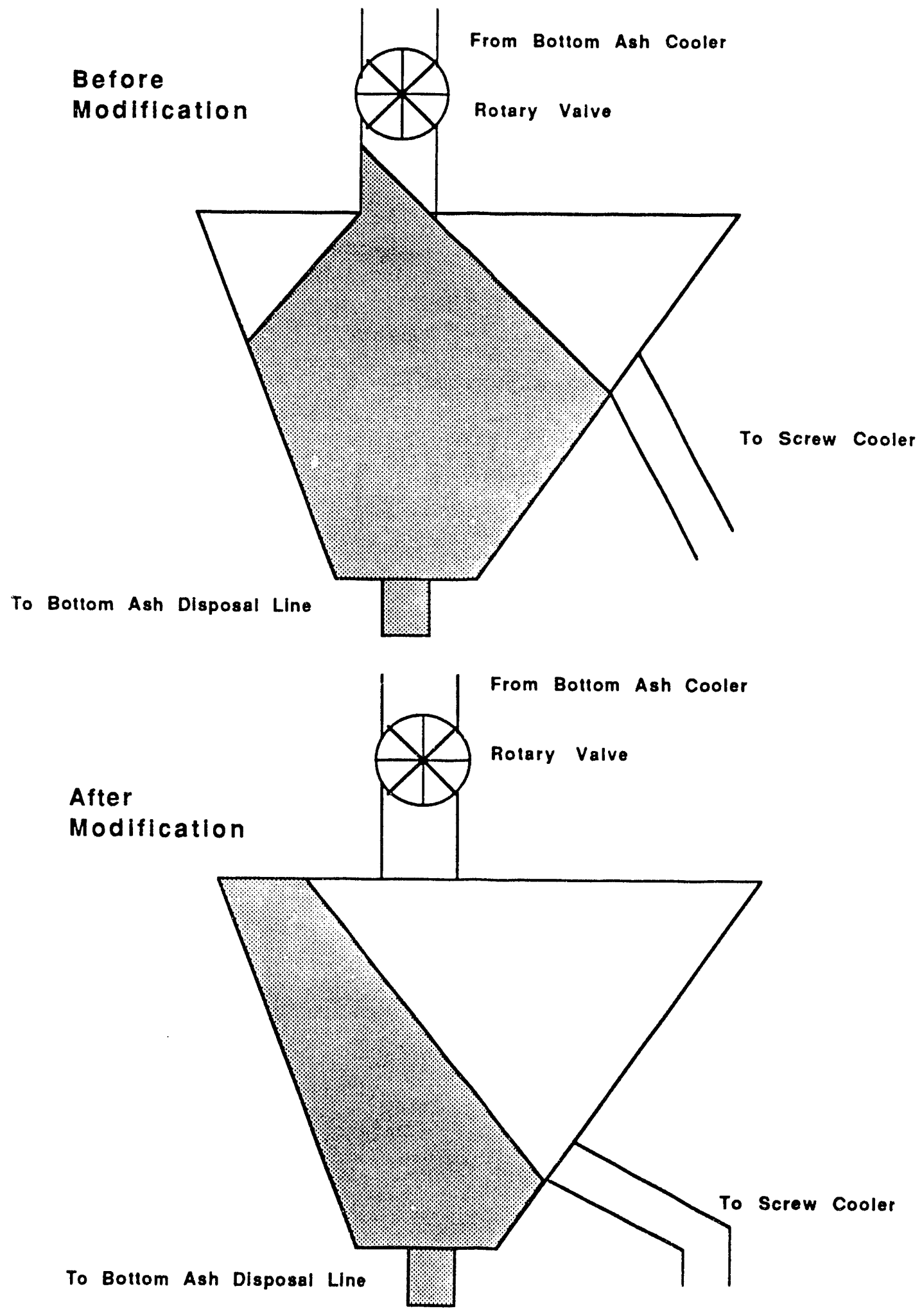

Figure 13-3. Modifications to Bottom Ash Weigh Hopper. 
of bearings in the screw coolers has been eliminated by a regular lubrication schedule.

The refractory transition at the base of the "top hats" have shown wear. Some return bends have been exposed, as shown in Figure 13-4.

In March of 1989, a tube leak developed in bottom ash cooler $4 \mathrm{D}$ due to impingement from a cooling water spray line and caused a small area of localized erosion adjacent to the leak site. There has also been periodic bubble cap loss, but only a small percentage of the total number of bubble caps have been affected.

\subsection{FLY ASH HANDLING SYSTEM}

\subsubsection{Fly Ash Handling System Description}

The fly ash handling system provides for removal, transfer, storage and disposal of fly ash from hoppers located on the bottom of the convection pass and air heater enclosures, and on the old and new baghouse hoppers. Fly ash is transported to a 720 ton capacity storage silo before being discharged via a conditioning system to trucks for disposal. The system includes all fly ash handling equipment and components from the various collection hoppers to the fly ash storage silo and truck loading facility. The system is shown schematically in Eigure 13-5.

Two independent $27 \mathrm{ton} / \mathrm{h}$, vacuum-type pneumatic conveying systems are provided to transfer fly ash from the collection hoppers to a new fly ash silo. One system serves the three existing baghouses; the second system services the new baghouse, the boiler convection pass hoppers and the air heater hoppers.

Ely ash is conveyed to a new 60,000 cubic foot mass flow storage silo. The two trains operate continuously and each have cyclone separators operating in series with pulsed-jet bag filters. The bag filters are sized for a maximum air-tocloth ratio of $3.5 \mathrm{acfm} / \mathrm{ft} 2$. Three identical vacuum blowers are provided; one for each fly ash conveying network and one spare.

A fly ash silo rotary drum unloader/conditioner with a capacity of 160 tons/h is provided. The unloader is fed by a screw feeder equipped with a charge hopper and operates on a batch basis. The unloader mixes a controlled amount of water with the fly ash to prevent dusting during unloading, transport, and disposal. 


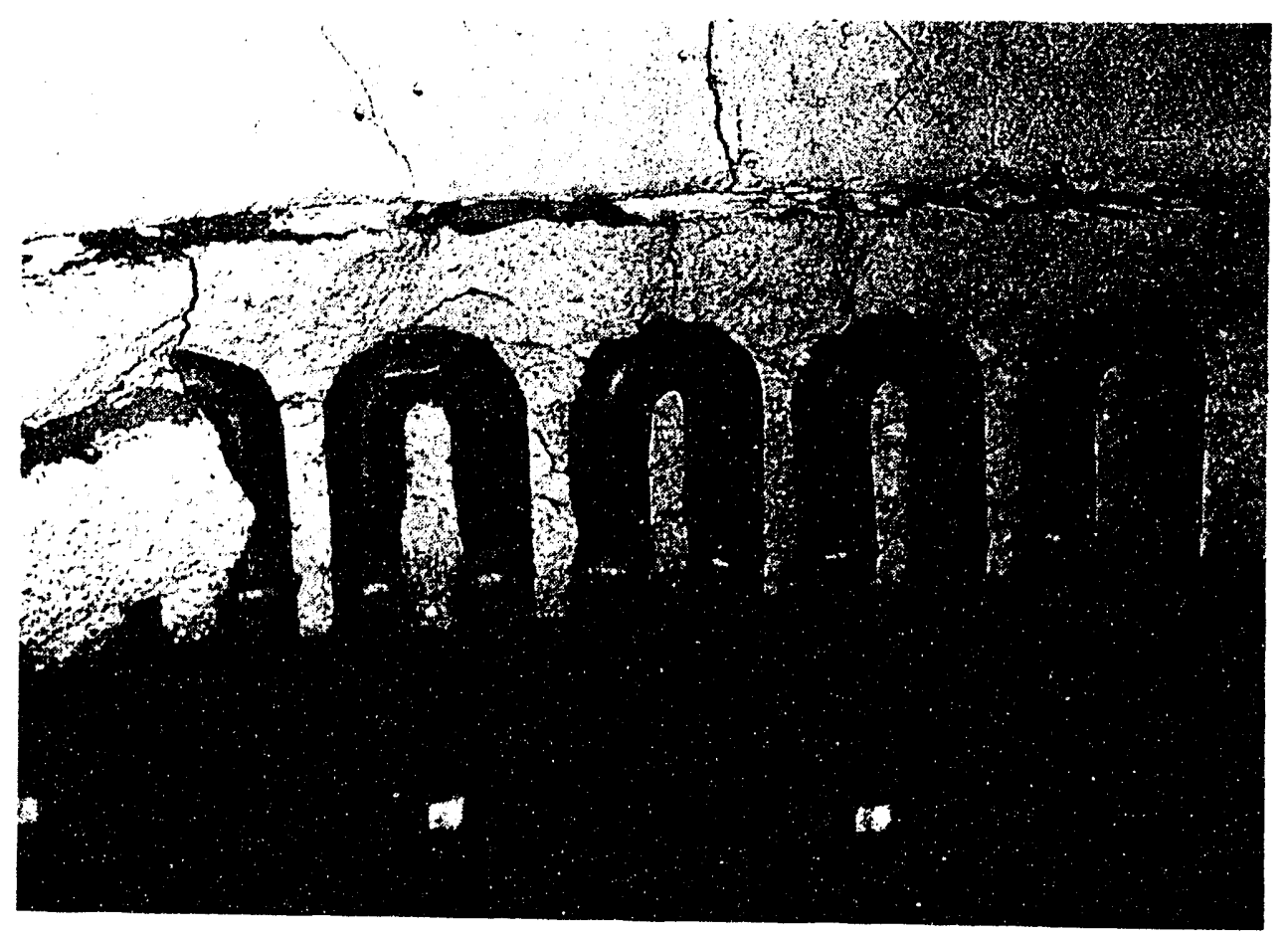

Figure 13-4. Exposed Return Bends. 


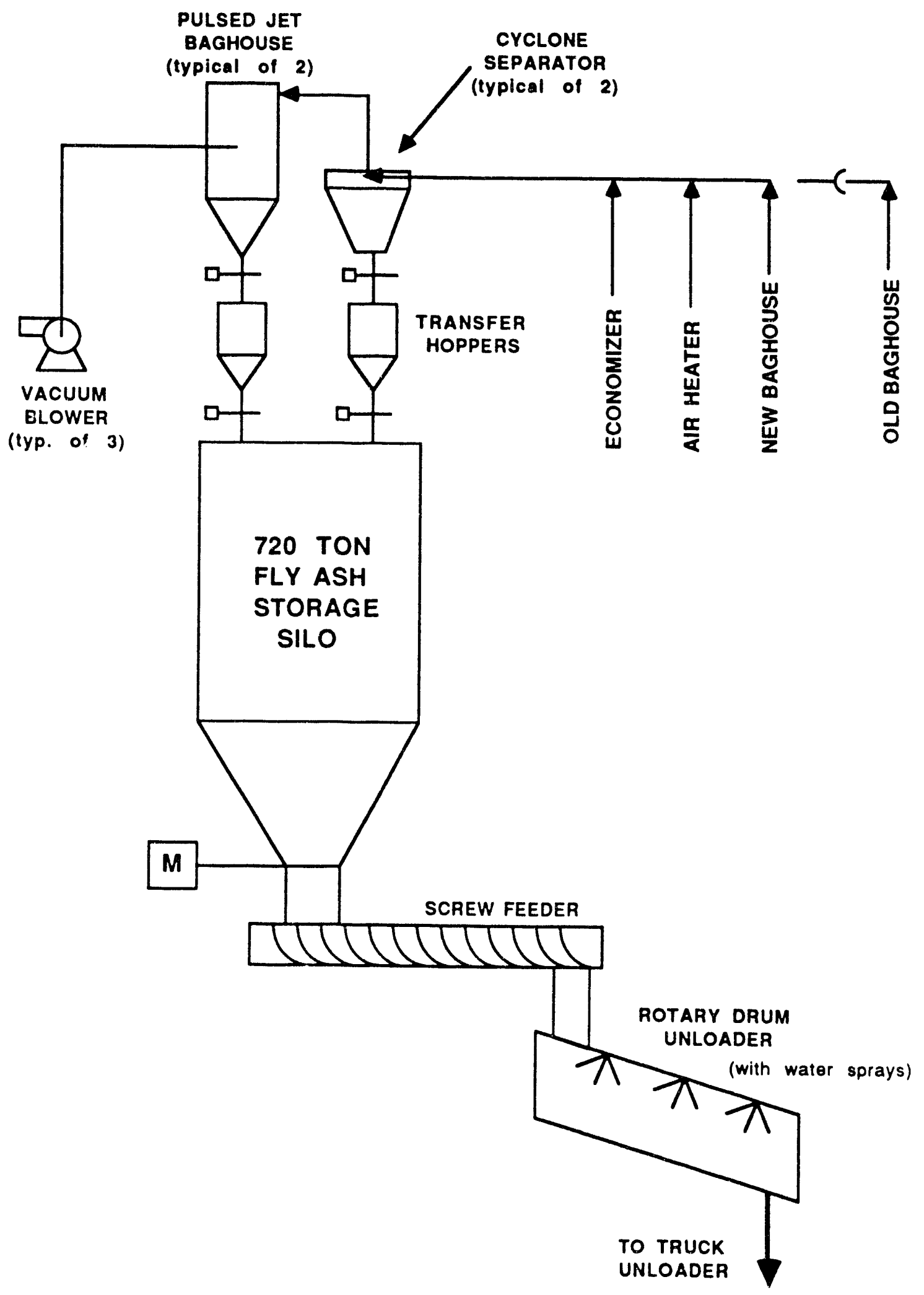

Figure 13-5. Schematic of Fly Ash Disposal System. 


\subsubsection{Fly Ash Handing System Operating Problems}

Problem areas with this system have included erosion of solids separation equipment, high pressure drop across the transport system due to vaghouse filter pluggage, and fly ash leakage around the shaft of the screw feeder at the discharge of the fly ash storage silo. These problems have resulted in high maintenance requirements, but have not caused anything but temporary reductions in unit capacity.

Erosion has occurred mainly on the inlet target area of the cyclone separator and around the dump valves on each side of the transfer hoppers. A modified inlet design to the cyclone has prevented additional erosion failures. Presently, new plate and sea? materials are being tested to circumvent the dump valve erosion.

With high ash loads from high ash fuel, bag filters have plugged on the pulse-jet baghouse separator. Typically, the transport blowers are shut down and the baghouse is allowed to time through several cleaning cycles before being put back into service. Bags have been changed on this system once since initial start-up. The addition of a longer vortex finder on the upstream cyclone may reduce solids loading to the baghouse and improve performance.

Leakage of fly ash around the screw feeder shaft seals at the base of the fly ash storage silo has been a source of high maintenance. Shaft seals have been replaced on several occasions, although fugitive dust emissions continue to be a periodic problem. 
Section 14

\section{TUBULAR AIR HEATER PERFORMANCE}

\subsection{OBJECTIVES AND SYSTEM DESCRIPTION}

The air heater at the Nucla CFB is of tubular-type design containing over 150,000 square feet of surface area. Flue gas flows inside the tubes and heats both primary and secondary air, which flows over the tubes in multiple passes. There are a total of three primary air passes and two secondary air passes within the air heater, as shown in Figure 14-1.

A methodology was developed for calculating the effectiveness of this air heater design. Knowledge of air heater effectiveness will aid designers and planners in matching surface area requirements with desired outlet temperatures. This information may also improve capital cost estimates and allow better cost comparisons to be made between alternative air heater designs.

\subsection{OPERATIONAL PERFORMANCE}

The tubular air heater at Nucla has performed well during the Phase I and II test periods and has not required maintenance of any components comprising the air heater design. Periodic inspections of the air heater have not revealed any fouling or erosion at the gas-side inlet or outlet. $\mathrm{O}_{2}$ measurements at the inlet and outlet during unit acceptance tests in July and October 1988 confirmed the absence of air-to-gas-side leakage.

However, problems with air leakage from the primary to secondary air flow paths became apparent during early operation of the unit in 1987 and 1988. This leakage is more pronounced at half load when the difference between primary and secondary air pressures is greatest and secondary air flows are reduced to a minimum. Temperature and pressure measurements at the inlet to the secondary air fan at half load indicate a reversal of flow from the primary air fan back through the secondary air fan.

During investigations for the cause of this problem, the tube sheets separating the primary and secondary flow paths, shown in Figure 14-1, were found to have 0.25-0.5 inch gaps along lines formed where the four sections of the air heater were joined together during construction. These gaps were welded shut during the operating period prior to the first 


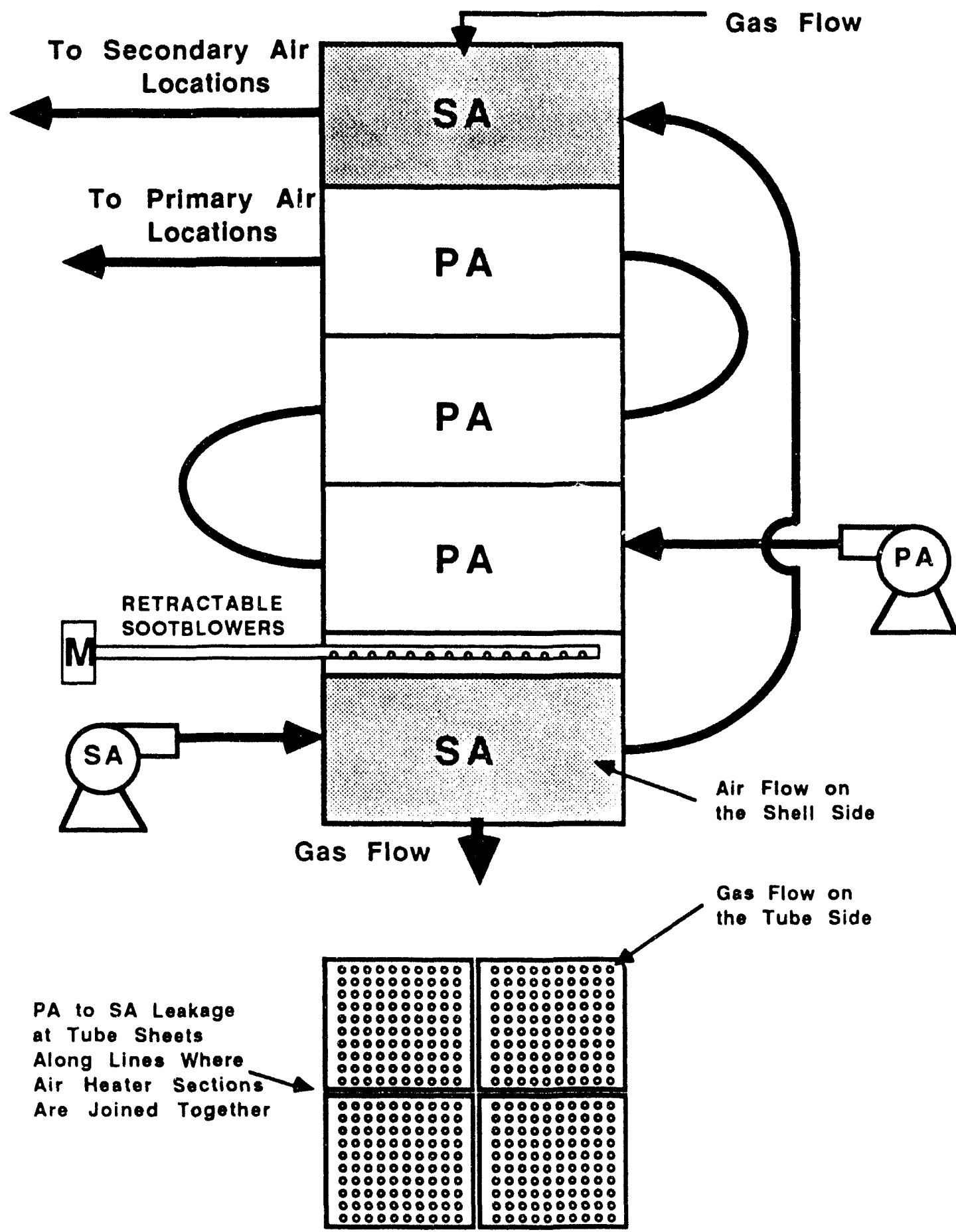

PLAN VIEW OF TUBULAR

AIR HEATER (typical of 2)

Eigure 14-1. Schematic of Tubular fir Heater Arrangement. 
acceptance test in July 1988. This correction reduced the problem, although subsequent operating data at half load indicated some degree of leakage from the primary to the secondary air flow paths.

Primary to secondary air leakage of the tubular air heater does not affect the CFB boiler, but does have a negative impact on secondary air fan performance and auxiliary power consumption at half load. The effect on air heater performance (if any) was not quantified. This leakage may occur around tube penetrations through the tube sheets separating the primary and secondary flow paths, or through some undiscovered flow path. At the conclusion of the phase I I test program, the source of this leakage had not been identified.

\subsection{CALCULATION OF AIR HEATER EFFECTIVENESS}

The heat exchanger effectiveness, $E$, is calculated using the following equation:

$$
E=\frac{q}{q_{\max }}=\frac{\text { MFFG CPF (FTMP 1 - FTMP 2) }}{\text { MFA CPA }\left(\text { FTMP 1 }-\frac{\text { MFPA PTMP 1 }+ \text { MFSA STMP 1 }}{M F P A+M F S A}\right)}
$$

Where:

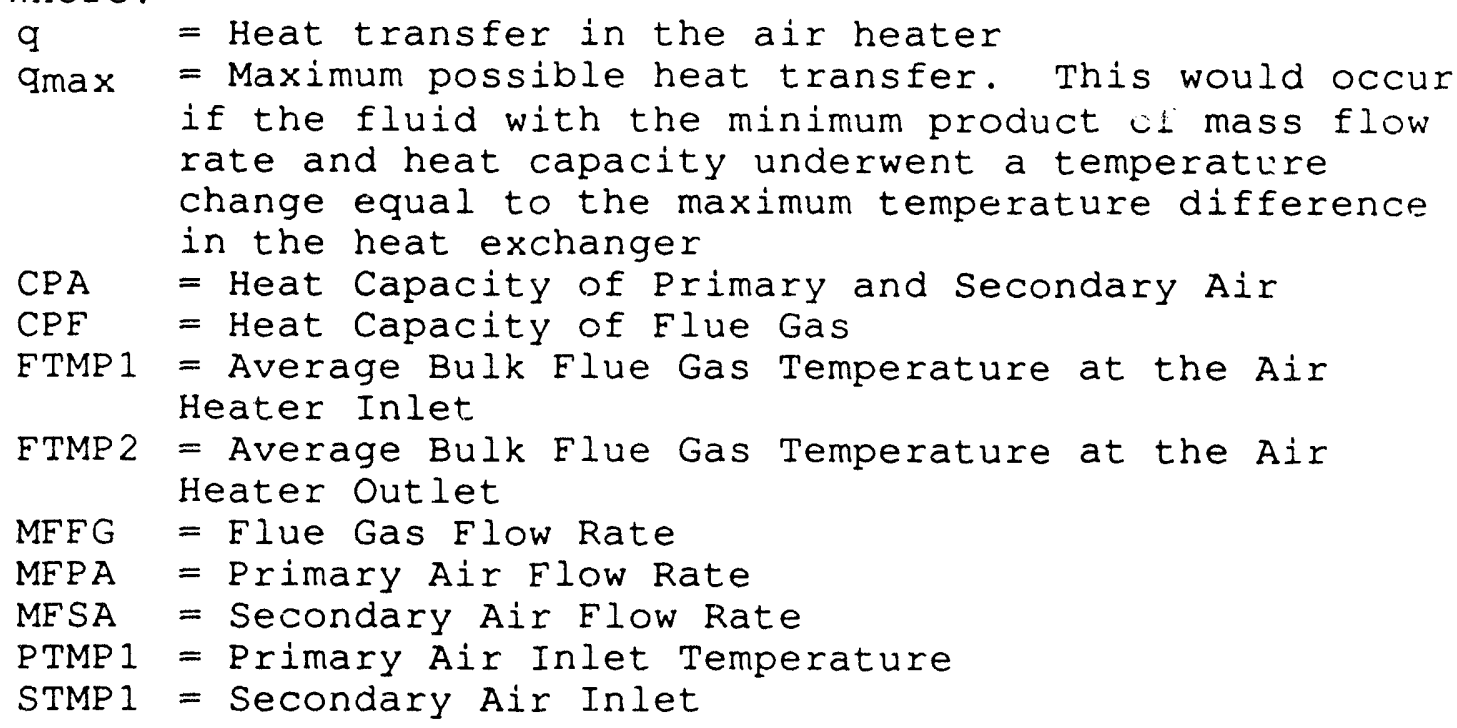

This method of calculating the air heater effectiveness considers the air heater as a "black box" with a flue gas stream (cooled fluid) and both primary and secondary air streams (heated fluids) entering and leaving the air heater. The internal arrangement of the passes in the air heater is disregarded. The total air through the air heater is obtained using the $\mathrm{O}_{2}$ method. 
The assumptions implicit in the above equation are:

- The heat capacity of the flue gas, primary air, and secondary air do not vary with temperature and are therefore constant in all parts of the ieat exchanger. The derivation for log mean temperature difference (LMTD) involves this assumption which is normally not restricting.

- The primary air, secondary air, and flue gas flow rates are uniform in all parts of the heat exchanger.

- Heat losses are negligible.

- Air leakage from the primary or secondary air side of the air heater to the flue gas side does not occur. A provision to adjust for air leakage of this type will be added as necessary.

- The ratio of primary air flow to secondary air flow given by MFPA and MFSA are approximately correct. This ratio is used to calculate a weight averaged air heater air inlet temperature.

\subsection{RESULTS}

Air heater effectiveness values were calculated for Phase I and Phase II tests for Peabody, Salt Creek and Dorchester coals. Figure 14-2 is a plot of air heater effectiveness versus gross unit output for both Phase I and Phase II steady state tests. Effectiveness values for Phase I tests ranged from $69.6 \%$ to $75.5 \frac{\circ}{\circ}$ over the load range of $54.9 \mathrm{MW}$ to $110.9 \mathrm{MW}$. Effectiveness values for Phase II tests ranged from $71.5 \%$ to $83.8 \%$ over the load range of 55.1 MW to $111.4 \mathrm{MW}$. Air heater effectiveness generally decreased with load, particularly for the Phase II tests. The Phase I air heater effectiveness values remained fairly constant over the load lange.

Air heater effectiveness is plotted versus flue gas inlet temperature in Figure 14-3, which shows a slight general trend toward higher air heater effectiveness with decreasing flue gas inlet temperature, and is particularly evident with the salt Creek coal phase II test results. Air heater effectiveness increased somewhat with increasing flue gas temperature for the Dorchester coal tests. Scatter in the results for total air heater effectiveness may be due, in part, to differences in the inlet flue gas temperatures between combustors.

Figure 14-4 shows a general trend of increasing air heater effectiveness with decreasing flue gas moisture, particularly for the phase II tests.

Figure 14-5 shows a plot of the air heater effectiveness versus the air heater $\log$ mean temperature difference. This figure 


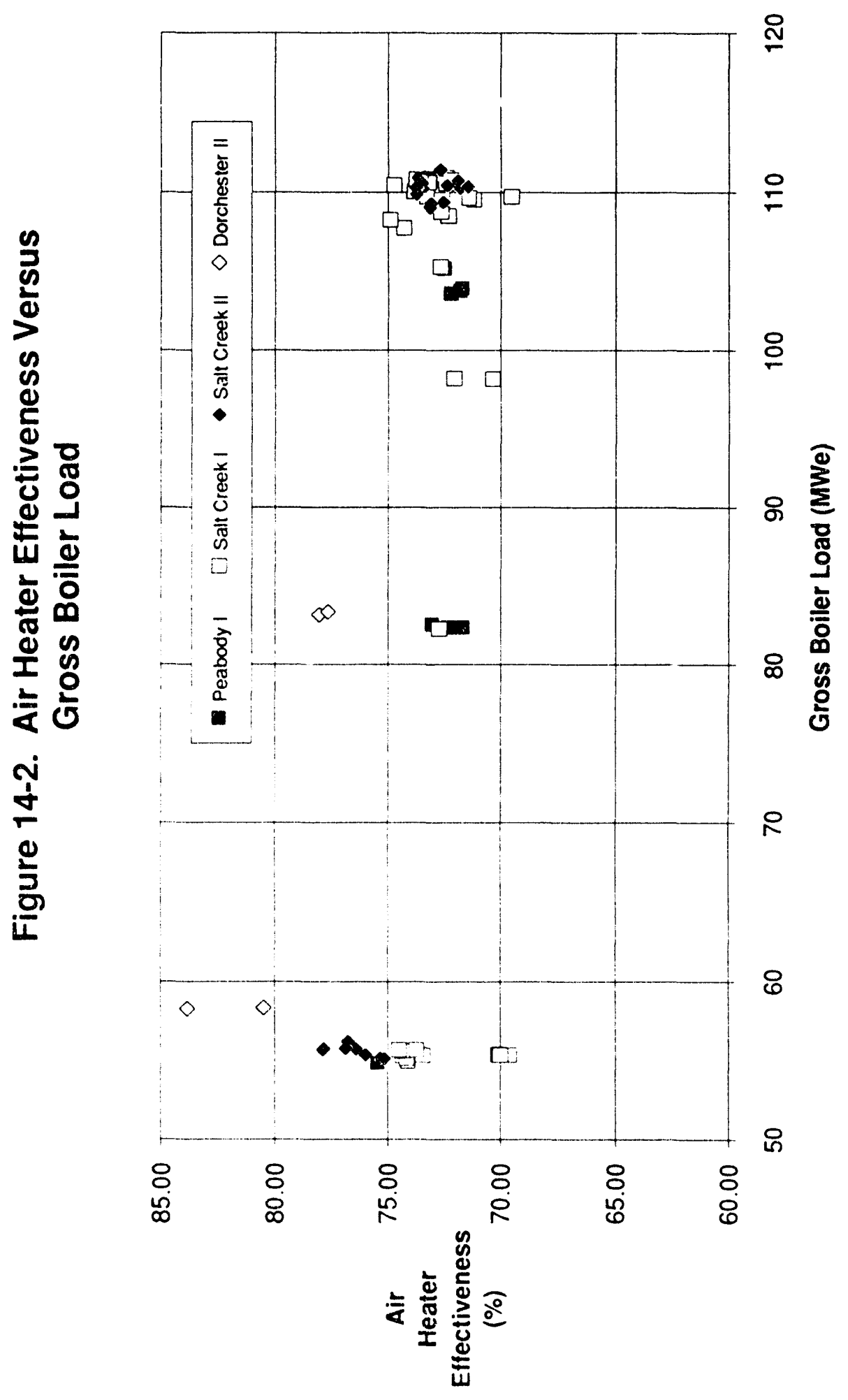




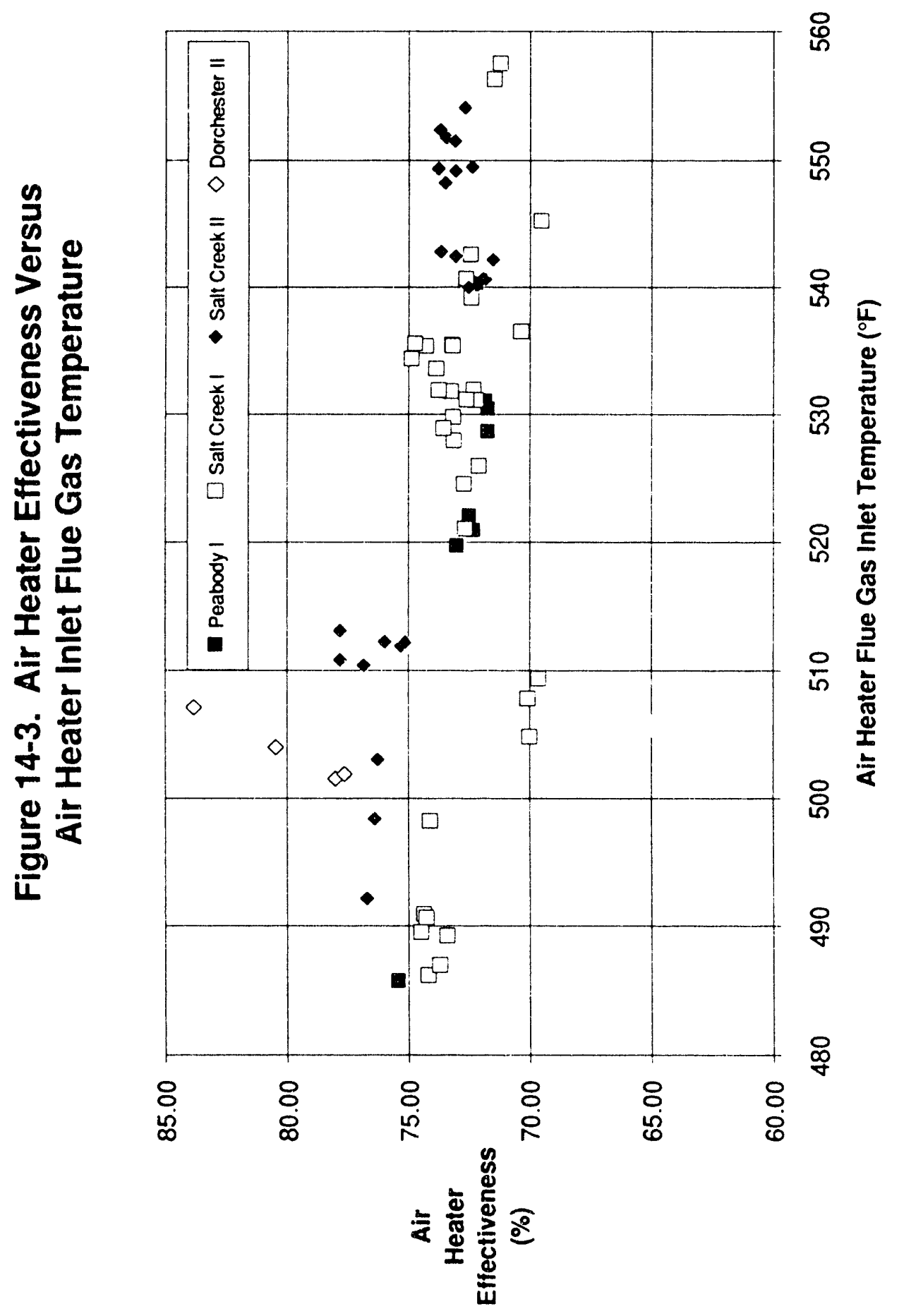




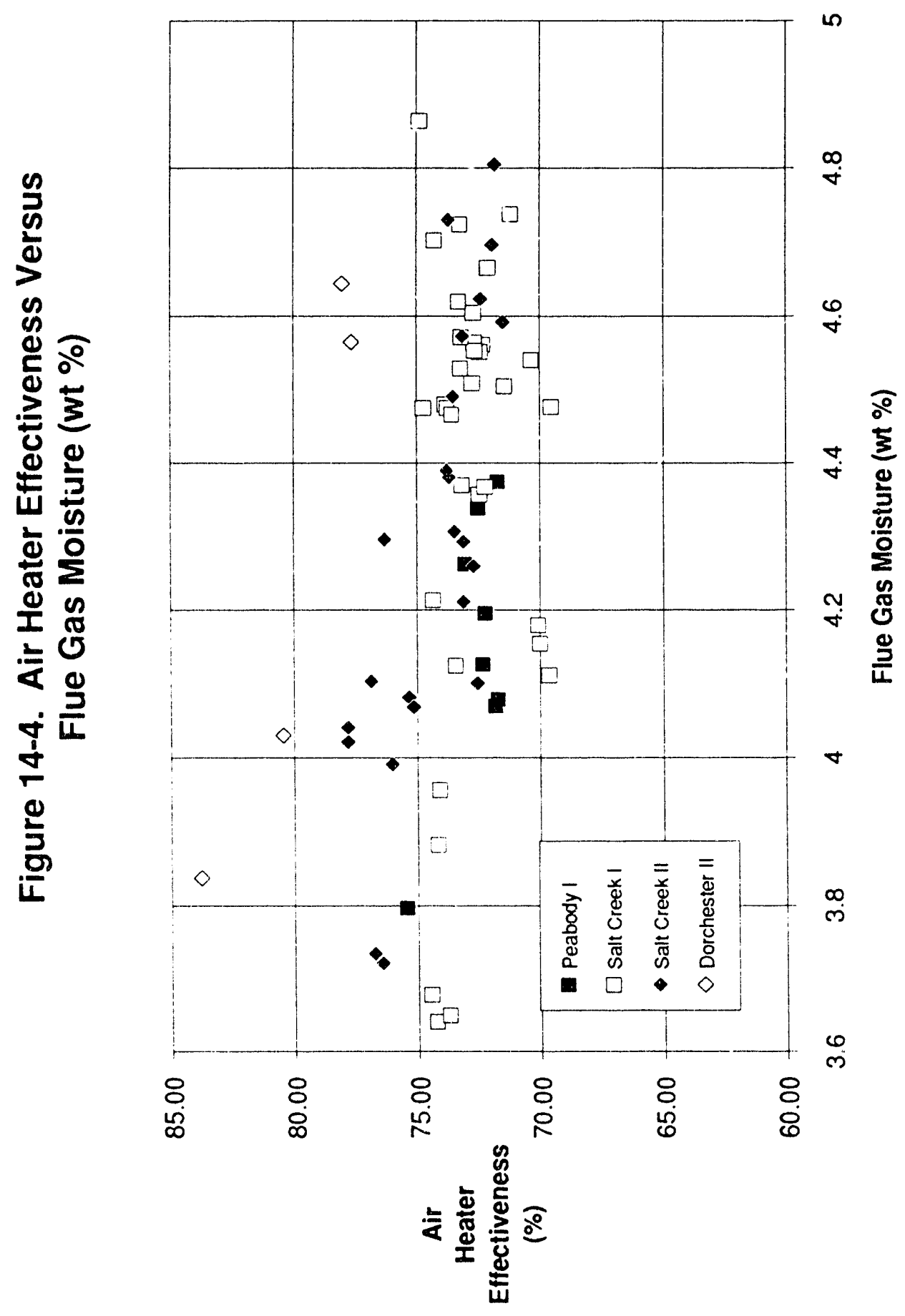




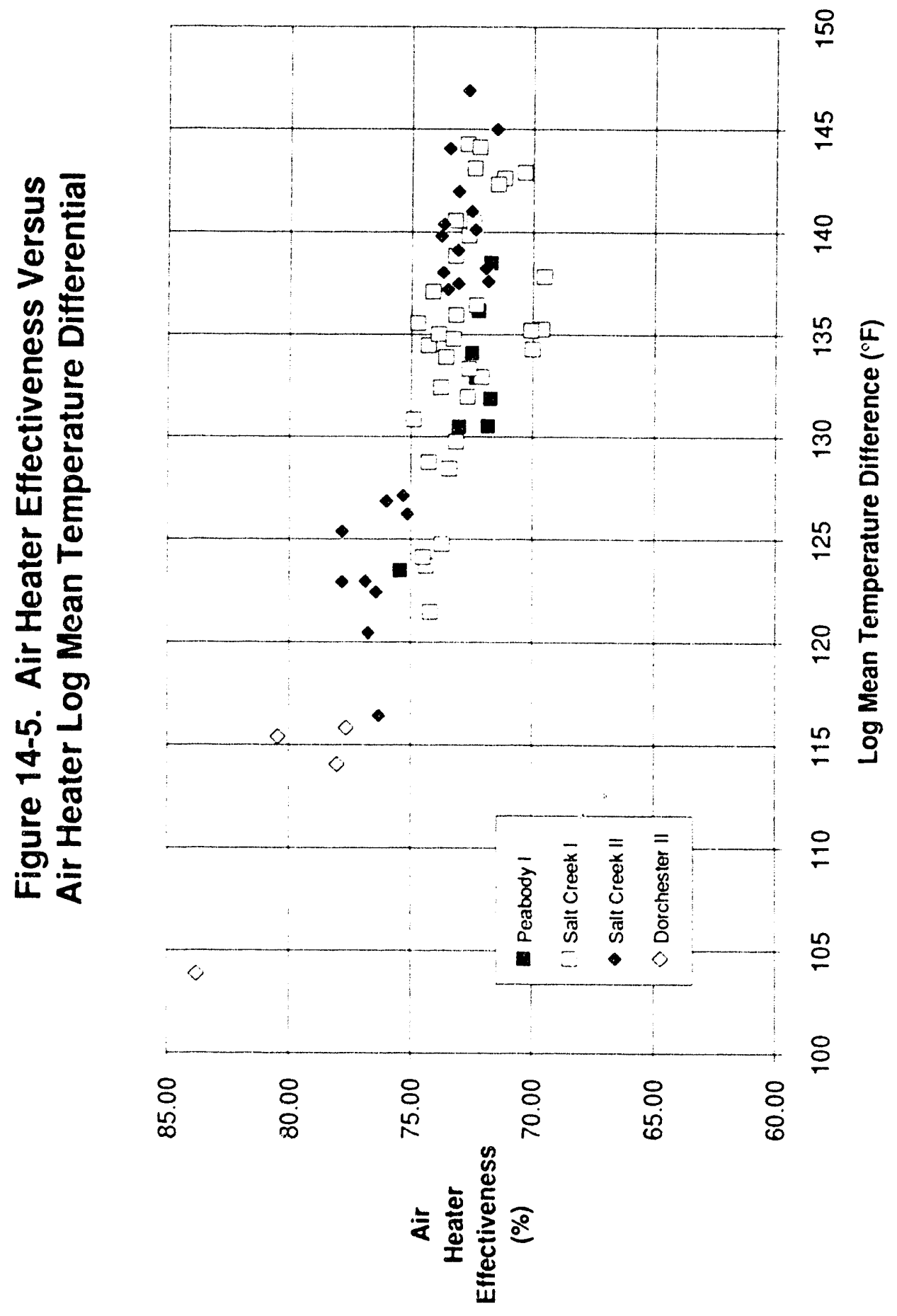

$14-8$ 
shows a good correlation between increasing air heater effectiveness with decreasing log mean temperature difference. The Salt Creek coal tests, which did not follow the general trend in Figure 14-3, show good agreement at the lower end of the log mean temperature difference scale.

\subsection{EFFECT OF SOOT BLOWING ON AIR HEATER GAS OUTLET TEMPERATURES}

During a limited number of controlled soot blowing sequences, data were collected to determine the effect of soot blowing on air heater performance. Steam from the four air heater soot blowers at Nucla is provided from the superheater I outlet header and is reduced to $600 \mathrm{psig.} \mathrm{The} \mathrm{four} \mathrm{air} \mathrm{heater} \mathrm{soot}$ blowers are retractable lance-type soot blowers and are located in the area between the air heater tube sections.

Six soot blowing tests were carried out under full load conditions. Results are shown in Table 14-1.

Table 14-1.

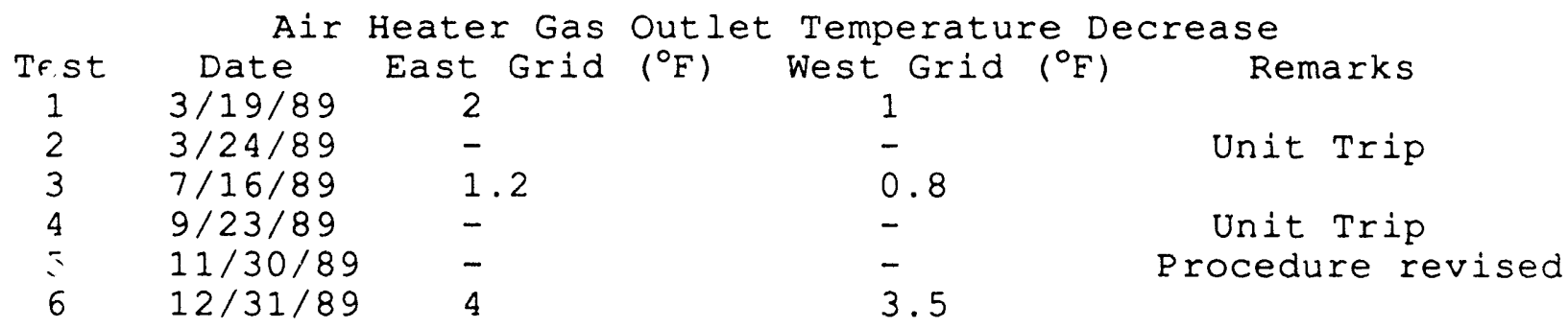

Data for test 6 is shown in Figure 14-6. The reduction in air heater gas outlet temperatures after a one-week soot blowing sequence of the economizer and air heater resulted in a gain in boiler efficiency of approximately 0.1\%. A soot blowing interval should be established that will provide the maximum improvement in performance relative to steam generation costs. 


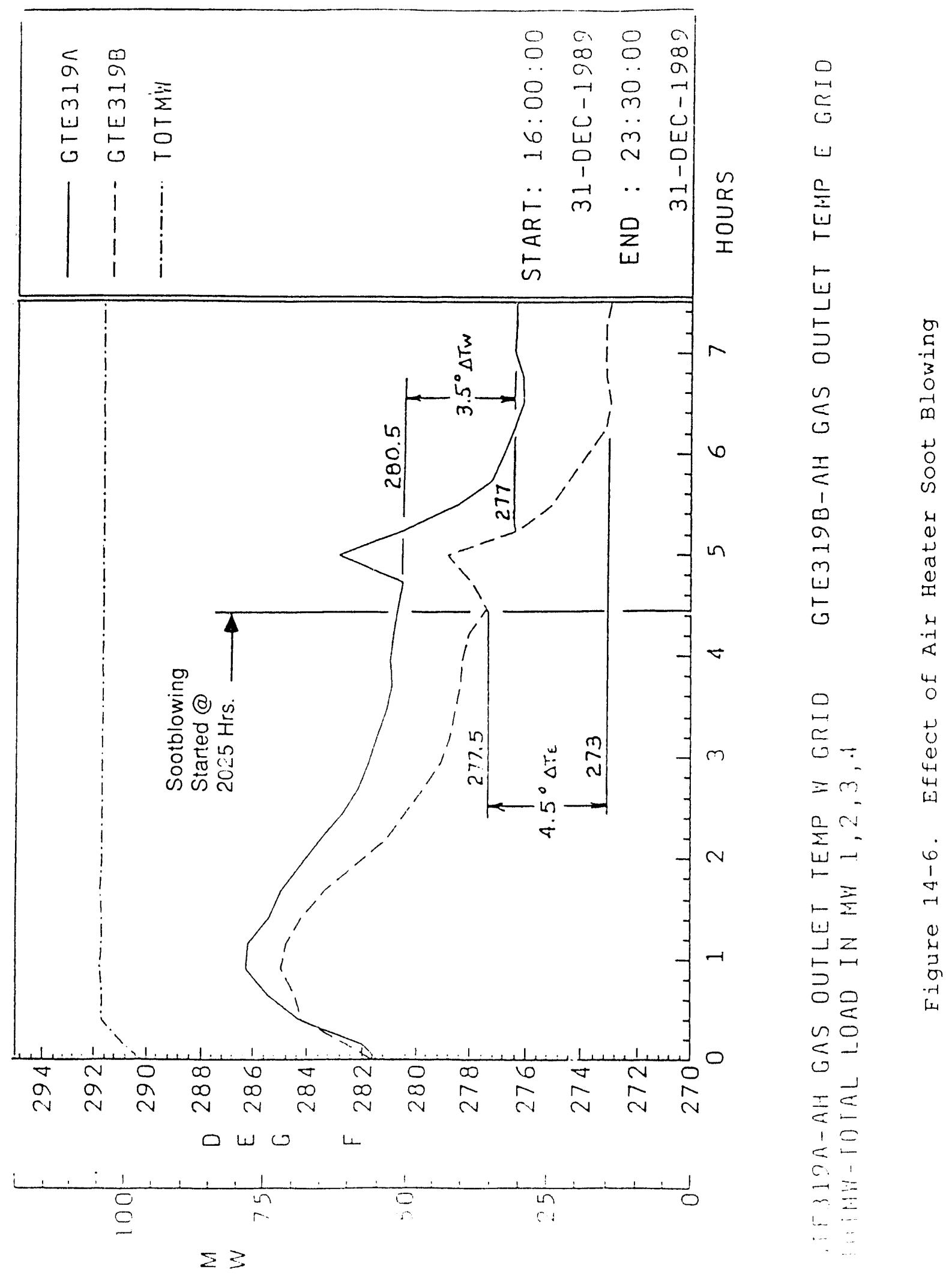


Section 15

\section{BAGHOUSE OPERATION AND PERFORMANCE}

\subsection{OBJECTIVES AND APPROACH}

An extensive baghouse monitoring program was performed during the test program. The objectives of this program were to develop operating data on baghouse operation of CFB's and to establish design specification parameters for CFB baghouses. Data collection involved continuous measurement of baghouse $\Delta \mathrm{P}$, tube sheet $\Delta \mathrm{P}$, and flue gas flow rate. In addition, several isokinetic measurements were taken to determine the collection efficiency, fractional collection efficiency, and size distribution of the inlet and outlet fly ash. Samples of the fly ash were analyzed both chemically and mechanically to determine properties important to baghouse specifications. Individual bag flow monitoring (IBFM) devices were installed to obtain detailed operating data on individual bags.

Data were also obtained on bag materials. Two bag types were tested in the Nucla baghouses. Most of the bags installed in the baghouses are manufactured with the fabric oriented in the normal warp-out configuration. This means that the texturized side of the fabric is facing the dirty gas stream. This fabric material has a $3 \times 1$ twill weave, with 75 percent of the texturized fill yarns facing the dirty gas (sometimes referred to as having a $75 \frac{\circ}{0}$ exposed surface texturization). In compartment $Q$ of unit 2 baghouse, the bags were manufactured "inside out", and therefore had a warp-in construction. In these bags, the bag has a $25 \%$ exposed surface texturization. The bag material is the same, only the smooth side is facing the gas. Previous testing at EPRI's Arapahoe Test Facility with reverse-gas cleaning indicated that a lower surface texturization could result in lower residual dust cake weights, providing the possibility for lower drag without compromising particulate emissions. Measurements made on the two bag types included IBFM devices, bag weight measurements, and residual dust cake drag measurements.

During the course of the Phase I and Phase II test programs, the Nucla baghouses experienced numerous bag failures, equal to approximately $8 \%$ of the total number of installed bags. Considerable effort went into identifying the cause of the failures and finding remedies to the problem. These cperational difficulties are also discussed in this section. 


\subsection{SYSTEM DESCRIPTION}

The CFB boiler at Nucla is equipped with four separate baghouses that operate in parallel. The first three, units 1,2 , and 3 , were existing baghouses that serviced the three 12 MWe stoker-fired boilers that the CFB replaced. These three bághouse were built by wheelabrator-Frye and were the first utility scale shake/deflate baghouses used in the United States. The fourth baghouse, unit 4, was a new baghouse built by Research-Cottrell and also utilizes the shake/deflate cleaning method. Table 15-1 lists design information for the four baghouses. Figure 15-1 shows the general layout of the four baghouses at Nucla.

Table 15-1. Design Information for the Nucla Baghouses

$$
\text { Baghouse \#1, \#2, \& \#3 Baghouse \#4 }
$$

Baghouse manufacturer Number of compartments per Baghouse

Bags per compartment

Bag size

Bag manufacturer

Bag model number

Bag fabric

Bag finish

Bag cleaning method

Cloth area per bag ft ${ }^{2}$

Cloth area/compartment $\mathrm{ft}^{2}$

Cloth area/baghouse $\mathrm{ft}^{2}$
Wheelabrator-Frye 6

112

8 in $x 22 \mathrm{ft}, 25 / 8 \mathrm{in.}$ Fabric Filters \#504

$3 \times 1$ twill, warp ou 10\% Teflon B Shake/deflate 44.31

4,962

29,778
Research-Cottrel1 12

180

8 in $x 22 \mathrm{ft}$ Eabric Filters \#504

$3 \times 1$ twill, warp out 10\% Tefion B Shake/deflate 44.31 7,976 95,712

Total cloth area $\mathrm{ft}^{2}$

Gross air/cloth ratio acfm/ft ${ }^{2}$

Net air/cloth ratio $\mathrm{acfm} / \mathrm{ft}^{2}$

185,045

2.24

2.50

Net-net air/cloth ratio acfm/ft ${ }^{2}$

2.76

The baghouse cleaning cycle is initiated by the flange-toflange pressure drop across the baghouse. Units 1, 2, and 3 have the same cleaning cycles, while baghouse 4 has a slightly different cycle. The three small baghouses have a slow and a fast cleaning cycle. When the flange-to-flange pressure drop across any of the baghouses reaches 5 inches wg., a slow cleaning mode cycle is initiated. In the slow cycle, all three baghouses are cleaned one compartment at a time with a 25 second pause between compartment cleaning. The entire cleaning cycle takes about 33 ininutes to clean all 18 compartments. If the pressure drop across any of the baghouses reaches 6 inches $\mathrm{wg}$. , the fast cleaning cycle is initiated. In this cycle, the pause between compartments is 


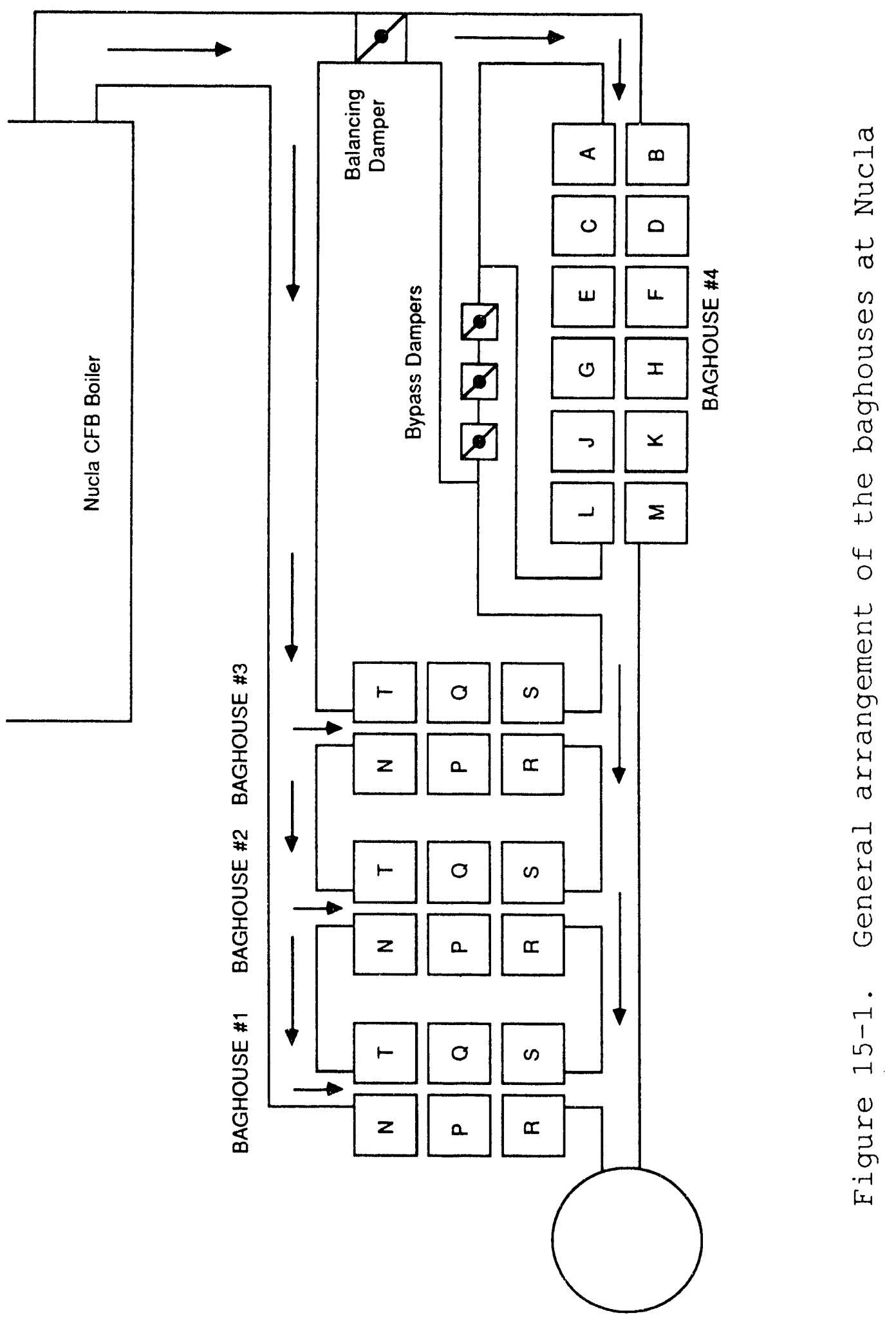


reduced to 10 seconds and the total cycle takes about 28 minutes. If the pressure drop reaches 7 inches wg., an alarm sounds in the control room and appropriate action is taken.

Baghouse number 4 also has a slow and fast cleaning cycle. When the flange-to-flange pressure drop reaches 6 inches $w g$, the slow cleaning cycle is initiated. In the slow cleaning cycle, there is a 360 second pause between compartment cleanings. The slow cycle requires 90 minutes to clean all 12 compartments. If the pressure drop reaches 7 inches wg., then the fast cleaning cycle is initiated. In this mode there is only a 10 second delay between compartments, and the entire cycle requires 19 minutes to clean all 12 compartments. If the pressure drop reaches 8 inches $w g .$, an alarm will sound at the control room. At 9 inches wg. pressure drop, the bypass dampers will open to protect the baghouse and the flue gas will bypass the baghouse.

In order to study the performance of two different bag materials, individual bag flow monitor (IBEM) sensors were installed in six bags in compartments $P$ and $Q$ of the number 2 baghouse. Five other IBFM sensors were installed in

compartment $E$ of baghouse 4. The IBFM sensors are orifice plate devices that fit into the inlet thimble on an individual bag. These orifices allow measurement of the gas flow through the bag for calculation of the air-to-cloth ratio and drag.

\subsection{OPERATIONAL AND PERFORMANCE DATA}

Measurements made during the baghouse monitoring program included inlet and outlet particulate loadings, inlet and outlet size distribution and fractional collection efficiency, chemical and physical analyses of the baghouse ash, flow rate and pressure drop measurements and IBFM measurements on individual bags to compare two types of bag construction (warp-in versus warp-out). Results of these measurements are discussed in separate sections below.

\subsubsection{Inlet and Outlet Particulate Loading}

Inlet and outlet particulate loading measurements were made twice during the test program. The first time was on June 20 and 21, 1989 when the unit was burning Peabody coal. These tests were conducted around the unit 4 baghouse. The second test was conducted using salt Creek coal on september 19 and 22,1989 , again around the unit 4 baghouse. Table 15-2 gives the results of both test periods.

On June 20 and 21, 1989, isokinetic measurements of the inlet and outlet dust loadings were taken around baghouse 4 . These measurements were taken just after test A08 was completed, arid operating conditions were not changed. Isokinetic measurements of inlet and outlet dust loadings were made on 


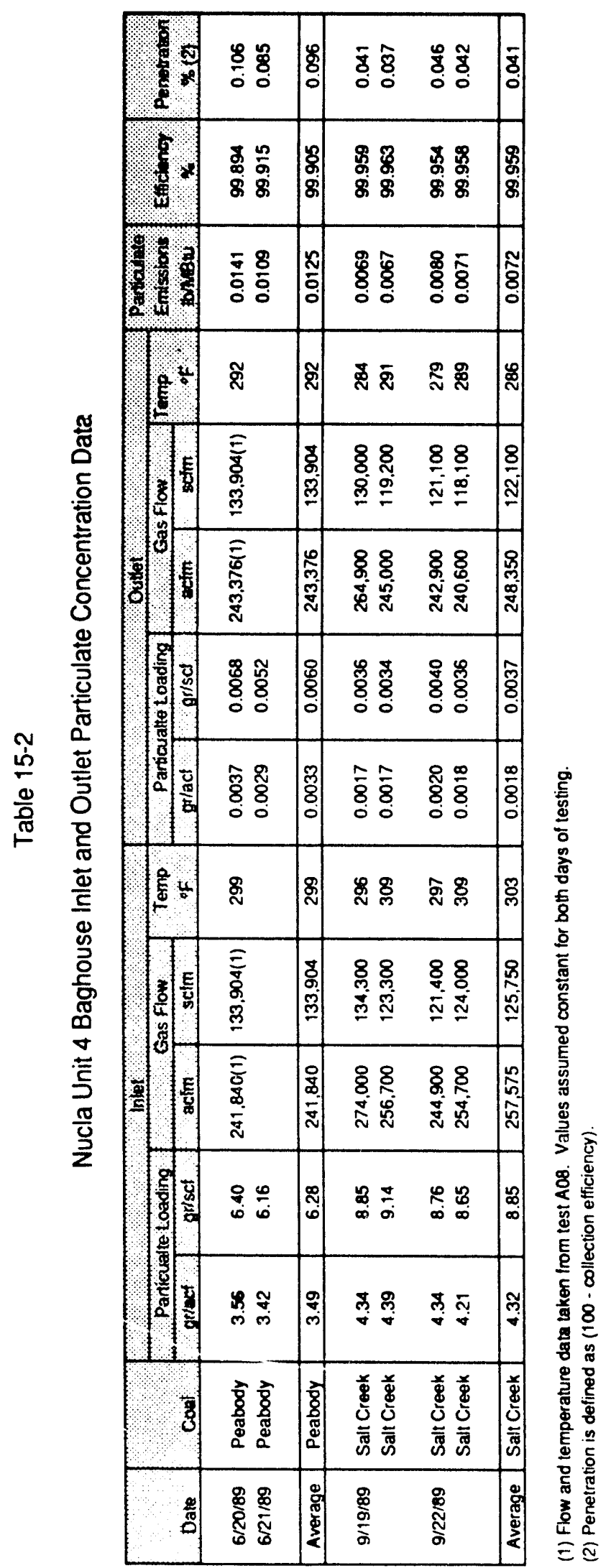


both days. The inlet mass flow rate of solids was 7,350 $\mathrm{lb} / \mathrm{hr}$ on June 20 and $7,066 \mathrm{lb} / \mathrm{hr}$ on June 21 . The out let mass flow rate of solids was $7.762 \mathrm{lb} / \mathrm{hr}$ on June 20 and $6.02 \mathrm{lb} / \mathrm{hr}$ on June 21. Collection efficiency averaged over the two days was 99.905\%. The particulates emissions from these two tests averaged $0.0125 \mathrm{lb} / \mathrm{MBtu}$, which is well below the New Source Performance Standards (NSPS) of $0.03 \mathrm{lb} / \mathrm{MBtu}$.

On September 19 and 22, 1989, isokinetic tests were conducted while the unit was firing Salt Creek coal. During these test periods, two 96-minute tests were conducted each day at both the inlet and outlet of baghouse 4. Also during this time period, tests were conducted to determine the size distribution of the inlet and outlet baghouse streams. The size distribution data is discussed in the next section. The average inlet concentration of the baghouse for these tests was 8.85 grains/standard cubic foot $(\mathrm{gr} / \mathrm{SCF})$. The average outlet dust loading was $0.0037 \mathrm{gr} / \mathrm{SCF}$. Collection efficiency averaged $99.959 \%$ and the particulate emissions averaged $0.0072 \mathrm{lb} / \mathrm{MBtu}$.

Based on these tests, it appears that the salt Creek coal ash had a slightly better collection efficiency over the peabody coal ash. This may be due to different properties of the two coal ashes, or to operational problems in the baghouse during the Peabody tests. The differences between the two coals will be examined in other sections of this report.

\subsubsection{Flow Rate Versus Pressure Drop}

Table 15-3 lists baghouse 4 performance data for a selected number of tests. The data are plotted in Figure 15-2 as flange-to-flange pressure drop versus air-to-cloth ratio. Figure 15-3 shows the same plot for all of the performance tests conducted during the test program. The points identified as salt Creek I were tests conducted during Phase I testing and the ones marked salt Creek II were conducted during phase II testing. There is considerable scatter in the data, particularly at the lower loads. Figure 15-4 shows the tube sheet pressure drop versus the air-to-cloth ratio from this data compared to the data obtained from the TVA 20 MW baghouse. This figure shows that the Nucla baghouse, using shake/deflate cleaning, appears to be operating at a lower $\Delta \mathrm{P}$ than the cleaning methods used at TVA.

From Figures $15-2$ and $15-3$, it is difficult to determine if any of the coals operate at lower bag pressure drops. This is because of the large amount of scatter in the data. The reason. for this scatter can be seen in Figure 15-5. This figure shows a plot of baghouses 4 and 1 's pressure drops versus time for Peabody and Salt Creek coal during operation at $60 \mathrm{MW}$ and $101 \mathrm{MW}$. (Note that at $60 \mathrm{MW}$ the pressure drop across the bags takes between 7 and 8 hours after cleaning to increase to the point where another cleaning cycle is 


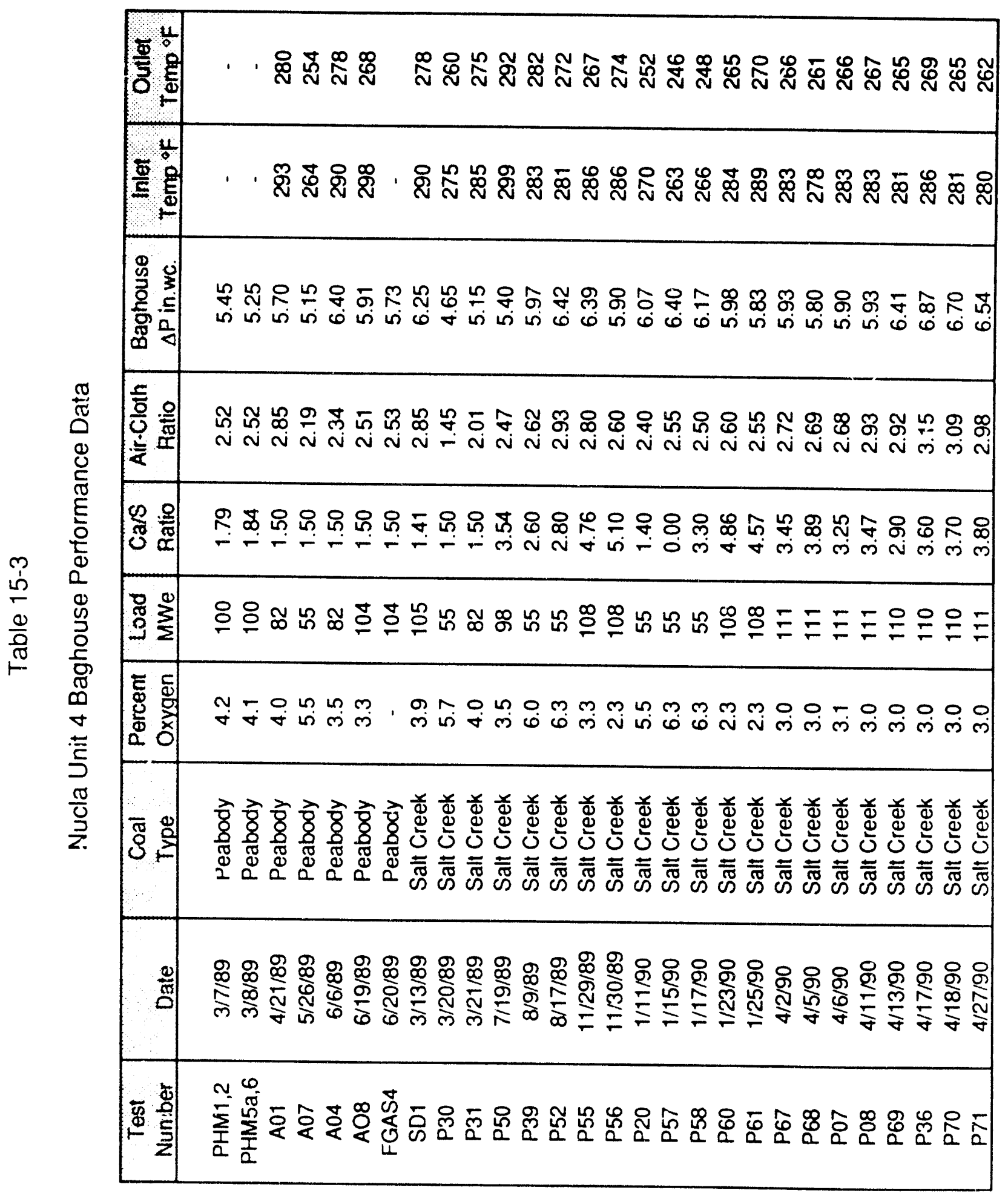




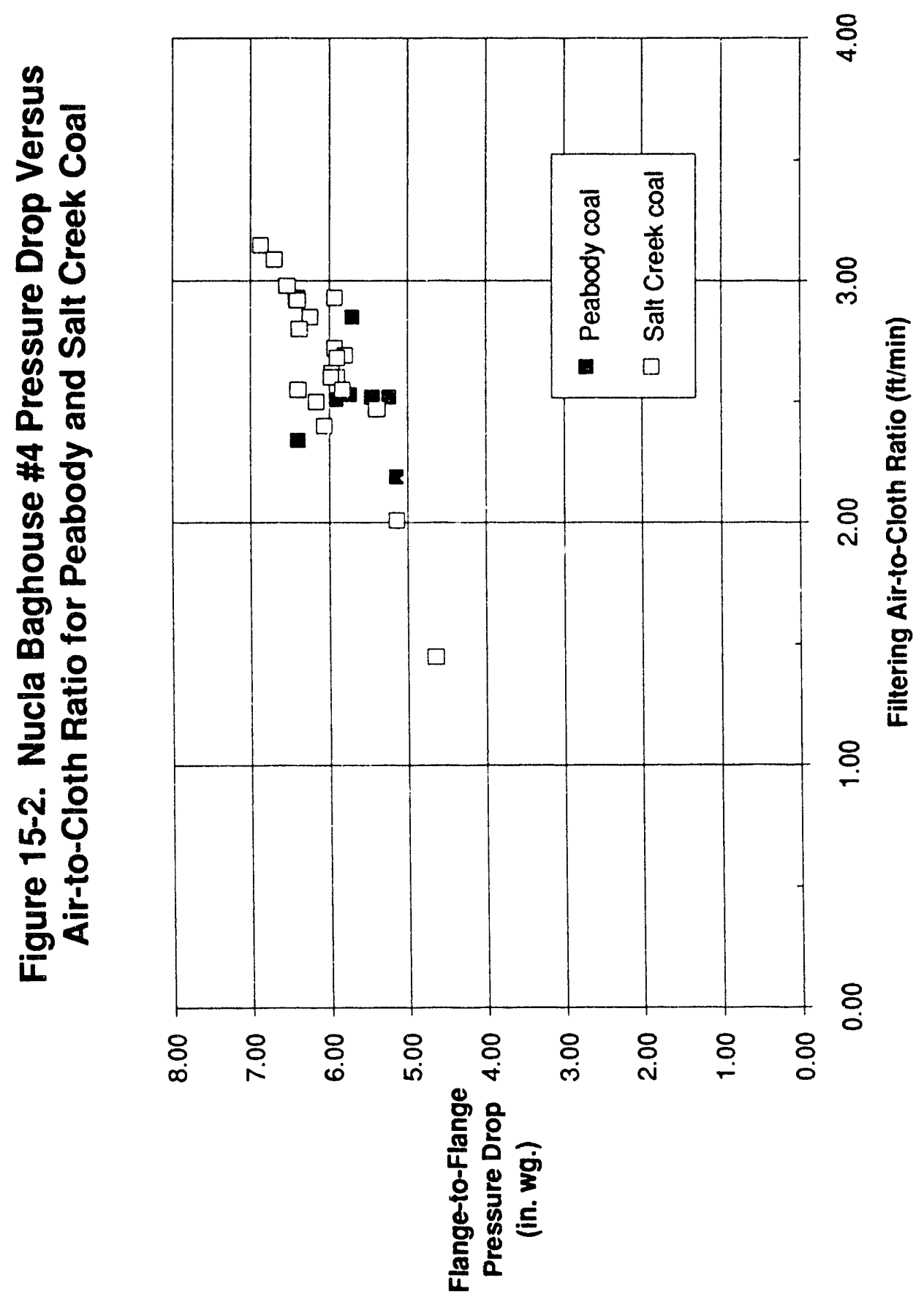




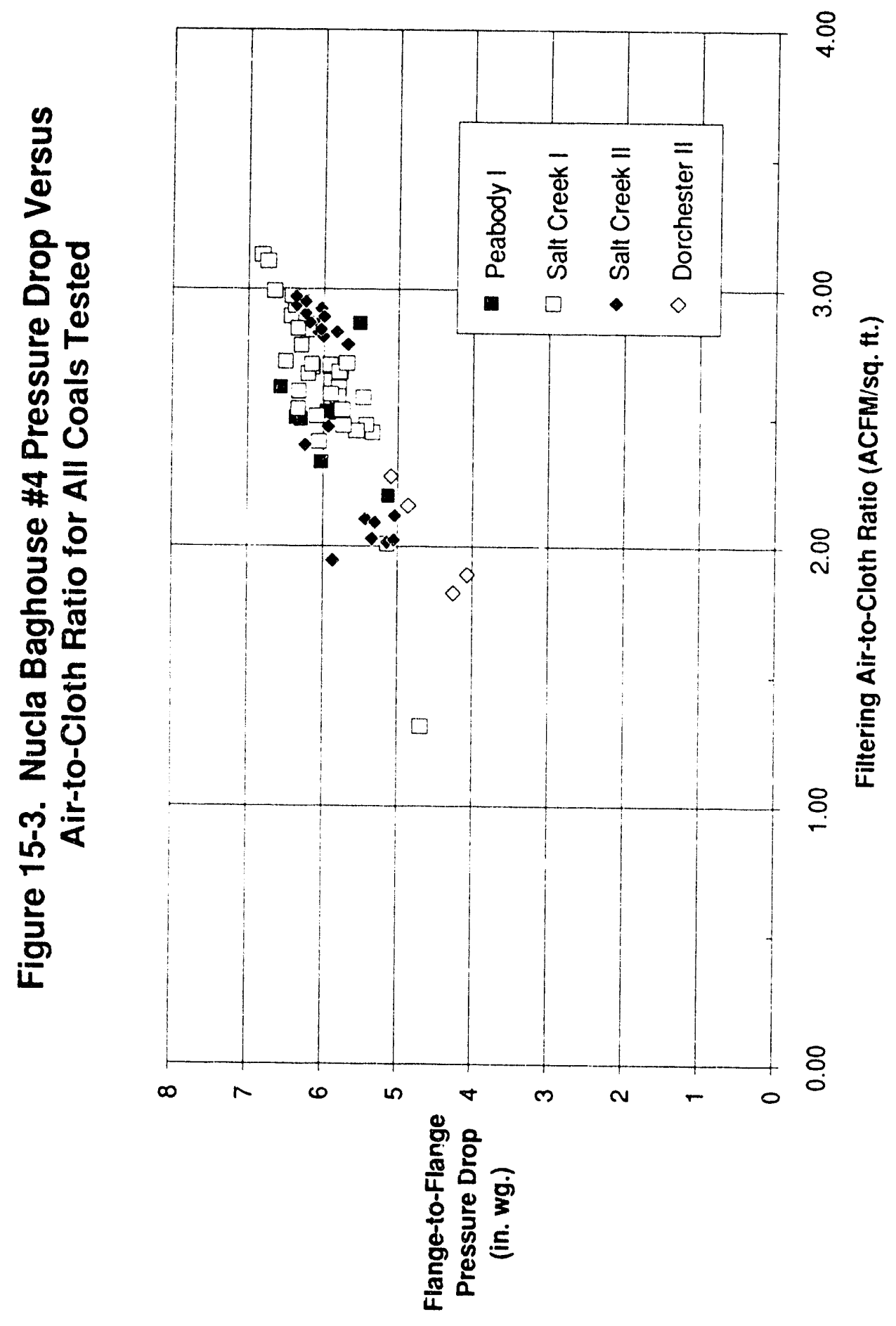




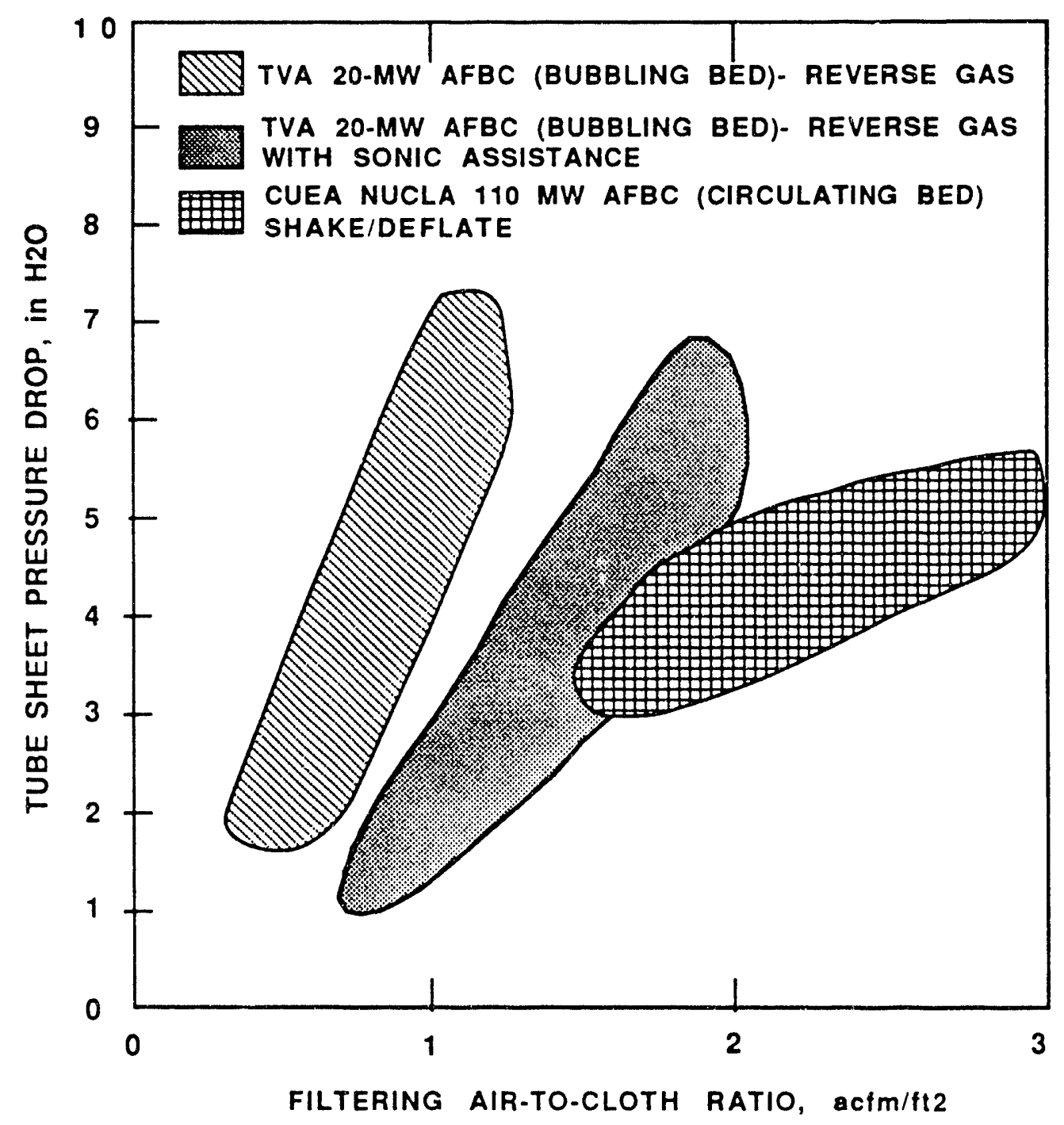

Figure 15-4. Comparison of tubesheet pressure drop versus air-to-cloth ratio for the Nucla \#4 baghouse and the TVA $20 \mathrm{MW}$ AFBC baghouse. 


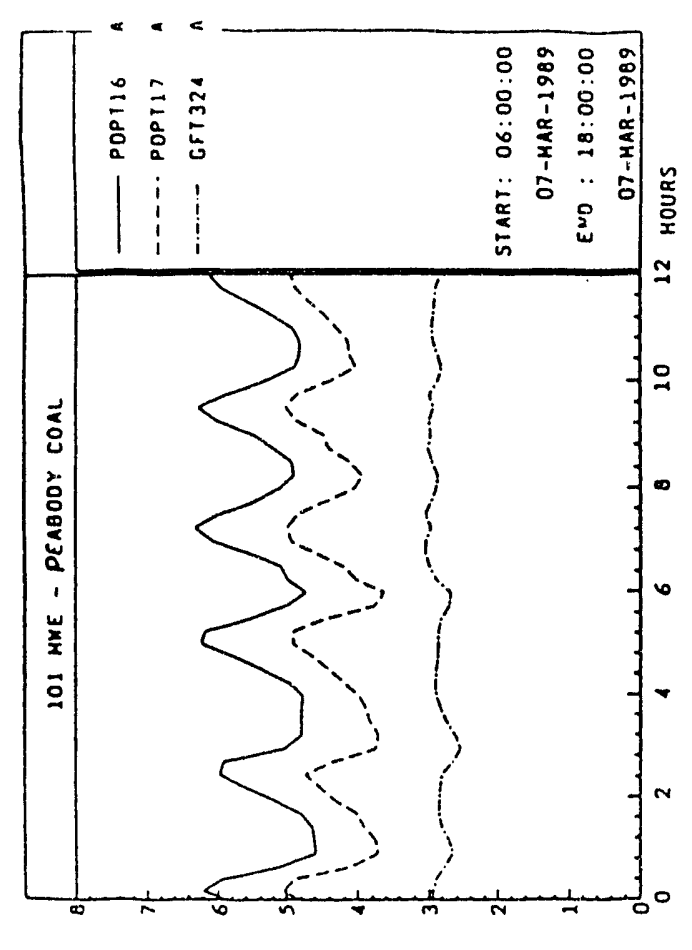

سلسلس

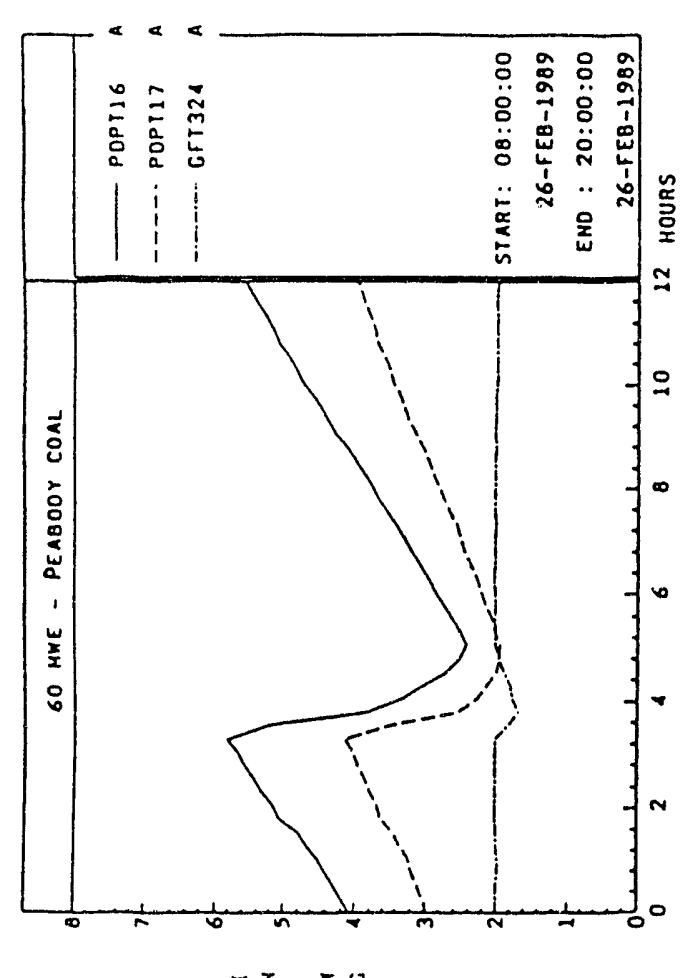

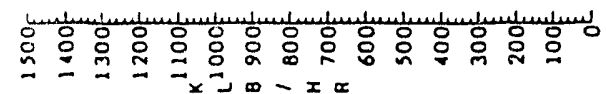
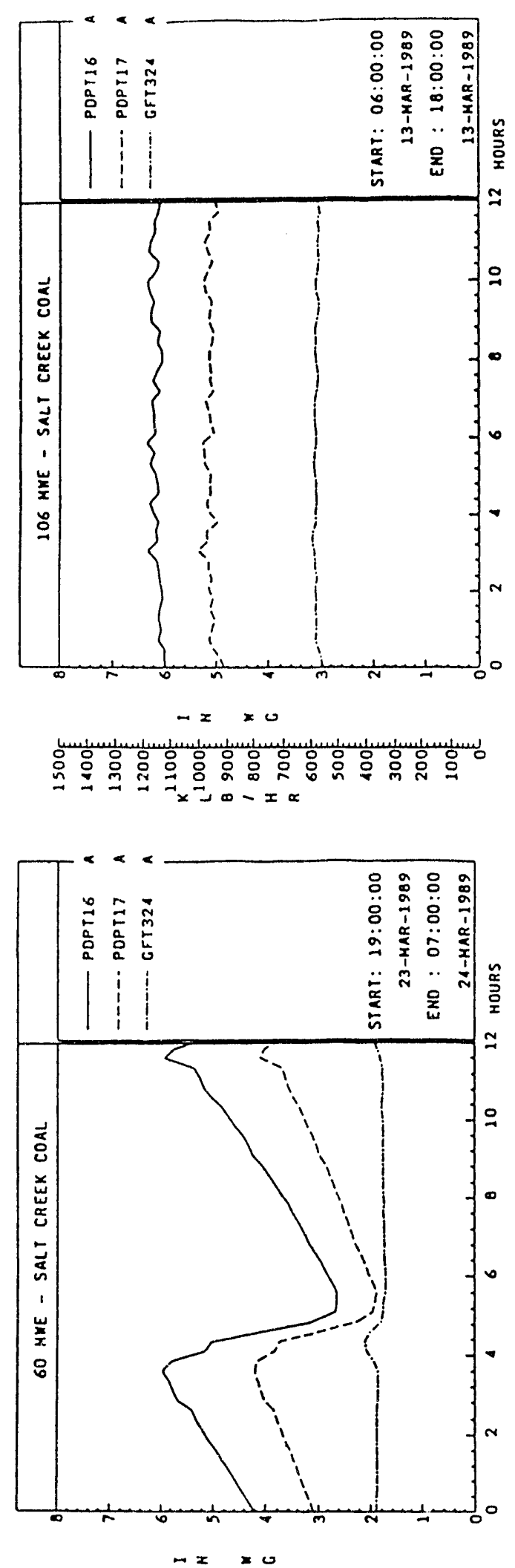

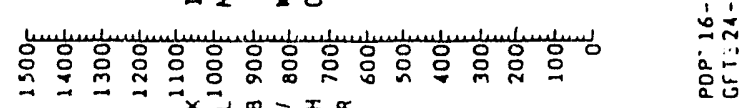

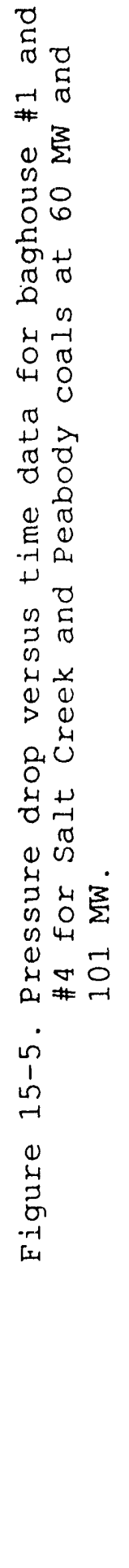


initiated). Since a performance test is approximately 8 hours long, the pressure drop averaged over this time period will be strongly dependent on the time in the cleaning cycle when the test was started. At full load, the pressure drop rise is so fast that the unit is cleaning almost

continuously. For the Salt Creek coal the rise is such that the unit operates continuously in the slow clean cycle. The Peabody coal at full load cleans about once every 3 hours. These faster cycles will improve the accuracy of the average value, thereby reducing the scatter in the data. However, the slopes of these graphs do indicate that salt creek is building a filter cake at a faster rate than peabody coal. This observation is validated by the higher inlet dust loadings for Salt Creek in Table 15-2.

\subsubsection{Inlet and Outlet Particle Size Distribution}

During the september 18 to 22, 1990 baghouse tests, samples were collected to allow calculation of the fractional collection efficiency of the baghouse. Particle size distribution measurements were conducted at the inlet and outlet of baghouse 4. Sixteen inlet measurements were made using six-stage modified Brink Cascade Impactors with a cyclone precollector. Eight outlet size distributions were made using seven-stage University of Washington Mark II I Source Test Cascade Impactors with an impaction-type precollector.

The mass median diameter (physical) of the particles in the inlet flue gas stieam was determined to be 17.3 microns. The mass median diameter of the outlet stream was determined to be 8.3 microns. However, further analysis of the data by Southern Research Institute, the contractor that performed the tests, revealed that the inlet particle size data were biased toward the larger particles. This was due to the small diameter nozzle required on the Brink Impactors for isokinetic sampling and the subsequent impaction losses that occurred in the cyclone precollector due to high gas velocity exiting the nozzle. In order to obtain information on the baghouse inlet particle size distribution, the mass samples collected during measurements of the inlet mass concentratior. (Method 17) were submitted for particle size classification. The samples were analyzed by the Southern Research Institute using a BACHO analyzer.

The particle size distribution curve for the baghouse inlet sample is shown in Figure 15-6. This graph shows the cumulative weight percent of the inlet sample obtained by the BACHO analysis. The inlet distribution below 1.5 microns was estimated due to the fact that the BACHO is not able to fractionate below this particle size. The mass median diameter of the inlet sample was 7.1 microns, which is considerably smaller than the size determined by the impact cascaders. The outlet particle size distribution data are 

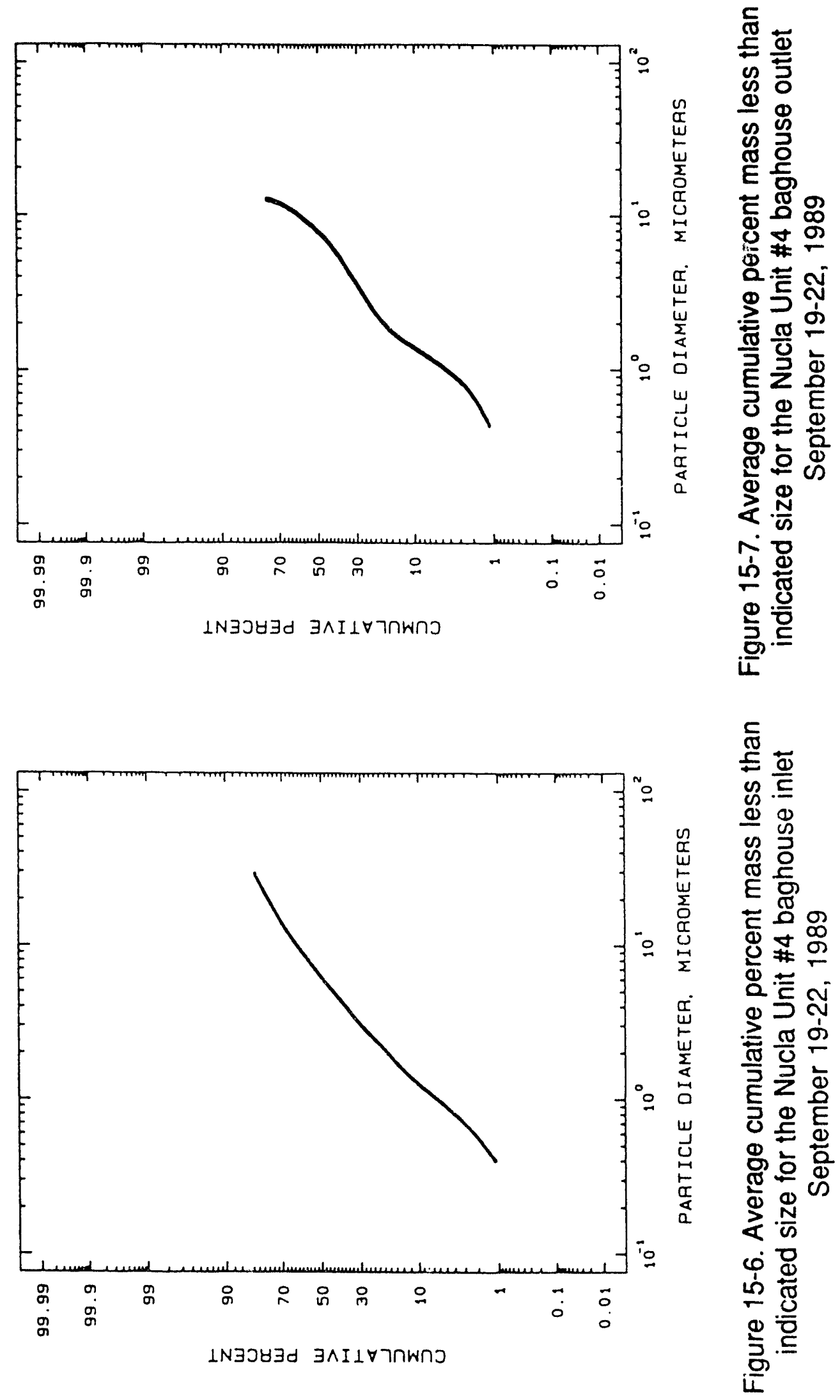
presented in Fibure 15-7. This graph shows the data presented in the same manner as Figure 15-6. The mass median diameter of the outlet dust is 8.0 microns, indicating that the baghouse apparently has a higher collection efficiency on smaller particles.

The data in Figures $15-6$ and 15-7, along with the flow rate data in Table 15-2, were used to calculate the fractional collection efficiency for the baghouse. The results of this calculation are shown in Figure 15-8. This figure shows that the collection efficiency does drop off slightly as the particle size increases.

\subsubsection{Chemical and Physical Properties of Ash}

Five samples of dust cake ash were removed from baghouse 4 and were analyzed by Southern Research Institute. Three of the samples were taken during operation with Salt Creek coal and two were taken during operation with Peabody coal. No samples were obtained during operation with Dorchester coal.

The results of the analyses are given in Table 15-4. The Salt Creek coal was found to have a higher gas flow resistance factor. The Salt Creek coal was also found to have a slightly smaller particle size. These analyses indicate that under identical operation conditions, the salt Creek coal should operate at a higher baghouse $\Delta \mathrm{P}$ than the Peabody coal. The increased $\Delta \mathrm{P}$ combined with the higher inlet dust loadings explain the operating curves that were discussed in Section 15.3.2.

\subsubsection{Comparison of Warp-in Versus Warp-out Bags}

Comparison of the warp-in versus warp-out bag material concentrated on measurements of the residual dust cake and measurements made with the IBFM meters. As was stated in Section 15.2, the experimental warp-in bags were installed in compartment $Q$ of baghouse 2. IBFM flow meters were installed in six bags in compartment 2Q. Six monitors were also installed in compartment $P$ of baghouse 2 and an additional five monitors were installed in compartment $E$ of baghouse 4 .

Bags from compartments $2 \mathrm{Q}, 2 \mathrm{P}$, and $4 \mathrm{E}$ were removed and weighed just after a cleaning cycle to determine the weight of the residual dust cake. Three bags were removed from compartment 2P. The weights of these bags were 12, 11, and 16 lbs. An additional four bags were removed from compartment $4 \mathrm{E}$. These bags were found to weigh $15,14,16$, and 17 lbs. The average weight of the warp-out bags was 14.4 1b. Six bags removed from compartment $2 Q$ and were found to weigh $8,6,7,6,6$, and $6 \mathrm{lbs}$, for an average weight of the warp-in bags of 6.5 lbs. A clean new bag weighs 4 pounds. Thus the residual dust cake weight was $10.4 \mathrm{lb}$ for the warpout bags and 2.5 lb for the warp-in bags. The residual dust 


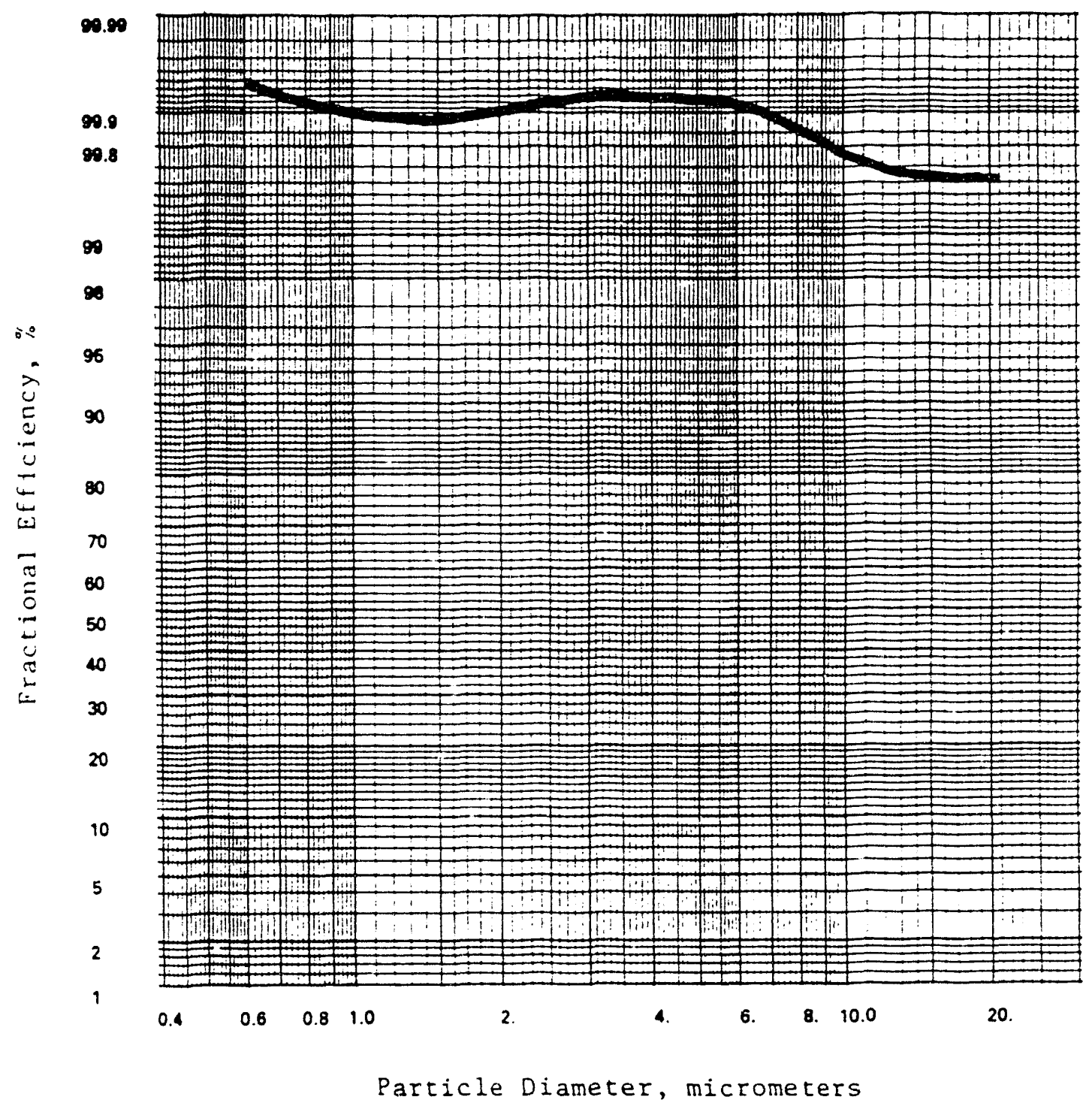

Figure 15-8. Average fractional efficiency versus particle size for the Nucla Unit \#4 baghouse, September 19-22, 1989 


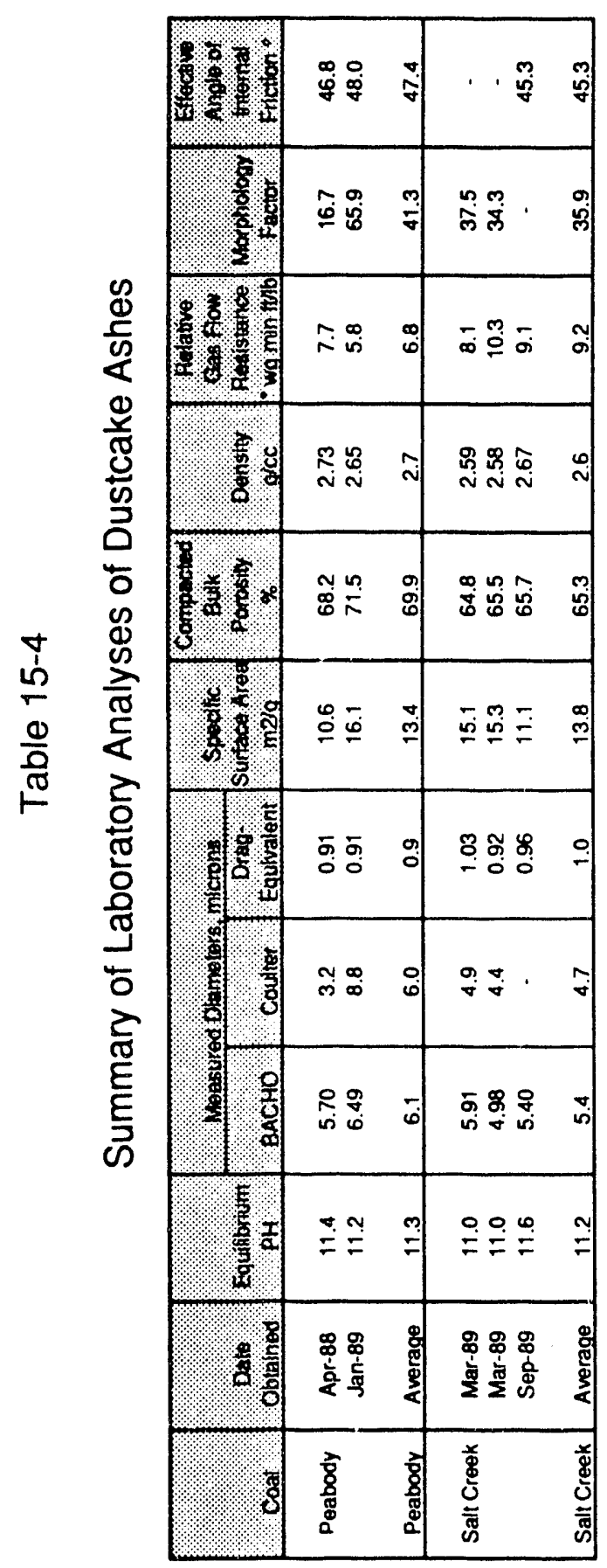

\begin{tabular}{|c|c|c|c|}
\hline 8 & $\underset{\infty}{\infty} \underset{\infty}{\infty}$ & 욧 & 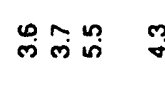 \\
\hline 6 & $\begin{array}{l}\infty \\
\infty \\
\infty\end{array}$ & के & 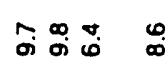 \\
\hline 8 & 冓 & $:$ & 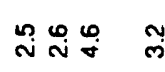 \\
\hline a & 菅。 & : & 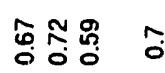 \\
\hline 8 & $\stackrel{\square}{=}$ & $\stackrel{\bullet}{\circ}$ & $\sim \mathcal{N} \sim$ \\
\hline 9 & $\bar{q} \dot{q}$ & क़े & 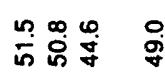 \\
\hline वृ. & $\stackrel{\leftrightarrow}{\tilde{N}} \underset{\sim}{\tilde{N}}$ & है & 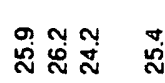 \\
\hline क्र & $\stackrel{\infty}{\infty} \infty$ & 8 & 바율 \\
\hline 8 & $\ddot{\Phi}$ & 吕 & 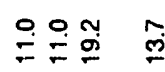 \\
\hline 인 & ब. & 용 & 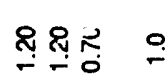 \\
\hline 용 & 胥 & ఖ. & 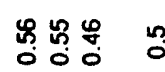 \\
\hline$\frac{8}{2}$ & $\stackrel{\infty}{\mathbb{N}}$ & $\overline{\text { ஸे }}$ & 兽웅융 뭉 \\
\hline : & : : : & : & 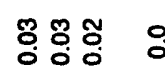 \\
\hline 8 & 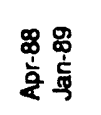 & $\begin{array}{l}\text { \& } \\
\text { 옇 }\end{array}$ & 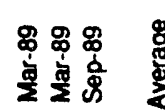 \\
\hline 8 & $\begin{array}{l}\text { ते } \\
\text { षूँ } \\
\text { व. }\end{array}$ & 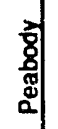 & 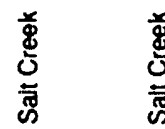 \\
\hline
\end{tabular}


cake areal density was $0.23 \mathrm{lb} / \mathrm{ft}^{3}$ for the warp-out bags and $0.06 \mathrm{lb} / \mathrm{ft}^{3}$ for the warp-in bags. These tests indicate that the warp-out bag retains a significant amount of dust cake compared to the warp-in bags.

Table 15-5 shows the IBFM results from compartments $2 \mathrm{P}$ and 20 of baghouse 2. These data show that there is apparently no significant difference between the two types of bags, despite the considerable differences in the residual dust cake. This result indicates that the residual dust cake does not significantly contribute to the drag of the cleaned bag.

Apparently, the only dust that contributes to the residual drag is the dust that filis the interstices of the bag fibers.

Table 15-5.

Average Flow and Pressure Drop Data

Eor Warp-in and Warp-out Bags

\author{
Air-to-cloth ratio, $a c f m / f t^{2}$ \\ Pressure drop, in. wg. \\ Drag, in. wg./fpm \\ Re:sidual drag, in. wg./fpm \\ Drag Coefficient, in. wg. min
}

\begin{tabular}{|c|c|}
\hline $\begin{array}{l}\text { Comp. } 20 \\
\text { Warp-In }\end{array}$ & $\begin{array}{l}\text { Comp. } 2 \mathrm{P} \\
\text { Warp-Out }\end{array}$ \\
\hline $\begin{array}{c}1.7 \\
5.5 \\
3.3 \\
2.3 \\
13.7\end{array}$ & $\begin{array}{c}1.6 \\
5.1 \\
3.1 \\
2.2 \\
13.9\end{array}$ \\
\hline
\end{tabular}

\section{4 SUMMARY OF BAG FAILURES}

Between October 1988 and May 1990 a total of 381 bag failures had been reported. Table 15-6 lists the the bag failures experienced at Nucla along with the reason for the failures. This number of failures represents a failure rate of $0.46 \% /$ month, which is unacceptably high. However, most of these failures were concentrated in baghouse 2 (313 bag failures $=2.33 \% /$ month). The failure rates for the other bughouses are: baghouse $1=0.15 \% /$ month; baghouse $3=$ $0.05 \% /$ month; and baghouse $4=0.09 \% /$ month. The high failure rate was found to be due to high deflate a ir flow rates in baghouse 2 . Baghouse 1 also operated with very high deflate air flow rates for an undetermined period of time, although not as long as baghouse 2 .

As a result of this analysis, the deflate flow rate to the older baghouses was adjusted to equal the deflate pressure in baghouse 4, the new baghouse, in May of 1989. Furthermore, the shake mechanism timer was changed to shake the bags after the deflate cycle is complete, rather than during the deflate cycle. Since the adjustment, the bag failure rate has decreased dramatically. The average failure rate before the adjustment was $1.61 \% / m o n t h$ for all four baghouses. After the adjustment, the failure rate dropped to $0.29 \% / \mathrm{month}$ for all 
Table 15-6

Page (1 of 2)

CUEA Nucla Station - Bag Failure Documentation

\begin{tabular}{|c|c|c|c|c|}
\hline Qate & untu & Qomonartment & otsongs & Connmert \\
\hline $10 / 5 / 88$ & 2 & $\mathbf{S}$ & 1 & Bottom of bag, ash abrasion \\
\hline $10 / 6 / 88$ & 2 & S & 5 & Bottom of bag, ash abrasion \\
\hline $10 / 7 / 88$ & 1 & $T$ & 3 & Top of bag, 1 in. holes \\
\hline & 2 & $\mathbf{P}$ & 2 & Bottom of bag, ash abrasion \\
\hline & 2 & S & 3 & Bottom of bag, ash abrasion \\
\hline $10 / 13 / 88$ & 2 & $\mathbf{S}$ & 3 & Bottom of bag, ash abrasion \\
\hline $12 / 7 / 88$ & 2 & S & 23 & Bottom of bag, ash abrasion \\
\hline $12 / 8 / 88$ & 2 & $\mathbf{P}$ & 24 & Bottom of bag, ash abrasion \\
\hline $12 / 9 / 88$ & 4 & $E$ & 5 & Rubbing on IFBM \\
\hline & 4 & $E$ & 11 & Bottom of bag, ash abrasion/impengement \\
\hline $12 / 22 / 88$ & 2 & Q & 17 & Bottom of bag, ash abrasion \\
\hline $12 / 28 / 88$ & 2 & $S$ & 26 & Bottom of bag, ash abrasion \\
\hline $1 / 4 / 89$ & 2 & N & 18 & Bottom of bag, ash abrasion \\
\hline $1 / 16 / 89$ & 1 & $R$ & 3 & Bottom of bag, ash abrasion \\
\hline & 1 & $S$ & 1 & Bottom of bag, ash abrasion \\
\hline & 2 & $N$ & 8 & Bottom of bag, ash abrasion \\
\hline & 2 & $\mathbf{P}$ & 5 & Bottom of bag, ash abrasion \\
\hline & 2 & Q & 11 & Bottom of bag, ash abrasion \\
\hline & 2 & S & 13 & Bottom of bag, ash abrasion \\
\hline & 2 & T & 8 & Bottom of bag, ash abrasion \\
\hline $1 / 17 / 89$ & 2 & $R$ & 4 & Bottom of bag, ash abrasion \\
\hline & 4 & $E$ & 1 & Bottom of bag, ash abrasion \\
\hline $1 / 18 / 89$ & 4 & B & 1 & Rubbing on top railing \\
\hline & 4 & $E$ & 5 & Bottom of bag, ash abrasion \\
\hline & 4 & $\mathrm{~F}$ & 1 & Bottom of bag, ash abrasion \\
\hline $3 / 27 / 89$ & 1 & 0 & 1 & Bottom of bag, ash abrasion \\
\hline & 1 & $R$ & 1 & $\begin{array}{l}\text { Botrom nf bag, ash abrasion } \\
\text { Bottom of bag, ash abrasion }\end{array}$ \\
\hline & 2 & $N$ & 6 & Bottom of bag, ash abrasion \\
\hline & 2 & $P$ & 3 & Bottom of bag, ash abrasion \\
\hline & 2 & Q & 1 & Bottom of bag, ash abrasion \\
\hline & 2 & $R$ & 2 & Bottom of bag, ash abrasion \\
\hline & 2 & $\mathbf{S}$ & 3 & Bottom of bag, ash abrasion \\
\hline & 3 & Q & 1 & Bottom of bag, manufacturing defect \\
\hline $3 / 28 / 89$ & 4 & $L$ & 1 & Bottom of bag, ash abrasion \\
\hline $6 / 6 / 89$ & 2 & S & 5 & Bottom of bag, ash abrasion \\
\hline $6 / 12 / 89$ & 2 & S & 5 & Bottom of bag, ash abrasion \\
\hline & 4 & $E$ & 4 & Bottom of bag, ash abrasion \\
\hline $6 / 14 / 89$ & 2 & $Q$ & 4 & Bottom of bag, ash abrasion \\
\hline $9 / 17 / 89$ & 2 & Q & 1 & Torn by IBFM sensor \\
\hline $9 / 22 / 89$ & 2 & S & 2 & Bottom of bag, ash abrasion \\
\hline $9 / 25 / 89$ & 2 & N & 12 & Bottom of bag, ash abrasion \\
\hline & 2 & $\mathrm{~T}$ & 3 & Bottom of bag, ash abrasion \\
\hline & 2 & $\mathbf{P}$ & 3 & Bottom of bag, ash abrasion \\
\hline & 2 & Q & 7 & Bottom of bag, ash abrasion \\
\hline & 2 & R & 1 & Bottom of bag, ash abrasion \\
\hline & 2 & $S$ & 10 & Bottom of bag, ash abrasion \\
\hline
\end{tabular}


Table 15-6

Page (2 of 2)

\section{CUEA Nucla Station - Bag Failure Documentation}

\begin{tabular}{|c|c|c|c|c|}
\hline Dato & tetiti & Compartment & Yumber & comment \\
\hline $9 / 26 / 89$ & 1 & $\mathbf{R}$ & 1 & Botiom of bag, ash abrasion \\
\hline & 1 & S & 1 & Bottom of bag, ash abrasion \\
\hline $10 / 26 / 89$ & 2 & $\mathbf{Q}$ & 2 & Bottom of bag, ash abrasion \\
\hline & 2 & $\mathbf{S}$ & 5 & Bottom of bag, ash abrasion \\
\hline $11 / 9 / 89$ & 1 & N & 1 & Bottom of bag, ash abrasion \\
\hline & 1 & $\mathbf{R}$ & 1 & Bottom of bag, ash abrasion \\
\hline $11 / 21 / 89$ & 3 & s & 2 & Bottom of bag, ash abrasion \\
\hline $11 / 28 / 89$ & 4 & A & 4 & Bottom of bag, ash abrasion \\
\hline & 2 & $Q$ & 5 & Bottom of bag, ash abrasion \\
\hline & 2 & $P$ & 4 & Bottom of bag, ash abrasion \\
\hline $12 / 4 / 89$ & 3 & N & 4 & Torn approximately $1 \mathrm{ft}$ from top \\
\hline $12 / 20 / 89$ & 2 & S & 3 & Bottom of bag, ash abrasion \\
\hline $12 / 21 / 89$ & 2 & S & 1 & Bottom of bag, ash abrasion \\
\hline & 2 & Q & 1 & Bottom of bag, ash abrasion \\
\hline $12 / 26 / 89$ & 2 & Q & 9 & Bottom of bag, ash abrasion \\
\hline & 4 & $E$ & 4 & Ash impingement from failed adjacent IBFM gasket \\
\hline $1 / 3 / 90$ & 4 & $E$ & 4 & Ash impingement from failed acjacent IBFM gasket \\
\hline $1 / 15 / 90$ & 2 & S & 1 & Bottom of bag, ash abrasion \\
\hline & 2 & $Q$ & 2 & Bottom of bag, ash abrasion \\
\hline & 1 & R & 2 & Bottom of bag, ash abrasion \\
\hline $1 / 26 / 90$ & 2 & $T$ & 4 & Bottom of bag, ash abrasion \\
\hline $2 / 23 / 90$ & 2 & $N$ & 5 & Bottom of bag, ash abrasion \\
\hline $3 / 12 / 90$ & 2 & $Q$ & 4 & Bottom of bag, ash abrasion \\
\hline $3 / 14 / 90$ & 1 & $\mathrm{~S}$ & 5 & Bottom of bag, ash abrasion \\
\hline $4 / 16 / 90$ & 2 & $\mathrm{~S}$ & 4 & Bottom of bag, ash abrasion \\
\hline $4 / 17 / 90$ & 2 & $Q$ & 13 & Bottom of bag, ash abrasion \\
\hline $5 / 1 / 90$ & 2 & S & 4 & Bottom of bag, ash abrasion \\
\hline $5 / 23 / 90$ & 2 & S & 4 & Bottom of bag, ash abrasion \\
\hline $5 / 24 / 90$ & 2 & $\mathrm{~s}$ & 3 & Bottom of bag, ash abrasion \\
\hline
\end{tabular}

Total Failures by Baghouse: Unit \#1=20, Unit\#2 = 313, Unit \#3=7, Unit \#4 = 41 Note: Ash abrasion is the primary or secondary cause for bag failure. 
four baghouses. The change in baghouse 2 was the most dramatic, having a failure rate of $6.4 \% /$ month before the adjustment and $1.46 \% /$ month after the change. The failure rate in baghouse 2 is still unacceptable. However, it is believed that the bags were damaged during the initial operations with the high deflate air flow rate.

Further analysis of baghouse 4 bag failures revealed that of the 41 bag failures reported during the 20 month period, 13 of these were caused by the IBFM monitors. Since these monitors are not normally installed in a baghouse, subtracting these failures from the total gives an average failure rate of $0.06 \% /$ month.

By far, the majority of the bag failures occurred in the bottom two feet of the bag, where the dirty gas enters the bags. These failures are identified as "Bottom of bag, ash abrasion". These failures are believed to be caused by abrasion of the bag material by the entering ash. The high deflate pressures experienced early in the program exacerbated the problem. This failure mechanism continues even after the adjustments to the deflate air pressure, although at a substantially reduced rate. Other causes of bag failures were due to the improper installation of the bags. This caused the bags to rub onto either a railing or another bag. A few of the bags were found to be torn. These could have been due to the bag rubbing another bag and bursting from the gas pressure.

In order to determine the remaining life of the bags, samples of bags were removed and shipped to Southern Research Institute for testing. Mullen burst strength tests were performed after 5,000 hours of operation and after 11,000 hours of operation. The average strength of the bags was 362 psi after 5,000 hours and 302 psi after 11,000 hours. These strengths correspund to a loss in strength of $39 \%$ after 5,000 hours and 49\% after 11,000 hours. The current strength of the bags is considered serviceable. The abraded areas had slightly higher Mullen strength than the bag as a whole. In contrast, the bags from compartment $2 \mathrm{~S}$ that failed at the bottom had a strength loss of $68 \%$ in the worn-but-not-yetfailed areas.

\subsection{CONCLUSIONS}

Despite numerous early bag failures, the baghouses at Nucla have performed as required during the test program. The baghouses are capable of providing low emissions rates for particulates $(0.0072$ to $0.0125 \mathrm{lb} / \mathrm{MBtu})$ at high air-to-cloth ratios ( 2.0 to $\left.3.4 \mathrm{acfm} / \mathrm{ft}^{2}\right)$ with low to moderate tube sheet ( 3.7 to 5.7 in.wg.) and flange-to flange ( 5 to 7 in. wg.) pressure differentials at near full load conditions. The shake/deflate cleaning method appears to allow operation at 
higher air-to-cloth ratios than the methods tested at the TVA 20 MWe AFBC pilot plant (reverse gas, and reverse gas with sonic assist).

The majority of bag failures experienced at Nucla have been attributed to the bag attachment mechanism that allows ash-laden gas to contact the lower two feet of the bags. These failures were intensified by high deflate air pressures and operation of the shake mechanism during the deflate cycle. One possible solution to the ash abrasion problem is to install bags that have an anti-collapse ring 8.5 inches above the bottom of the bag. This would prevent the bags from collapsing into the gas stream. One compartment of baghouse 2 had these bags installed just prior to the completion of the test program. Follow-up investigations of these bags is strongly recommended.

The bag failure problem was found to be a strong function of the deflate pressure. The deflate pressure for all of the baghouses have all been set to a range of 1 to 1.5 inches of water at full load. Further reductions to the deflate pressure could provide some additional improvement to the bag life. Southern Research Institute has recommended setting the deflate pressure to the range 0.25 to $0.5 \mathrm{in.} w g$. 
Section 16

MATERIALS MONITORING

This section summarizes the condition of the Nucla CFB boiler components at the conclusion of four years of unit operation with over 15,000 unit operating hours on coal. The results encompass the following components: windboxes, air distributor plate and bubble caps, lower combustor refractory, combustor water walls, secondary superheater panels, bottom ash coolers, cyclone refractory and vortex finder, cyclone downcomer and loop seals, convection pass, and tubular air heater. Also included are descriptions of significant materials-related events in each of the outlined areas which forced or extended unit outages. Details of periodic inspections over the duration of the test program are contained in the Annual Reports for 1987-1988, 1989, and 1990-1991.

\subsection{OVERVIEW AND SUMMARY}

The Nucla CFB represents one of the first large scale applications of circulating fluidized bed technology. In 1987, CUEA was the first utility in the United States to apply this technology for power generation. At the time, it was also the largest CFB boiler in operation in the world. The design and materials selection of several components at Nucla represent "first. generation" CFB design. Based on operating experience at Nucla and other units, new "second generation" designs are being offered which address many of the problems encountered with the early units.

Despite several materials-related problems during the first four years of operation of the Nucla CFB, there have been few significant changes in design and/or materials selection to circumvent problems which developed. Those of significance include, 1) a design change to refractory anchors and the addition of refractory "stops" in certain damaged regions of the cyclones, 2) a switch to brick and hard castable refractory in certain sections of the loop seals that had previously used "gunned-on" refractory, 3) a design modification to a percentage of air distributor bubble caps to reduce backsifting of bed material into the windbox and to improve retention, 4) the addition of 6" shelves over the top row of one secondary superheater panel (second panel from the bottom) to prevent tube erosion from the downward flow of solids.

A temporary change in unit operating philosophy was used to address a problem with overheating of the secondary 
superheaters located in the upper freeboard region of each combustion chamber. Although this operating modification addressed the immediate problem and improved unit availability, it did result in an increase in the plant heat rate of approximately 2 percent. Other problem areas have been addressed with periodic maintenance performed during unit outages with some minor design changes which are discussed in more detail below.

Localized water-wall and secondary superheater erosion has been one area that has required a degree of attention and periodic maintenance. As will be discussed, generalized water-wall and superheater tube erosion was not detectable after 5500 hours of unit operation on coal. Although this should be substantiated sometime in the following years, this conclusion is favorable for the Nucla CFB and if applicable, for other CFB's burning a similar fuel type. Although localized erosion is undesirable, it is believed that design changes on "second-generation" CFB's can significantly reduce or eliminate such occurrences.

From 1988 through 1990, the Nucla CFB was restarted over 165 times following outages which varied from one hour to over 500 hours. There are many factors which contributed to this high number of unit outages discussed elsewhere in this report. The impact of this frequency of thermal cycling on materials components is probably significant. This should be kept in mind with the discussion presented below.

At the conclusion of nearly four years of unit operation from June 1987 through February 1991, the significant problem areas of the Nucla CFB, which are currently being addressed with periodic maintenance, are:

1. Degradation of lower combustor refractory particularly around the recycle return line, manways, and ports for coal, start-up burners, limestone, and air.

2. Distributor plate bubble cap retention and erosion.

3. Water-wall tube erosion at the refractory/water-wall interface.

4. Water-wall tube erosion along warped (bowed) sections of wall left over from the overheat incident in October 1987. This is particularly troublesome on a section of water wall in combustor A approximately 22 feet above the distributor plate.

5. Secondary superheater erosion in regions conducive to channeling of the downward flow of solids. 
6. Long-tern overheat of secondary superheater tubes. This has been temporarily addressed through operating changes to the desuperheater sprays, but has resulted in a $40^{\circ} \mathrm{F}$ drop in final superheat temperature.

7. Long-term integrity of the cyclone vortex finder structure.

8. Refractory breakage around the "bull nose" section of the cyclone inlets.

9. Refractory erosion/abrasion along the impact/target area of the cyclone.

10. Periodic refractory spalling in the conical section of the cyclone and cyclone downcomers.

\subsection{OBJECTIVES AND APPROACH}

The objective of the Materials Plan at Nucla was to monitor selected boiler pressure and non-pressure components over the course of the Phase I and II test programs to determine:

1. Refractory integrity in several areas of application including the lower combustor regions, cyclones, cyclone downcomers, and loop seals.

2. Erosion/corrosion/fatigue of non-pressure components including air distributor bubble caps, tube hangers and supports, the combustion chamber windboxes, the cyclone vortex finders, tubular air heater, and miscellaneous fireside components.

3. Erosion/corrosion/fatigue of boiler pressure components including water walls, superheaters, economizer, watercooled superheater support tubes, steam cooled convection pass, and ash coolers.

In March 1987 prior to first fires in the boiler, a baseline inspection of the Nucla CFB was conducted. This inspection included tube thickness measurements in certain regions of the water-wall, superheater, and economizer tubes. An extensive photographic survey was completed and a detailed inspection plan was developed to serve as a guideline for future outages.

During the course of the four year test program, inspections were performed during unit outages which occurred over the normal course of operation (i.e., the inspections did not initiate outages). The duration and nature of the outages dictated the level of detail and extent to which the inspection plan was conducted. Each inspection included photographs, tube thickness measurements (where appropriate), 
and an inspection report. A summary of this information is included in the 1987-1988, 1989, and 1990 Annual Reports.

In fulfilling the objectives of the Materials Monitoring Plan, this information has provided a basis for identifying "root causes" and corrective changes in design and materials selection in certain regions of the Nucla CFB. Coupled with operating experience on other CFB units, it has also been beneficial in the "second-generation" design of CFB boilers.

\subsection{SUMMARY OF INSPECTIONS}

Table 16-1 summarizes the major inspections that were conducted during unit outages over the course of the test program. Tube wall thickness measurements were taken during a portion of these outages and the availability of these data in the Annual Reports is indicated in the table for each inspection.

During the baseline inspection and after 600 hours of unit operation on coal, an extensive tube thickness measurement matrix was completed over sections of the water walls, superheaters, economizer, and water-cooled superheater tube supports. The objective was to quantify any generalized erosion that might be occurring in these areas. During the inspection after 600 hours of operation on coal, measurements were taken on water-wall tubes in both combustors at the centerline, $-30^{\circ}$ and $+30^{\circ}$ from centerline on every tenth tube. This grid started at 20 feet above the air distributor plate and proceeded every 10 feet to the top of the combustor. These measurements were repeated on every twentieth tube at the same elevations in January, 1989 after 5500 hours of cperation on coal. These data are summarized in the 1989 Annual Report.

The results of these measurements indicated that no generalized erosion could be quantified on the water walls. Tube thickness measurements of the superheater and economizer surfaces during other outage inspections indicated the same result. However, erosion was visible in lncalized areas of the water walls and secondary superheaters that was not detected using a broad measurement matrix. Based on these findings, the emphasis for tube thickness measurements during subsequent inspections shifted to areas where localized erosion was apparent. These included water-wall tubes at the water-wall/refractory interface and sections of the secondary superheaters.

Quantifying and monitoring the progress of localized erosion using tube thickness measurements also has proven to be difficult. This is due to the nature of this erosion which can be characterized by "gouging" or "grooving" as opposed to "polishing" and "smoothing" that has been detected on in-bed tubes in bubbling bed FBC's. Erosion marks at Nucla are 


\begin{tabular}{|c|c|c|}
\hline DATE & COAI BOURS & $\begin{array}{l}\text { REPORTABIE TUBE } \\
\text { TEICRNESS MEASUREMENTS }\end{array}$ \\
\hline March, 1987 & baseline & yes \\
\hline November, 1987 & 600 & yes \\
\hline August, 1988 & 3600 & yes \\
\hline January, 1989 & 5500 & yes \\
\hline June, 1989 & 7600 & yes \\
\hline September, 1989 & 8750 & yes \\
\hline october, 1989 & 8850 & no * \\
\hline January, 1990 & 10300 & no * \\
\hline February, 1990 & 10500 & no $\star$ \\
\hline May, 1990 & 11800 & no * \\
\hline June, 1990 & 12100 & no * \\
\hline August, 1990 & 13000 & no * \\
\hline September, 1990 & 13150 & no * \\
\hline October, 1990 & 13600 & no * \\
\hline Fabruary, 1991 & 15800 & yes \\
\hline
\end{tabular}


often too narrow and uneven (but often deep) to obtain a reliable, repeatable measurement using an ultrasonic thickness (UT) measurement device. The presence of a nonuniform sacrificial weld overlay in certain areas also contributes to the difficulty taking these measurements.

During inspections subsequent to the 5500 hour outage, tube thickness measurements were taken (where possible) in localized erosion areas to identify tubes that required additional sacrificial "pad" welding. Even using this preventative maintenance approach, visual inspections, photographs, plaster casts of the most severe tubes, and the inspection reports proved to be more useful for identifying problem areas and tracking the progression of erosion.

As a result, detailed data on tube thickness measurements are not presented in the Final Report. Summaries of these data can be found in the Annual Reports where reportable data are available. The descriptions which follow highlight significant materials-related issues which developed over the course of four years of unit operation, along with any corrective actions taken. Where appropriate, some tube thickness data are presentec for the water-wall tubes. An attempt has been made to include photographs and descriptions from the most recent inspection that occurred during the February 1991 outage at the conclusion of the Phase II Test Program.

\subsection{SUMMARY OF MATERIALS RELATED PROBLEMS}

The following is a description of materials-related problems that developed between 1987 and early 1991 in the areas listed below. Only significant CFB-related problems are discussed and photographs are used for clarification where appropriate.

- Windboxes

- Lower Combustor Refractory

- Air Distributor

- Water Walls

- Superheater II Tubes

- Bottom Ash Coolers

- Cyclone Refractory and Vortex Finder

- Downcomer and Loop Seal Refractory and Outer Shell

- Convection Pass (Economizer and Superheaters)

- Tubular Air Heater

\subsubsection{Windboxes}

The windboxes on the Nucla $\mathrm{CFB}$ are situated below the air distribution plate and serve to direct pre-heated combustion air at $450{ }^{\circ} \mathrm{F}$ through the distributor plate into each combustion chamber. Each windbox uses plate steel construction, which is welded directly to the water-cooled 
air distributor floor near to the point at which the floor tubes attach to an outside header. A duct burner, used during unit start-up, is located in the primary air duct just upstream of the windbox (see Figure 16-1). During start-up, temperatures downstream of the duct burners reach $850^{\circ} \mathrm{F}$. As a result, the ductwork just upstream of the windbox is refractory-lined around all four walls. The windbox casing is not refractory-lined except for the bull nose section shown in the same figure.

Problem areas with the windboxes have been related to differential expansion and backsifting of bed material through the air distribution plate. High temperatures downstream of the duct burners during start-up have caused warping and cracking of the shell plates, welds, and auxiliary hardware. Backsifting of bed material has been mostly an operational problem of removing build-ups in the windboxes during unit operation. If not removed, these build-ups can block air flow to the front wall air nozzles. The hardware added during the first year of operation to remove bed material accumulations have suffered from both design and material limitations. Although none of these problems can be considered major or technology limiting, they have been a source of relatively high maintenance over the first four years of unit operation. Using lessons learned at Nucla coupled with good design, most of these problems can be eliminated in "second-generation" cosigns. Each are discussed in more detail below.

1. The duct burners shown in Figure 16-1 were subject to fouling in the first year of unit operation. The build-up of soot from a rich propane mixture caused some sections of the front burner face to over-carburize and become brittle. Some burner sections required replacement after the first year of operation. To increase primary air flow through the duct burner, the duct cross-sectional area immediately surrounding the burner was decreased to divert more air flow through the burner (see location Figure 16-1, item 5). This modification, along with adjusted firing rates during startup, has nearly eliminated this problem.

2. The refractory lining (item 3), which surrounds the duct burners and extends partially into the windbox, has suffered cracking and breakage. The refractory used in this application is relatively soft with good insulating properties. Part of the problem with breakage is related to warping of the underlying shell plates. This is particularly true around the bull nose region (item 6) of each windbox. Another major contributor was the presence of mechanical stiffeners (item 12) which were used to strengthen the windbox. These warped from high temperatures associated with the duct burners and consequently, distorted the windbox sidewalls at the point of attachment. Refractory in the vicinity of the mechanical stiffeners on the sidewalls 


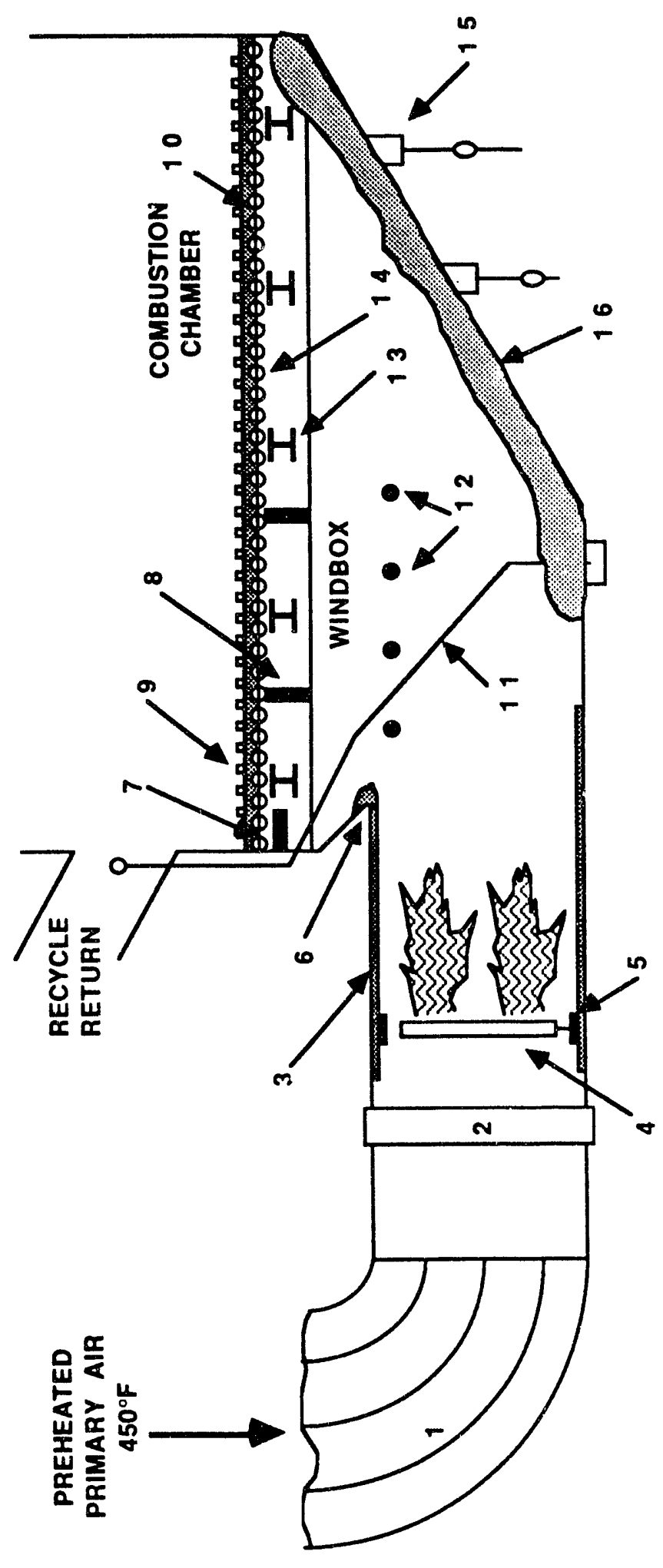

응을

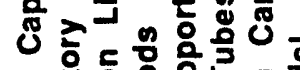

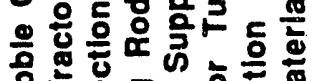

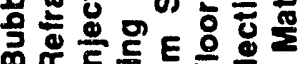

品它致

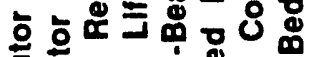

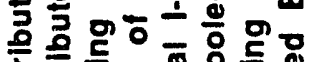

홍호은

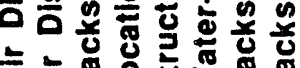

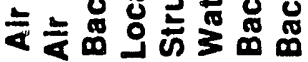

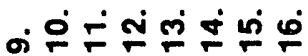

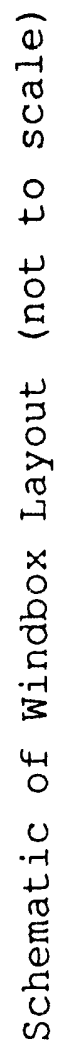

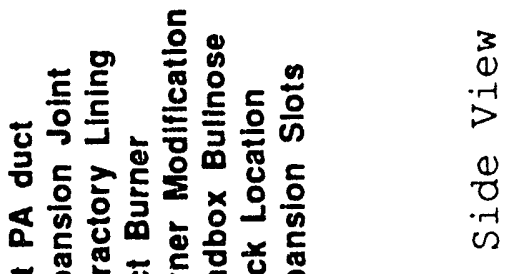

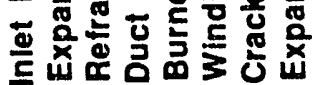

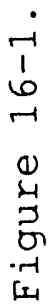


eventually broke away. To correct the problem, the front two mechanical stiffeners closest to the duct burners were removed in each windbox. Overall refractory performance in this area has been relatively good since this correction.

3. Cracks in the shell casing welds forming the windbox enclosure have occurred on several occasions. The location of these cracks is primarily to the rear of the windbox near the water-cooled air distributor floor (location 7). These windbox casing leaks result in leaks of pre-heated combustion air and entrained backsifted bed material to the outside boiler room. On three occasions, differential expansion between the water-cooled floor tube headers and the windbox shell plates have caused floor tube leaks which resulted in unit outages. The addition of expansion slots in the shell casing at location 8 has corrected this latter problem. Cracks still form in the rear corners of the windbox (location 7) and around the bull nose area. These are repaired periodically during unit outages.

4. Bed material backsifts from the combustion chambers through the air distributor bubble caps into the windboxes and accumulates on the sloped floor as shown in Figure 16-1 (item 16). This occurs to the greatest extent during shutdown, start-up, and low load operation when underbed air flows are at a minimum. Visual observation indicates that most of the material backsifts through bubble caps located in front of the recycle return, at the entrance to the sidemounted bottom ash coolers, and along the corners of the front wall. As bed material builds up in the windbox around the front structural I-beam shown in the figure, air flow becomes restricted to the bubble caps along the front rows of the combustor.

In order to provide on-line reinjection and removal of backsifted material, a reinjection line (item 11) was installed to transport accumulated material from the floor region to the loop seal return leg using windbox pressure for transport. In addition, collection canisters (item 15) were installed on the sloped floor to drain bed material accumulations in the front of the windbox. Drain lines were added to the bottom of these canisters to transport material directly into the bottom ash disposal system.

These design modifications have not worked well and, at the conclusion of the phase II test program, were not operational. Since the windbox floor is not tapered towards either the reinjection line drain or the collection canisters, bed material can only be removed in the immediate vicinity of these locations. The bulk of accumulated

material is not served by these drains. The reinjection line suffered from over-temperature due to its location directly in front of the duct burners. This problem was exacerbated by blockage of the line and loss of transport air which 
serves as the cooling medium. The drain pipes from the collection canisters to the bottom ash disposal line were too shallow in slope and eventually blocked and became hardpacked. Currently, accumulated backsifted bed material is shoveled from the windbox during unit outages. The effect of this material on flow distribution through the air distributor plate and the associated impact on combustion performance is not known.

\subsubsection{Lower Combustion Chamber Refractory}

The "gunned-on" refractory in the lower combustion chambers has not stood up well to conditions in the first four years of unit operation. Refractory breakage and spalling have been common over most surfaces and have been particularly pronounced around the the lower 2 to 3 feet above the air distribution plate, near the water-wall interface, around the recycle return line, and around start-up burners and manways. Each of these are discussed in more detail below.

1. During construction, the refractory thickness near the air distributor was increased to approximately 18 inches to close off the outside two rows of bubble caps. This reduces the open area of the air distributor and increases fluidizing velocities in the lower combustor. The latter assists in moving and lifting the dense bed in the bottom of the combustor. However, effective anchoring of this thickness of refractory has proven to be difficult.

Figures $16-2$ and $16-3$ show the condition of this refractory after the February 1991 outage following over 15,000 hours of unit operation on coal. Severe breakage and exposure of refractory anchors is apparent in this region. The electrical cord in Figure $16-2$ is exiting the combustion chamber from a manway door. On occasion, dislodged pieces have blocked the entrances to the bottom ash drain coolers which have forced unit outages for removal. No major repairs have been made to this area since initial start-up in June 1987 .

2. Refractory breakage has been common around the perimeter of the combustion chambers at the water-wall interface. Figure 16-4 is a photograph taken after 2 years of unit operation showing the region involved. In this example, "blue ram" plastic refractory (alumina phosphate bonaing) has been used to replace a failed section. The refractory is tapered in this region from 2 to 4 inches thick to provide a gradual transition into the water walls. This reduces the degree of discontinuity at this location which is known to contribute to water-wall erosion. However, the top 1 to 2 feet of this refractory was not anchored during the original installation. The downward flow of solids along the water walls initially tends to undercut the tapered, un-anchored section. Bed material works in behind the refractory when 
Figure 16-2. Combustor A Lower West Wall Refractory Condition (February 1991 Outage).

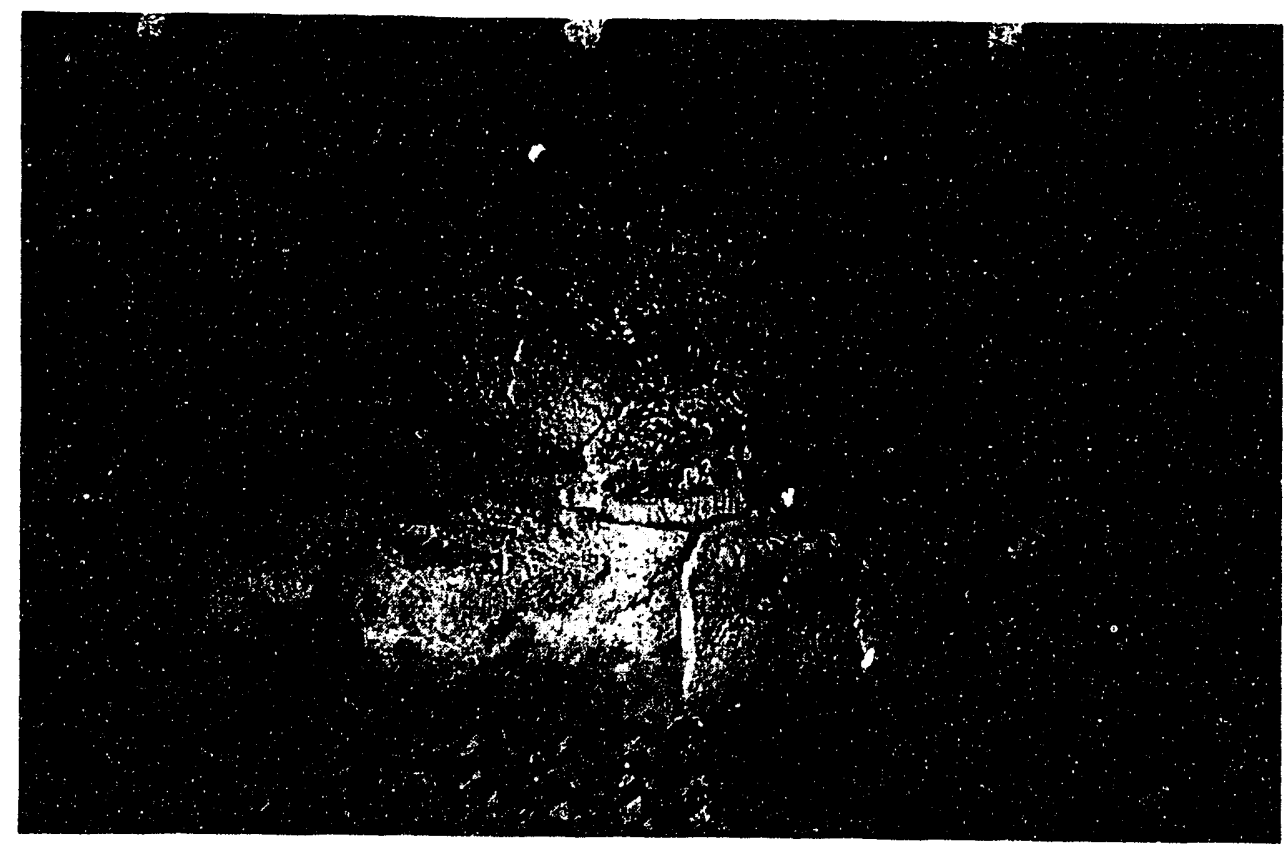

Figure 16-3. Combustor A Lower

Refractory Condition (February 1991

Outage). 


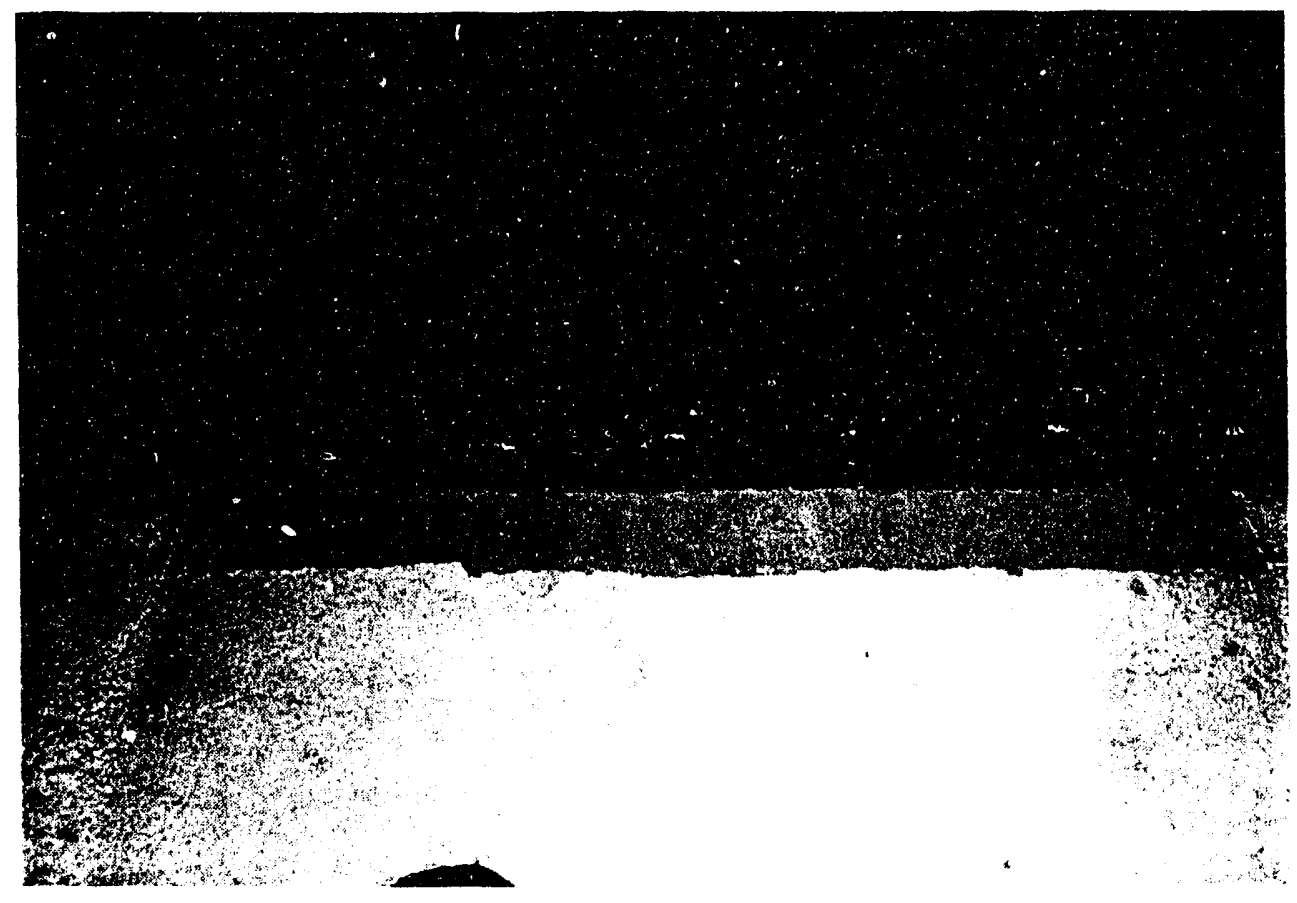

Figure 16-4. Refractory Breakage at Refractory/ water-wall Interface in Combustor B.

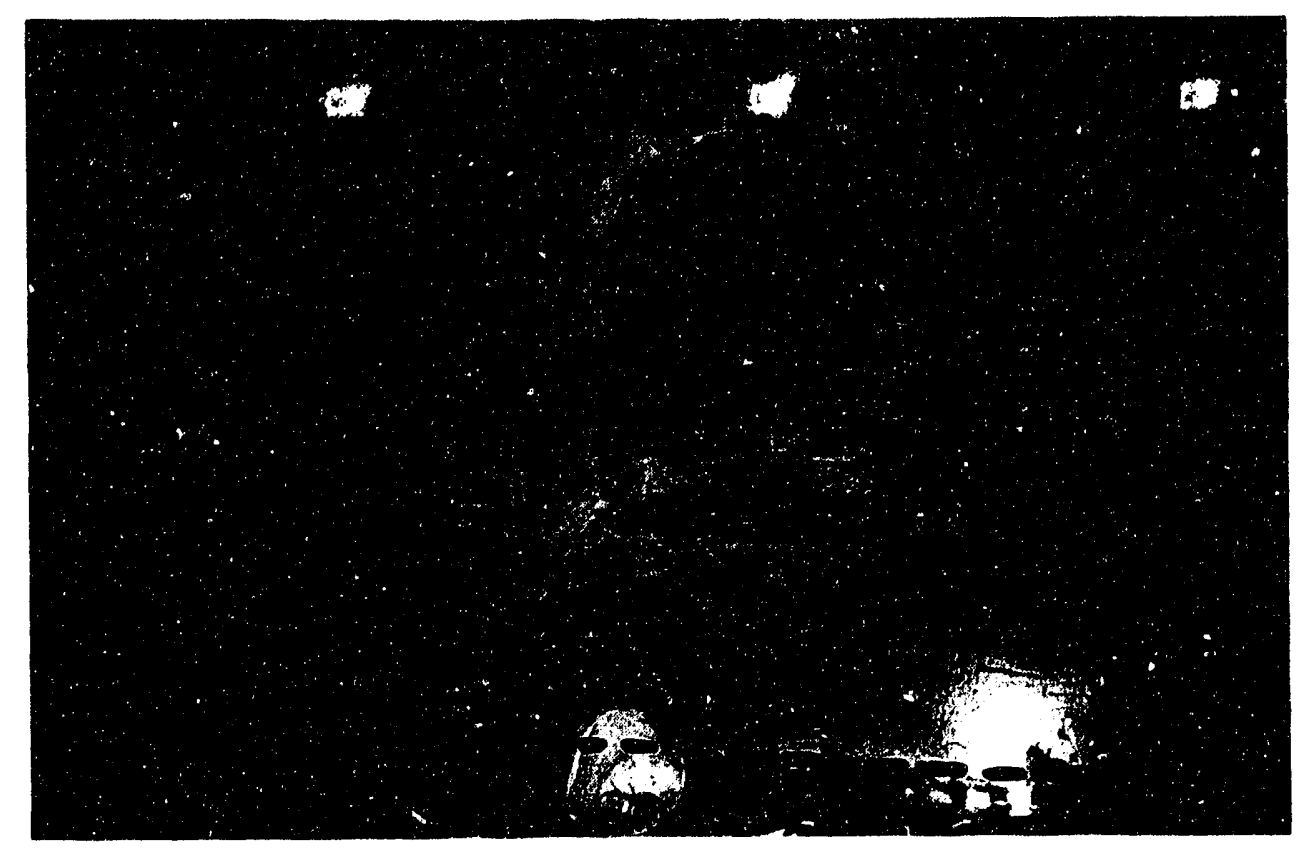

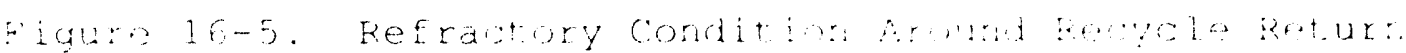

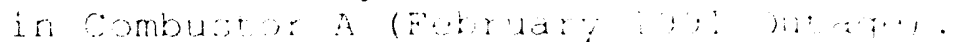


the water walls are hot and fully expanded. During cooldown, bed material is compressed in this region and through repetition, forms hard packed layers. Eventually, the buildup "jacks" the refractory off the wall. During the inspection outage at the conclusion of the Phase II test program, this problem was still apparent and additional maintenance was required. Improved anchoring in this region may help resolve the problem unless a design change is incorporated.

3. Refractory breakage around the recycle return has been severe and repeated over the first four years of unit operation. Figure 16-5 shows the general condition during the outage in February 1991. The region below and to the right of the recycle port (outlined) has recently been repaired with "blue ram" refractory and is still in relatively good condition. The area to the left of the recycle line is badly damaged with numerous exposed anchors and, on past occasions, water-wali tubes. The amount of breakage and movement of refractory in this area is beyond what is possible by "jacking". The recurring nature of this problem suggests inadequate anchoring and/or some degree of wall movement in this vicinity. Since the expansion joint on the loop seal has been inoperable for the past 2-3 years of operation, it is possible that differential expansion or movement between the refractory-lined recycle line and the combustion chamber produces a force on the rear wall and causes a deflection. To address this problem, the root cause must be further explored by studying the movement of the recycle system relative to the combustion chambers. At the conclusion of the test program, this remains an area of high maintenance.

\subsubsection{Air Distributor}

The air distributor at Nucla is water-cooled with a thin refractory layer covering the combustion-side surface. Stainless steel pipe nipples extend between rows of watercooled floor tubes through the protective refractory layer. A bubble cap is then affixad to the top of the nipple (see Eigure $16-6)$.

In the original design, a retention washer was used to prevent the bubble cap from coming unscrewed off the threaded pipe nipple. These washers eventually failed due to improper materials selection and, following the loss of numerous bubble caps, were replaced with a stainless steel washer in the manner shown in the figure. The original carbon steel washer was left in place on approximately $25 \%$ of the nipples to reduce damage to the pipe nipple when removed. Despite this, threads were damaged during the modification which prevented the bubble cap from being secured tightly onto the threaded pipe nipple. This, along with the prying action of bed material between the bubble cap and the washer, 

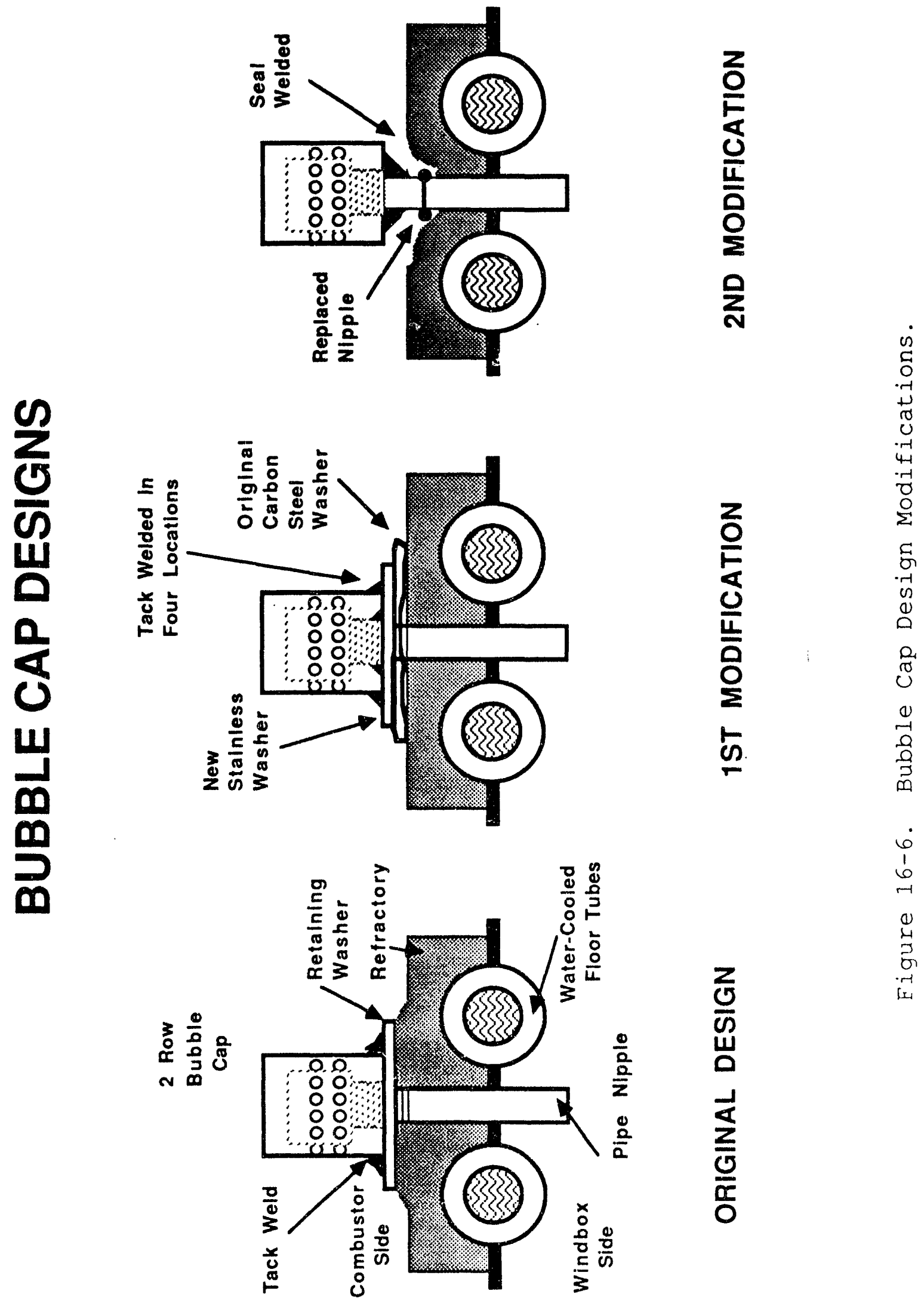

$\frac{Z}{0}$
$\frac{1}{u}$
$\frac{1}{2}$
$\frac{1}{0}$
$\frac{\pi}{0}$ 
eventually resulted in a significant number of additional failures.

A third design is presently used which eliminates the retention washer. Bubble caps are now replaced on an asfailed basis during unit outages by cutting off the pipe nipple below the damaged area. A new bubble cap is sealwelded to a short, matching pipe nipple which is, in turn, welded directly to the existing nipple. Although this has proven to be a more durable design, failures still occur primarily in the region directly in front of the recycle return line. During unit shutdown, a significant quantity of bed material flows back through the open pipe nipples into the windboxes. This continues to be an area of high maintenance.

Bubble cap erosion has also been pronounced in the region in front of the recycle return line and, on combustor $A$, extends three quarters of the distance across the air distributor to the front wall. This is shown in Figure 16-7 along with smaller affected areas directly in front of the bottom ash cooler inlets. An example of this erosion is shown in Figure 16-8. This figure also illustrates the two techniques currently used for affixing the bubble cap to the pipe nipple (with and without the retention washer). On many bubble caps, erosion has either progressed to the point of wearing through the top of the cap or has become severe enough that replacement has been required.

Three different bubble cap air hole configurations are currently in use. Most caps contain two rows of air holes drilled at a slight upward angle to prevent backsifting when bed material is slumped around the bubble cap. In order to increase fluidizing air flow and reduce backsifting, caps with three rows of air holes were added around the perimeter of the combustion chamber and in front of the recycle return line. Bubble caps using air holes with a steeper drill angle have also been added directly in front of the ash cooler inlets to reduce backsifting. It is difficult to evaluate the effectiveness of these design modifications in reducing backsifting.

\subsubsection{Combustor Water Walls}

The water walls have suffered from localized particle erosion in four areas, each of which are described below. As discussed in the summary, generalized erosion of water-wall tubes was not detectable following the completion of an extensive tube thickness measurement matrix after 5500 hours of operation on coal. Periodic visual inspections and "spot check" tube thickness measurements have not revealed any change in this condition. 

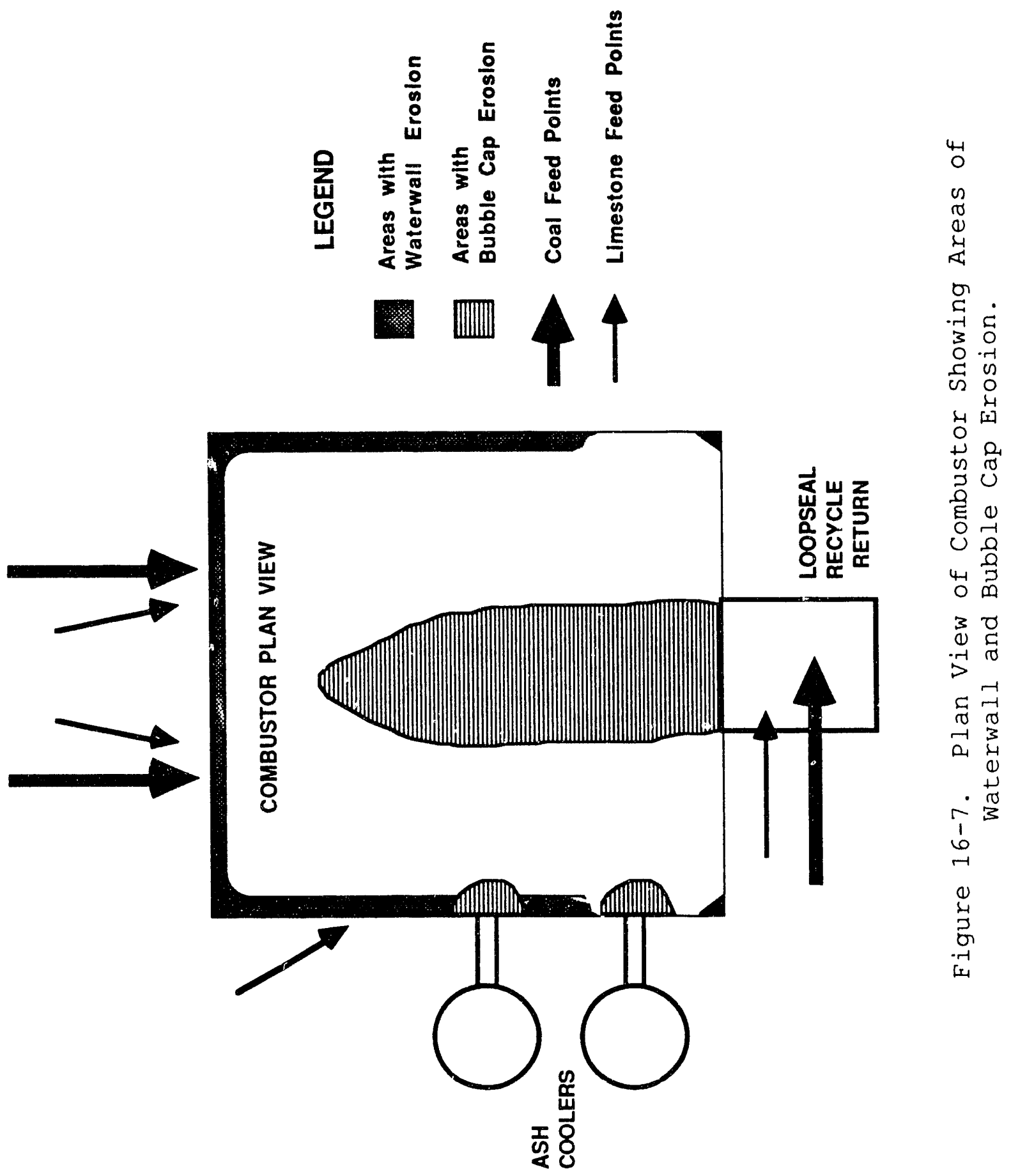


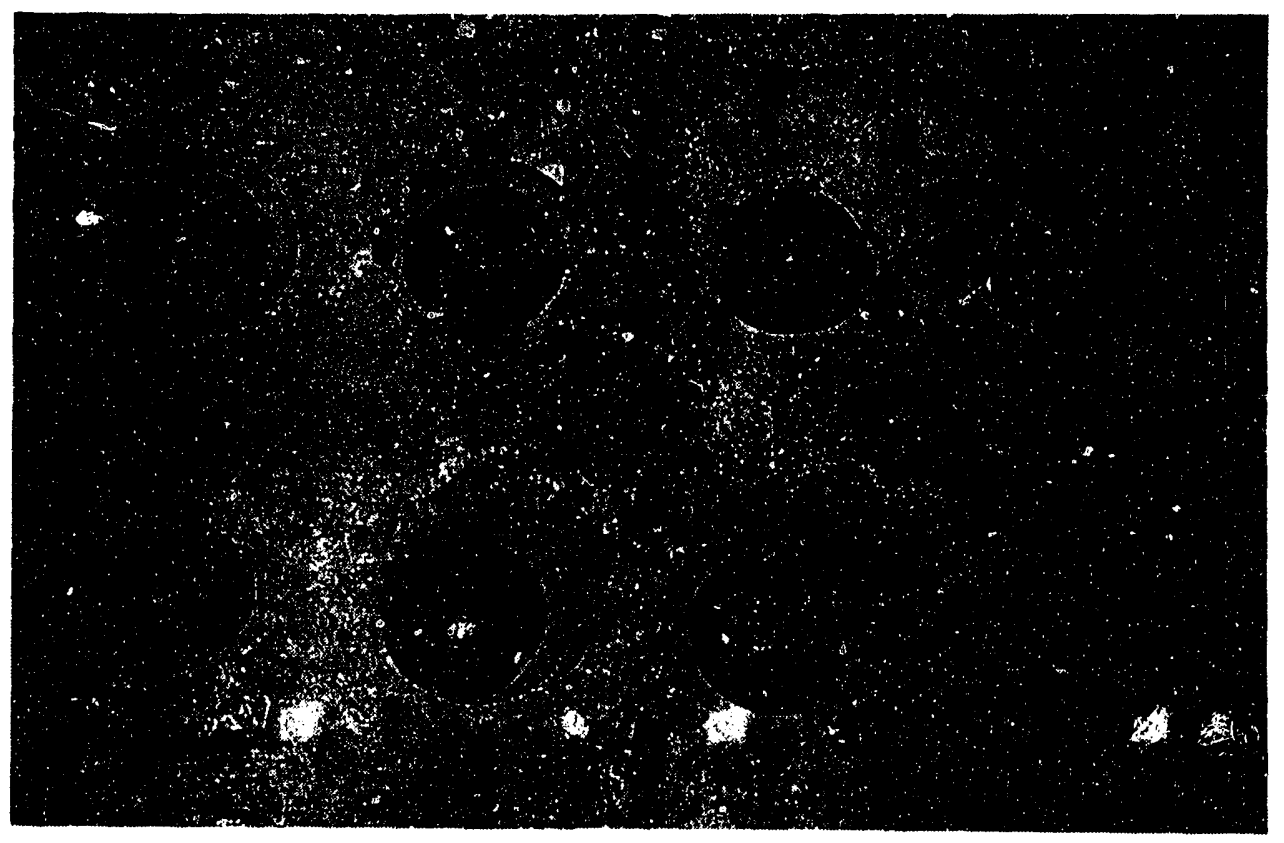

\section{Figure 16-8. Bubble Cap Erosion in Combustor A (February 1991 Outage).}


1. Erosion at the water-wall/refractory interface has been common on CFB's and is widely reported in the literature. At Nucla, water-wall tubes in this region are protected with a hard, horizontal weld overlay that extends approximately 4 inches above the top of the lower combustor refractory. Figure 16-9 is an example of the: sacrificial weld overlay in almost "as new" condition during the inspection in February 1991 with over 15,000 operating hours on coal. Some erosion and loss of weld overlay is visible near the top of the weld, but does not extend down into the base tube metal in this example.

This type of erosion is not uniform around the perimeter of the combustion chambers. As shown in Figure 16-7, it is more severe along the front walls and the front two thirds of the side walls opnosite the recycle return line. Within this shaded region, the corners of the combustor appear more eroded, suggesting a greater amount of solids down-flow in these areas. In some instances, erosion of the weld overlay will progress beyond that shown in Figure 16-9 to that shown in Figure 16-10 and eventually to Figure 16-11. In these examples, erosion has not progressed into the underlying tube metal and in this regard, the sacrificial weld overlay has performed as intended, but remains a potentially high maintenance item.

However, in other areas as shown in Figure 16-12 and Figure 16-13, small ledges form in the weld overlay and erosion begins to cut into the underlying tube metal. When this occurs, the ledge is ground off and smoothed during unit outages and new weld overlay is applied in areas with significant tube metal loss. In other instances, erosion will progress in the weld overlay in strange, unpredictable patterns. The term "cat scratch" erosion has been coined to describe these patterns. Again, if a shelf or major discontinuity forms, it is ground off and weld overlay is applied to areas with significant losses in base tube metal thickness.

A major contributor to the most severe erosion in this area is the presence of horizontal weld overlay in the membranes between tubes. During the original application in 1987, the horizontal weld overlay extended around the tubes and across the membrane. Since a large portion of the downward flow of solids along the water walls is in the membrane, the discontinuity created by this overlay acted as an initiation site for erosion to surrounding tubes. This pattern is illustrated in Figure 16-14. To the best extent possible, the top of this overlay has been ground smooth during unit outages. However, with time, this discontinuity reappears in certain areas and begins to deflect solids flow from the membrane into surrounding tubes. This is clearly illustrated in Figures 16-15 and 16-16. 


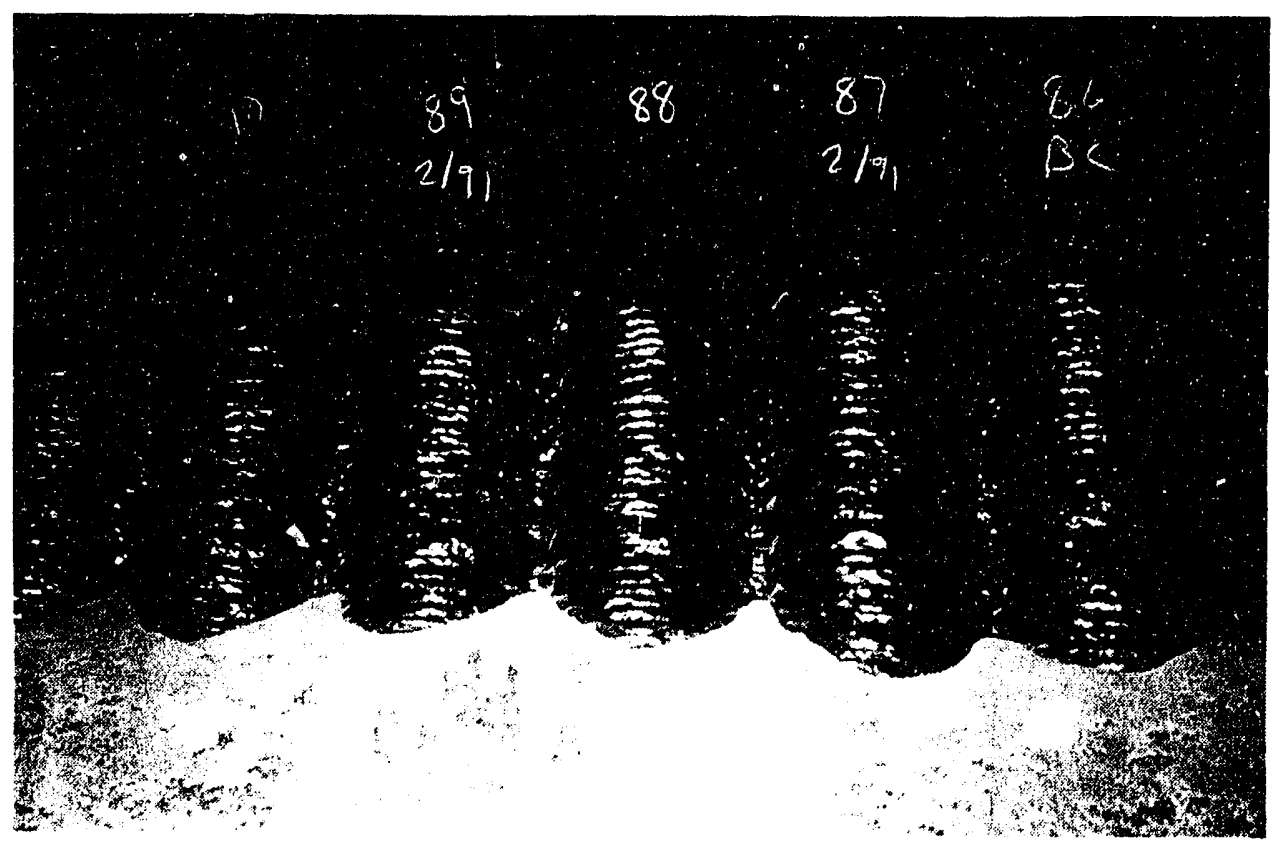

Figure 16-9. Weld Overlay in Good Condition at Refractory/Water-wall Interface in Combustor $B$ (February 1991 Outage). 


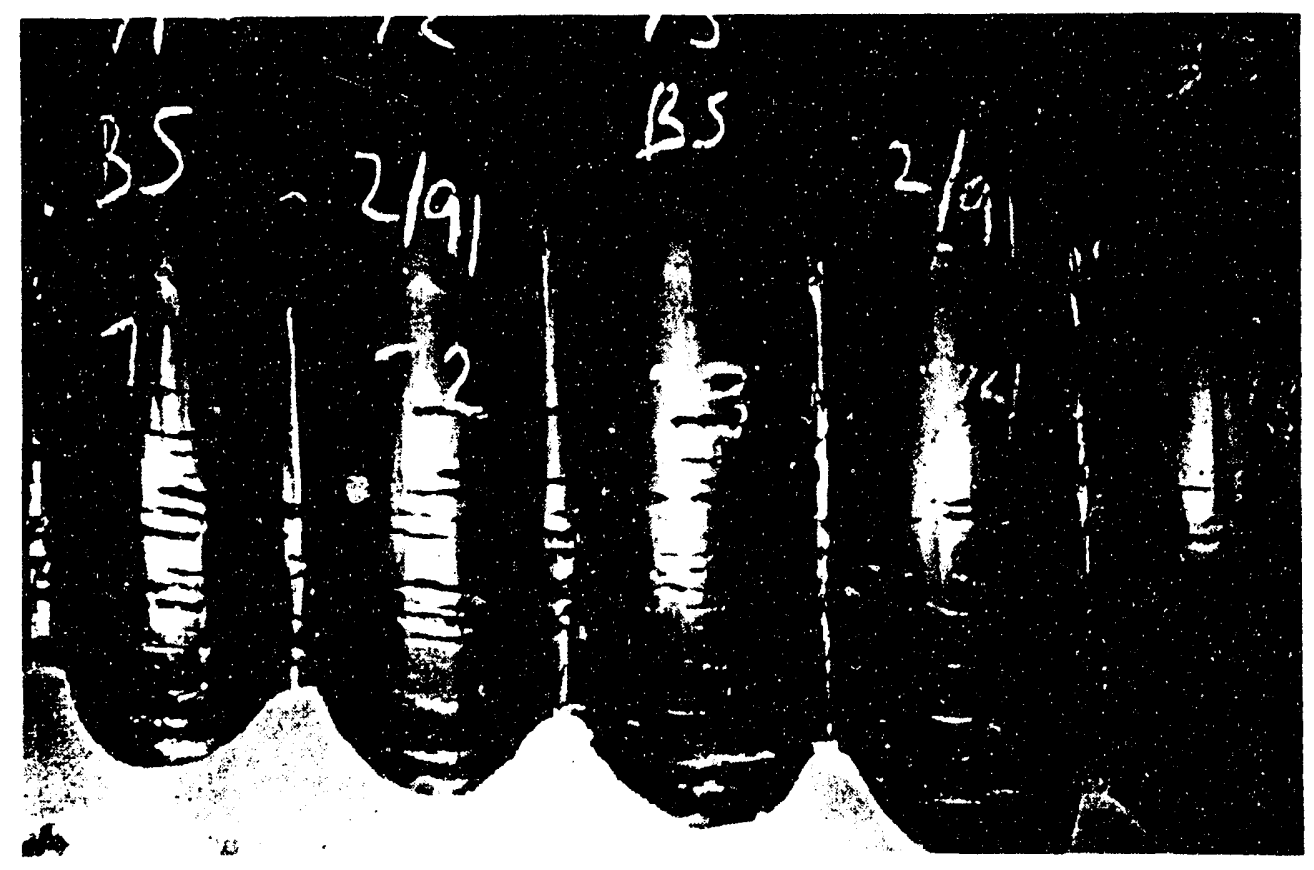

Figure 16-10. Worn Weld Overlay at Refractory/ water-wall Interface in Combustor B (February 1991 Outage).

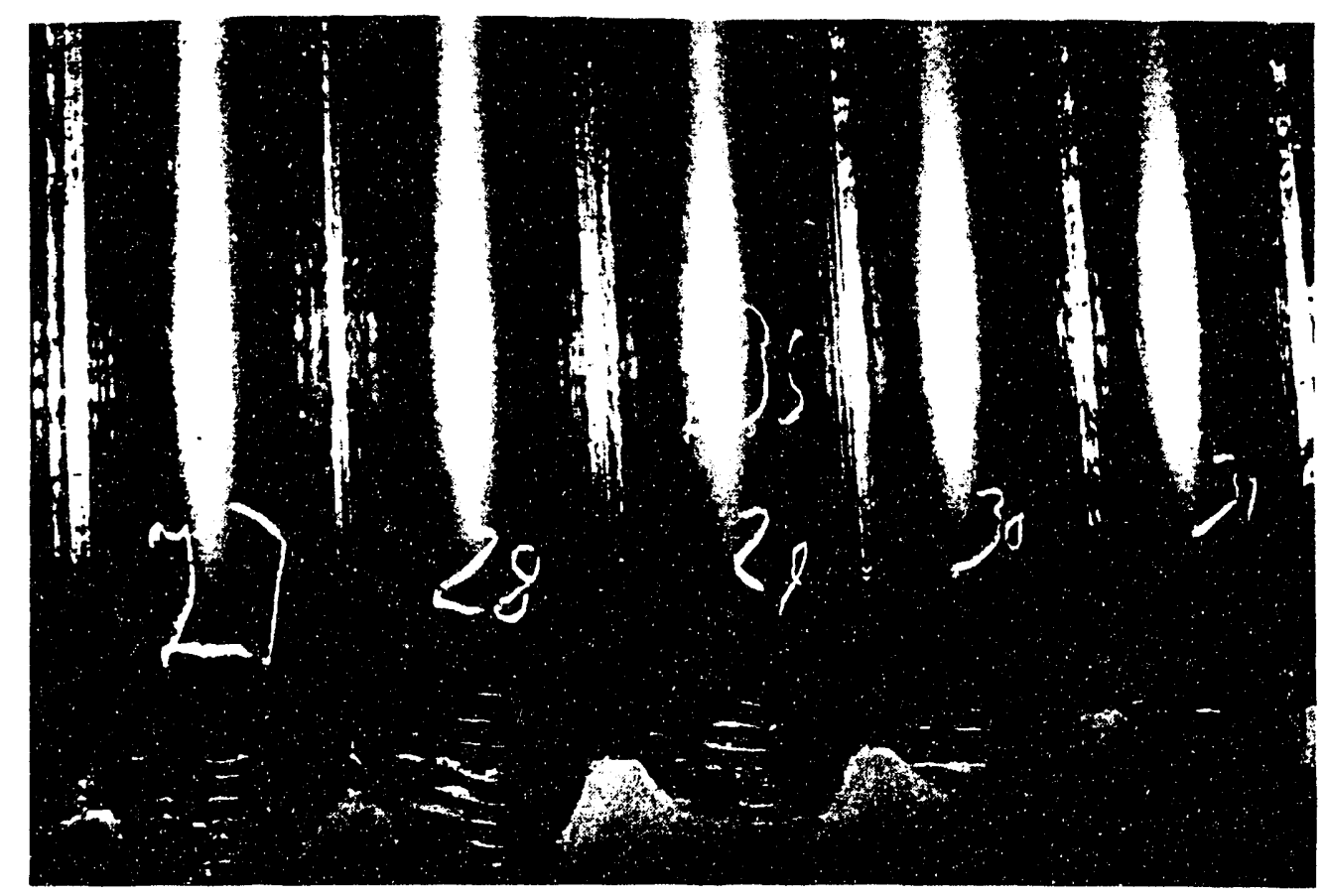

Figure 16-11. Worn Weld overlay at Refractory/ Water-wall Interface in Combustor B (February 1991 Outage). 


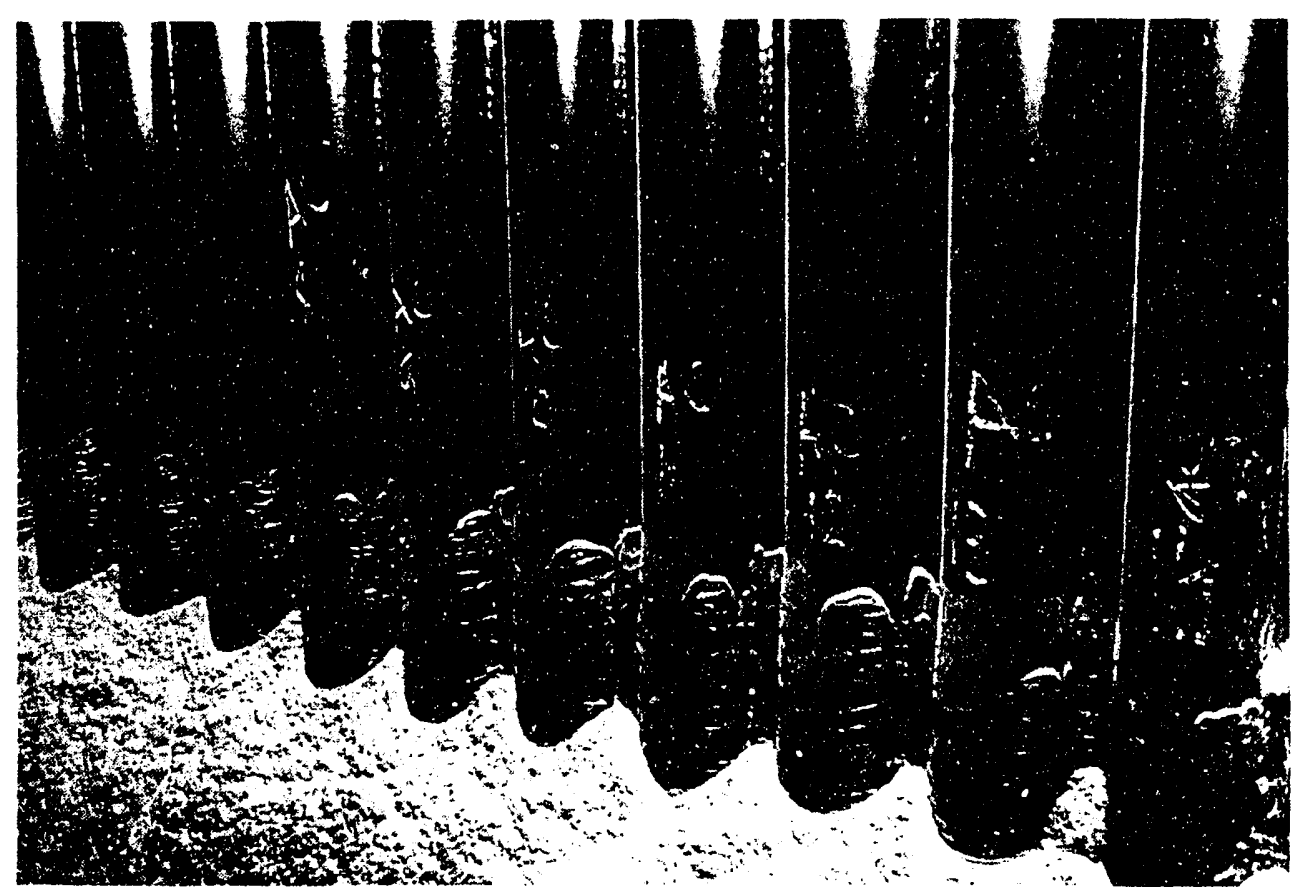

Eigure 16-12. Shelf Formation in the weld Overlay in Combustor A (February 1991 Outage).

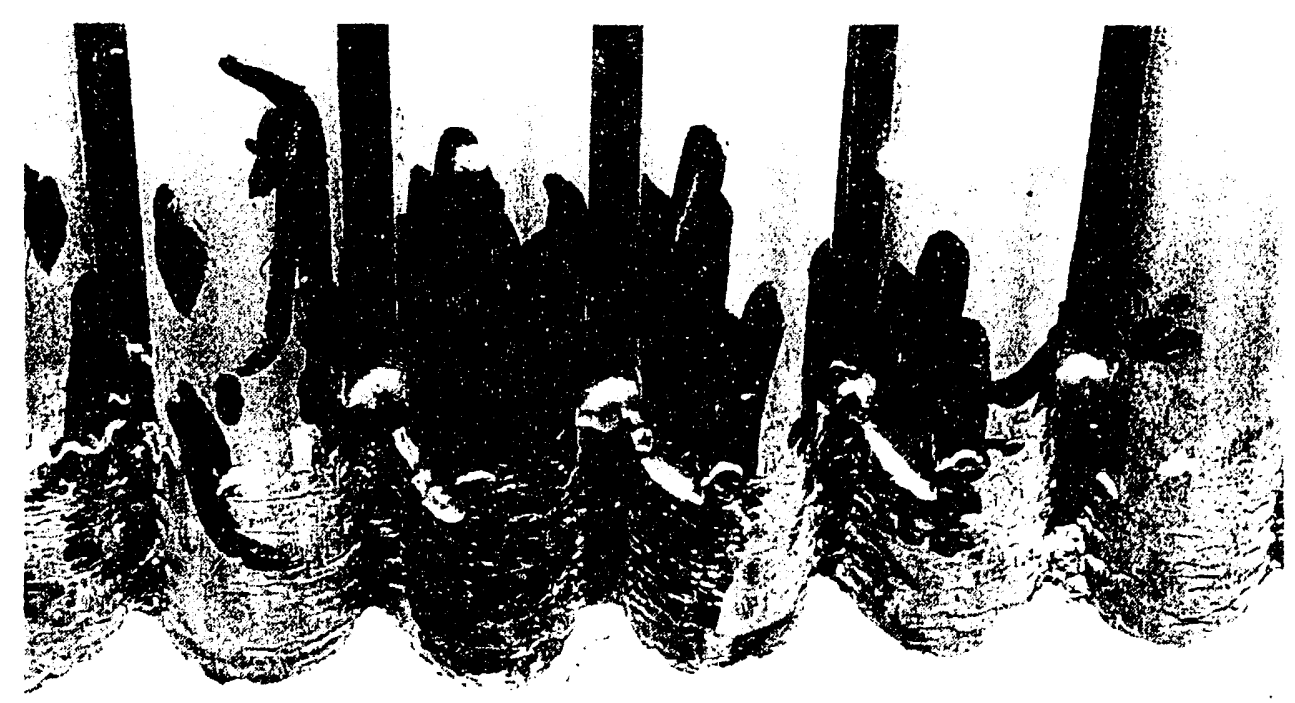




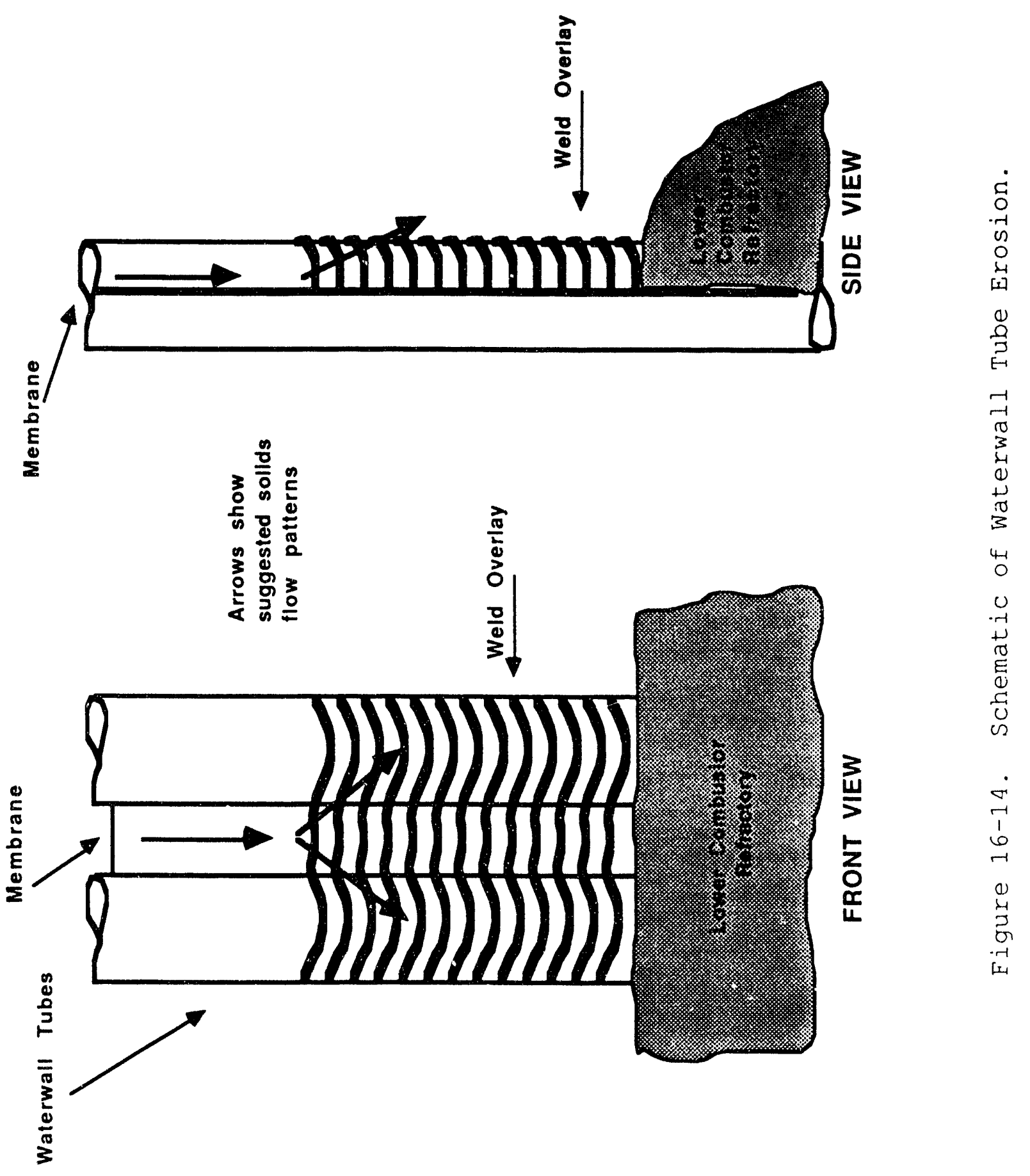




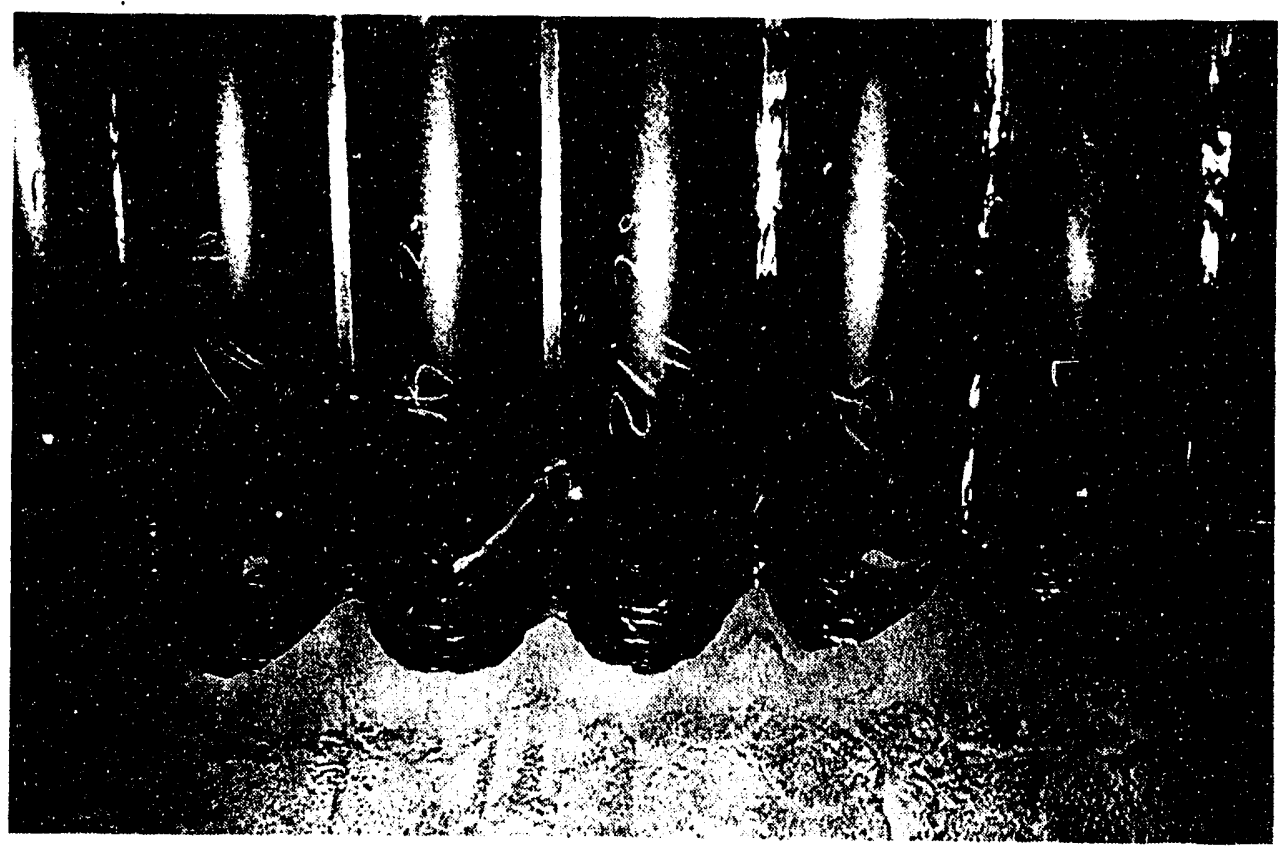

Figure 16-15.

Erosion

Patterns

Initiating

from the

Membrane in

Combustor A

(February

1991 Outage).

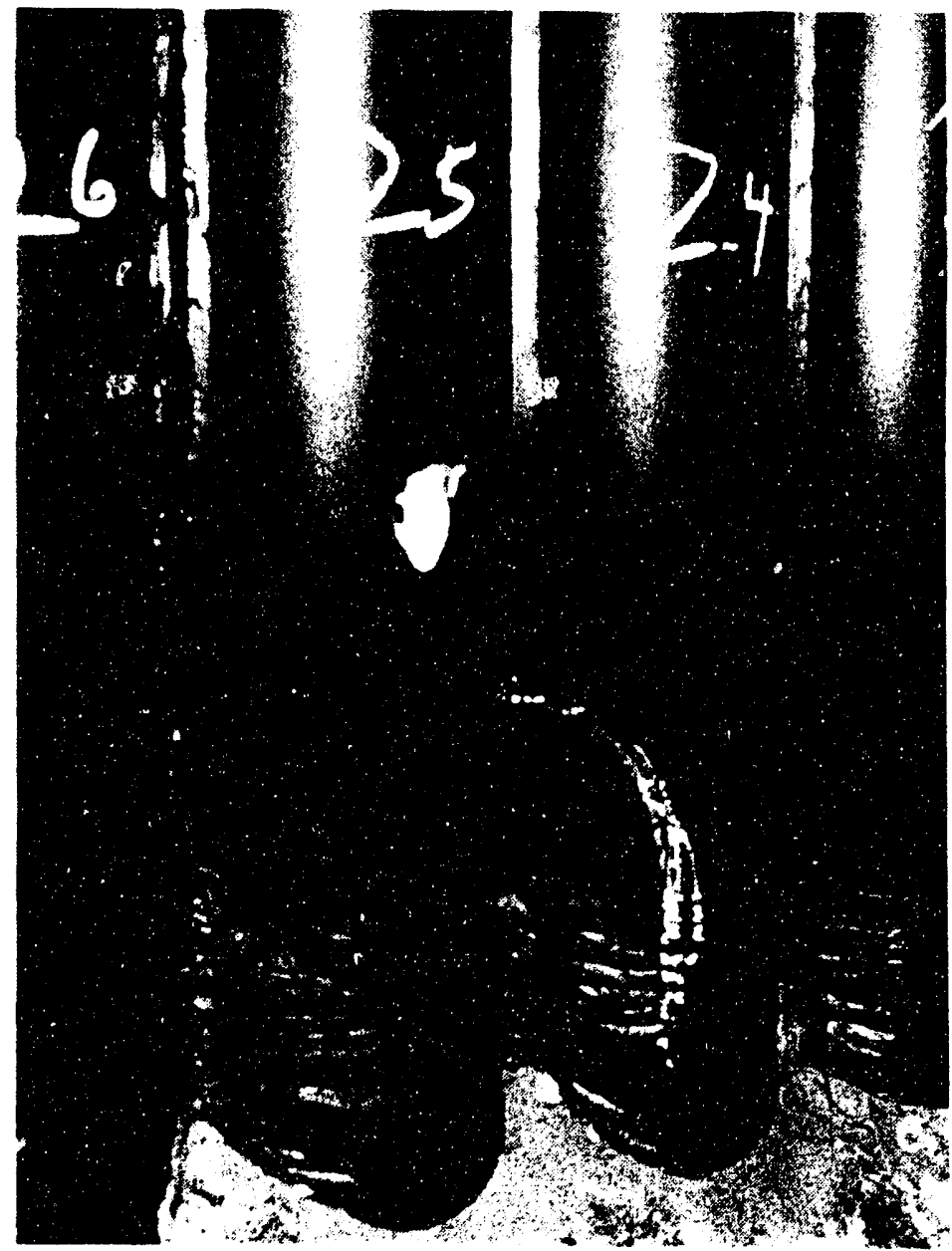

Figure 16-16. Erosion Patterns Initiating from the Membrane in

Combustor B (February 1991 Outage). 
Because of the narrow, uneven nature of this type of localized erosion, tube thickness measurements as part of preventative maintenance are difficult. There may be several such locations on a single tube which further compounds the problem. In most instances, tube thickness measurements are made in areas with the greatest visual erosion. During the February 1991 inspection, a total of 66 tubes were measured with spots less than 180 mils. Of theses tubes, 33 were measured with thicknesses less than 150 mils. The original tube wall thickness without weld overlay is a nominal 220 mils.

It is difficult to correct the erosion problem at the wiaterwall/refractory interface at Nucla without major design changes to the water walls and refractory. Currently, the problem is being controlled with periodic maintenance by applying weld overlay to eroded areas during unit outages. Grinding of "ledges", which form in the weld overlay on tubes and in the membrane, is also performed on an as-needed basis.

2. Erosion has also occurred on water-wall tubes at butt welds where water-wall panels were joined together during construction, as shown ir Figure 16-17. Not all welds display this type of erosion pattern. There are three contributing factors whish influence the degree of erosion at these locations (if present). The first of these, tube alignment, creates a problem if the lower tube projects slightly into the furnace section relative to the upper tube. In this case, the butt weld wears smooth but the downward flow of solids begins to undercut into the lower tube. The second is the quality of the weld, particularly in the adjacent membrane. In Figure 16-17, bar stock has been welded into the gap in the membrane from the back side (cold side), creating a significant discontinuity. Third, the water-wall location is important. Butt welds on the front walls (opposite the recycle line) show more instances of erosion than those on the rear walls (directly above the recycle line). After 15,000 hours of operation, no corrective action (i.e. weld overlay), has been taken in these areas. This erosion area continues to be monitored closely by the plant.

3. During the overheat incident in October 1987 (see 19871988 Annual Report), a permanent deflection of the water walls occurred due to differential expansion between the two combustion chambers. This "bowing" of the water walls was corrected to \pm 1.5 inches from the true centerline during the ensuing repair outage. The deflections are more severe in combustion chamber $A$ and occur approximately every 10 feet up the water walls, or the distance between the buckstays on the outside of the boiler. On combustion chamber $B$, only one deflection exists approximately half way up the center wall. 


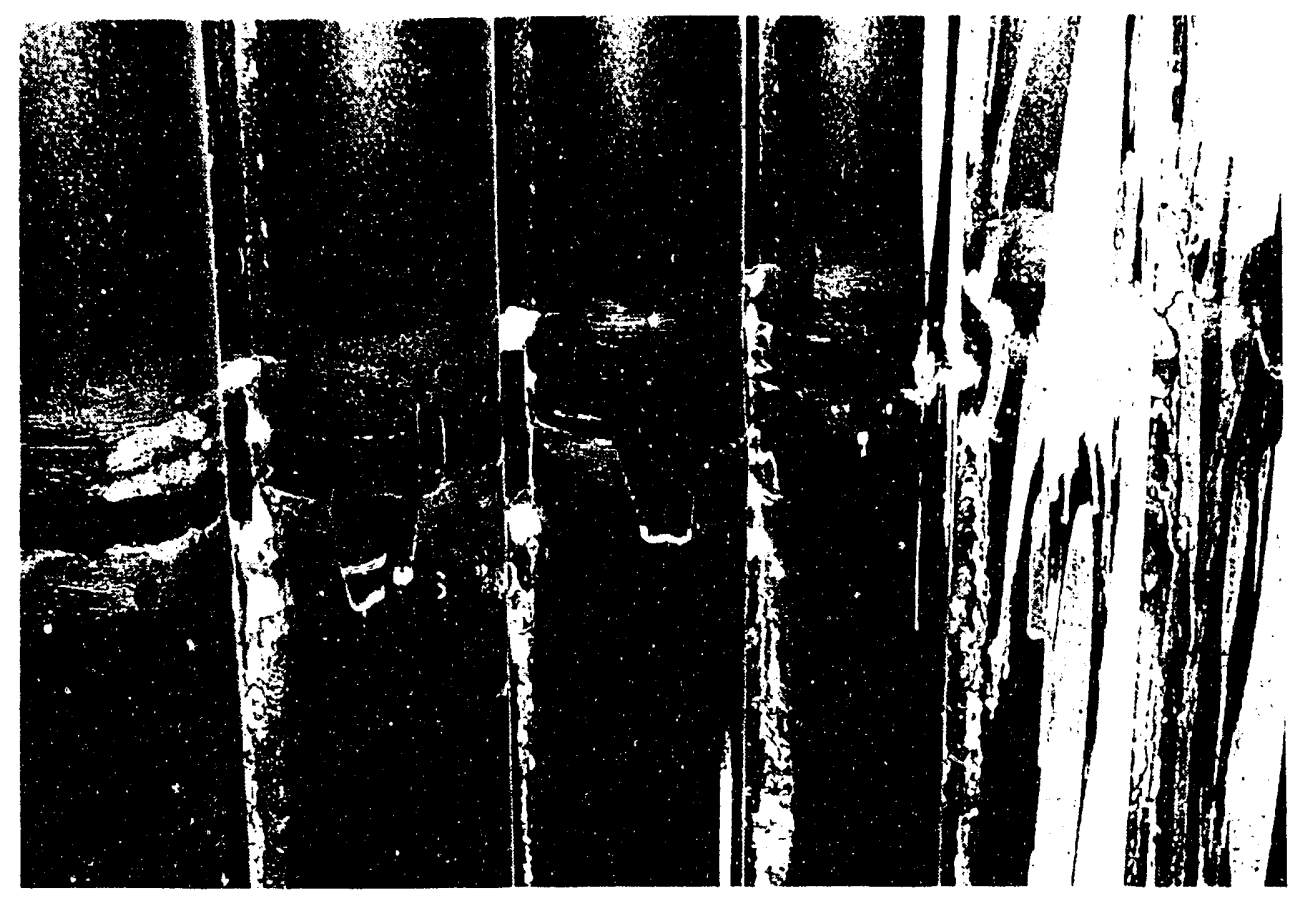

Figure 16-17. Erosion of Butt Welds at Adjoining Water-wall Panels (February 1991 Outage).

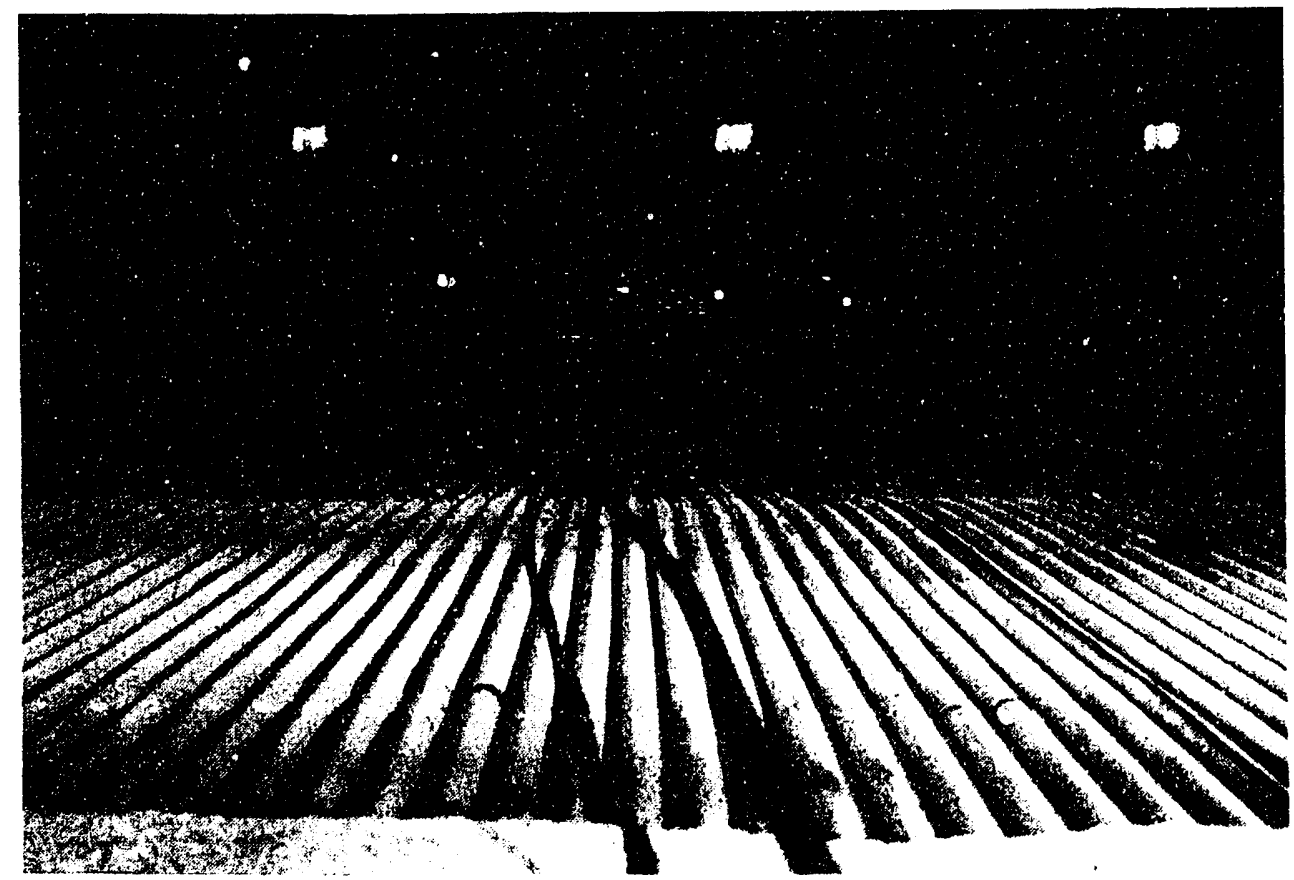

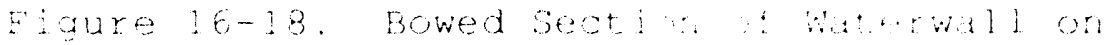

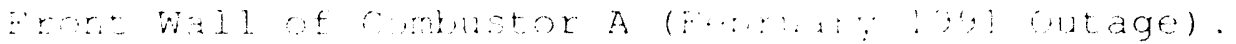


A photograph of this deflection can be seen in Figure 16-18 from the front wall of combustion chamber $A$.

The crest or "nose" of one of these bows on the front wall of combustion chamber $A$ has eroded severely since the time of the repairs in December 1987 . This can be seen in the photograph taken in February 1990 (see Figure 16-19). The location of this bow is approximately 22 feet above the air distributor. It appears that this deflection has a deeper and sharper radius compared to other locations. The erosion extends across all tubes at this location to within 5 to 10 tubes of the side walls. The length of this "cat scratch" erosion pattern is approximately 2 to 3 feet. Areas with deep gouging have been pad welded during unit outages in 1990. During the February 1991 outage, a total of? tubes were identified with erosion spots having less that $180 \mathrm{mils}$ of tube thickness. As with the erosion area at the waterwall/refractory interface, tube thickness measurements for identifying sites for pad welding are difficult. There have been no tube failures in this region to date and this, as well as other areas, continue to be closely monitored by the plant during unit outages.

4. Also during the overheat incident in October 1987, a hard $10 \mathrm{mil}$ scale deposit was left on water-wall tubes in combustion chamber A. In time, some of this scale becomes dislodged and exposes the underlying tube. In certain isolated locations, the discontinuities created by these deposits will form erosion sites. An example of this is shown in Figure 16-20. The extent and frequency of these occurrences is probably related to the relative location of these deposits to the water-wall "bows". The problem is difficult to monitor since it is isolated. To date, no action has been taken on this type of erosion.

\subsubsection{Superheater II Tubes}

The wrap-around superheater panels are situated in the upper freeboard region of each combustion chamber. There are four panels in each chamber, each consistirg of 64 tubes (see Figure 16-21). Each panel is situated against the water walls with approximately a 2" spacing between the water-wall tubes and the superheater tubes. From October 1989 to January 1991, there have been a total of 7 separate tube failures of the secondary superheaters accounting for a total of 2718 outage hours for repairs. A comparison of these outages to other unit outages during the period is shown in Table 16-2. 


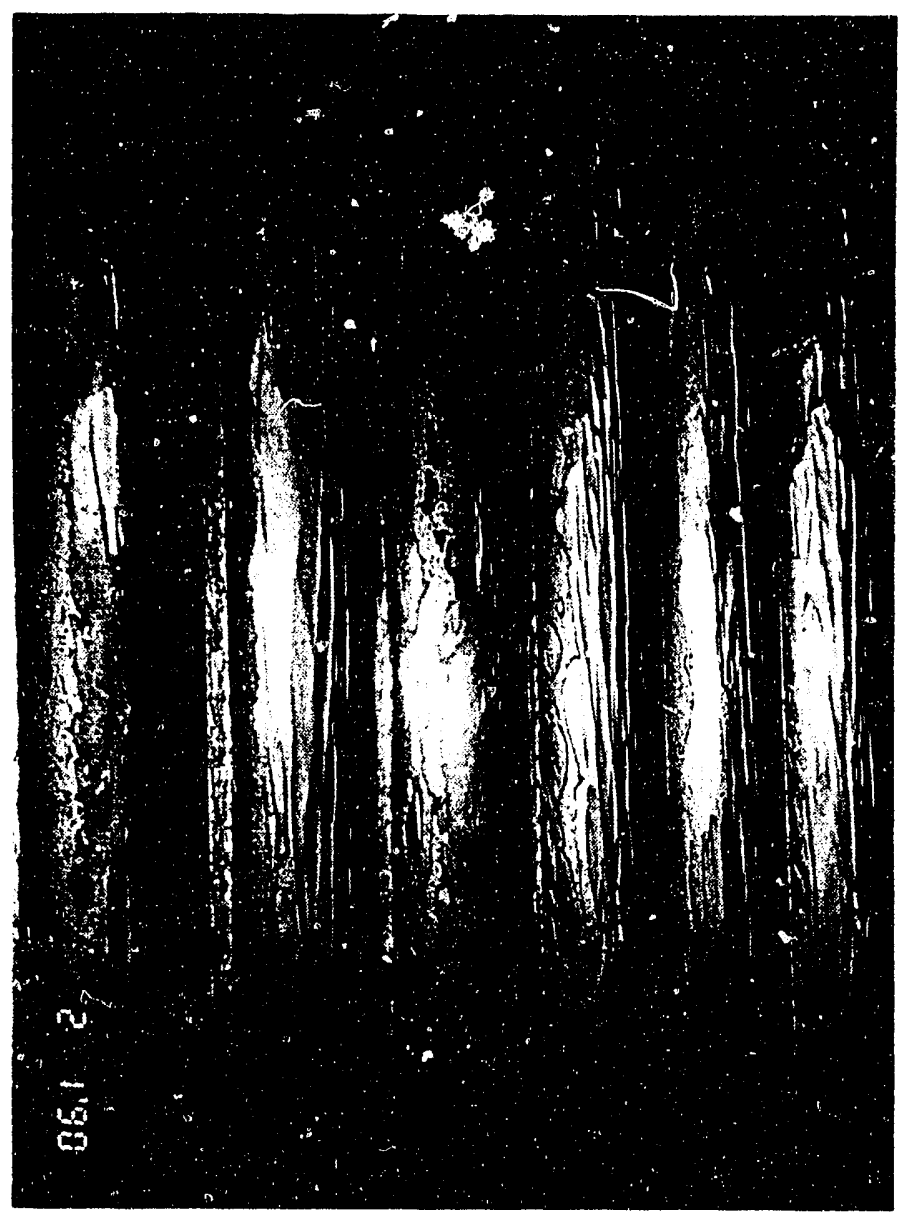

Figure 16-19. Erosion in Waterwalls at the Nose of the Bowed Water-wall

Section, Combustor $A$ at

22 ft Elevation (February 1991 Outage).

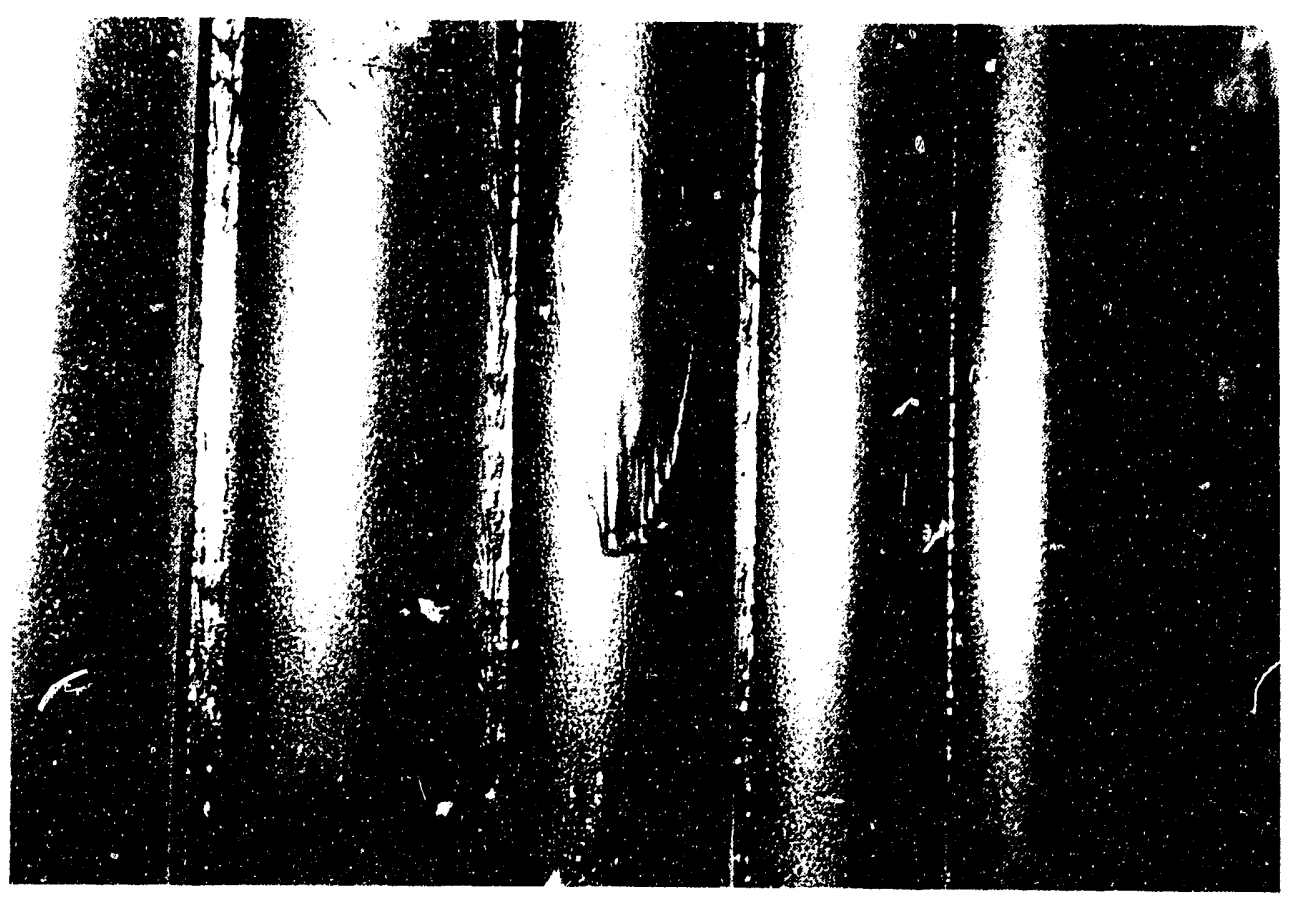

Figure 16-20.

Localized

water-wall

Erosion Site at the

Location of a Scale

Discontinuity 


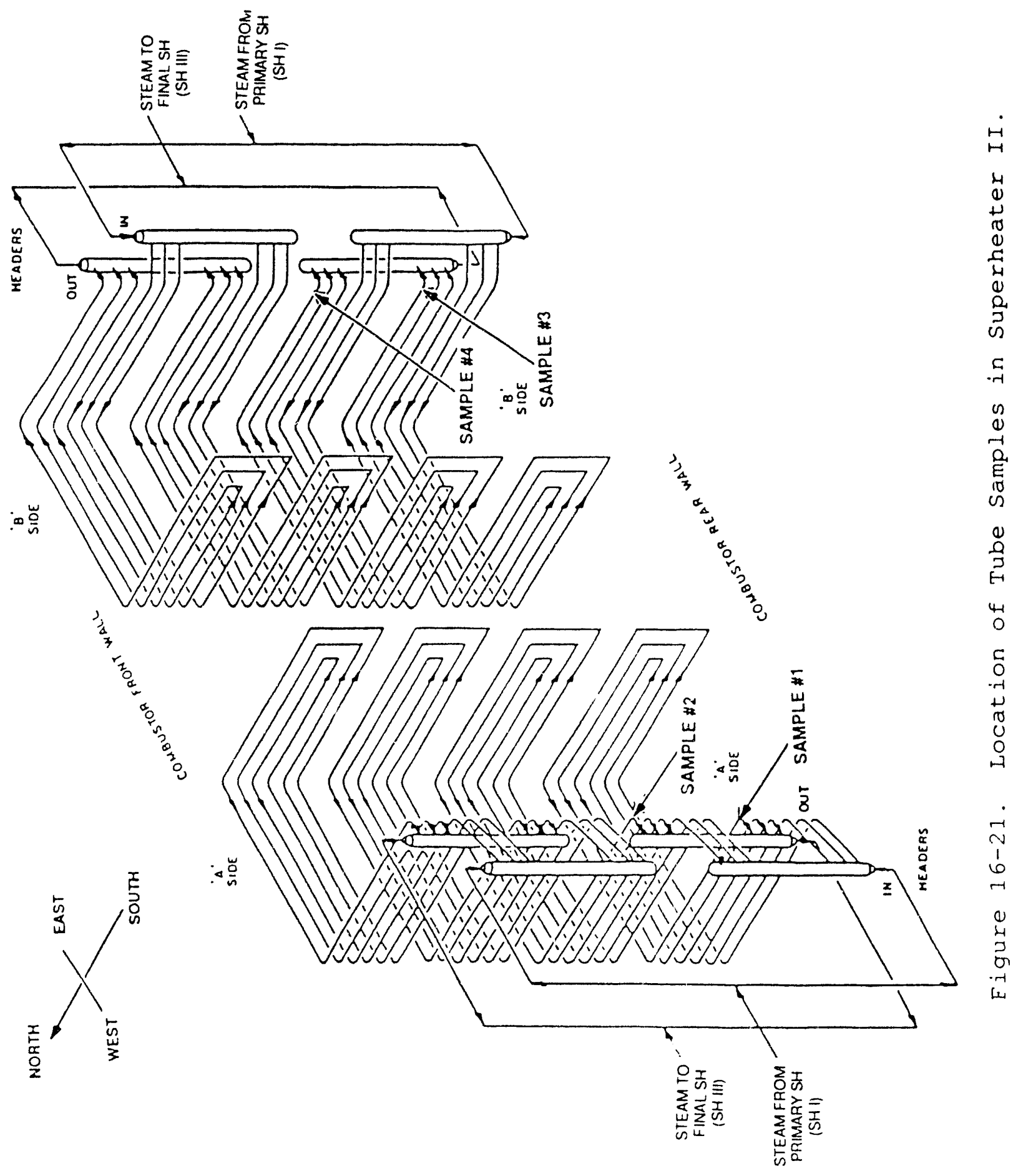


Table 16-2.

Outage Summary from October 1989 to January 1990.

\begin{tabular}{|c|c|c|c|}
\hline Qutage Description & Qutage : & Heurs & Ne.ef Outages \\
\hline Superheater II Failures & 70.4 & 2718 & 7 \\
\hline Cyclone Vortex Finder & 10.7 & 414 & 2 \\
\hline $\mathrm{PA}, \mathrm{SA}, \&$ ID Fans & 8.0 & 307 & 12 \\
\hline Generator Exciter/Relay & 4.7 & 183 & 5 \\
\hline Boiler Water-wall Tubes & 4.1 & 158 & 2 \\
\hline Miscellaneous & 2.1 & 82 & 10 \\
\hline Totals & 100 & 3862 & 38 \\
\hline Outage Duration & $35.2 \%$ & 3862 & \\
\hline Operating Availability & $64.8 \%$ & 7106 & \\
\hline Period Hours & $100.0 \%$ & 10968 & \\
\hline
\end{tabular}

There are three causes for the high failure rate of the secondary superheater tubes. These include particle erosion, long term overheat, and short term overheat from flow restrictions. Each are discussed in more detail below.

1. The first of the superheater II failures occurred in October 1989 on the center-wall of combustion chamber $B$ on the second superheater panel from the bottom. The initial leak occurred on the inside bottom radius of the lower tubes where the steam flow reverses direction and exits the boiler through the same path as the inlet tubes. Subsequent steam/ash washing resulted in additional superheater and water-wall tube failures. Damaged areas were removed from the boiler and were laid out for inspection as shown in Figure 16-22. The superheater tube bends are shown lying on top of a center water-wall panel section that was also damaged and removed. The water-wall tubes in the left of the photograph (with the 6 inch cut-out) are from an adjacent panel on the rear wall that was also damaged.

During a detailed inspection of the superheaters which followed this initial failure, erosion was discovered at other locations. Although the sites are localized and somewhat random, they seem to occur on the lower three panels in regions conducive to solids flow channeling. These sites include the vertical superheater tubes that form the wraparound superheat panels (all other superheater tube runs are horizontal), the corners of the panels, and around the vertical water tube supports which hold the panels in place.

Erosion in these areas almost always takes place on tubes that project out into the downward solids flow path or force a 


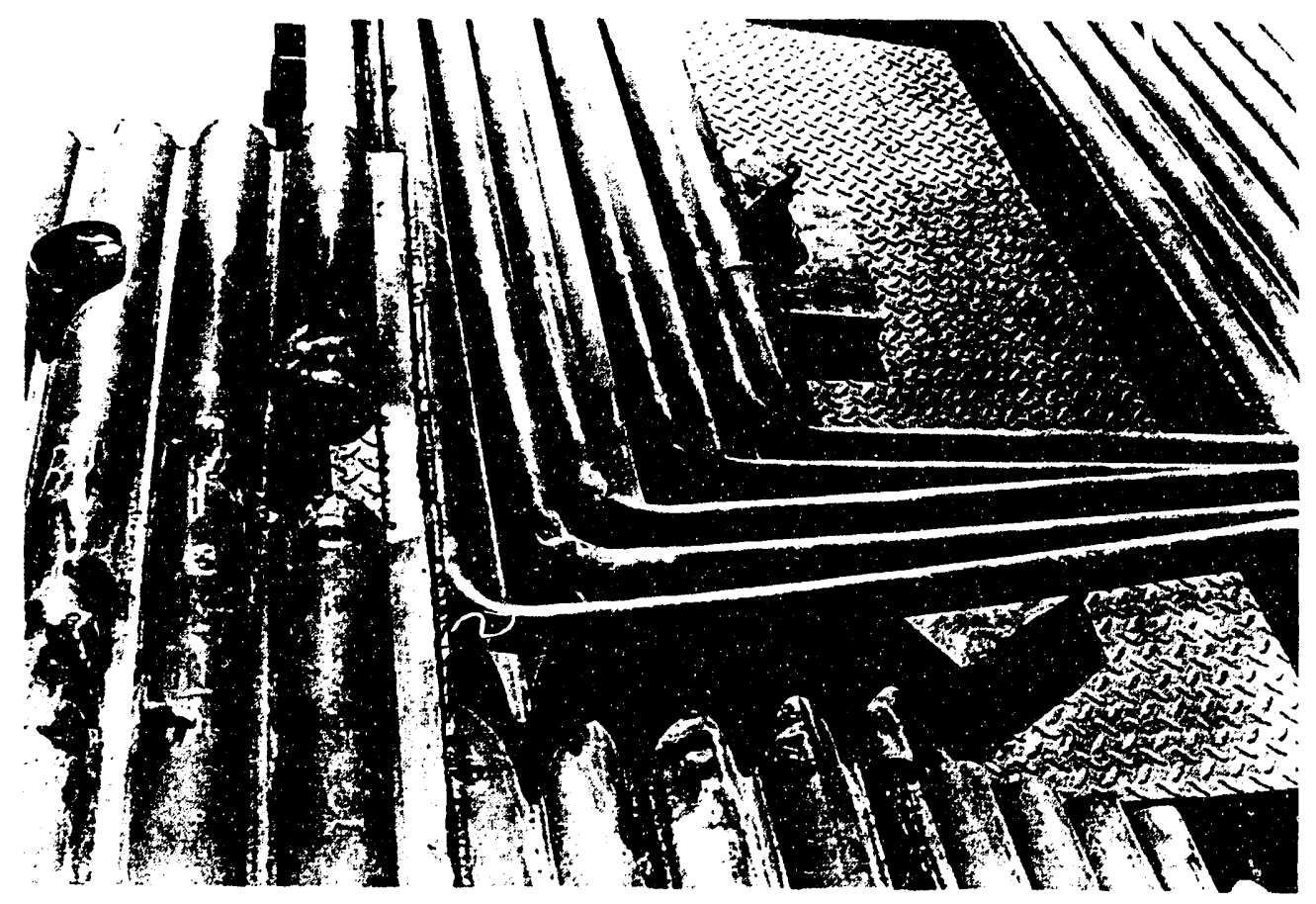

Figure 16-22. Superheater Tube Failures from Combustor B, Second Panel from Erosion on Inside Radius

(October 1989 Outage).

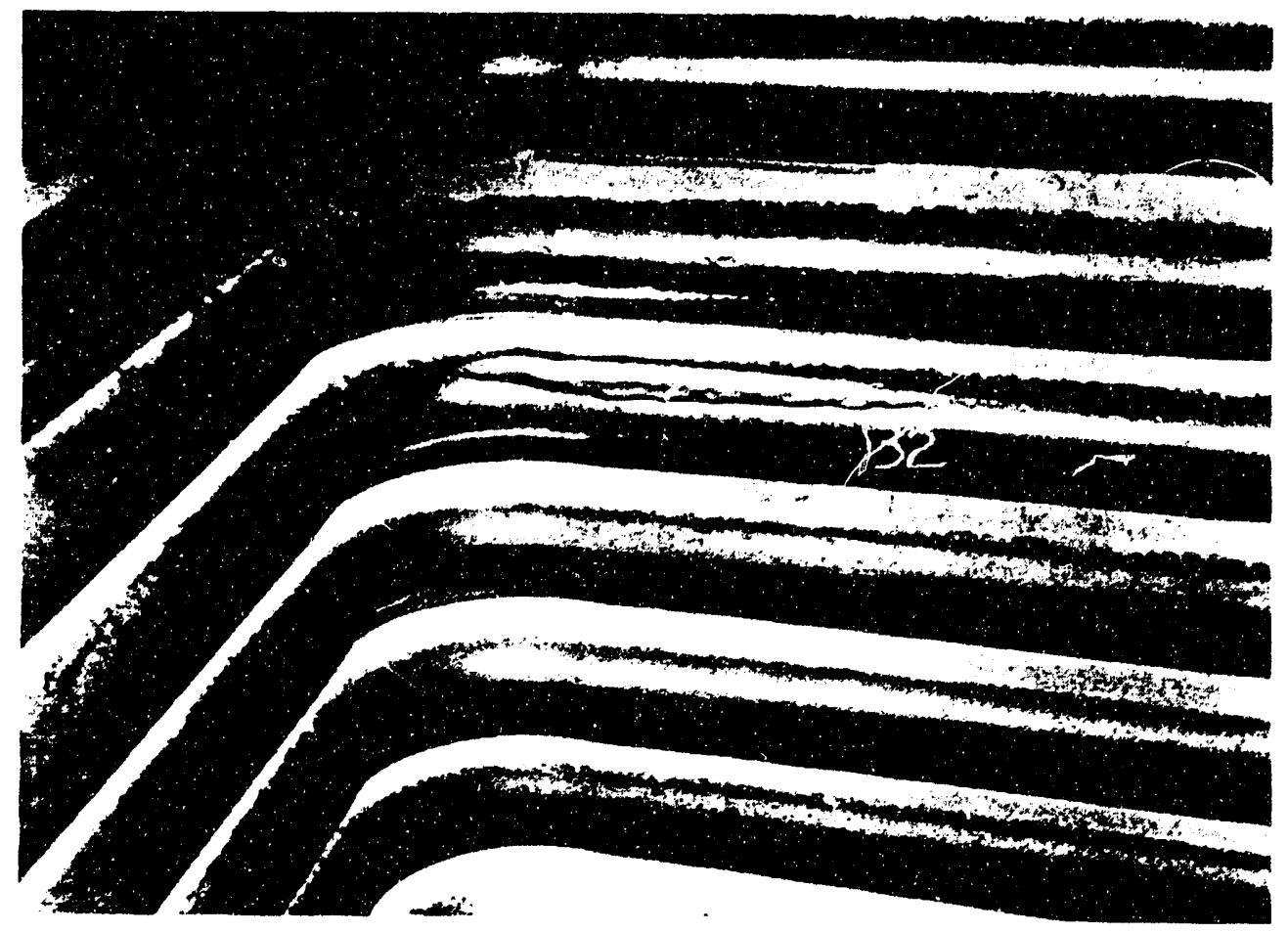

Figure 16-23. Erosion to Superheater Tubes on Panel 3, Northwest Corner, Tube 32 (February 1991 Outage). 
directional change in solids flow, such as the failure described above. An example of corner erosion is shown in Figure 16-23 where tube number 32 projects slightly out of alignment into the combustion chamber. Similar erosion patterns can be found on some superheater tubes that are out of alignment along straight sections of panel. Erosion can also be found on superheater tubes immediately surrounding the water-wall tube supports and on the lower bends of the tube supports. These areas are marked in Figure 16-24. More alarming, erosion was discovered on the back-side of the superheater tubes and adjacent water-wall sections during the repair from the failure shown in Figure 16-22. These locations are impossible to see or measure during routine inspections and were only discovered in one area because of removal of a section of superheater II panel for repairs.

To address this problem, horizontal shelves were installed along the top tube of the second superheater panel and at locations directly above the water-wall tube support as shown in Figure 16-24. Shelves were not installed on any of the other three panels. The intent of these shelves is to break up and deflect the downward flow of solids back out into the combustion chamber. At the same time, this concept prevents solids from flowing behind the panel and eroding the backside of superheater tubes and adjacent water-wall tubes. Since October 1989, this shelf design has not held up well in this application and has suffered numerous failures. It is also difficult to evaluate the effectiveness of this design in reducing particle erosion. The fact that a good shelf design protects the top tubes on each panel and prevents solids from flowing behind the panel does seem to hold some merit.

Currently, the superheaters are inspected during periodic outages and any major erosion sites, such as that shown in Figure 16-23, are pad-welded during the outage. There have been no additional failures of superheater tubes from erosion damage since the October 1989 failure.

2. A series of five superheater tube failures occurred in February, May, July, and September of 1990 as the result of long-term overheat. This type of failure is shown in Figure 16-25, which is located in combustor $A$ on the top tube of the first superheater panel near to where the tubes exit the combustion chamber and tie into the outlet header. Failures typically have occurred on the top tubes in each of the two lower panels. These tubes have a higher surface area exposure to boiler heat sources than other tubes in the panel and are also subjected to direct impingement from the downward flow of hot solids.

Sections of failed tubes were sent off to an outside testing laboratory for analysis. The conclusions from tests performed on these specimens were that the tubes had suffered from longterm overheat (creep damage) and that this was not related to 


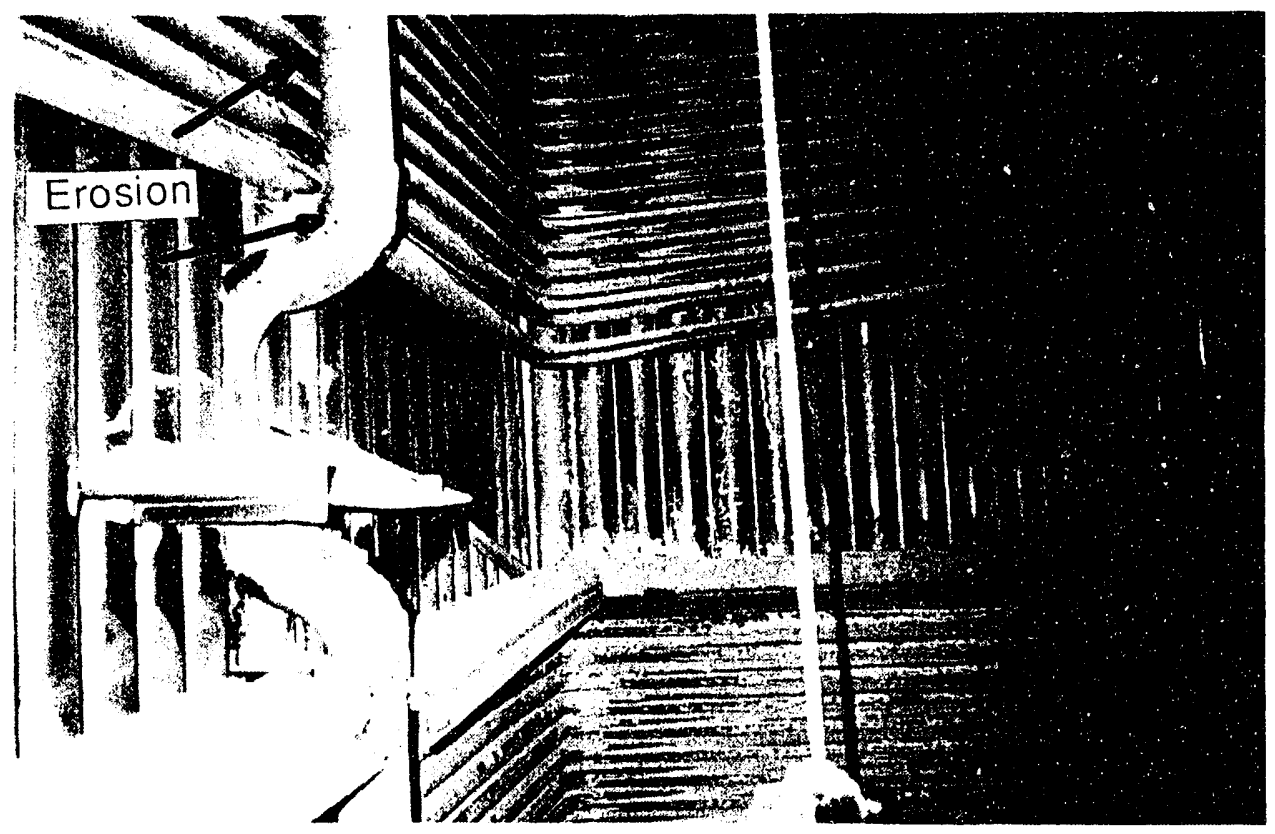

Figure 16-24. Secondary Sliperheater Shelf Arrangement and Erosion Locations Around Water-Tube Supports (February 1991 Outage).

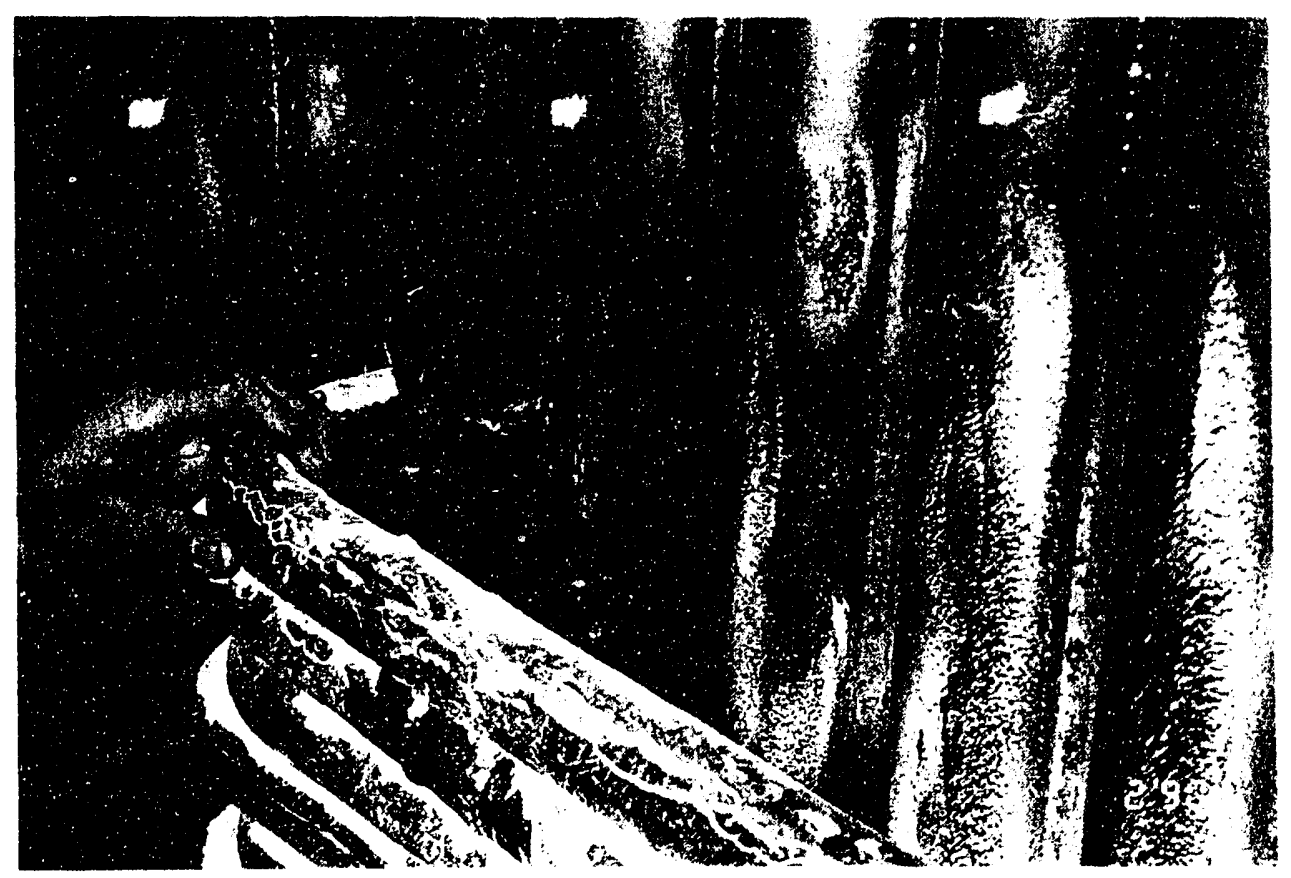


the overheat incident in October 1987. Details from this report are contained in the 4th Quarterly Report for 1990 and in the 1990 Annual Report. Damaged outside tubes (tube nos. $1,2,63$, and 64) on panel 1 in combustor $A$ were removed and blanked-off following a series of failures in May, June, and September 1990.

To determine the root cause for overheat, thermocouples were mounted on select superheater tubes near the outlet header and the metal temperatures were measured during unit operation. The data indicated higher operating temperatures on the outside tubes compared to other locations. Metal temperatures as high as $1075^{\circ} \mathrm{F}$ were recorded during full load operation. A series of attemperator spray flow tests were then performed to reduce this metal temperature to $1025^{\circ} \mathrm{F}$. To accomplish this, superheater II inlet spray flows were increased from 40 $\mathrm{klb} / \mathrm{hr}$ to approximately $60 \mathrm{klb} / \mathrm{hr}$. This lowered the final steam temperature to the turbine from $1000^{\circ} \mathrm{F}$ to $960^{\circ} \mathrm{F}$, resulting in 2 percent increase in plant heat rate.

In this instance, an operational change was made to temporarily correct the problem with long-term overheat of superheater tubes. There have been no additional failures since the modification to the attemperator spray flow logic in early October 1990. Superheater tube failures of this sort typically require a two week outage for repairs. In several instances, the initial leak resulted in a cascade of additional water-wall and superheater tube failures to the surrounding areas. Water-wall tube leaks have also resulted in the agglomeration bed material. Removal of this hardened material is time consuming, particularly when bubble cap air holes become plugged.

The plant now regularly monitors process performance parameters to identify initial failures and prevent additional tube damage. Induced draft fan speed and inlet pressure, furnace temperatures and pressures, attemperator spray flows, and carbon monoxide emissions are among the variables monitored. In the event of a water-wall tube leak, which normally results in the sudden loss of drum level and a unit MFT, fans are slowly restarted to percolate air flow through the bed and prevent agglomeration. Bed material is then removed from the combustion chambers through the ash coolers.

3. Following a tube leak, air flow is slowly initiated through the bed and bed material is removed through the ash coolers. During this process, solids are suspended in the freeboard region of the combustion chambers and become ingested into the opening left by the tube leak(s). If undetected during repairs, this material causes flow blockages in water-wall and superheater tubes. These blockages result in tubes overheating from lack of an adequate cooling medium. 
This phenomenon contributed to some of the later superheater tube failures in July and september 1990. It was also directly responsible for two water-wall tube failures during the same period in August 1990. In this instance, cemented bed material was found at various locations in the lower water-wall tube headers and inside the two failed tubes. To reduce the likelihood of solids ingestion into failed tubes, plant operations now waits until drum pressure has decreased to below 25 psig before restarting fans. At this time, a steam tie is opened from the auxiliary boiler to maintain a positive pressure at the rupture location. Following repairs and restart of the unit, boiler chemistry, including silica levels, are closely monitored. Since the water-wall failure in September 1990, there have been no further superheater or water-wall tube failures caused by flow restrictions.

\section{4 .6 Bottom Ash Coolers}

There have been no major problems with the main ash cooler hardware other than infrequent losses of bubble caps. Minor problem areas are listed below.

1. The drains from the combustors leading to the ash coolers have occasionally blocked with refractory and with large pieces of bed material. To dislodge these, an air lance is inserted into a port near the bottom of the ash cooler and through the inlet drain. The auxiliary hardware for fluidizing these inlet drains have suffered from some blockage by bed material, erosion, and damage from the air lances (see Figure 16-26). In isolated instances while burning high ash coals, restrictions in these lines prevented removal of bed material from the combustors and forced unit outages. This is probably more of a design-related issue rather than a materials issue.

2. At the inlet and outlet of the ash coolers between the combustors, manual isolation gates were installed in the original design to allow for maintenance work during unit operation. In addition to becoming warped, the slides pack with bed material and have not been operational throughout the period of the test program.

\subsubsection{Cyclone Refractory and Vortex Finders}

The "gunned-on" hydro-bonded refractory used in the cyclones has not held up well over the first four years of unit operation. Two 6 inch layers of insulating and abrasion resistant refractory are used on all internal cyclone surfaces for a total thickness of $1 \mathrm{ft}$. This refractory was applied during construction after the cyclone shell and structural supports were in place. While the cyclone roofs and outlet ducts have held up well, the abrasion resistant layers on the inlet spirals, cyclone barrels, and conical sections of the 


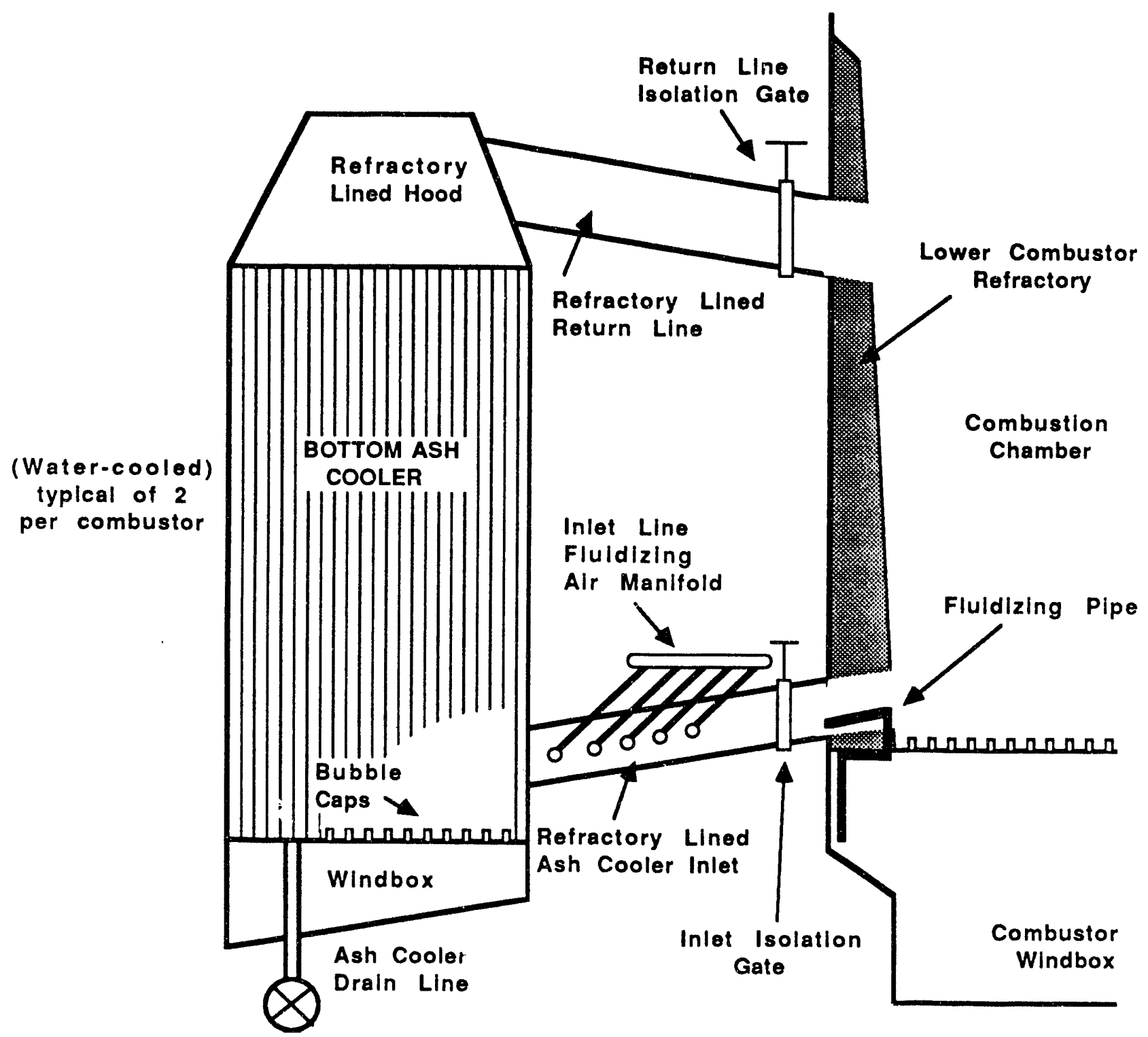

Figure 16-26. Bottom Ash Cooler Arrangement. 
cyclones have suffered from spalling and breakage (see Figure 16-27 for locations).

Refractory loss in the cyclones is undesirable for two reasons. First, it can lead to hot spots on the outside shell if breakage and erosion progresses through the outside insulating layer. Second, loose refractory pieces accumulate in the loop seals located at the bottom of the cyclone downcomers. This accumulation can restrict recycle flow through the loop seals and force unit outages. Because of these occurrences, a major refractory repair outage was initiated in January 1989 after 5500 unit operating hours on coal. The outage duration was approximately 950 hours.

During this outage, the abrasion resistant layer was removed around the inlet spiral shelves, the inlet "bull noses", and the conical section of the cyclone. Modified refractory anchors were installed in certain regions and refractory "stops" were placed around the bull nose to reduce movement and breakage. Other than these design changes, refractory spalling and breakage during the first 5500 hours of service were attributed to poor installation. The primary cause cited was the excessive shrinkage of the abrasion layer due to high water content during installation. The latter resulted from low refractory mix temperatures which necessitated the addition of excess water to improve workability.

Following these repairs and 10,000 additional operating hours on coal, problems with "pinch" spalling and refractory breakage in the cyclones have reappeared. Repairs are periodically made to damaged areas using "blue ram" phosphatebonded refractory. These areas are discussed in more detail below.

1. The inlet spiral shelves on both cyclones have been subjected to refractory breakage, primarily due to poor anchoring. The location of this shelf is shown in Figure 1627. Major sections of the shelf were replaced with improved anchoring during the January 1989 repairs. This shelf continues to break and is repaired during unit outages using "blue ram" refractory

2. Large sections of the "bull nose" on both cyclones have broken away on repeated occasions. The location of the bull nose is shown in Figure 16-27 and the general condition during the outage inspection at the conclusion of the Phase II test program in February 1991 is shown in Figure 16-28. As the result of similar breakage after 5500 hours of service, refractory "stops" or plates were installed at two locations in the cyclone shown in Figure 16-27 and refractory was reapplied using new refractory anchors. This modification has not improved the performance of this section of the cyclone and periodic repairs are required during unit outages. It may be possible that cyclone movement, as opposed to refractory 


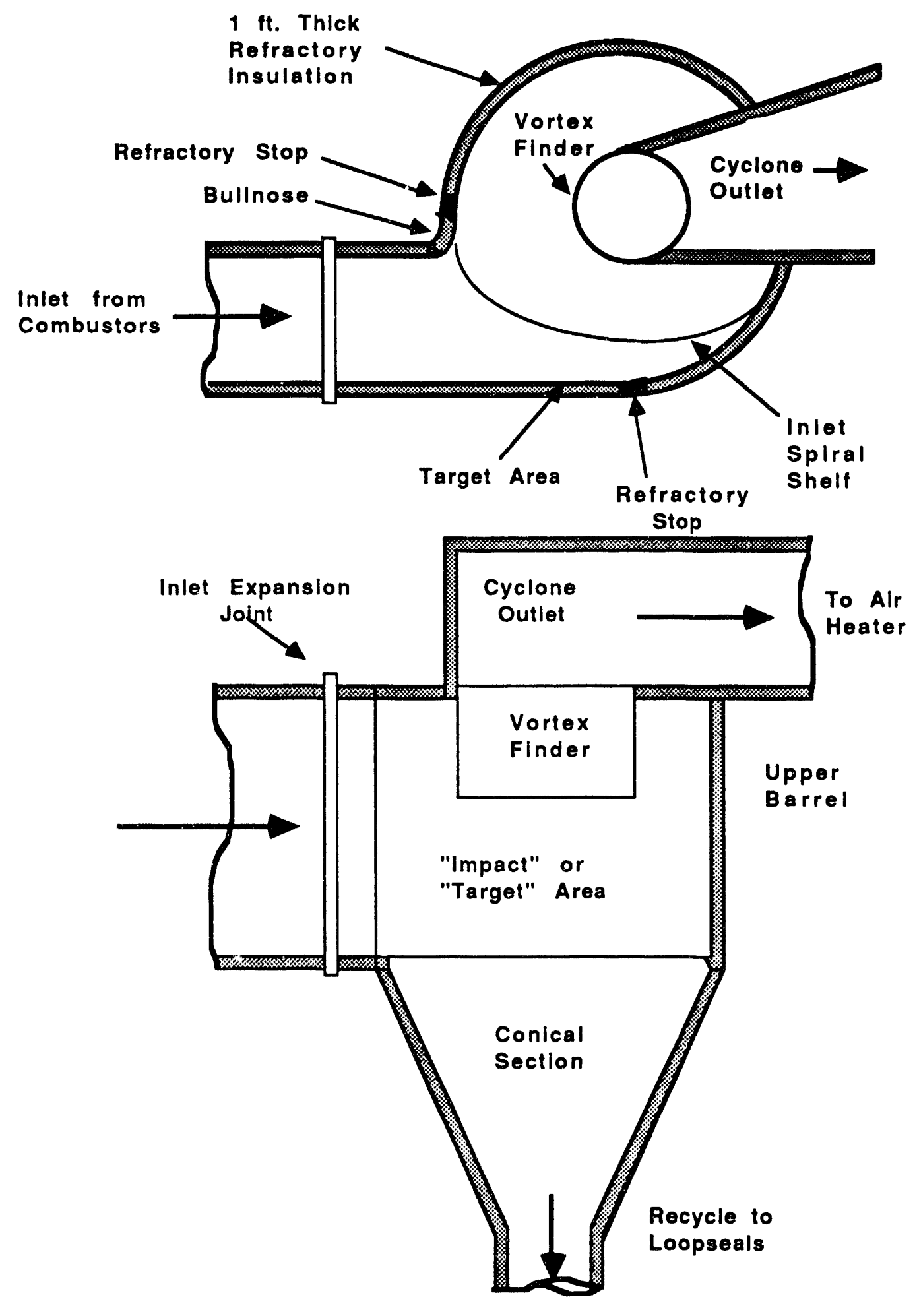

Figure 16-27. Schematic of Cyclone Arrangement (typical of two) 
Figure 16-28. "Bullnose" Refractory Condition

(February 1991 Outage).

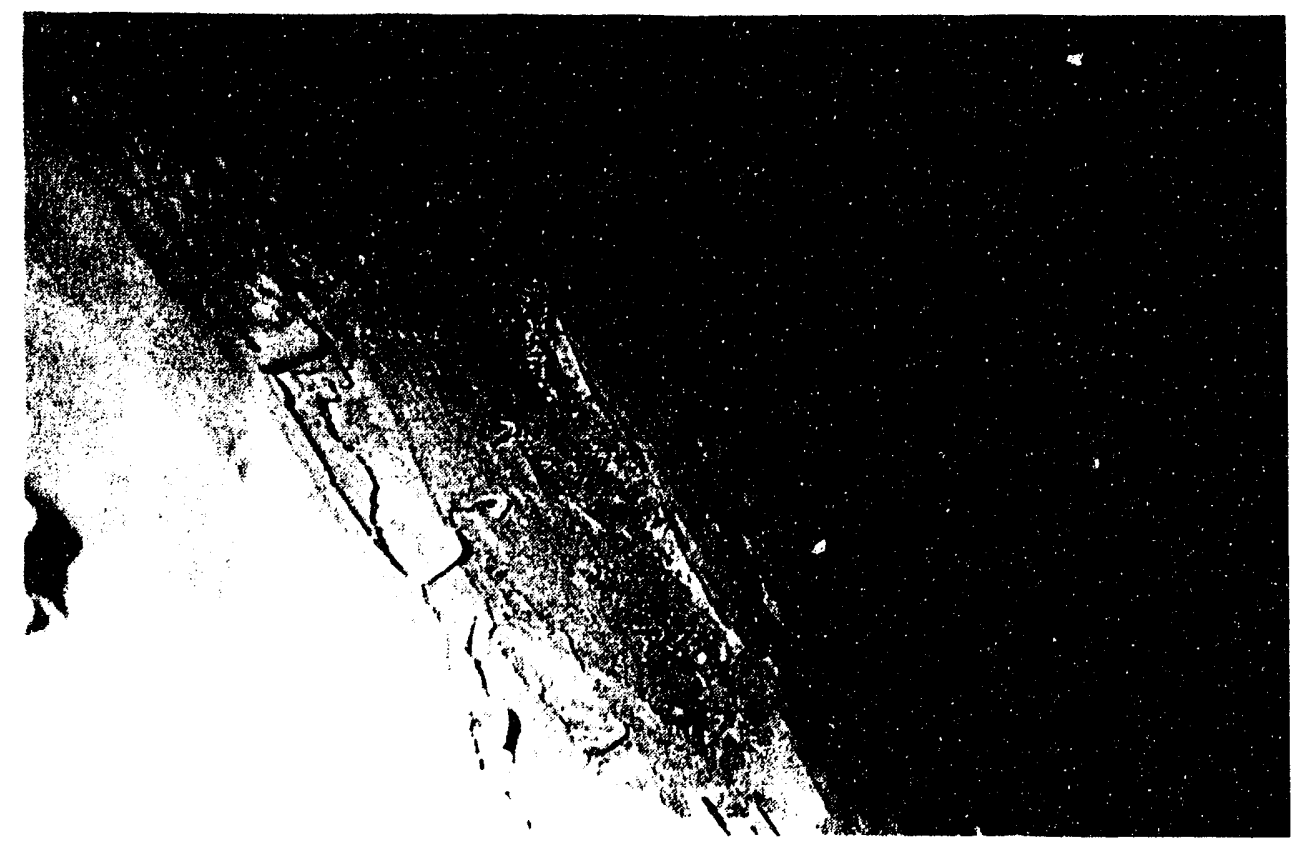

Figure 16-29. Refractory Erosion at Impact Area on Cyclone $B$ (February 1991 Outage). 
expansion, is the cause for breakage in this area. The problem remains under investigation.

3. The "impact" or "target" area of the cyclones shown in Figure 16-27 shows significant particle erosion following 15,000 hours of service. The condition during the February 1991 outage is shown in Figure 16-29. In areas, the outer 6" abrasion resistant refractory layer has worn almost completely through and refractory anchors are exposed in several locations. The refractory shown in this photograph is the original gunnite abrasion resistant layer. Repairs to the most severe areas are periodically made during unit outages using blue ram refractory. The severity of this problem could probably be reduced using a harder abrasion resistant brick. The problem continues to be monitored by the plant.

4. The inlet expansion joint shown in Figure 16-27 is packed with a hard mineral wool insulation on the hot side. This material has suffered from particle erosion and has been replaced on two occasions during 15,000 hours of unit service. There have been no problems with the expansion joint on the outside casing.

5. The conical sections of the cyclones have suffered from repeated refractory spalling and breakage. This area has not faired as well as the upper barrel section of the cyclone, the cyclone roof, and the outlet ducts. This is probably due to the.higher concentration of solids coupled with the effects of gravity, which forces solids down into openings. Much of the problem occurs at cold joints which are formed during installation at shift changes. These joints also provide some tolerance for expansion. During operation, solids work into these expanded joints and become trapped during cool-down and contraction. Through repetition of this process, solids become layered and packed in the joint as shown in Figure 1630. Eventually, the strength of the compacted material exceeds the strength of the surrounding reiractory. When this occurs, pieces of refractory break away around the crack, increasing the size of the opening. This phenomena is known as "pinch spalling". In this type of application and service, there is not much that can be done to prevent it from occurring. Brick applications also suffer from pinch spalling (an example is shown below), but the damaged area is usually confined to the surrounding bricks.

During the refractory repair outage in January 1989 following 5500 hours of service, the outer 6" abrasion resistant layer was completely replaced in the conical section of both cyclones. New refractory anchors were installed and improved quality control was applied during installation of the abrasion resistant layer. The latter included 1) careful control of the refractory mix water content, 2) square-edged cold joints were formed where necessary, 3) the application proceeded from bottom to top to reduce the amount of "rebound" 


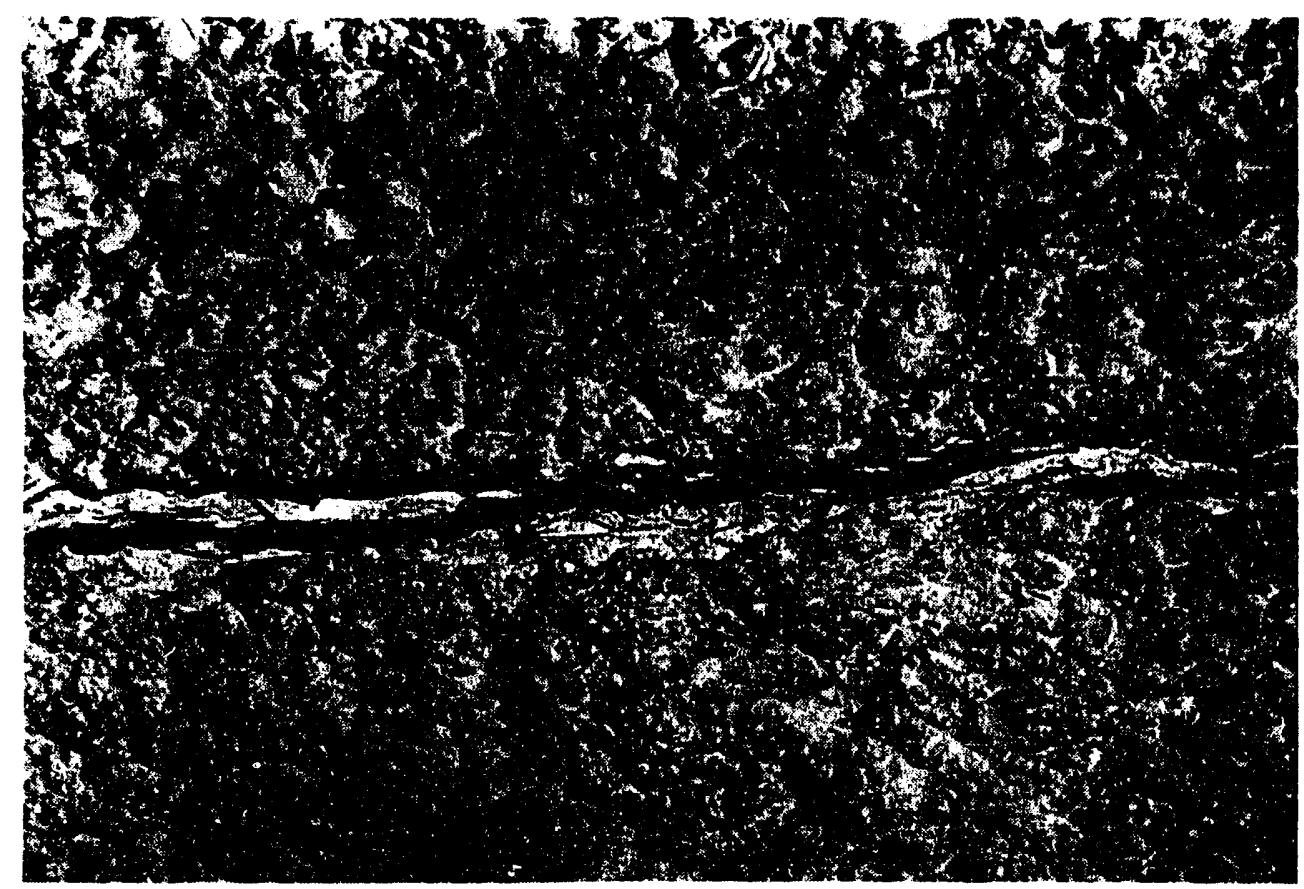

Figure 16-30. Example of Solids Layering at a cold Joint.

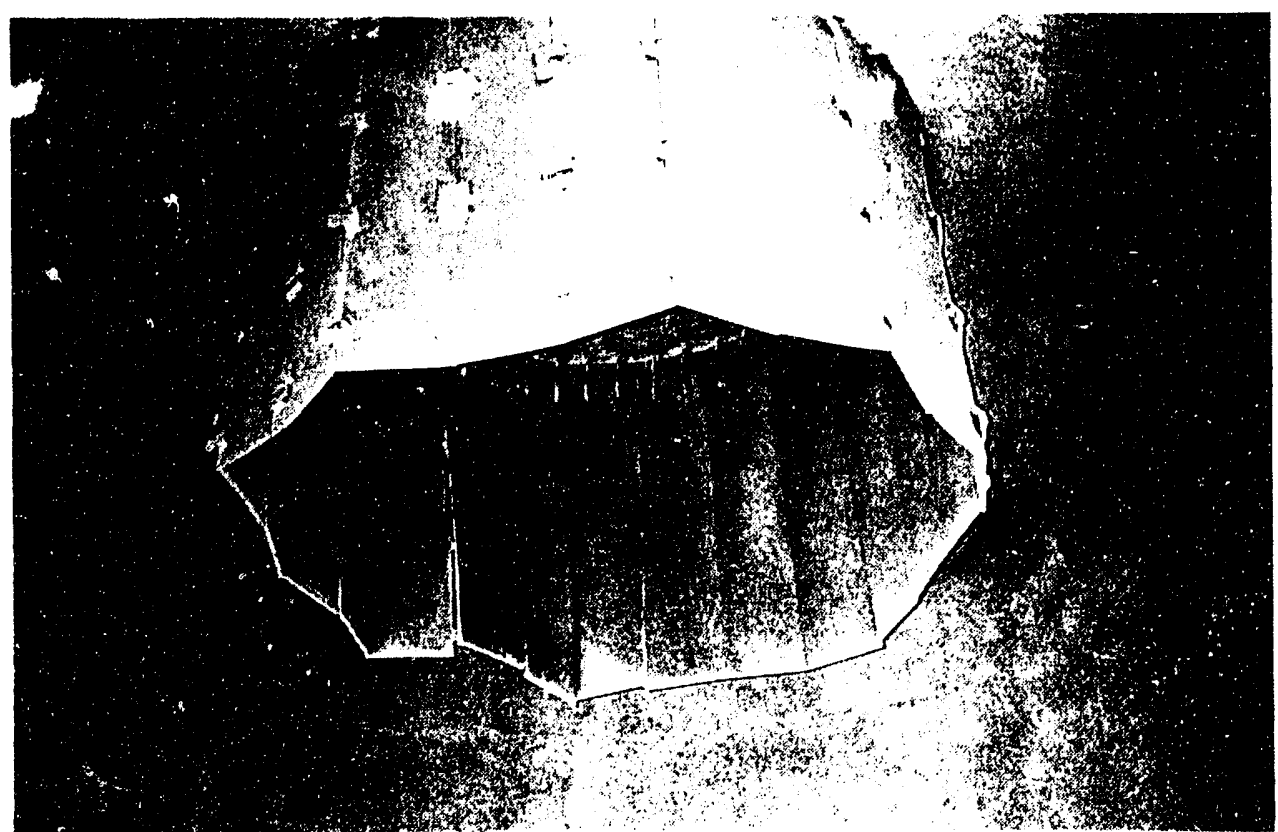


material contaminating the anchors. Rebound is an unwanted dry refractory material present in the gunning process.

These changes have not improved refractory performance in the conical sections of the cyclones. Refractory spalling and breakage at cold joints still occurs and accumulates in the recycle loop seals. The area is carefully inspected during all outages and requires periodic repairs with blue ram refractory. Frequent cold unit start-ups have been experienced at Nucla during the first four years of service. These are probably not conducive to refractory life in this type of application.

6. The cyclone vortex finders are situated at the cyclone outlets and are constructed from high alloy steel plates approximately $8 \mathrm{ft}$. in length (see location in Figure 16-27). These have distorted in service and plate sections were replaced during an outage in March 1990. Since this time, the vortex finders have continued to distort as shown in Figure 16-31, which is a photograph taken during the February 1991 outage. Solid construction of the vortex finders or a shorter plate length may correct this problem. zurrently, the distortion is monitored and the problem remains under investigation.

\subsubsection{Downcomer and Loop Seal Refractory}

The loop seals represent a severe application for refractory due to the density of the high temperature recycled solids coupled with directional changes in flow. Prior to the refractory repair outage in January 1989, a hot spot developed on the outside shell of the loop seals in the vicinity of the archways (see Figure 16-32 for location). Stress cracks in the outside shell near the archways were also discovered at this time and were repaired.

The original archways were formed using an abrasion resistant gunnite layer which suffered severe breakage after 5500 hours of service (resulting in the hot spot). During the outage, the original refractory was removed and a combination of brick, castable refractory, and gunned-on refractory were reapplied. Figure 16-33 shows two layers of abrasion resistant and insulating refractory brick being applied in the cyclone loop seals. The archways were cast with a high density hydro-bonded abrasion resistant refractory. These modifications have held up well in the 10,000 hours of service since these repairs. As shown in Figure 16-34, pinch spalling still occurs at the brick joints, but is localized and confined to the area of the brick. Some breakage was apparent around the loop seal arches during the February 1991 inspection. These areas were repaired and will be inspected during future outages. 


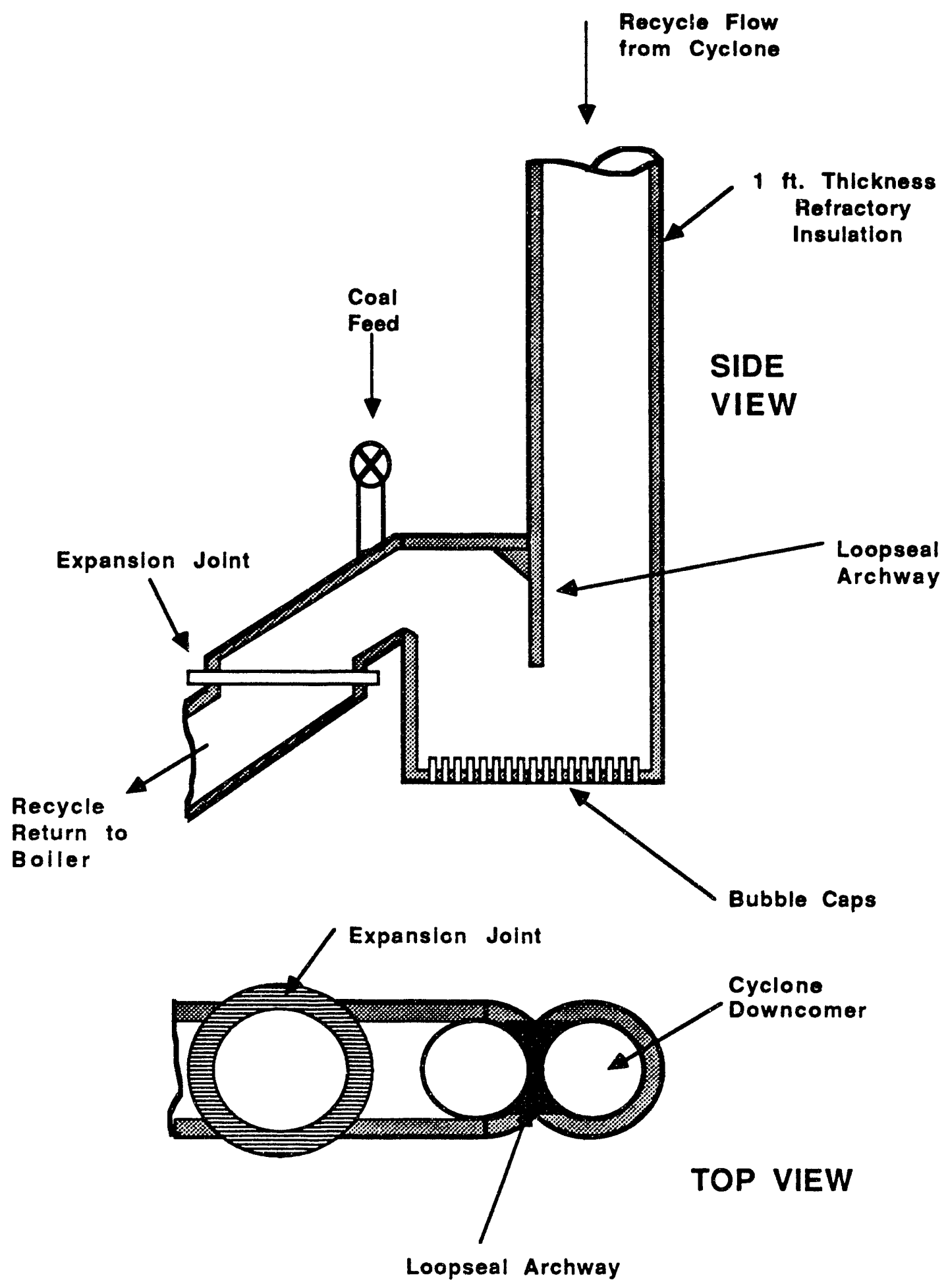

Eigure 16-32. Schematic of Loopseal Arrangement. 


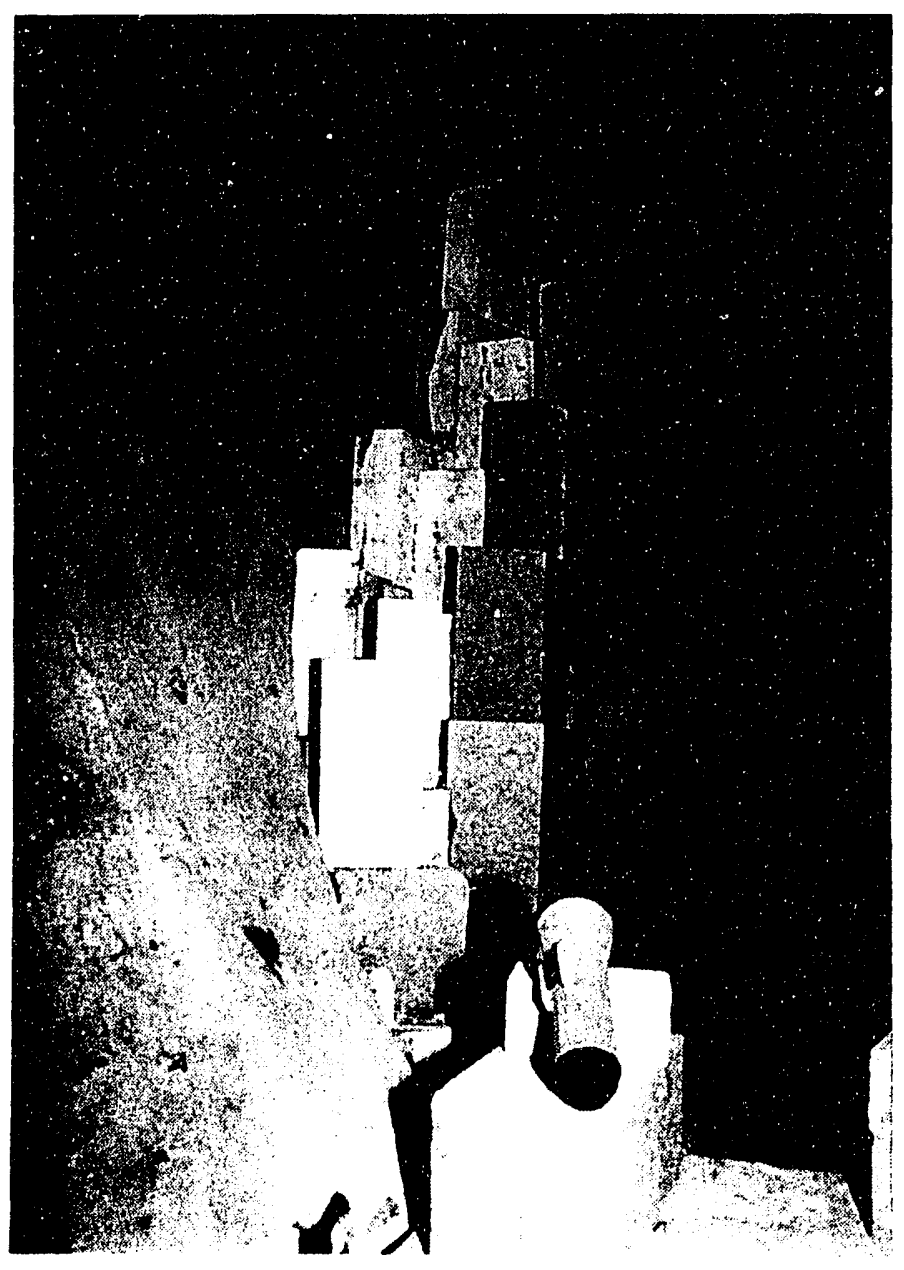

Figure 16-33. Brick Reconstruction in Loop Seals (January 1989 Outage).

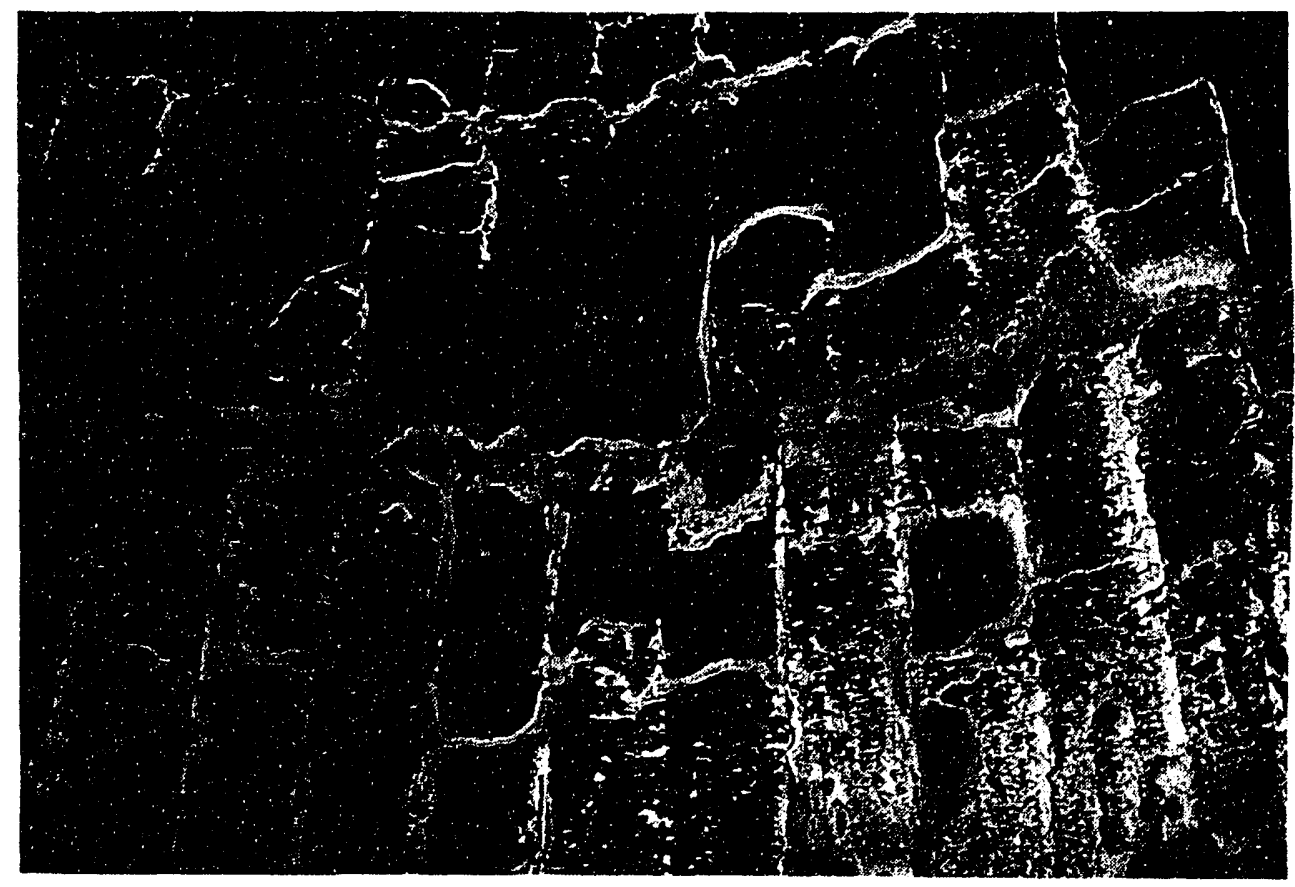

Figure 16-34. Pinch

Spalling at Brick Joints in the Loop seals. 
During the first year of unit operation, the area directly below the coal feed point to each loop seal showed signs of erosion from falling coal particles. An area directly below the coal feed points was replaced at this time with a hard abrasion resistant brick. This has held up well in the following three years of unit service.

The expansion joints located in the loop seals (see Figure 1632) were damaged during the overheat incident in October 1987 and were repaired. Sometime after this incident, the air space around the joints became packed with bed material. Based on visual observation of the inside of these joints, there does not appear to be movement between the upper and lower sections. The apparent inoperability of this joint remains under investigation.

Refractory in the downcomers connecting the lower cyclones to the loop seals was not in good condition during the inspection outage in February 1990. Refractory in this area represents the original gunned-on insulating and abrasion resistant layers. Damaged areas in the downcomers were repaired during the refractory outage in January 1989. This area is a good application for brick refractory since it is a confined area difficult to maneuver in when applying gunnite. The condition of the gunned-on refractory should be carefully monitored in the future and replaced at some point in a manner similar to that shown for the loop seals.

\subsubsection{Backpass (Economizer and Superheaters)}

There are no major materials-related problems to report with the economizer and superheater bundles, and the water-cooled superheater hanger tubes. There have been no signs of erosion or corrosion on these tubes following detailed tube thickness measurements after 5500 hours of service and periodic inspections since this time. The tube clips on the economizer and superheaters are functional and all components were generally in good condition as of the inspection in February 1991.

There is a significant ash build-up in the primary and final superheater bundles between adjacent vertical tubes. This ash build-up is soft and can be removed easily with a finger. Since soot blowers were provided on the economizer tubes and since the tube spacing is wider, there is no build-up in this area. Ports were provided for soot blowers on the superheater jundles in the original convection pass design. If final steam temperatures deteriorate in the future, the installation of soot blowers should be considered on the superheater tube bundles. 
16.4.10 Tubular Air Heater

The back end of the tubular air heater has been inspected periodically during the course of the test program for corrosion. As of February 1991, there are no signs of corrosion or fouling in the final gas pass through the air heater and there are no other materials-related problems to report.

The tubular air heater has suffered from leakage of primary air into the secondary air paths during low loads. In April 1988, gaps between air heater sections that were left during construction were welded closed. Although this reduced the cross-leakage, the problem is still persistent at low loads. This remains under investigation and is more of a design problem than a materials-related problem. 


\title{
Section 17
}

\author{
RELIABILITY MONITORING
}

The reliability monitoring plan for the Nucla CFB was conceived by the Electric Power Research Institute (EPRI) as a means of developing an equipment reliability database strictly for atmospheric fluidized bed combustion (AFBC) boilers. The intent was to complement and expand on the North American Electricity Reliability Council/Generation Availability Data system (NERC/GADS) database for fossilfired units. The new database would accommodate plant equipment components and causes for failure unique to this new technology. The database could then be used for the following:

- Predicting the availability of future commercial AFBC plants

- Evaluating the reliability of proposed designs

- Assessing the impact of design changes on system reliability

- Evaluating life extension work on specific plant components

- Allocating research and development funds for reliability improvement

By tracking the frequency of equipment failures, the equipment run time between failures, and the time required for repair, it was intended to predict the mean time to failure (MTTF) and mean time to repair (MTTR) for specific AFBC plant equipment components. This quantitative information could then be used as a planning tool to satisfy the objectives outlined above.

Accomplishing this plan required three steps. First, uniform codes, established by EPRI, were given to plant equipment components on three utility AFBC's under construction or in start-up: Northern States Power's 125 MWe Black Dog Bubbling Bed AFBC, TVA's 160 MWe Bubbling Bed AFBC, and Colorado-Ute Electric Association's 110 MWe Nucla CFB. This would eventually allow direct comparisons to be made between these three plants. Second, the equipment codes, cause of failure codes, and time required for repair were added to the plant maintenance work request forms. This information could be manually or automatically collected into a database. Third, equipment component run times were collected by either the 
plant digital control system (DCS) or by a host computer using specially developed software.

The first step was completed during the cold-mode shakedown period of the Demonstration Program at Nucla. Fifteen digit numbers were assigned to approximately 620 pieces of plant equipment to a level of detail consistent with that presented on the P\&ID drawings. For example, the limestone feed system was broken down into transport blowers, transport piping, weigh system, rotary valves, bin shaker, isolation gate, shaker motor, vent system, etc. For identical equipment used on several systems (i.e., two limestone feed systems) each equipment component was given a unique equipment

identification number. The same numbering scheme was used at the other demonstration plants.

To accomplish the second step at Nucla, a software program called PERFORM was developed by EPRI for generating hard copy maintenance work requests (MWR's). This program contains the uniform equipment codes assigned to each piece of plant hardware in step 1 (see Reliability Monitoring Database pages 17-5 through 17-13). As MWR's are generated by the plant, the cause and nature of the failure (if any), the work priority of the problem (1. Immediate Action Required, 2. Possible Curtailment, 3. At Earliest Convenience, 4. Outage Item), the hours required for repair, the date, and other information are automatically stored in a database. The software allows MWR's to be sorted by MR number, equipment ID number, and date. This software has been in use at the Nucla CFB since the fourth quarter of 1988 and remains the system by which the plant generates maintenance work requests. The three PERFORM software set-up sheets to be completed by the plant maintenance staff in order to generate an MWR are shown in Figure 17-1.

To complete the third step, software was developed to run on the Demonstration Program's DEC VAX computer which is tied directly into the plant's Westinghouse WDPF control system. Analog and digital information are recorded on the VAX via the WDPF for over 540 points. These data are used to accumulate run times for the 620 pieces of equipment identified as part of reliability monitoring.

At periodic intervals (i.e., once per month), data from the Perform software identified in step 2 were collected along with the run time data in step 3. These data were transferred on floppy disk to an off-site EPRI contractor for analysis and comparison with the other demonstration programs.

Due to difficulties outside of the work completed at the Nucla CFB, the program was cancelled in late 1989. As a result, collection of run time data as part of step 3 was terminated. However, the PERFORM software for generating 


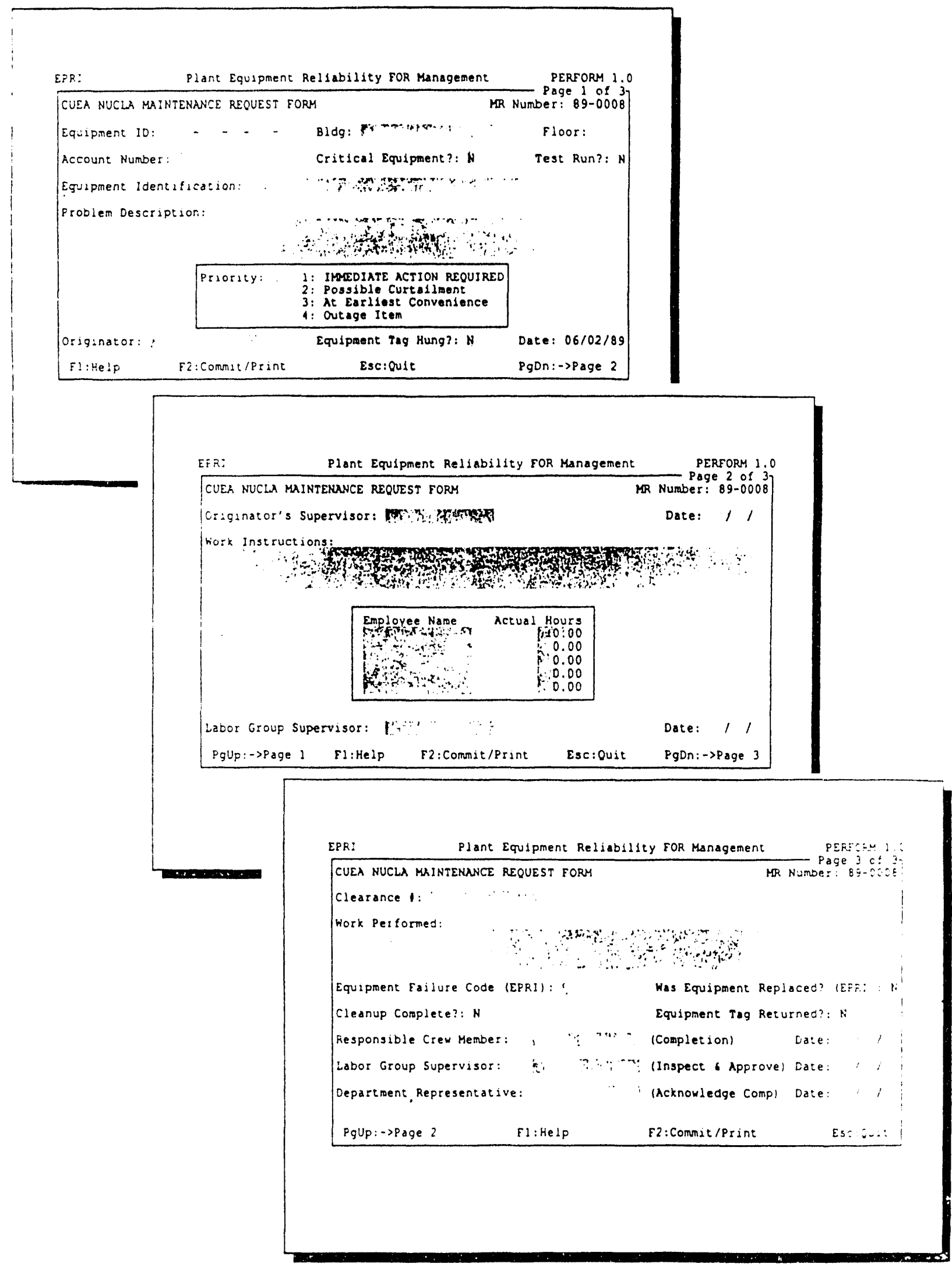

Figure 17-1. PEREORM Reliability Monitoring set-up sheets Required for Generating MWR's. 
maintenance work requests remains in use at Nucla and a substantial database is being generated. Although it will not be possible to calculate mean time to failure and repair for specific equipment components for comparisons to other plants, the frequency of failures for each equipment component at Nucla can be tracked. This will allow the following type of analyses to be performed:

1. Relative comparisons can be made between plant equipment areas. Equipment with the highest failure rates and/or maintenance requirements can be identified.

2. The effect of equipment upgrades on overall plant and component reliability can be assessed by comparing quarterly or annual "frequency of failure" charts and plant operating data.

3. Data can be used as a planning tool for maintenance outages. Equipment areas with the highest frequency of maintenance repair can be identified.

4. Prospective owners and designers of a plant can use the database as a means of selecting equipment components which provide a high level of overall equipment reliability and availability.

The 1989 annual report contains information on the frequency of failure for the coal and limestone feed systems for the period between september 1988 and September 1989. These data are not totally representative of normal plant operation because the information was collected before the completion of unit acceptance tests. During this period, a portion of the repair work was performed by the boiler vendor outside of normal plant maintenance work request system. A more reliable database will be generated for the 3 to 5 year period subsequent to the acceptance tests completed in october 1989. 
CUEA No.

$002409001494001 \mathrm{Cl}$ $002109001001001 \mathrm{cA}$ $002109001601001 \mathrm{cs}$ $002113001001001 \mathrm{CA}$ $002113001560001 \mathrm{CA}$ $002413001601001 \mathrm{CA}$ $002613001001001 \mathrm{cJ}$ $002113001222001 \mathrm{cl}$ $002413001851001 \mathrm{CA}$ $002413001183001 \mathrm{CA}$ $002113501222001 \mathrm{CA}$ $002413501851001 \mathrm{CA}$ $00241350122200 \mathrm{~s} \mathrm{C4}$ $002413501850001 \mathrm{cl}$ $002113501560001 \mathrm{C4}$ $002413501601001 \mathrm{cl}$ $002413501001001 \mathrm{ct}$ $002413501222002 \mathrm{ct}$ $002413501851002 \mathrm{Cl}$ $002413501850002 \mathrm{ct}$ $002413501222004 \mathrm{ct}$ $002601501001001 \mathrm{C}$ $002601501001002 \mathrm{~N}$ $002601501507001 \mathrm{C}$ $002601503545001 \mathrm{C}$ $002601511515001 \mathrm{C}$ $002601511515002 \mathrm{C}$ $002601511545003 \mathrm{Cl}$ $002601511545004 \mathrm{Cl}$ $002601503001001 \mathrm{C}$ $002601502545003 \mathrm{C}$ $002601502545003 \mathrm{C}$ $002601502587001 \mathrm{C}$ $002601502545004 \mathrm{C}$ $002601502545001 \mathrm{C}$ $002602002290001 \mathrm{CJ}$ $002602002290002 \mathrm{cJ}$ $002602001+94001 \mathrm{Cl}$ $002602001579002 \mathrm{C}$ $002602001579001 \mathrm{C}$ $002601508709004 \mathrm{cz}$ $002601508001004 \mathrm{C}$ $002601508582004 \mathrm{C2}$ $002601508709001 \mathrm{C2}$ $002601508001001 \mathrm{C}$ $002601508582001 \mathrm{C2}$ $002601508709002 \mathrm{cz}$ $002601508001002 \mathrm{C}$ $002601508582002 c 2$ $002601508709003 \mathrm{C2}$ $002601508001003 \mathrm{C}$ $002601508582003 \mathrm{CZ}$ $002602001852002 \mathrm{C}$ $002602001500002 \mathrm{C}$ $002602001001001 \mathrm{C}$ $002602001852001 \mathrm{C}$ $002602001500001 \mathrm{C}$ $002601511494001 \mathrm{CA}$ $002601514001001 \mathrm{C4}$ $002601514601001 \mathrm{C4}$ $002601503705001 \mathrm{C}$ $002601503705002 \mathrm{c}$ $002605509130001 \mathrm{C2}$ $002604506710001 \mathrm{C2}$ $002604506710002 \mathrm{C2}$ $002604506710003 \mathrm{c2}$ $002604506710004 \mathrm{C2}$ $002601516181001 \mathrm{C2}$ $002601516001001 \mathrm{C}$ $002601516181002 \mathrm{C2}$
EPRI No.

\author{
Description
}

02147010 OJ OL SERVICE WATER PIPING

0214701001 OI SERUICE WATER SYSTEM HISC SERVICE WATER VALVES, MISC

$02146010 \quad 06$ OI INST AIR SYS PIPES AND VLVS

202116010

02146010

02146002

02146010

02146010

02146010

02146010

02146010

02146010

02146010

202146010

02116010

02116010

02116010

02146010

02146010

02116010

02141611

02141611

02111611

02141409

02111409

02141409

02141409

02141409

02141107

02111405

02141405

02141211

02141404

02141406

02243402

02143401

02143610

02143213

02143213

02143243

02143243

02143243

02143243

02143243

02143243

02143243

02143243

02143243

02143243

02143243

02143243

$021+3104$

02143104

02143050

02143104

02143104

02141010

02141010

02144010

02110056

02140056

02141503

02145401

02145402

02145402

02145101

02149201

02149201

02149201
04 OI INSTR AIR RECEIVER TANKS

OS OI INSTR AIR SAPETY VALVES

O 1 OI INSTRUMENT AIR SYSTEM

O1 OI INSTR AIR COMPRESSOR IA

OI OI INSTR AIR COHPRESSOR IA MOTOR

02 OI INSTE AIR COMPRESSOR AFTER COOLER

O) OL SERVICE AIR COMPRESSOR $4 A$

O 3 O SERVICE AIR COMPRESSOR $1 A$ MOTOR

O3 OJ SERUICE AIR COMPRESSOR STANDBY

OJ OL SERVICE AIR COMPRESSOR STANDBY MTE

04 OI SERVICE AIR RECEIVER TANKS

05 OI SERVICE AIR SAFETY VALVES

06 OI SERVICE AIR SYS PIPES AND VLVS

03 O2 SERVICE AIR COMPRESSOR $1 B$

0302 SERVICE AIR COMPRESSOR 10 MOTOR

OJ 01 SEAVICE AIA COMPRESSOR EMERG MTR

O3 OL SERUICE AIR COMPRESSOR EMERGENCY

Ol OI BOILER STEAM DRUM, MISC

OJ OI BOILER STM DRUM, INTERNALS

02 O1 BOILER STH DRUM, SAFETY VALVES

O3 OL BOILER WATER COOLED HANGER RODS

01 O 1 BOILER HATER HALL 4 A TUBES

0102 BOILER WATER WALL 18 TUBES

02 OI BOTLER WTR WALL IA HNGR TUBES

0202 BOILER HTR WALL IB HNGR TUBES

01 O ECONOMIZER TUBES, CONV. PASS

OS OL SUPEAHEAT IA TBS,SEC,RAD.FRBD

0502 SUPERHEAT $4 B$ TBS, SEC,RAD.FRED

Ol OL SUPERHEAT SAFETY VALVES

O 1 OL SUPERHEAT TUEES, FNSHG, CON.PASS

01 OL SUPERHEAT TUBES, PRI, CONV. PASS

01 O2 TEDWATER HTR 4D, HIGH PRESS

01 OLEEDATER HTR IE, HIGH PRESS

01 OI FEDHATER PIPING

02 OI FEEDWATER REG VALVE-STARTUP 3*

O 1 FEEDWTER REGULATOR VLY - "

O4 ATTEMPERATOR LD, FLOW ELEMENT

04 ATTEHPERATOR ID, MISC

O4 ATTEMPERATOR ID, SPRAY VALVE

OL ATTEMPERATOR IA, FLOW ELEMENT

OL ATTEHPERATOR IA, MISC

O 1 ATTEMPERATOR 4A, SPRAY VALVE

02 ATTEMPERATOR 4B, FLOW ELEMENT

02 ATTEMPERATOR $4 B$, MISC

02 ATTEMPERATOR $4 B$, SPRAY VALVE

03 ATTEMPERATOR IC, FLOW ELEMENT

OJ ATTEMPERATOR IC, MISC

03 ATTEMPERATOR IC, SPRAY VALVE

02 BOILER PEED PUMP $1 B$ MOTOR

02 BOILER PEED PUMP $1 B$, MISC

O 1 FEDWATER SYSTEM INSTR. CNTRL

01 BOILER FEED PUMP IA MOTOR

01 BOILER PEED PUMP IA, MISC

01 PROPANE TUEL PIPING

01 PROPAHE FUEL SYS - MISC

01 PROPANE TUEL VALVES

O3 GAS AHALYZER-O2, ECON IN EAST

04 GAS ANALYZER-O2, ECON IN WEST

O 1 BAGHOUSE BAL DFT DMPR (OLD/W1)

01 BTM ASH CLR IA INLET AERATION

02 BTH ASH CLR 4B INLET AERATION

O3 BTA ASH CLR IC INLET AERATION

04 BTH ASH CLR ID INLET AERATION

01 RECYCLE LOOP SEAL IA AIR NZLS

05 OL RECYCLE LOOP SEAL IA FLUID SYS

02 O2 RECYCLE LOOP SEAL IB AIR NZLS
TAG No.

CLT 62

CLT62

CLT62

CPTSO

CPT 50

CPT50

CPTSO

C2S1

C2S1

C2S1

C25 2

C2S 2

C2s $2,3,51$

$\operatorname{czs} 2,3,51$

c252, 3, 51

c2s 2, 3, 51

c252,3,51

C2S 3

C253

C2S51

CZS5I

DPT 1

DPT 1

DPT 1

DPT 1

DPT 1

DPT1

DPT 1

DPT 1

DPT 1

DPT 1

DPT 1

DPT 1

DPT 1

DPT 1

EPT 3

EPT 3

EPT 3

EPT 3

EPT 3

ETCVIO

ETCVIO

ETCVIO

ETCV 7

ETCV 7

ETCV 7

ETCV

ETCV8

ETCV8

ETCV 9

ETCV 9

ETCV 9

E251

E2S1

E2S1, 2

E252

E2S 2

GASFLOW

GASFLOW

GASTLOW

GAT9A

GAT9B

GMT 20

GPT 4

GPT 4

GPT 4

GPT 4

GPT 4

GPT 1

GPT 
CUEA No.

$002601516001002 C$ $002603509266001 \mathrm{CA}$ $002601510101001 \mathrm{~N}$ $002601510181002 \mathrm{~N}$ $002601510263001 \mathrm{~N}$ $002601510263002 \mathrm{~N}$ $002603509709001 \mathrm{C2}$ $002603509709002 \mathrm{C2}$ $002603509228001 \mathrm{C2}$ $002603509228002 \mathrm{C2}$ $002603509130001 \mathrm{C2}$ $002603509130002 \mathrm{C2}$ $002603509250001 \mathrm{C}$ $002603509516001 \mathrm{C}$ $002603509516002 \mathrm{C}$ $002603509860001 C$ $002603509562001 \mathrm{C}$ $002603509852001 \mathrm{C}$ $002606531220004 \mathrm{C}$ $002606531228003 c$ $002603509340001 \mathrm{C}$ $002603007290001 \mathrm{C}$ $002408509228001 \mathrm{C}$ $002603001266001 \mathrm{CA}$ $002408509228003 \mathrm{~N}$ $002603001250001 \mathrm{C}$ $002603001516001 \mathrm{C}$ $002603001516002 \mathrm{C}$ $002603001860001 \mathrm{C}$ $002603001560001 \mathrm{C}$ $002603001560002 \mathrm{C}$ $002603001852001 \mathrm{C}$ $0026065.31220002 \mathrm{C}$ $002606531228001 \mathrm{C}$ $002603001341001 \mathrm{C}$ $002603004001,01 \mathrm{C2}$ $002603511266001 \mathrm{CA}$ $002603511709001 \mathrm{Cl}$ $002603511709002 \mathrm{C2}$ $002603512228001 \mathrm{C2}$ $002603511228002 \mathrm{C2}$ $002603511130001 \mathrm{C2}$ $002603511130002 \mathrm{C2}$ $002606504228006 \mathrm{c}$ $002603511250001 \mathrm{C}$ $002603511516001 \mathrm{C}$ $002603511860001 \mathrm{c}$ $002603511852001 \mathrm{C}$ $002606531228005 \mathrm{C}$ $002603511341001 \mathrm{C}$ $002601516341001 \mathrm{C}$ $002601516851001 \mathrm{c}$ $002601516250001 \mathrm{C}$ $002601516311002 \mathrm{C}$ $002601516851002 \mathrm{C}$ $002601516250002 \mathrm{c}$ $002604506130002 \mathrm{C2}$ $002604506263001 \mathrm{Cl}$ $002604506263002 \mathrm{Cl}$ $002604506263003 \mathrm{C2}$ $002601506263004 \mathrm{C2}$ $002601506181001 \mathrm{CL}$ $002604506261001 \mathrm{C2}$ $002604506181002 \mathrm{c} 2$ $002604506264002 \mathrm{C2}$ $002601506101003 \mathrm{C2}$ $002604506261003 \mathrm{C}$ $002604506181004 \mathrm{C2}$ $002604506264004 \mathrm{C2}$ $002604506341001 \mathrm{C}$
EPRI No.

\author{
Description
}

02149201 OS 02 BECYCLE LOOP SEAL AB FLUID SYS

02141610 OL O1 BOILER DUCT - PRIMARY AIR

0214162003 OI DISTR PLATE 4A AIR NOZZLES

0214162003 O2 OISTR PLATE 18 AIR NOZZLES

02141620 OL OI DISTRIBUTOR PLATE 1A, MISC

02141620 O1 O2 DISTRIBUTOR PLATE 1B, MISC

02141621 O1 OI PA AA AIR FOIL, 1A

02141621 OL O2 PA AA AIR FOIL, 18

0214162202 OI PA AA DAMPER AUTO CONTRLR, 4A

021416220202 PA IA DAMPER AUTO CONTRLR, 1 B

02141622 O1 OI PA 4A DAMPER, 4A

0214162201 O2 PA 4A DAMPER, 4B

0214111002 O1 PA 1A PAN COUPLING

02141140 O4 O1 PA AA FAM DC REACTOR, 1A

02141140 O4 02 PA 1A FAN DC REACTOR, 18

02141140 O 7 OL PA IA FAN ISOLATION TRANSFORMR

02141140 O9 OI PA IA FAN LUBE OIL COMSOLE

02141140 11 OL PA IA FAN MOTOR

0214114013 O1 PA 1A FAN VARI SD DR CNTR-STRT

0211114012 OL PA 1A FAN VARI SPD DR CNTR-RUN

02141140 O1 01 PA 1A FAM, MISC

0214140401 OI AIR PREHEATER - TUBULAR

02140003 O1 OI BOILER AIR FLOW/DRAFT CONTRL

2141615 O1 01 BOILER DUCT - FLUE GAS

02140005 OL OI COMBUSTION CONTROL

0214110202 O1 ID FAN 4A COUPLING

02141102

02141102

02141102

02141102

02141102

02141102

$021+1102$

02141102

02141102

02141613

02141610

02111623

02141624

02111624

02141624

02111624

02141624

0214114

02141141

02111142

02141141

02141111

02141111

02141141

02149127

02149127

02149127

02149127

02149127

02149127

02145401

02145401

02145401

02145101

02145401

02145401

02145401

02145401

02145401

02145401

02145101

02215101

02145101

02145101
04 OI ID FAN 1A DC REACTOR, 4A

04 O I D FAN IA DC REACTOR, 4B

07 I ID FAN IA ISOLATION TRANSFORMR

10 OI ID FAN 4A LUBE OIL PUMP

101 ID FAN IA MOTOR

13 OI ID FAN IA VARI SD DR CNTR-STRT

1201 ID PAN AA VARI SPD DR CNTR-RUN

$0 \perp$ I ID FAN IA, MISC

01 OI STACK

0201 BOILER DUCT - SECONDARY AIR

01 OI SA IA AIA FOIL IA

01 OZ SA IA AIR FOIL 18

02 OI SA AA DAMPER AUTO, IA

02 O SA IA DAMPER AUTO, IB

01 OI SA IA DAMPER, IA

0102 SA AA DAMPER, 18

14 OI SA IA FAN BACXUP STARTER

02 OL SA IA FAN COUPLING

04 OL SA AA FAN DC REACTOR

0701 SA IA FAN ISOLATION TRANSFORMR

11 OL SA IA PAN MOTOR

12 OI SA AA FAN VARI SPD DR CONTR

OI 01 SA IA FAN, MISC

O1 RECYCLE HP PLUID BLOWER AA

OI RECYCLE HP PLUID BLOWER AA MTR

01 RECYCLE HP ILUID BLWR IA CPLNG

02 RECYCLE HP PLUID BLOWER AB

02 RECYCLE HP PLUID BLOWER 1 B HTR

02 RECYCLE HP PLUID BLWR 18 CPLNG

02 BOH ASH CLR 1 A AIR CNTRL DHPR

O1 BOTTOM ASH CLR IA DISTR PLATE

02 BOTTOM ASH CLR 1 B DISTR PLATE

OJ L JTTOM ASH CLR IC DISTR PLATE

O4 DOTTOM ASH CLR 1D DISTR PLATE

O 2 BOTTOM ASH COOLER IA AIR NZL

O1 DOTTOM ASH COOLER IA DRAIN

02 BOTTOM ASH COOLER IB AIR NZL

02 BOTTOM ASH COOLER IB DRAIN

OJ BOtTOM ASH COOLER IC AIR NZL

OJ BOTTOM ASH COOLER IC DRAIN

O4 BOTTOM ASH COOLER ID AIR NZL

OI BOTTOM ASH COOLER ID DRAIN

01 BOTTOM ASH COOLING PAN
08 O I D FAN 4A LUBE OIL CONSOLE
TAG No.

GPT 1

GWM 325

GWM3 25

GWM 325

GWM 25

GWM3 25

GWM 325

GWM3 25

GWM3 25

GWM32S

GWM3 25

GWM3 25

GWM3 25

GWM3 25

GWM 25

GWM3 25

GWM 25

GWM3 25

GWM3 25

GWM 325

GWM 25

GWM3 27

GWM 21

GWM3 27

GWM3 27

GWM 327

GWM3 27

GWM 27

GWM 27

GWM3 27

GWM 327

GWM 327

GWM 327

GWM 27

GWM 327

GWM 327

GZS 2

GZS 2

6252

G 252

O2S 2

GZS2

GZS 2

G2S 2

GZS2

GZS 2

OZS 2

G2S 2

GIS2

OZS 2

G2S1A

GesiA

GZS4A

C254B

G2548

G2548

G255

C2S 5

G255

0255

02s5

G255

GZSS

6255

6255

GIS5

G255

G2S5

GZS 5

G2S5 
CUEA No.

$002504506250001 \mathrm{C}$ $002604506851001 \mathrm{c}$ $002604501351001 \mathrm{C}$ $002604501351002 \mathrm{C}$ $002604501351003 \mathrm{C}$ $002604501351004 c$ $002604506130001 \mathrm{C2}$ $002604506709001 \mathrm{c} 2$ $002604506709002 \mathrm{cz}$ $002604506130003 \mathrm{C} 2$ $002604506709003 \mathrm{C2}$ $002604506130004 \mathrm{C2}$ $002604506709004 \mathrm{C} 2$ $002604506374001 \mathrm{C}$ $002604506251001 \mathrm{~N}$ نิ03 $2604506374002 \mathrm{C}$ $002604506251002 \mathrm{~N}$ $002604506374003 \mathrm{C}$ $002604506251003 \mathrm{~N}$ $002604506374004 \mathrm{C}$ $002604506251004 N$ $002604506378001 \mathrm{C2}$ $002604506378003 \mathrm{C2}$ 002604506378002 C2 $002604506378004 \mathrm{c2}$ $002604505850001 \mathrm{C}$ $002604505850002 \mathrm{C}$ $002604505850003 \mathrm{C}$ $002604505850004 \mathrm{C}$ $002602502290001 \mathrm{CJ}$ $002602502290002 \mathrm{cJ}$ $002602503290001 \mathrm{CJ}$ $002602501001001 \mathrm{C3}$ $002602501510001 \mathrm{CJ}$ $002602501050001 \mathrm{cJ}$ $002602501510002 \mathrm{CJ}$ $002602501850002 \mathrm{CJ}$ $002614501001001 \mathrm{C}$ $002602501397001 \mathrm{CJ}$ $002602002495001 \mathrm{c}$ $002602502495001 \mathrm{c}$ $002600104598001 \mathrm{C}$ $002900106495001 \mathrm{C}$ $002600106581001 \mathrm{~N}$ $002600100001001 \mathrm{C2}$ $002701001001001 \mathrm{CJ}$ $002700500001001 \mathrm{C}$ $002606501001001 \mathrm{CA}$ $002801001001001 \mathrm{CJ}$ $002800500001002 \mathrm{c}$ $002706501001001 \mathrm{CA}$ $002901001001001 \mathrm{c} 3$ $002900500001003 \mathrm{C}$ $002806501001001 \mathrm{CA}$ $002702501397001 \mathrm{cJ}$ $002700104590001 \mathrm{C}$ $002600106495001 \mathrm{CA}$ $002700106581001 \mathrm{C}$ $002700100001001 \mathrm{C2}$ $002802501397001 \mathrm{C} 3$ $002800104598001 \mathrm{C}$ $002700106495001 \mathrm{C}$ $002800106581001 \mathrm{~N}$ $002800100001001 \mathrm{C2}$ $002902501397001 \mathrm{CJ}$ $002900104598001 \mathrm{C}$ $002800106495001 \mathrm{CA}$ $002900106501001 \mathrm{~N}$ $002900100001001 \mathrm{C2}$ $002702502290001 \mathrm{CJ}$
EPRI No.

Description

TAG No.

02145102 OL 02 BOTTOM ASH COOLING PAN CPLNG 02145101 OL OJ BOTTOM ASH COOLING PAN MOTOR 02115665 OI OL BOTTOM ASH ROTARY AIR LOCX AA 021456650102 BOTTOM ASH ROTARY AIR LOCX 4B 02115665 OI 03 BOTTOM ASH ROTARY AIR LOCX ir. 0214566501 O4 BOTTOM ASH ROTARY AIR LOCX 4D 021451010201 BTM ASH CLR AA AIR CNTRL DMPR 02145101 O3 OL BTM ASH CLR IA AIR FLOW SNSR 0214540103 O2 BTM ASH CLR AA AIR FLOW SNSR 021454010203 BTK ASH CLR 1C AJK CNTAL DMPR 0214540103 OJ BTM ASH CLR IC AIR ELOW SNSR 0214540102 OL BTM ASH CLR AD AIR CNTRL DHPR 0211540103 O1 BTM ASII CLR TD AIR FLOW SNSR 0214540109 OI BTM ASH COOLER AA SLIDE GATE 02145101 02145101 02145101 02145101 02145402 02145401 02145401 02115661 02145661 $021+5661$ 02115661 02145665 02145665 02145665 02115665

02143402

02143402

02143110

02148110

02143110

02143110

02143110

02143110

02140648

02148410

02143401

01243402

02142329

02142329

02112329

02112329

02112330

02112330

02142710

02112330

02142330

02142710

02142330

02142330

02142710

02140110

02142329

02142329

02142323

02142329

02140410

02142329

02142329

02142329

02142329

02148410

02112329

02142329

02142329

02142329

02143102
01 BTM ASH COOLER AA, MISC

02 BTM ASH COOLER $1 B$ SLIDE GATE

02 BTM ASH COOLER 4B, MISC

OJ BTM ASH COOLER IC SLIDE GATE

03 BTM ASH COOLER IC, MISC

O4 BTM ASH COOLER 1D SLIDE OATE

O1 BTM ASH COOLER 1D, MISC

OI ETM ASH HPR AA COLD DIV GATE

01 BTM ASH HPR 4A HOT DIV GATE

02 BTM ASH HPR 1 B COLD DIV GATE

02 BTM ASH HPR 1 B HOT DIV GATE

OI BTM ASH ROTARY AIR LCK IA MTR

02 BTM ASH ROTARY AIR LCK 4 B MTR

O 3 BTM ASH ROTARY AIR LCK IC MTR

O1 BTM ASH ROTARY AIR LCK ID MTE

02 FEDWATER HTR AA, LOW PRESS

O 1 PEEDWATER HTR 18, LOW PRESS

O4 DEAERATOR, (HEATER (C) UNIT ।

02 SONDENSER, UNIT 1

07 HOTWELL PUMP IA

07 HOTWELL PUMP IA MOTOR

O. HOTWELL PUMP 1B

08 HOTWELL PUMP 48 MOTOR

01 AUX STMIIS $002614501 \times \times \times \times \times \times \times)$

O4 CONDENSER 4 HTWLL (DRN RCVR)

01 FEEDWATER HTR, HP-EXTR PPING

OI FEEDWATER HTR, LP EXTR PPING

O TURBINE CONTROL VALUES, UNIT 1

O4 TURBINE EXT PIPING, UNIT 1

04 TURBINE EXTRACT VLUS, UNIT ।

O4 TURBINE, MISC UNIT 1

OL GEMERATOR EXCITER, UNIT I

01 GENERATOR UNIT 1 , MIS

O I TRANSFORMER, UNIT I GENERATOR

02 GENERATOR EXCITER, UNIT 2

02 GENERATOR UNIT 2 , MISC

02 TRANSFORMER, UNIT 2 GENERATOR

OJ GENERATOR EXCITER, UNIT 3

OJ GENERATOR UNIT 3, MISC

O 3 TRANSFORMER, UNIT J GENERATOR

O1 COHDENSER 1 HTWLL (DRN RCVR)

O 1 TURBINE CONTROL VALVES, UNIT 1

01 TURBINE EXT PIPING, UNIT 1

O I TURBINE EXTRACT VLVS, UNIT 1

01 TURBINE, MISC UHIT 1

02 CONDENSER 2 HTWLL (DRN RCVR)

02 TURBINE CONTROL VALVES, UNIT 2

02 TURBINE EXT PIPING, UNIT 2

02 TURAYNE EXTRACT VLVS, UNIT 2

02 TURBINE, MISC UNIT 2

03 CONDENSER 3 HTWLL (DRN RCVR)

O3 TURAINE CONTROL VALVES, UNIT 3

03 TURBINE EXT PIPING, UNIT 3

OJ TURBINE EXTRACT VLUS, UNIT 3

OJ TURBINE, MISC UNIT 3

OB FEEDWTER HTR IA, LOW PRESS
G255

G2S5

G2S5

c255

Giss

G2S5

G2SS

G255

G2S 5

0255

GZS5

G2S5

GZS5

G2S 5

G2S5

G2S5

G2S5

G25 5

G255

6255

G2S 5

G2S5

6255

G255

G255

G255

G2S 5

G2S5

G2S5

HFT 3

H.T 3

HLT3

HPT 72

HZS 1

HZS 1

HZS 2

HZS 2

JPT 1

KPT 2

KPT 2

XPT 2

KPT 2

KPT 2

XPT 2

KPT 2

LMWI

LMW 1

LMW 1

LMW 2

LMW 2

LMW 2

LMW 3

LMW 3

LMW 3

LPT 64

LPT 64

LPT 64

LPT 64

LPT6 1

LPT 65

LPT 65

LPT 65

LPT 65

LPT 65

LPT 66

LPT 66

LPT 66

LPT 66

LPT 66

NPT105 
CUEA No.

$002702502290002 \mathrm{cJ}$ $002402502290001 \mathrm{cJ}$ $002802502290002 \mathrm{cJ}$ $002902502290001 \mathrm{cl}$ $002902502290002 \mathrm{cJ}$ $002702503290001 \mathrm{CJ}$ $002802503290001 \mathrm{cJ}$ $002902503290001 \mathrm{CJ}$ 002702501001001 002802501001001 002902501001001 $002702501510001 \mathrm{cJ}$ $002702501850001 \mathrm{CJ}$ $002702501510002 \mathrm{cJ}$ $002702501850002 \mathrm{cl}$ $002702503850001 \mathrm{CJ}$ $002702503500001 \mathrm{c3}$ $002802501510001 \mathrm{C3}$ $002802501850001 \mathrm{CJ}$ $002802501510002 \mathrm{CJ}$ $002802501050002 \mathrm{CJ}$ $002802503850002 \mathrm{CJ}$ $002802503500002 \mathrm{cJ}$ $002902501510001 \mathrm{cJ}$ $002902501850001 \mathrm{cJ}$ $002902501510002 \mathrm{c}$ $002902501850002 \mathrm{cl}$ $002902503150003 \mathrm{cJ}$ $002902503500003 \mathrm{cJ}$ $002601511517001 \mathrm{C}$ $002601511570001 \mathrm{C}$ $002601515517001 \mathrm{C2}$ $00260151553001 \mathrm{C}$ $002616008001001 \mathrm{C2}$ $002616008001001 \mathrm{C2}$ $002616008001002 \mathrm{cz}$ $002604506517001 \mathrm{c} 2$ $002604506517002 \mathrm{C2}$ $002601510517001 \mathrm{~N}$ $002601516814001 \mathrm{C}$ $002601516517003 \mathrm{c2}$ $002601516135001 \mathrm{C}$ $002601511517002 \mathrm{C}$ $002601515517002 \mathrm{c2}$ $002601515530002 \mathrm{C}$ $002604506517003 \mathrm{cz}$ $002604506517004 \mathrm{C2}$ $002601510517002 \mathrm{~N}$ $002601516844002 \mathrm{C}$ $002601516517004 \mathrm{Cl}_{2}$ $002601516435002 \mathrm{C}$ $002601514190005 \mathrm{C}$ $002601511190006 \mathrm{C}$ $002601514190008 \mathrm{C}$ $002601514190007 \mathrm{C}$ $002601514190001 \mathrm{C}$ $002601511190002 \mathrm{C}$ $002601514190003 \mathrm{C}$ $002601514190004 \mathrm{C}$ $002605506340001 \mathrm{C}$ $002605505950002 \mathrm{C}$ $002605505341001 \mathrm{~A}$ 002605505850004 $002605505341002 \mathrm{C}$ $002605505850001 \mathrm{C}$ $002605505341003 \mathrm{~N}$ $002605505850002 \mathrm{~N}$ 002605505341004 $002605505850003 N$ $002603502350002 \mathrm{C}$
EPRI No.

Description

TAG No.

0211310202 O7 PEEDWATER HTR 18, LOW PRESS 0214340201 OG FEEDWATER HTR 2A, LOW PRESS 02143402 O1 OS FEEDWTER HTR 2B, LOW PRESS 02143402 O1 O4 PEEDWATER HTR 3A, LOW PRESS 02143402 O1 O3 PEEDWATER HTR 3B, LOW PRESS 02113410 O1 OL DEAERATOR, (HEATER IC) UNIT 1 02143110 OI O2 DEAERATOR, (HEATER 2C) UNIT 2 02143410 O1 O3 DEAERATOR, (HEATER 3C) UNIT J UNIT I CONDENSER

UNIT 2 CONDENSER

UNIT 3 CONDENSER

02143110 02143110 02113110

02113110

02113120

02143120

02143110

02143110

02143110

02143110

02143120

02143120

02143110

02143110

02143110

02143110

02143120

02143120

02141400

02111100

02111801

02111802

02111400

02141400

02141400

02145401

02145401

02141620

02149201

02149201

02149201

02141400

02141001

02141801

02145401

$02145+01$

02141620

02149201

02149201

02249201

02142662

0214166

02111662

0214166 :

02141662

02141662

02111662

02141662

02141503

02141503

02141503

02141503

02141503

02111503

02141503

02111503

02111503

02141503

02144621
OI HOTWELL PUMP IA

02 OI HOTWELL PUMP IA MOTOR

02 HOTWELL PUMP 18

02 HOTWELL PUMP 1 B MOTOR

02 O1 CONDENSATE FORW PUMP 1A MTR

O \& CONDENSATE FORH PUMP IA, MISC

03 HOTWELL PUMP $2 A$

03 HOTWELL PUMP 2A MOTOR

04 HOTWELL PUMP 28

O4 HOTWELL PUMP 2B MOTOR

02 CONDENSATE TORW PUMP $2 A$ MTR

02 CONDENSATE TORH PUMP $2 A$, MISC

OS HOTWELL PUMP $3 A$

OS HOTWELL PUMP JA MOTOR

06 HOTWELL PUMP $3 B$

06 HOTWELL PUMP 38 MOTOR

03 CONDENSATE FORW PUMP 3A MTR

03 CONDENSATE TORW PUMP 3A, MISC

OL BOILER BED zOME IA RERRACTORY

Ol BOILER CASING

Ol BOILEA CYCLONE AA REFRACTORY

O 1 BOILER CYCLONE, COMB IA

OI BOILER TRAMING

01 BOILER INSULATION

01 BOILER LAGGING

01 BTH ASH COOLER AA REPRACTORY

02 BTM ASH COOLEH 4 B REFAACTORY

OI DISTRIBUTOR PLT COMB IA REFRCT

01 RECYCLE LOOP SEAL IA EXP JNT

01 RECYCLE LOOP SEAL IA REFRCTRY

O1 BECXCLE LOOP SEAL, COMB AA

02 BOILER BED ZONE 1 B REPRACTORY

02 BOILER CYCLONE AB REPRACTORY

02 HOILEK CYCLONE, COMB 18

O3 BTM ASH COOLER IC REFRACTORY

O4 BTM ASH COOLER 1D REPRACTORY

02 DISTRIBUTOR PLT COMB 1 B REFRCT

02 RECYCLE LOOP SEAL $4 B$ EXP JNT

O 2 RECYCLE LOOP SEAL 40 REERCTRY

02 RECYCLE LOOP SEAL, COMB AB

OS BURNER, START-UP, IE

O 6 BURMER, START-UP, IF

O1 BURNER 1A; PRIMARY AIR DUCT

Q2 BUANER 1B, PRIMARY AIR DUCT

O1 BURHER, START-UP, IA

02 BURAER, START-UP, 4

03 BURAER, START-UP, IC

O4 BURNER, START-UP, ID

O1 BAGHOUSE II PURGE AIR TAN

O2 BAGHOUSE II PURGE AIR IAN MTR

O4 BAGHOUSE II DEFLATE AIR FAN

O4 BAGHOUSE 14 DEFLATE FAN MOTOR

01 BAGHOUSE I DEFLATE AIR FAN

01 BAGHOUSE 1 DEFLATE TAN MOTOR

02 BAGHOUSE 12 DEPLATE AIR FAN

02 BAGHOUSE 22 DEPLATE PAN MOTOR

O3 BAGHOUSE IJ DEFLATE AIR FAN

03 BAGHOUSE IJ DEPLATE PAN MOTOR

02 COAL TEEDER $4 B$ GRAVAMTRIC MISC
NTT105

NFT 106

NTT106

MFT 107

MET 107

NLT50

NLT63

NLT68

NPT 108

NPT 109

NPT 110

M2S11

Mrsil

azs 12

MZS12

M2S13

N2S13

N2S21

NZS21

NZS22

UzS 22

N2S 23

N2S 23

N2S31

N2S31

MZS 32

N2S 2

N2S 33

N2S3 3

$0001 \times 195$

$0001 \times 195$

$0001 \times 195$

$0001 \times 195$

$0001 \times 195$

$0001 \times 195$

$0001 \times 195$

$0001 \times 195$

$0001 \times 195$

$0001 \times 195$

$0001 \times 195$

$0001 \times 195$

$0001 \times 195$

$0003 \times 115$

$0003 \times 115$

$0003 \times 115$

$0003 \times 115$

$0003 \times 115$

$0003 \times 115$

$0003 \times 115$

$0003 \times 115$

$0003 \times 115$

OPT10

OrT 12

OrT14

OrT 16

OFT 2

OrT 4

ort 6

ort8

PSWI 71

PSWI 71

PSWI 72

PSWI 72

PSWOLO

PSWOLO

PSWOL1

PSWO11

PSWOL 2

PSWO12

QFT 1 
CUEA No.

$002603502850002 \mathrm{CA}$ $002603502850008 \mathrm{C}$ $002603502370002 \mathrm{C2}$ $002603502510002 \mathrm{C}$ $002603502377002 \mathrm{C}$ $002603502220002 \mathrm{C}$ $002603502351002 \mathrm{C}$ $002603502350003 \mathrm{C}$ $002603502850003 \mathrm{CA}$ $002603502850009 \mathrm{C}$ $002603502378003 \mathrm{C2}$ $002603502540003 \mathrm{C}$ $002603502377003 \mathrm{C}$ $002603502228003 \mathrm{C}$ $002603502351003 \mathrm{C}$ $002603502244003 \mathrm{C}$ 002603502850015 $002603502241001 \mathrm{C}$ $002603502050013 \mathrm{C}$ $002603502350001 \mathrm{C}$ $002603502850001 \mathrm{CA}$ $002603502850007 \mathrm{C}$ $002603502378001 \mathrm{Cl}$ $002603502540001 \mathrm{C}$ $002603502377001 \mathrm{C}$ $002603502228001 \mathrm{C}$ $002603502351001 \mathrm{C}$ $002603502244004 \mathrm{C}$ $002603502850016 \mathrm{C}$ $002603502244002 \mathrm{C}$ $002603502850014 \mathrm{C}$ $002603502350004 \mathrm{C}$ $002603502850004 \mathrm{CA}$ $002603502050010 \mathrm{C}$ $002603502378004 \mathrm{C2}$ 002603502540004 $002603502377004 \mathrm{c}$ $002603502228004 \mathrm{C}$ $002603502351004 \mathrm{C}$ $002603502350006 \mathrm{C}$ $002603502850006 \mathrm{cA}$ $002603502850012 \mathrm{C}$ $002603502378006 \mathrm{C2}$ $002603502540006 \mathrm{C}$ $002603502377006 \mathrm{C}$ $002603502228006 \mathrm{C}$ $002603502351006 \mathrm{C}$ $002603502350005 \mathrm{C}$ $002603502850005 \mathrm{cs}$ $002603502050011 c$ $002603502378005 \mathrm{C2}$ $002603502540005 \mathrm{C}$ $002603502377005 \mathrm{C}$ $002603502220005 \mathrm{C}$ $002603502351005 \mathrm{C}$ $002601503705003 \mathrm{C}$ $002601503705004 \mathrm{C}$ $002606001352002 \mathrm{c}$ $002606030529002 \mathrm{Cl}$ $002606030378002 \mathrm{C}$ $002606030228002 \mathrm{C}$ $002606030350002 \mathrm{C}$ $002606030850002 \mathrm{C}$ $002606030245002 \mathrm{C} 4$ 002606001352001 $002606030529001 \mathrm{C} 2$ $002606030378001 \mathrm{C}$ $002606030220001 \mathrm{C}$ $002606030350001 \mathrm{C}$ $002606030850001 \mathrm{C}$
EPRI No.

Description

TAG No.

0214162102 O2 COAL FEEDER 10 GRAVAATRIC MTR 0214162202 O2 COAL TEEDER IS MOTOR - ROTARY

0214462601 O2 COAL FEEDER 1 B ROTARY ISO GATE 021416230102 COAL FEEDER 4B SCALE

0214162401 O2 COAL FELDER 1 B SLIDE GATE

0214462501 O2 COAL FEEDER 1B SPEED CONTROL

0214462201 O2 COAL FEEDER 1B - ROTARY MISC

02144621

02144621

02144622

02141626

02141623

02141624

02141625

02144622

02144630

02144630

02144630

02144621

02144621

02114622

02144626

02144623

02144624

02144665

02144622

02144630

02144630

02144630

02144630

02144621

02144621

02144622

02141626

02144623

02144624

02141625

02144622

02144621

02141621

02144622

02141626

02144623

02144624

02144625

02144622

02141621

02141621

02144622

02111626

02144623

02184624

02141625

02114622

02110057

02140057

02111665

02144665

02111665

02141665

02111665

02144664

02141665

02114665

02144665

02141665

02141665
03 COAL FEEDER IC GRAVAMTAIC MISC

03 COAL FEEDER IC GRAVAMTRIC MTR

O3 COAL FEEDER IC MOTOR - ROTARY

O3 COAL TEEDER IC ROTARY ISO GATE

O3 COAL TEEDER IC SCALE

03 COAL FEEDER IC SLIDE GATE

O3 COAL FEEDER IC SPEED CONTROL

03 COAL FEEDER IC - ROTARY MISC

O I COAL CONVEYOR IA HORIZ MISC

COAL CONVEYOR AA HORIZ MTR

02 COAL CONVEYOR $4 \lambda$ INCLINED MISC

02 COAL CONVEYOR AA INCLINED MTR

OI COAL TEEDER IA GRAVAMTRIC MISC

OI COAL FEEDER AA GRAVAMTRIC MTR

01 COAL FEEDER 4A MOTOR - ROTARY

OI COAL PEEDER AA ROTARY ISO GATE

OI COAL FEEDER 4A SCALE

O I COAL FEEDER AA SLIDE GATE

OI COAL FEEDER AA SPEED CONTROL

OI COAL FEEDER IA - ROTARY MISC

O 3 COAL CONVEYOR TD HORIZ MISC

O3 COAL CONVEYOR 1D HORIZ MTR

O4 COAL CONUEYOR ID INCLINED MISC

O4 COAL CONVEYOR 4D INCLINED MTR

04 COAL PEEDER ID GRAVAMTRIC MISC

O4 COAL TEEDER ID GRAVAMTRIC MTR

O4 COAL FEEDER ID MOTOR - ROTARY

O4 COAL FEEDER ID ROTARY ISO GATE

O4 COAL PEEDER ID SCALE

O4 COAL TEEDER ID SLIDE GATE

O4 COAL TEEDER ID SPEED CONTROL

O4 COAL FEEDER 4D - ROTARY MISC

06 COAL TEEDER IP GRAVAMTRIC MISC

06 COAL FEEDER IF GRAVAMTRIC MTR

06 COAL TEEDER IF MOTOR - ROTARY

O6 COAL FEEDER IF ROTARY ISO GATE

O6 COAL FEEDER IP SCALE

06 COAL FEEDER IF SLIDE GATE

O6 COAL FEEDER AF SPEED CONTHOL

06 COAL FEEDER TF - ROTARY MISC

O5 COAL PEEDER IE GRAVAMTRIC MISC

O5 COAL FEEDER IE GRAVAMTRIC MTR

OS COAL FEEDER IE MOTOR - ROTARY

O5 COAL FEEDER IE ROTARY ISO GATE

O5 COAL TEEDER IE SCALE

01 OS COAL FEEDEA IE SLIDE GATE

01 OS COAL PEEDER IE SPEED CONTROL

01 OS COAL FEEDER IE - ROTARY MXSC

01 OI GAS ANALYZER-SO2, ECON 4A OUT

02 GAS AHALYZER-SO2, ECON 4 B OUT SORB SILO IB VIBR BIH DISCH

O4 OI SORBENT LOS WT FDR 4 B SCTR PLT

02 SORBENT LOS WT POR IB SLD GATE

02 SORBENT LOSS WT POR 1 B MICPROS

02 SORBENT LOSS WT PDA 4 B MISC

02 SORBENT LOSS WT PDR 1 B MOTOR

02 SORBENT TRANSPORT PIPING, 1 B SORB SILO IA VIBR BIN DISCH

O1 OI SORBENT LOS WT PDR IA SCTR PLT

0501 SORBENT LOS WT FDR AA SLD GATE

0201 SORBENT LOSS WT PDR 1A MICPROS

0101 SORBENT LOSS WT FDR IA MISC

03 OI SORBENT LOSS WT FOR IA MOTOR
QFT1

QFT 1

OrT1

QTT 1

QFT 1

QFT 1

QRT 1

QrT 2

QFT 2

QFT 2

QFT 2

QFT 2

QrT2

QTT 2

QRT 2

QFT25

QFT 25

Q8T 25

QFT 25

QFT 25

QFT 25

QFT 25

QFT 25

QFT25

QFT 25

QFT 25

QFT 25

OPT 26

QrT26

QFT 26

QFT26

QFT 26

QFT 26

QPT 26

QFT 26

QFT 26

QFT26

QTT26

QPT 26

QFT 3

QFT 3

QFT 3

QFT 3

QRT 3

QFT 3

QRT 3

QFT 3

QFT4

QPT 1

QPT 4

QPT 4

QFT 4

QPT 4

QPT 4

QRT

RAT 1

RAT 2

RPTIJ

RFT13

RFT13

APT13

RPT 13

RPT 13

RFT 13

RPT 4

RFT 4

DFT4

APT 1

art 1

RFT 
CUEA No.

$002606030245001 \mathrm{C}$ $002408509220002 \mathrm{~N}$ $002606030185005 \mathrm{C}$ $002606030850005 \mathrm{C}$ $002606030579005 \mathrm{cl}$ $002606030352005 \mathrm{C}$ $002606030350013 \mathrm{C}$ $002606030185006 \mathrm{C}$ $002606030850006 \mathrm{C}$ $002606030579006 \mathrm{C2}$ $002606030351006 \mathrm{C}$ $002606030350014 \mathrm{C}$ $002606030185007 \mathrm{C}$ $002606030850007 \mathrm{C}$ $002606030579007<2$ $002606030351007 \mathrm{C}$ $002606030350015 \mathrm{C}$ $002606030185008 \mathrm{C}$ $002606030850008 \mathrm{C}$ $002606030579008 \mathrm{c2}$ $002606030351008 \mathrm{C}$ $002606030350016 \mathrm{C}$ $002606030105001 \mathrm{C}$ $002606030850001 \mathrm{c}$ $002606030579001 \mathrm{C2}$ $002606030351001 \mathrm{C}$ $002606030350009 \mathrm{C}$ $002606030185002 \mathrm{C}$ $002606030850002 \mathrm{C}$ $002606030579002 \mathrm{C2}$ $002606030351002 \mathrm{C}$ $002606030350020 \mathrm{C}$ $002606030185003 \mathrm{C}$ $002606030850003 \mathrm{C}$ $002606030579003 \mathrm{C2}$ $002606030351003 \mathrm{C}$ $002606030350011 \mathrm{C}$ $002606030185004 \mathrm{C}$ $002606030850004 \mathrm{C}$ $002606030579004 \mathrm{C2}$ $002606030351004 \mathrm{c}$ $002606030350012 \mathrm{C}$ $002603005460001 \mathrm{C4}$ 002603005705002 002603005705003 $002604503528001 \mathrm{C}$ $002604503851001 \mathrm{C}$ $002604503528002 \mathrm{C}$ $002604503851002 \mathrm{C}$ $002604503528003 \mathrm{C}$ $002604503851003 \mathrm{C}$ $002604506251005 \mathrm{C}$ $002604506850001 \mathrm{C}$ $002604506251006 \mathrm{C}$ $002604506850002 \mathrm{C}$ $002604503590004 \mathrm{C}$ $002604503330002 \mathrm{C}$ $002604503530002 \mathrm{C}$ $002605503850001 \mathrm{C}$ $002605503850002 \mathrm{C}$ $002605503850003 \mathrm{C}$ $002605503850004 \mathrm{C}$ $002605503850005 \mathrm{C}$ $002605503850006 \mathrm{C}$ $002605503850007 \mathrm{C}$ $002605503850008 \mathrm{Cl}$ $002605503850009 \mathrm{C}$ $002605503850010 \mathrm{C}$ $002605503850011 \mathrm{C}$ $002605503850012 \mathrm{C}$
EPRI No.

Description

4

02144664 02140005

02144663

02144663

02144667

02144666

02144666

02144663

02144663

0.3144667

02144666

02144666

02144663

02144663

02144667

02144666

02144666

02144663

02144663

02144667

02144666

02144666

02144663

02144663

02144667

02144666

02144666

02144663

02144663

02144667

02144666

02144666

02144663

02144663

02144667

02144666

$0214 \$ 666$

02141663

02144663

02144667

02141666

02144666

02140027

02145125

02145125

02145125

02145125

02145125

02145125

02145402

02145402

02145402

02145402

02145216

02141503

02141503

02141503

02141503

02141503

02811503

02111503

02141503

02141503

02141503

02141503

02111503

02142503

$021+1503$
01 O SOREENT TRANSPORT PIPING, 4A

0101 CA/S RATIO CONTROL

01 OS SORBENT BLOWER 4E, MISC

02 OS SORBENT BLOWER MOTOR, IE

OI OS SORBENT BOILER ISO GATE VLV IE

01 OS SORBENT ROTARY FEEDER IE MISC

02 OS SORBENT ROTAHY FEEDER IE MTR

01 O6 SORBENT BLOWER IF, MISC

02 O6 SORBENT BLOWEA MOTOR, IF

0106 SORBENT BOILER ISO GATE VLV IF

0106 SORBENT ROTARY FEEDER IP MISC

0206 SORBENT ROTARY FEEDER IF MTR

07 SORBENT BLOWER $4 G$, MISC

02 OT SORBENT BLOWEA MOTOR, 16

0107 SORBENT BOILER ISO GATE VLV $4 G$

O 7 SORBENT ROTARY FEEDER IG MISC

07 SORBENT ROTARY FEEDER IG MTR

O\& SORBENT BLOWER 4H, MISC

OA SORBENT BLOWER MOTOR, IH

O SORBENT BOILER ISO GATE VLV 4 H

OA SORBENT ROTARY FEEDER AH MISC

O SORBENT ROTARY FEEDER IH HTR

01 SORBENT BLOWER \&A, MISC

O1 SORBENT BLOWER MOTOR, IA

OI SOREENT BOILER ISO GATE VIV IA

OI SORBENT ROTARY FEEDER IA MISC

01 SORBENT ROTARY FEEDER 4 A MTR

02 SORBENT BLOWER 4B, MISC

02 SORBENT BLOWER MOTOR, 1 B

02 SORBENT BOILER ISO GATE VLV $4 B$

02 SORBENT ROTARY FEEDER 4 B MSC

02 SORBENT ROTARY FEEDER 1 B MTR

03 SORBENT BLOWER IC, MISC

03 SORBENT BLOWER MOTOR, IC

O3 SORBENT BOILER ISO GATE VLV IC

O) SORBENT ROTARY FEEDER IC MISC

O3 SORBENT ROTARY FEEDER $\triangle C$ MTR

04 SORBENT BLOWER ID, MISC

O4 SORBENT BLOWER MOTOR, 10

04 SORBENT BOILER ISO GATE VLV ID

O4 SORBENT ROTARY FEEDER ID MISC

04 SORBENT ROTARY FEEDER ID MTR

01 OPACITY MONITORING SYSTEM

GAS ANALYZER-NOX CEM

GAS ANALYZER-SO2 CEM

OI OI FLYASH EXHAUSTER IA MISC

0201 FLYASH EXHAUSTER IA HOTOR

0102 FLYASH EXHAUSTER 4 BISC

0202 FLYASH EXHAUSTER 4 BOTOR

0103 PLYASH EXHAUSTER IC HISC

0203 FLYASH EXHAUSTER IC MOTOR

01 OL BOTTOM ASH IA SCREH COOLER

0201 BTM ASH SCREW COOLER IA MOTOR

0102 BOTTOLA ASH 4 B SCREW COOLER

0202 BTN ASH SCREW COOLER IB MOTOR

01 OL BAGHOUSE 4 TRANS LINE ISO VLV

09 O4 BAGHOUSE ASH MECH SEP FILTR $1 \mathrm{~B}$

0902 BAGIIOUSE ASII MECII SEPARATOR 4

13 OL BAGHOUSE SHAKER MOTOR, COMP IA

13 OL BAGHOUSE SHAKER MOTOA, COMP $4 \mathrm{~B}$

O BAGHOUSE SHAKER MOTOR COMP AC

O4 BAGHOUSE SHAKER MOTOR, COMP ID

O4 BAGHOUSE SHAKER HOTOR,COMP IE

04 BAGHOUSE SHAKER MOTOR, COMP IF

O4 BAGHOUSE SHAKER MOTOR, COMP IG

O BAGHOUSE SHAKER MOTOR, COMP IH

O BAGHOUSE SHAKER MOTOR, COMP IJ

O 4 BAGHOUSE SHAKER MOTOR, COMP IK

O 4 BAGHOUSE SHAKER MOTOR, COMP IL

O4 BAGHOUSE SHAKER MOTOR, COMP IM
TAG No.

RET

RTT 4,13

R2S16A

RZS16A

Q2S16A

R2S16A

A2S16A

R2S16B

RZS16B

R2S168

R2S16B

A2S16B

R2S16C

RZS16C

RzS16C

R2S16C

RZS16C

R2S160

R2S16D

R2S16D

R2S160

R2S16D

R2S7A

RZSTA

$\operatorname{azs} 7 A$

RZSTA

R2S7A

R2S78

RZS 7日

A257B

R2S7B

R2s7u

azs?c

R2STC

R2S7C

a2s $7 \mathrm{C}$

R2STC

R2S7D

R2S7D

R2S7D

RESTD

Q2S7D

SAT 50

SAT 51

SAT52

TAEA52A

TAEA $52 A$

TAEB5 2A

TAEB52A

TAEC52A

TAECS2A

TCSA52AS, F

TCSASZAS, $F$

TCSB52AS,

TCSB5 $2 A S, F$

TPT31

TPT 31

TPT31

TPT了1

TPT 31

TPT31

TPT31

TPT 31

TPT 31

TPT31

TPT 31

TPT31

TPT 1

TPT31

TPT 1 
CUEA NO.

$002605503330004 c$ $002604503590004 \mathrm{~N}$ $002605503525004 \mathrm{C}$ $002605508130001 \mathrm{C}$ $002605508130002 \mathrm{C}$ $002605508130003 \mathrm{C}$ $002601503001004 \mathrm{C}$ $002601503215001 \mathrm{C}$ $002601503330001 \mathrm{C}$ $002604503530001 \mathrm{C}$ $002605503850013 \mathrm{C}$ $002605503850014 \mathrm{C}$ $002605503850015 \mathrm{C}$ $002605503850016 \mathrm{C}$ $002605503850017 \mathrm{C}$ $002605503050018 \mathrm{C}$ $002605503050019 \mathrm{C}$ $002605503850020 \mathrm{C}$ $002605503850021 \mathrm{C}$ $002605503850022 \mathrm{C}$ $002605503850023 \mathrm{C}$ $002605503850024 \mathrm{C}$ $002605503850025 \mathrm{c}$ $002605503850026 \mathrm{C}$ $002605503850027 \mathrm{C}$ $002605503850028 \mathrm{C}$ $002605503850029 \mathrm{C}$ $002605503850030 \mathrm{C}$ $002605503330001 \mathrm{C}$ $002604503590001 \mathrm{C2}$ $002605503525001 \mathrm{C}$ $002601503001001 \mathrm{C}$ $002605503330002 \mathrm{C}$ $002604503590002 \mathrm{~N}$ $002605503525002 \mathrm{C}$ $002601503001002 \mathrm{C}$ $002605503330003 \mathrm{C}$ $002604503590003 \mathrm{~N}$ $002605503525003 \mathrm{C}$ $002601503001003 \mathrm{C}$ $002604505330001 \mathrm{C}$ $002604505245001 \mathrm{C}$ $002604505330001 \mathrm{~N}$ $002604505530001 \mathrm{C}$ $002601506222001 \mathrm{~N}$ $002601505250005 \mathrm{C}$ $002604505280001 \mathrm{C}$ $002604505851001 \mathrm{C}$ $002604505200002 \mathrm{C}$ $002604505851002 \mathrm{C}$ $002600112252001 \mathrm{CA}$ $002600112330001 \mathrm{CA}$ $002600112850001 \mathrm{CA}$ $002600112509001 \mathrm{Cl}$ $002604003851002 \mathrm{Cl}$ $002604003500002 \mathrm{CA}$ $002604001001001 \mathrm{~N}$ $002604003851001 \mathrm{CA}$ $002601003500001 \mathrm{CA}$ $002501003851001 \mathrm{CA}$ $002501003499001 \mathrm{C}$ $002504001001001 \mathrm{cl}$ $002504003851002 \mathrm{C} 4$ $002504003499002 \mathrm{C4}$ $002504003851003 \mathrm{CA}$ $002504003499003 \mathrm{C}$ $002601008290001 \mathrm{C}$ $002601506515001 \mathrm{C2}$ $002604506545002 \mathrm{C2}$ $002601506515003 \mathrm{C2}$
EPRI No.

Description

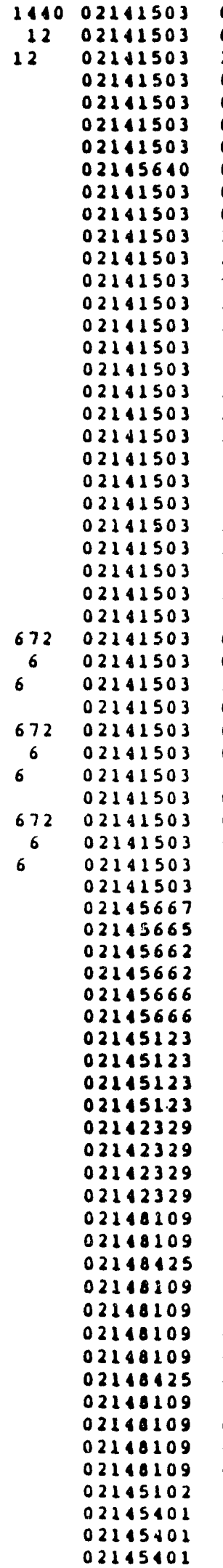

02 O4 BAGHOUSE 14 BAGS

OS O4 BAGHOUSE 14 CMP HPR DUST VALVE

12 O4 BAGHOUSE 14 SHAKER

O1 O1 BAGHOUSE 11, BYPASS DAMPER 1

01 O2 BAGHOUSE 14 , BXPASS DAMPER 2

04 O3 BAGHOUSE 4 , BYPASS DAMPER 3

01 OI BAGHOUSE 4 , MISC

01 O PLYASH TRANSPORT PIPING

09 O3 BAGHOUSE ASH MECH SEP FILTR AA

09 OI BAGHOUSE ASH MECH SEPARATOR IA

13 OI BAGHOUSE SHAKER MOTOR, COMP IN

13 OI BAGHOUSE SHAKER MOTOR, COMP 18

13 O 1 BAGHOUSE SHAKER MOTOR, COMP 10

3 O 1 BAGHOUSE SHAKER MOTOR, COMP IR

13 Ol BAGHOUSE SHAKER MOTOR, COMP IS

13 O 1 BAGHOUSE SHAKER HOTOR, COMP IT

13 O2 BAGHOUSE SHAKER MOTOR, COMP 2 N

1302 BAGHOUSE SHAKER MOTOR, COMP $2 P$

1302 BAGHOUSE SHAKER MOTOR, COMP 20

13 O2 BAGHOUSE SHAKER MOTOR, COMP $2 R$

1302 BAGHOUSE SHAKER MOTOR, COMP $2 S$

13 O 2 BAGHOUSE SHAKER MOTOR, COMP $2 T$

13 O3 BAGHOUSE SHAKER MOTOR, COMP 3 N

13 O3 BAGHOUSE SHAKER MOTOR, COMP $3 P$

13 O BAGHOUSE SHAKER MOTOR, COMP $3 Q$

13 O3 BAGHOUSE SHAKER MOTOR, COMP $3 R$

13 O3 BAGHOUSE SHAKER MOTOR, COMP IS

13 O3 BAGHOUSE SHAKER MOTOR, COMP $3 \mathrm{~T}$

02 O 1 BAGHOUSE 12 BAGS

05 OI BAGHOUSE I CMP HPR DUST VALVE

12 OI BAGHOUSE I SHAKER

01 O BAGHOUSE 1 , MISC

02 O2 BAGHOUSE 2 BAGS

05 O2 BAGHOUSE 2 CMP HPR DUST VALVE

12 O2 BAGHOUSE 2 SHAKER

01 O BAGHOUSE 2 , MISC

02 O3 BAGIIOUSE 3 BAGS

OS O3 BAGIIOUSE I CMP HPR DUST VALVE

12 O3 BAGLOUSE 3 SHAKER

01 OJ BAGHOUSE 3 , MISC

01 O1 BOTTOM ASH CONVEYING BAG FILTR

0101 BOTTOM ASH TRANSPORT PIPING

02 O1 BTM ASH MECHANICAL SEP FILTER

01 OL BTM ASH MECHANICAL SEPARATOR

O5 01 BTM ASH SILO PULS CLNG CMP

06 OL BTM ASH SILO PULS CLNG CMP MTR

01 O1 BOTTOH ASH EXHAUSTER IA

0201 BOTTOH ASH EXHAUSTER AA MTR

0102 BOTTOH ASH EXHAUSTER 18

0202 BOTTOH ASH EXHAUSTER 4 BTR

12 OI TURBINE OYL COOLER U4

15 O4 TURBINE OIL PILTER UA

10 O4 TURB OIL AUX LUBE PMP MTR UA

09 O4 TURBINE OIL AUX LUBE PMP UA

0202 CONDENSER CIRC PMP IA MTR

0102 CONDENSER CIRC PUHP AA

01 OI COOLING TOWER IAA

02 O 1 CONDENSER CIRC PMP $4 B$ MTR

0101 CONDENSER'CIRC PUHP $1 B$

0201 CONDENSER CIBC PHP I MTR

0101 CONDENSER CIRC PUMP 1

0101 COOLING TOWER EXISTING

0202 CONDENSER CIRC PMP 2 MTR

01 O 2 CONOENSER CIRC PUMP 2

0203 CONDENSER CIRC PMP 3 MTR

0103 CONDENSER CIRC PUMP 3

03 O1 DOTTOM ASH COOLING WTR HT EXCH

10 O 1 BTM ASH COOLER IA WATERWALLS

1002 BTM ASH COOLER 4 B WATERWALLS

10 OJ BTM ASH COOLER IC WATERWALLS
TAG No.

TPT 31

TPT 31

TPT 31

TPT 31

TPT31

$\operatorname{TPT} 31$

TPT31

TPT31.34

$\operatorname{TPT} 34$

TPT 34

TPT34

TPR 34

TPT 34

TPT 34

TPT 34

TPT34

TPT 34

TPT 34

TPT 34

TPT 34

TPT34

TPT 34

TPT 34

TPT 34

TPT 34

TPT 34

TPT 34

TPT 34

TPT 34

TPT 34

TPT 34

TPT 34

TPT 34

TPT 34

TPT 34

TPT 34

TPT 4

IPT 34

TPT 34

TPT 34

TPT 39

TPT 39

TPT 39

TPT 39

TPT 39

TPT39

TSEA 52A

TSEA 52A

TSEB 52A

TSEBS 2A

VPT5O

VPT 50

VZSIA

visia

WZS1

W2SI

WIS1, 2

W2S 2

W2S 2

W2S61

H2S61

W2561,62,63

H2S62

W2S62

W2S63

พ2S63

XFT300

XPT300

XFT300

XFT300 
CUEA No.

$002604506545004 \mathrm{c}_{2}$ $002604004290001 \mathrm{C4}$ $002604004050001 \mathrm{CA}$ $002604004500001 \mathrm{ct}$ $002601004001001 \mathrm{C}$ $002604004560001 \mathrm{c}$ $002604004290002 \mathrm{c}$ $002604004850002 \mathrm{c4}$ $002604004500002 \mathrm{c}$ $002604008850002 \mathrm{C}$ $002601008500001 \mathrm{C}$ $002604008500002 \mathrm{~N}$ $002604008290002 \mathrm{~N}$ $002607002001001 \mathrm{C4}$ $002607001001001 \mathrm{CA}$ $002606502001001 \mathrm{CA}$ $002601001001001 \mathrm{C}$ $002600500001004 \mathrm{C}$ $002906501001001 \mathrm{CA}$ $002606508837001 \mathrm{C}$ $002406505001001 \mathrm{C4}$ $002406503001001 \mathrm{cq}$ $002601504187001 \mathrm{C}$ $002601504187002 \mathrm{C}$ $002601504187003 \mathrm{C}$ $002601504107004 \mathrm{C}$ $002604504350001 \mathrm{C}$ $002604504280001 \mathrm{~N}$ $002604504850001 \mathrm{~N}$ $002004504245002 \mathrm{C}$ $002612001001001 \mathrm{c}$ $002612001850001 \mathrm{C4}$ $002612001001002 \mathrm{c}$ $002612001850002 \mathrm{ct}$ $002612001001003 \mathrm{C}$ $002612001850003 \mathrm{cA}$ $002612001001004 \mathrm{Cl}$ $002612001850004 \mathrm{C4}$ $002612005398001 \mathrm{cA}$ $002612015540001 \mathrm{C}$ $002612006530001 \mathrm{c}$ $002612010255003 \mathrm{C}$ $002612010851001 \mathrm{H}$ $002612010255001 \mathrm{C}$ $002612010851002 \mathrm{~N}$ 002612001244005 002612010850005 002612001241006 002612010850006 $002612009352001 \mathrm{c}$ $002612001376002 \mathrm{c}$ $002612009352002 \mathrm{c}$ 002612002374001 002612002378001 002612005398007 002612005850007 002612005398008 002612005850008 002612010255001 002612010850003 $002612009352004 \mathrm{C4}$ $002612014515001 \mathrm{CS}$ $002612014515002 \mathrm{cs}$ 002612010255002 $002612009352003 \mathrm{C4}$ 002612010850004 $002612009352005 \mathrm{CA}$ $002612009352006 \mathrm{c} 4$ $002408509001001 \mathrm{C2}$ $002612012001001 \mathrm{CA}$
EPRI No.

Description

02145101
02148010
02148010
02118010
02148010
02148010
02118010
02148010
02148010
02145102
02145102
02145102
02145102
01210740
012140740
01240710
02142330
02142330
02142710
01240702
02142713
02142711
02141009
02141009
02141009
02141009
02145663
02145124
02145124
02145661
02141610
02144610
02144640
02144610
02144640
02141640
$0214 \$ 640$
02114640
0

2144013 02144610 02144631 02144631 02144631 02144631

02144640 02144235 02141640 01
01
04

02144640 04

02144640

02144640 02144640 02140005 02144090

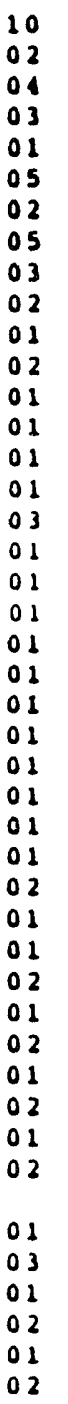

OI COAL CRUSKER IA

02 COAL CRUSHER IB

01 OI COMPUTER, HDPP
O4 BTH ASH COOLER ID WATERWALLS

O4 CLOSED COOLING WTR CLR IA

01 CLOSED COOLING WTR PHP MTR $4 A$

04 CLOSED COOLIHG WTR PUMP $4 A$

01 CLOSED COOLIAG WATER SYS

01 CLOSED COOLING WTA HEAD TANK

O5 CLOSED COOLIHG WTA CLR $4 \mathrm{~B}$

01 CLOSED COOLING WTR PHP MTR 4 B

OS CLOSED COOLIKG WTR PUMP IB

OI BOTTOH ASH CLNG WTR PMP 4 A MTR

01 BOTTOM ASH COOLING WTR PMP, IA

02 BOTTOM ASH CLNG HTR PHP 18 MTR

02 BOTTOH ASH COOLING WTR PHP, 48

O 1 ELECTRICAL UNINTER PWR SUP

01 ELECTRICAL SW GEAR $125 V$ DC

OI ELECTRICAL ISO-PHASE BUSS

04 GENERATOR EXCITER, UNIT 1

04 GENERATOR UNIT 4, MISC

04 TRANSFORMER, UNIT 4 GENERATOR

01 ELECTRICAL SW GEAR $1160 \mathrm{~V}$

O 1 TRANSFORMERS, LOAD CENTER

O 1 TRAASFORHER, UNIT AUX

O I AIR UTR SOOTBLOWER I

02 AIR HTR SOOTBLOWER 2

O3 AIR HTA SOOTBLOWER IJ

O4 AIR HTR SOOTBLOWER I4

O 1 BOTTOH ASH REINJ (NUVA) TDR

01 BOTTOM ASH REINJECT OLWR MISC

O 1 BOTTOM ASH REINJECT BLWR MTR

OI BOTTOM ASH REINJECTION PIPING

01 COAL CONVEYOR IA MISC

01 COAL CONVEYOR IA MOTOR

02 COAL CONVEYOR A MISC

02 COAL CONVEYOR A MOTOR

O3 COAL CONVEYOR B MISC

O3 COAL CONVEYOR B MOTOR

O4 COAL CONVEYOR C MISC

O4 COAL CONVEXOR C MOTOR

COAL CONVEYOR SURGE HOPPER

OI COAL CONVEYOR WEIGHTOMETER

OI COAL CONVEYOR - MAG SEP

OL COAL CRUSHER IA, MTR

02 COAL CRUSHER 4 B, MTR

COAL HANDL INCL CONVEYOR D KISC

COAL HANDL INCL CONVEYOR D MTA

COAL MANDL INCL CONVEYOR E MISC

COAL HANDL INCL CONVEYOR E MT:

01 COAL HANDL PRIMARY TEEDER I

01 COAL HANDLING FLOP GATES

02 COAL HANDLING PAIMARY FEEDER 2

COAL HDL TRIP CONVEY MAN SLIDE GATES

COAL HDL TRIP CONVEY PNEUMA SLIDE GATES

COAL HDL TRIPPER CONVEXOR MISC

COAL HDL TAIPPER CONUEYOR FTR

COAL HDL TAIPPEA CONVEYOR G HISC

COAL HDL TRIPRER CONVEXOR G MTR

COAL PRIMARY CRUSHER

COAL PRIMARY CRUSHER MTR

O4 COAL RECLAIM VIBRATIOH FEEDER

COAL SAMPLING SYS- AUTO AS IIRED

COAL SAMPLING SYS- AUTO AS REC

COAL SECONDARY CRUSHER

03 COAL SECONDARY CRUSHER FEEDER

COAL SECONDARY CRUSHER MTH

04 OS COAL VIBRATING FEEDER IA

0406 COAL VIBRATING PEEDER A

0101 DUST COLLECTION SYSTEM-COAL
TAG No.

XFT 300

$x 251$

$x 251$

$x 251$

$\times 251,2$

$x 251,2$

$x \times 52$

$\times 252$

$x \geq 52$

$x 254$

$x \geq 54$

$x 256$

X256

YAL44

XAL4 6

YAM14

YAM14

YAMI 4

YAMI 4

YVM 23

XVMZ3

Y UM 23

\section{$17-12$}




\section{RELIABILITY MONITORING DATABASE - 9}

CUEA No.

\begin{tabular}{|c|c|c|c|}
\hline $\begin{array}{l}002606009001001 \\
002613302001001\end{array}$ & $\begin{array}{ll}C 4 \\
C 4\end{array}$ & & $\begin{array}{l}02144091 \\
01240728\end{array}$ \\
\hline 002606508838001 & Ci & & 01210705 \\
\hline 002604503500002 & C & & 02147102 \\
\hline 002604503500001 & c & & 02147102 \\
\hline 002604503850001 & c & & 02147102 \\
\hline 002604503850002 & C & & 02147102 \\
\hline 002604503050003 & C & & 02145641 \\
\hline 002604503850004 & $c$ & & 02145641 \\
\hline 002604503222001 & c & & 02145641 \\
\hline 002604503222002 & C & & 02145641 \\
\hline 002604503291001 & C & & 02145642 \\
\hline 002604503850005 & C & & 02145642 \\
\hline 002604503242001 & C & & 02145643 \\
\hline $\begin{array}{l}002604503850006 \\
002603005705001\end{array}$ & c & & 02145643 \\
\hline 002109001519001 & C4 & & 02147010 \\
\hline 002409001500001 & Ci & 2 & 02147010 \\
\hline 002409001851001 & C4 & 2 & 02147010 \\
\hline 002601501228002 & C & & 02141007 \\
\hline 002601501185001 & C & & 02141008 \\
\hline 002601501185010 & C & & 02141008 \\
\hline 002601501185011 & C & & 02141008 \\
\hline 002601504185012 & C & & 02141008 \\
\hline 002601504185002 & C & & 02141008 \\
\hline 002601501185003 & c & & 02141000 \\
\hline 002601501185004 & C & & 02141008 \\
\hline 002601504185005 & c & & 02141008 \\
\hline 002601501185006 & c & & 02141008 \\
\hline 0026015041.5007 & C & & 02141008 \\
\hline 002601504185008 & c & & 02141008 \\
\hline 002601504185009 & C & & 02141000 \\
\hline 002601504579001 & c & & 02111007 \\
\hline 002606001001001 & $\mathbf{C 2}$ & & 02141660 \\
\hline 002606001302001 & C4 & & 02144672 \\
\hline 002606001394001 & ct & & 02144671 \\
\hline 002606001850001 & c4 & & 02144671 \\
\hline 002606001510001 & C4 & & 02144014 \\
\hline 002606001240001 & C4 & & 02144671 \\
\hline 002606002255001 & C 3 & & 02144661 \\
\hline 002606001352001 & C4 & & 02144671 \\
\hline 002606001530001 & C4 & & 02144673 \\
\hline 002606001388001 & $E 4$ & & 02144662 \\
\hline 002606002410001 & c4 & & 02144662 \\
\hline 002606009246001 & C4 & & 02141662 \\
\hline 002606009001001 & $\mathrm{C4}$ & & 02144662 \\
\hline 002606002341001 & c4 & & 02141662 \\
\hline 002606001851001 & C4 & & 02144662 \\
\hline 002606030245003 & $\mathbf{N}$ & & 02144664 \\
\hline 002700112850001 & $C_{4}$ & & 02142329 \\
\hline 002800112850001 & C4 & & 02142329 \\
\hline $\begin{array}{l}002900112050001 \\
002700112509002\end{array}$ & $\begin{array}{ll}C_{4} \\
C_{4}\end{array}$ & & $\begin{array}{l}02142329 \\
02142329\end{array}$ \\
\hline 002800122509001 & $c_{4}$ & & 02142329 \\
\hline 002900112509001 & C4 & & 02142329 \\
\hline 002700112252001 & C4 & & 02142329 \\
\hline 002800112252001 & c4 & & 02142329 \\
\hline 002900112252001 & C4 & & 02142329 \\
\hline 002700112330001 & C4 & & 02142329 \\
\hline 002000112330001 & Ct & & 02112329 \\
\hline 02900112330001 & & & \\
\hline
\end{tabular}

EPRI No.
Description

OI OI DUST COLLECTION SYSTEM-SORB 01 OI ELECTRICAL RELAYS - MISC 01 OI ELECTRICAL SW GEAR $180 \mathrm{~V}$ 01 OL FYASH CND WTR PMP (OLD) MISC 0102 FLYASH COND WTR PMP IA MISC 0202 PLYASH COND WTA PMP IA MTR 02 OL PLYASH COND WTR PMP (OLDI MTR O 01 FLYASH PLS AIR CLNG CMP IA MTR O9 02 FLYASH PLS AIR CLNG CMP 1 B MTR O8 01 PLYASH PULSE AIR CLNG CMP 4A O 02 FLYASH PULSE AIR CLNO CMP 48 01 O1 FLYASH UNLOADER

02 O1 PLYASH UNLOADER MOTOR

O1 O1 FLYASH UNLOADER SCRW CONV

0201 PLYASH UNLOADER SCRW CONV HTR GAS ANALYZER-CO2 CEH

0601 SERV WTR TRAVELING SCREENS

O4 OI SERUICE WATER PUMP MISC

05 OL SERUICE WATER PUMP MOTOR

0101 SOOTBLOWER CONTROLS

0101 SOOTBLOWER CONV PASS 1

0110 SOOTBLOWER CONV PASS 10

0111 SOOTBLOWER CONU PASS 11

0112 SOOTBLOWER CONU PASS 12

0102 SOOTBLOWER CONV PASS 2

0103 SOOTBLOWER CONV PASS I3

OI SOOTBLOWER CONV PASS II

O5 SOOTBLOWER CONV PASS IS

06 SOOTBLOWER CONV PASS 16

07 SOOTBLOWER CONV PASS I?

O SOOTBLOWER CONV PASS 10

O9 SOOTBLOWER CONV PASS I9

02 SOOTBLOWER STM SUP VLV

01 SORB PREP (1S $002606001 \times \times \times)$

OI SORBENT BUCKET CLEVATOR

01 SORBENT CHUTE/HOPPER

O1 SORBENT CONUEYOR MTR-BELT

O 1 SORBENT CONUEYOR WEIGHTMTR

01 SORBENT CONUEYOR - BELT

01 SORBENT CRUSHER

01 SORBENT FEEDER VIBRATING

01 SOREENT HAG SEPARATOR-BELT

01 SORBENT PLVRZR AIR HTR/DRY

OI SORBENT PULVERIZER

01 SORBENT PULUERIZER CYCL

01 SORBENT PULVERIZER DST COL

01 SORBENT PULVERIZER PAH

OI SORBENT PULVERIZER MOTOR

03 SORBENT TRANS X-PIPING (1A-B)

01 TURB OIL AUX LUBE PMP MTR UI

02 TURB OIL AUX LUBE PMP MTR U2

03 TURB OIL AUX LUBE PMP MTR U3

OL TURAINE OIL AUX LUBE PMP UI

02 TURBINE OIL AUX LUBE PAP U 2

03 TURBINE OIL AUX LUBE PMP UJ

OI TURBINE OIL COOLER UI

02 TURBINE OIL COOLER U2

O 3 TURBINE OIL COOLER U3

OI TURBINE OIL FILTER UI

02 TURBINE OIL FILTER U2

O 3 TURBINE OIL FILTER U3 
Section 18

\section{ALTERNATE FUELS TESTING}

During the Phase I and II test programs, two alternate fuels were tested in addition to salt Creek coal, which formed the baseline fuel for the majority of testing. These fuels included a Peabody coal mined locally some eight miles from the power station, and a Dorchester coal available approximately 100 miles from the plant in western Colorado. Both of these coals are western bituminous grade coals. The plant was originally designed to burn the peabody coal, which has a high variability in ash, heating value, moisture, and sulfur content. In order to take advantage of a more economical fuel supply, the fuel was switched to Salt creek coal in the summer of 1989. This fuel is more homogeneous than the Peabody coal with lower ash ( 17 wt. 8 ) and sulfur contents $(0.5 \mathrm{wt} . \%)$. Because of its consistency, Salt Creek coal formed a better fuel for comparative performance testing as part of the test program.

Prior to this change, eight steady-state performance tests were conducted on the Peabody coal ( 0.7 wt. o sulfur). In order to test the effects of higher sulfur content in the fuel on sulfur capture efficiency and overall unit performance, a series of four performance tests were conducted on the Dorchester coal with an average sulfur content of 1.5 wt. $\frac{\circ}{8}$. The fuel properties of these three coals are compared in Table 18-1. Test results for the three coals were compared in section 6, "Performance Testing", and are also highlighted in this section.

\subsection{TEST MATRIX AND EUEL PROPERTIES}

Table 18-1 shows the tests conducted on the local peabody and Dorchester coals, including a summary of pertinent emissions performance data. For two tests on the Dorchester coal (AF08 and AF 09), emissions data are presented for each combustion chamber due to a temperature differential that existed during the tests. This necessitates testing each combustion chamber individually for emissions performance since temperature has a strong impact on $\mathrm{NO}_{x}, \mathrm{CO}$, and $\mathrm{SO}_{2}$ emissions. Combustion and boiler efficiencies are also presented for the averages of the individual tests on each combustor. This is necessary since fly ash samples are common to both combustion chambers and is an important input into these two calculations. In Section 6 (Performance Testing), strong correlations between combustion/boiler efficiency and operating temperatures were 


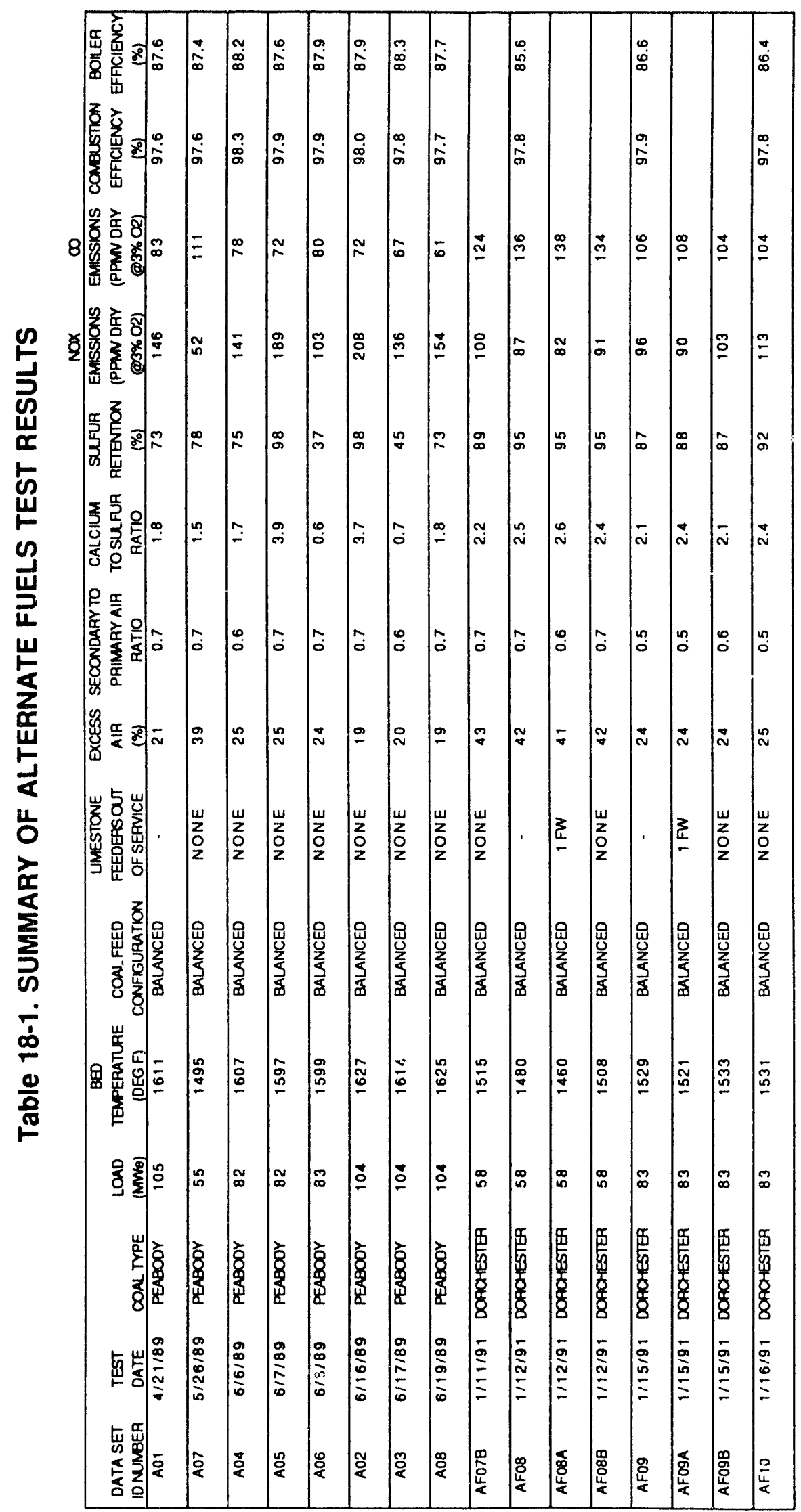


not apparent. Therefore, averages of the tests on the individual combustors for these calculations are appropriate.

For test $\mathrm{AFO} 7$ on Dorchester coal, orly combustion chamber $\mathrm{B}$ was tested due to differences in solids feed configuration and bed temperatures between combustors. Both tests AF07 and AF0 8 were conducted at 58 MWe gross output. Data from combustion chamber $B$ represent duplicate operating conditions for these two tests. Data from combustor A for test AF08 represent emissions performance at lower operating temperatures with the sidewall limestone feed point out of service. The maximum load tested on Dorchester coal was 83 MWe gross output due to limitations with the coal handling and preparation equipment from wet coal. There did not appear to be any CFB-related boiler limitations burning Dorchester coal.

For Peabody coal, eight steady-state performance tests were conducted. One test was completed at half load (test A07), three tests at $75 \% \mathrm{MCR}$ with various $\mathrm{Ca} / \mathrm{S}$ molar ratios and corresponding sulfur retentions, and four tests at $95 \% \mathrm{MCR}$. Three of the $95 \%$ MCR tests were completed at different $\mathrm{Ca} / \mathrm{S}$ molar ratios and the fourth test was a duplicate baseline test whose purpose was to establish repeatability. Load was restricted to $95 \frac{\circ}{\circ} \mathrm{MCR}$ for these tests due to primary air fan limitations.

Table 18-2 is a summary of the averages of Salt Creek, Peabody, and Dorchester coal properties for all tests completed during the Phase I and II test programs.

As can be seen from the table, Dorchester coal has the highest ash and sulfur contents, the lowest heating value, and the highest moisture content. Peabody and Salt Creek coal properties are similar except for a slightly higher sulfur content and lower fuel-bound nitrogen content for the Peabody coal. The latter is important in the formation of $\mathrm{NO}_{\mathrm{x}}$ emissions. Fuel properties for the Peabody coal were also more variable between tests compared to the other coals. 
Table 18-2.

Summary of Fuel Properties for Salt Creek, Peabody, and Dorchester Coals

\section{Salt Creek}

10406

8.79

3.58

32.3

42.0

16.9

- $\operatorname{Ash}\left(\frac{0}{0}\right)$

Constituents $\left(\frac{8}{2}\right)$

$\mathrm{C}$

$\mathrm{H}$

O

$\mathrm{N}$

$S$

$\mathrm{Ca}$

$\mathrm{Mg}$

$\mathrm{Fe}$
(응

Air Dry Loss

(옹)

- Volatiles ( $\left.\frac{\circ}{0}\right)$

Fixed Carbon

응)
Reabody

10680

6.08

2.63

29.1

46.4

18.5

61.4

3.4

9.0

0.8

0.70

0.47

0.09

0.40

\section{Derchester}

9041

10.97

$5 \cdot 30$

30.4

35.8

22.8

51.7

3.1

8.6

1.2

1.53

0.57

0.11

0.58

\subsection{TEST RESULTS}

Results of performance testing on Peabody and Dorchester coals are presented in section 6 along with data from the Salt Creek coal tests. Comparative data are shown in the following figures:

- Figure 6-3. Calcium Requirements and Sulfur Retentions

- Figure 6-11. NOx Emissions by Fuel Type.

- Figure 6-15. CO Emissions by Fuel Type.

- Figure 6-18. Temperature versus Combustion Efficiency.

The important conclusions from these tests are presented below.

1. Figure $6-3$ shows $\mathrm{Ca} / \mathrm{S}$ requirements to achieve various sulfur retentions for each of the three coals during tests 
with operating temperatures less than $1620^{\circ} \mathrm{F}$. Data indicate no significant differences in performance between Salt Creek and Peabody coals. However, the higher sulfur content of Dorchester coal provides a greater driving force for capture by calcined limestone and results in higher sulfur retentions for similar Ca/s ratios compared with the other coals. Data suggest a 10-15\% absolute increase in sulfur retention at $\mathrm{Ca} / \mathrm{S}$ molar ratios between 2.0 and 2.5 for Dorchester coal compared to Salt Creek and Peabody coals. Test data indicated 95\% sulfur retention at $\mathrm{Ca} / \mathrm{S}$ ratios of 2.5 .

Table 18-2 indicates that the calcium content of Dorchester coal is slightly higher than salt Creek and Peabody coals. Tests conducted on Salt Creek coal without limestone addition indicated a 50\% utilization of this calcium for sulfur retention. This will also influence the data to some degree.

2. Combustor operating temperatures for Dorchester coal are generally lower under similar operating conditions compared to the other coals due to higher ash and moisture contents. This is important since operating temperatures have a significant impact on emissions performance, as indicated in section 6 .

3. Figure 6-11 shows $\mathrm{NO}_{\mathrm{X}}$ emissions versus operating temperature for the three coals. As can be seen, the Dorchester coal had higher $\mathrm{NO}_{\mathrm{x}}$ emissions compared to the other two fuels. The fuel-bound nitrogen content of Salt Creek and Dorchester coals are similar. The difference is probably due to the higher sulfur content of the Dorchester coal, which necessitates a higher limestone feed rate to maintain $\mathrm{SO}_{2}$ emissions compliance. As is indicated in section 6, higher limestone feed rates under similar operating conditions results in slightly higher $\mathrm{NO}_{x}$ emissions. This is believed to be a result of the catalyzing effects of CaO on $\mathrm{NO}_{x}$ formation from fuel-bound nitrogen sources.

4. Figure 6-15 is a plot of CO emissions versus bed temperature for the three fuels tested. Dorchester and salt Creek coals produced comparable co emissions while those from tests with peabody coal are slightly below the correlation. As can be seen in Table 18-1, the volatile content of peabody coal was lower and the fixed carbon content was higher compared to the other two coals. Although the differences are subtle, this may suggest that increased volatile fraction in the fuel may result in higher $C O$ emissions.

5. Figure 6-18 shows combustion efficiencies versus bed temperature for the three fuels tested. Below $1550{ }^{\circ} \mathrm{F}$, combustion efficiencies for Peabody and Dorchester coals were generally lower by approximately $0.5 \%$ absolute compared with Salt Creek coal. This may be related to the lower volatile fraction and higher ash contents in these two fuels compared 
to Salt Creek coal. Above $1550^{\circ} \mathrm{F}$, data from Peabody and Salt Creek coals fall within the general data scatter.

6. Tables $6-7,6-8$, and $6-9$ in section 6 show the contributions to boiler efficiencies calculated for salt

Creek, Peabody, and Dorchester coals. Tests with Peabody coal exhibited the highest average boiler efficiencies ( 87.88 ), while those of Salt Creek and Dorchester coals averaged $87.4 \%$ and $86.3 \%$, respectively. The descending order in efficiencies results primarily from moisture in the fuel and sorbent. In addition, for Dorchester coal, higher losses from the calcination of limestone contribute to the lower efficiencies. This results from the higher sulfur content of the fuel and the correspondingly higher limestone feed requirements for maintaining $\mathrm{SO}_{2}$ compliance.

Future testing should be attempted on the Nucla CFB with higher sulfur eastern coals ( $>3 \frac{\circ}{6}$ sulfur) duplicating the test matrix completed on the Peabody coal. This would further substantiate that lower $\mathrm{Ca} / \mathrm{S}$ ratios are required to achieve a similar sulfur retention for high sulfur fuels. This is an important issue in the economics of circulating fluidized bed combustion technology. 
Section 19

ENVIRONMENTAL MONITORING

The purpose of this plan is to collect and present an environmental database from the operation of the Nucla Circulating Fluidized Demonstration Project. The database consists of data input as a part of compliance monitoring, as required in permits and regulations, and supplemental or additional monitoring as part of the demonstration test program. This information is presented below.

\subsection{SUMMARY OF ENVIRONMENTAL PERMITTING AND APPROVAL PROCESS}

Prior to financing and construction, CUEA obtained permits for air emissions, waste-water discharge, and ash disposal. A Prevention of Significant Deterioration (PSD) permit was applied for on April 18, 1984. EPA issued a PSD permit on October 11, 1984 for construction of the Nucla CFB unit. Emission permit applications were for the CFB boiler, coal crushers, ash silos, ash loader, limestone storage silos, limestone pulverizer, limestone handling, coal handling and construction activities. Initial emission permits for these activities were issued on October 25, 1984 by the Colorado Department of Health, Air Pollution Control Division (CAPCD). CUEA submitted an air pollution permit application for the limestone stockpile to the CAPCD on May 27, 1986 and received the permit on september 29, 1986. An air pollution permit application for the propane vaporizer system was submitted on December 18, 1986 to the CAPCD. The permit was issued on March 27, 1987. The last air pollution emission permit application was submitted on February 6, 1987 for the ash disposal facility. CAPCD issued this permit on April 22, 1987.

The Nucla station had an existing waste-water discharge permit which was modified to allow for additional flow resulting from the increased size of the plant from 36 MWe to 110 MWe (gross). The amended permit was issued on February 21, 1985 by the Colorado Water Quality Control Division (CWQCD) .

Colorado Hazardous Materials and Waste Management Division (CHMWMD) regulations require review and approval of an engineering design and operations report prior to commencement of waste disposal. CUEA submitted this report to CHMWMD on February 6, 1987 and received approval on October 19, 1987. 
The Rural Electrification Administration (REA) completed an Environmental Assessment prior to construction of the CFB boiler. CUEA initiated this process with submittal of an Environmental Analysis to the REA on March 22, 1984. The REA completed its review and approval on December 7, 1984 and allowed construction to begin on this date.

\subsection{COMPIIANCE MONITORING}

Compliance monitoring is required by federal and state regulations and permits for air emissions, waste-water discharge, and waste disposal. Air emissions are monitored by the Continuous Emissions Monitoring (CEM) system and the coal sampling system. The Model 400 opacity monitor and the Model 200 gaseous emission monitor analyze stack emissions. The data acquisition system (DAS) receives input from the opacity and gaseous monitors and generates emissions monitor reports. Coal samples are collected to determine potential $\mathrm{SO}_{2}$ emissions. This value is compared with previously monitored emission rates to determine percent reduction of $\mathrm{SO}_{2}$.

Waste-water discharge compliance monitoring is conducted according to the requirements of the discharge permit issued by the Colorado Water Quality Control Division. The results are summarized each calendar quarter and are reported on the applicable discharge monitoring report forms.

Waste disposal compliance monitoring, as approved by the Colorado Hazardous Materials and Waste Management Division, requires the following monitoring practices:

1. Record waste quantities daily

2. Monitor groundwater annually

These monitoring results were submitted quarterly to the U.S. Department of Energy (DOE).

\subsection{ADDITIONAL MONITORING BY THE TEST PROGRAM}

A detailed final test plan was developed for the DOE by the Radian Corporation covering aspects of a field study of disposed solid waste from the Nucla CFB. The title of this report is "Field Testing of Disposed Solid Waste from Advanced Coal Processes", which was developed under DOE agreement No. DE-AC21-86MC22118. The report was issued in June 1988. The Electric Power Research Institute (EPRI) is a participant in this research effort with DOE Morgantown Energy Technology Center through a cooperative research agreement.

The overall objective of the study is to develop design and implementation guidelines for the safe disposal of wastes 
from advanced coal combustion processes. The research will provide greater understanding of the effects which pozzolanic reactions have on in-situ permeability and leachability of these wastes. In addition, the demonstration phase of this research will provide data on the environmental behavior of the wastes to support the acquisition of waste disposal permits.

The Final Test Plan addresses the construction design and environmental monitoring specifications of a field test cell for coal-fired $C F B$ waste at a disposal site near the Nucla Station. The site represents a semi-arid, temperate climate with near-surface geology consisting of mud stones and shales of the Cretaceous Dakota Formation.

The test plan consists of seven major sections covering the following:

1. Description of site characteristics.

2. Test cell design and construction specifications.

3. Procedures related to monitoring meteorological, hydrological, and soils and waste conditions.

4. Guidance for sample preservation and shipping.

5. Physical and chemical characterization procedures to be performed on soil and waste samples collected from the site. Also included is a summary of chemical characterization procedures to be conducted on samples of surface runoff, pore water, and ground water.

6. Quality assurance/quality control procedures for field and laboratory measurements associated with the project.

7. Description of data management procedures for capturing, organizing, reducing, and displaying data.

Additional monitoring was to be performed by EPRI as part of an environmental characterization plan included in their Detailed Test Plan for the Nucla CFB. The plan only involves air emissions (gaseous and particulate) and solid wastes. Air emissions will be sampled between the baghouse and the stack. Solid waste samples will be collected from the bed drain and fly ash hoppers. Testing will be corducted on the design fuel at half and full load. Measurements of gaseous emissions will include on-line gas analysis for determination of $\mathrm{SO}_{2}, \mathrm{NO} / \mathrm{NO}_{\mathrm{X}}, \mathrm{CO}_{2}, \mathrm{O}_{2}$ and $\mathrm{CO}$. Particulate and trace metal emissions will be collected isokinetically using a standard $E P A$ method 5 stack sampling train. Volatile organics will be sampled along with nitrosamines using acetic acid in the impinger train.

Physical properties will be determined for solid waste samples (fly ash and bottom ash) including specific gravity, bulk density, particle size distribution, permeability, hygroscopicity, adhesion, compaction and compressive 
strength. Chemical properties include elemental analysis, organic compounds, $\mathrm{pH}$, and leaching.

\subsection{RESULTS FROM COMPLIANCE MONITORING}

The following is a summary of the results obtained from compliance monitoring activities conducted between 1988 and the conclusion of the test program during the first quarter of 1991 .

\subsubsection{Air Emissions Monitoring}

Figures 19-1 through 19-4 show the daily average and 30 day rolling average for $\mathrm{SO}_{2}$ emissions in lbs/MMBtu measured by the stack CEM system from the fourth quarter of 1988 through the first quarter of 1991. The permit level for the 30-day rolling average of $0.4 \mathrm{lbs} / \mathrm{MMBtu}$ is shown by the heavy shaded line on the figures. The permit also requires at least $70 \%$ reduction of potential $\mathrm{SO}_{2}$ emissions on the 30-day rolling average basis, however, plots of this are not included. For the period presented, there are no violations of the 30-day rolling average for $\mathrm{SO}_{2}$ emissions and average values are well below the permit limits. There were some violations of the 30 -day rolling average $70 \%$ reduction requirement during the summer of 1989. There is no permit restriction on the daily average value, but these values have been included in the figures for completeness. Daily averages were often affected during this period by performance testing as part of the demonstration test program.

Figures 19-5 through 19-8 show the daily average and 30 day rolling average for $\mathrm{NO}_{x}$ emissions in lbs/MMBtu measured by the stack CEM system from the fourth quarter of 1988 through the first quarter of 1991. The permit limit for tre 30-day rolling average of $0.55 \mathrm{lbs} / \mathrm{MMBtu}$ is shown by the heavy shaded line on the figures. For the period presented, there are no violations of the 30-day rolling average for NOx emissions, and average values are well below the permit limit. Again, there is no permit restriction on the daily average value, but these values have been included for completeness.

There are no permit restrictions on CO emissions. However, as indicated in section 6, these emissions varied with combustor operating temperature from approximately 140 ppmv at $1450^{\circ} \mathrm{F}$ to $70 \mathrm{ppmv}$ at $1700^{\circ} \mathrm{F}$.

Opacity exceedences are based on six minute averages and are submitted to the Colorado Air pollution Control District on a quarterly basis for opacities greater than 20\%. Opacity at Nucla is generally quite low with an average around 5\%. This value can exceed $10 \%$ if baghouse bag tears become numerous. If this occurs, operators remove baghouse compartments from 


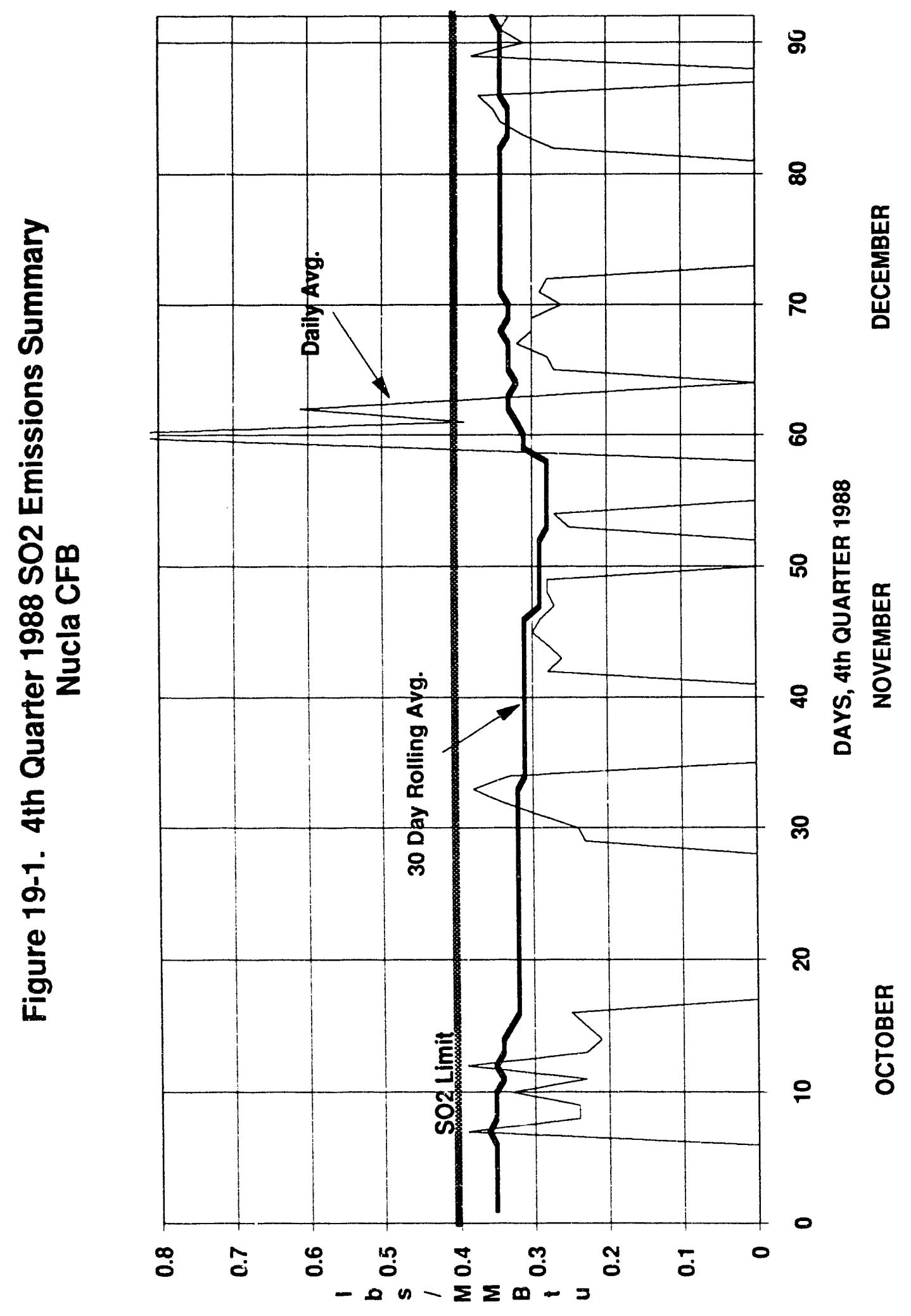




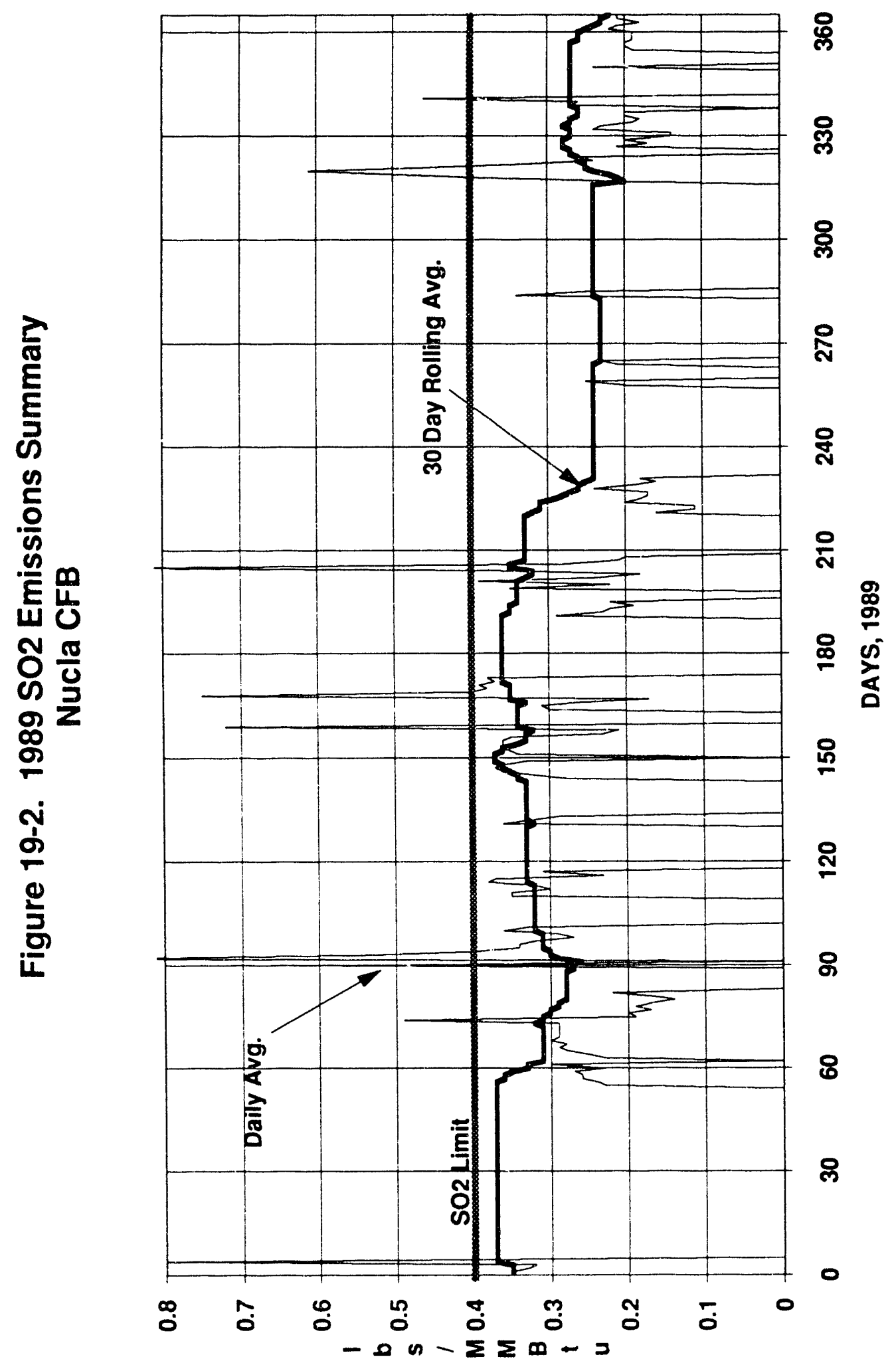




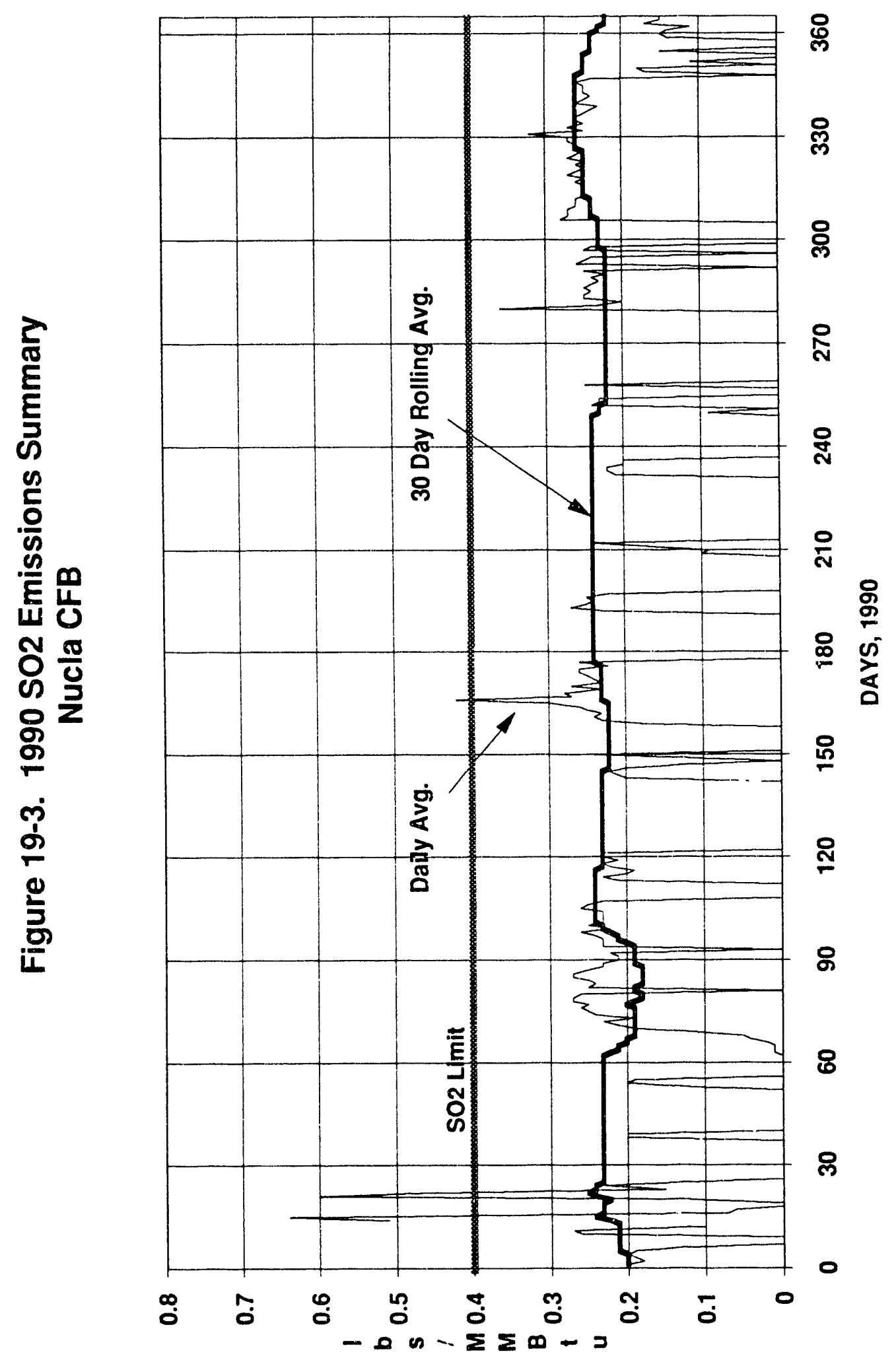




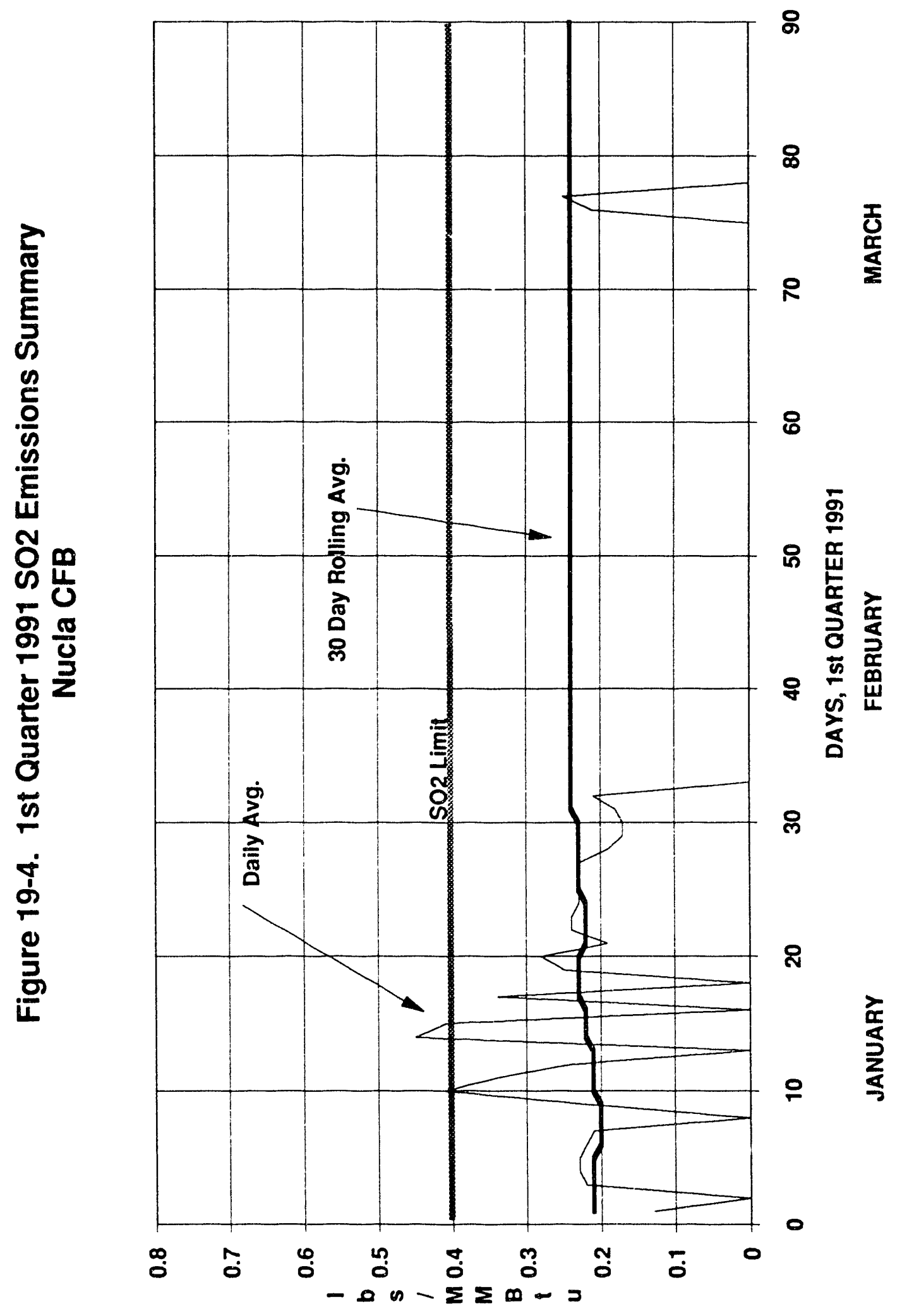




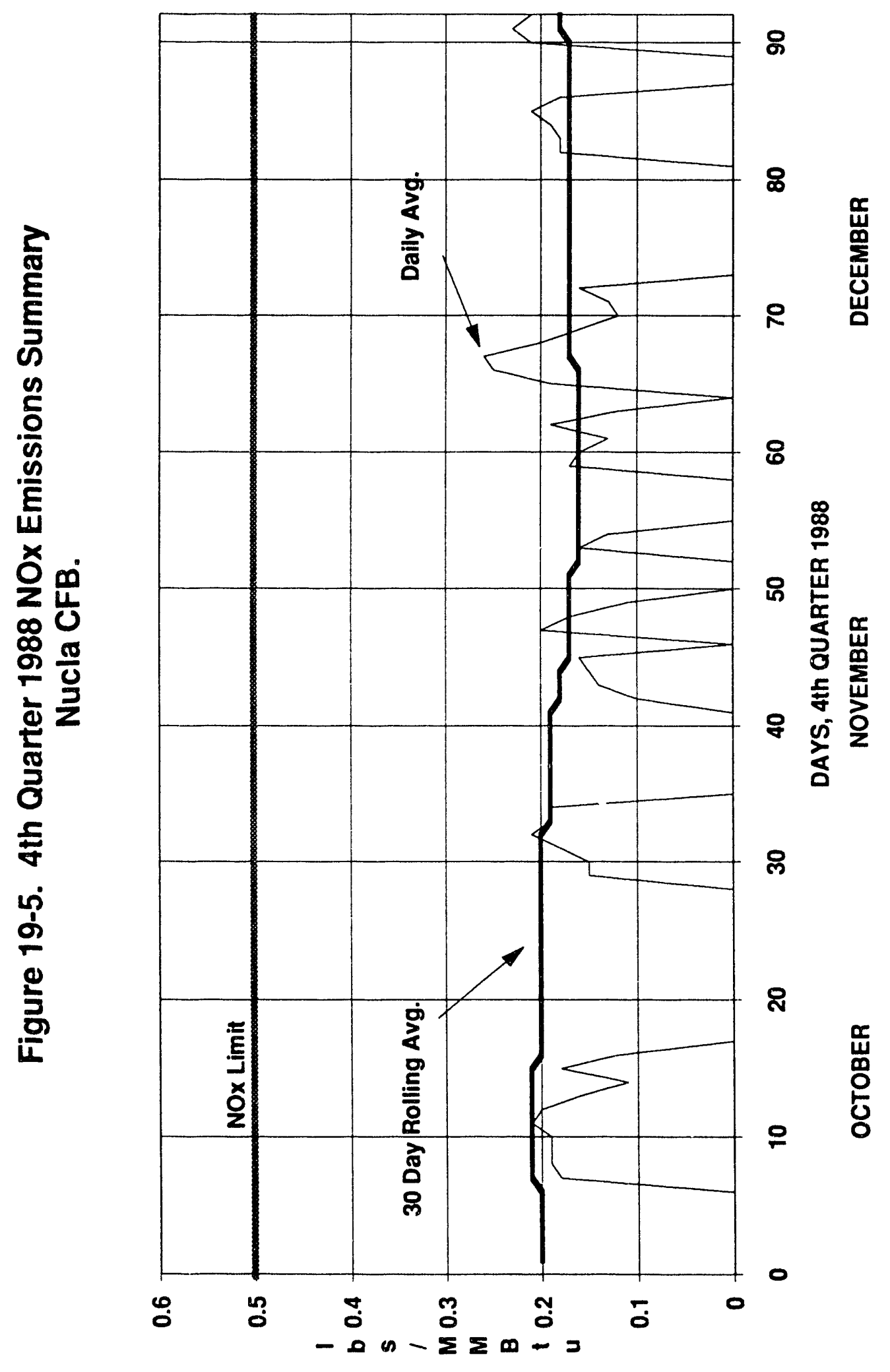




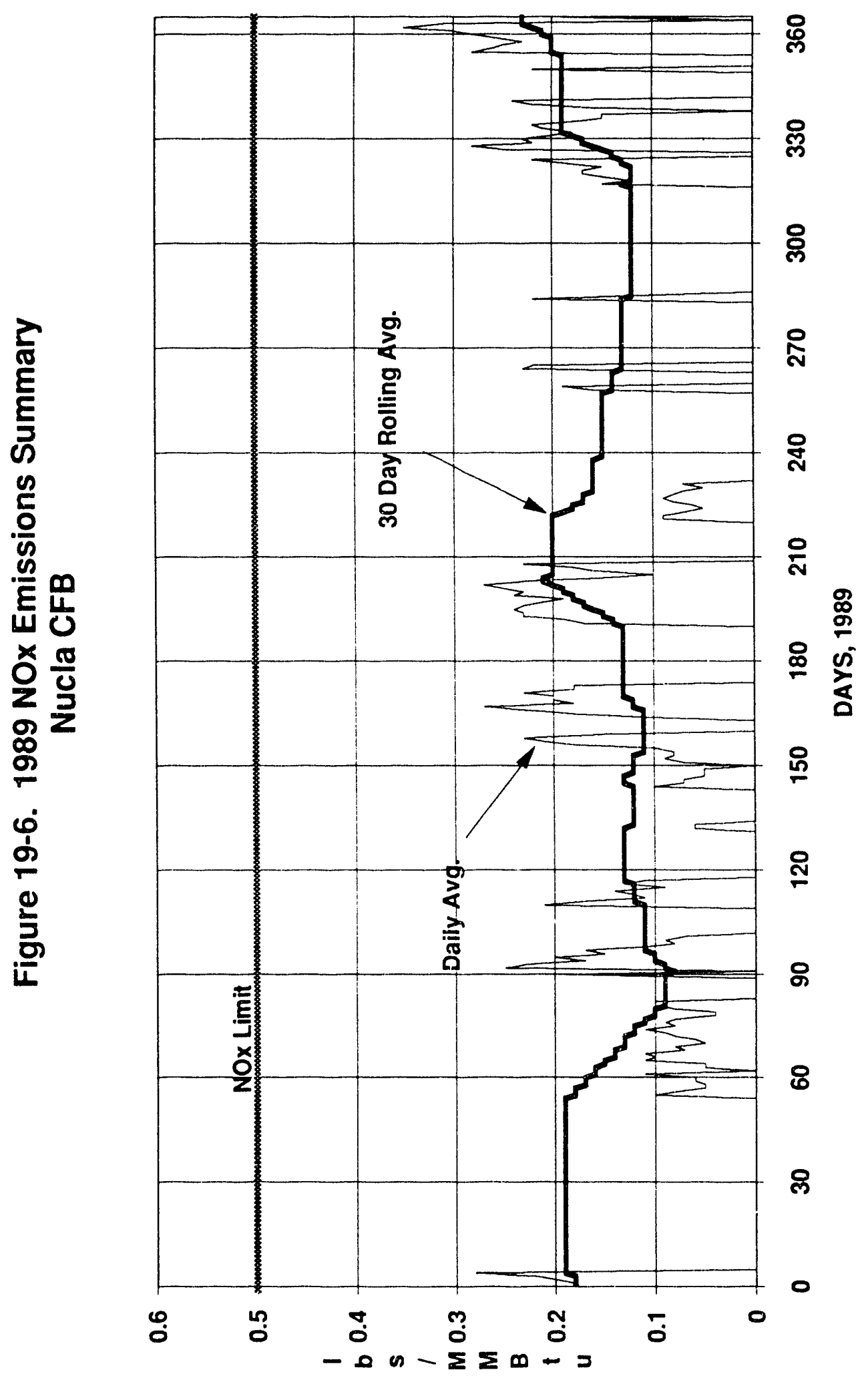




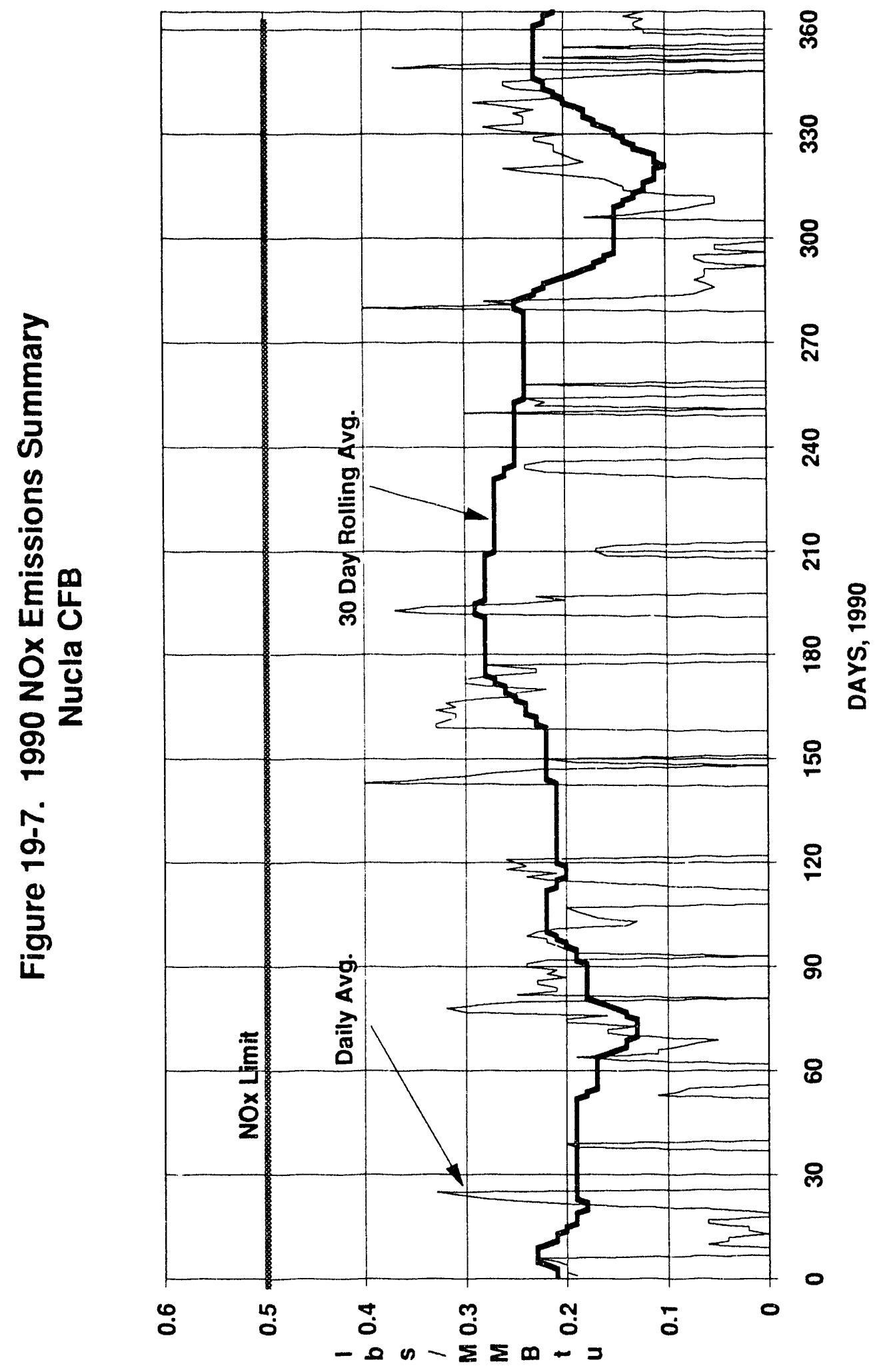




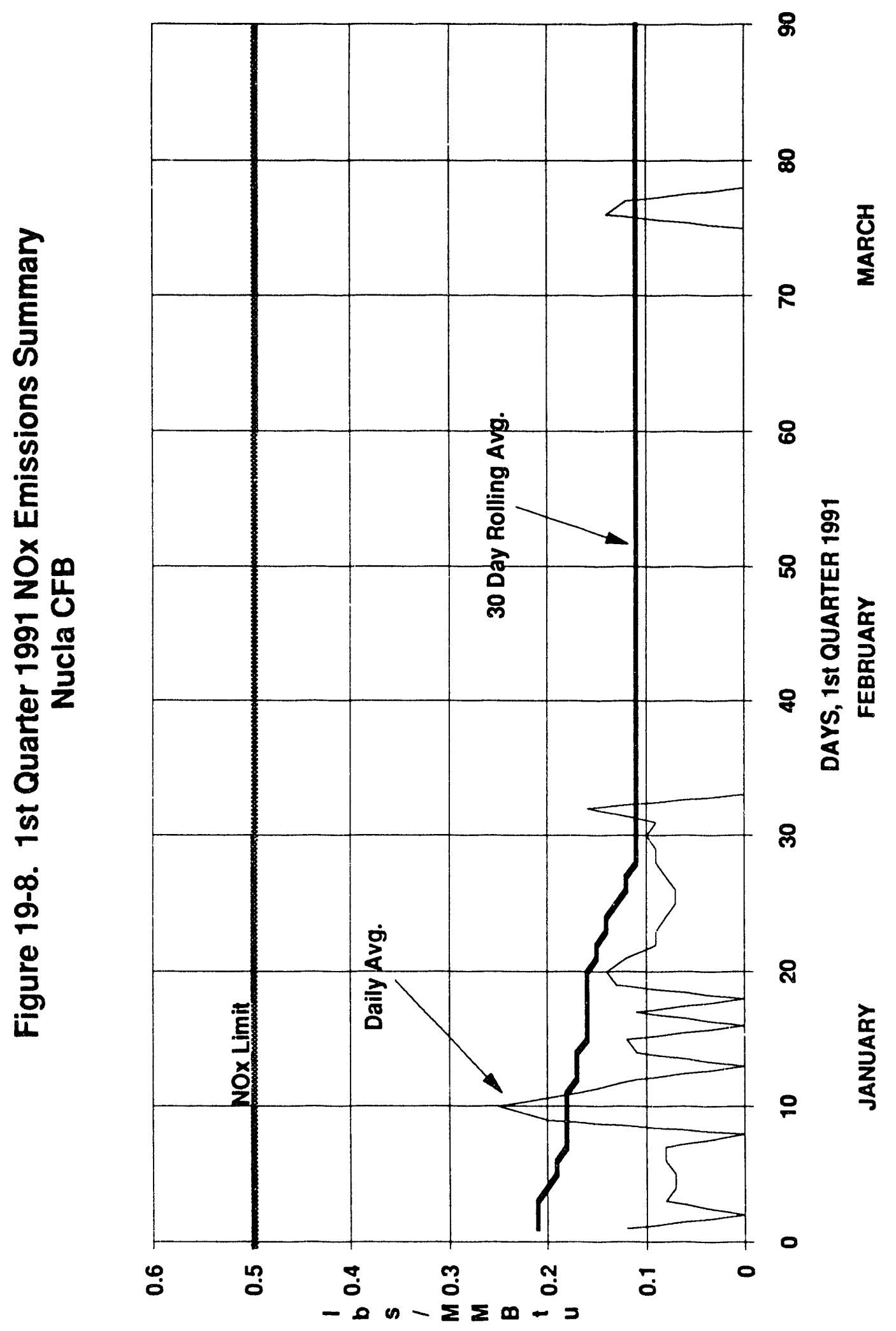


service to isolate the location of these tears, and then replace the bags. The frequency of these replacements is summarized in Section 15 on "Baghouse Operation and Performance".

Generally, opacity exceedences will occur during unit startups when gas burners are in service and baghouse inlet temperatures are less than $140^{\circ} \mathrm{F}$. During these periods, combustion air flows through the bed material in the combustion chambers and carries solids past the baghouses to the stack. Until the baghouse inlet temperature reaches $140^{\circ} \mathrm{F}$, the baghouse is bypassed to avoid problems associated with condensation. Opacity will generally exceed $20 \%$ during this 1 to 4 hour interval on start-up. During the period covering the test program on the Nucla CFB, there has never been any enforcement action required as a result of excessive opacity exceedences.

\subsubsection{Waste-water Discharge}

Data from waste-water discharge to the upper and lower cooling ponds are shown in Tables 19-1 through 19-8 from the first quarter of 1988 through the first quarter of 1991 . The tables include the minimum, average, and maximum quarterly values (where applicable) for $\mathrm{pH}$, total suspended solids, oil and grease, total copper, total iron, the flow in the conduit of treatment valve, visual oil and grease, total chromium, total chlorine, total zinc, and total dissolved solids. As can be seen from the tables, the same monitoring does not apply to the upper and lower ponds. For both ponds, the permit values are listed for the average and maximum values. The upper pond contains cooling tower blowdown, while the lower pond contains discharge from the boiler system, such as steam drum blowdown.

\subsubsection{Waste Disposal}

Waste disposal includes summaries of solids waste quantities of fly ash and bottom ash generated during the course of the test program, along with groundwater monitoring. Fly ash and bottom ash quantities generated for 1988, 1989, 1990, and the first quarter of 1991 are summarized in Tables 19-9 through 19-12 respectively. Data are summarized by month and total values are given for each year. The tables include the quantity of fly ash generated by the combustion of coal (adjusted for the addition of limestone), and the quantity of ash removed during the period. The difference is shown in column 10 for each table. All data in these tables should be compared with monthly unit capacity factors presented in

Section 3.

A summary of groundwater data is shown in Table 19-13. Data are presented from two wells from the fourth quarter of 1989 through the first quarter of 1991. The maximum standurd is 


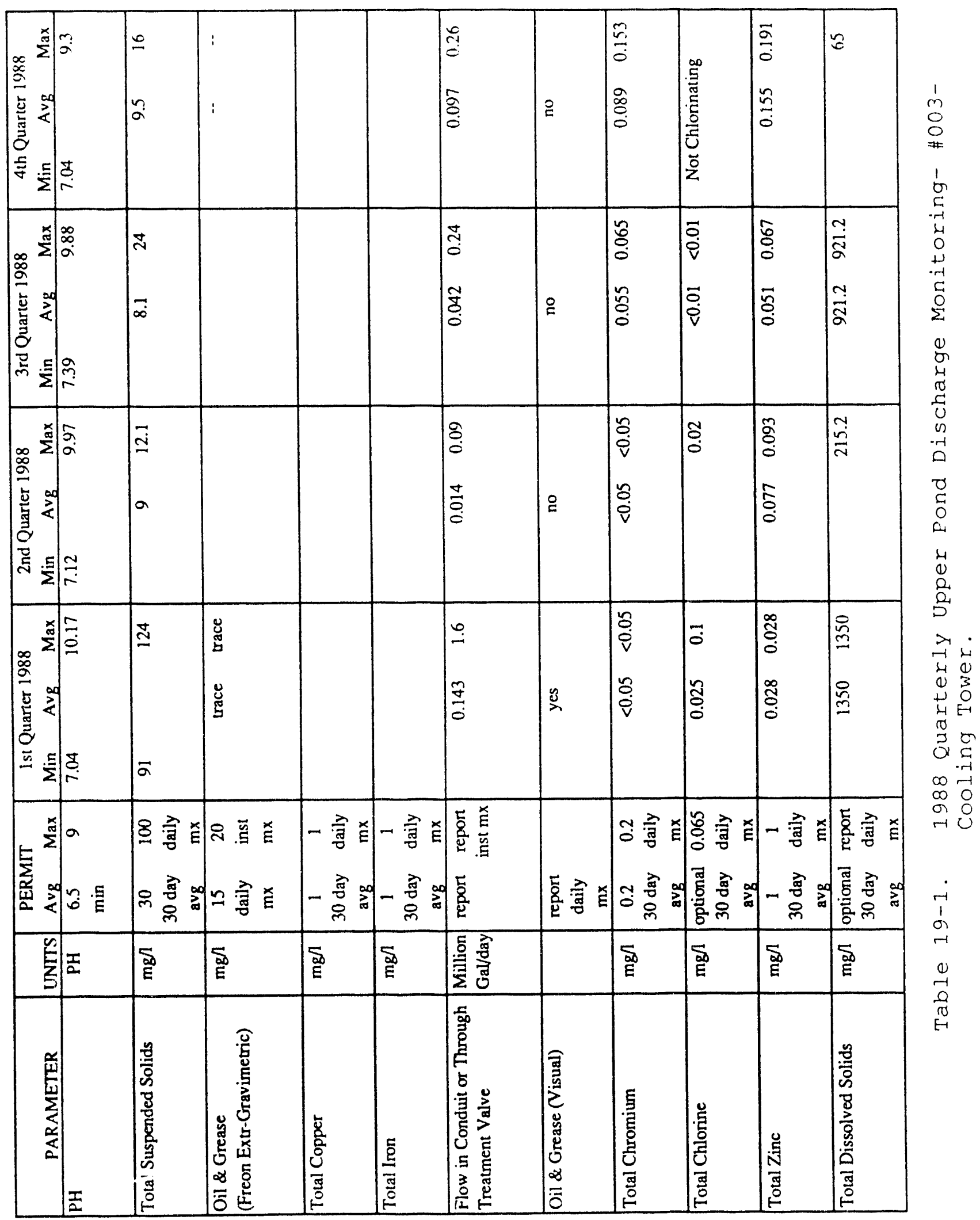




\begin{tabular}{|c|c|c|c|c|c|c|c|c|c|c|c|}
\hline 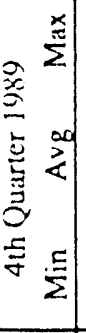 & 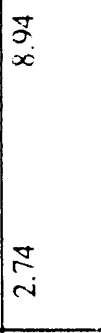 & 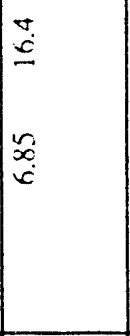 & 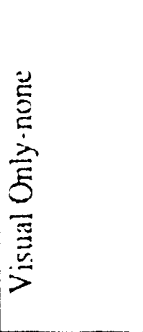 & & & $\begin{array}{l}\infty \\
0 \\
0 \\
0 \\
0 \\
0\end{array}$ & $\stackrel{\circ}{\check{2}}$ & 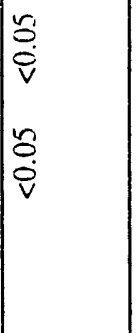 & $\left.\right|_{0} ^{0}$ & $\begin{array}{l}3 \\
0 \\
8 \\
0\end{array}$ & 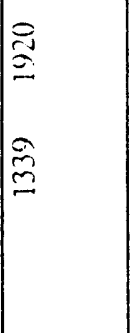 \\
\hline 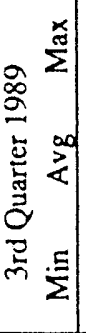 & \begin{tabular}{l}
0 \\
\multirow{2}{*}{} \\
$\dot{0}$
\end{tabular} & 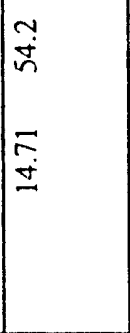 & 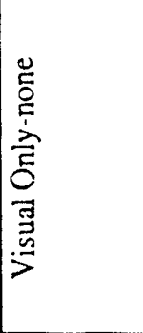 & & & $\mid \begin{array}{l}n \\
0 \\
0 \\
0\end{array}$ & 을 & $\begin{array}{l}\because \\
0 \\
0 \\
v \\
0 \\
0 \\
0\end{array}$ & 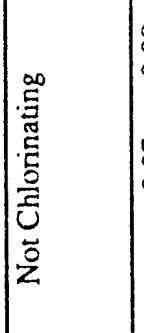 & $\mid \begin{array}{l}0 \\
0 \\
0\end{array}$ & $\mid \begin{array}{l}0 \\
\cdots \\
m \\
0 \\
0 \\
m\end{array}$ \\
\hline 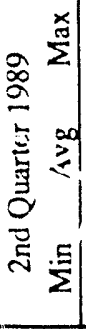 & $\begin{array}{l}0 \\
0 \\
10\end{array}$ & $\mid$\begin{tabular}{l}
$\bar{\infty}$ \\
\hdashline \\
0
\end{tabular} & 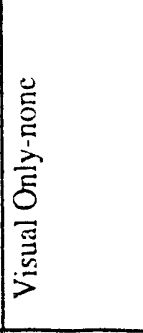 & & & 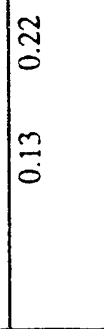 & $\stackrel{\circ}{\rightleftarrows}$ & $\mid \begin{array}{l}\overline{0} \\
0 \\
0 \\
0\end{array}$ & $0_{0}^{0}$ & $\begin{array}{l}\bar{Z} \\
0 \\
0 \\
0 \\
0\end{array}$ & $\begin{array}{l}\approx \\
6 \\
6 \\
6 \\
0\end{array}$ \\
\hline 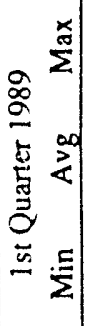 & $\mid \begin{array}{l}5 \\
0 \\
0 \\
0 \\
0\end{array}$ & 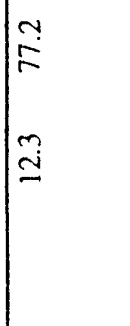 & : & & & $\mid \begin{array}{l}\infty \\
0 \\
0 \\
0 \\
\tilde{z} \\
0 \\
0\end{array}$ & $\stackrel{2}{2}$ & 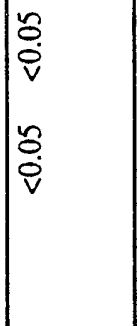 & 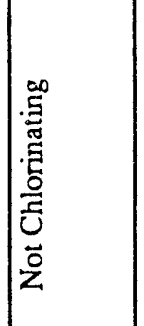 & $\begin{array}{l}\frac{0}{0} \\
0 \\
0\end{array}$ & $\stackrel{\circ}{\sim}$ \\
\hline 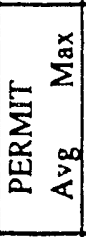 & $\left\{\begin{array}{l}a \\
0.5\end{array}\right.$ & 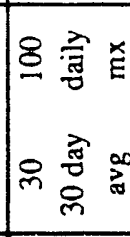 & 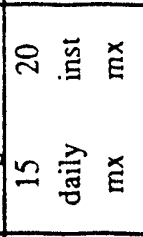 & 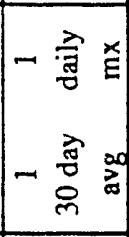 & 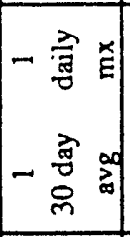 & 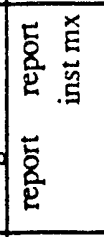 & 总希芘 & 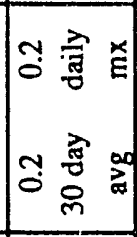 & 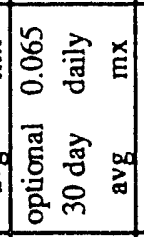 & 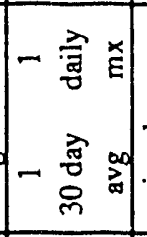 & 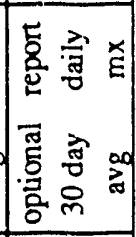 \\
\hline 号 & 5 & 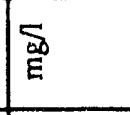 & 施 & 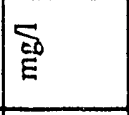 & $\underset{E}{\Phi}$ & 递 & & 离 & Бే & 离 & 品 \\
\hline 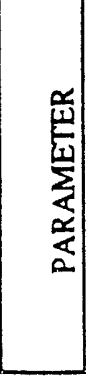 & 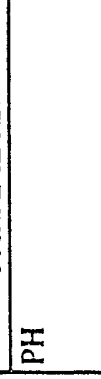 & 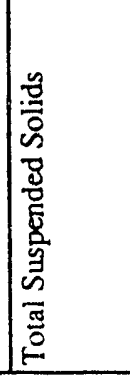 & 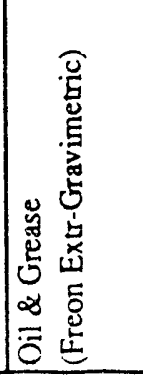 & 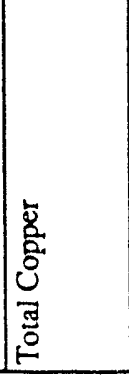 & 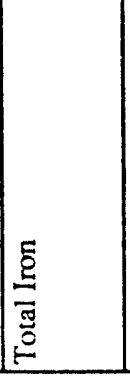 & 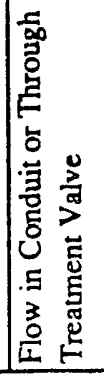 & 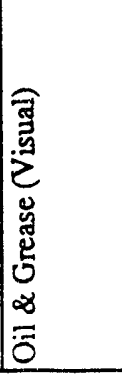 & 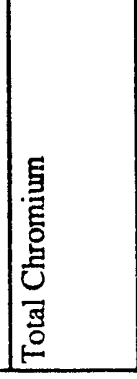 & 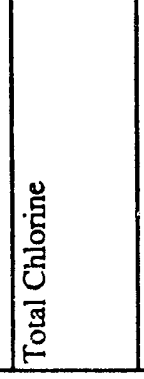 & 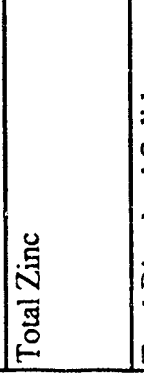 & 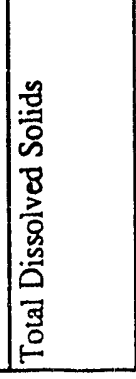 \\
\hline
\end{tabular}




\begin{tabular}{|c|c|c|c|c|c|c|c|c|c|c|}
\hline 紟 & 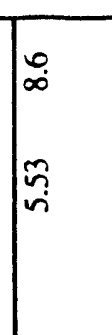 & $\mid$ & & & 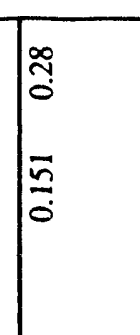 & 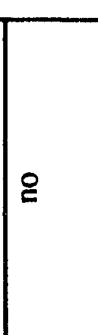 & & 0 & 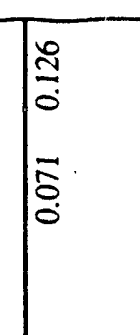 & $\begin{array}{l}\tilde{\check{g}} \\
\bar{\Xi}\end{array}$ \\
\hline & $\begin{array}{l}\tilde{\Xi} \\
\ddot{\Xi} \\
\ddot{0}\end{array}$ & 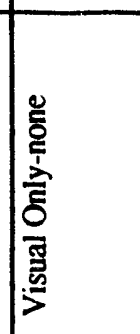 & & & 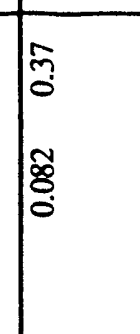 & $\approx$ & 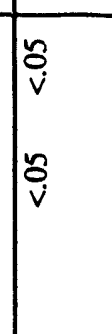 & 0 & 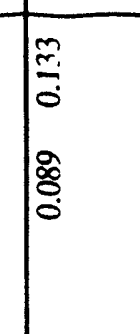 & 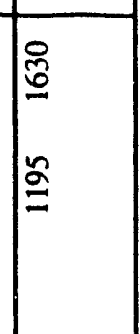 \\
\hline & $\begin{array}{l}\pi \\
0 \\
\infty \\
\infty \\
\infty \\
\infty\end{array}$ & $\mid$ & & & 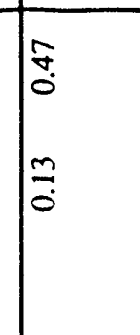 & $\approx$ & 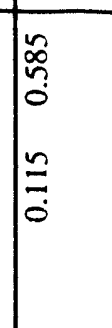 & 0 & 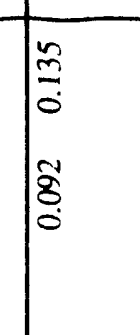 & 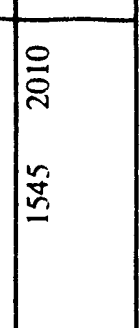 \\
\hline & 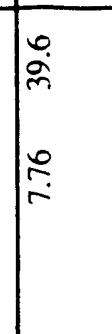 & 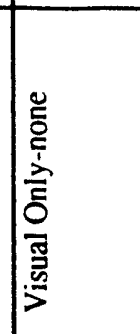 & & & \begin{tabular}{l}
$\approx$ \\
\hdashline \\
\hdashline
\end{tabular} & $\because$ & 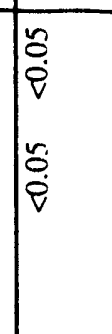 & 0 & $\begin{array}{l}\overrightarrow{0} \\
8 \\
8 \\
0\end{array}$ & 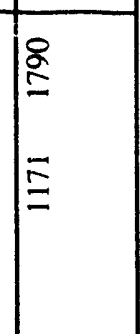 \\
\hline 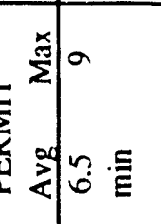 & 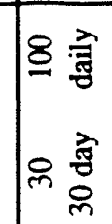 & $\nabla \alpha$ & 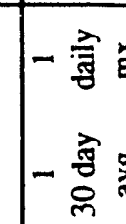 & & 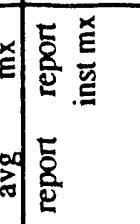 & 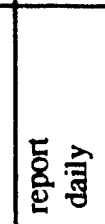 & & 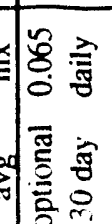 & 슨 & 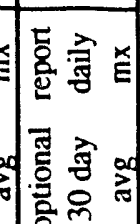 \\
\hline$\frac{y}{3}=\frac{1}{2}$ & 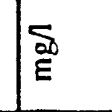 & D & 部 & D & 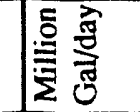 & & 离 & D & 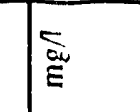 & 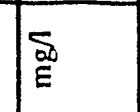 \\
\hline 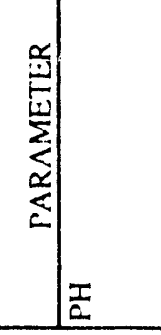 & 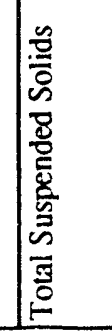 & 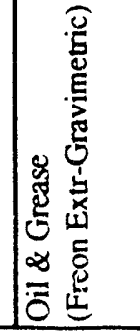 & 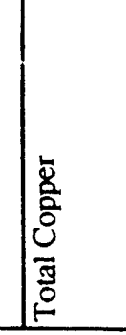 & \begin{tabular}{|l|}
$\underline{\underline{\underline{g}}}$ \\
$\underline{\underline{\underline{g}}}$ \\
\end{tabular} & 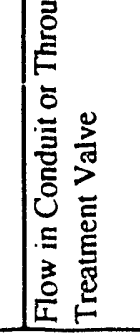 & 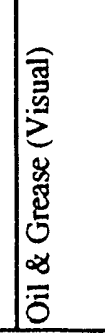 & 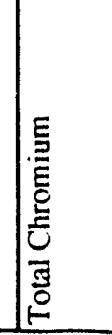 & 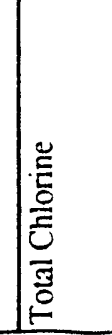 & | & 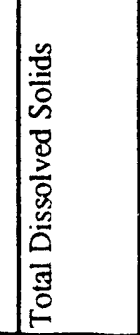 \\
\hline
\end{tabular}




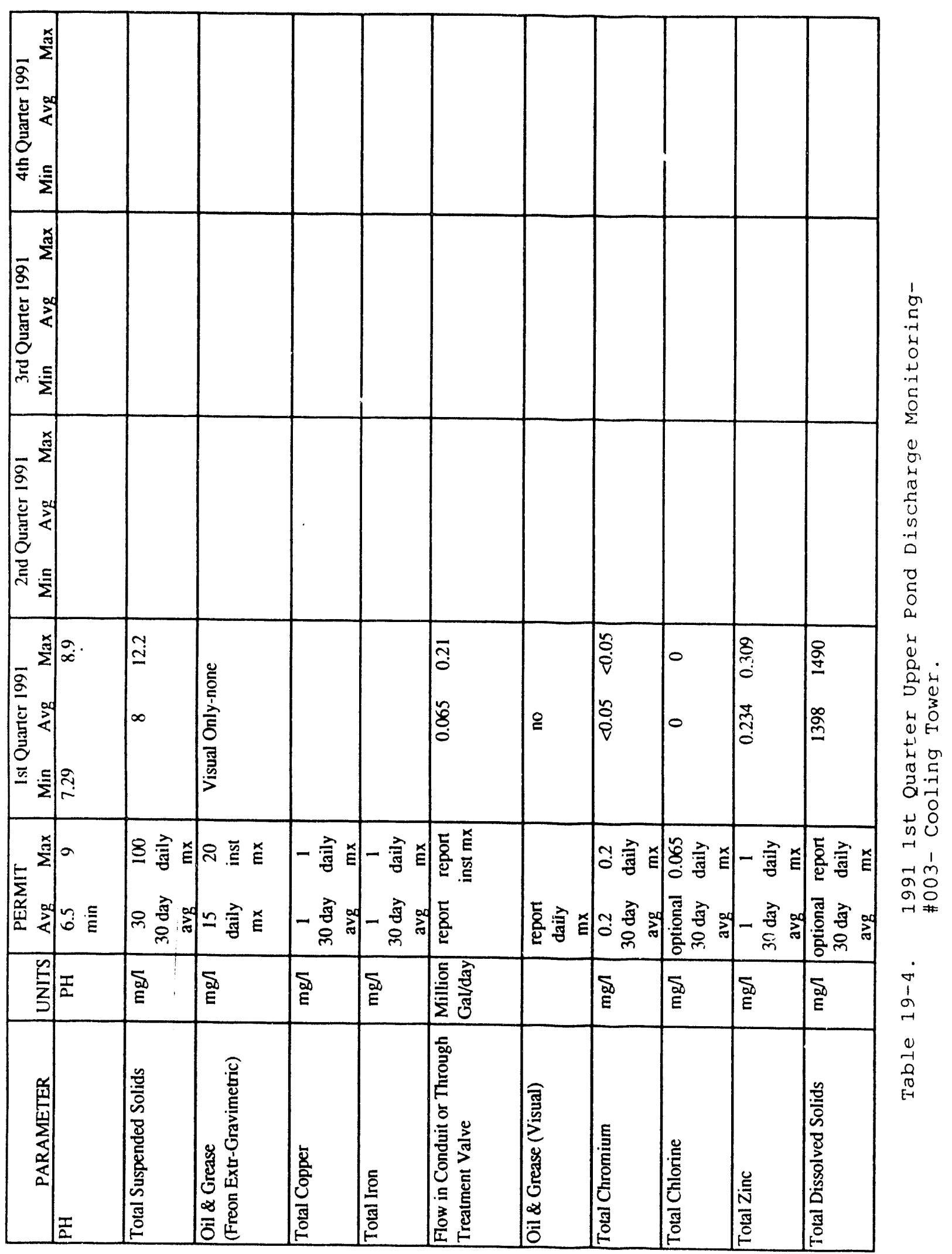




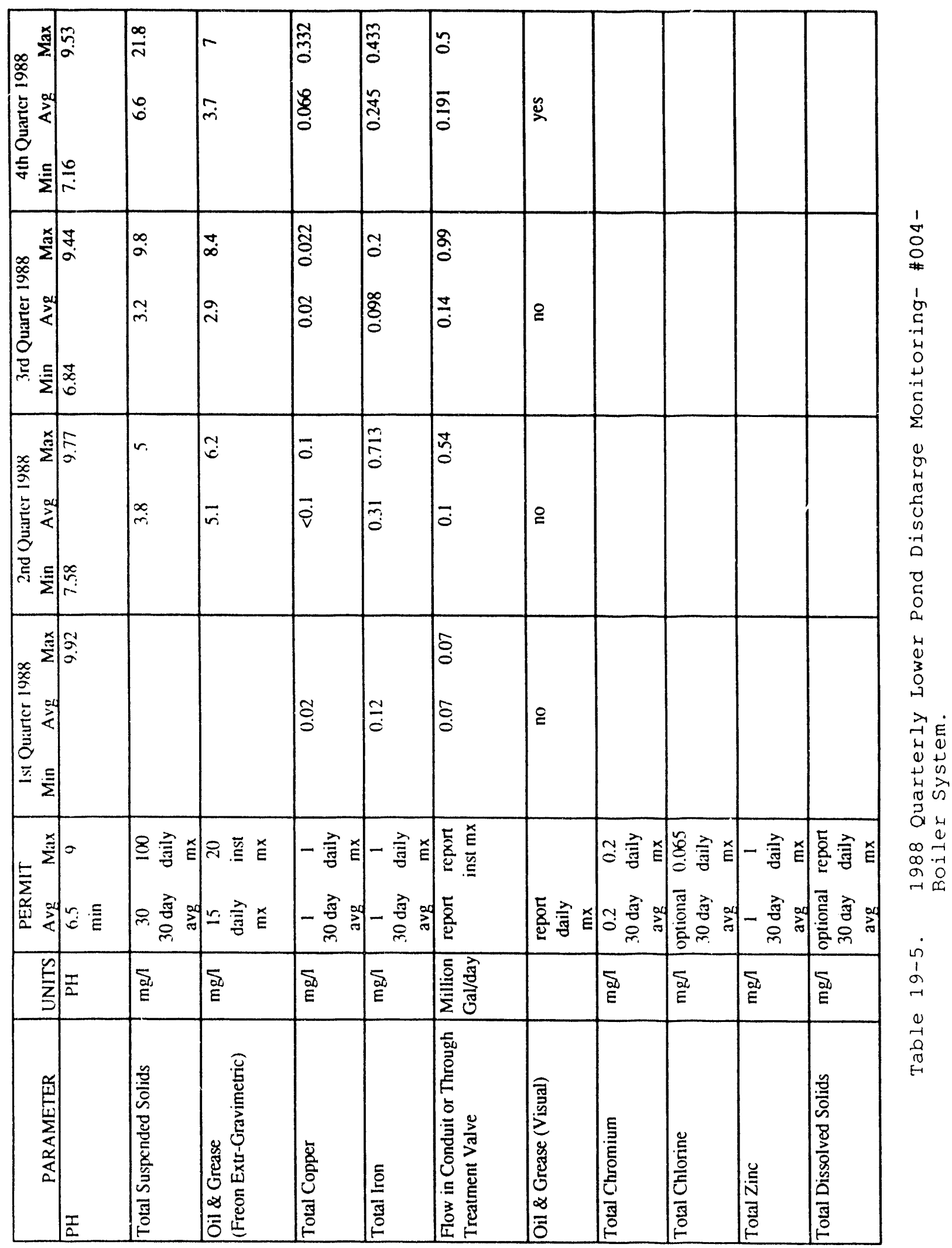




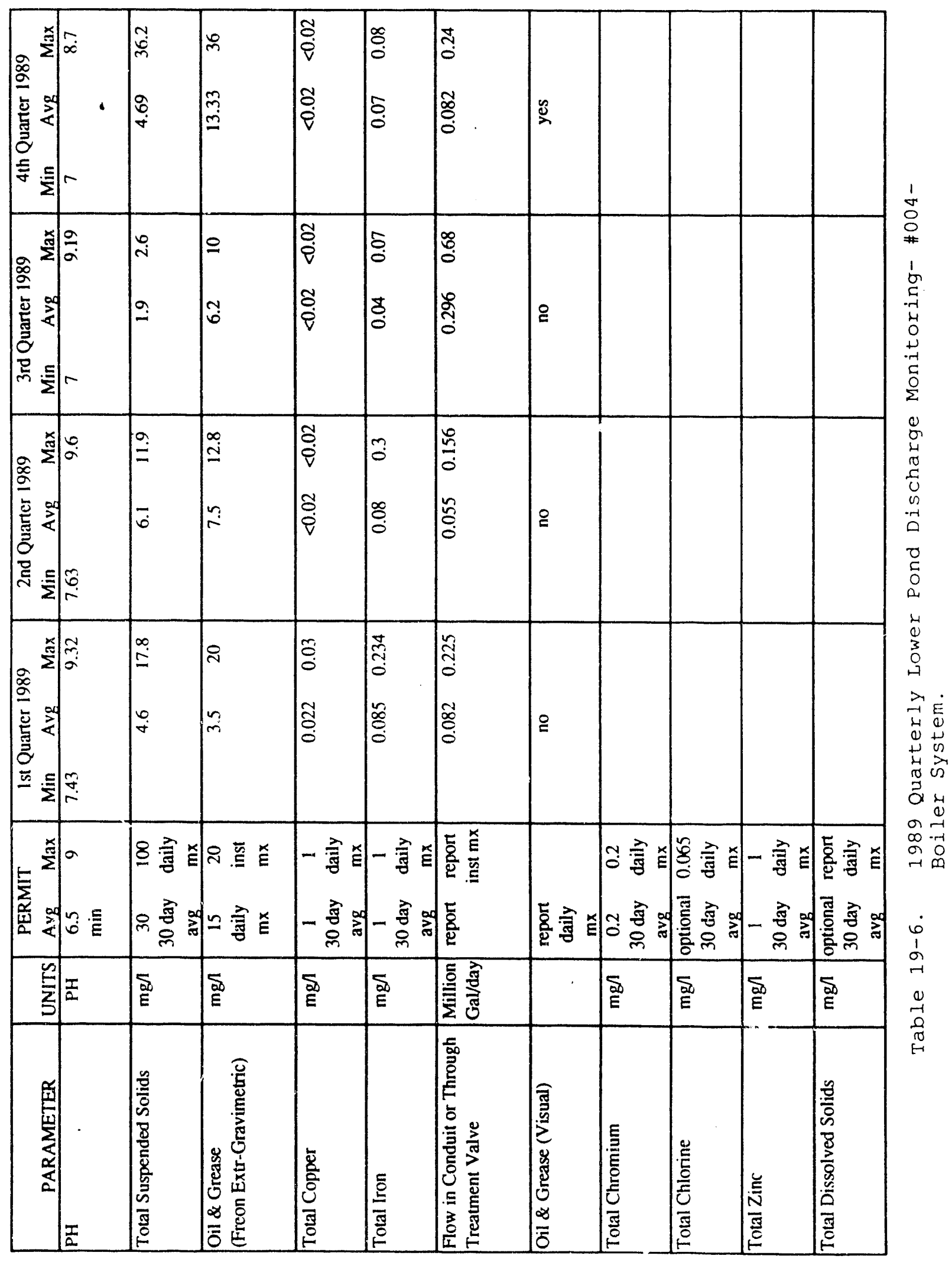




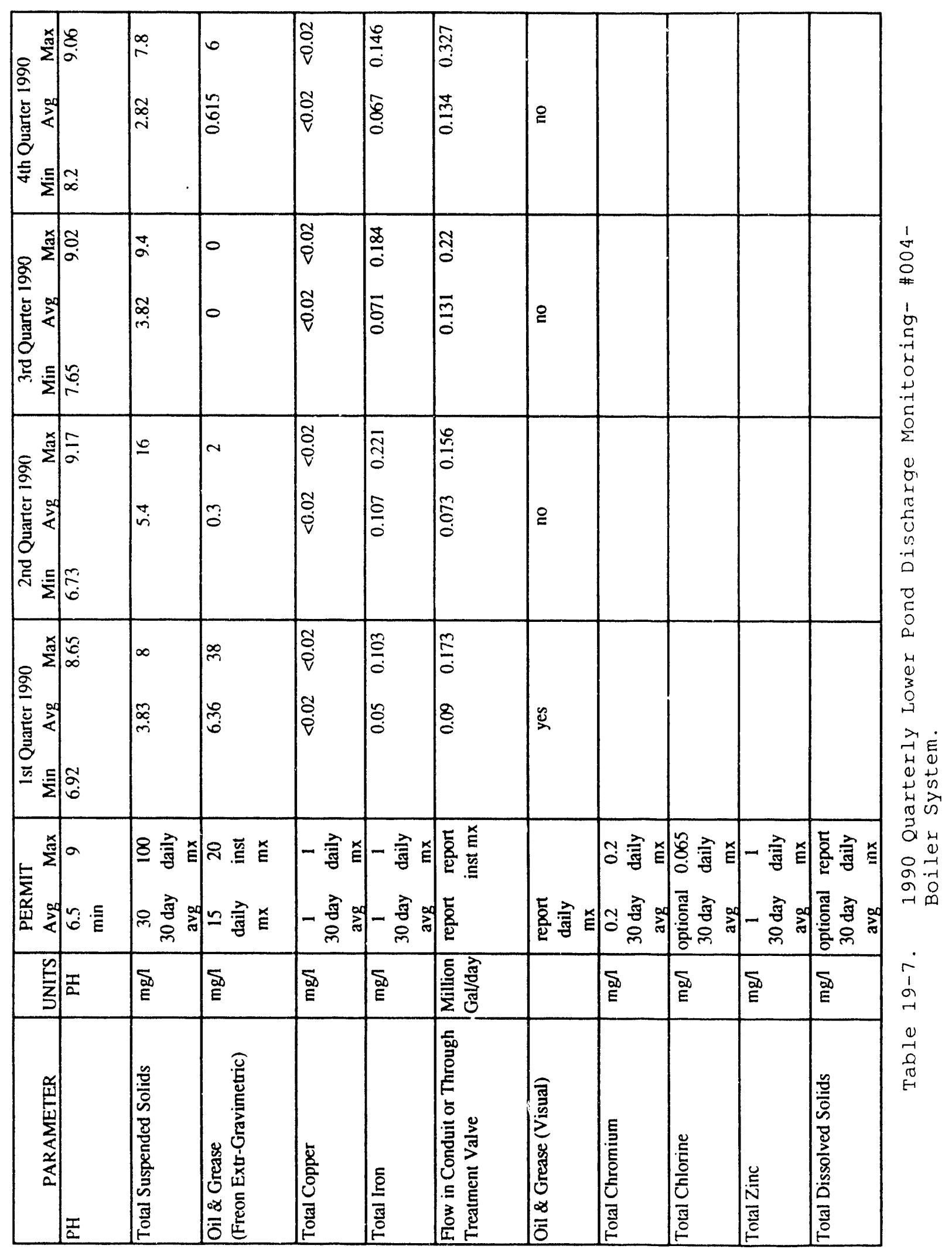




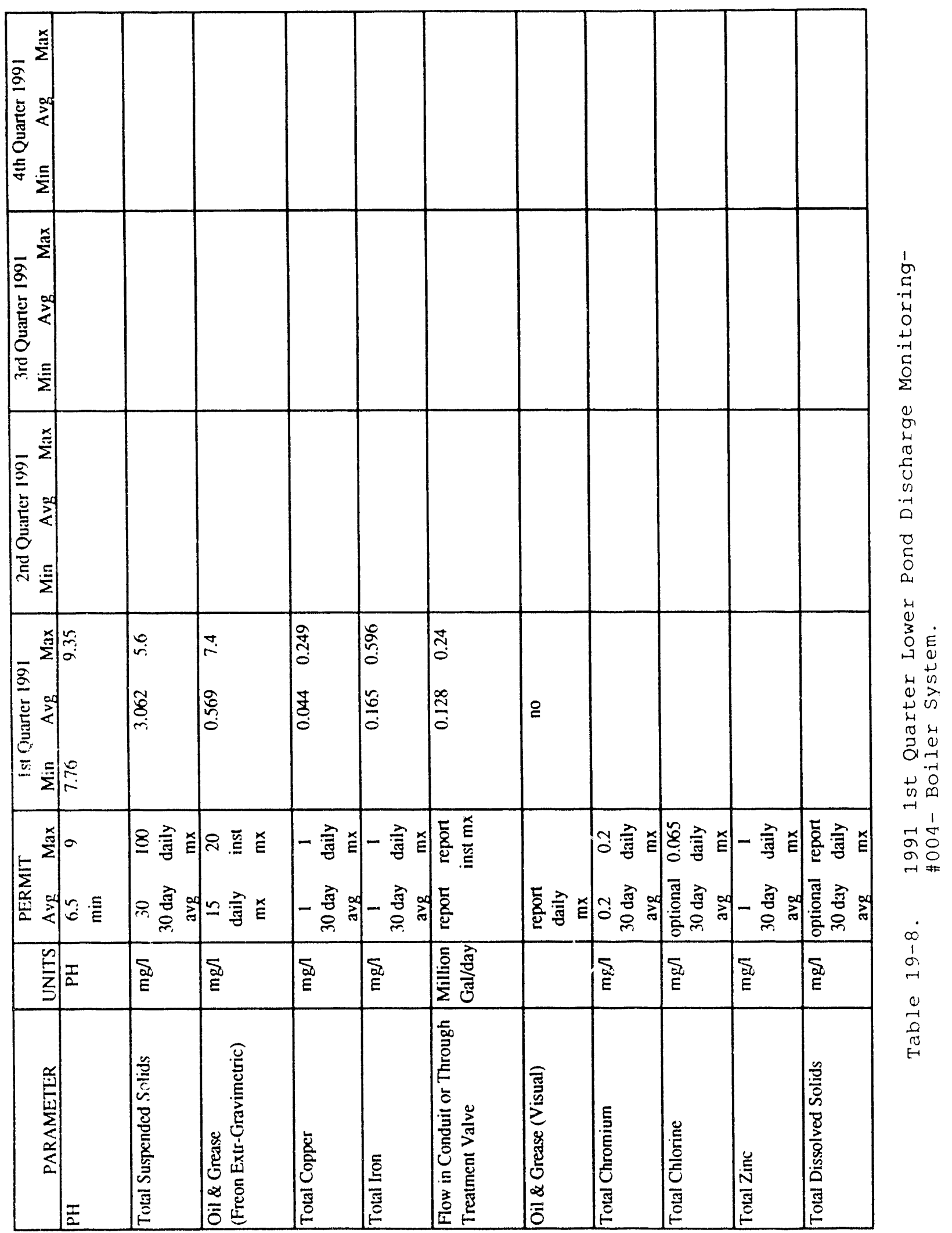




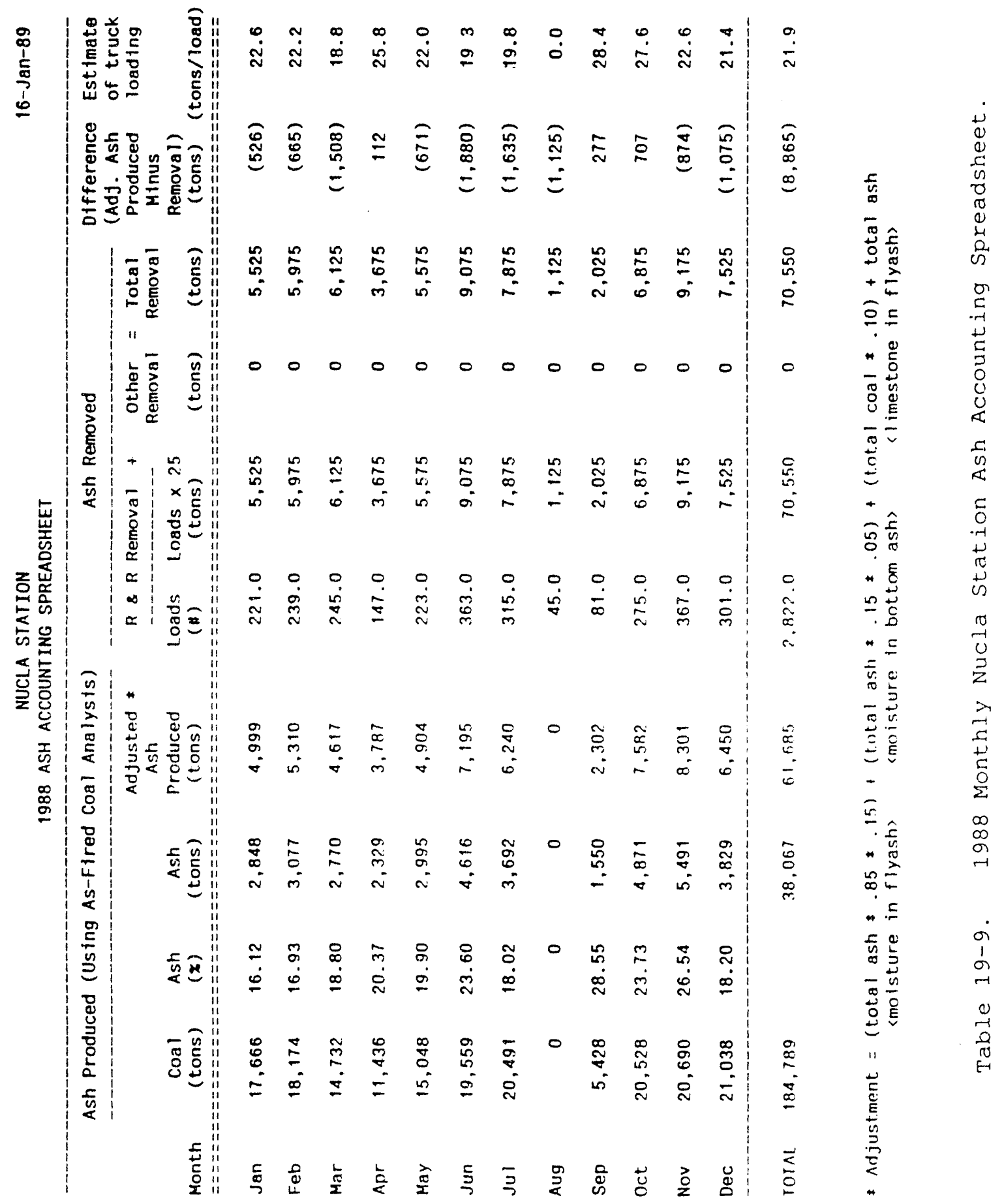




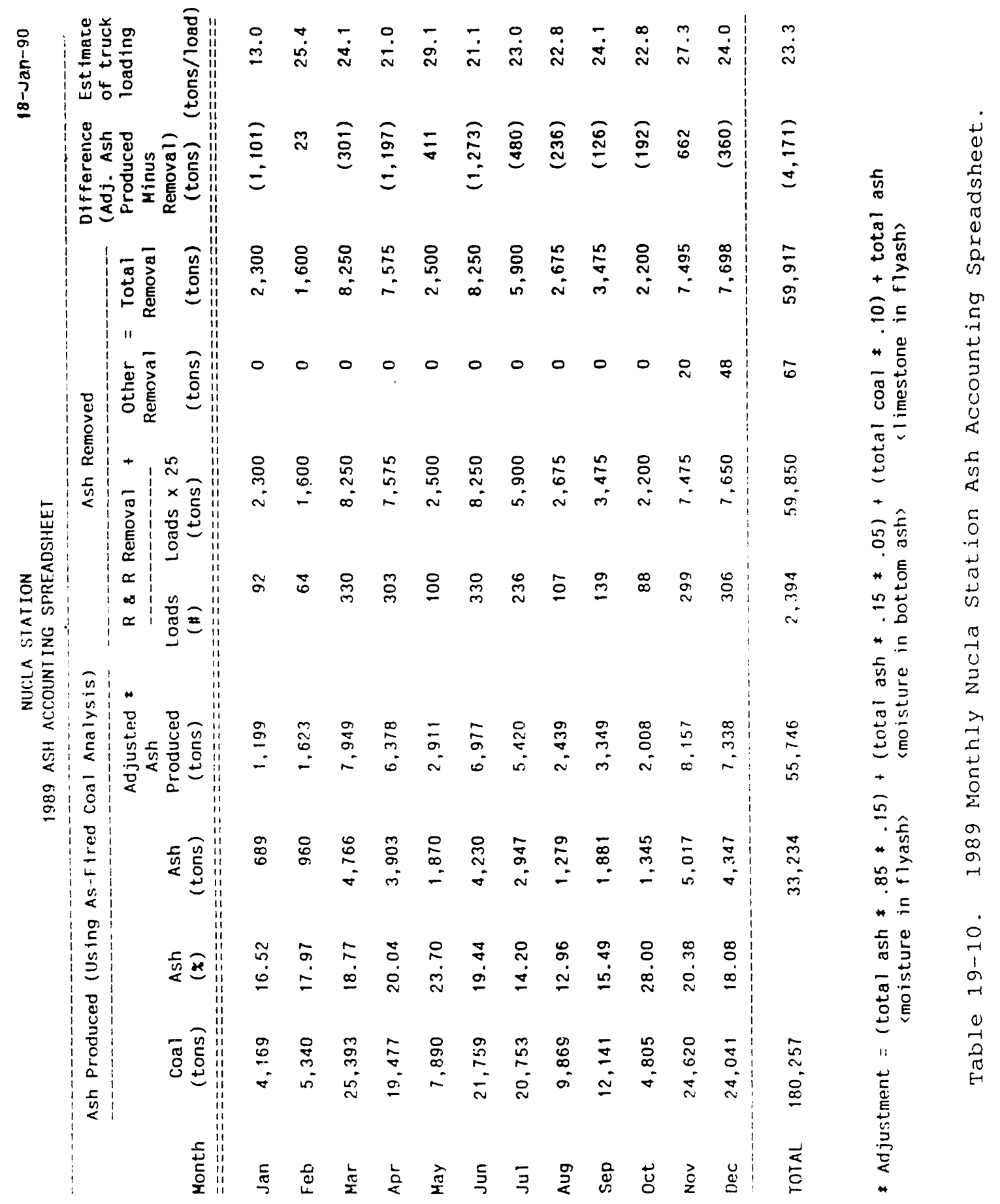




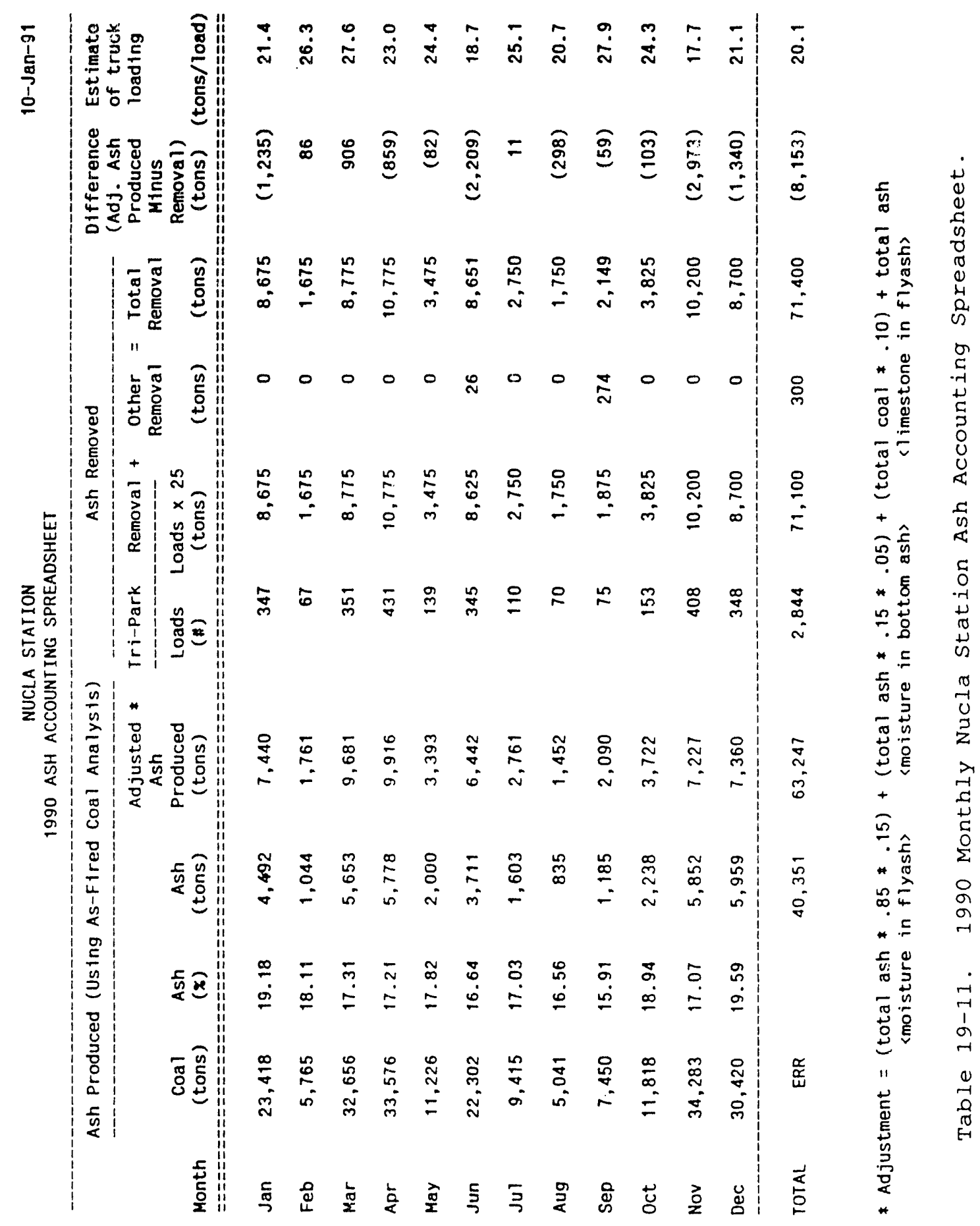




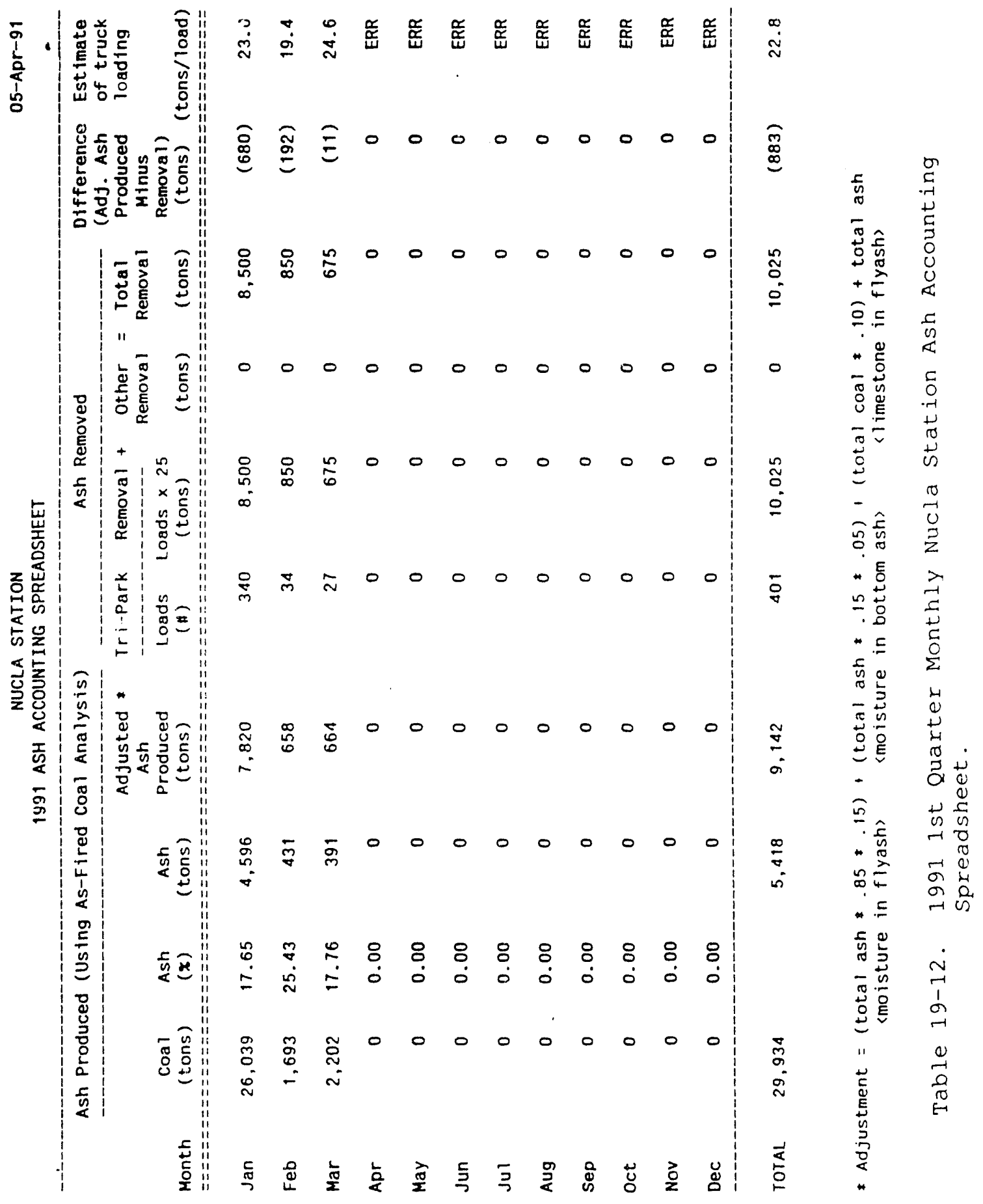




\begin{tabular}{|c|c|}
\hline$\stackrel{\bar{z}}{\bar{z}} \overline{\bar{c}}$ & 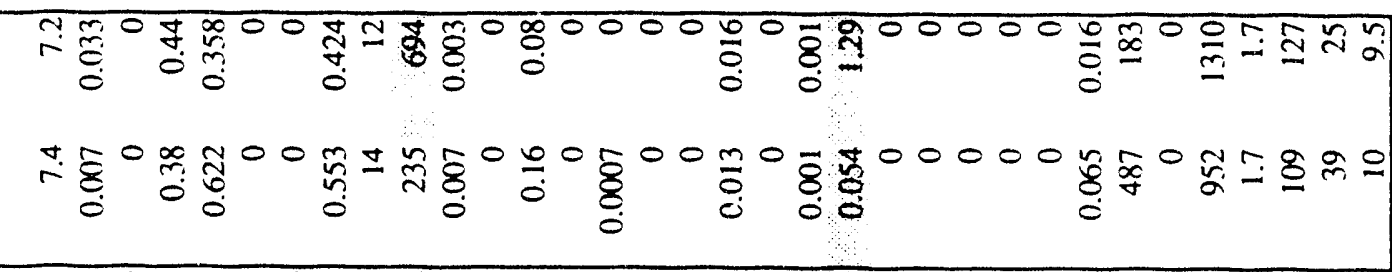 \\
\hline $\begin{array}{l}\bar{z} \\
\bar{\sigma} \\
\bar{c}\end{array}$ & 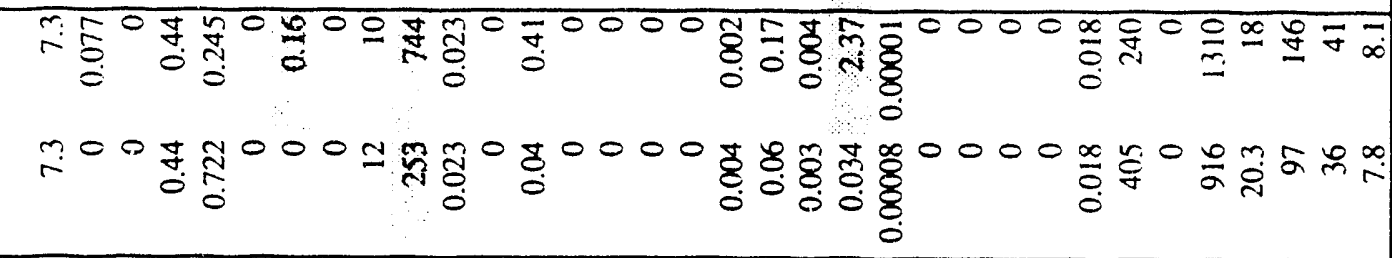 \\
\hline $\begin{array}{l}\bar{z} \\
\overline{2} \\
\overline{2}\end{array}$ & 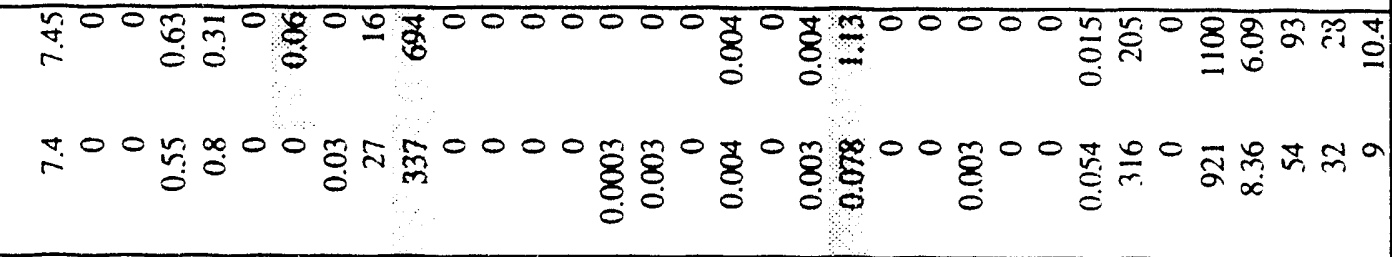 \\
\hline$\frac{2}{2}$ & 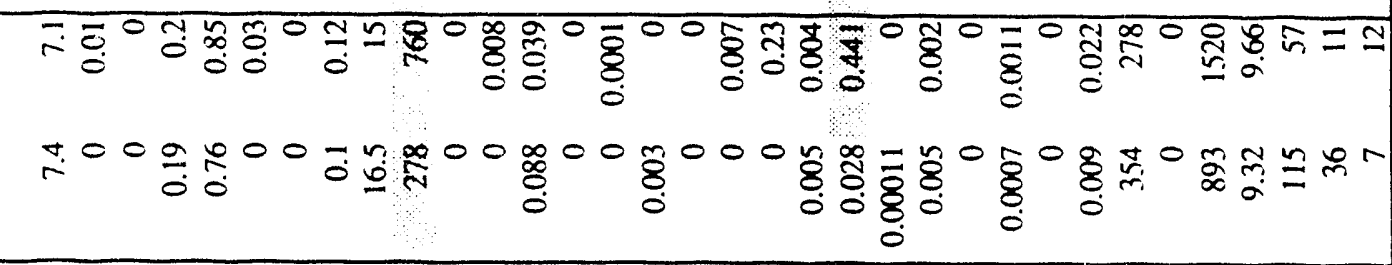 \\
\hline$\frac{\partial}{\bar{z}}$ & 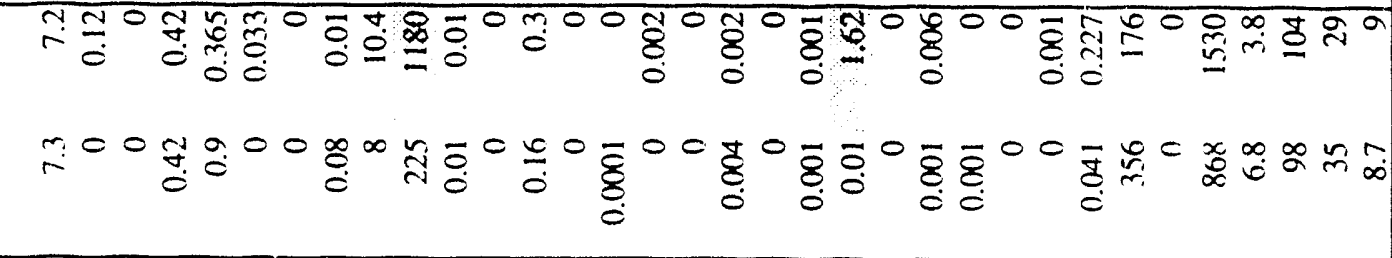 \\
\hline 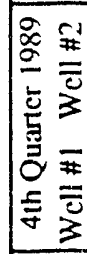 & 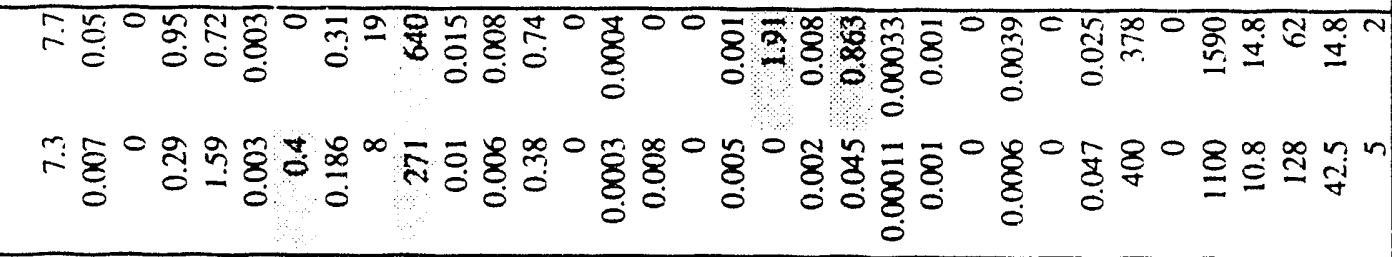 \\
\hline & 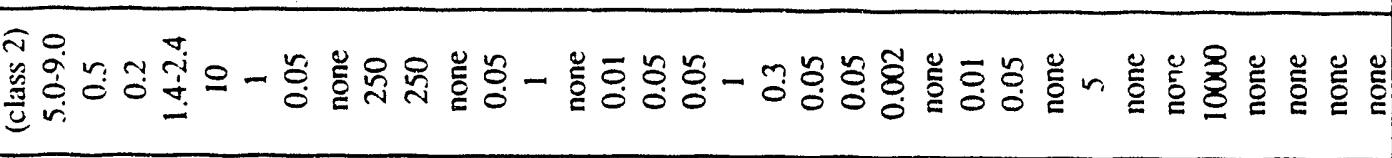 \\
\hline & 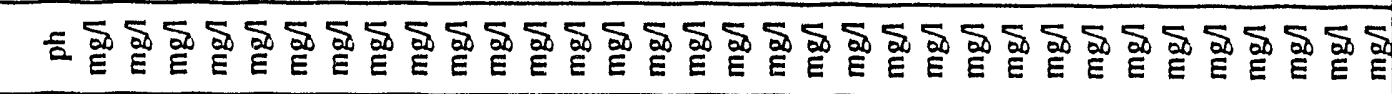 \\
\hline & 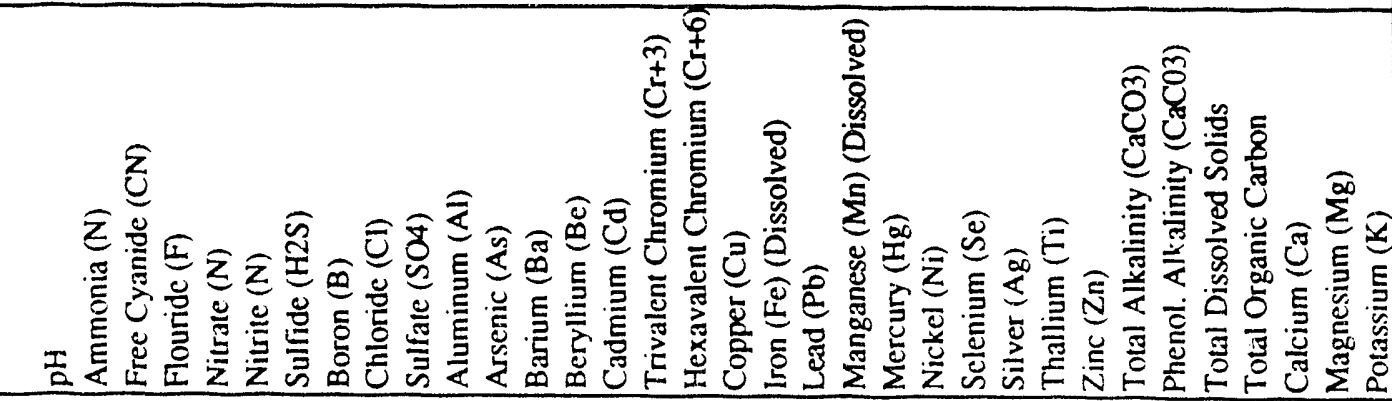 \\
\hline
\end{tabular}


listed along with each constituent, where applicable. Values in excess of these standards are shown highlighted in gray.

The wells were installed in late 1989 and were sampled for the first time on December 20, 1989. Well \#1 is at the northwest corner of the plant site (up gradient), and Well \#2 is near the southeast boundary (down gradient). Well \#1 is dug approximately 54 feet deep and contains 35 feet of water on average. Well \#2 is dug approximately 33 feet deep and contains about 28 feet of water on average. Quarterly sampling continued until the conclusion of the Phase II test program in early 1991. The final sample was taken February $27,1991$.

Certain constituents were generally higher in the down gradient well \#2. These are ammonia, sulfate, manganese, and total dissolved solids. Other constituents were higher in the up gradient well, including nitrate, total alkalinity, and magnesium. There were generally no detectable quantities of cyanide, beryllium, hexavalent chromium, thallium, or phenolphthalein alkalinity.

\subsection{ADDITIONAL TEST PROGRAM MONITORING}

The DOE/METC landfill test cell has been constructed, filled with fly ash from the Nucla CFB, covered, and instrumented. Data from this cell have been collected and preliminary results have been reported at the 1991 11th International Conference on Fluidized Bed Combustion. This report is presented in volume 2 , page 865 of the proceedings from this conference which is available from the American Society of Mechanical Engineers. The title of the paper is "Field study of Wastes from Fluidized Bed Combustion Technologies" by Andrew Weinberg, Larry Holcomb, and Ray Butler. The following is extracted from the conclusions of this report.

Preliminary chemical analysis of the waste and soils in the vicinity of the test cell has been completed. Three sets of quarterly core samples have been analyzed. The work to date has demonstrated that landfill construction using FBC wastes is straight-forward. No problems were encountered with rapid set-up of the conditioned waste, nor with excessive dusting of the material.

Preliminary chemical characterization of the waste indicates that its large available lime content initiates pozzolanic reactions that form secondary cementing phases and clays as weathering products. Waste in the test cell has solidified into a coherent mass due to the cementing action of the pozzolanic reactions, even in the semi-arid conditions of western Colorado. Secondary cement and mineral phases formed by weathering and pozzolanic reactions were confirmed by $x-$ ray diffraction analysis. 
The ASTM leachate from the FBC waste is characterized by a high $\mathrm{pH}$, low metals content and high concentrations of calcium, potassium, sodium, chloride and sulfate. The ASTM leachates show the degree of equilibrium with some cementitious phases and weathering products in the landfilled waste. The growth of the secondary phases in the waste may alter the leachate chemistry as these reactions proceed. The secondary phases preferentially incorporate some ions into the new solids, while other ions not compatible with the growing crystal structures enrich the leachate solution.

Solidification of the wastes is expected to decrease their permeability markedly, slowing the infiltration of additional water into the wastes. Laboratory tests have shown permeability values of about $3 \times 10^{-5} \mathrm{~cm} / \mathrm{sec}$ in the upper 0.3 $\mathrm{m}$ ( $1 \mathrm{ft}$ ) of ash and permeabilities of $2 \times 10^{-5}$ to $1 \times 10^{-5}$ $\mathrm{cm} / \mathrm{sec}$ at depths of 0.9 and $1.5 \mathrm{~m}$ ( 3 and $5 \mathrm{ft}$ ), respectively. In general, the ash was delivered to the cell with $30 \%$ moisture, which is about $7 \frac{\circ}{\circ}$ below the optimum moisture of $37 \%$ (at 76 pcf maximum dry density) determined in laboratory testing. The moisture in the ash initiated pozzolanic reactions in the field test cell, resulting in a reduction in the permeability of the material to the observed values of about $2 \times 10^{-5} \mathrm{~cm} / \mathrm{sec}$. Very little rainfall has been received at the site since June 1989, limiting further pozzolanic reactions in the ash.

Table 19-14 has been included from this report which includes the initial characterization of the ash. Table 19-15 shows the results of ASTM water extractions from three core samples taken in September 1989, December 1989, and March 1990.

The EPRI Environmental Characterization Plan was implemented by the Radian Corporation at the site in April 1990. The plan called for the collection of three sets of all samples to provide verification of results. During the week of testing, the unit tripped from a superheater tube leak and was down for a three-week repair outage. Only one set of samples were collected prior to this incident. Since the data was not complete and had not been substantiated by backup samples, it was not published and released by EPRI. In June of 1990, EPRI concluded performance testing on the Nucla unit and the Environmental Characterization Plan was terminated at this time. 


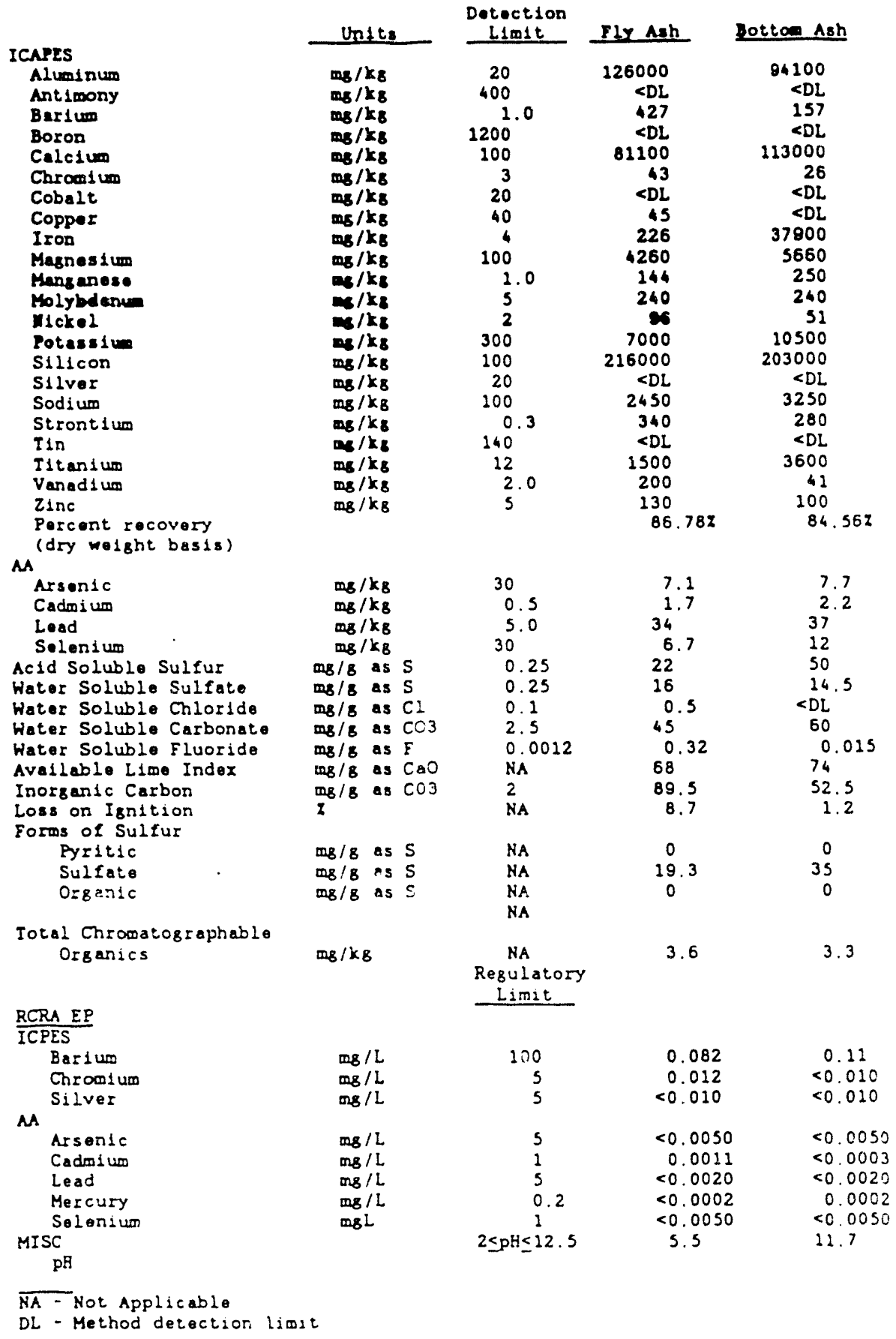

Table 19-14. Initial Nucla CEB Ely Ash Characterization. 


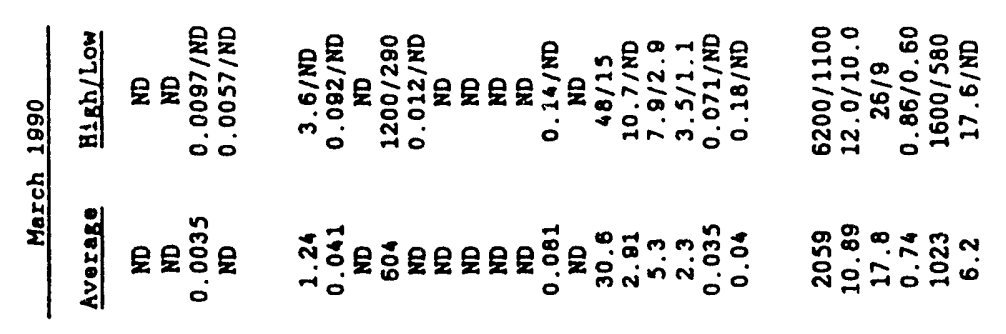

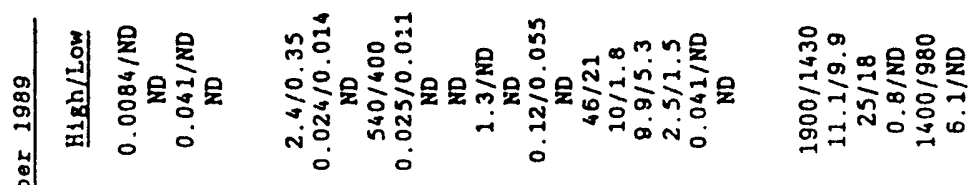

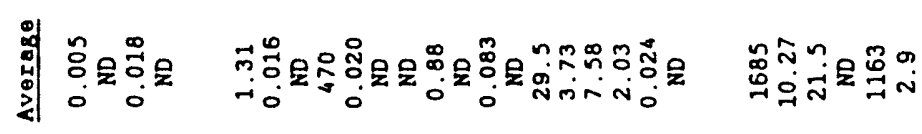

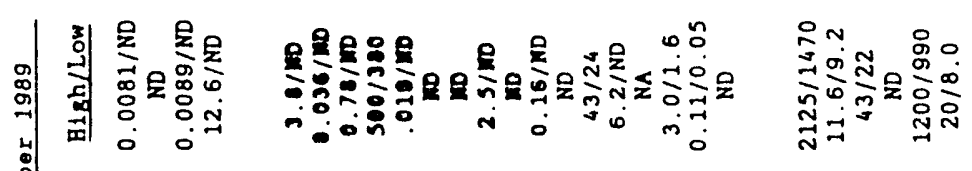

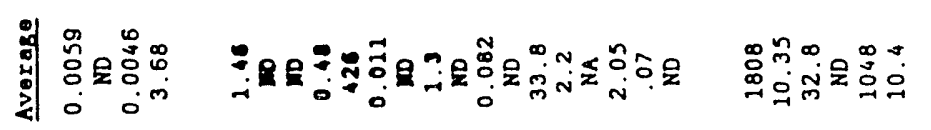

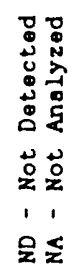

茂

0
0
-1
-1
-4
0
0
0
0
-1

号

ชิ

त)

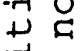

点

山ै

o 0

द

先.

芹

岃完

เป

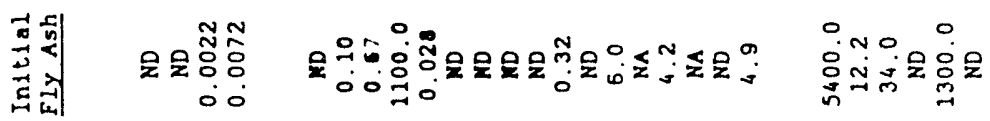

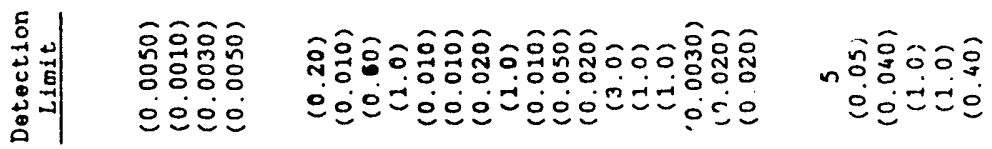

4.

$+$

तो

$\sum^{5}$

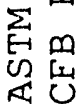

$n$
-1
1
0
-1
0
0
0
0
0
$0-1$ 
Appendix A

TEST INSTRUMENTATION CALIBRATION SCHEDULE 


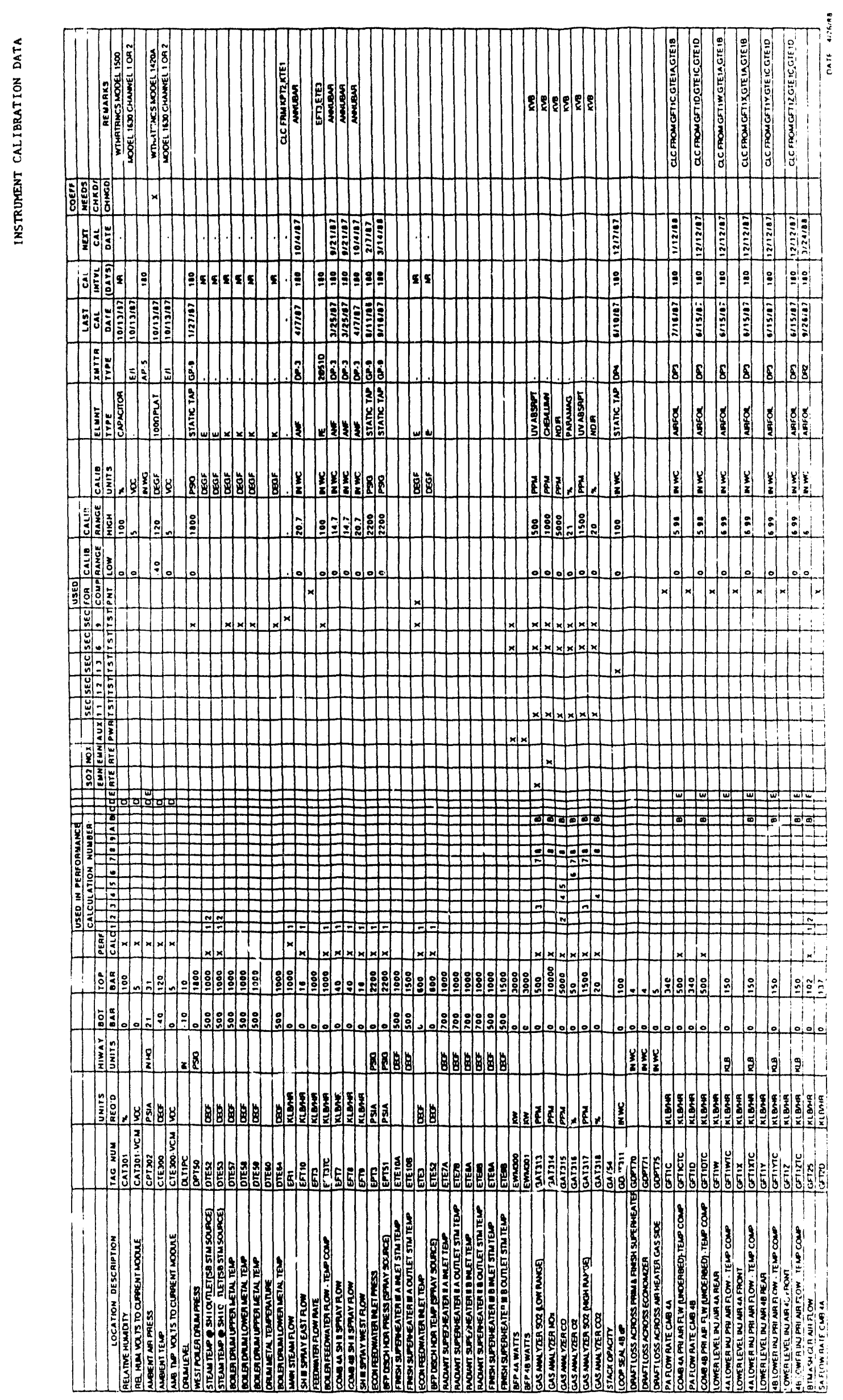

A-1 


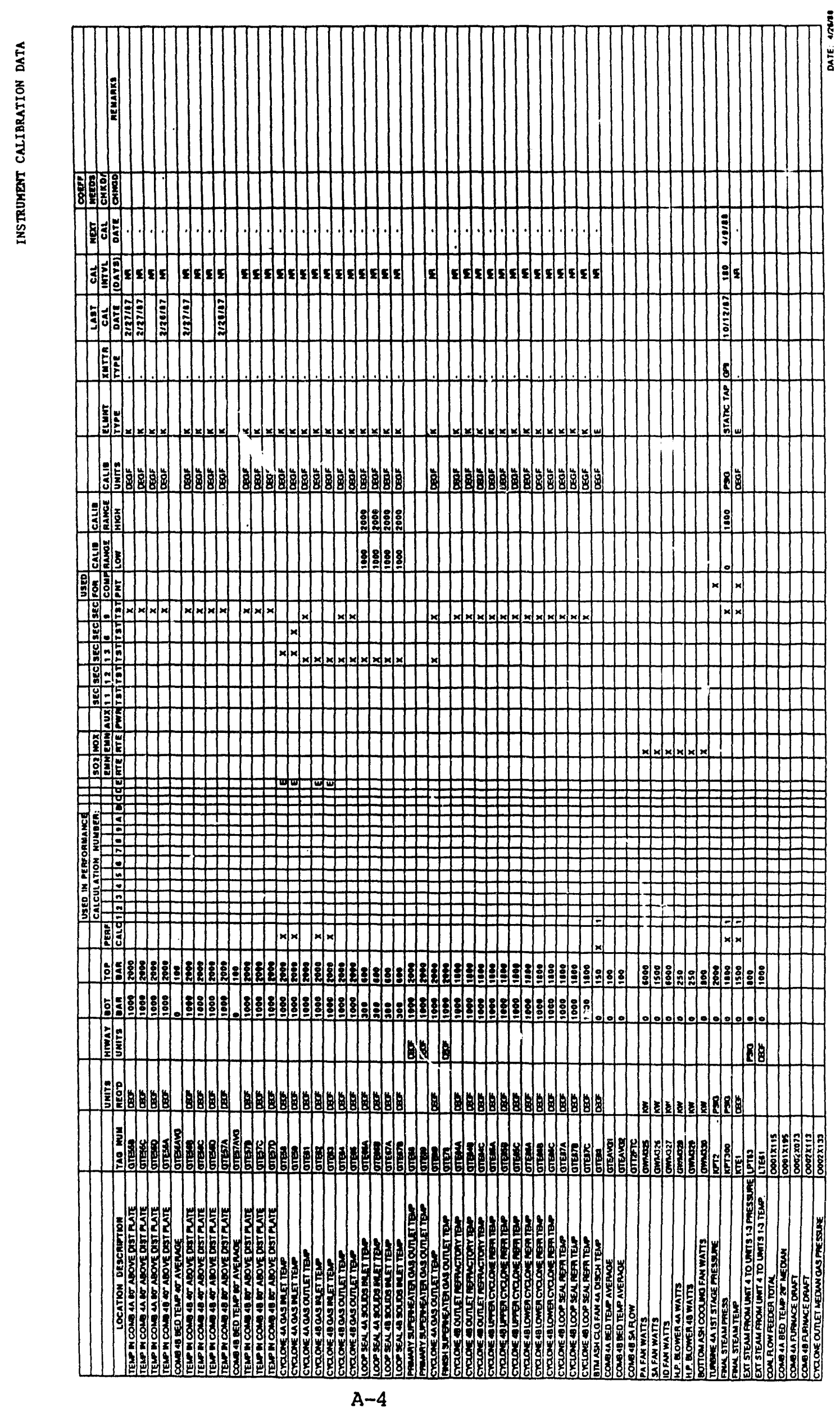




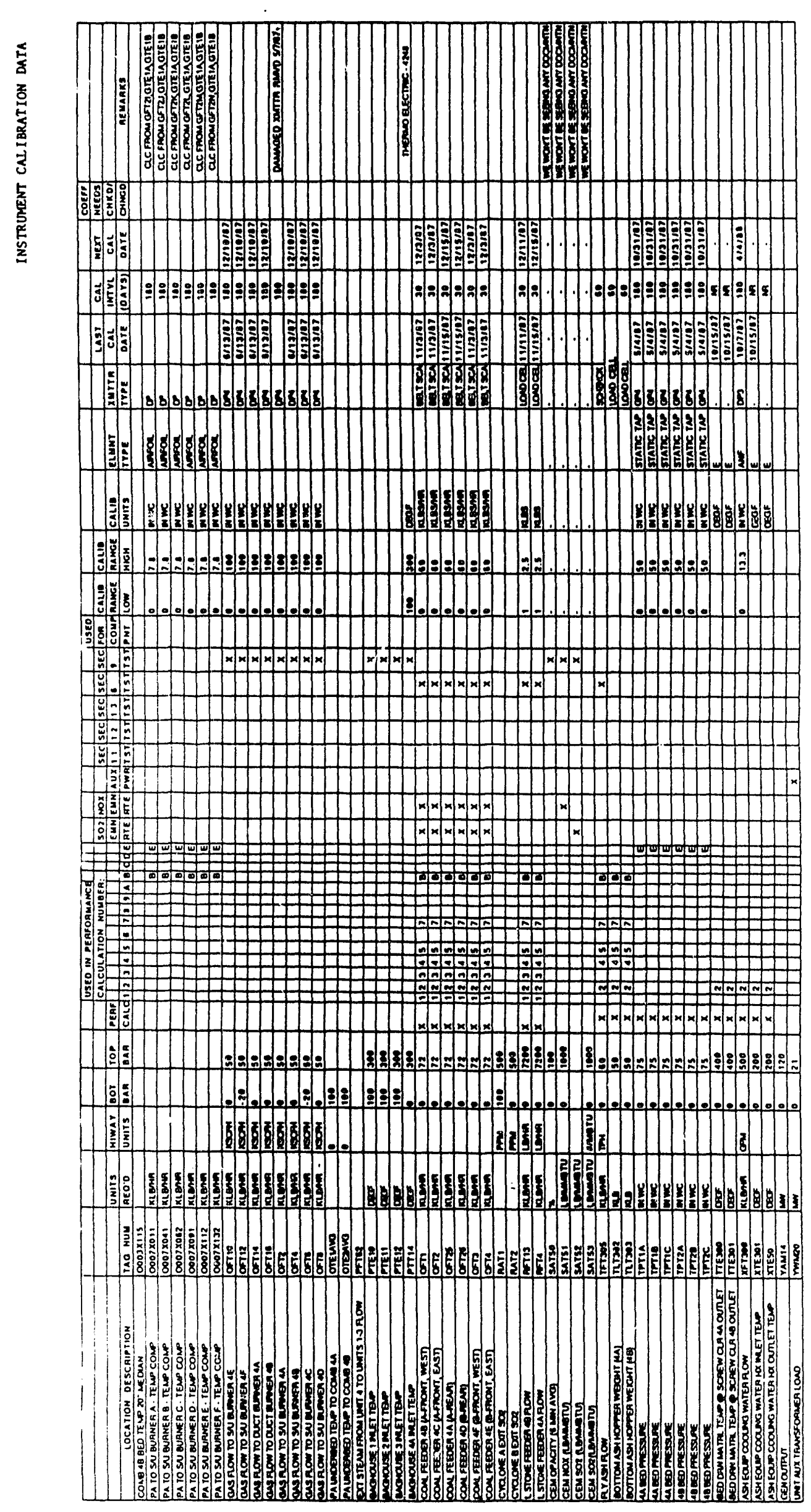

A-5 
Appendix B

UNIT START-UP SEQUENCE

In order to facilitate understanding of the start-up and loading procedure for a large CFB boiler in the repowered plant setting, a checklist was made depicting the sequential events. The fairly lengthy sequential process is primarily due to the repowering concept, where four complete turbine generator units must be started. Certain flow, pressure, and temperature criteria required to proceed with the start-up sequence are identified, although specific values are not included.

\section{DETAILED NUCLA STATION START-UP SEQUENCE}

1. Verify that the unit 4 cooling tower basin water is full.

2. Check the unit 4 circulating water system valve line up.

3. Check the unit 4 circulating water pump lube oil.

5. Start the unit 4 circulating water pump.

6. Vent circulating water system high points.

7. Vent hydrogen cooler water side.

8. Start closed cooling water system pump.

9. Check that combustion chamber, backpass, air heater, baghouse and ducting dcors are closed.

10. Open drum vents.

11. Open main steam lead drains.

12. Open superheater vents and dxains.

13. Place condenser hot well sparger in service using steam from aux boiler.

14. Place deaerator 4C storage tank sparger in service using steam from aux boiler.

15. Start one condensate pump on unit 4.

16. Start one bgiler feed pump on unit 4 and verify that recirculation system is functional. 
17. Fill boiler to 2" below drum centerline.

18. Verify adequate condensate/DI water in storage tanks.

19. Verify adequate propane supply in storage tank.

20. Start propane vaporizers.

21. Isolate baghouses 1-4 and open baghouse bypass.

22. Fill coal bunkers.

23. Fill limestone silos.

24. Verify all PA and SA flow control dampers open.

25. Start ID fan lube oil system.

26. Start PA fan lube oil system.

27. Verify ID fan closed, coupled, and ready.

28. Verify HP air blower closed, coupled, and ready.

29. Verify SA fan closed, coupled, and ready.

30. Verify PA fan closed, coupled, and ready.

31. Place ID fan control selector in manual and run speed demand to minimum.

32. Start ID fan motor.

33. Place back-up HP air blower motor in Auto (Standby) mode.

34. Run inlet butterfly damper to minimum position on HP air blower.

35. Start one HP air blower motor.

36. Verify and adjust fluidizing air flows to various injection ports.

37. Place SA fan control selector in manual and run demand to minimum.

38. Verify $S A$ fan speed demand at minimum.

39. Verify SA fan inlet damper position at minimum stop.

40. Start SA fan motor.

41. Verify furnace draft stable through fan start-up. 
42. Place PA fan control selector in manual and run speed demand tc minimum.

43. Manually increase ID fan speed until the furnace draft reaches 2.5 inches w.c.

44. Run in-bed start-up burner air dampers to minimum.

45. Start PA fan motor.

46. Pulse up the ID and PA fan motor speeds until flow is established and the bed (if present) fluidizes.

47. Adjust ID fan speed to obtain furnace draft of 0.5 inches w.c.

48. Automate furnace draft loop.

49. Verify furnace draft stability.

50. Bring PA underbed air flow up to minimum.

51. Open SA fan inlet damper.

52. Raise SA fan speed.

53. Adjust SA air flow to in-bed start-up burners above light off interlock.

54. Adjust SA flow to bring total air flow to required purge air flow rate.

55. Verify bottom ash fan closed, coupled, and ready.

56. Run bottom ash cooling air fan inlet damper to minimum.

57. Start bottom ash cooling air fan.

58. Adjust bottom ash cooling air fan inlet damper and control dampers on feed to each ash cooler to achieve desired flows.

59. Automate bottom ash cooling air fan control.

60. Verify all purge permissives satisfied.

61. Initiate purge timer.

62. When purge is complete, unit is ready for light-off.

63. Start bottom ash cooling water pump.

64. Verify flow at bottom ash coolers through sight glasses.

65. Verify that the propane gate valve at the propane pipe entrance to the boiler room is open. 
66. Verify all in-bed start-up burner and duct burner gas guns are coupled.

67. Open the main propane gas header safety shutoff valve to pressurize gas header.

68. Verify duct burners coupled.

69. Start duct burners for both combistors.

70. Automate duct burner controls.

71. Adjust duct burner fuel gas flow as necessary to increase bed temperature.

72. Run gas firing rate control valves on in-bed start-up burners to be lighted to minimum.

73. Start a pair of in-bed start-up burners (one in each combustor).

74. Automate primary air flow control to each active in-bed startup burner.

75. Automate gas flow control to each active in-bed start-up burner and set gas firing rate to each burner to required value (same for each combustor).

76. Light additional burner pairs when the boiler can absorb additional heat input without exceeding rate of warm up limitations while maintaining drum level control.

77. Adjust firing rate as needed to follow the cyclone inlet temperature vs. time curves available in the control room. These curves are based upon the various transient temperature limitations of boiler components including refractory, drum, radiant superheater tubing and steam headers. Specific rate of change restrictions to be monitored include:

- Rate of saturation temperature rise not greater than 100F/hr;

- Differential drum metal temperature top to bottom not greater than $200{ }^{\circ} \mathrm{F}$;

- Cyclone refractory temperature rise not greater than 100 ${ }^{\circ} \mathrm{F} / \mathrm{hr}$;

- Gas temperature at radiant superheater not greater than 1000 ${ }^{\circ} \mathrm{F}$ until steam flow is established;

- Radiant and finishing superheater out let tube metal temperature not greater than $1025^{\circ} \mathrm{F}$. 
78. When drum pressure reaches 25 psig (steam billowing from the drum vents) close the drum vent valves, superheater vents and drains, except for the main steam lead drains.

79. Adjust continuous blowdown valve as necessary to dispose of excess water in the drum resulting from swell. Also employ east and west drum drains to the blowdown tank to supplement water disposal.

80. When drum pressure reaches 25 psig, open low load feed water regulator valve to establish water flow.

81. When drum pressure reaches 100 psig, adequate steam pressure should exist to warm up and place in service the auxiliary steam system supplied from the primary superheater source.

82. Initiate main deaerator pegging using the auxiliary steam supply from the main boiler.

83. Secure deaerator storage tank steam sparger steam supply.

84. Place or verify that the main turbine is on turning gear.

85. Start steam packing exhauster.

86. Establish the steam seal system on the no. 4 turbine generator.

87. Establish auxiliary steam supply to the hogging ejector and the tri.m ejector.

88. Pull vacuum on the no. 4 condenser.

89. Open main steam lead drains to the condenser 3 turns in order to commence steam lead warm up.

90. Determine from turbine metal temperature thermocouples as to whether the unit is in a cold start (rotor metal temperature less than $250^{\circ} \mathrm{F}$ ) or hot start (rotor metal temperature greater than $250^{\circ} \mathrm{F}$ ).

91. Refer to Westinghouse data for appropriate heat soak periods, acceleration rates, and initial steam conditions based upon the circumstances of the start-up.

92. Throttle conditions of at least $100^{\circ} \mathrm{F}$ superheat but not greater than $800^{\circ} \mathrm{F}$ are required to roll the turbine generator.

93. Use superheater and steam lead drains as needed to control pressure rise while attaining adequate superheat.

94. Verify turbine electrohydraulic control system fully in service including EFiC fluid pumps and fluid coolers.

95. Latch turbine. 
96. When throttle steam conditions are satisfactory, roll turbine to 600 RPM.

97. Check that exhaust hood sprays are in service.

98. Fill the turbine exhaust hood seat trough.

99. Bring speed to 2100 RPM.

100. Heat soak turbine as necessary.

101. Bring speed to 3425 RPM.

102. Prior to valve transfer, verify that throttle temperature meets requirements.

103. Execute valve transfer program.

104. Raise speed to 3600 RPM.

105. If necessary, test overspeed trip mechanism.

106. Select the AC bearing oil pump and backup seal oil pump to auto (standby) and verify that both stop.

107. Establish or verify cooling water flow to the hydrogen coolers.

108. Establish excitation.

109. Synchronize the generator to the system.

110. Close the generator breaker.

111. Raise unit output to approximately 5\% generator load (5 MWe).

112. Hold initial load for 30 minutes plus 1 minute for each $3{ }^{\circ} \mathrm{F}$ throttle temperature change during this hold period.

113. Place feed water heaters in service starting with low pressure heater and proceeding to top heater.

114. When baghouse $\$ 4$ inlet temperature reaches $150^{\circ} \mathrm{F}$, open inlet gates and close the bypass damper.

115. Close main steam lead drains.

116. Automate boiler desuperheater sprays.

117. Open coal feeder inlet gate to coal feeders.

118. Automate feed water regulator controls.

119. Verify bottom ash transport exhauster, coupled, and ready.

$$
B-6
$$


120. When bed temperature reaches the minimum value necessary for permission to light coal:

- Feed coal intermittently 90 seconds on and 90 seconds off to both combustors simultaneously;

- When bed temperature commences increasing by more than $15{ }^{\circ} \mathrm{F}$, energize feeder continuously;

- Place one feeder in continuously in both combustors.

121. Place throttle pressure limit control in service.

122. Start limestone feed to both combustors.

123. With one coal feeder established in each combustor, raise coal feed in gradual steps keeping fuel input equal between combustors. Limit rate of fuel increase to limit refractory temperature rise at cyclone inlet to not greater than 100

${ }^{\circ} \mathrm{F} / \mathrm{hr}$. Place additional coal feeders in service.

124. Verify silica within limits prior to exceeding 1250 psig drum pressure.

125. When throttle pressure nears 1450 psig, automate the governor MW loop.

126. Raise MW demand in gradual steps and increase coal firing as needed to hold throttle pressure.

127. When bed temperature is greater than $1400^{\circ} \mathrm{F}$, secure duct burners and start-up burners

128. Automate PA duct pressure control loop.

129. Automate SA duct pressure control loop.

130. Automate PA underbed flow controls.

131. Automate PA overbed flow controls.

132. Automate SA flow controls.

133. Automate coal feeders to the boiler master.

134. When necessary to hold bed inventory, start rotary valves on bottom ash coolers and set valve speed as needed.

135. Using bypass around extraction line stop valve, header vents and header drains, warm up extraction line to old turbines.

136. Place or verify that the available 12 MW unit is on turning gear. 
137. Start circulating water system on the $12 \mathrm{MW}$ unit which is available for service. (This keeps as much of the extraction line warm as practicable.)

138. Start a condensate pump on the selected 12 MW unit.

139. When the extraction line to the $12 \mathrm{MW}$ turbines is fully warmed, open the extraction line stop valve.

140. Apply seal steam to the selected 12 MW unit.

141. Pull vacuum on the condenser for the selected unit.

142. When throttle conditions meet existing turbine generator requirements, roll the selected machine.

143. When heat soak is complete, synchronize and tie on the selected unit's generator.

144. Start a condensate forwarding transfer pump fiom the selected unit's deaerator to the no. 4 deaerator.

145. Assume the minimum load required for the oncoming turbine.

146. Automate boiler master to throttle pressure control.

147. Proceed to the next turbine generator to be started and repeat the starting sequence until desired number of machines are on line for target load. 

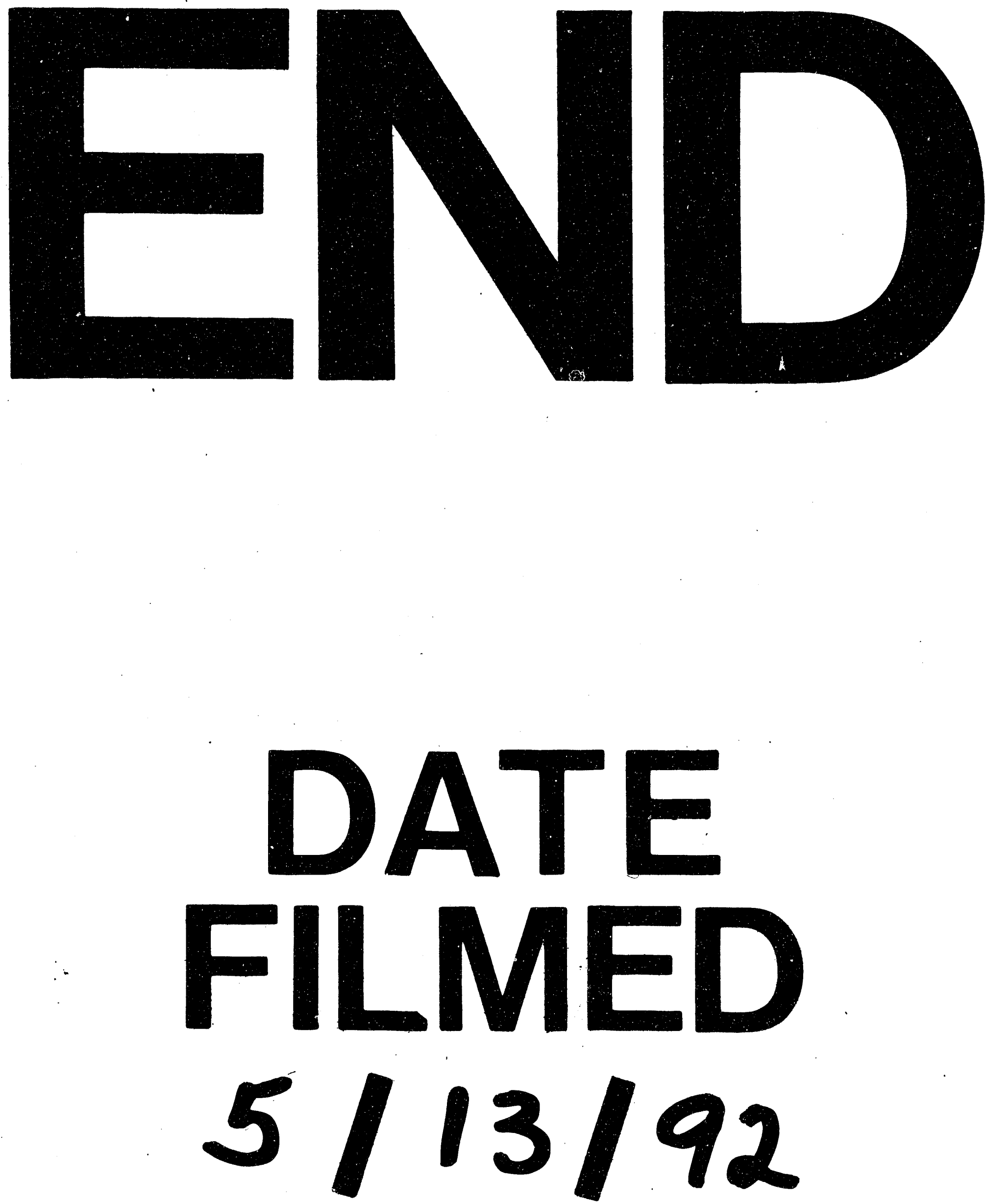
